\title{
AN EXPERIMENTAL SURVEY OF THE FACTORS THAT AFFECT LEACHING FROM LOW-LEVEL RADIOACTIVE WASTE FORMS
}

\author{
TOPICAL REPORT
}

D.R. Dougherty, R.F. Pietrzak, M. Fuhrmann and P. Colombo

September 1988

Prepared for the

UNITEO STATES DEPARTMENT OF ENERGY

NATIONAL LOW-LEVEL WASTE MANAGEMENT PROGRAM

UNDER CONTRACT NO. DE-ACO2-76CHOOO16

NUCLEAR WASTE RESEARCH GROUP

MASTER

DEPARTMENT OF NUCLEAR ENERGY

BROOKHAAVEN NATIONAL LABORATORY

ASSOCIATED UNIVERSITIES, INC.

UPTON, LONG ISLAND, NEW YORK 11973 
1. INTRODUCTION $\ldots \ldots \ldots \ldots \ldots \ldots \ldots \ldots \ldots \ldots \ldots \ldots \ldots \ldots \ldots \ldots \ldots$

1.1 Leaching Mechanisms and Long-Term Leachability........... 1

1.2 Effects of Waste Form Composition.................. 2

2. FACTORS THAT AFFECT LEACHING OF LOW-LEVEL WASTE FORMS ......... 3

2.1 Temperature........................... 4

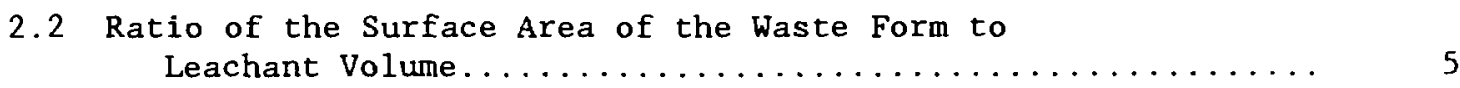

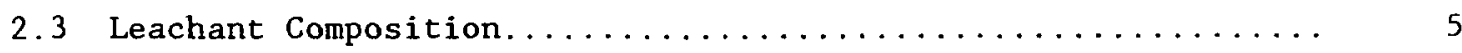

2.4 Leachant $\mathrm{pH} \ldots \ldots \ldots \ldots \ldots \ldots \ldots \ldots \ldots \ldots \ldots \ldots \ldots \ldots \ldots$

2.5 Leachant Flow Rate or Replacement Frequency............ 6

2.6 Composition of the Waste Form.................. 6

2.7 Volume to Surface Area Ratio of the waste Form.......... 7

2.8 Porosity of the Waste Form $\ldots \ldots \ldots \ldots \ldots \ldots \ldots \ldots \ldots \ldots \ldots$

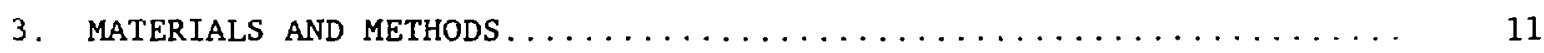

3.1 Waste Form Types......................... 16

3.1.1 Portland I Cement Containing Sodium Sulfate as Simulated Waste....................... 16

3.1.2 Portland I Cement Containing Incinerator Ash

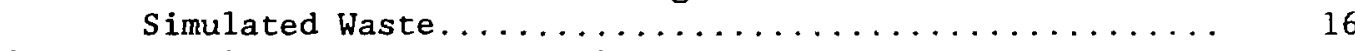

3.1.3 Vinyl Ester-Styrene Emulsion with Aqueous Sodium Sulfate as simulated Waste................. 17

3.1.4 Vinyl Ester-Styrene Containing Sodium Sulfate as

Simulated waste....................... 17

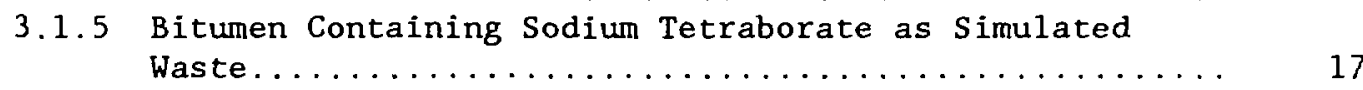

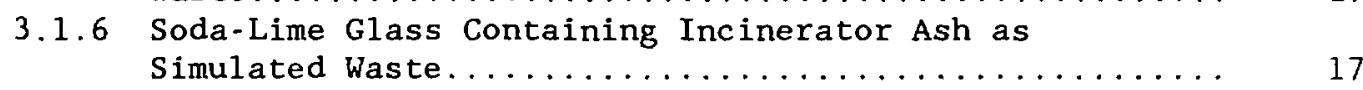

3.2 Sample Preparation........................ 17

3.3 Leaching Tests........................... 18

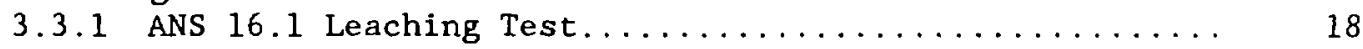

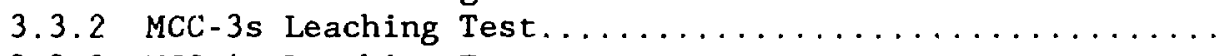

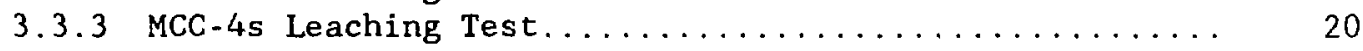




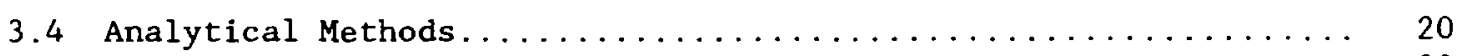

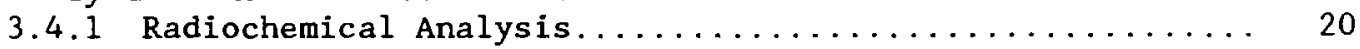

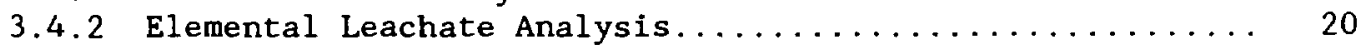

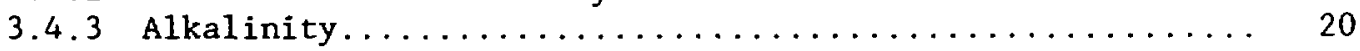

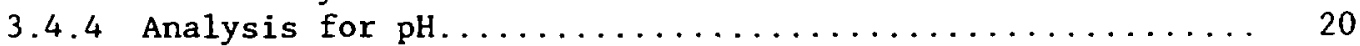

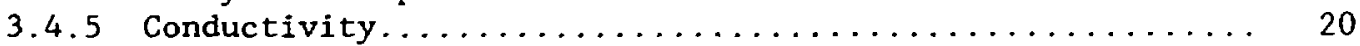

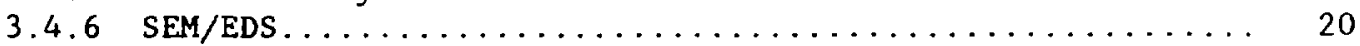

4. PORTLAND TYPE I CEMENT CONTAINING SODIUM SULFATE SALT AS

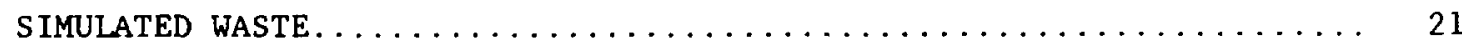

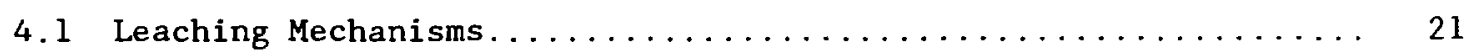

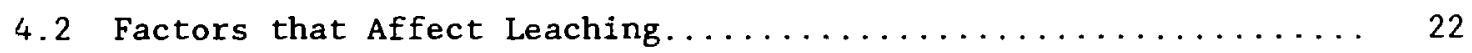

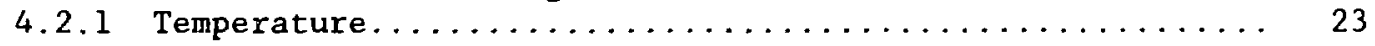

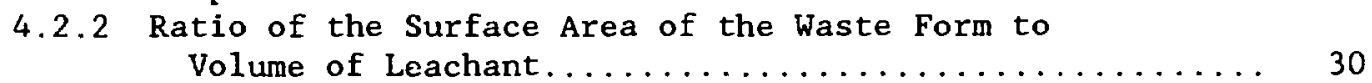

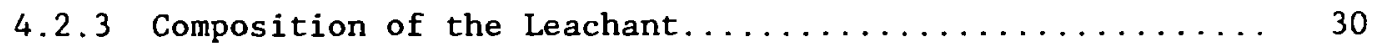

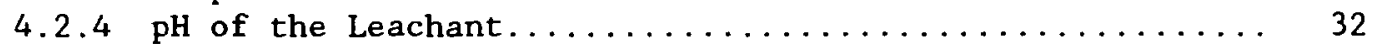

4.2.5 Leachant Flow Rate or Replacement Frequency.......... 33

4.2 .6 Composition of the Waste Form............... 34

4.2.7 Ratio of the Volume to Surface Area of

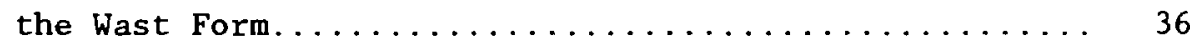

4.2.8 Effect of Surface Condition and Porosity.......... 37

5. PORTLAND TYPE I CEMENT CONTAINING INCINERATOR ASH AS SIMULATED

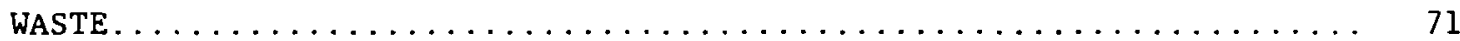

5.1 Leaching Mechanisms........................ 71

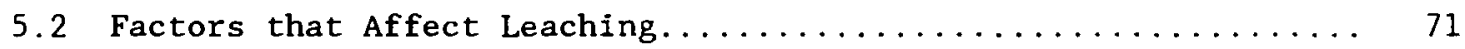

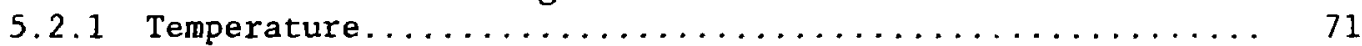

5.2.2 Ratio of Waste Form Surface Area to Leachant Volume.... 75

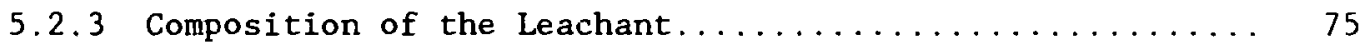

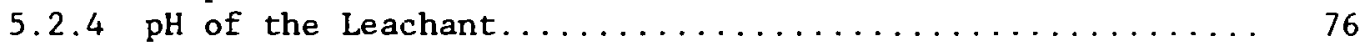

5.2.5 Leachant Flow Rate or Replacement Frequency.......... 77

5.2 .6 Composition of the Waste Form............... 77

5.2.7 Ratio of Volume to Surface Area in the Waste Form...... 78

5.2 .8 Surface Condition and Porosity............... 79

6. VINYI. ESTER-STYRENE EMULSION WITH AQUEOUS SODIUM SULFATE AS

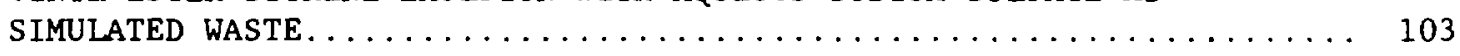

6.1 Leaching Mechanisms......................... 103 
TABLE OF CONTENTS (cont.)

Page

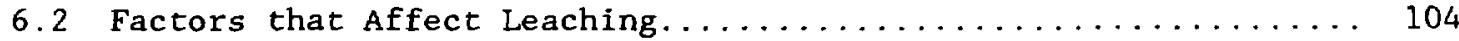

6.2 .1 Temperature............................. 104

6.2.2 Ratio of Leachant Volume to Waste Form Surface Area..... 105

6.2 .3 Composition of the Leachant.................. 105

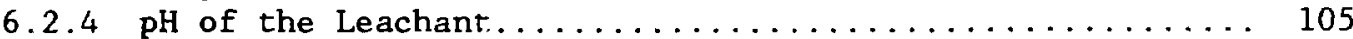

6.2.5 Effect of the Flow Rate or Replacement

Frequency of the Leachant on VES Emulsion with

Sodium Sulfate Solution................... 106

6.2 .6 Composition of the Waste Form.................. 106

6.2.7 Ratio of Volume to Surface Area of the Waste Form....... 107

6.2.8 Porosity and Surface Condition of the Waste Form....... 108

7. VINYL ESTER-STYRENE CONTAINING SODIUM SULFATE SALT AS SIMULATED

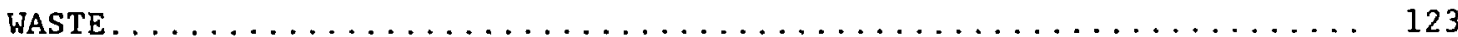

7.1 Mechanisms of Leaching........................ 123

7.2 Factors that Affect Leaching.......................... 124

7.2 .1 Temperature............................ 124

7.2.2 Ratio of Waste Form Surface Area to Leacharit Volume..... 124

7.2 .3 Composition of the Leachant.................. 125

$7.2 .4 \mathrm{pH}$ of the Leachant........................ 125

7.2.5 Flow Rate or Replacement Frequency of the Leachant...... 126

7.2 .6 Composition of the Waste Form................ 126

7.2 .7 Waste Form Volume to Surface Area Ratio.............. 126

7.2.8 Porosity and Surface of the Waste Form............ 127

8. BITUMEN CONTAINING SODIUM TETRABORATE SALT AS SIMULATED WASTE...... 147

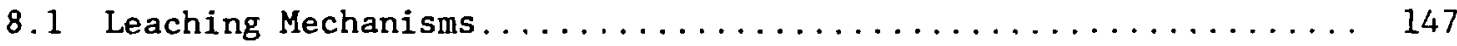

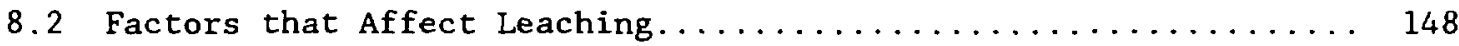

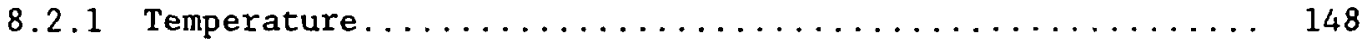

8.2.2 Surface Area of the Waste Form to Leachant Volume....... 149

8.2 .3 Leachant Composition...................... 149

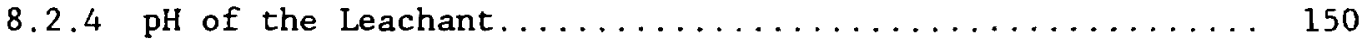

8.2.5 Flow and Replacement Frequency of the Leachant......... 151

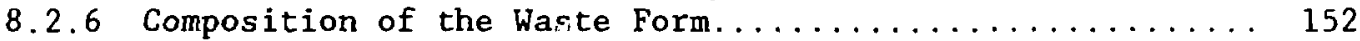

8.2.7 Ratio of Surface to Volume $(\mathrm{V} / \mathrm{S})$ in the Waste Form...... 153

8.2.8 Porosity and Surface Condition of the Waste Form........ 154

9. SODA-LIME GLASS CONTAINING INCINERATOR ASH AS SIMULATED WASTE. . . . . 177 


\section{TABLE OF CONTENTS (cont.)}

Page

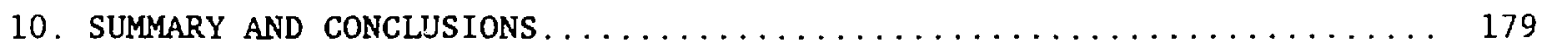

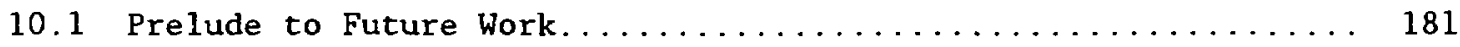

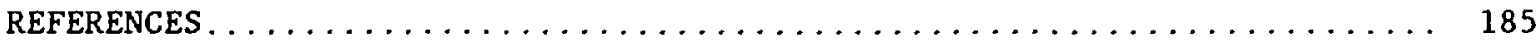

APPENDIX A

APPENDIX B 


\section{LIST OF FIGURES}

Figure 3.1 Schematic summary of waste form types listed by solidi-

fication agent, waste type and waste loading(s) .........

Figure 4.1 Cs-137 cumulative fraction leached vs. time from portland I cement containing 5 wt sodium sulfate at 20,40 and $50^{\circ} \mathrm{C}$. Samples were leached in

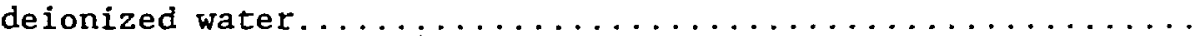

Figure 4.2 Linear correlation plots for Cs-137 leaching from portland I cement containing 5 wto sodium sulfate at 20,40 and $50^{\circ} \mathrm{C}$. Correlations are relative to the $20^{\circ} \mathrm{C}$ data. Samples were leached in deionized

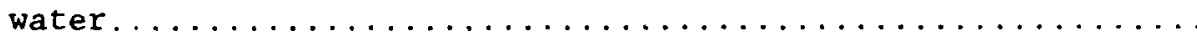

Figure 4.3 Arrhenius plot of Cs-137 incremental leach rates

from portland I cement containing 5 wto sodium sulfate leached at 20,40 and $50^{\circ} \mathrm{C}$ in deionized water.

Figure 4.4 Linear correlation plots for Cs-137 leaching from pure portland I cement at $20,30,40,50$ and $70^{\circ} \mathrm{C}$. Correlations are relative to the $20^{\circ} \mathrm{C}$ data. Samples were leached in deionized water.......... 40

Figure 4.5 Arrhenius plot of Cs-137 incremental leach rates from pure portland I cement leached at $20,30,40,50$

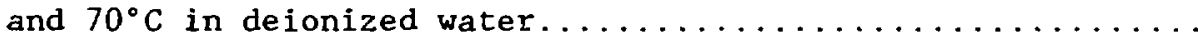

Figure 4.6 Sr-85 cumulative fraction leached vs. time from portland I cement containing 5 wto sodium sulfate at 20,40 and $50^{\circ} \mathrm{C}$ leached in deionized water.............

Figure 4.7 Linear correlation plots for Sr-85 leaching from portland I cement containing 5 wt sodium sulfate at 20,40 and $50^{\circ} \mathrm{C}$. Correlations are relative to the $20^{\circ} \mathrm{C}$ data. Samples were leached in

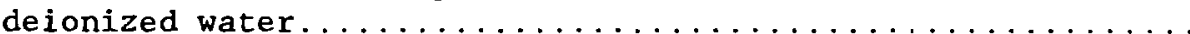

Figure 4.8 Arrhenius plot of Sr-85 incremental leach rates from portland I cement containing 5 wto sodium sulfate leached at 20,40 and $50^{\circ} \mathrm{C}$ leached in deionized water.

Figure 4.9 Sodium cumulative amount (mg) leached vs. time from portland I cement containing 5 wto sodium sulfate at 20 and $50^{\circ} \mathrm{C}$. Samples were leached in deionized water. 
LIST OF FIGURES (cont.)

Figure 4.10 Potassium cumulative amount (mg) leached vs. time from portland I cement containing 5 wto sodium sulfate at 20 and $50^{\circ} \mathrm{C}$. Samples were leached

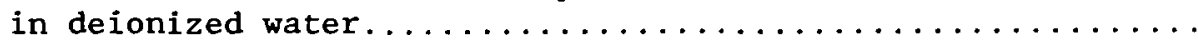

Figure 4.11 Calcium cumulative amount (mg) leached vs. time from portland I cement containing $5 \mathrm{wt}$ sodium sulfate at 20 and $50^{\circ} \mathrm{C}$. Samples were leached in

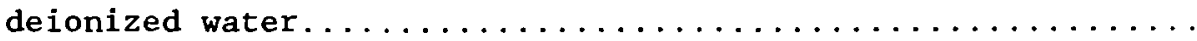

Figure 4.12 Strontium cumulative amount (mg) leached vs. time from portland I cement containing 5 wto sodium sulfate at 20 and $50^{\circ} \mathrm{C}$. Samples were leached in deionized water.

Figure 4.13 Linear correlation plot for Sodium, Potassium and Cs-137 leaching at 20 and $50^{\circ} \mathrm{C}$ from portland I cement containing 5 wto sodium sulfate. Correlations are relative to the Cs-137 data. Samples were leached in deionized water...............

Figure 4.14 Linear correlation plot for Strontium and Sr-85

leaching at 20 and $50^{\circ} \mathrm{C}$ from portland $\mathrm{I}$

cement containing 5 wto sodium sulfate. Correlations are relative to the $\mathrm{Sr}-85$ data. Samples were leached

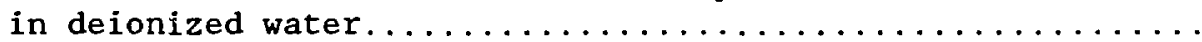

Figure 4.15 Cs-137 cumulative fraction leached vs. time from portland I cement containing 5 wto sodium sulfate at leachant volume to waste form surface area ratios of $10,20,30$ and 50:1. Samples were leached in deionized water at $20^{\circ} \mathrm{C}$

Figure 4.16 Sr-85 cumulative fraction leached vs. time from portland I cement containing 5 wt sodium sulfate at leachant volume to waste form surface area ratios of $10,20,30$ and 50:1. Samples were leached in

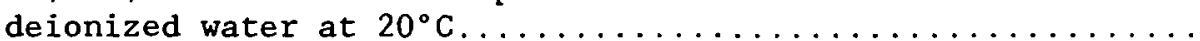

Figure 4.17 Cs-137 cumulative fraction leached vs, time from portland I cement containing 5 wto sodium sulfate leached in DIW, oxic and anoxic groundwaters at $20^{\circ} \mathrm{C}$ 
LIST OF FIGURES (cont.)

Page

Figure 4.18 Cs-137 cumulative fraction leached vs. time from portland I cement containing 5 wto sodium sulfate leached in DIW and in DIW containing $100 \mathrm{ppm}$ disodium

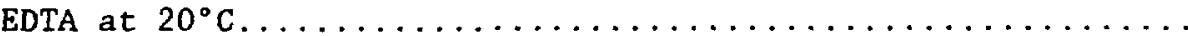

Figure 4.19 Linear correlation plots for Cs-137 leached from portland I cement containing 5 wto sodium sulfate leached in DIW, oxic and anoxic groundwaters at

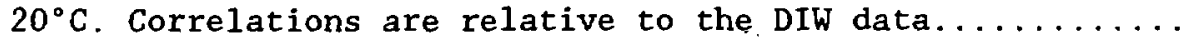

Figure 4.20 Linear correlation plots for Cs-137 leached from portland I cement containing 5 wto sodium sulfate leached in DIW and DIW containing 100 ppm disodium EDTA at $20^{\circ} \mathrm{C}$. Correlations are relative to

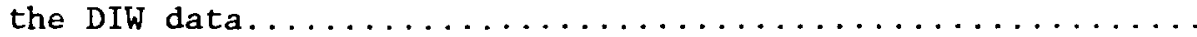

Figure 4.21 Sr-85 cumulative fraction leached vs. time from portland I cement containing 5 wt sodium sulfate leached in DIW, oxic and anoxic groundwaters at

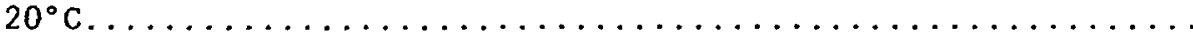

Figure 4.22 Sr-85 cumulative fraction leached vs. time from portland I cement containing 5 wto sodium sulfate leached in DIW and in DIW containing $100 \mathrm{ppm}$ disodium

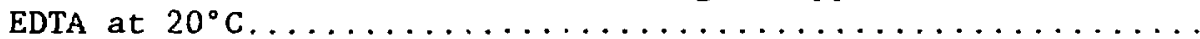

Figure 4.23 Linear correlation plots for Sr-85 leached from portland I cement containing 5 wto sodium sulfate in DIW, oxic and anoxic groundwaters. Correlations are relative to the DIW data. Samples were leached at $20^{\circ} \mathrm{C}$.

Figure 4.24 Linear correlation plots for $\mathrm{Sr}-85$ leached from portland I cement containing 5 wt 8 sodium sulfate in DIW and DIW containing $100 \mathrm{ppm}$ disodium EDTA at $20^{\circ} \mathrm{C}$. Correlations are relative to the DIW data..........

Figure 4.25 Sodium cumulative amount leached (ppm) vs. time from portland I cement containing 5 wto sodium sulfate leached in $\mathrm{DIW}$ and oxic groundwater at $20^{\circ} \mathrm{C}$

Figure 4.26 Potassium cumulative amount leached (ppm) vs. time from portland I cement containing 5 wto sodium sulfate leached in DIW and oxic groundwater at $20^{\circ} \mathrm{C}$. 
LIST OF FIGURES (cont.)

Page

Figure 4.27 Calcium cumulative amount leached (ppm) vs. timie from portland I cement containing 5 wto sodium sulfate

leached in DIW and oxic groundwater at $20^{\circ} \mathrm{C} \ldots \ldots \ldots \ldots \ldots$

Figure 4.28 Strontium cumulative amount leached (ppm) vs. time from portland I cement containing 5 wto sodium sulfate leached in DIW and oxic groundwater at

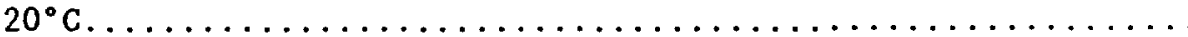

Figure 4.29 Linear correlation plots for Sodium leached from portland I cement containing 5 wto sodium sulfate in DIW and oxic groundwater at $20^{\circ} \mathrm{C}$.

Correlations are relative to the DIW data............. 53

Figure 4.30 Linear correlation plots for Potassium leached from portland I cement containing 5 wto sodium sulfate in DIW and oxic groundwater at $20^{\circ} \mathrm{C}$.

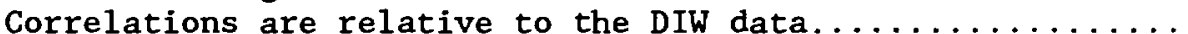

Figure 4.31 Linear correlation plots for Calcium leached from portland I cement containing 5 wto sodium sulfate in DIW and oxic groundwater at $20^{\circ} \mathrm{C}$.

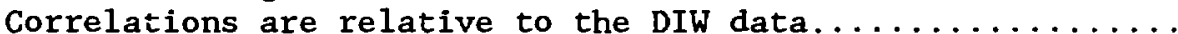

Figure 4.32 Linear correlation plots for Strontium leached from portland I cement containing 5 wto sodium sulfate in DIW and oxic groundwater at $20^{\circ} \mathrm{C}$.

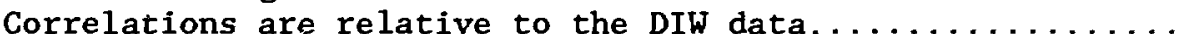

Figure 4.33 Cs-137 cumulative fraction leached vs. time from portland I cement containing 5 wto sodium sulfate leached at $20^{\circ} \mathrm{C}$ in leachants with initial $\mathrm{pH}$

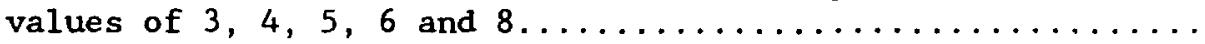

Figure 4.34 Linear correlation plots for Cs-137 leached from portland I cement containing 5 wto sodium sulfate in leachants with initial $\mathrm{pH}$ values of $3,4,5,6$ and 8 . Correlations are relative to the $\mathrm{pH} 6$ (DIW) data.

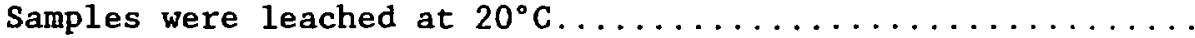

Figure 4.35 Sr-85 cumulative fraction leached vs. time from portland I cement containing 5 wto sodium sulfate leached at $20^{\circ} \mathrm{C}$ in leachants with initial $\mathrm{pH}$ values of $3,4,5,6$ and 8 
Figure 4.36 Linear correlation plots for $\mathrm{Sr}-85$ leached from portland I cement containing 5 wts sodium sulfate in leachants with initial $\mathrm{pH}$ values of $3,4,5,6$ and 8 . Correlations are relative to the pH 6 (DIW) data.

Samples were leached at $20^{\circ} \mathrm{C} \ldots \ldots \ldots \ldots \ldots \ldots \ldots \ldots \ldots$

Figure 4.37 Cs-137 cumulative fraction leached vs. time from daily leachant replacement and from modified ANS 16.1 leachant replacement schedule for portland I cement waste forms containing 5 wto sodium sulfate leached

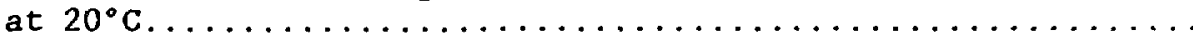

Figure 4.38 linear correlation plots for Cs-137 leached at $20^{\circ} \mathrm{C}$ using daily leachant replacement and the modified ANS 16.1 leachant replacement schedule for portland I cement waste forms containing 5 wto sodium

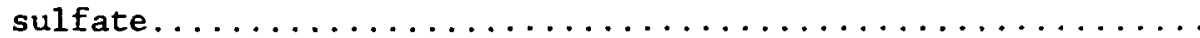

Figure $4.39 \mathrm{Sr}-85$ cumulative fraction leached vs. time from daily leachant replacement and from modified ANS 16.1 leachant replacement schedule for portland I cement waste forms containing 5 wto sodium sulfate leached

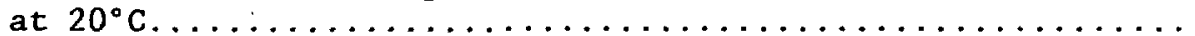

Figure 4.40 Linear correlation plots for Sr-85 leached at $20^{\circ} \mathrm{C}$ using daily leachant replacement and the modified ANS 16.1 leachant replacement schedule for portland I cement waste forms containing 5 wto sodium sulfate. Correlations are relative to the ANS 16.1

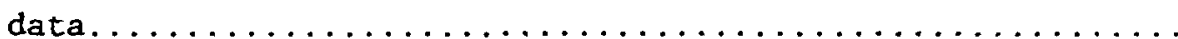

Figure 4.41 Portland I cement waste forms containing 5 weight o sodium sulfate. The one at left is as fabricated. The one at right was leached for 403 days in deionized water at $20^{\circ} \mathrm{C}$. Samples were $4.8 \mathrm{~cm}$ diameter by $6.4 \mathrm{~cm}$ high right cylinders.............

Figure 4.42 Cs-137 cumulative fraction leached vs. time from portland I cement waste forms containing 5 wto sodium sulfate and from pure portland I cement at $20^{\circ} \mathrm{C}$.

Figure 4.43 Linear correlation plots for Cs-137 leached at $20^{\circ} \mathrm{C}$ for portland I cement waste forms containing 5 wto sodium sulfate and pure portland I cement. Correlations are relative to pure cement.......... 
LIST OF FIGURES (cont.)

Page

Figure $4.44 \mathrm{Sr}-85$ cumulative fraction leached vs. time from portland I cement waste forms containing 5 wto sodium sulfate and from pure portland I cement at

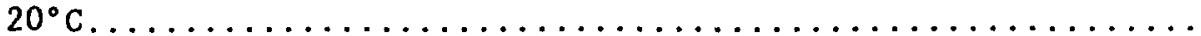

Figure 4.45 Linear correlation plots for Sr-85 leached at $20^{\circ} \mathrm{C}$ for portland I cement waste forms containing 5 wto sodium sulfate and pure portland I cement. Correlations are relative to pure cement...........

Figure 4.46 Linear correlation plot for Sr-85 versus Cs-137

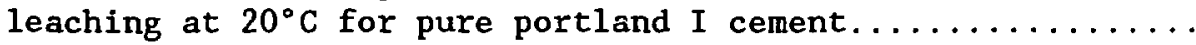

Figure 4.47 Linear correlation plot for Sr-85 versus Cs-137

leaching at $20^{\circ} \mathrm{C}$ for portland I cement

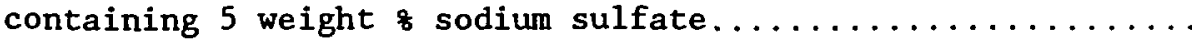

Figure 4.48 Leaching curves of cumulative release (ppm) vs. time of sodium, potassium, calcium and strontium from portland I cement containing 5 weight $\%$ sodium sulfate. Samples were leached at $20^{\circ} \mathrm{C}$ in

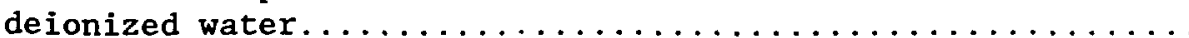

Figure 4.49 Cs-137 cumulative fraction leached vs. time from portland I cement containing 5 wto sodium sulfate at waste form volume to surface area (V/S) ratios of $0.42,0.61,0.85$ and 1.85 . Samples were leached in

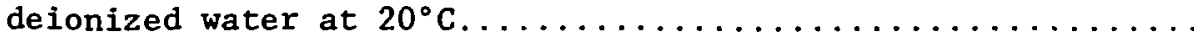

Figure 4.50 Linear correlation plots for Cs-137 leached from portland I cement containing 5 wto sodium sulfate at waste form volume to surface area ratios of 0.42 , $0.61,0.85$ and 1.85 . Correlations are relative to $\mathrm{V} / \mathrm{S}=0.85$. Samples were leached in deionized water

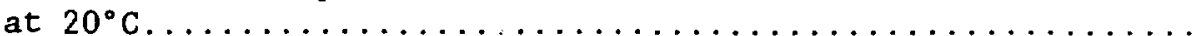

Figure 4.51 Sr-85 cumulative fraction leached vs. time from portland I cement containing 5 wto sodium sulfate at waste form volume to surface area (V/S) ratios of $0.42,0.61,0.85$ and 1.85 . Samples were leached in

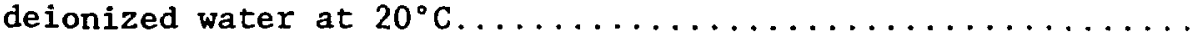




\section{LIST OF FIGURES (cont.)}

Figure 4.52 Linear correlation plots for $\mathrm{Sr}-85$ leached from portland I cement containing 5 wto sodium sulfate at waste form volume to surface area (V/S) ratios of $0.42,0.61,0.85$ and 1.85 . Correlations are relative to $\mathrm{V} / \mathrm{S}=0.85$. Samples were leached in deionized

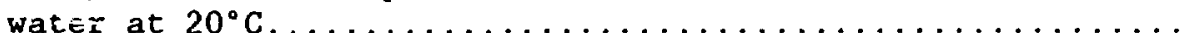

Figure 4.53 Outer surface: of an unleached cement sample containing 5 \& sodium sulfate at a magnification of 400 times. Tìis surface is indistinguishable from that of unleached pure cement....................

Figure 4.54 Outer surface of an unleached cement sample containing 58 sodium sulfate at a magnification of

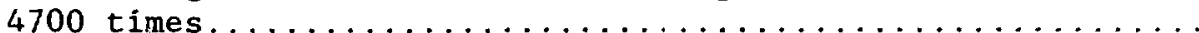

Figure 4.55 Outer surface of a cement sample containing 58 sodium sulfate after static leaching for 55 days at $50^{\circ} \mathrm{C}$. Magnification is 400 times. Profuse crystal

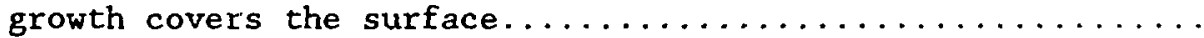

Figure 4.56 Outer surface of a cement sample containing 58 sodium sulfate after static leaching for 55 days at

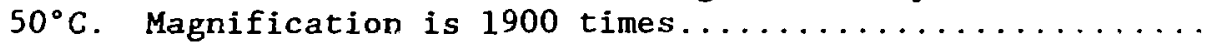

Figure 4.57 Interior of a cement sample containing 58 sodium sulfate after static leaching for 55 days at $50^{\circ} \mathrm{C}$. This is a cut sample from $2 \mathrm{~mm}$ inside the outer edge.

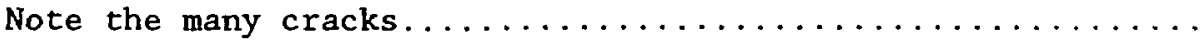

Figure 4.58 A bubble that after leaching was full of crystals. This was typical of voids in the sample...............

Figure 4.59 EDS spectrum of the outer surface of unleached cement sample containing 58 sodium sulfate. Note that $s^{-1} 1$ sodium and potassium peaks are present and that sulfur is enriched compared to pure cement..............

Figure 4.60 EDS spectrum of one of the crystals from Figure 4.58 . This spectrum is significantly different from that of the unleached cement containing sodium sulfate shown in Figure 4.59. Sulfur and aluminum are enriched while silicon is depleted relative to the unieached composition. 
LIST OF FIGURES (cont.)

Page

Figure 4.61 EDS spectrum of the leached surface of cement containing 58 sodium sulfate using a large analytical area. This spectrum is identical to that in Figure 4.60 from a single crystal in a pore.................

Figure 4.62 EDS spectrum of the center of the leached specimen. This more closely resembles the spectrum of the unleached material, Figure 4.59, than it does the

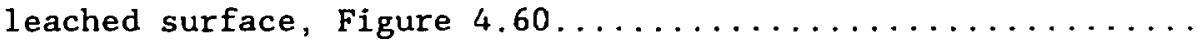

Figure 5.1 Cs-137 cumulative fraction leached vs. time from portland I cement containing 15 wto incinerator ash

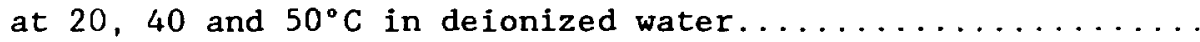

Figure 5.2 Linear correlation plots for Cs-137 leaching at 20 , 40 and $50^{\circ} \mathrm{C}$ in deionized water from portland I cement containing 15 wto incinerator ash.

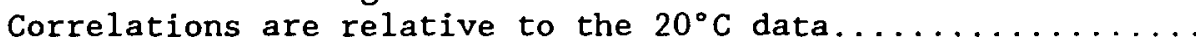

Figure 5.3 Arrhenius plot of Cs-137 incremental leach rates from portland I cement containing 15 wto incirierator ash leached at 20,40 and $50^{\circ} \mathrm{C}$ in deionized

Figure 5.4 Sr-85 cumulative fraction leached vs. time from portland I cement containing 15 wto incinerator ash

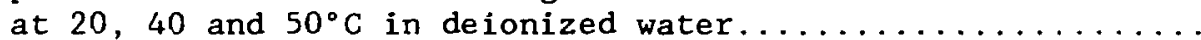

Figure 5.5 Linear correlation plots for Sr-85 leaching at 20, 40 and $50^{\circ} \mathrm{C}$ in deionized water from portland $\mathrm{I}$ cement containing 15 wto incinerator ash.

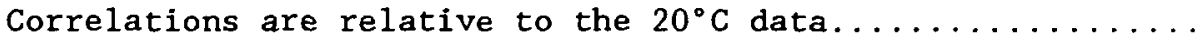

Figure 5.6 Arrhenius plot of Sr-85 incremental leach rates from portland I cement containing 15 wto incinerator ash leached at 20,40 and $50^{\circ} \mathrm{C}$ in deionized

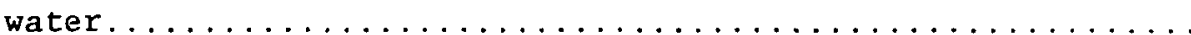

Figure 5.7 Sodium cumulative amount leached (ppm) vs. time from portland I cement containing 15 wt incinerator ash

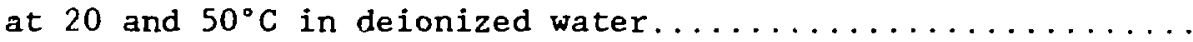

Figure 5.8 Potassium cumulative amount leached (ppm) vs. time from portland I cement containing 15 wto incinerator

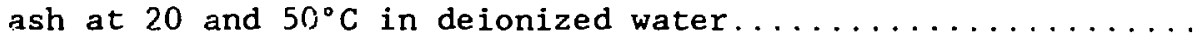




\section{LIST OF FIGURES (cont.)}

Figure 5.9 Galcium cumulative amount leached (ppm) vs. time from

portland I cement containing 15 wto incinerator ash

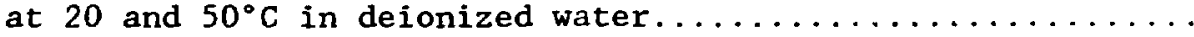

Figure 5.10 Strontium cumulative amount leached (ppm) vs. time

from portland I cement containing 15 wt incinerator

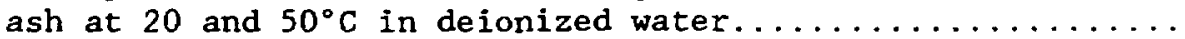

Figure 5.11 Linear correlation plots for Sodium, Potassium and

Cs -137 leaching at 20 and $50^{\circ} \mathrm{C}$ in deionized

water from portland $I$ cement containing 15 wto

incinerator ash. Correlations are relative to the

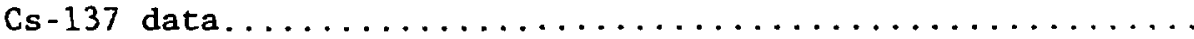

Figure 5.12 Linear correlation plots for Strontium and Sr-85

leaching at 20 and $50^{\circ} \mathrm{C}$ in deionized water

from portland I cement containing 15 wt\& incinerator

ash. Correlations are relative to the $\mathrm{Sr}-85$ data.........

Figure $5.13 \mathrm{Cs}-137$ cumulative fraction leached vs. time from

portland I cement containing 15 wto incinerator ash

leached in DIW and oxic groundwater at $20^{\circ} \mathrm{C} \ldots \ldots \ldots \ldots \ldots$

Figure 5.14 Linear correlation plots for Cs-137 leached at $20^{\circ} \mathrm{C}$ from portland I cement containing 15 wts

incinerator ash leached in DIW and oxic groundwater.

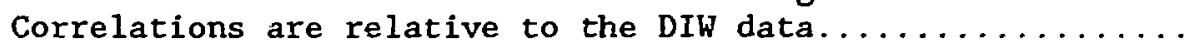

Figure $5.15 \mathrm{Sr}-85$ cumulative fraction leached vs. time from portland I cement containing 15 wto incinerator ash leached in DIW and oxic groundwater at $20^{\circ} \mathrm{C} \ldots \ldots \ldots \ldots \ldots$

Figure 5.16 Linear correlation plots for Sr-85 leached at $20^{\circ} \mathrm{C}$ from portland I cement containing 15 wts incinerator ash in DIW and oxic groundwater. Correlations are relative to the DIW data..............

Figure 5.17 Sodium cumulative amount leached (ppm) vs. time from portland I cement containing 15 wto incinerator ash leached in DIW and oxic groundwater at $20^{\circ} \mathrm{C} \ldots \ldots \ldots \ldots \ldots$

Figure 5.18 Potassium cumulative amount leached (ppm) vs. time from portland I cement containing 15 wto incinerator ash leached in DIW and oxic groundwater at

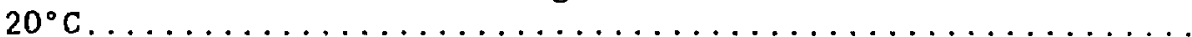


LIST OF FIGURES (cont.)

Page

Figure 5.19 Calcium cumulative amount leached (ppm) vs. time from portland I cement containing 15 wts incinerator ash leached in DIW and oxic groundwater at $20^{\circ} \mathrm{C}$. incinerator ash in DIW and oxic groundwater. Correlations are relative to the DIW data..............

Figure 5.20 Strontium cumulative amount leached (ppm) vs. time from portland I cement containing $15 \mathrm{wt} \%$ incinerator ash leached in DIW and oxic groundwater at

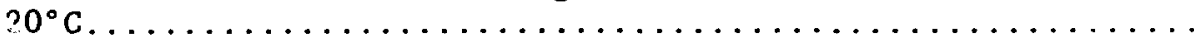

Figure 5.21 Linear correlation plots for Sodium leached at $20^{\circ} \mathrm{C}$ from portland I cement containing 15 wt: incinerator ash in DIW and oxic groundwater.

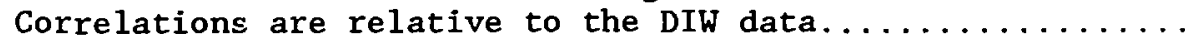

Fi.gure 5.22 Linear correlation plots for potassium leached at $20^{\circ} \mathrm{C}$ from Portland I cement containing 15 wt 8 incirerator ash in DIW and oxic groundwater.

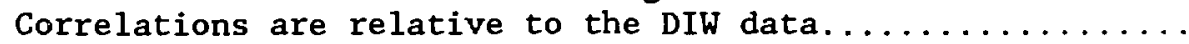

Figure 5.23 Linear correlation plots for Calcium leached at $20^{\circ} \mathrm{C}$ from portland I cement containing 15 wts incinerator ash in DIW and oxic groundwater.

Correlations are relative to the DIW data..............

Figure 5.24 Linear correlation plots for Strontium leached at $20^{\circ} \mathrm{C}$ from portland I cement containing 15 wt: incinerator ash in DIW and oxic groundwater. Correlations are relative to the DIW data..............

Figure 5.25 Cs -137 cumulative fraction leached vs. time from portland I cement containing 15 wto incinerator ash leached at $20^{\circ} \mathrm{C}$ in leachants with initial $\mathrm{pH}$

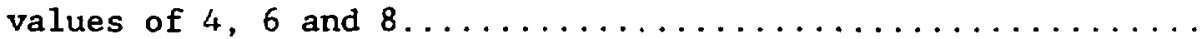

Figure 5.26 Linear correlation plots for Cs-137 leached at $20^{\circ} \mathrm{C}$ from portland I cement containing 15 wto incinerator ash in leachants with initial $\mathrm{pH}$ values of 4,6 and 8 . Correlations are relative to the $\mathrm{pH} 6$

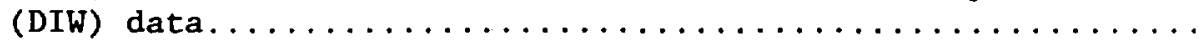

Figure 5.27 Sr-85 cumulative fraction leached vs. time from portland I cement containing $15 \mathrm{wto}$ incinerator ash leached at $20^{\circ} \mathrm{C}$ in leachants with initial $\mathrm{pH}$ values of 4,6 and 8 


\section{LIST OF FIGURES (cont.)}

Figure 5.28 Linear correlation plots for Sr-85 leached at $20^{\circ} \mathrm{C}$ from portland I cement containing 15 wt: incinerator ash in leachants with initial $\mathrm{pH}$ values of 4,6 and 8 . Correlations are relative to the $\mathrm{pH} 6$

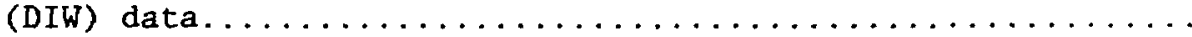

Figure 5.29 Cs-137 incremental leach rate vs. time from portland I cement containing 15 wto incinerator ash comparing results of MCC $-4 S$ flow test to modified ANS 16.1 leachant replacement schedule. Samples were leached at $20^{\circ} \mathrm{C}$

Figure 5.30 Sr-85 incremental leach rate vs. time from portland I cement containing 15 wto incinerator ash comparing results of $\mathrm{MCC}-4 \mathrm{~S}$ flow test to modified ANS 16.1 leachant replacement schedule. Samples were leached

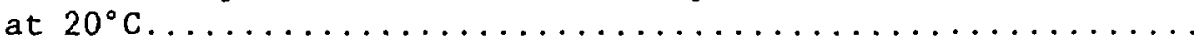

Figure 5.31 Portland I cement containing 15 weight \& incinerator ash. The form at left is as fabricated. The one at $20^{\circ} \mathrm{C}$. Samples were $4.8 \mathrm{~cm}$ diameter by $6.4 \mathrm{~cm}$ high

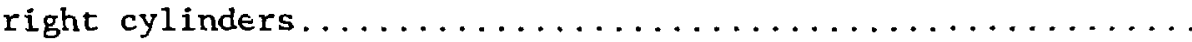

Figure 5.32 Cs-137 cumulative fraction leached vs. time from portland I cement containing 15 to incinerator ash and from pure portland $\mathrm{I}$ cement at $20^{\circ} \mathrm{C} \ldots \ldots \ldots \ldots \ldots \ldots$

Figure 5.33 Linear correlation plots for Cs-137 leached at $20^{\circ} \mathrm{C}$ for portland I cement containing $15 \mathrm{wt} \%$ incinerator ash and pure portland I cement. Correlations are relative to pure cement...............

Figure $5.34 \mathrm{Sr}-85$ cumulative fraction leached vs. time from portland I cement containing $15 \mathrm{wts}$ incinerator ash and from pure portland $I$ cement leached in DIW at $20^{\circ} \mathrm{C}$.

Figure 5.35 Linear correlation plots for Sr-85 leached from portland I cement containing 15 wto incinerator ash and from pure portland I cement. Correlations are relative to pure cement. Samples were leached in

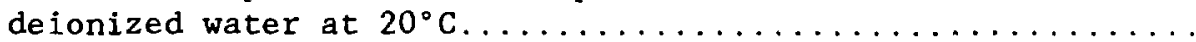

Figure 5.36 Linear correlation plot for Sr-85 versus Cs-137 leached from portland I cement containing 15 wto incinerator ash in deionized water at $20^{\circ} \mathrm{C} \ldots \ldots \ldots \ldots \ldots$ 
Figure 5.37 Leaching curves of cumulative release (ppm) vs. time for sodium, potassium, calcium and strontium from portland I cement containing 15 weight o incinerator ash. Samples were leached at $20^{\circ} \mathrm{C}$ in

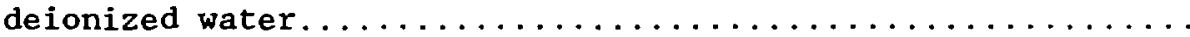

Figure 5.38 Cs-137 cumulative fraction leached vs. time from portland I cement containing 15 wto incinerator ash at waste form volume to surface area $(\mathrm{V} / \mathrm{S})$ ratios of $0.42,0.61$ and 0.91 . Samples were leached in

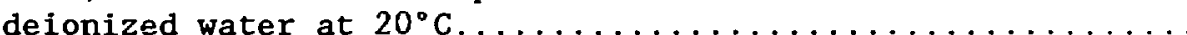

Figure 5.39 Linear correlation plots for Cs-137 leached from portland I cement containing 15 wto incinerator ash at waste form volume to surface area $(\mathrm{V} / \mathrm{S})$ ratios of $0.42,0.61$ and 0.91 . Correlations are relative to $\mathrm{V} / \mathrm{S}=0.91$. Samples were leached in deionized water

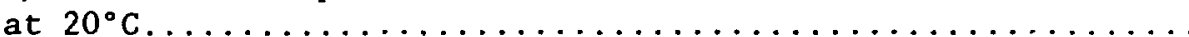

Figure $5.40 \mathrm{Sr}-85$ cumulative fraction leached vs. time from portland I cement containing 15 wt incinerator ash at waste form volume to surface area (V/S) ratios of $0.42,0.61$ and 0.91 . Samples were leached in

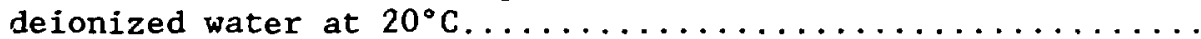

Figure 5.41 Linear correlation plots for Sr-85 leached from portland I cement containing 15 wto incinerator ash at waste form volume to surface area (V/S) ratios of $0.42,0.61$ and 0.91 . Correlations are relative to $\mathrm{V} / \mathrm{S}$ $=0.91$. Samples were leached in deionized water at

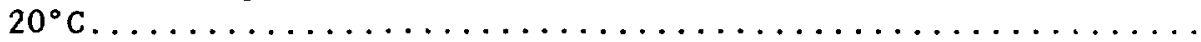

Figure 5.42 The ash itself is often more porous than the cement

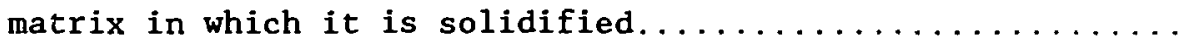

Figure 5.43 Large voids form possibly due to gas generation or differential water sorption between the cement and the ash.

Figure 6.1 Cs-137 cumulative fraction leached vs. time from VES emulsion with aqueous sodium sulfate at 20,40 and $50^{\circ} \mathrm{C}$. Samples were leached in deionized water.

Figure 6.2 Linear correlation plots for Cs-137 leaching from VES emulsion with aqueous sodium sulfate at 20,40 and $50^{\circ} \mathrm{C}$. Correlations are relative to the $20^{\circ} \mathrm{C}$ data. Samples were leached in deionized water............ 


\section{LIST OF FIGURES (cont.)}

Page

Figure 6.3 Sr-85 cumulative fraction leached vs. time from VES emulsion with aqueous sodium sulfate at 20,40 and $50^{\circ} \mathrm{C}$. Samples were leached in deionized water.......... 110

Figure 6.4 Linear correlation plots for Sr-85 leaching from VES emulsion with aqueous sodium sulfate at 20,40 and $50^{\circ} \mathrm{C}$. Correlations are relative to the $20^{\circ} \mathrm{C}$

data. Samples were leached in deionized water.......... 110

Figure 6.5 Co-57 cumulative fraction leached vs. time from VES emulsion with aqueous sodium sulfate at 20,40 and

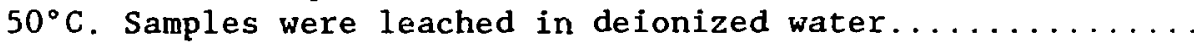

Figure 6.6 Linear correlation plots for Co-57 leaching from VES emulsion with aqueous sodium sulfate at 20,40 and $50^{\circ} \mathrm{C}$. Correlations are relative to the $20^{\circ} \mathrm{C}$

data. Samples were leached in deionized water...........

Figure 6.7 Cs-137 cumulative fraction leached vs. time from VES emulsion with aqueous sodium sulfate leached in DIW

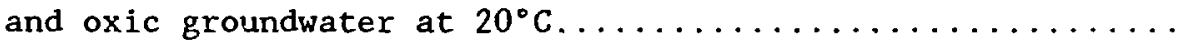

Figure 6.8 Sr-85 cumulative fraction leached vs. time from ves emulsion with aqueous sodium sulfate leached in DIW

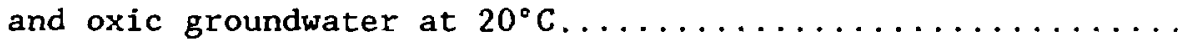

Figure 6.9 Co-57 cumulative fraction leached vs. time from VES emulsion with aqueous sodium sulfate leached in DIW

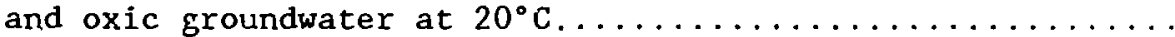

Figure 6.10 Cs-137 cumulative fraction leached vs. time from VES emulsion with aqueous sodium sulfate leached at $20^{\circ} \mathrm{C}$ in leachants with initial pH values of 4,6

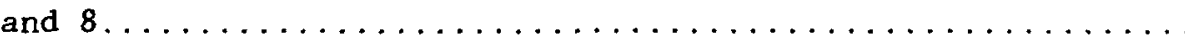

Figure 6.11 Sr-85 cumulative fraction leached vs. time from VES emulsion with aqueous sodium sulfate leached at $20^{\circ} \mathrm{C}$ in leachants with initial $\mathrm{pH}$ values of 4,6

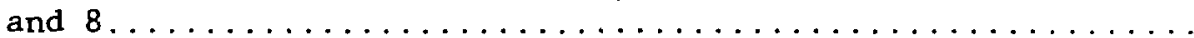

Figure 6.12 Co-57 cumulative fraction leached vs. time from VES emulsion with aqueous sodium sulfate leached at $20^{\circ} \mathrm{C}$ in leachants with initial $\mathrm{pH}$ values of 4,6 and 8 
LIST OF FIGURES (cont.)

Page

Figure $6.13 \mathrm{Cs}-137$ incremental leach rate vs. time from VES emulsion with sodium sulfate comparing results from MCC-4S flow test to modified ANS 16.1 leachant replacement schedule. Samples were leached at

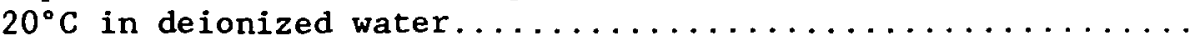

Figure 6.14 $\mathrm{Sr}-85$ incremental leach rate vs. time from VES emulsion with sodium sulfate comparing results from MCC-4S flow test to modified ANS 16.1 leachant replacement schedule. Samples were leached at

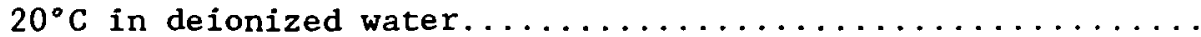

Figure 6.15 Co-57 incremental leach rate vs. time from VES emulsion with sodium sulfate comparing results from MCC-4S flow test to modified ANS 16.1 leachant replacement schedule. Samples were leached at

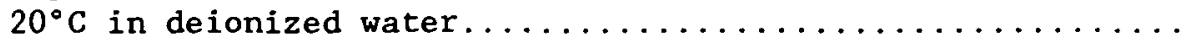

Figure 6.16 VES emulsion with aqueous sodium sulfate. The form at left is as fabricated. The one at right was leached for 403 days in deionized water at $20^{\circ} \mathrm{C}$. Samples were $4.8 \mathrm{~cm}$ diameter by $6.4 \mathrm{~cm}$ high right

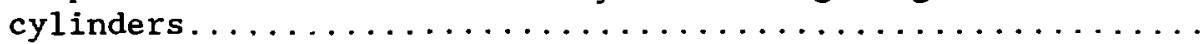

Figure 6.17 Sectioned specimen of VES emulsion with sodium sulfate solution that was leached for 100 days at

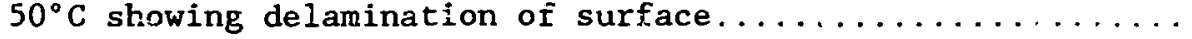

Figure 6.18 Cs-137 cumulative fraction leached vs. time from VES emulsion with aqueous sodium sulfate and from VES emulsion with DIW. Samples were leached at

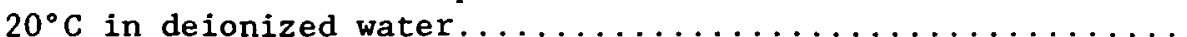

Figure 6.19 Sr-85 cumulative fraction leached vs. time from VES emulsion with aqueous sodium sulfate and from VES emulsion with DIW. Samples were leached at

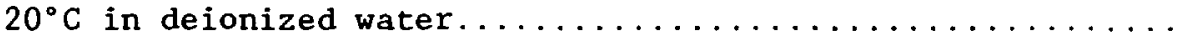

Figure 6.20 Co-57 cumulative fraction leached vs, time from VES emulsion with aqueous sodium sulfate and from VES emulsion with DIW. Samples were leached at $20^{\circ} \mathrm{C}$ in deionized water. 
Figure 6.21 Cs-137 cumulative fraction leached vs. time from VES emulsion with aqueous sodium sulfate at waste form volume to surface area $(\mathrm{V} / \mathrm{S})$ ratios of $0.42,0.62$ and 0.91 . Samples were leached in deionized water at $20^{\circ} \mathrm{C}$.

Figure 6.22 Sr-85 cumulative fraction leached vs. time from VES emulsion with aqueous sodium sulfate at waste form volume to surface area $(\mathrm{V} / \mathrm{S})$ ratios of $0.42,0.62$ and 0.91 . Samples were leach in deionized water at

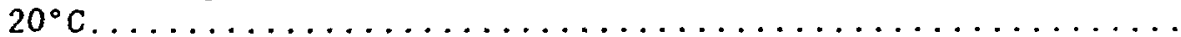

Figure 6.23 Co-57 cumulative fraction leached vs. time from vES emulsion with aqueous sodium sulfate at waste form volume to surface area $(\mathrm{V} / \mathrm{S})$ ratios of $0.42,0.62$ and 0.91 . Samples were leached in deionized water at

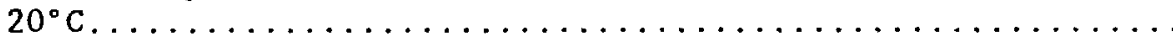

Figure 6.24 Surface of a VES emulsion saxple at a magnification of 400 times. Most pores are approximately 5-10

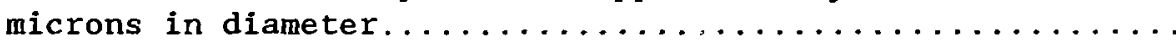

Figure 6.25 Interior section of a VES emulsion sample at a magnification of 400 times. The intexior structure appears similar to that of the surface shown in

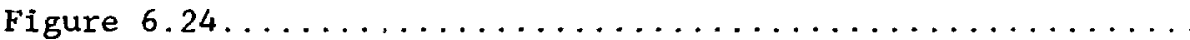

Figure 6.26 Surface of a VES emulsion sample at a magnification of 1900 times. Much smaller pores are visible with

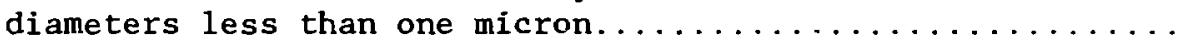

Figure 6.27 Interior section of a VES emulsion sample at a magnification of 1900 times. There is considerable saw debris, but the pores are in the same size range as those at the surface, shown in Figure $6.26 \ldots \ldots \ldots \ldots \ldots$

Figure 7.1 Cs-137 cumulative fraction leached vs. time from VES containing 40 wt 8 sodium sulfate at 20,40 and $50^{\circ} \mathrm{C}$. Samples were leached in deionized water.

Figure 7.2 Cs-137 cumulative fraction leached vs. time from VES containing 40 wto sodium sulfate at 20,40 and $50^{\circ} \mathrm{C}$ leached in deionized water. Initial 35

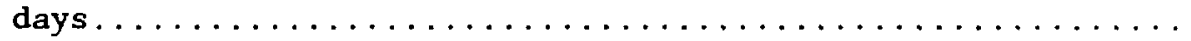


Figure $7.3 \mathrm{Sr}-85$ cumulative fraction leached vs. time from vES containing 40 wto sodium sulfate at 20,40 and

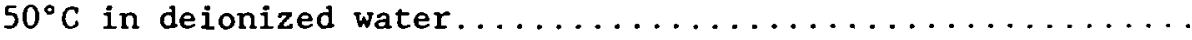

Figure 7.4 Co-57 cumulative fraction leached vs. time from VES containing 40 wt sodium sulfate at 20,40 and

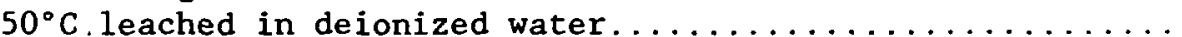

Figure 7.5 Linear correlation plots for Cs-137 leaching from VES containing 40 wto sodium sulfate at 20,40 and $50^{\circ} \mathrm{C}$. Correlations are relative to the $20^{\circ} \mathrm{C}$

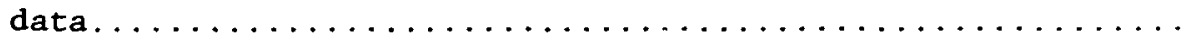

Figure 7.6 Linear correlation plats for Sr-85 leaching from VES containing 40 wto sodium sulfate at 20,40 and $50^{\circ} \mathrm{C}$. Correlations are relative to the $20^{\circ} \mathrm{C}$ data. Samples were leached in deionized water...........

Figure 7.7 Linear correlation flots for Co-57 leaching from VES containing 40 wto sodium sulfate at 20,40 and $50^{\circ} \mathrm{C}$. Correlations are relative to the $20^{\circ} \mathrm{C}$

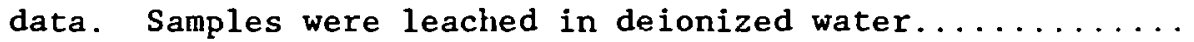

Figure 7.8 Cs-137 cumulative fraction leached vs. time from VES containing 40 wto sodium sulfate at leachant volume to waste form surface area ratios of $10,20,30$ and 50:1. Samples were leached in deionized water at

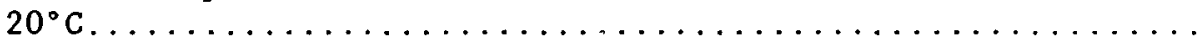

Figure 7.9 Sr-85 cumulative fraction leached vs, time from VES containing 40 wto sodium sulfate at leachant volume to waste form surface area ratios of $10,20,30$ and $50: 1$. Samples were leached in deionized water at

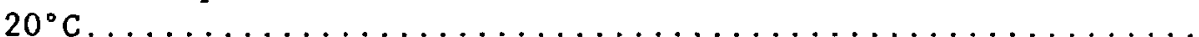

Figure 7.10 Co-57 cumulative fraction leached vs. time from VES containing 40 wto sodium sulfate at leachant volume to waste form surface area ratios of 10, 20, 30 and $50: 1$. Samples were leached in deionized water at

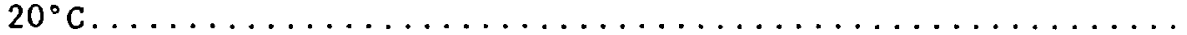

Figure 7.11 Cs-137 cumulative fraction leached vs. time from VES containing 40 wto sodium sulfate leached in DIW, oxic and anoxic groundwaters at $20^{\circ} \mathrm{C} \ldots \ldots \ldots \ldots \ldots \ldots$ 


\section{LIST OF FIGURES (cont.)}

Page

Figure 7.12 Sr-85 cumulative fraction leached vs. time from

VES containing 40 wto sodium sulfate leached in DIW, oxic and anoxic groundwaters at $20^{\circ} \mathrm{C} \ldots \ldots \ldots \ldots \ldots \ldots$

Figure 7.13 Co-57 cumulative fraction leached vs. time from VES containing 40 wt sodium sulfate leached in DIW, oxic

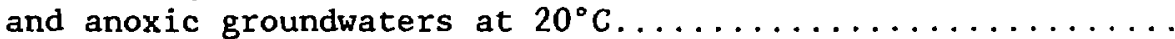

Figure 7.14 Cs-137 cumulative fraction leached vs. time from VES containing 40 wt sodium sulfate leached in DIW and in DIW containing 100 ppm disodium EDTA at $20^{\circ} \mathrm{C} \ldots \ldots \ldots \ldots \ldots$

Figure $7.15 \mathrm{Sr}-85$ cumulative fraction leached vs. time from VES containing 40 wto sodium sulfate leached in DIW and in DIW containing $100 \mathrm{ppm}$ disodium EDTA at $20^{\circ} \mathrm{C} \ldots \ldots \ldots \ldots$

Figure 7.16 Co-57 cumulative fraction leached vs. time from VES containing 40 wto sodium sulfate leached in DIW and in DIW containing $100 \mathrm{ppm}$ disodium EDTA at $20^{\circ} \mathrm{C} \ldots \ldots \ldots \ldots \ldots$

Figure 7.17 Cs-137 cumulative fraction leached vs. time from VES containing 40 wt sodium sulfate leached at $20^{\circ} \mathrm{C}$ in leachants with initial $\mathrm{pH}$ values of 3 ,

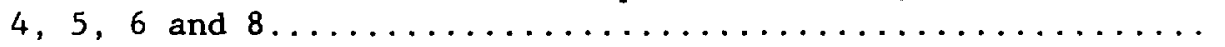

Figure $7.18 \mathrm{Gs}-137$ cumulative fraction leached vs. time from VES containing 40 wto sodium sulfate leached at $20^{\circ} \mathrm{C}$ in leachants with initial pH values of 3 , $4,5,6$ and 8 . First twenty days................ 136

Figure $7.19 \mathrm{Sr}-85$ cumulative fraction leached vs. time from VES containing 40 wto sodium sulfate leached at $20^{\circ} \mathrm{C}$ in leachants with initial $\mathrm{pH}$ values of 3 ,

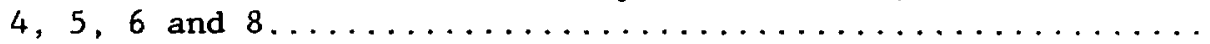

Figure 7.20 Co-57 cumulative fraction leached vs. time from VES containing 40 wto sodium sulfate leached at $20^{\circ} \mathrm{C}$ in leachants with initial $\mathrm{pH}$ values of 3 ,

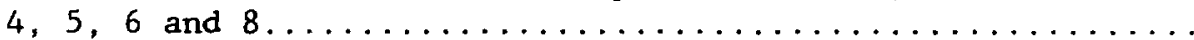

Figure 7.21 Linear correlation plots for Cs-137 leached from VES containing 40 wto sodium sulfate in leachants with initial $\mathrm{pH}$ values of $3,4,5,6$ and 8 at $20^{\circ} \mathrm{C}$. Correlations are relative to the $\mathrm{pH} 6$ (DIW) data......... 
LIST OF FIGURES (cont.)

Page

Figure 7.22 Cs-137 cumulative fraction leached vs. time from daily leachant replacement and from modified ANS 16.1 leachant replacement schedule for VES waste forms containing 40 wto sodium sulfate leached at $20^{\circ} \mathrm{C} \ldots \ldots \ldots \ldots$

Figure 7.2.3 $\mathrm{Sr}-85$ cumulative fraction leached vs. time from daily leachant replacement and from modified ANS 16.1 leachant replacement schedule for VES waste forms containing 40 wt sodium sulfate leached at $20^{\circ} \mathrm{C} \ldots \ldots \ldots \ldots$

Figure 7.24 Co-57 cumulative fraction leached vs. time from daily leachant replacement and from modified ANS 16.1 leachant replacement schedule for VES waste forms containing 40 wto sodium sulfate leached at $20^{\circ} \mathrm{C} \ldots \ldots \ldots \ldots$

Figure $7.25 \mathrm{Cs}-137$ incremental leach rate vs. time from VES containing 40 wto sodium sulfate comparing results of MCC-4S Flow test to modified ANS 16.1 leachant

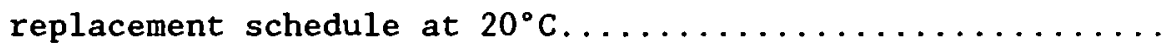

Figure $7.26 \mathrm{Sr}-85$ incremental leach rate vs. time from VES containing 40 wto sodium sulfate comparing results of MCC-4S Flow test to modified ANS 16.1 leachant

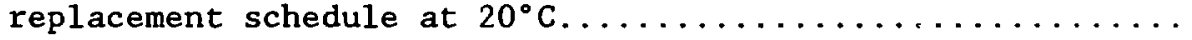

Figure 7.27 Co-57 incremental leach rate vs. time from VES containing 40 wto sodium sulfate comparing results of MCC-4S Flow test to modified ANS 16.1 leachant

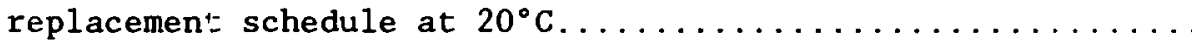

Figure 7.28 Cs-137 cumulative fraction leached vs. time from VES containing 20,30 and 40 wto sodium sulfate. Samples were leached in deionized water at $20^{\circ} \mathrm{C} \ldots \ldots \ldots \ldots \ldots \ldots$

Figure $7.29 \mathrm{Sr}-85$ cumulative fraction leached vs. time from VES containing 20,30 and 40 wto sodium sulfate. Samples were leached in deionized water at $20^{\circ} \mathrm{C} \ldots \ldots \ldots \ldots \ldots \ldots$

Figure 7.30 Co-57 cumulative fraction leached vs. time from VES containing 20,30 and 40 wt sodium sulfate. Samples were leached in deionized water at $20^{\circ} \mathrm{C} \ldots \ldots \ldots \ldots \ldots \ldots$

Figure 7.31 Cs-137 cumulative fraction leached vs. time from VES containing 40 wto sodium sulfate at waste form volume to surface area $(\mathrm{V} / \mathrm{S})$ ratios of $0.42,0.62$ and 0.91 . Samples were leached in deionized water at $20^{\circ} \mathrm{C} \ldots \ldots \ldots \ldots$ 


\section{LIST OF FIGURES (cont.)}

Page

Figure $7.32 \mathrm{Sr}-85$ cumulative fraction leached vs. time from VES containing 40 wto sodium sulfate at waste form volume to surface area (V/S) ratios of $0.42,0.62$ and 0.91 . Samples were leached in deionized water at $20^{\circ} \mathrm{C} \ldots \ldots \ldots \ldots$

Figure 7.33 Co-57 cumulative fraction leached vs. time from VES containing 40 wto sodium sulfate at waste form volume to surface area $(\mathrm{V} / \mathrm{S})$ ratios of $0.42,0.62$ and 0.91 . Samples were leached in deionized water at $20^{\circ} \mathrm{C} \ldots \ldots \ldots \ldots \ldots$

Figure 7.34 Vinyl ester-styrene forms containing 40 wto sodium sulfate. The ons at left is as fabricated. The one at right was leached for 403 days in deionized water at $20^{\circ} \mathrm{C}$. Samples were $4.8 \mathrm{~cm}$ diameter by $6.4 \mathrm{~cm}$ high

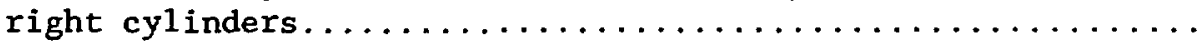

Figure 7.35 Interior of a sectioned, unleached VES specimen containing $40 \mathrm{wt}$ sodium sulfate. There appears to be little contact between grains of salt...............

Figure 7.36 Unleached surface of a VES specimen containing 40 wto sodium sulfate. No salt grains are visible but several open pores are evident. A leached surface is similar in appearance. Magnification is 400 times.........

Figure 7.37 Two grains of salt separated by VES polymer. This specimen had been leached but no obvious effect from the leaching was noted. No sodium or silfur was detected by EDS in the polymer between the grains.......... 146

Figure 8.1 Cs-137 cumulative fraction leached vs. time from bitumen containing 40 wto sodium tetraborate at 20 ,

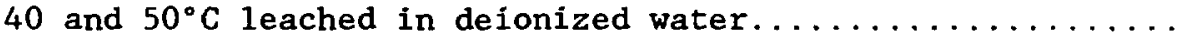

Figure 8.2 Linear correlation plots for Cs-137 leaching from bitumen containing 40 wto sodium tetraborate at 20 , 40 and $50^{\circ} \mathrm{C}$. Correlations are relative to

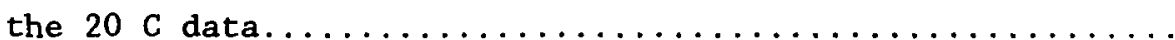

Figure 8.3 Sr-85 cumulative fraction leached vs. time from bitumen containing 40 wto sodium tetraborate at 20 ,

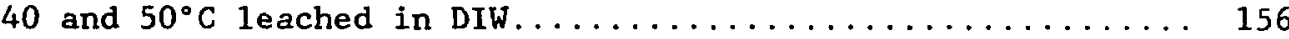


LIST OF FIGURES (cont.)

Page

Figure 8.4 Linear correlation plots for Sr-85 leaching from bitumen containing 40 wto sodium tetraborate at 20 , 40 and $50^{\circ} \mathrm{C}$. Correlations are relative to

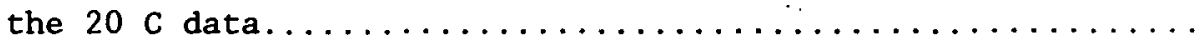

Figure 8.5 Co-57 cumulative fraction leached vs. time from bitumen containing 40 wto sodium tetraborate at 20 ,

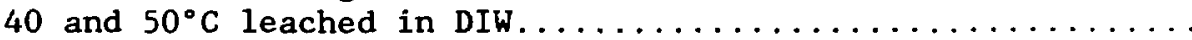

Figure 8.6 Linear correlation plots for Co-57 leaching from bitumen containing 40 wt sodium tetraborate at 20 , 40 and $50^{\circ} \mathrm{C}$. Correlations are relative to

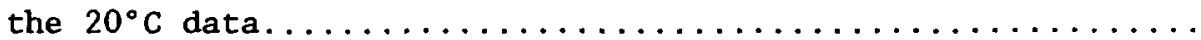

Figure 8.7 Cs-137 cumulative fraction leached vs. time from bitumen containing 40 wto sodiun tetraborate at leachant volume to waste form surface area ratios of 10,30 and 50:1. Samples were leached in DIW at

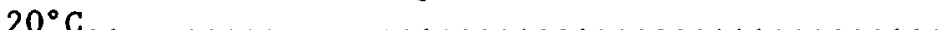

Figure 8.8 Sr-85 cumulative fraction leached vs. time from bitumen containing 40 wt sodium tetraborate at leachant volume to waste form surface area ratios of 10,30 and 50:1. Samples were leached in DIW at

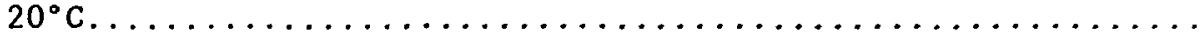

Figure 8.9 Co-57 cumulative fraction leached vs. time from bitumen containing 40 wt sodium tetraborate at leachant volume to waste form surface area ratios of 10,30 and 50:1. Samples were leached in DIW at $20^{\circ} \mathrm{C}$

Figure 8.10 Cs-137 cumulative fraction leached vs. time from bitumen containing 40 wto sodium tetraborate leached in DIW, oxic and anoxic groundwaters at $20^{\circ} \mathrm{C} \ldots \ldots \ldots \ldots \ldots$

Figure 8.11 Cs-137 cumulative fraction leached vs. time from bitumen containing 40 wt sodium tetraborate leached in DIW and in DIW containing 100 ppm disodium EDTA at $20^{\circ} \mathrm{C}$

Figure 8.12 Sr-85 cumulative fraction leached vs. time from bitumen containing 40 wts sodium tetraborate leached in DIW, oxic and anoxic groundwaters at $20^{\circ} \mathrm{C}$ 


\section{LIST OF FIGURES (cont.)}

Page

Figure $8.13 \mathrm{Sr}-85$ cumulative fraction leached vs. time from bitumen containing 40 wto sodium tetraborate leached in DIW and in DIW containing 100 ppm disodium EDTA at $20^{\circ} \mathrm{C}$

Figure 8.14 Co-57 cumulative fraction leached vs. time from bitumen containing 40 wto sodium tetraborate leached in $\mathrm{DIW}$, oxic and anoxic groundwaters at $20^{\circ} \mathrm{C} \ldots \ldots \ldots \ldots 16 \ldots \ldots$

Figure 8.15 Co-57 cumulative fraction leached vs. time from bitumen containing 40 wto sodium tetraborate leached in DIW and in DIW containing $100 \mathrm{ppm}$ disodium EDTA at

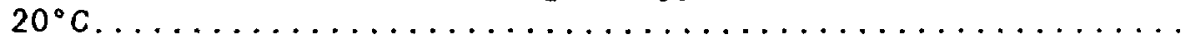

Figure 8.16 Linear correlation plots for Co-57 leached from bitumen containing 40 wto sodium tetraborate in DIW, oxic and anoxic groundwaters. Correlations are

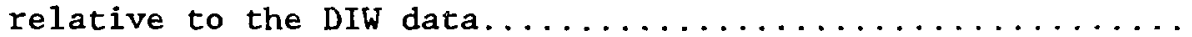

Figure 8.17 Linear correlation plots for Sr-85 leached from bitumen containing 40 wt sodium tetraborate in DIW and DIW containing $100 \mathrm{ppm}$ disodium EDTA. Correlations are relative to the DIW data.............. 163

Figure 8.18 Sodium, Boron cumulative amounts leached (ppm) vs. time from bitumen containing 40 wto sodium tetraborate leached in DIW and oxic groundwater at

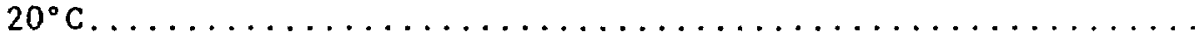

Figure 8.19 Linear correlation plots for Sodium, Boron and Cs-137

leached from bitumen containing 40 wt 8 sodium tetraborate in DIW and oxic rroundwater at $20^{\circ} \mathrm{C}$. Correlations are relative to the data for Cs -137 leached in DIW.......................... 164

Figure $8.20 \mathrm{Cs}-137$ cumulative fraction leached vs. time from bitumen containing 40 wto sodium tetraborate leached in leachants with initial $\mathrm{pH}$ values of 4,6 and 8 at $20^{\circ} \mathrm{C}$

Figure $8.21 \mathrm{Sr}-85$ cumulative fraction leached vs. time from bitumen containing 40 wt sodium tetraborate leached in leachants with initial $\mathrm{pH}$ values of 4,6 and 8 at $20^{\circ} \mathrm{C}$. 
LIST OF FIGURES (cont.)

Page

Figure 8.22 Co-57 cumulative fraction leached vs. time from bitumen containing 40 wt sodium tetraborate in leachants with initial pH values of 4,6 and 8

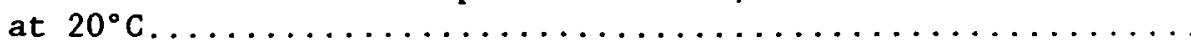

Figure 8.23 Linear correlation plots for Co-57 leached from bitumen containing 40 wto sodium tetraborate in leachants with initial pH values of 4,6 and 8 . Correlations are relative to the $\mathrm{pH} 6$ (DIW) data......... 166

Figure 8.24 Cs-137 cumulative fraction leached vs. time from daily leachant replacement and from modified ANS 16.1 leachant replacement schedule for bitumen waste forms containing 40 wto sodium tetraborate leached at

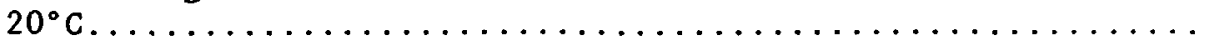

Figure 8.25 Linear correlation plots for Cs-137 leached from bitumen waste forms containing 40 wt 8 sodium tetraborate using daily leachant replacement and the modified ANS 16.1 leachant replacement schedule. Correlations are relative to the ANS 16.1 data............

Figure $8.26 \mathrm{Gs}-137$ incremental leach rate vs. time from bitumen waste forms containing 40 wt sodium tetraborate comparing results of MCC-4S Flow test to modified ANS 16.1 leachant replacement schedule at $20^{\circ} \mathrm{C} \ldots \ldots \ldots \ldots \ldots$

Figure $8.27 \mathrm{Sr}-85$ cumulative fraction leached vs. time from daily leachant replacement and from modified ANS 16.1 leachant replacement schedule for bitumen waste forms containing 40 wto sodium tetraborate leached at $20^{\circ} \mathrm{C}$.

Figure 8.28 Linear correlation plots for $\mathrm{Sr}-85$ leached from bitumen waste forms containing 40 wto sodium tetraborate using daily leachant replacement and the modified ANS 16.1 leachant replacement schedule. Correlations are relative to the ANS 16.1 data............

Figure 8.29 Sr-85 incremental leach rate vs. time from bitumen waste forms containing 40 wto sodium tetraborate comparing results of MCC-4S Flow test to modified ANS 16.1 leachant replacement schedule at $20^{\circ} \mathrm{C} \ldots \ldots \ldots \ldots \ldots \ldots$ 
LIST OF FIGURES (cont.)

Page

Figure 8.30 Co-57 cumulative fraction leached vs. time from daily leachant replacement and from modified ans 16.1 leachant replacement schedule for bitumen waste forms containing 40 wto sodium tetraborate leached at

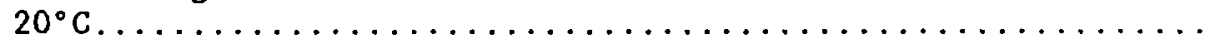

Figure 8.31 Linear correlation plots for Co-57 leached from bitumen waste forms containing 40 wto sodium tetraborate using daily leachant replacement and the modified ANS 16.1 leachant replacement schedule. Correlations are relative to the ANS 16.1 data.......... 170

Figure 8.32 Co-57 incremental leach rate vs. time from bitumen containing 40 wto sodium tetraborate comparing results of MCC-4S Flow test to modified ANS 16.1 leachant replacement schedule at $20^{\circ} \mathrm{C} \ldots \ldots \ldots \ldots \ldots \ldots$

Figure 8.33 Bitumen forms containing 40 wt8 sodium tetraborate. The one at left is as fabricated. The one at right was leached for 320 days in deionized water at $20^{\circ} \mathrm{C}$. Samples were $4.8 \mathrm{~cm}$ diameter by $6.4 \mathrm{~cm}$ high right

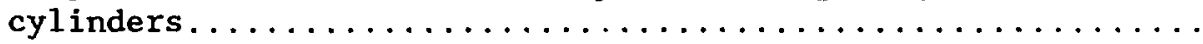

Figure 8.34 Cs-137 cumulative fraction leached vs. time from bitumen containing $0,20,30$ and 40 wto sodium tetraborate. Samples were leached in DIW at $20^{\circ} \mathrm{C} \ldots \ldots \ldots \ldots$

Figure $8.35 \mathrm{Sr}-85$ cumulative fraction leached vs. time from bitumen containing $0,20,30$ and 40 wto sodium tetraborate. Samples were leached in DIW at $20^{\circ} \mathrm{C} \ldots \ldots \ldots \ldots$

Figure 8.36 Co-57 cumulative fraction leached vs. time from bitumen containing $0,20,30$ and 40 wto sodium tetraborate. Samples were leached in DIW at $20^{\circ} \mathrm{C} \ldots \ldots \ldots \ldots$

Figure 8.37 Cs-137 cumulative fraction leached vs. time from bitumen containing 40 wto sodium tetraborate at waste form volume to surface area $(\mathrm{V} / \mathrm{S})$ ratios of 0.42 , 0.62 and 0.91 . Samples were leached in deionized water at $20^{\circ} \mathrm{C}$.

Figure 8.38 Sr-85 cumulative fraction leached vs. time from bitumen containing 40 wto sodium tetraborate at waste form volume to surface area (V/S) ratios of 0.42 , 0.62 and 0.91 . Samples were leached in deionized

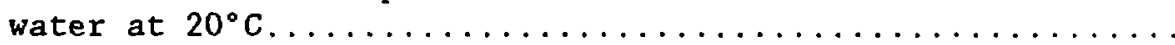




\section{LIST OF FIGURES (cont.)}

Figure 8.39 Linear correlation plots for Sr-85 leached from bitumen waste forms containing 40 wto sodium tetraborate at waste form volume to surface area ratios $(\mathrm{V} / \mathrm{S})$ of $0.42,0.62$ and 0.91 . Correlations are

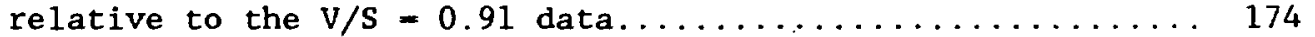

Figure 8.40 Co-57 cumulative fraction leached vs. time from bitumen containing 40 wt sodium tetraborate at waste form volume to surface area (V/S) ratios of 0.42 , 0.62 and 0.91 . Samples were leached in deionized water at $20^{\circ} \mathrm{C} \ldots \ldots \ldots \ldots \ldots \ldots \ldots \ldots \ldots \ldots \ldots \ldots \ldots$

Figure 8.41 Linear correlation plots for Co-57 leached from bitumen waste forms containing 40 wts sodium tetraborate at waste form volume to surface area ratios $(\mathrm{V} / \mathrm{S})$ of $0.42,0.62$ and 0.91 . Correlations are

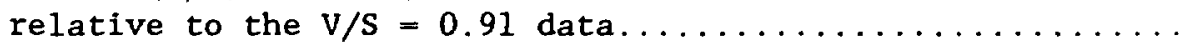




\section{LIST OF TABLES}

Page

Table No.

2.1 Factors That Affect Leaching of Low-Level Radioactive Waste Forms That Were Experimentally Investigated in This Program...

3.1 Composition (weight 8 ) for Each of the Waste Form Types

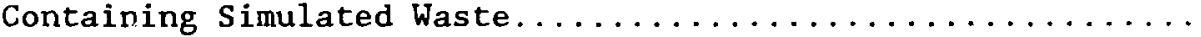

3.2 Composition of the Waste Forms of Pure Solidification Agent

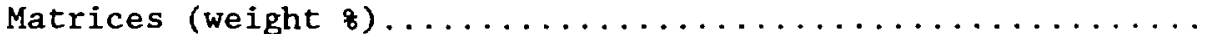

3.3 Major Cation and Anion Concentrations in Synthetic Oxic and

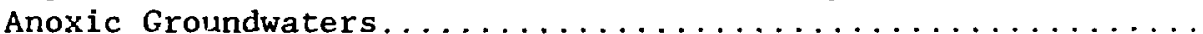

4.1 Apparent Activation Energies at Each Leachant Replacement Interval for Cs-137 Leaching from Portland Type I Cement Containing 5 wto Sodium Sulfate. Values are Listed in SI Units $(\mathrm{J} / \mathrm{mol})$ and CGS Units $(\mathrm{kcal} / \mathrm{mole}) \ldots \ldots \ldots \ldots \ldots \ldots$

4.2 Cs-137 CFL From Portland Cement at Temperatures of 20, 30, 40, 50 and $70^{\circ} \mathrm{C*}$. Each Row Represents a Leachant Replacement Interval (Time of Leachant Replacement in Days)............

4.3 Linear Correlations From the Leaching Data for Cs-137 From Pure Portland Cement at Temperatures of $20,30,40,50$ and $70^{\circ} \mathrm{C}$. The $20^{\circ} \mathrm{C}$ Data Set is the Standard Against which the Data at Elevated Temperatures Were Compared. The Slope of the Linear Correlation is Listed One Standard Deviation....

4.4 Activation Energies Calculated for Each Leachant Replacement Interval for Cs-137 Leaching from Pure Cement. Values are Listed in SI Units $(\mathrm{J} / \mathrm{mol})$ and CGS Units $(\mathrm{kcal} / \mathrm{mole}) \ldots . . .$.

4.5 Apparent Activation Energies for Sr-85 From Cement Containing

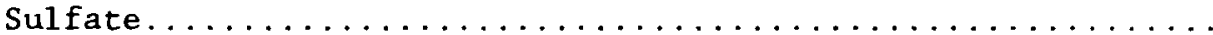

5.1 Apparent Activation Energies at Each Leachant Replacement Interval for Sr-85 and Cs-137 from Portland Type I Cement

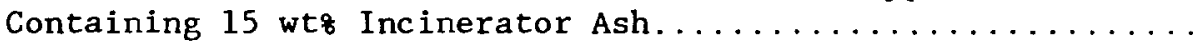

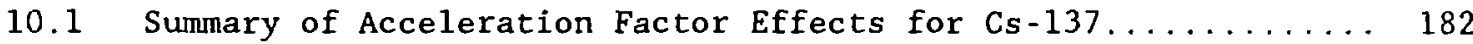

10.2 Summary of Acceleration Factor Effects for $\mathrm{Sr}-85 \ldots \ldots \ldots 183$

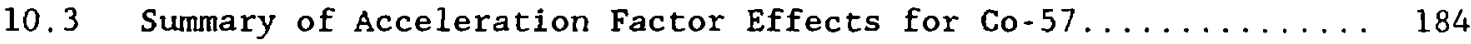


ABSTRACT

This report presents the results of an experimental survey of the factors that affect leaching from several types of solidified low-level radioactive waste forms. The goal of these investigations was to determine those factors that accelerate leaching without changing its mechanism(s). Typically, although not in every case, the accelerating factors include:

- increased temperature

- increased waste loading (i.e., increased waste to binder ratio)

- decreased size (i.e., decreased waste form volume to surface area ratio)

Additional factors that were studied were: increased leachant volume to waste form surface area ratio, $\mathrm{pH}$, leachant composition (groundwaters, natural and synthetic chelating agents), leachant flow rate or replacement frequency and waste form porosity and surface condition. Other potential factors, including the radiation environment and pressure, were omitted based on a survey of the literature.

Types of waste forms that were investigated included: portland I cement containing sodium sulfate, portland I cement containing incinerator ash, vinyl ester-styrene emulsion (Dow process) with sodium sulfate solution, vinyl ester-styrene with dry sodium sulfate salt, and bitumen containing sodium tetraborate as simulated wastes. Glass waste forms produced by a glassfurnace incinerator under an R\&D program at Mound Laboratory also were studied.

Evaluation of the factors as potential accelerating factors was based on comparison of the results from "standard samples," which were defined as nominal $4.8 \mathrm{~cm}$ diameter by $6.4 \mathrm{~cm}$ tall right cylinders leached in $1300 \mathrm{ml}$ of demineralized water at $20^{\circ} \mathrm{C}$. Comparisons included Arrhenius plots for experiments at increased temperature, linear correlations with the data from the standard samples, and microscopic examination.

Generally, accelerated leaching can be accomplished, but statistical variability of the results is increased by acceleration. Further, fabrication of the sample must be tightly controlled, especially for bitumen samples.

Cesium-137 leaching from cement was accelerated by increased temperature, with an activation energy of $4-6 \mathrm{kcal} / \mathrm{mole}$, which is consistent with diffusion of simple ions in water. For strontium-85 leaching from cement, the results of increased temperature were not clear because leaching does not occur by diffusion alone. Increased waste loading produced either a clear acceleration or an indication of acceleration accompanied by increased statistical variability for every system except $\mathrm{Sr}-85$ from cement, for which there was no acceleration. Decreased size produced increased acceleration for every system, again with increased statistical variability. Cobalt-57 leaching from bitumen was accelerated at $\mathrm{pH} 8$ and in groundwater, and was strongly accelerated in the presence of chelating agents in the leachant. 


\section{INTRODUCTION}

This report presents the results of investigations of factors that affect the leaching of solidified low-level radioactive waste (LLW) forms. The results continue earlier work that included a literature survey [1] of leaching mechanisms, and two annual reports [2,3] that gave our interim results. Our literature survey [1] identified thirteen individual factors contained in three categories that affect leaching. However, most of the experimental work associated with the identification and specification of these categories came from studies of glass waste forms under consideration for high-level waste. Little of the work on glass was applicable to low-level waste forms, which typically are fabricated from cement, bitumen or polymer solidification agents and contain different types of waste than the high-level waste. Glass solidification of LLW was investigated [4] under a DOE R\&D effort and remains an option for future application; however, glass is not currently used for solidification of LLW.

The principal types of waste forms selected for investigation in this program are typical of those currently produced by government and commercial nuclear activities.

The particular reason for investigating factors that affect LLW leaching is to provide a technical basis for development of accelerated leach tests that can predict the long-term leachabilities of LLW forms in disposal conditions. Also, since long-term prediction of leachabilities must be based on a knowledge of leaching mechanisms, these mechanisms are reviewed for the specific waste forms investigated in this task.

Sections 4 through 9 presents the results of leaching experiments and solid phase analysis for each combination of waste type/solidification agent investigated. Section 10 has tables that summarize the effectiveness of each factor. It may be useful for the reader to refer to these tables while reading the individual sections.

\subsection{Leaching Mechanisms and Long-Term Leachability}

If the long-term prediction of the leaching behavior of waste forms must be based on knowledge of leaching mechanisms, then the validity of characterizing a waste form by an effective diffusion coefficient, De, depends on diffusion being the leaching mechanism over the time of the prediction. If diffusion is not the leaching mechanism, then the following question must be answered: of what use is an effective diffusion coefficient measured from short-term tests for the long-term prediction of leachabilities of waste forms?

This question was addressed quantitatively for waste forms in which the short-term leaching mechanism is well represented as diffusion, but for which the long-term leachability is controlled by dissolution of a slightly soluble contaminant [5]. Specifically, at long times the release by leaching is underestimated by diffusion when dissolution becomes the controlling mechanism. If dissolution replaces diffusion control of leaching release before 
the latter is affected by depletion, which occurs at approximately 20 for diffusion [6], then long-term predictions of leachability from the semiinfinite medium model, as well as diffusion models that account for waste-form depletion, will underestimate the release at long times. The underestimation grows with time since the dissolution-controlled release remains constant (until depletion begins to decrease it) while diffusion-controlled release decreases steadily (i.e., as the inverse of the square root of time). Underestimation by diffusion model can become large if the contaminant inventory consists of relatively little of the initially mobile form compared to a relatively large amount of the slightly soluble form.

Another long-term problem can result from loss of integrity of the initial monolithic waste form by cracking, swelling, surface spalling and other processes that increase surface area. Such problems commonly occur when the solidification agent and the waste are not compatible, either physically or chemically. Waste forms consisting of ion exchange resins in cement generally disintegrate sometime after exposure to water due to swelling of the resins and the brittle nature of cement [7]. Sulfate salts in cement react to form the mineral ettringite, which may degrade the waste form over time by cracking [8].

Finally, authigenic mineral formation on the waste form surface and/or within the waste form may change the controlling leaching mechanism over time. Carbonate deposition on cement waste forms is well known, as is ettringite formation in cement waste forms containing sulfate salt.

\subsection{Effects of Waste Form Composition}

Our initial studies involved leaching experiments on pure solidification agents incorporating radioactive tracers of cesium, strontium and cobalt as the only "waste". These studies provided baseline information on the leaching behavior of the matrices of the pure solidification agent. Studies on more realistic waste forms incorporating simulated waste were started after the baseline experiments were well underway. The comparison between these two studies showed the importance of waste effects (i.e., chemical reaction) and of waste loading effects (i.e., physical consequences of composite waste forms) on both the short-and long-term leaching behavior of low-level waste forms. Indeed, the waste and waste loading effects were so dominant that substantially more effort was directed at these investigations than was initially planned. 


\section{FACTORS THAT AFFECT LEACHING OF LOW-LEVEL WASTE FORMS}

In 1981 Stone [9] reviewed the factors that might affect leachability. These factors were listed under three categories: (i) system factors, (ii) leachant factors, and (iii) waste form factors. System factors included time, temperature, pressure, radiation environment and the ratio of waste form surface area to leachant volume. Leachant factors included composition, $\mathrm{pH}$, Eh and flow rate or replacement frequency. Waste form factors included composition, surface condition and porosity. Some or all of these individual factors could be important for any given type of waste form.

A literature review of the factors affecting leachability specifically for LLW forms [1] concluded that pressure and the radiation environment were probably not significant for LLW forms. The relatively small overburden pressures (20-50 psi) in shallow land burial seemed unlikely to affect the leachability of LLW forms, with the possible exception of bitumen forms which could deform by creep. Studies of radiation effects on LLW forms showed that there were no changes in leachability up to $100 \mathrm{Mrad}$, although generation of radiolytic gas from organic materials occurred. Cement waste forms withstood substantially greater doses with no adverse effect on leachability.

Recently, two factors were noted that were not in Stone's original list which may have a substantial effect on LLW form leachability: wet-dry cycling $[10,11]$ and container effects [12]. Wet-dry cycling of leaching conditions is important for cement and other porous waste forms because it allows direct transport of solubilized radionuclides to the surface as the wet waste form dries. Container effects may result from damage due to swelling of a waste form inside a container. Wet-dry cycling has been well substantiated as affecting cement waste forms. Container effects were observed in leach tests made on partially exposed test samples, as in the original IAEA leach test [13], but have not been studied directly. The procedure for the IAEA leach test recommends using a containerized waste form with one face exposed to the leachant. The effects of wet-dry cycling and container effects may be important factors in the long-term behavior of LLW forms in actual disposal environments. However, because cognizance of these factors is relatively recent, little work on them is included in this program and in this report.

Table 2.1 lists the factors specifically addressed in this report. Time is not 1 isted as a factor because each factor includes time in the leaching results. Additionally, Eh is not considered independently because it is dependent on leachant composition and cannot be experimentally isolated; therefore, Eh is considered to be an aspect of leachant composition. Since the initial $\mathrm{pH}$ of the leachant is easily adjusted, $\mathrm{pH}$ is evaluated as an independent factor, although it is also an aspect of leachant composition.

Evaluation of the factors is based on comparison with leaching data for nominally identical waste forms (except for the factor being varied) at $20^{\circ} \mathrm{C}$ in deionized water (DIW) for a standard sample designated as a right cylinder with nominal dimensions of $4.8 \mathrm{~cm}$ diameter by $6.4 \mathrm{~cm}$ high. Data from the standard samples gives the baseline figures listed in Table 2.1. The baseline data were taken for long times to assure that they are representative of the 
leaching behavior of the sample over its, i.e., until depletion and/or degradation of the waste form occurs.

Table 2.1

Factors That Affect Leaching of Low-Level Radioactive Waste Forms That Were Experimentally Investigated in This Program

\section{System Factors}

- Temperature

- Ratio of Leachant Volume to Waste Form Surface Area

\section{Leachant Factors}

- Composition

$-\mathrm{pH}$

- Flow Rate or Replacement Frequency

\section{Waste Form Factors}

- Composition

- Volume to Surface Area Ratio

- Porosity

- Surface Condition

\subsection{Temperature}

Temperature is usually the first variable considered in attempts to change or analyze rate processes. This is because: (i) small changes in temperature often lead to large changes in the observed rates of many processes, and (ii) the variation of the rate with temperature often is well represented by the Arrhenius equation, shown in Equation 2.1 and stated in terms of the rate rather than the rate constant. 
where $R(T)$ is the rate at (absolute) temperature $T, A$ is a constant, $R$ 'is the gas constant and $E_{a}$ is the 'Apparent Activation Energy' of the rate process. Equation 2.2 results from the logarithm of Equation 2.1:

$$
\ln (R(T))=\ln \{A\}-\frac{E_{a}}{R T}
$$

A plot of the $\log$ of the rate parameter versus (1/T) from Equation 2.2 produces a straight line of slope $\left(-E_{d} / 2.303 R\right)$ for an activated process. A change in slope is indicative of a change in activation energy associated with a change in mechanism.

\subsection{Ratio of the Surface Area of the Waste Form to Leachant Volume}

The ratio of the surface area of the waste form to leachant volume affects how fast the leaching system can approach steady state as the leachant becomes saturated with leached material. This factor is not independent of leachant flow rate and replacement frequency, nor of the surface area to volume ratio of the waste form.

\subsection{Leachant Composition}

Standard leachants include demineralized water (DIW) and brine, although testing is also done with tap water, whose composition may or may not be specified, and other aqueous solutions. DIW generally results in higher leach rates than brine except for ion-exchange-resin wastes, in which the catonic radionuclides on the resin exchange for cations in the brine.

Some elements of concern to LLW management exhibit more than one chemical oxidation state, e.g., Co and Tc. In the absence of chelation complexes, the solubility of these elements depends on the chemical oxidation state, which is a function of $\mathrm{Eh}$. The two most important oxidation states of cobalt are II and III. Cobalt(II) is the only significant oxidation state in aqueous solutions without complexing agents. Few simple Co(III) salts exist, since Co(III) oxidizes water. On the other hand, cobalt(II) forms an extensive group of simple and dehydrated salts. Few compounds of Co(I) are known since $C o(I)$ readily oxidizes to Co(II). For elements with only one oxidation state, such as $\mathrm{Cs}$ and $\mathrm{Sr}$, Eh conditions probably have little effect on the solubility of the ions.

2.4 Leachant $\mathrm{pH}$

Since LLW forms are typically two-phase systems, pH effects result from the interaction between the leachant, waste and solidification agent. 
Percolate water from rain and runoff may be expected to be close to neutral, depending on dissolved atmospheric gases such as carbon dioxide and interaction with the overburden soil.

\subsection{Leachant Flow Rate or Replacement Frequency}

Leachant flow rate or, approximately equivalently [14], the replacement frequency of a specific volume of leachant in semi-dynamic leach tests is a major factor in determining leachability: it also determines the boundary conditions which apply to any data analysis.

Static leach tests, such as the MCC-1 [15], ideally are of long enough to allow the leachant and sample to attain equilibrium. Information from static tests includes solubility limits for the specific leachant-waste form under the conditions of the test, and kinetic data if the approach to equi-. librium is followed. Knowledge of saturation levels and the kinetic approach to saturation are important not only for static leaching but also for estimating adherence to boundary conditions in flowing and semi-dynamic tests.

Flowing and semi-dynamic leach tests ideally maintain the leachant at such low concentrations of leached substances that redeposition onto the sample is insignificant. However, this condition is seldom assured since experiments rarely vary the fixed schedule of leachant replacement in most tests, and there are no specific test procedures to assure that concentration effects are not significant.

\subsection{Composition of the Waste Form}

The composition of a waste form determines its fundamental nature, including its physicochemical properties and the mechanism of leaching. A waste form consists of a type and quantity of waste fixed in a solidification agent. Other materials such as sorbents often are added to cemented waste forms to improve performance in specific ways. The nature of the waste also affects the selection of the solidification agent. The waste stream may need treatment to become compatible with a solidification process. Such treatments may include adjustment of $\mathrm{pH}$ and/or water content or, in the case of glass, incineration.

Low-level waste forms are generally two or more phase systems in which the solidification agent matrix is physically and chemically distinct from the incorporated waste. Because LLW forms are inherently not 'one substance' there is the possibility of interaction between the waste and the solidification agent.

Generally, the leachability of a waste form increases as the waste loading is increased. If increased waste loading produces a reproducible increase in leachability, then waste loading may provide an acceleration factor. 


\subsection{Volume to Surface Area Ratio of the Waste Form}

When certain conditions are met, increasing the sample surface area to volume ratio may be useful as an accelerating factor in leach testing. There are different requirements for leaching which is diffusion-controlled to those for corrosion-controlled.

The argument for corrosion-controlled leaching is contained in Reference 1.11-1.12 [16]. Briefly, the concentration of species, $i$, in the leachant, $C_{i}$, may be related to the leach rate, $L_{i}$, the fraction of species in the waste form, $f_{i}$, the surface area to volume ratio of the waste form, $(S / V)$, and the contact time of the leachant with the waste form, $t$, as in Equation 2.3.

$$
C_{i}=L_{i} f_{i}(S / V) t
$$

$\mathrm{L}_{\mathrm{i}}$ depends on the chemical composition of the leachant and may also be a function of time and/or $(S / V)$ explicitly [17]. If $L_{i}$ depends only on leachant composition and Equation 2.3 holds, then increasing (S/V) will effectively shorten the time required to reach a given concentration level in the leachant thus accelerating the leaching process. This is shown in Equation 2.4.

$$
(S / V)_{1} t_{1}=(S / N)_{2} t_{2}
$$

The subscripts 1 and 2 in Equation 2.4 indicate different conditions of $(S / V)$ and $t$. The validity of Equation 2.4 for glass leaching was experimentally demonstrated once the leach rate has become linear with time $[16,18,19,20]$.

Alternatively, under diffusion-controlled conditions, the relationship of the cumulative fraction leached from different sized samples, which are otherwise identical and are leached under identical conditions, can be shown to be:

$$
\left\{\frac{\Sigma a_{n}}{a_{0}}\right\}_{1} \quad\left\{\frac{v}{S}\right\}_{1}=\left\{\frac{\Sigma a_{n}}{a_{0}}\right\}_{2} \quad\left\{\frac{V}{S}\right\}_{2}
$$

$a_{n}=$ amount of substance of interest leached in interval $n$

$a_{0}=$ total amount of substance of interest originally present

$\Sigma a_{n}=$ cumulative fraction leached through interval $n$.

$a_{0}$ 
where subscripts 1 and 2 indicate the different size samples. This conclusion is based on the solution to the problem of diffusional release from the semiinfinite medium (Reference 21, p. 32), which may be stated as in Equation 2.6.

$$
\left(\frac{\Sigma a_{n}}{A}\right)\left(\frac{V}{S}\right)=2\left(\frac{D t}{\pi}\right)^{1 / 2}
$$

For samples which are nominally identical, except for size, D should be the same. If they are leached under similar conditions for the sare length of time, $t$, then the right-hand side of Equation 2.6 is the same for both samples and Equation 2.5 follows. There is experimental evidence supporting Equation $2.5[22,23,24]$. However, the leaching results used to validite Equation 2.5 were limited to a relatively small range of fractional release early in the leach test, such that the semi-infinite medium approximation might be valid.

To summarize, based on diffusion theory and supported by experiments, it has been shown that leaching from small-scale test samples can be used to predict leaching release of larger waste forms under certain conditions. The complete set of conditions under which this result may be valid include the conditions set forth above, plus those which lead to Equation 2.6 as the quantitative expressior. of cumulative release versus the square root of time. These conditions include:

- Diffusion is the mass transport mechanism and the diffusion coefficient is constant.

- The diffusant is uniformly distributed throughout an effectively horogeneous medium before leaching.

- The leachant and the surface of the waste form are maintained at effectively zero concentration with respect to the diffusant during leaching.

If test conditions on small-scale samples can be controlled to effectively simulate actual burial conditions and Equation 2.6 holds, then it should be possible to predict long-term leaching release for the specified conditions. Thus, small-scale tests would provide an accelerating factor to estimate long-term release.

\subsection{Porosity of the Waste Form}

An inert matrix which is physically porous can only retard the leachability of other substances embedded in the matrix compared to simply exposing the substances directly to the leachant. This is not equivalent to the effect of porosity acting to increase surface area because of microscopic surface roughness, as was found to be important for glass $[9,16]$. Porous LLW forms in which the waste and matrix of the solidification agent are distinct may be better described by formally considering the effect of the porous matrix, 
rather than considering the effect of porosity as simply increasing surface area.

The physical considerations necessary to account for the effect of porosity on diffusion in a porous matrix along with mathematical models incorporating these considerations were reviewed by Van Brakel and Heertjes [25]. In general, the diffusibility, $Q$, of a porous matrix is described as:

$$
\mathrm{Q}=\frac{\mathrm{PC}}{\mathrm{T}^{2}}
$$

where $P$ is the porosity, $C$ is the constrictivity and $T$ is the tortuosity. $P$ and $\mathrm{T}$ depend only on the porous matrix, whereas $C$ depends both on the porous matrix and the diffusant since the relative sizes of porosity and diffusing species are important. $Q$ is defined as the ratio of the effective diffusion coefficient in the porous medium to the diffusion coefficient in the absence of the porous medium. 


\section{MATERIALS AND METHODS}

The materials for making waste form, the leach test methods and the analytical methods used in the experimental studies are summarized in this section. Previous reports $[2,3]$ from this program also contain similar descriptions. The solidification agents, portland type I cement, bitumen, vinyl ester-styrene copolymer and glass, were selected because they were either in use or being considered for use by the defense or commercial nuclear industries. The (simulated) waste types chosen for study are common waste streams produced by power reactors--the sulfate and borate salts--plus incinerator ash, which is likely to become a major waste stream as advanced processes for volume reduction become common.

Four classes of waste forms were investigated:

(i) Solidification agent matrices incorporating only radiotracers as simulated waste.

(ii) Solidification agent matrices without radiotracers. These are nominally identical to the samples in (i) except for the absence of radiotracers and are termed, "Solidification Agent Blanks."

(iii) Waste forms incorporating simulated bulk waste plus radiotracers.

(iv) Waste forms incorporating simulated bulk waste without radiotracers. These are nominally identical to the samples in (iii) except for the absence of radiotracers. These samples are termed, "Waste Form Blanks."

The samples in class (i) were fabricated to investigate the leaching behavior of the radionuclides of cesium, strontium and cobalt from pure solidification agent matrices. The samples in ( $i$ ) were used to study the leaching of the components of the solidification agent. The samples in (i) could not be used for both studies because of the possibility of radioactive contamination of the instruments used for analysis of the samples in (ii).

The samples in (iii) and (iv) were made to investigate the leaching of the radionuclides listed above and of solidification agent and waste components, respectively. Again, the samples in (iii) could not be used for both investigations because of the possibility of contaminating the analytical instrument with radioactivity.

Figure 3.1 summarizes the waste form types containing simulated wastes that were selected for study. Table 3.1 lists the compositional parameters for these waste forms corresponding to the abbreviated summary in Figure 3.1. Table 3.2 lists compositional parameters for the samples consisting of the pure solidification agent with no otherwise bulk waste. The "blanks," i.e., those samples without radiotracers, are nominally identical to the sample formulations listed in Tables 3.1 and 3.2. 

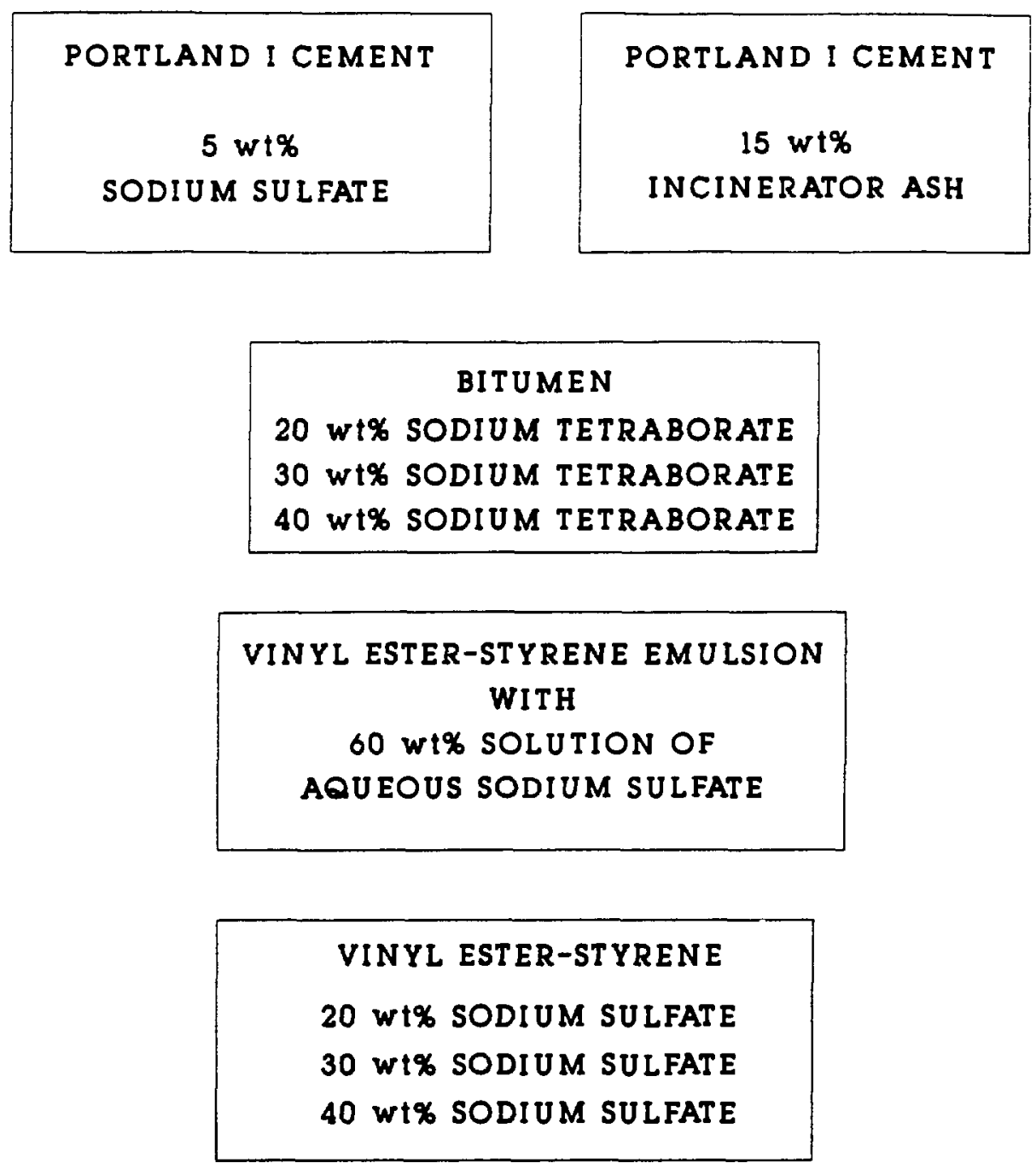

SODA-LIME GLASS

INCINERATOR ASH

Figure 3.1 Schematic summary of waste form types listed by solidification agent, waste type and waste loading(s). 
Table 3.1

Composition (weight \&) for Each of the Waste Form Types

Containing Simulated Waste

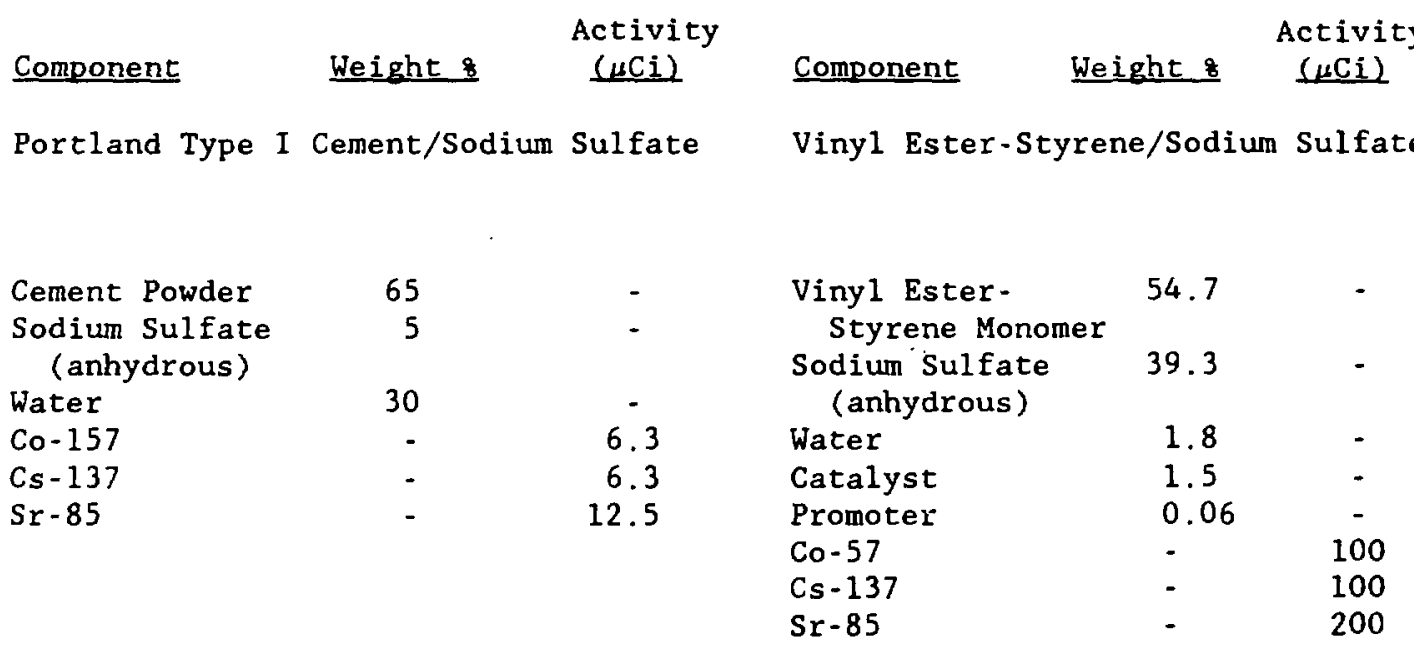

Portland I Cement/Incinerator Ash

Vinyl Ester-Styrene/Sodium Sulfate

$\begin{array}{lcc}\text { Cement Powder } & 60 & - \\ \text { Incinerator Ash } & 15 & - \\ \text { Water } & 25 & - \\ \text { Co }-57 & - & 100 \\ \text { Cs }-137 & - & 100 \\ \text { Sr }-85 & - & 200\end{array}$

Vinyl Ester-Styrene/Aqueous Sodium Sulfate Emulsion

$\begin{array}{lcr}\begin{array}{l}\text { Vinyl Ester- } \\ \text { Styrene Monomer }\end{array} & 67.6 & - \\ \begin{array}{l}\text { Sodium Sulfate } \\ \quad \text { (anhydrous) }\end{array} & 30.0 & - \\ \text { Water } & 0.6 & - \\ \text { Catalyst } & 1.7 & - \\ \text { Promoter } & 0.07 & - \\ \text { Co-57 } & - & 16.5 \\ \text { Cs }-137 & - & 16.5 \\ \text { Sr-85 } & - & 25.5\end{array}$

Vinyl Ester-

Styrene Monomer

Sodium Sulfate

(anhydrous)

Water

Catalyst

Promoter

Co -57

Cs -137

Sr -85
39.0

15.0

45.0

1.0

0.04

- 100

- 100

- 100
Vinyl Ester-Styrene/Sodium Sulfate

Vinyl Ester- $\quad 77.3$

Styrene Monomer

Sodium Sulfate 20.0

(anhydrous)

Water

Catalyst

Promoter

Co- 57

Cs -137

Sr -85

$\begin{array}{cc}0.6 & - \\ 2.0 & - \\ .08 & - \\ . & 16.5 \\ . & 16.5 \\ . & 25.5\end{array}$


Table 3.1 (cont.)

Composition (weight \&) for Each of the Waste Form Types Containing Simulated Waste

\begin{tabular}{|c|c|c|c|c|c|}
\hline Component & Weight 8 & $\begin{array}{c}\text { Activity } \\
(\mu \mathrm{Ci}) \\
\end{array}$ & \multicolumn{2}{|c|}{ Weight 8} & $\begin{array}{l}\text { Activity } \\
(\mu \mathrm{Ci}) \\
\end{array}$ \\
\hline Bitumen/Sodium & m Tetraborate & & Glass/Incinerato & Ash & \\
\hline Bitumen & 60.0 & - & Soda-Lime Glass & a & - \\
\hline $\begin{array}{l}\text { Sodium } \\
\text { Tetraborate }\end{array}$ & $\begin{array}{c}40.0 \\
\text { (anhydrous) }\end{array}$ & - & $\begin{array}{l}\text { Incinerator Ash } \\
\text { Co- } 60\end{array}$ & a & $0.01-0.05$ \\
\hline Co- 57 & - & 91 & Cs -137 & - & $0.01-0.05$ \\
\hline $\begin{array}{l}\mathrm{Cs}-137 \\
\mathrm{Sr}-85\end{array}$ & - & $\begin{array}{r}91 \\
182\end{array}$ & $M n-54$ & - & $0.01-0.04$ \\
\hline
\end{tabular}

Bitumen/Sodium Tetraborate

a. The waste form composition was not determined.

$\begin{array}{lcc}\text { Bitumen } & 70.0 & - \\ \text { Sodium } & 30.0 & - \\ \text { Tetraborate } & \text { (anhydrous) } & \\ \text { Co }-57 & - & 39 \\ \text { Cs }-137 & - & 39 \\ \text { Sr }-85 & - & 78\end{array}$

Bitumen/Sodium Tetraborate

$\begin{array}{lcc}\text { Bitumen } & 80.0 & - \\ \text { Sodium } & 20.0 & - \\ \text { Tetraborate } & \text { (anhydrous) } & \\ \text { Co- } 57 & - & 100 \\ \text { Cs }-137 & - & 100 \\ \text { Sr }-85 & - & 200\end{array}$


Table 3.2

Composition of the Waste Forms of Pure Solidification Agent Matrices (weight \&)

Component

Cement Powder
Water
Co- 60
Cs -137
Sr -85

Weight 8

Portland I Cement

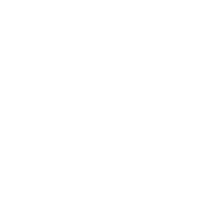

70

30

$-$

$-$

-

16.3

9.9

23.6

Pioneer 321 Bitumen

Bitumen

Co- 60

Cs -137

Sr -85
100

-

$-$

$-$

\section{Activity $(\mu \mathrm{Ci})$}

Vinyl Ester-Styrene/Water Emulsion

Vinyl Ester-

Styrene

Water

Catalyst

Promoter

Co- 60

Cs -137

Sr -85
49.2

49.5

1. 26

0.05
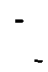

-
13.8

8.4

20.0

Vinyl Ester-Styrene

Vinyl Ester-
Styrene
Water Comonomer
Catalyst
Promoter
Co- 60
Cs -137
Sr -85

97.9

0.7

1.3

0.05

15.4

9.3

22.3 
The choice of solidification agents was based on two criteria: (i) That they were either in use or being considered for in low-level waste management, and (ii) that the solidification agents cover a range of materials properties. By providing detailed knowledge of several types of materials, e.g., hydraulic cement, thermoplastic binders, and thermosetting polymers, we hoped that these results would apply in a general way to solidification agents that may be developed in the future. The glass solidification process for low-level waste was investigated at the Mound Laboratory [4], and the glass waste-form samples used in this program were provided by Mound.

\subsection{Waste Form Types}

Studies were made to select the best formulation of solidification agent and waste type. Since many waste types are incompatible with their solidification agents (e.g., cement and sodium sulfate, bitumen and dried salts), formulations were optimized to provide stability for 90 days in immersion while maximizing the waste loading.

3.1.1 Portland I Cement Containing Sodium Sulfate as Simulated Waste. The compositional phase diagram for the solidification of aqueous sodium sulfate with portland type I cement is available [26].

Sodium sulfate waste is a product of the regeneration of ion exchange resin at BWR power stations. The waste is usually concentrated to an approximately 22 wt solution at $25^{\circ} \mathrm{C}$. Evaporation of this solution to dryness results in sodium sulfate decahydrate (Glauber's salt): Glauber's salt dehydrates to anhydrous sodium sulfate at temperatures above $32^{\circ} \mathrm{C}$.

Up to approximately 45 wt sodium sulfate can be solidified with cement. However, waste forms containing more than approximately 8 wt 8 sodium sulfate were unstable on immersion in deionized water and disintegrated before a 90day immersion test was completed. A waste form formulation of 5 wto sodium sulfate, 30 wto water and 65 wto cement was selected for testing, corresponding to a waste-to-binder ratio, i.e., evaporator concentrate to cement of 0.54 .

\subsubsection{Portland I Cement Containing Incinerator Ash as Simulated Waste.} The solidification of incinerator ash with portland type I cement and its compositional phase diagram have been reported $[3,27-30]$. Up to 50 wtz incinerator ash can be solidified by portland I cement without free standing water being present. However, on curing specimens swell with the development of large voids. A waste form formulation of 15 wto ash, 25 wto water and 60wt cement was selected for leach testing because this composition produced waste forms with few voids.

Incinerator ash was obtained from the Tennessee Valley Authority's waste incinerator. The major components of incinerator ash are typically uncombusted carbon, aluminum oxide $\left(\mathrm{Al}_{2} \mathrm{O}_{3}\right)$, ferric oxide $\left(\mathrm{Fe}_{2} \mathrm{O}_{3}\right)$ and silicon dioxide $\left(\mathrm{SiO}_{2}\right)$. The ash was passed through a $2.38 \mathrm{~mm}$ sieve to produce a uniform powder free of large clinkers and metal objects. 
3.1.3 Vinyl Ester-Styrene Emulsion With Aqueous Sodium Sulfate as Simulated Waste. The amount of sodium sulfate that can be solidified by the vinyl ester-styrene polymer emulsion is limited by the 22 wt 8 solubility at $25^{\circ} \mathrm{C}$ of sodium sulfate in water. A mixture of 15 wto sodium sulfate, 45 wto water and 37 wto vinyl ester-styrene monomer produced a satisfactorily polymerized form with hard surfaces that was stable when immersed in water.

\subsubsection{Viny1 Ester-Styrene Containing Sodium Sulfate as Simulated Waste.} Mixtures of up to 60 wto dry sodium sulfate with vinyl ester-styrene monomer polymerized satisfactorily to produce waste forms with hard surfaces. The leaching of sodium sulfate from solidified waste forms was used to select a composition which maximized the amount of incorporated waste, while minimizing its leaching. The amount of sodium leached at waste loadings above 40 wt rapidly increased, so this value was the maximum used.

\subsubsection{Bitumen Containing Sodium Tetraborate as Simulated Waste. Boric} acid waste generated at a typical PWR Plant contains approximately 12 wto boric acid in aqueous solution. Solidification of the waste with bitumen requires the removal of water by evaporation. Because boric acid dehydrates at $160^{\circ} \mathrm{C}$, the loss of water would cause foaming of the bitumen mixture.

A satisfactory method of solidification is to neutralize the boric acid solution with sodium hydroxide. Sodiun tetraborate is the predominant product when the waste stream is neutralized to $\mathrm{pH} 9.3$ [31]. Evaporation of the solution to dryness results in the hydrated crystalline substance, sodium tetraborate decahydrate (borax). The borax must be further dried at $200^{\circ} \mathrm{C}$ to produce the anhydrous borate.

A uniform solid waste can be produced by mixing the anhydrous sodium tetraborate with molten bitumen. Waste loadings of 208,308 and 408 by weight sodium tetraborate in bitumen were used.

\subsubsection{Soda-Lime Glass Containing Incinerator Ash as Simulated Waste.} The glass-waste form has been used at the Monsanto-Mound Facility in a process that simultaneously incinerates low-level waste and incorporates the ash in the glass [4]. The glass waste form consists of two solid phases:

(i) the glass matrix in which part of the waste components are dissolved, and

(ii) particulates of ash residue.

\section{2 Sample Preparation}

The samples prepared for leaching experiments were cylindrical with approximate dimensions of $4.8 \mathrm{~cm}$ diameter and $6.4 \mathrm{~cm}$ length $(\mathrm{V} / \mathrm{S}=0.91)$. Based on past experience this sample size is convenient for laboratory studies. Additional samples were prepared for configurational studies; these included smaller cylinders, approximately $2.5 \mathrm{~cm}$ diameter by $2.5 \mathrm{~cm}$ tall (V/S=0.42), a disk, approximately $14 . \mathrm{cm}$ diameter by $1.2 \mathrm{~cm}(\mathrm{~V} / \mathrm{S}=0.61)$ tall and a larger cement cylinder that was approximately $10 . \mathrm{cm}$ diameter by $13 . \mathrm{cm} \mathrm{tal1}$ (V/S $=1.85)$. 
Radioactive samples prepared for leach testing had radioactive tracers incorporated into the waste. The radioisotopes were Co-57, Cs-137 and Sr-85. The low energy gamma ray emitted by Co-57 $\left(\mathrm{T}_{1 / 2}=270\right.$ days $)$ is better suited to the automated $\mathrm{NaI}$ counting system than is Co-60 and works well with the Geli counting system.

The cylinders of soda-lime silica glass, which were produced at the Mound facility, were approximately $2.5 \mathrm{~cm}$ diameter and $2.5 \mathrm{~cm}$ in height, which contained Cs-137, Mn-54 and Co-60.

\subsection{Leaching Tests}

Three leach tests were used to determine the leachability of various radionuclides and constituents of solidification agents.

3.3.1 ANS 16.1 Leaching Test. The ANS 16.1 Leach Tesis is a semidynamic leaching test in which the leachate is replaced after intervals of static leaching [32]. Specimens are placed into the leachant solution with all the external surface area directly exposed. Specimens are tested in individual containers containing sufficient leachant to provide a leachant/ specimen external geometric surface area ratio of $10 \mathrm{~cm}$ unless otherwise specified. Specimen formulations are usually tested in duplicate or triplicate to determine the extent of specimen variation in leaching. Leach test data are expressed as incremental fraction release, as cumulative fraction release or as a release rate to facilitate alternative methods of treating the data.

The leachant is typically distilled water with a conductance of less than $5 \mu$ mhos $/ \mathrm{cm}$. The sampling interval was modified to more frequent intervals and to extend the duration of the test beyond the 90-day standard.

In addition to DIW, two simulated groundwaters and a $100 \mathrm{ppm}$ solution of EDTA (disodium ethylenediaminetetraacetate hexahydrate) were used as leachants. The groundwaters were of two types: An oxygen-saturated groundwater (oxic) based on the composition of an ORNL groundwater from a potential waste burial site $[3,33]$ and an oxygen-deficient groundwater (anoxic) which could be formed by the biodegradation of waste in the presence of the former groundwater. The compositions of these leachants are shown in Table 3.3.

3.3.2 MCC-3s Leaching Test. The MCC-3s Agitated Powder Leach Test Method is a static leach test developed for determining the solubility limits and the dissolution rates of materials used for the encapsulation of highlevel wastes [34].

This method was adapted for use with low-level waste materials to determine solubilities of sample components in the leachate. Leachate elemental concentration must be monitored for chemical saturation to eliminate retardation of leach rates, or mechanistic variations due to saturation conditions. 
Table 3.3

\begin{abstract}
Major Cation and Anion Concentrations in Synthetic Oxic and Anoxic Groundwaters ${ }^{a}$
\end{abstract}

\begin{tabular}{lcc} 
Species & \multicolumn{2}{c}{ Concentration (ppm) } \\
$\mathrm{Na}^{+}$ & 3.80 & 5.25 \\
$\mathrm{~K}^{+}$ & 0.46 & 0.91 \\
$\mathrm{Ca}^{+2}$ & 57.00 & 114.02 \\
$\mathrm{Mg}^{+2}$ & 2.86 & 5.72 \\
$\mathrm{NH}_{4}^{+}$ & 0.00 & 5.95 \\
$\mathrm{Fe}^{+2}$ & 0.00 & 6.16 \\
$\mathrm{Cl}^{-}$ & 2.30 & 32.59 \\
$\mathrm{SO}_{4}{ }^{-2}$ & 3.20 & 0.00 \\
$\mathrm{HCO}_{3}^{-}$ & 120.00 & 361.06
\end{tabular}

a. The composition of an Oak Ridge National Lab groundwater was used as a model for the synthesis of these waters. The concentrations reported for well \#313 ( $6.3 \mathrm{~m}$ deep) at ORNL Area C Engineered Test Facility were used $[3,33]$. 
3.3.3 MCC-4s Leaching Test. The MCC-4s Low Flow Rate Leach Test Method is a single-pass flow-through test which eliminates the effects of sampling interval and of large changes leachate concentration, providing better control over the boundary conditions of leachant composition [35].

This leaching test was also developed for evaluation of high-level waste forms. Because of the nature of the materials used for this study, some modifications were made in the test procedure by increasing the flow-rates.

\subsection{Analytical Methods}

Leachates were analyzed for a variety of materials depending on the composition of the solidification agent. Cement leachates had the most analyses, since reactions within the matrix cause significant differences in leaching among different isotopes. Specific analytical methods are given below.

3.4.1 Radiochemical Analysis. The radiochemical component of the leachate such as Cs-137, Sr-85 and Co-60 (or Co-57) was analyzed by gamma-ray spectroscopy using an intrinsic Germanium detector or a sodium iodide detector in accordance with the methods described in ASTM D3648-78 [36] and ASTM D3649-78 [37].

3.4.2 Elemental Leachate Analysis. Analysis of leachates for non-radioactive elements was conducted with standard methods such as ASTM E663 [38] and those in, Analytical Methods for Atomic Absorption Spectrophotometry, revised January 1982, Perkin-Elmer Corporation [39].

3.4.3 Alkalinity. Analysis of leachates for total alkalinity was measured by titration to the phenolphthalein and methyl orange end points according to Method Number 403 from Standard Methods for the Examination of Water and Waste Water, 15 th edition, 1980 [40].

3.4.4 Analysis for $\mathrm{pH}$. Analysis of leachates for $\mathrm{pH}$ was performed using ASTM D1293 [41] with a platinum combination probe.

\subsubsection{Conductivity. Conductivity was measured by ASTM D1125 [42].}

3.4.6 SEM/EDS. Waste forms will be analyzed before and after leaching by Scanning/Electron Microscopy (SEM) to observe change in physical morphology and by Energy Dispersive Spectroscopy (EDS) to determine elemental ratios in profile and on waste form surfaces. Methods used will be those discussed by Goldstein and Yakowitz in Practical Scanning Electron Microscopy, Electron and Ion Microprobe Analysis, (1975) [43]. 


\section{PORTLAND TYPE I CEMENT CONTAINING SODIUM SULFATE SALT AS SIMULATED WASTE}

Portland cement, either by itself or blended with additives to enhance radionuclide retention, is the most commonly used solidification agent for low-level radwaste. As the result of hydration reactions with water, portland cement solidifies to form a porous, hydrophilic matrix of high surface area. The physical and chemical properties of portland cement have been well documented $[44-50]$.

In general, portland cement evidences a rapid release of cesium in leaching experiments while strontium and cobalt leach substantially less readily $[1-3,10,11,29,51-58]$. As a result, sorbents for cesium are commonly blended with cement to reduce its leachability [51-61]. These blended cement + sorbent mixtures are often formulated for specific waste streams.

This section presents results obtained from leaching studies investigating the factors deemed potentially important for LLW forms, as discussed in Section 2 of this report, consisting of portland type I cement incorporating 5 wt sodium sulfate salt as simulated waste.

\subsection{Leaching Mechanisms}

The following overview summarizes the leaching mechanisms for cement as determined from the literature survey [1] and from the experimental work in this task.

Cesium leaches from cement by diffusion within and out of the porous cement matrix. Cesium is present in the cement matrix in trace quantities as a waste radionuclide. It is not limited by solubility in the cement and is not sorbed to any significant extent on the solid components of the cement. Thus, all of the cesium inventory should be available for leaching immediately. The presence of sulfate waste does not substantially alter these mechanistic observations, even though the sulfate reacts with the cement over time and strongly affects the long-term physical integrity of the waste form. In a practical sense, cesium release is retarded only by the tortuous nature of the porous matrix and not by any significant chemical interaction. Finally, cesium leaching from the cement waste form containing 58 sodium sulfate as simulated waste was not sensitive to variations in the replacement interval of the leachant (i.e., from weekly to daily, Section 4.2.5). This supports the observations in the literature that cesium sorbs only weakly on cement since the cesium concentration in the leachate replaced weekly was substantially greater than in that replaced daily. We recently found that calcium carbonate minerals that form on cement surfaces during leaching have a significant capacity to sorb cesium [62]. 
Strontium leachability from cement is more complex than that for cesium for several reasons.

(i) Strontium is present as a minor component in cement; thus the trace amounts of radiostrontium (principally $\mathrm{Sr}-90$ ) are subject to the common ion effect for solubility and sorption distributions.

(ii) Strontium may have limitations on its solubility imposed by the hydroxide and/or sulfate concentrations in cement waste forms containing sulfate salts.

(iii) The sorption of strontium onto cement components is relatively smal1, but certainly larger than that for cesium [1]. This would be expected to decrease the effective diffusion coefficient but would not otherwise affect diffusion.

(iv) Strontium leachability was shown to be strongly dependent on the frequency of leachant replacement (Section 4.2.5) in cement waste forms containing $5 \%$ sodium sulfate. This suggests a limit on solubility, a sorption equilibrium, or both.

(v) Strontium leachability appears to be retarded by carbonate buildup on the surface of the cement waste form (reference 1 and references therein). This has the effect of progressively reducing strontium leachability over time; thus a calculated effective diffusion coefficient for strontium would decrease with time as the carbonate builds up.

In sum, strontium leachability from the cement waste forms investigated in this task may be affected by solubility limitations, sorption, and surface effects that grow with time and by the complication that strontium is naturally in cement as a minor, but not insignificant, component. In carbonate-rich environments, the surface buildup of carbonate/bicarbonate precipitates may control strontium leachability through a solubility product (Ksp) or sorption equilibrium (Keq) in the long-term.

Cobalt leaching from both the pure cement waste forms and from the cement waste forms containing $5 \%$ sodium sulfate was not measurable, because the very low solubility of cobalt in the high $\mathrm{pH}$ cement limits leachability. These results are not consistent with the observed leaching of radiocobalt from waste forms containing actual radwaste. The latter appears to result from cobalt having been mobilized by chelation and/or complexation by organic chelating, and/or complexing agents in the waste.

\subsection{Factors that Affect Leaching}

Results from experiments designed to investigate each of the factors listed in Table 2.1 for the cement waste forms containing sodium sulfate are discussed in the following sections. The basis for evaluating the effect of each of the factors is by comparison with tests on standard samples, i.e., 4.8 $\mathrm{cm}$ diameter by $6.4 \mathrm{~cm}$ high right cylinders, at $20^{\circ} \mathrm{C}$ in deionized water. 
Replicate tests, generally triplicates, provided a measure of the variability of the data.

4.2.1 Temperature. The effect of temperature on the leachability of portland type I cement waste forms containing 5 wt sodium sulfate was investigated between 20 and $50^{\circ} \mathrm{C}$. Cesium release evidenced Arrhenius behavior with an activation energy of $22 \pm 7 \mathrm{~J} / \mathrm{mol}(5.2 \pm 1.7 \mathrm{kcal} / \mathrm{mole})$. Strontium release was little affected by temperature and did not evidence Arrhenius behavior; this was not surprising, given the large number of factors affecting strontium leachability (Section 4.1). Temperature had no effect on cobalt leaching; cobalt was not detected in any of the leachates.

Figures $4.1,4.2$ and 4.3 summarize the effect of temperature on the leaching of Cs-137. Figure 4.1 presents the cumulative fraction leached (CFL) versus time, for triplicate samples at 20 and $50^{\circ} \mathrm{C}$ and for duplicate samples at $40^{\circ} \mathrm{C}$. Figure 4.2 plots linear correlations of these data versus the $20^{\circ} \mathrm{C}$ data. Figure 4.3 is an Arrhenius plot of the incremental leach rates of these data.

Figure 4.1 shows that increasing temperature increases Cs-137 leachability. This figure also shows that the reproducibility, as indicated by the scatter of data, is decidedly better for the $20^{\circ} \mathrm{C}$ data than for the data at 40 and $50^{\circ} \mathrm{C}$. Although temperature clearly accelerates leaching of Cs-137 from these samples, the loss of reproducibility at the higher temperatures reduces the reliability as an accelerating factor.

The correlation plots in Figure 4.2 indicate that the two $40^{\circ} \mathrm{C}$ data curves remain linear with respect to the $20^{\circ} \mathrm{C}$ data, while the $50^{\circ} \mathrm{C}$ data deviate from linearity beyond approximacely $0.6 \mathrm{CFL}$. Since the $40^{\circ} \mathrm{C}$ data correlate with the $20^{\circ} \mathrm{C}$ data up to releases of approximately $0.8 \mathrm{CFL}$, depletion seems unlikely to be the cause of the deviation from linearity for the $50^{\circ} \mathrm{C}$ data. The reason for this deviation is unknown.

In the Arrhenius plots of Figure 4.3, least-square lines were been drawn through the 20,40 and $50^{\circ} \mathrm{C}$ data for each leachant replacement interval. Since the leach rate decreases with time, the least-square lines for each of the replacements proceed down the figure. Table 4.1 1ists the apparent activation energies calculated from the slopes of these lines. The data for leachant replacements 12 to 14 of the $50^{\circ} \mathrm{C}$ set are not included. Scanning down the 1 ist in Table 4.1 suggests that the apparent activation energy, $E_{a}$, is near 5 $\mathrm{kcal} / \mathrm{mole}$ through replacement interval 9; a dashed line was drawn between the data for replacement intervals 9 and 10 . Starting with interval 10 the $E_{a}$ values decrease, indicating that factors other than the activated process are beginning to affect the leach rates. Sample depletion of both the 40 and $50^{\circ} \mathrm{C}$ samples seems the most likely cause. Therefore, the $E_{a}$ values for the process is taken to be the average of the individual $E_{a}$ values for leachant replacement intervals 1 through 9 , as listed in Table 4.1 
Apparent Activation Energies at Each Leachant Replacement Interval for Cs-137 Leaching from Portland Type I Cement Containing 5 wt Values are Listed in SI Units ( $\mathrm{J} / \mathrm{mol}$ ) and CGS Units ( $\mathrm{kcal} / \mathrm{mole})$.

Leachant Replacement Interval

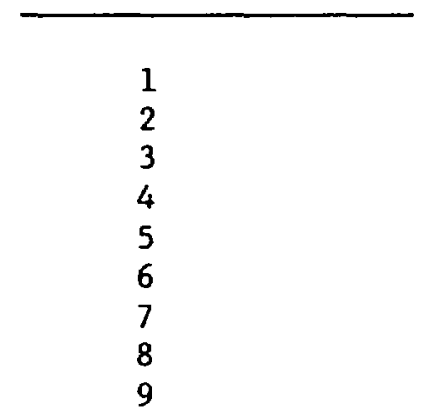

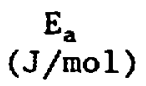

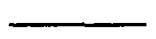

34

18

24

27

27

13

23

20

11

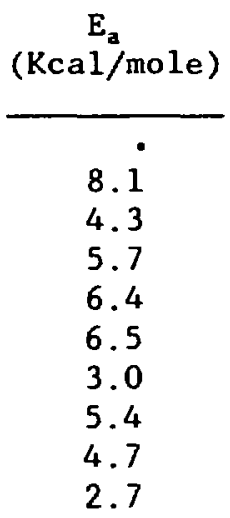

\section{0}

11

12

13

14

$$
9.0
$$

4.2

6.7

7.1

$-39.0$
2.1

1.0

1.6

1.7

$-9.3$

Leaching at elevated temperature was also measured on portland type I cement samples containing radiotracers, but № simulated bulk waste. The CFL versus time plots for Cs-137 leaching from these pure cement samples are not presented, but linear correlation plots and Arrhenius plots are shown in Figures 4.4 and 4.5 , respectively, for comparison with the results in Figures 4.2 and 4.3 .

Figure 4.4 shows that the Cs-137 leaching releases at elevated temperature correlated well with that at $20^{\circ} \mathrm{C}$, with the exception of the last two points at $70^{\circ} \mathrm{C}$. Since over three quarters of the Cs-137 activity had been leached, the deviation of these last two $70^{\circ} \mathrm{C}$ data points probably results from depletion. There is no estimate of the variability of the releases at the elevated temperatures as replicates were not leached at elevated temperature. The data plotted in Figure 4.4 are 1 isted in Table 4.2 since these data are not listed in Appendix A. Table 4.3 lists the least-squares slopes of the lines in Figure 4.4. These slopes provide a measure of the acceleration of leaching release at each temperature relative to the average leachability at $20^{\circ} \mathrm{C}$ over the range of validity of the linear correlation. 
Table 4.2

Cs-137 CFL From Portland Cement at Temperatures of 20,30,40, 50 and $70^{\circ} \mathrm{C*}$. Each Row Represents a Leachant Replacement Interval

(Time of Leachant Replacement in Days).

TEMPERATURE $\left({ }^{\circ} \mathrm{C}\right)$

20

30

40

50

60

70

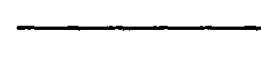

.

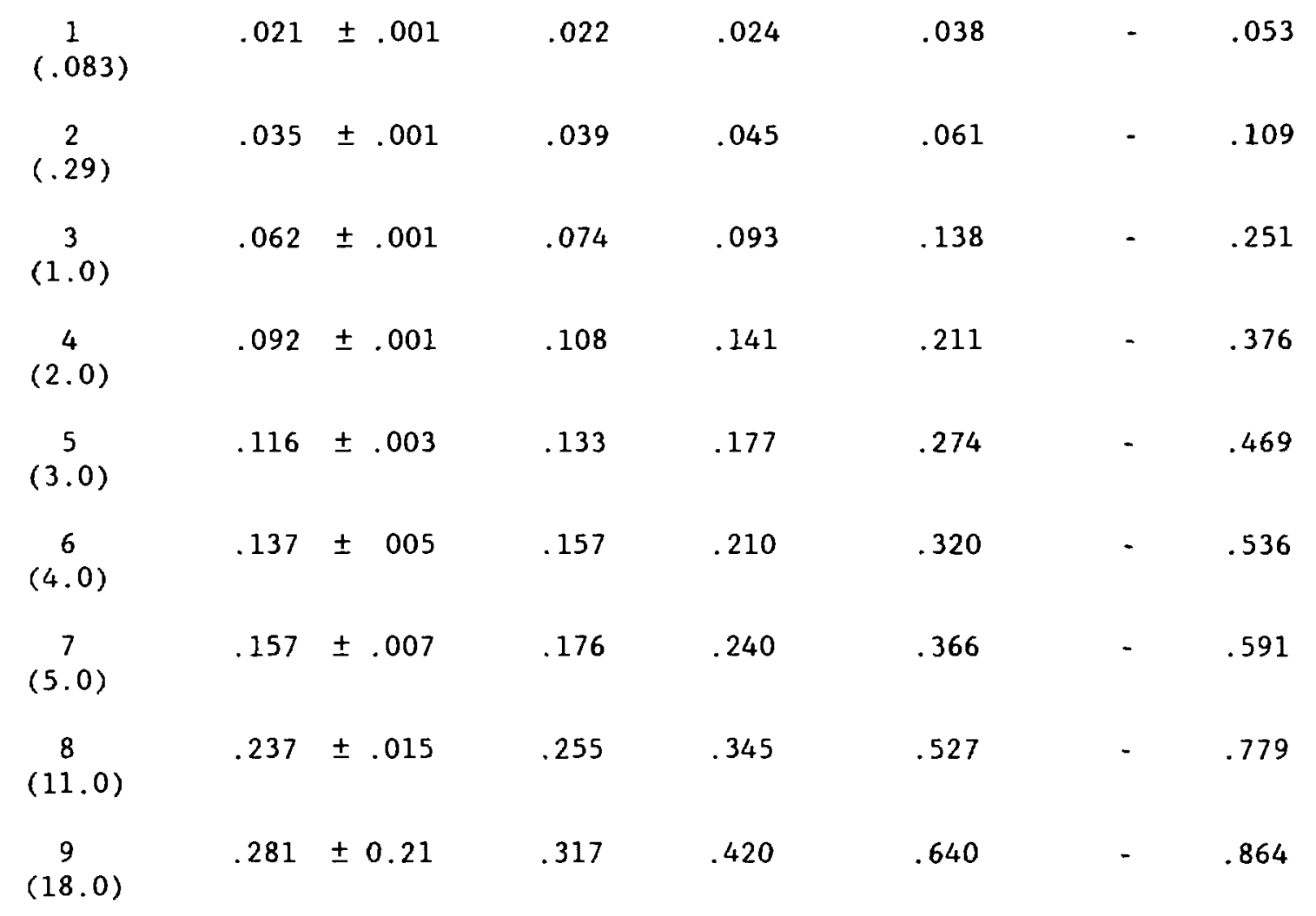

* All of the samples were nominally identical. The $20^{\circ} \mathrm{C}$ data are from triplicate samples which were made and tested separately from those tested at the higher temperatures. The $20^{\circ} \mathrm{C}$ data are the average CFL one standard deviation for the triplicate samples. 
Table 4.3

Linear Correlations From the Leaching Data for Cs-137 From Pure Portland Cement at Temperatures of $20,30,40,50$ and $70^{\circ} \mathrm{C}$. The $20^{\circ} \mathrm{C}$ Data Set is the Standard Against Which the Data at Elevated Temperatures Were Compared. The Slope of the Linear Correlation is Listed \pm One Standard Deviation.

TEMPERATURE $\left({ }^{\circ} \mathrm{C}\right)$

\begin{tabular}{lccccc} 
& 20 & 30 & 40 & 50 & $70^{\mathrm{a}}$ \\
\cline { 2 - 5 } slope $\pm s$ & 1.0 & $1.1 \pm .1$ & $1.5 \pm .1$ & $2.3 \pm .2$ & $4.0 \pm .2$ \\
intercept & 0.0 & .003 & -.001 & -.004 & -.016 \\
$\mathbf{r}^{\mathrm{b}}$ & 1.0 & .999 & .999 & .999 & .996
\end{tabular}

a. The data for leachant replacement intervals 8 and 9 were not used for calculating the linear relationship for the $70^{\circ} \mathrm{C}$ data since they deviated substantially from the line determined from the first seven data points.

b. $r$ is the correlation coefficient. A value of 1 represents a perfect correlation while a value of zero indicates no correlation. 
Figure 4.5 is an Arrhenius plot of the Cs-137 leach rates during each leachant replacement interval at the various temperatures for the pure cement samples. The apparent activation energies calculated from the least-squares slopes of the lines for each leachant replacement interval are listed in Table 4.4. The average $E_{a}$ of $5.4 \pm 0.9 \mathrm{kcal} / \mathrm{mole}$ is consistent with that (4-6 $\mathrm{kcal} / \mathrm{mole}$ ) for diffusion of simple ions in water.

Table 4.4

Activation Energies Calculated for Each Leachant Replacement Interval for Cs-137 Leaching from Pure Cement. Values are Listed in SI Units $(\mathrm{J} / \mathrm{mol})$ and CGS Units ( $\mathrm{kcal} / \mathrm{mole}) *$

Leachant Replacement Interval
1

2

3

4

5

6

7

8

9

Average $\pm s:$

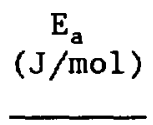

17.9

22.6

28.7

25.3

24.3

20.5

19.7

19.7

23.0

$22.4 \pm 3.4$

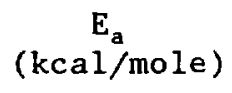

4.3

5.4

6.9

6.0

5.8

4.9

4.7

4.7

5.5

$5.4 \pm 0.9$

* The $70^{\circ} \mathrm{C}$ values for intervals 8 and 9 were not used in the calculation of $\mathrm{E}_{\mathrm{a}}$ since sample depletion appears to affect the leach rate. 
Figures $4.6,4.7$ and 4.8 summarize the effect of temperature on the leaching of $\mathrm{Sr}-85$ from portland type I cement waste forms containing 5 wtz sodium sulfate salt. Figure 4.6 presents the cumulative fraction leached (CFL) versus time for triplicate samples at 20 and $50^{\circ} \mathrm{C}$ and for duplicate samples at $40^{\circ} \mathrm{C}$. Figure 4.7 plots linear correlations of these data versus the $20^{\circ} \mathrm{C}$ data. Figure 4.8 is an Arrhenius plot of the incremental leach rates of these data.

Figure 4.6 shows that increasing temperature clearly increases Sr-85 leachability. The reproducibility, i.e., the scatter of data at the same temperature, is somewhat better for the $20^{\circ} \mathrm{C}$ data than for the data at 40 and $50^{\circ} \mathrm{C}$. The lack of reproducibility limits the reliability of temperature as an accelerating factor.

Although the initial portions of the 40 and $50^{\circ} \mathrm{C}$ data curves are linear with respect to the $20^{\circ} \mathrm{C}$ data, the correlation plots in Figure 4.7 show that they deviate from linearity as the leachant replacement intervals become longer than a week (i.e., approximately at interval 9). Depletion cannot be the cause of the deviation from linearity, as the CFL is less than 208. It is probable that the deviation results from carbonation of the surface of the waste form, which could reduce the solubility of strontium and thus reduce the leachability of strontium. This is a particularly likely mechanism since strontium is contained naturally in cement in amounts well above the trace levels of radiostrontium present in radwaste.

In the Arrhenius plots of Figure 4.8, least-squares 1ines were drawn through the 20,40 and $50^{\circ} \mathrm{C}$ data for the first nine replacement intervals. Since the leach rate decreases with time, the least-squares lines for each of the leachant replacements proceed down the figure. Table 4.51 ists the apparent activation energies calculated from the slopes of these lines.

: arly, these $E_{a}$ values are outside the 4-6 $\mathrm{kal} / \mathrm{mole}$ range that is typical of $\therefore$ riusion of simple ions in water. Therefore, $\mathrm{Sr}-85$ leaching from this waste form type is not simple diffusion based on the measured $E_{a}$ values.

No Co-57 activity above background was seen in any of the leachates for the cement samples containing sodium sulfate as simulated waste. This is a reasonable finding since insoluble cobalt hydroxide is presumably precipitated in the high $\mathrm{pH}$ cement. 
Table 4.5

\begin{abstract}
Apparent Activation Energies for Sr-85 From Cement Containing 5 Wt Sodium Sulfate
\end{abstract}

Leachant Replacement
Internal

1
2
3
4
5
6
7
8
9

10

11

12

13

14

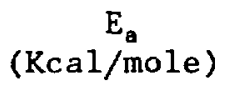

25

16

15

10

11

13

14

11

14

$-3.6$

12

6. 31 .

5. 2

2. 6
$E_{a}$ (J/mol)

103

64

64

43

44

56

58

44

57

$-15$

49

27

22

11

The leaching of sodium, potassium, calcium and strontium was measured from portland type I cement waste forms containing 5 wto sodium sulfate, but no radiotracers. These "Blanks" were otherwise nominally identical to the samples containing radiotracers. Previous results $[2,3,29]$ showed that the first three elements comprise the bulk of leachable cations from cement, while the strontium that is in cement naturally may affect the leaching of radiostrontium. In the cement waste forms containing sodium sulfate salt, the leached sodium comes from both the cement and from the salt; however, the bulk of it comes from the salt.

Figures $4.9,4.10,4.11$ and 4.12 show the cumulative amounts leached (mg) versus time plots for, respectively, sodium, potassium, calcium and strontium from duplicate cement blanks. The sodium and potassium data all show "typical" leaching curves--i.e., monotonically increasing at a decreasing rate. However, the leaching of calcium and strontium behave differently. Specifically, calcium leaching starts slowly and then increases to a relatively rapid and linear rate of release. This behavior appears to result from a solubility limit for calcium from the large concentration of sulfate initially present. Calcium leaches rather slowly until the bulk of the sulfate, as the sodium salt, has leached from the sample or has reacted with the calcium that 
was available; at this point the leach rate of calcium increases substantially and becomes linear with tine. Strontium releases generally parallel those of calcium.

Figure 4.13 is the correlation plot of sodium and potassium leaching from the blanks compared to the Cs-137 leaching from nominally identical portland I cement waste forms containing 5 wt 8 sodium sulfate. Sodium and potassiun releases correlate very well with those of Cs-137.

Figure 4.14 is the correlation plot for strontium leaching from the blanks compared to the Sr-85 leaching from nominally identical portland I cement waste forms containing radiotracers. The strontium releases at $20^{\circ} \mathrm{C}$ appear to correlate with $\mathrm{Sr}-85$ after a delay, but at $50^{\circ} \mathrm{C}$ they do not correlate. This may be caused by different rates of carbonation.

\subsubsection{Ratio of the Surface Area of the Waste Form to Volume of}

Leachant. The ANS 16.1 leach test procedure specifies that the ratio of the leachant volume (cubic $\mathrm{cm}$ ) to the geometric surface area (square $\mathrm{cm}$ ) of the test specimen be $10 \pm 0.2(\mathrm{~cm})$. To investigate the effect of increasing this ratio on leaching, ratios of 20,30 and 50 were used. In Figures 4.15 and 4.16, respectively show the results for $\mathrm{Cs}-137$ and $\mathrm{Sr}-85$ leaching from portland I cement waste forms containing 5 wt 8 sodium sulfate salt.

For the Cs-137 leaching (Figure 4.15) there is no apparent effect of increasing the ratio of leachant volume to waste form surface area. The decrease in Cs-137 leachability with increasing leachant volume is probably an artifact. Specifically, although all of the samples in these experiments were nominally identical, only the three sets at the larger leachant volumes were replicates whereas the samples at $1300 \mathrm{ml}$ (i.e., ratio of $10: 1$ ) were made at a different time. Increasing the ratio of leachant volume to surface area was not promising as an accelerating factor for Cs-137, so the experiments were not pursued.

Figure 4.16 shows the results on $\mathrm{Sr}-85$ leaching from increasing the leachant volume to waste form surface area. Although there appears to be a small increase in leachability of strontium, the lack of reproducibility is so dominant that the increase is lost in the scatter. These results were considered marginal at best, and the use of increasing leachant volume to waste form surface area was not pursued as a potential accelerating factor for strontium leachability from these waste forms under the conditions of these tests.

\subsubsection{Composition of the Leachant. Deionized water (DIW) was the} standard leachant used in the ANS 16.1 Leach Test. The effect of leachant composition on the leaching of portland I cement waste forms containing 5 wts sodium sulfate was examined with DIW, a simulated groundwater from Oak Ridge National Laboratory (ORNL) [63] and DIW containing 100 ppm disodium EDTA. Table 3.3 gives the composition of the ORNL groundwater. In addition, the ORNL-simulated groundwater was used (i) in a well oxygenated state (i.e., oxic groundwater), and (ii) depleted of oxygen (i.e., anoxic groundwater). Both the oxic and anoxic groundwaters contained soil-extracted humic and fulvic acids to make the compositions more realistic. Humic and fulvic acids have 
strong affinities for metal ions and can act as complexing and chelating agents. The experiments using $100 \mathrm{ppm}$ disodium EDTA in the leachant were used to examine the effect of very strong chelating agent on leaching.

Figure 4.17 shows the leaching curves for Cs-137 from portland I cement containing 5 wto sodium sulfate leached at $20^{\circ} \mathrm{C}$ in DIW, oxic and anoxic groundwaters. Figure 4.18 shows the same leaching curves for Cs-137 leached in DIW, plus those for leaching in DIW containing $100 \mathrm{ppm}$ disodium EDTA. In both figures Cs-137 leachability is greatest in DIW. This result is in accord with other findings [9] and was expected [3] because of the high ionic strength of the groundwater leachant. However, it is interesting that the DIW leachant containing disodium EDTA also retards leaching of Cs-137 to about the same extent as oxic groundwater. However, this may be within the normal variation for nominally identical but non-replicate samples. Since the disodium EDTA would not affect the solubility of Cs-137 (it would not decrease the solubility), the increase in ionic strength of the leachant is the only obvious affect that it would have. This conclusion is also suggested from the comparison of oxic versus anoxic groundwater leaching since the anoxic groundwater has a substantially greater ionic strength than does the oxic groundwater (Table 3.3). In sum, increasing the ionic strength of the leachant appears to decrease Cs-137 leachability. Further, the presence of chelating agents and the oxic or anoxic state of the leachant make little, if any, difference in Cs-137 leachability from these waste forms.

Figures 4.19 and 4.20 are the linear correlation plots for the data in Figures 4.17 and 4.18 , respectively, on the effect of leachant composition on Cs-137 leachability from portland I cement containing sodium sulfate. Figure 4.19 shows that both the oxic and anoxic groundwaters decrease Cs-137 leachability and increase the statistical scatter compared to leaching in DIW. In contrast, Figure 4.20 shows that Cs-137 leaching in the DIW leachant containing $100 \mathrm{ppm}$ disodium EDTA is retarded but is as reproducible as in DIW itself. Buildup of calcium carbonate on the surface of the waste form from the chemical reaction between the carbonate in the groundwaters and calcium from the cement may cause the scatter in the groundwater leaching results. This surface buildup may also retard leachability if the porosity of the cement is reduced or if sorption of Cs-137 is significant on the carbonate surface.

Figure 4.21 shows the leaching curves for Sr-85 from portland I cement containing 5 wto sodium sulfate leached at $20^{\circ} \mathrm{C}$ in DIW, oxic and anoxic groundwaters. Figure 4.22 shows the same leaching curves for $\mathrm{Sr}-85$ leached in DIW and in DIW containing 100 ppm disodium EDTA. In Figure $4.21 \mathrm{Sr}-85$ leachability is greatest in DIW, while in Figure 4.22 it is greater in the EDTA-containing leachant. The results in Figure 4.21 are in accord with other groundwater leaching results [64-65]. Both the high carbonate content of the groundwater and the high ionic strength of the groundwater leachant are expected to reduce $\mathrm{Sr}-85$ leachability. However, it is interesting that the DIW leachant containing the disodium EDTA increases leaching of $\mathrm{Sr}-85$, as could be expected since the disodium EDTA effectively increases the solubility of Sr-85 by forming soluble chelation complexes. This increase in solubility apparently overcomes the tendency to decrease leachability expected from the increased ionic strength of the leachant (the only obvious affect that it 
would have). In sum, carbonate content and increased ionic strength of the groundwater leachant appear to decrease Sr-85 leachability. Further, the presence of the natural chelating agents, i.e., the humic and fulvic acids make little, if any, difference in Sr-85 leachability from these waste forms while the chelating agent EDTA increases Sr-85 leachability.

Figures 4.23 and 4.24 plot the linear correlations of the data from Figures 4.21 and 4.22 , respectively, showing the effect of leachant composition on Sr-85 leachability from portland I cement containing sodium sulfate.

No measurable Co-57 activity above background was leached from the waste forms in any of these experiments.

As described in Section 4.2.1 the leaching of sodium, potassium, calcium and strontium was measured from non-radioactive "Blank" waste forms containing sodium sulfate. Figures $4.25,4.26,4.27$ and 4.28 show the cumulative amounts leached (ppm) versus time for, respectively, sodium, potassium, calcium and strontium from duplicate samples in DIW and in oxic groundwater.

While leaching of potassium and sodium is slightly suppressed by groundwater, the basic curve shape of releases in groundwatr are similar to those in distilled water: releases of calcium, however, are markedly different. The groundwater contained $57 \mathrm{ppm}$ calcium at the start of the experiment. Nevertheless, calcium releases in the groundwater are much faster during the first seven days of the experiment, than in the distilled water. After one week, the calcium concentrations in the groundwater remains constant at about $145 \mathrm{ppm}$. Calcium concentration in the distilled water continues to increase, with a significant change in leach rate occurring between 10 and 16 days. The difference in behavior is caused by solubility limits on the calcium in the groundwater; probably by $\mathrm{CaCO}_{3}$ precipitation.

Strontium releases are not limited by solubility constraints directly but are significantly reduced in the groundwater. This reduction is probably due to inclusion of strontium in the $\mathrm{CaCO}_{3}$ precipitate.

Figures $4.29,4.30,4.31$ and 4.32 plot the linear correlations of the data shown in Figures 4.25-4.28, respectively.

4.2.4 $\mathrm{pH}$ of the Leachant. The $\mathrm{pH}$ of deionized water (DIW), which is the standard leachant in the ANS 16.1 leach test, is nominally 7 at $20^{\circ} \mathrm{C}$ but is actually about 6 due to dissolution of carbon dioxide from the air, making the DIW slightly acidic. For cement waste forms the initial $\mathrm{pH}$ of the leachant is not maintained since dissolution of soluble material in the cement matrix, primarily calcium hydroxide, shifts the $\mathrm{pH}$ higher. To investigate the effect of leachant $\mathrm{pH}$, initial values of $3,4,5$ and 8 were compared with the nominal leaching results obtained in $\mathrm{DIW}$ at $\mathrm{pH} 6$. These results for $\mathrm{Cs}-137$ and Sr-85 leaching from portland I cement waste forms containing 5 wto sodium sulfate salt are shown in Figures 4.33 to 4.36 . 
Figure 4.33 shows that the leachability of Cs-137 decreases as initial leachant $\mathrm{pH}$ values were made more acidic and more basic than the nominal $\mathrm{pH}$ of 6. The decrease in Cs-137 leachability with both decreased and increased leachant $\mathrm{pH}$ may be due to the increased ionic strength of the leachant solutions at $\mathrm{pH}$ values other than 6 (i.e., pure DIW). However, the last point at $\mathrm{pH} 8$ seems notable in that it is below its expected position, based on comparison with other data. This may be due to more rapid carbonation of the system since carbon dioxide dissolves rapidly in basic solutions. This observation is clear in the linear correlation plot of Figure 4.34. Changing the leachant $\mathrm{pH}$ was not promising as an accelerating factor for $\mathrm{Cs}-137$, so the experiments were not pursued.

Figure 4.35 shows the results of changing initial leachant $\mathrm{pH}$ on $\mathrm{Sr}-85$ leaching. There is an apparent increase in leachability of $\mathrm{Sr}-85$, which is clearer in the linear correlations plotted in Figure 4.36. These correlations show that acidic leachants may be useful for accelerating Sr-85 leaching since the plots at $\mathrm{pH}$ values of 3,4 and 5 remain linear over the course of the experiments. Part of the acceleration effect may result from reducing carbonation of the system, since carbon dioxide from the air dissolves to a much lesser extent in acidic solution.

No measurable Co-57 activity above background was leached from the cement waste forms in any of these experiments.

As described in Section 4.2.1, the leaching of sodium, potassium, calcium and strontium was measured from nonradioactive "Blank" portland I cement waste forms containing sodium sulfate. However, since changing the initial leachant $\mathrm{pH}$ was not an accelerating factor for Cs-137 and was somewhat marginal for Sr-85, no experiments were performed on this waste form type.

4.2.5 Leachant Flow Rate or Replacement Frequency. If the buildup of leached material in the leachant affects leachability, then flow rate or replacement frequency is a factor in accelerated test development. The ANS 16.1 leach test requires daily replacement of leachant through day five following replacements at 2 hours and 7 hours on the first day. After day five the replacement intervals are much longer. To investigate the effect of replacement interval on the leachability of the portland I cement waste forms containing 5 wto sodium sulfate, daily replacements were continued for 32 days. These results for $\mathrm{Cs}-137$ and $\mathrm{Sr}-85$ leachability are shown in Figures 4.37 through 4.40 .

Figure 4.37 presents the Cs -137 leaching data for daily replacements compared to data from testing using the standard replacement intervals. Leachability from the daily replacements is less than from the reference data, but the reproducibility is good for both sets of replicate samples. The difference in Cs-137 leachability between the two sets of data is larger than we had hoped, but is consistent with differences between nominally identical samples that are not actual replicates.

Figure 4.38 plots the linear correlations of the data in Figure 4.37. Only corresponding points are used from the daily replacement data. These data are well correlated and there is no evidence that the buildup of leached 
material at the longer replacement intervals affects Cs-137 leaching from these samples.

The effect of daily replacement on Sr-85 leaching from portland I cement containing $5 \mathrm{wtz}$ sodium sulfate is shown in Figure 4.39. Sr-85 leaching is notably greater from the daily replacement experiments than from the reference data at longer intervals. Interestingly, this is the reverse of the relative leaching behavior of Cs-137. Although Sr-85 leaching from the daily replacements starts out, and remains, greater than that from the normal replacements, the divergence increases when the replacement intervals lengthen after day five.

In the linear correlations plotted in Figure 4.40, the divergence between Sr-85 CFL from the daily replacements and that from the longer replacement intervals in the reference ANS 16.1 data is more evident. Specifically, the slope of the line through the last three triplicate data points from the daily replacements noticeably increases compared to that for the first seven triplicate data points.

No measurable Co-57 activity above background was leached in any of these experiments.

As described in Section 4.2.1 the leaching of sodium, potassium, calcium and strontium was measured from nonradioactive "Blank" samples. However, since changing the initial leachant $\mathrm{pH}$ was not an accelerating factor for Cs-137 and was a marginal accelerating factor for $\mathrm{Sr}-85$, no experiments were performed on this waste form.

4.2.6 Composition of the Waste Form. Sulfate salts are not totally compatible with portland cements since sulfate is known to attack cement $[44,45]$. Nevertheless solidification of sulfate evaporator bottoms in portland cements has been a common practice.

The presence of 5 wto sulfate causes cracking of waste forms after about 100 days of leaching. Figure 4.41 shows the cracking after 330 days leaching. The formation of authigenic minerals growing on the surfaces of the specimen and filling the pores causes swelling, cracking, and ultimately, cracking of the waste form.

Radionuclide releases from cement containing 5 wto sodium sulfate salt are shown in Figure 4.42 for a set of triplicate specimens. Intersample variability is small, for example 1.48 at the 45-day interval, until cracking of the waste form began at about 100 days. Comparison of these data with the baseline samples, (also shown in Figure 4.42) shows that Cs-137 leaching is faster from the samples containing waste than from those without waste.

To determine if the leaching mechanism of cement was altered by inclusion of waste, the CFL for Cs-137 from samples without waste was plotted against the CFL of samples that contained $\mathrm{Na}_{2} \mathrm{SO}_{4}$. Figure 4.43 indicates that a linear relationship exists between releases from the two types of samples. 
There was no change in leaching mechanism. The slope of the line for specimens containing waste is approximately 1.15 , indicating a small increase in leach rate.

Typical of cement, Sr-85 releases are significantly lower than those of Cs-137. Figure 4.44 shows the CFL for $\mathrm{Sr}-85$ from baseline specimens and cement specimens containing $\mathrm{Na}_{2} \mathrm{SO}_{4}$. During the first 90 days of the tests, $\mathrm{Sr}-85$ from the specimens with the $\mathrm{Na}_{2} \mathrm{SO}_{4}$ leached slightly slower than from the baseline specimens. These differences are significant at the 958 confidence interval. After 90 days the scatter in the sulfate samples increases dramatically as do their release rates relative to the baseline: this is caused by cracking of the samp'a due to the sulfate salt.

Figure 4.45 shows $\mathrm{Sr}-85 \mathrm{CFL}$ data for sulfate samples plotted against the baseline $\mathrm{Sr}-85 \mathrm{CFL}$. The slope of this curve is quite different than that of Cs-137 (Figure 2). Sample depletion is not a factor for Sr-85 since CFL never reached $10 \%$. The relationship between sulfate and baseline samples is linear until a baseline CFL of 0.035 is reached, equivalent to 46 days leaching. After this point the $\mathrm{Sr}-85$ releases from the two types of samples dramatically depart from a linear relationship. Cracking and swelling were observed in these samples shortly after the leach rate began to increase.

Plots of CFL vs Time, as in Figure 4.44 indicate that $\mathrm{Sr}-85$ releases from samples containing $\mathrm{Na}_{2} \mathrm{SO}_{4}$ are initially slightly lower than the baseline but then begin to increase rapidly, as does the scatter among the samples, when swelling and cracking begins. The effect of disruption of the solid specimen is more acute in the $\mathrm{Sr}$ data than in the Cs. By the time the samples begin to crack most Cs has leached out, so that the cracks expose areas already depleted in Cs. However, Sr only lost about 38 of its original concentration so the cracks open areas of high $\mathrm{Sr}$ concentrations, leading to greater release rates of this nuclide. Figure 4.46 shows Sr-85 CFL plotted against Cs-137 CFL for a specimen without waste, to clarify the differences in leaching mechanisms of the two radionuclides. This figure shows a linear relationship among the data points representing daily sampling intervals (Region A). With the change in sampling interval, a second linear region (Region B) develops with a lower release rate for strontium. This region extends to the end of the Sr-85 data at 130 days. The causes of this change in behavior are probably related to carbonate formation on the surface of the specimen [1] and is discussed further in the solid phase section of this report.

Treating the data from a specimen containing sulfate waste in the same manner illustrates the difference in Sr-85 leaching behavior between specimens with and without waste. Figure 4.47 shows that Regions $A$ and $B$ are also present in a specimen containing waste. In both regions, however, the slopes are lower than in their respective regions for the base line specimen indicating that $\mathrm{Sr}-85$ releases are lower (relative to $\mathrm{Cs}-137$ releases) from specimens containing sulfate than from the baseline. More importantly, a third region developed where Sr-85 leaching accelerated relative to Cs-137, illustrating the affects of cracking. 
No measurable Co-57 activity above background was leached from the cement waste forms in any of these experiments.

Elemental composition data for leachate from nonradioactive samples of portland cement containing $\mathrm{Na}_{2} \mathrm{SO}_{4}$ are presented in Figure 4.48. The calcium concentrations are of particular interest. During the first 40 to 60 days of leaching, calcium releases from the sulfate samples are significantly lower than calcium from the baseline. Later, release rates are much higher. Sulfate in the specimen probably reacts with free calcium to form $\mathrm{CaSO}_{4} \cdot 2 \mathrm{H}_{2} \mathrm{O}$ or with aluminum and calcium to form ettringite. Only later, when the sulfate causes the cement to crack, does calcium leaching increase. Conductance values for samples containing $\mathrm{Na}_{2} \mathrm{SO}_{4}$ salt were extremely high compared to those of the baseline indicating that large quantities of additional ions from the salt were released.

4.2.7 Ratio of the Volume to Surface Area of the Waste Form $(\mathrm{V} / \mathrm{S})$. As reviewed in section 2.7 , under certain conditions, small-scale test specimens can be used to accelerate the leaching that would be expected from full-scale waste forms. There are data that support the use of small-scale test samples to accelerate leaching from cement waste forms containing various types of bulk waste, including sulfate salts $[19,20,22]$. The ANS 16.1 leach test specifies that the minimum dimensions of the sample must be one cm. Experiments were performed using small-scale samples of various sizes to evaluate decreasing size (i.e., decreasing $V / S$ ) as an accelerating factor, and to determine how small the samples can be and still produce reliable data. These results for Cs-137 and Sr-85 leaching from portland I cement waste forms containing 5 wto sodium sulfate salt are shown in Figures 4.49 through 4.52.

The Cs-137 leaching results (Figure 4.49) indicate that leachability increases as $\mathrm{V} / \mathrm{S}$ decreases sodium sulfate. The increase in Cs-137 leachability with decreasing $\mathrm{V} / \mathrm{S}$ appears to saturate, or become ineffective, as $\mathrm{V} / \mathrm{S}$ decreases below approximately 0.6 , since there is no significant difference in Cs-137 leachability between the samples at $\mathrm{V} / \mathrm{S}$ values of 0.61 and 0.42 .

However, this data may be misleading, because the specimens with $\mathrm{V} / \mathrm{S}=0.61$ are disc-shaped as opposed to cylinders. Since the aspect ratio of height to diameter is not consistent with those of other $V / S$ ratios, these specimens may become depleted too rapidly. Also, smaller specimens will require a sampling schedule that is more intensive in the early part of the experiment.

Figure 4.51 shows the results of changing the ratio of waste form volume to surface area $(\mathrm{V} / \mathrm{S})$ on $\mathrm{Sr}-85$ leaching for the portland I cement waste forms containing 5 wto sodium sulfate. There is an increase in leachability of Sr-85, which is clearer in the linear correlations plotted in Figure 4.52. These correlations show that decreasing $\mathrm{V} / \mathrm{S}$ may be useful for accelerating Sr-85 leaching since the plots at $V / S$ values of 1.85 remain 1 inear over the course of the experiments, while those at $V / S$ values of 0.61 and 0.42 remain linear until the samples begin to be affected by carbonation.

No measurable Co-57 activity above background was leached from the waste forms in any of these experiments. 
4.2.8 Effect of Surface Condition and Porosity. No direct information on waste form porosity is available. This is not a factor one can alter to provide acceleration; it can only be observed. It is unclear to what extent surface coatings on cement waste forms significantly influence radionuclides releases. There is compelling evidence that under some conditions, there are controls on Sr-85 releases exerted by calcium carbonate coatings that form during leaching in seawater [66]. Other data are show that carbonate reaction rims, that form on portland cement in distilled water, have a greater capacity to sorb Cs-137 compared to solidified cement [62].

When sulfate waste is included in the cement, the surfaces that develop are structurally different, but there are no data to assess its effect on leaching. Preliminary analysis of cement containing 5 wto $\mathrm{Na}_{2} \mathrm{SO}_{4}$ has been done and results provide some insight into the processes that occur in this material during immersion in water.

Before immersion, the surface of the cement waste form containing 5 wto sodium sulfate salt looked similar to that of the baseline cement sample which contained no added salt (Figure 4.53). Even at high magnification, no discrete particles of salt were observed. Figure 4.54 shows the typical texture of cement, with intergrown fibrils that form the bonds that give cement its strength. Elemental analysis of the surface shows some enrichment of sulfur. A low intensity sodium peak also was observed in the saltcontaining sample, whereas none was seen in the baseline sample. Before leaching, pores and bubbles in the salt-containing cement were empty or occasionally exhibited a few portlandite crystals, as was the case with unleached samples of plain cement.

After immersion for 55 days at $50^{\circ} \mathrm{C}$ a replicate of the sample discussed above was examined: slight cracking around the bottom of the sample was noted. Figure 4.55 shows the leached surface at a magnification of 400 times and Figure 4.56 at 1900 times. Before leaching, this surface was porous and open, now was covered by a profuse growth of crystals. Little porosity was evident.

Cut surfaces from inside this waste form also were examined. Figure 4.57 shows a sample of this material, taken about $2 \mathrm{~mm}$ from the surface. There is much cracking, apparently the result of swelling. No grains of salt were found. On examining this section at high magnification and using EDS, distinct chemical differences were found. Areas near the cracks were depleted of sulfur compared to spectra of the unleached cement/sulfate salt waste form, implying that there was significant mobility of sulfate in the cement after curing and during leaching.

Examination of larger bubbles, which were empty in the unleached sample, revealed that most were filled with crystals. Figure 4.58 shows a typical bubble at magnification of 400 times. The spectrum shown in Figure 4.60 is from an EDS analysis of a single crystal in this cavity. It is significantly different than the spectrum of the unleached waste form: no potassium or sodium are observed and the silicon peak is much reduced. The sulfur from the waste had apparently reacted with aluminum, silicon and calcium to form one or two phases that preferentially grew into the open cavities in the waste form. 
Most of this growth may be ettringite and gypsum, but x-ray diffraction mineralogy of this material has not been performed.

Comparison of the bulk chemical composition of the leached surface (Figure 4.61) with a single crystal from inside an air bubble (Figure 4.60) showed essentially identical spectra. The surface is composed entirely of this crystalline mineral, with no other material observable by EDS. This surface, however, is chemically different than the bulk leached cement containing sodium sulfate. Figure 4.62 is an EDS spectrum of the center of the specimen from which the surface spectrum was obtained. There is much more silicon present and the mobile elements, sodium and potassium are also present. This spectrum is similar to that of unleached material.

The great diversity of chemistry from the outer surface to the interior of the same specimen and between leached and unleached specimens, compounded by structural differences, do not appear to cause any significant alteration of the leaching mechanism of Cs-137. Activation energies and leach rates are quite similar for Cs-137 from plain cement and from cement containing sodium sulfate (and the reaction products of the cement and the salt). More work is necessary to confirm this opinion. 


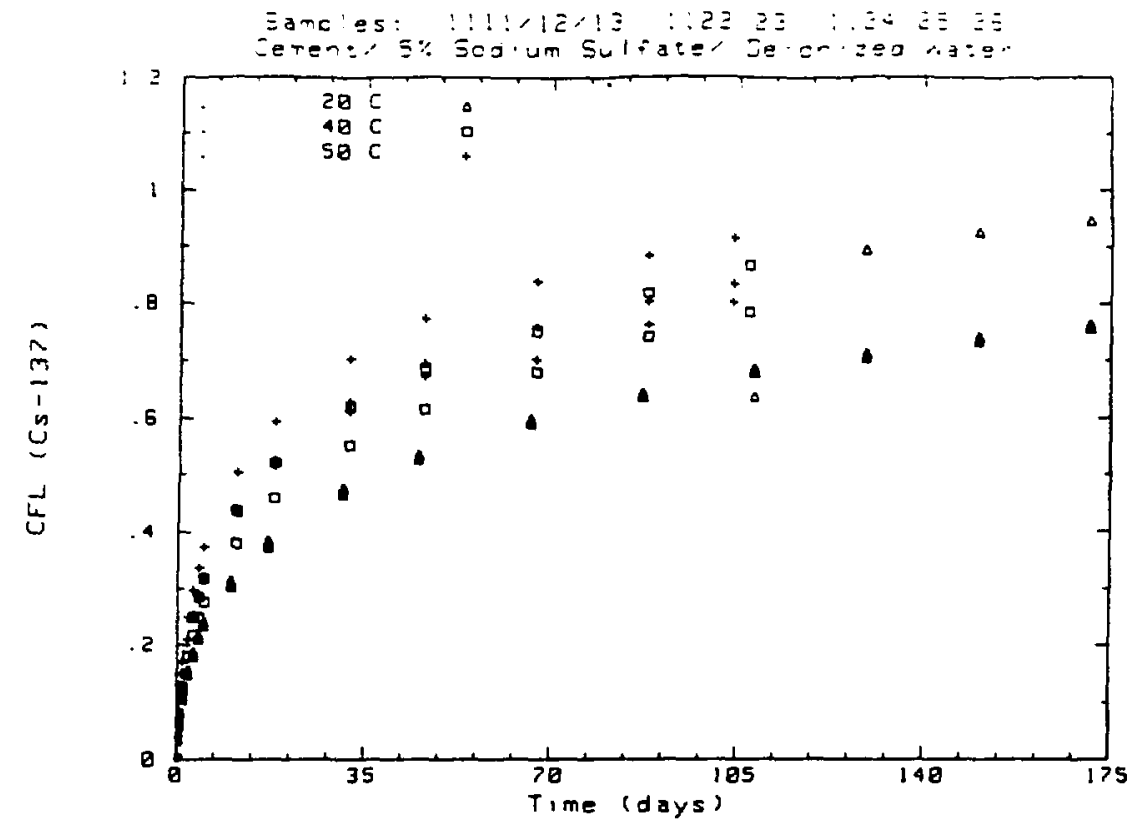

Figure 4.1

Cs-137 cumulative fraction leached vs. time from portland I cement containing 5 wt sodium sulfate at 20,40 and $50^{\circ} \mathrm{C}$. Samples were leached in deionized water.

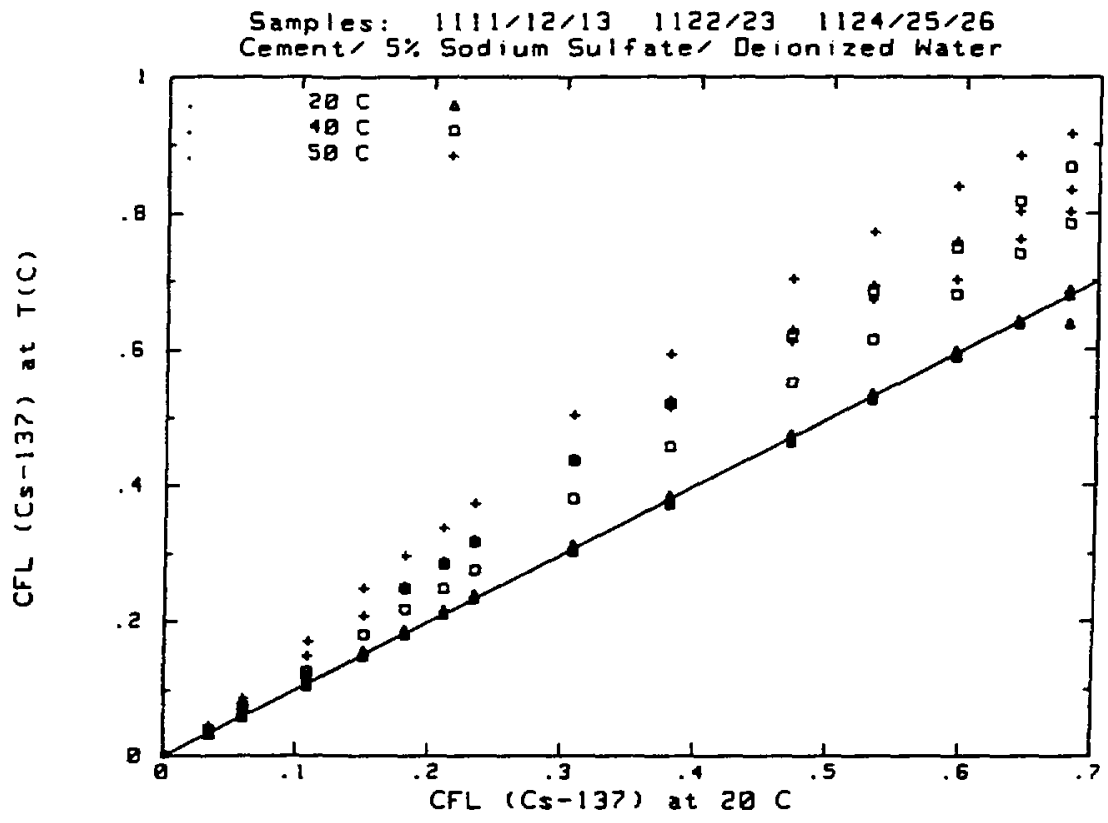

Figure 4.2

Linear correlation plots for Cs-137 leaching from portland I cement containing 5 wt sodium sulfate at 20,40 and $50^{\circ} \mathrm{C}$. Correlations are relative to the $20^{\circ} \mathrm{C}$ data. Samples were leached in deionized water. 


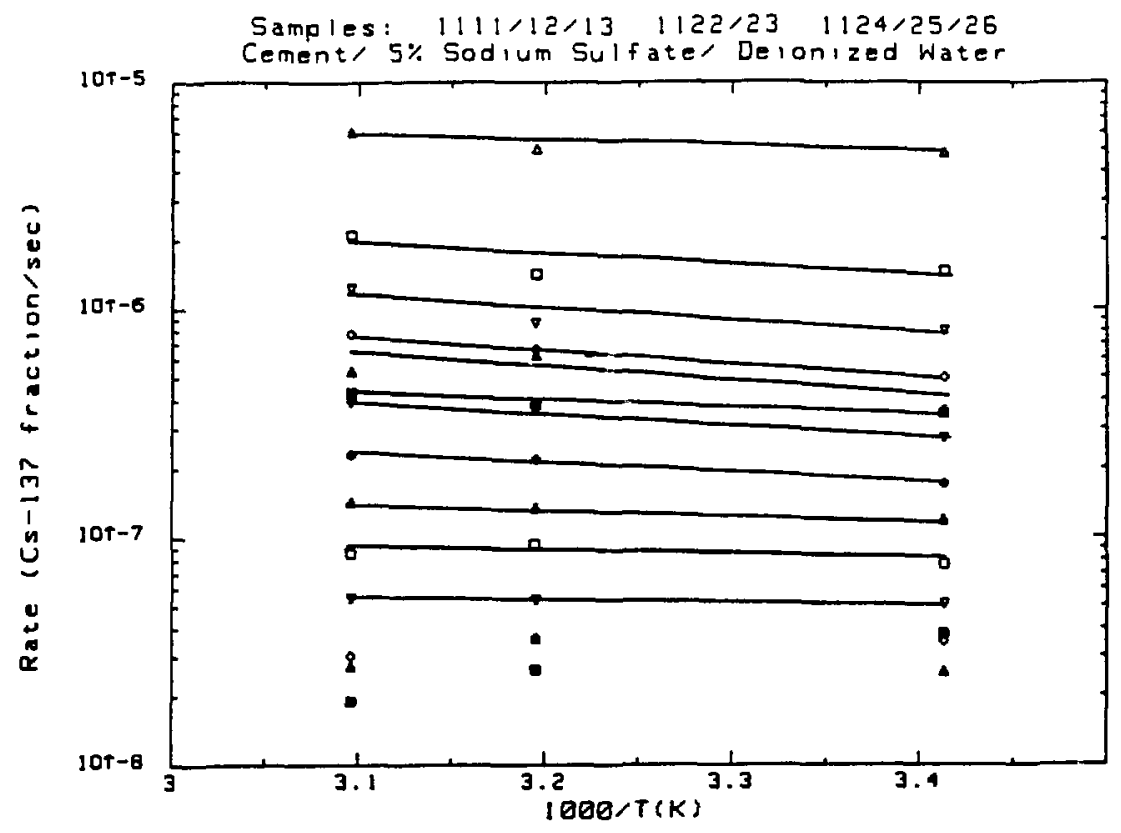

Figure 4.3

Arrhenius plot of Cs -137 incremental leach rates from portland I cement containing 5 wt sodium sulfate leached at 20,40 and $50^{\circ} \mathrm{C}$ in deionized water.

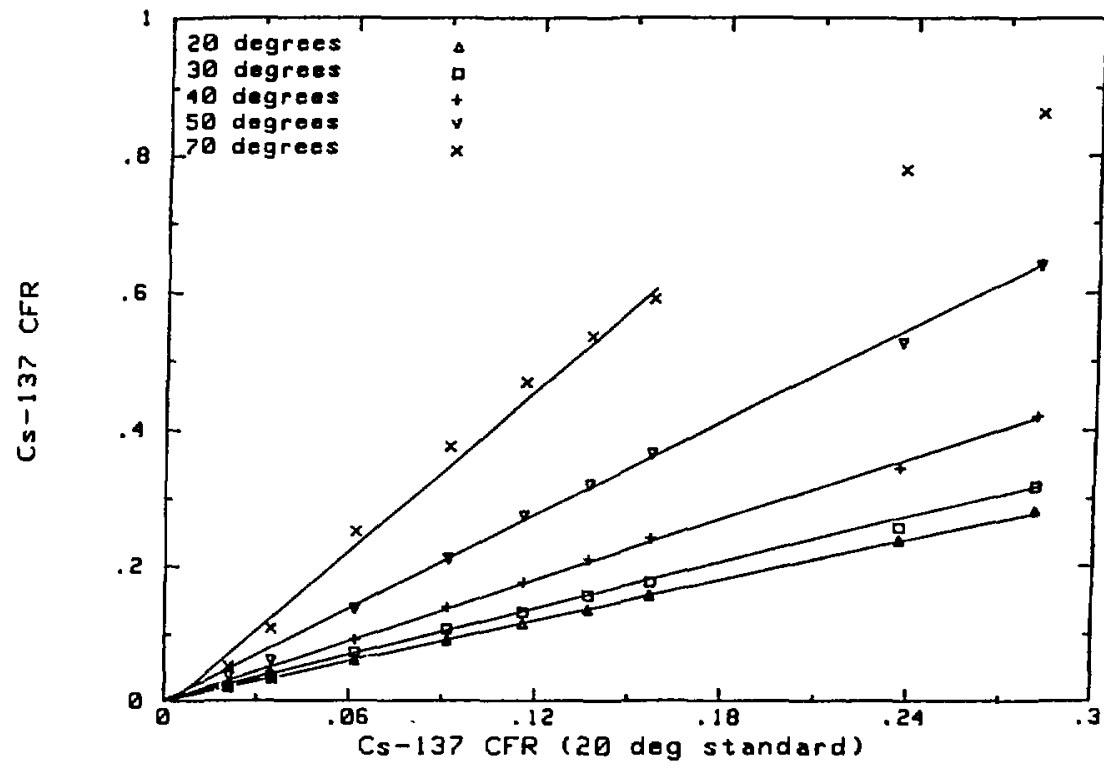

Figure 4.4

Linear correlation plots for Cs-137 leaching from pure portland I cement at $20,30,40,50$ and $70^{\circ} \mathrm{C}$ Correlations are relative to the $20^{\circ} \mathrm{C}$ data. Samples were leached in deionized water. 


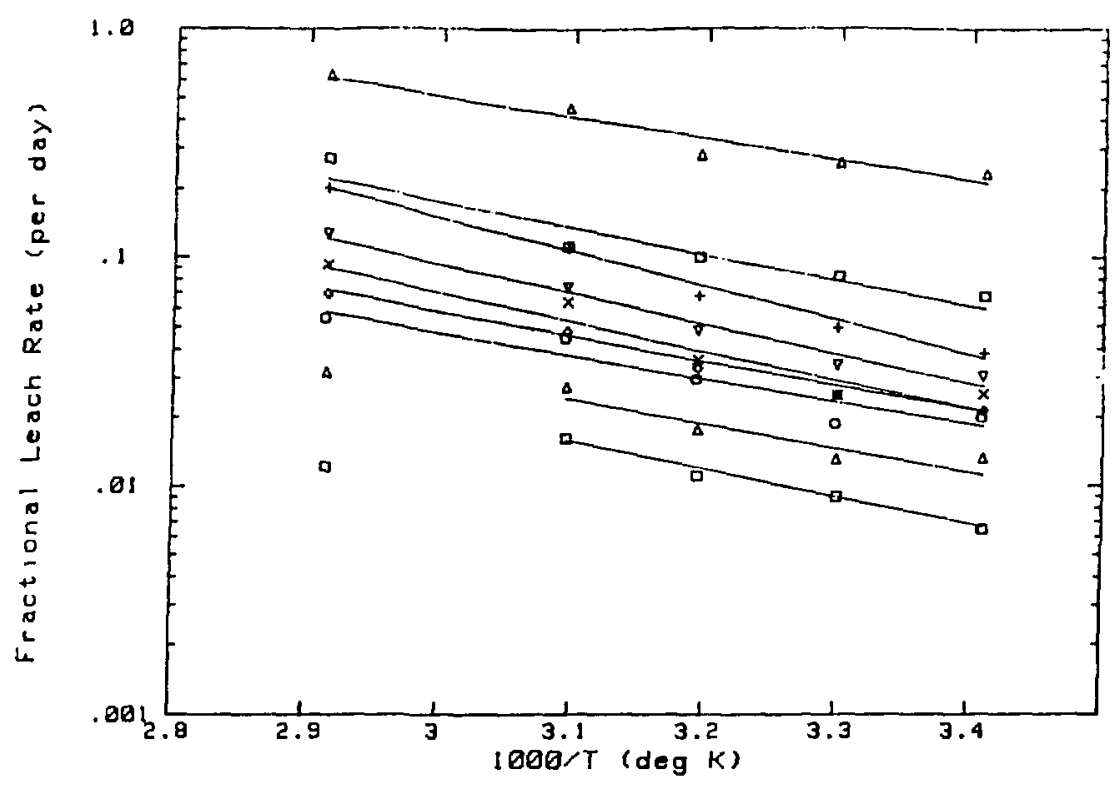

Figure 4.5 Arrhenius plot of Cs-137 incremental leach rates from pure portland I cement leached at $20,30,40,50$ and $70^{\circ} \mathrm{C}$ in deionized water.

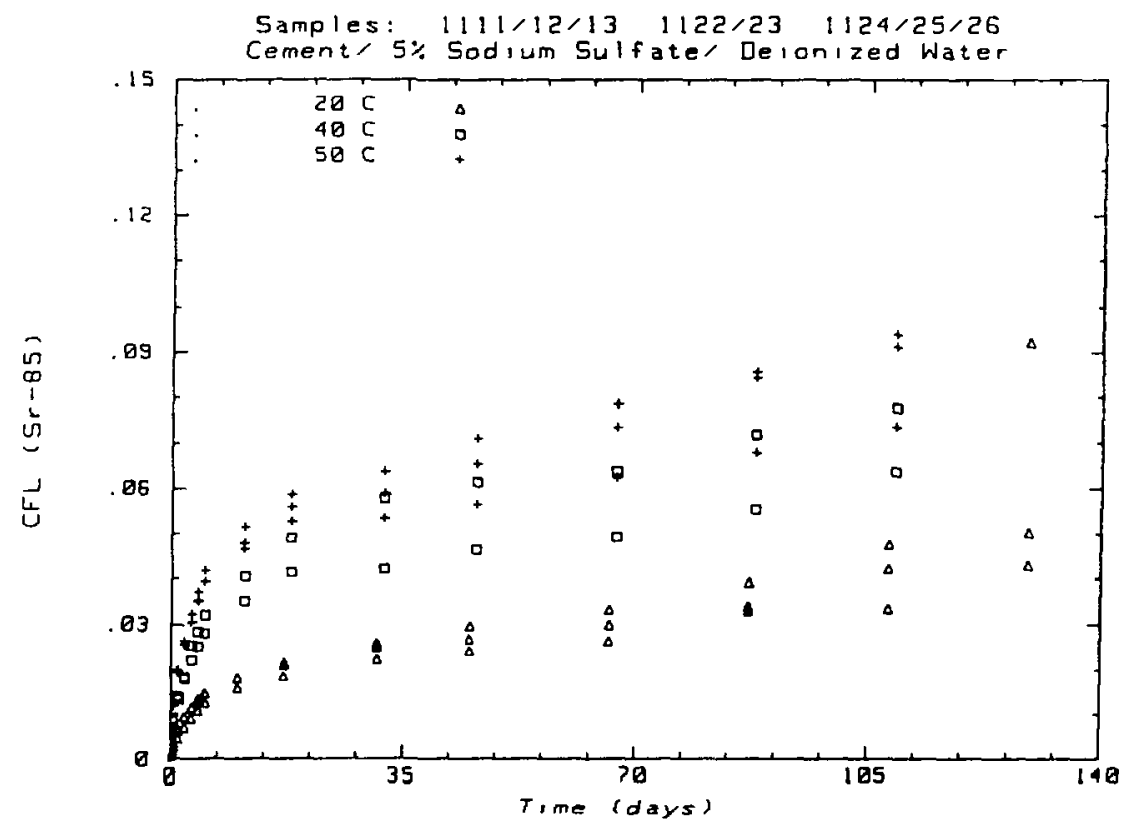

Figure 4.6

Sr-85 cumulative fraction leached vs. time from portland I cement containing 5 wto sodium sulfate at 20,40 and $50^{\circ} \mathrm{C}$ leached in deionized water. 


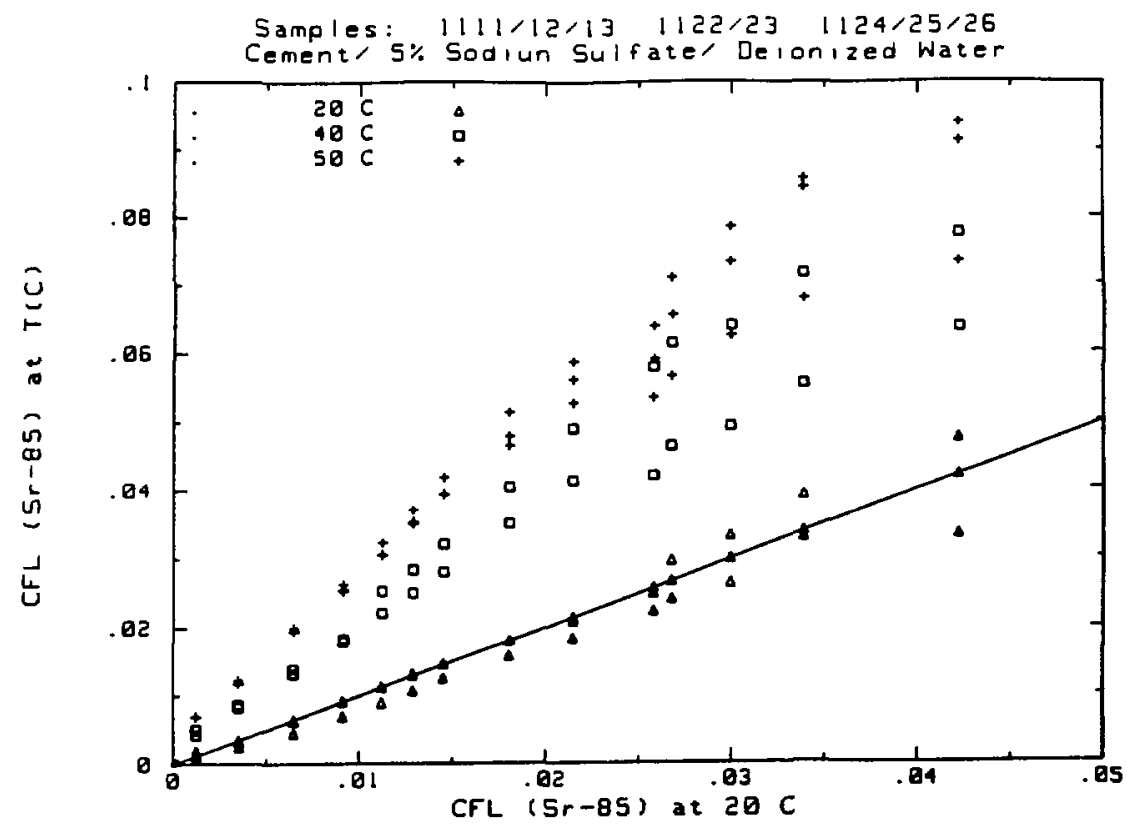

Figure 4.7

Linear correlation plots for Sr-85 leaching from portland I cement containing 5 wt sodium sulfate at 20,40 and $50^{\circ} \mathrm{C}$. Correlations are relative to the $20^{\circ} \mathrm{C}$ data. Samples were leached in defonized water.

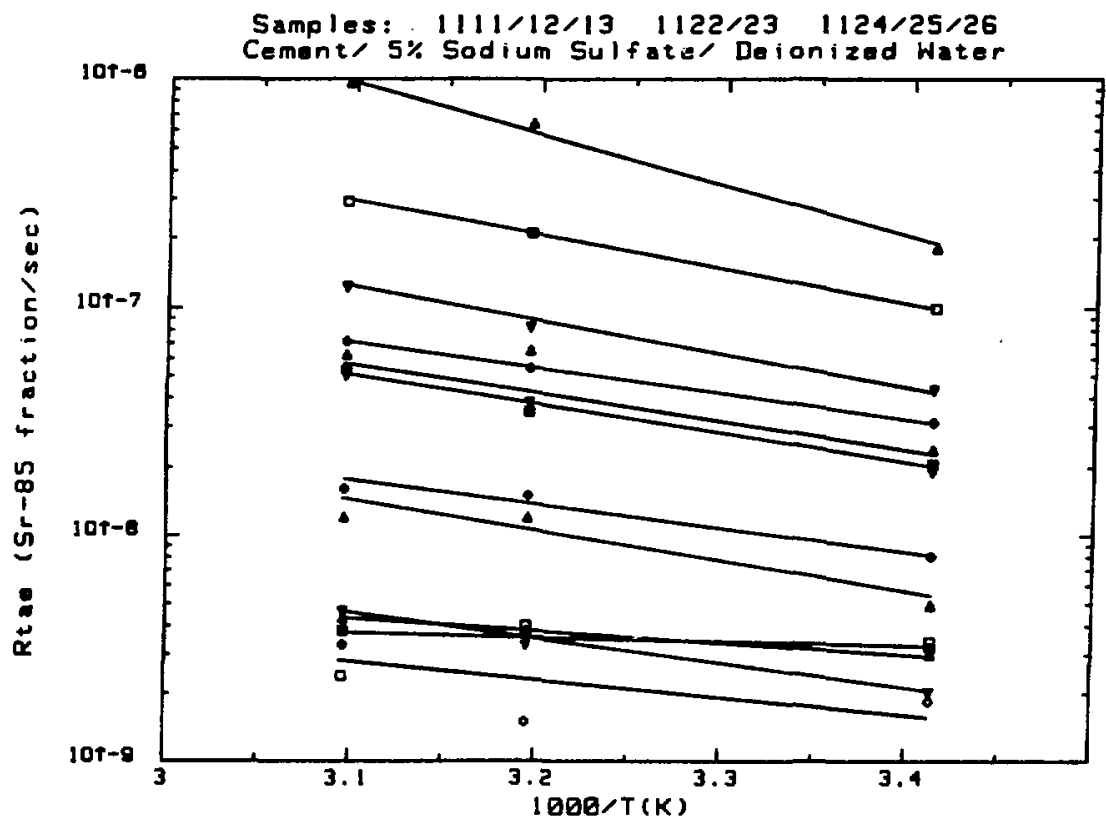

Figure 4.8

Arrhenius plot of Sr-85 incremental leach rates from portland I cement containing 5 wt sodium sulfate leached at 20,40 and $50^{\circ} \mathrm{C}$ leached in deionized water. 


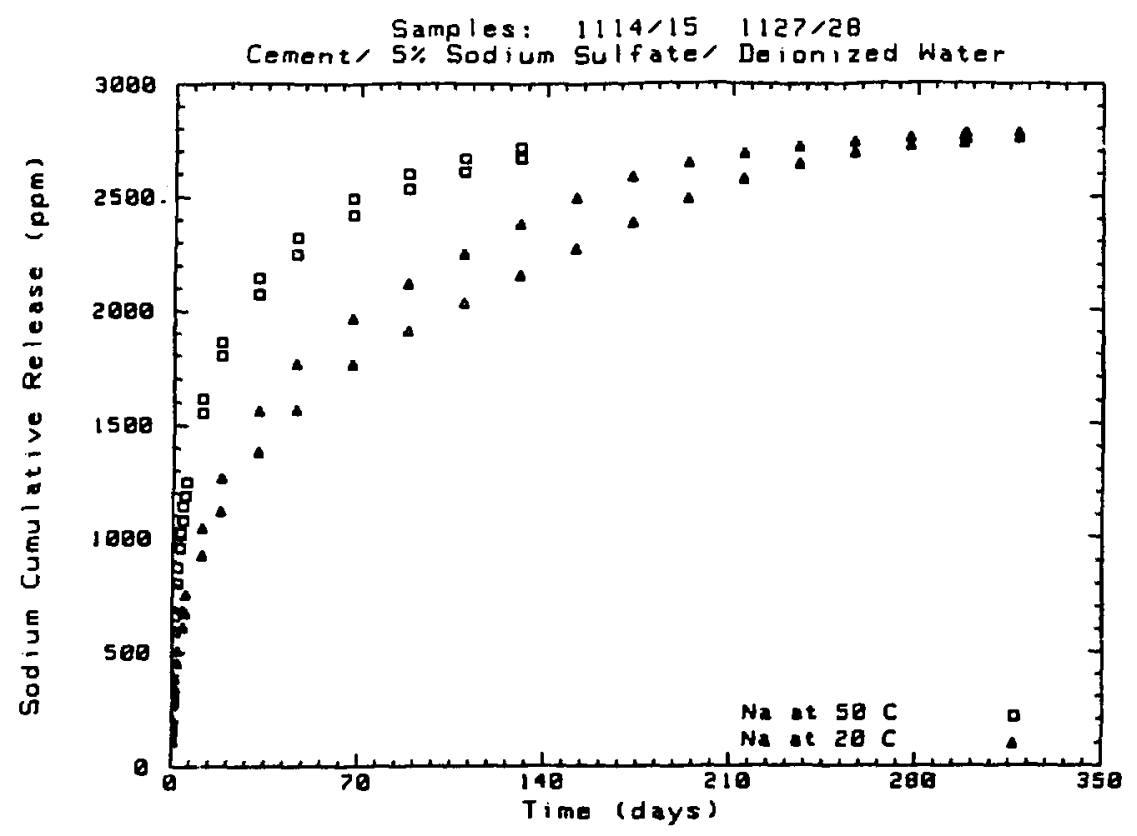

Figure 4.9

Sodium cumulative amount (ppm) leached vs. tine fron portland I cement containing 5 wt sodiun sulfate at 20 and $50^{\circ} \mathrm{C}$. Samples were leached in delonized water.

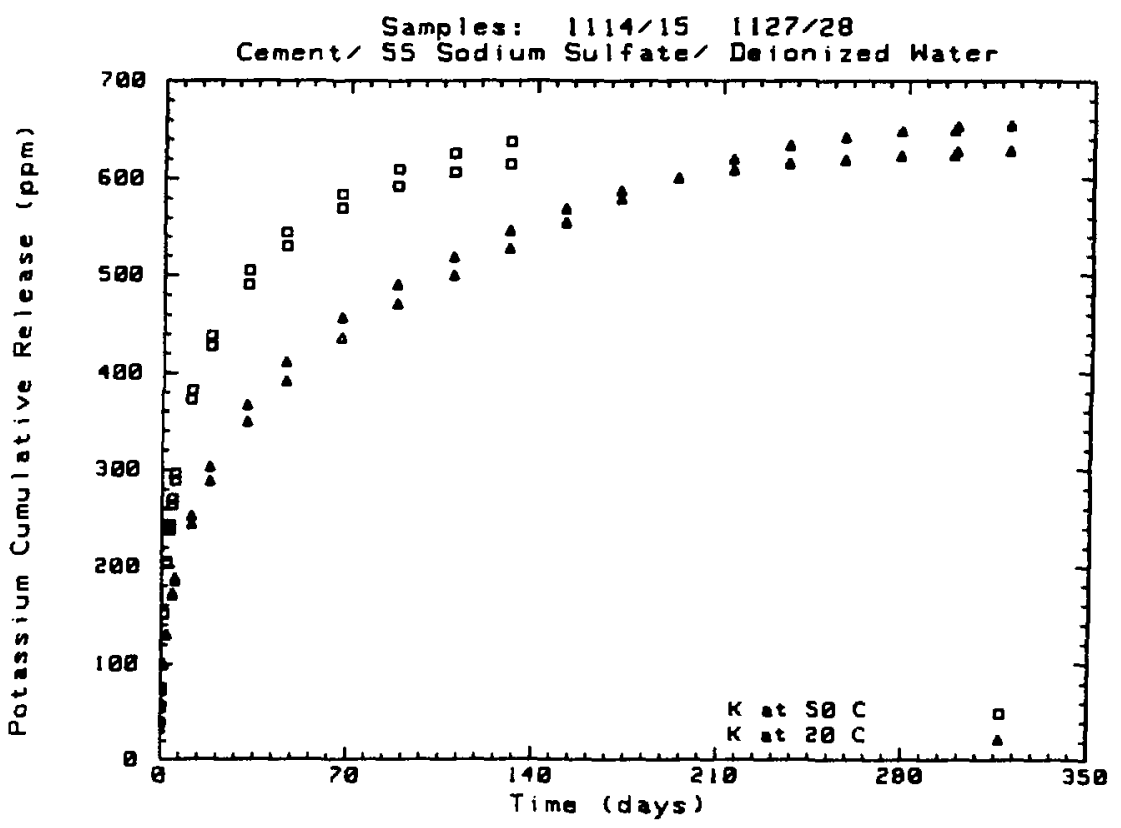

Figure 4.10

Potassium cumulative amount (ppm) leached vs. time from portland I cement containing 5 wts sodium sulfate at 20 and $50^{\circ} \mathrm{C}$. Samples were leached in delonized water. 


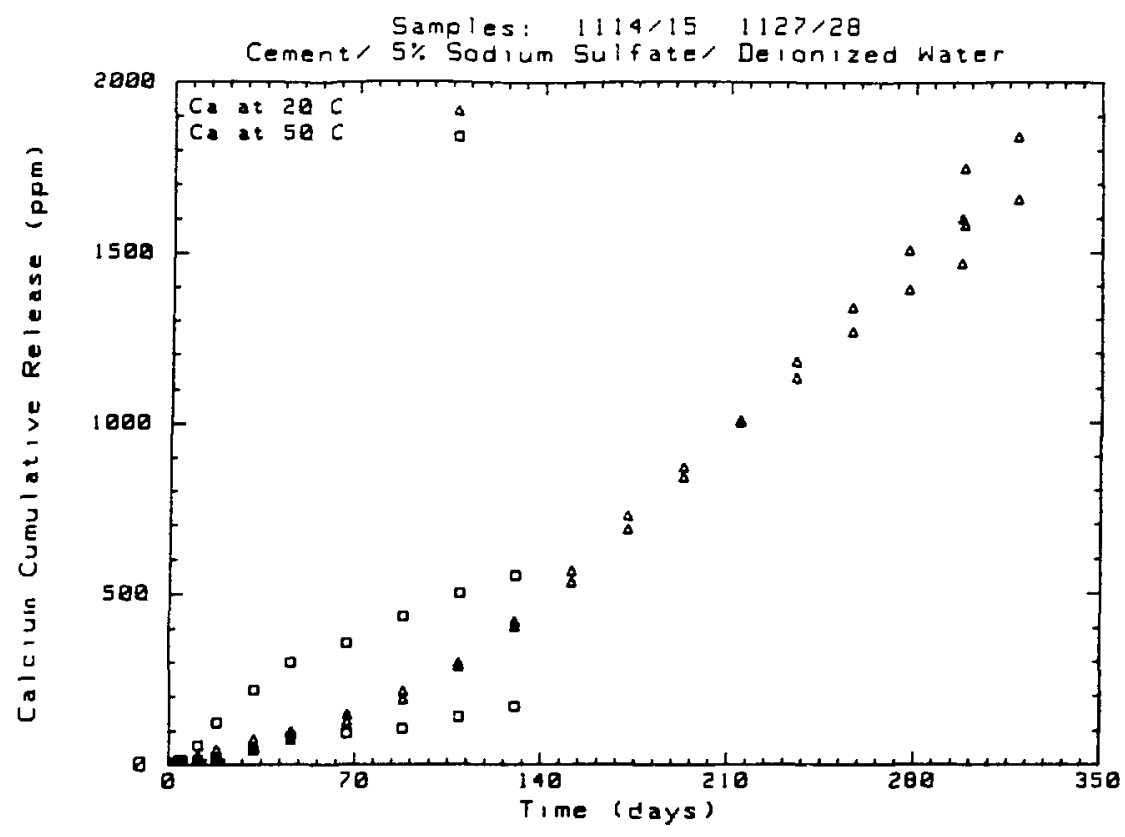

Figure 4.11

Calcium cumulative amount (ppm) leached vs. time from portland I cement containing 5 wt sodium sulfate at 20 and $50^{\circ} \mathrm{C}$. Samples were leached in deionized water.

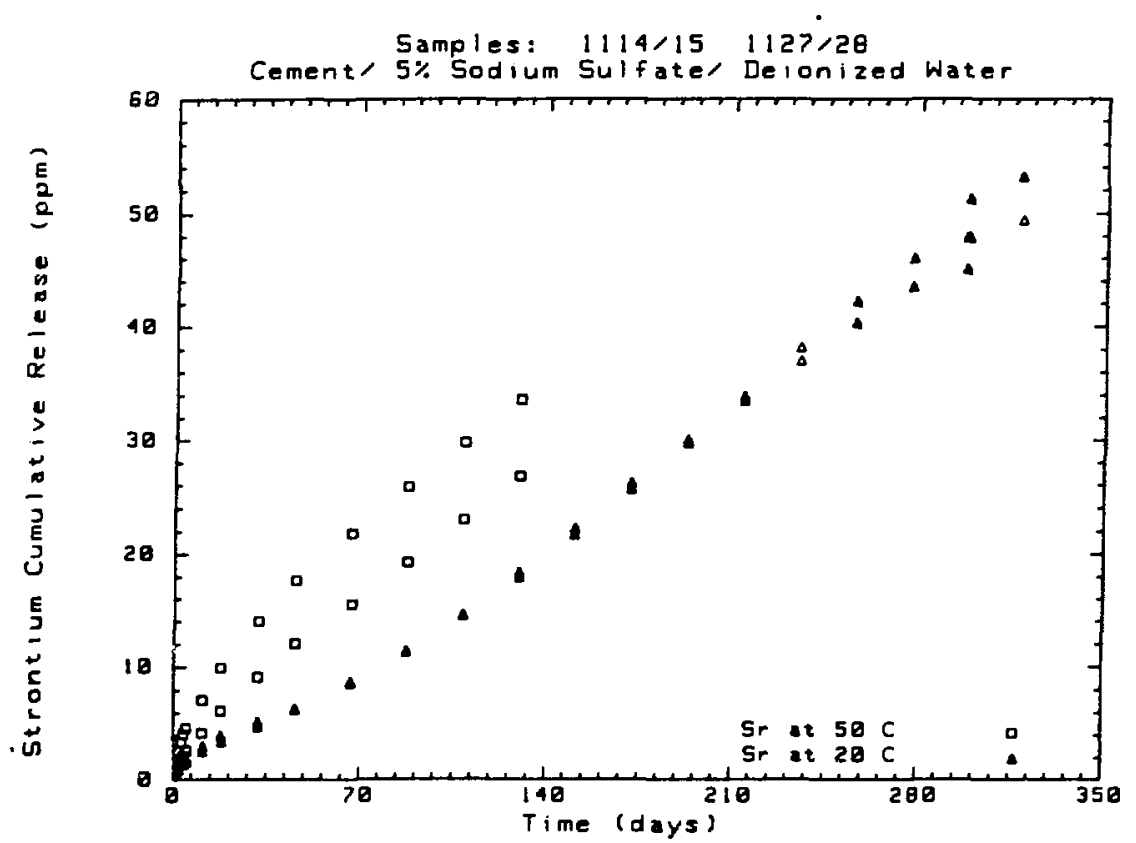

Figure 4.12

Strontium cumulative amount (ppm) leached vs. time from portland I cement containing 5 wt sodium sulfate at 20 and $50^{\circ} \mathrm{C}$. Samples were leached in deionized water. 


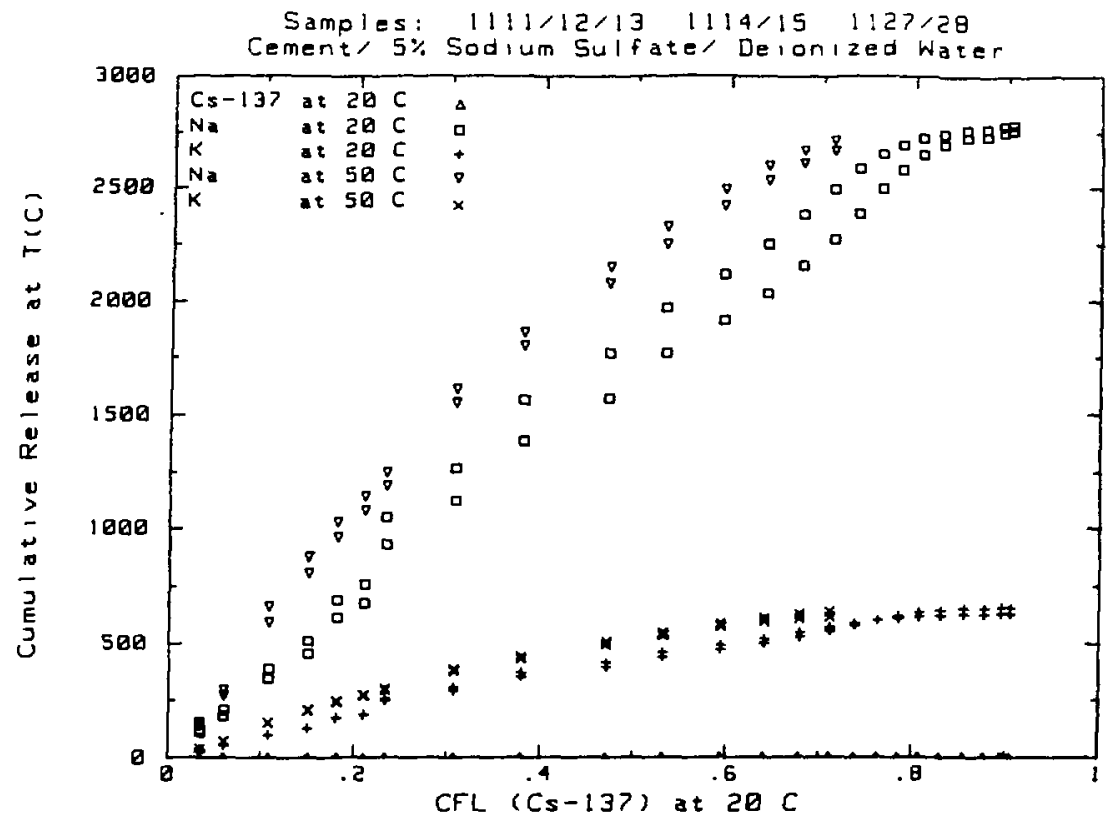

Figure 4.13 Linear correlation plot for sodium, potassium and $\mathrm{Cs}-137$ leaching at 20 and $50^{\circ} \mathrm{C}$ from portland I cement containing 5 wt sodium sulfate. Correlations are relative to the Cs-137 data. Samples were leached in deionized water.

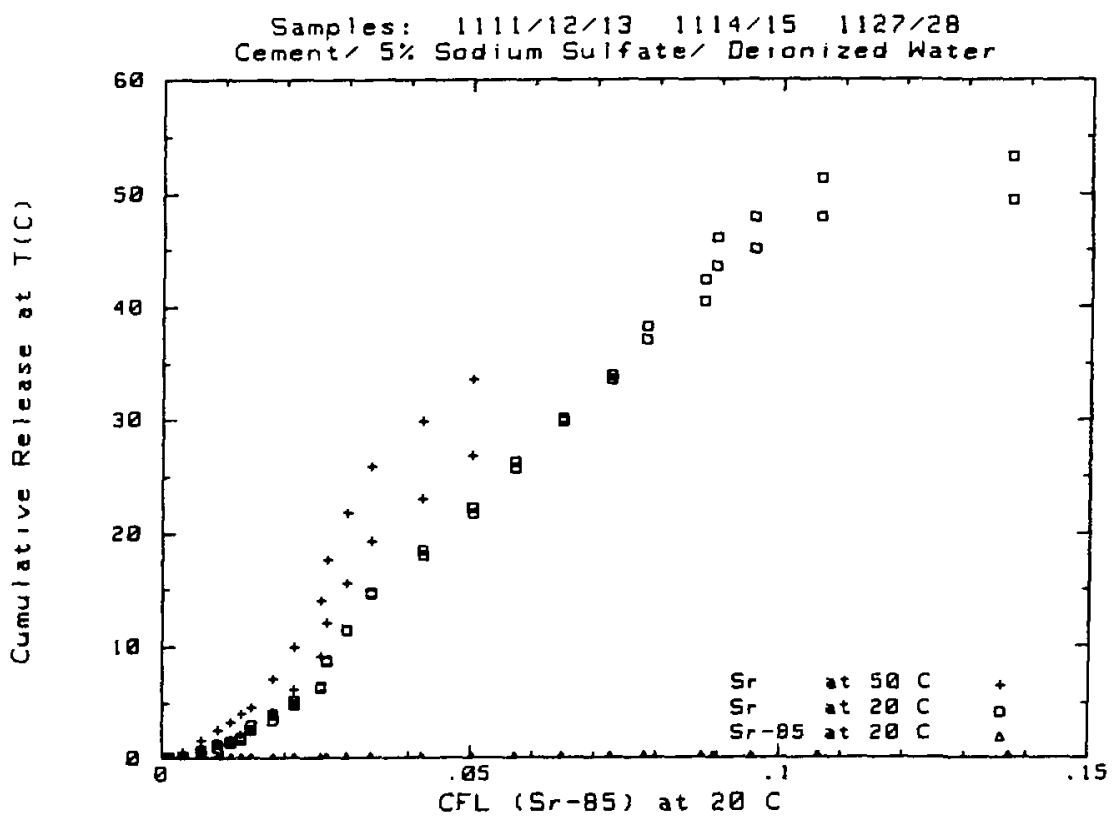

Figure 4.14 Linear correlation plot for strontium and Sr-85 leaching at 20 and $50^{\circ} \mathrm{C}$ from portland I cement containing 5 wto sodium sulfate. Correlations are relative to the $\mathrm{Sr}-85$ data. Samples were leached in deionized water. 


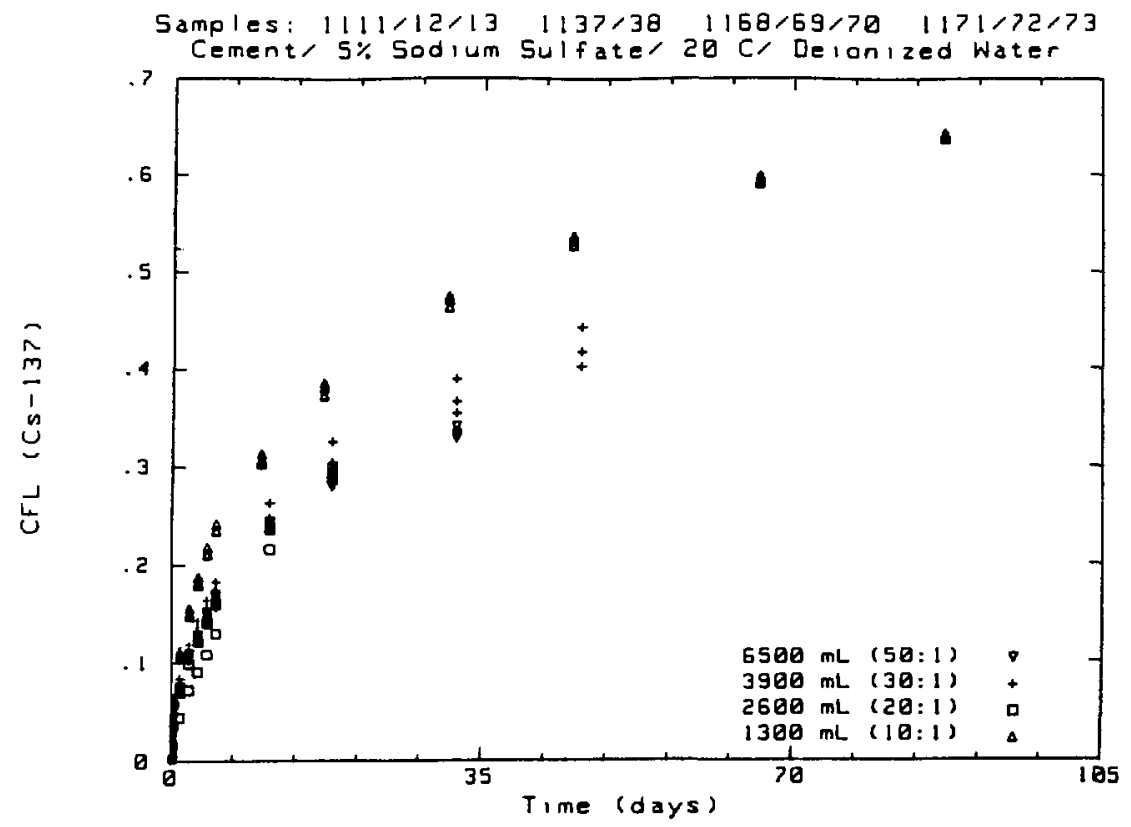

Figure 4.15

Cs-137 cumulative fraction leached vs. time from portland I cement containing 5 wt sodiun sulfate at leachant volune to waste form surface area ratios of $10,20,30$ and 50:1. Samples were leached in deionized water at $20^{\circ} \mathrm{C}$.

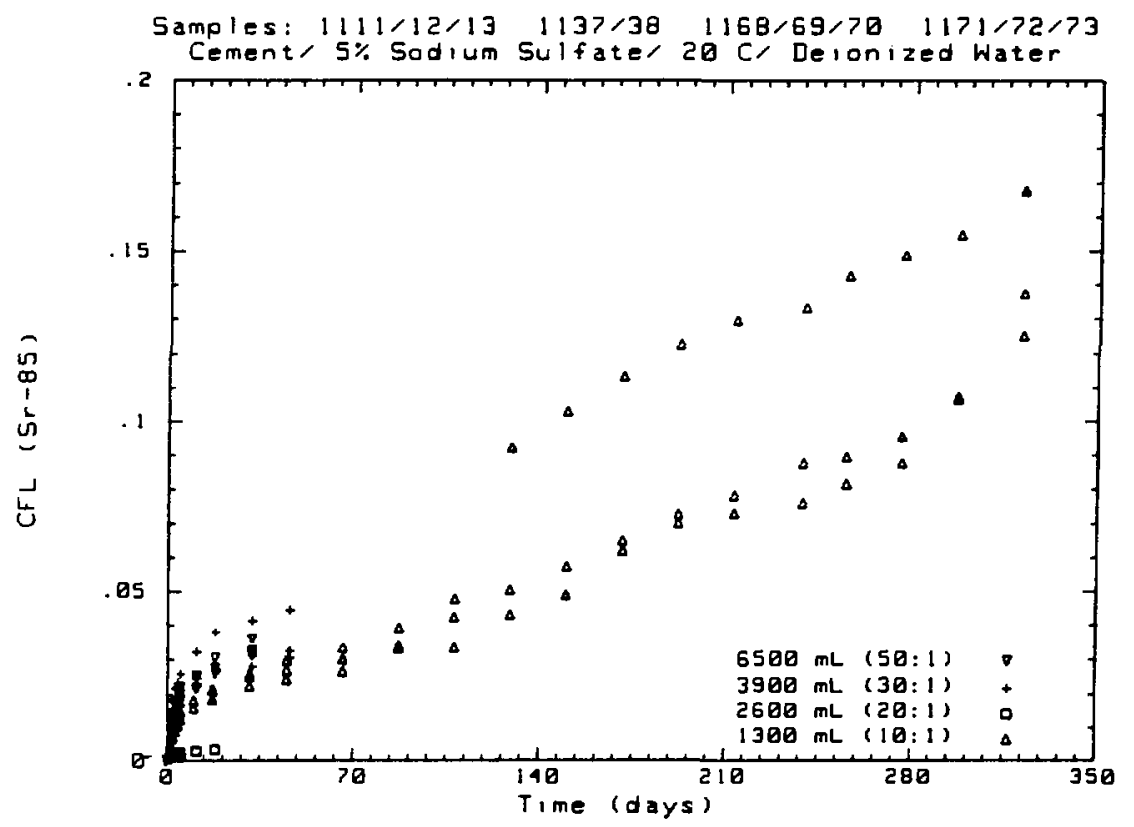

Figure 4.16

Sr-85 cumulative fraction leached vs. time from portland I cement containing 5 wtz sodium sulfate at leachant volume to waste form surface area ratios of $10,20,30$ and 50:1. Samples were leached in deionized water at $20^{\circ} \mathrm{C}$. 


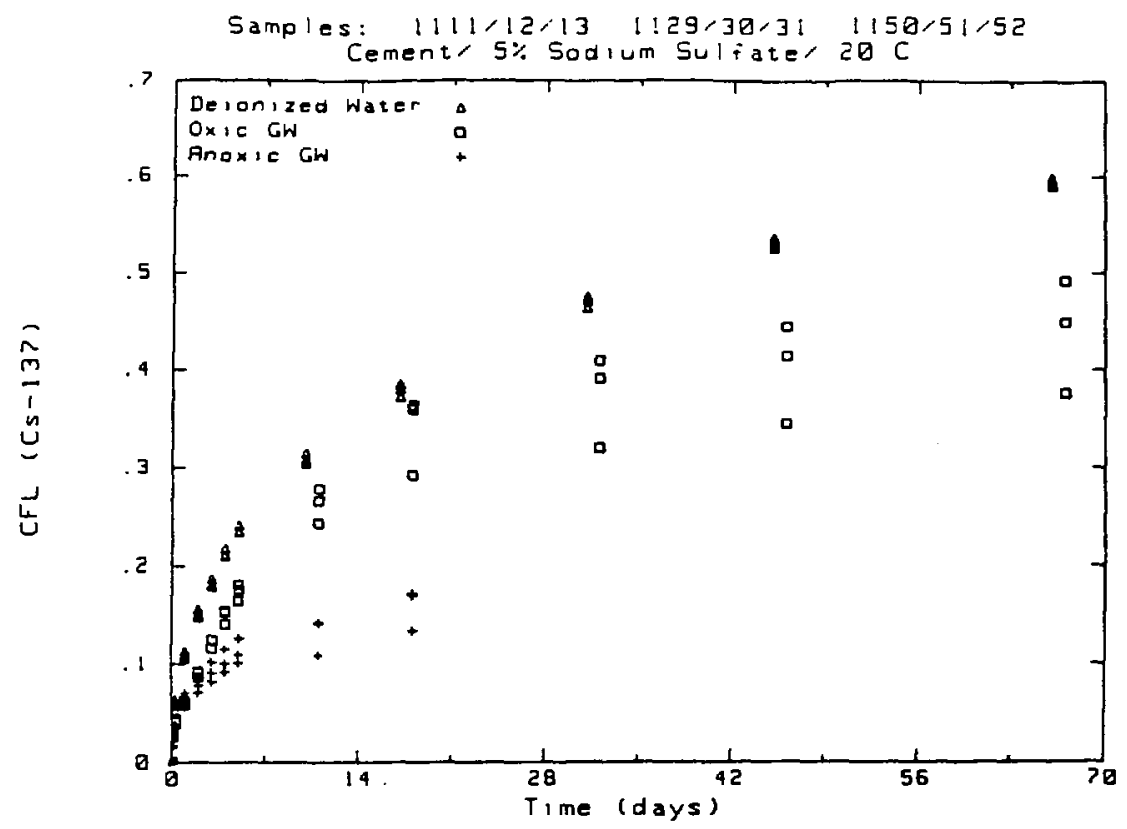

Figure 4.17 Cs -137 cumulative fraction leached vs. time from portland I cement containing 5 wto sodium sulfate leached in DIW, oxic and anoxic ground waters at $20^{\circ} \mathrm{C}$.

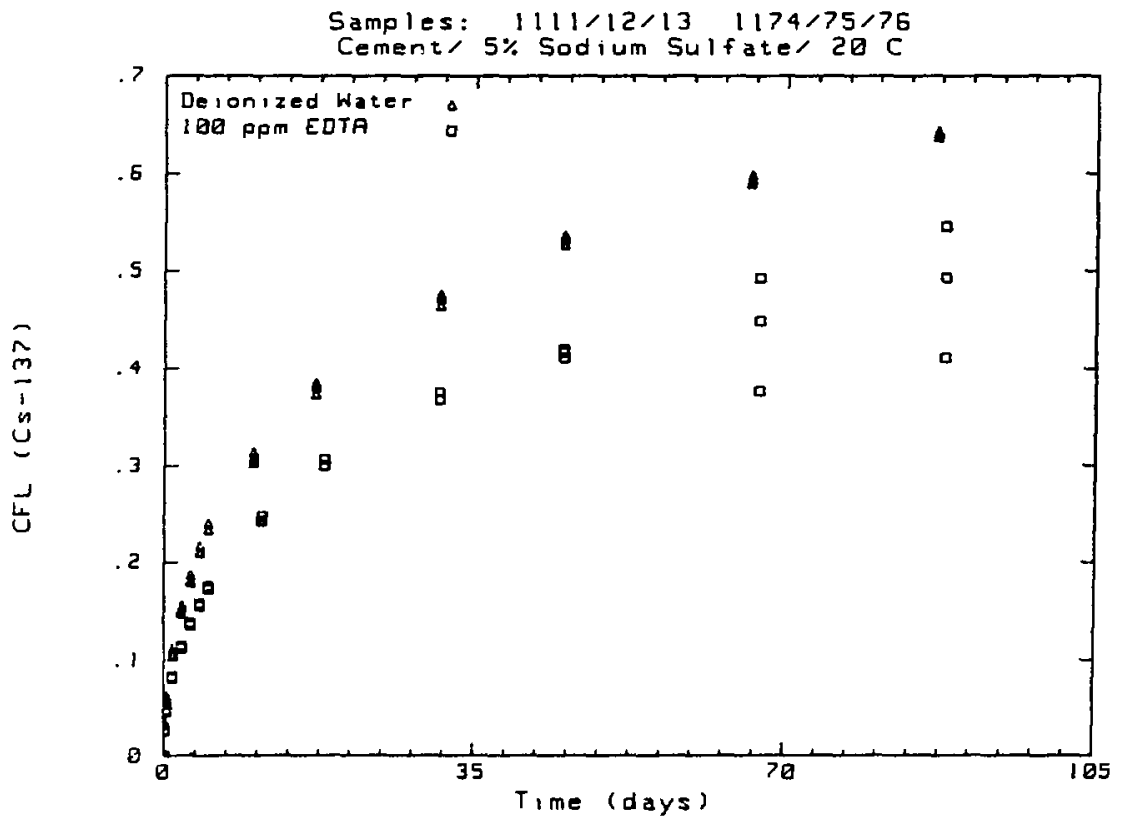

Figure 4.18

Cs-137 cumulative fraction leached vs. time from portland I cement containing 5 wto sodium sulfate leached in DIW and in DIW containing 100 ppm disodium EDTA at $20^{\circ} \mathrm{C}$. 


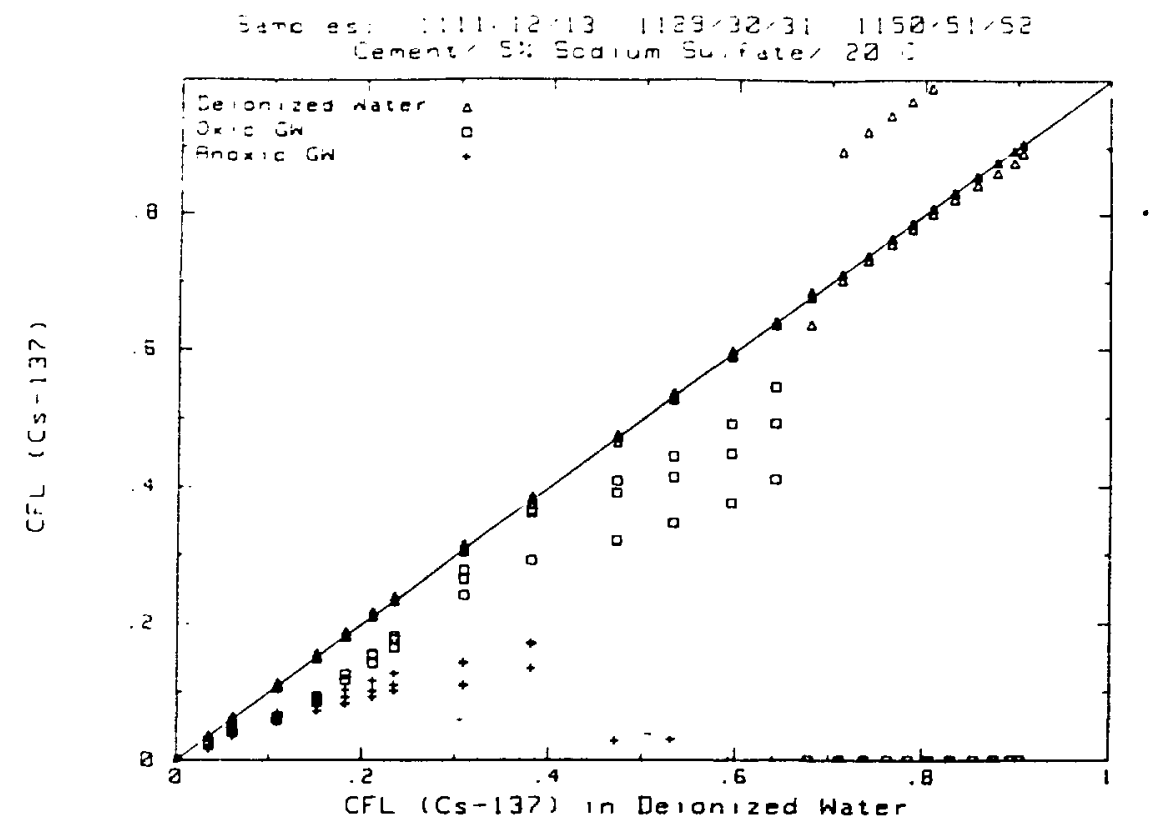

Figure 4.19 Linear correlation plots for Cs-137 leached from portland I cement containing 5 wt sodium sulfate leached in DIW, oxic and anoxic ground waters at $20^{\circ} \mathrm{C}$. Correlations are relative to the DIW data.

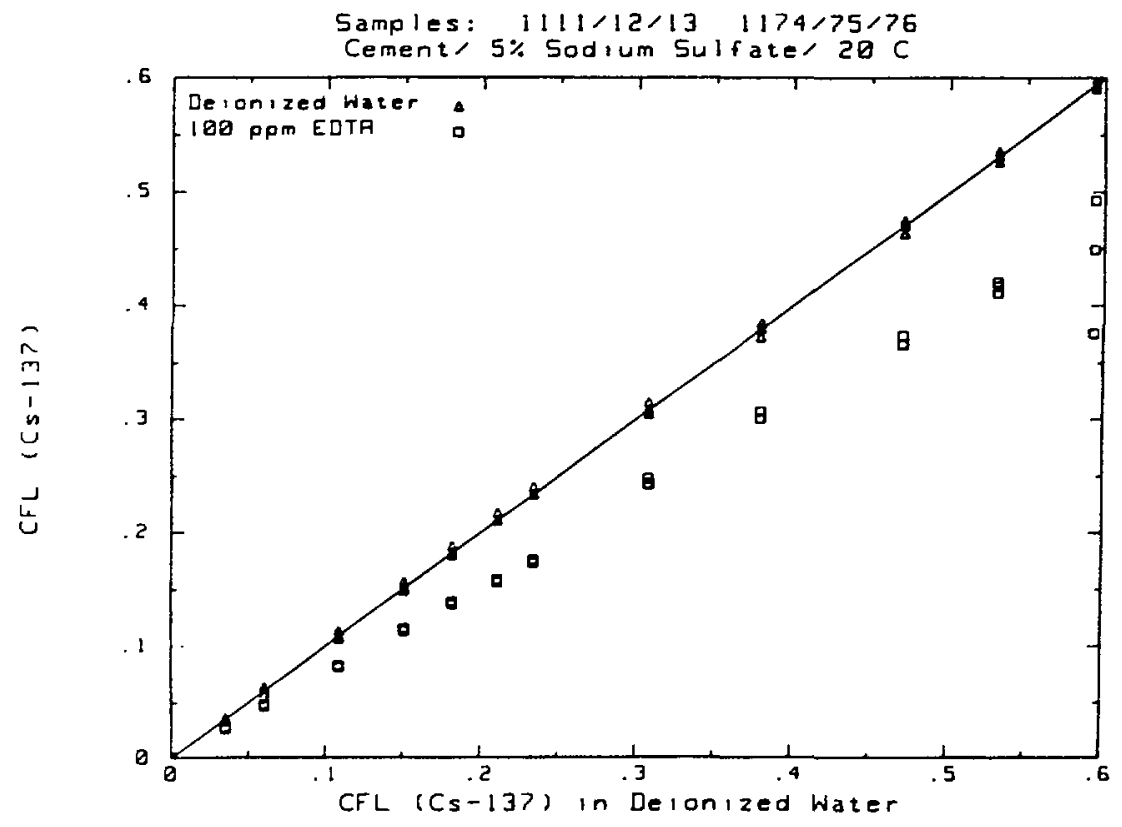

Figure 4.20

Linear correlation plots for Cs-137 leached from portland I cement containing 5 wt sodium sulfate leached in DIW and DIW containing 100 ppm disodium EDTA at $20^{\circ} \mathrm{C}$. Correlations are relative to the DIW data. 


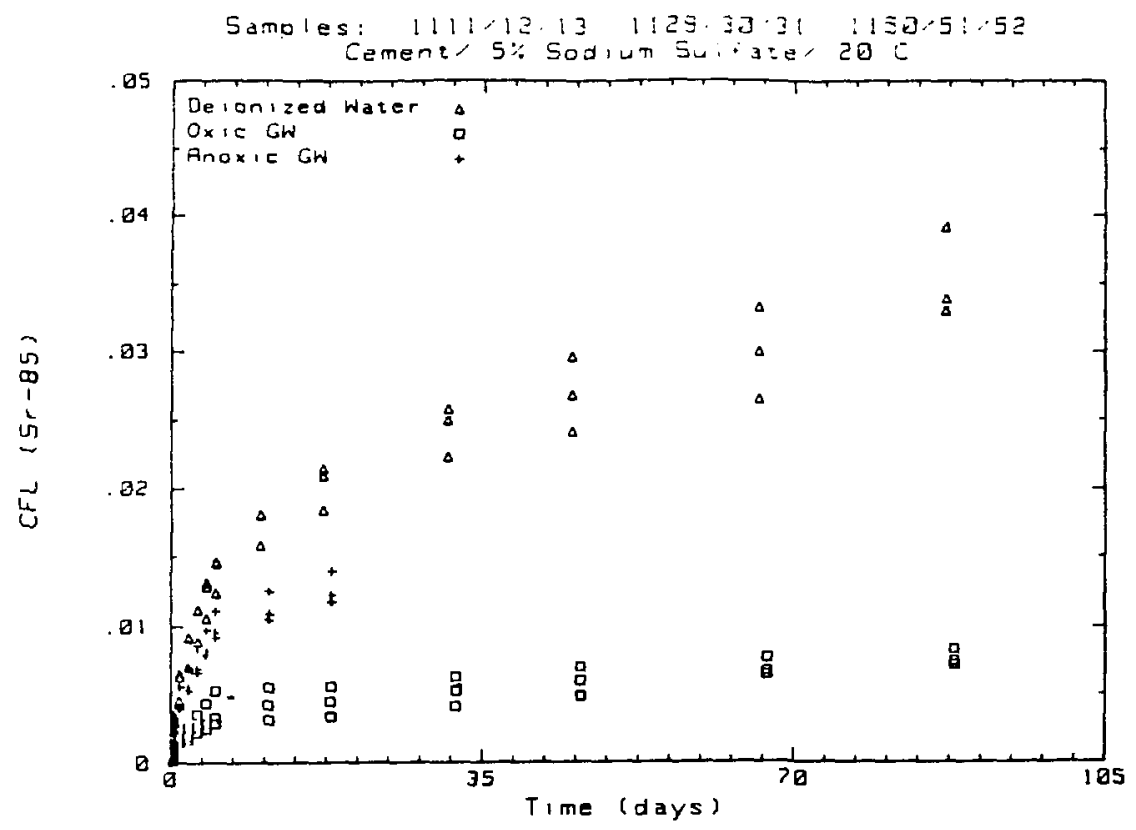

Figure 4.21 Sr-85 cumulative fraction leached vs. time from portland I cement containing 5 wt sodium sulfate leached in DIW, oxic and anoxic ground waters at $20^{\circ} \mathrm{C}$.

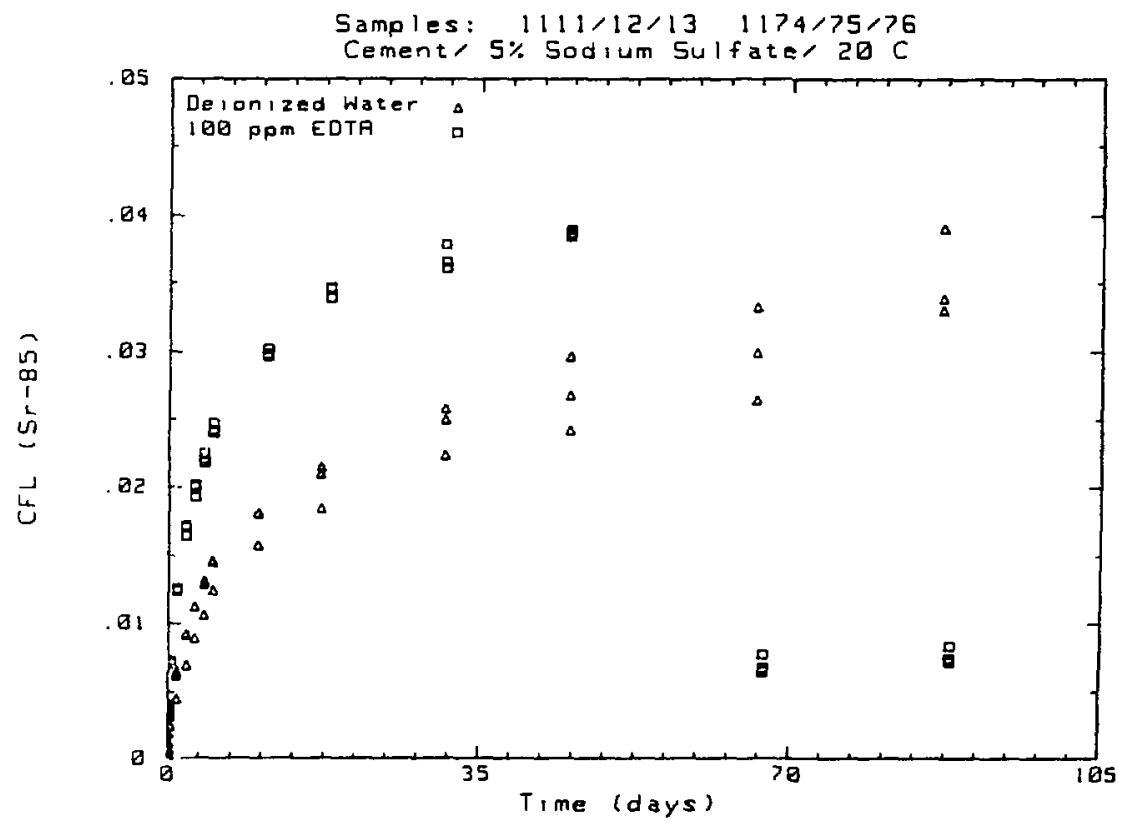

Figure 4.22 Sr-85 cumulative fraction leached vs. time from portland I cement containing 5 wto sodium sulfate leached in DIW and in DIW containing $100 \mathrm{ppm}$ disodium EDTA at $20^{\circ} \mathrm{C}$. 


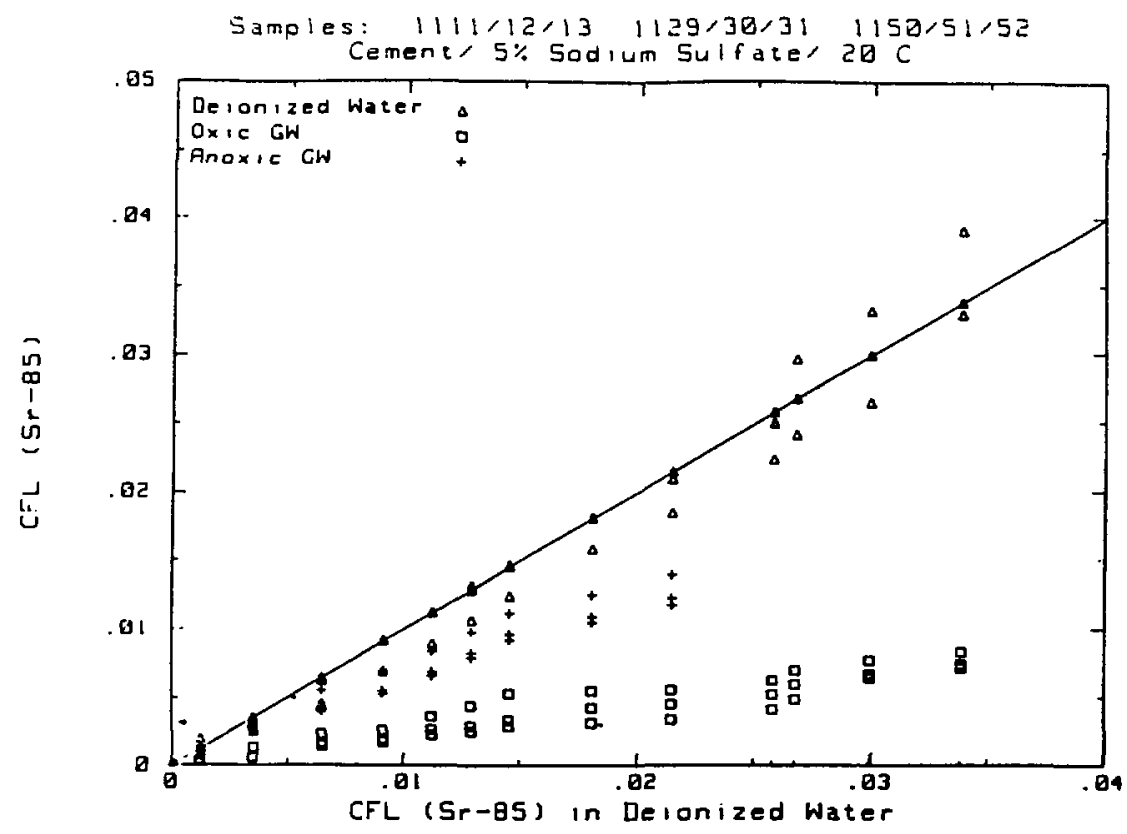

Figure 4.23

Linear correlation plots for Sr-85 leached from portland I cement containing 5 wt sodium sulfate in DIW, oxic and anoxic ground waters. Correlations are relative to the DIW data. Samples were leached at $20^{\circ} \mathrm{C}$.

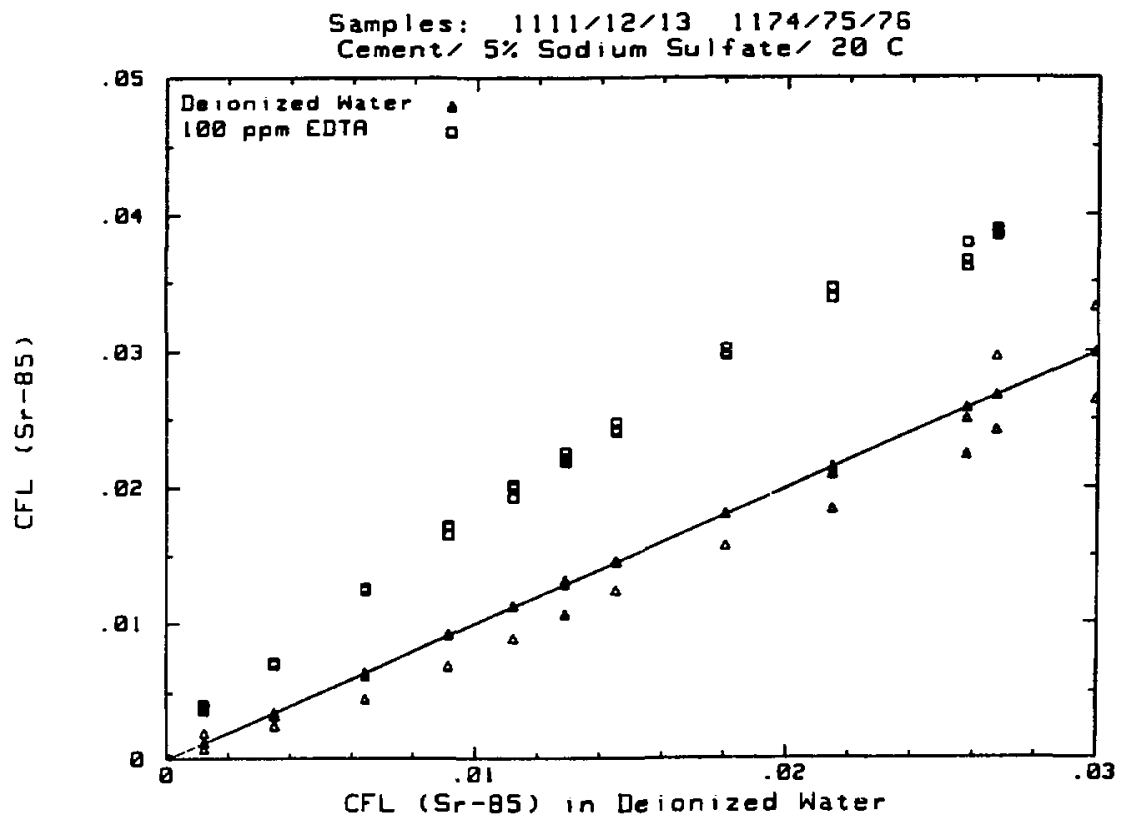

Figure 4.24

Linear correlation plots for $\mathrm{Sr}-85$ leached from portland I cement containing 5 wt sodium sulfate in DIW and DIW containing $100 \mathrm{pPm}$ disodium EDTA at $20^{\circ} \mathrm{C}$. Correlations are relative to the DIW data. 


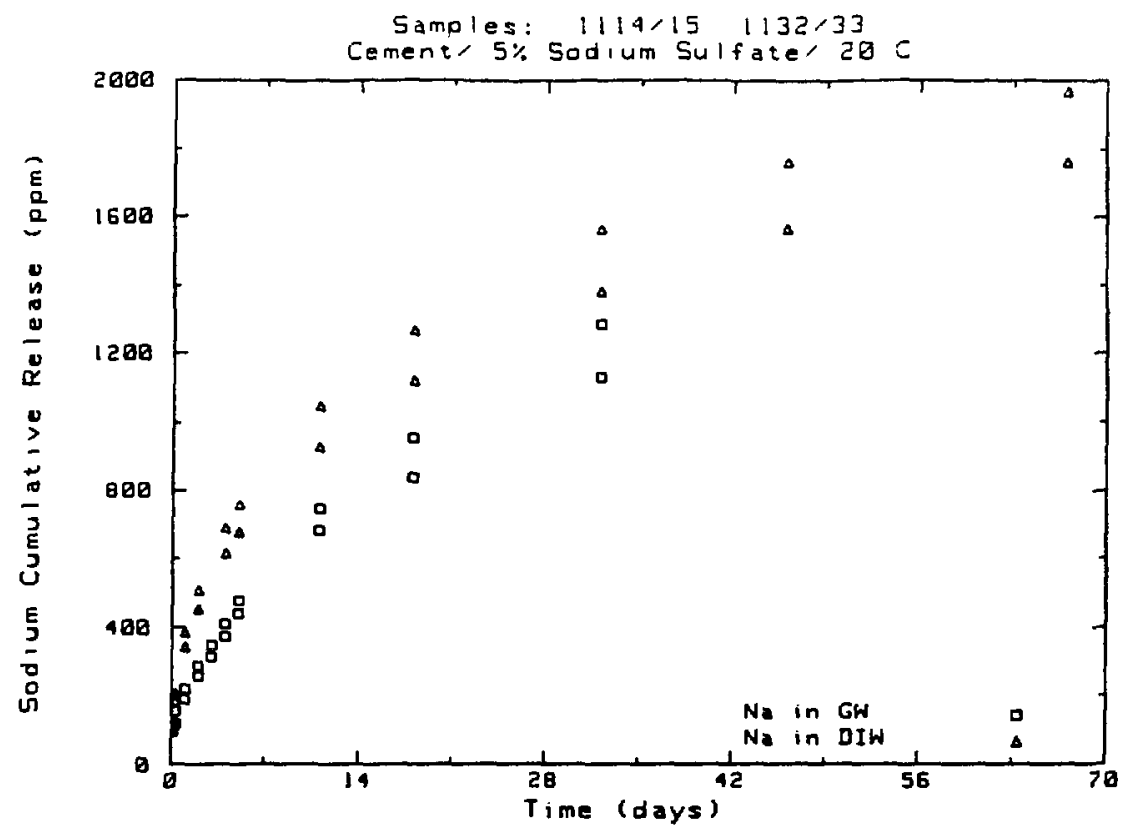

Figure 4.25

Sodium cumulative anount leached (ppm) vs. time from portland I cement containing 5 wt sodium sulfate leached in DIW and oxic ground water at $20^{\circ} \mathrm{C}$.

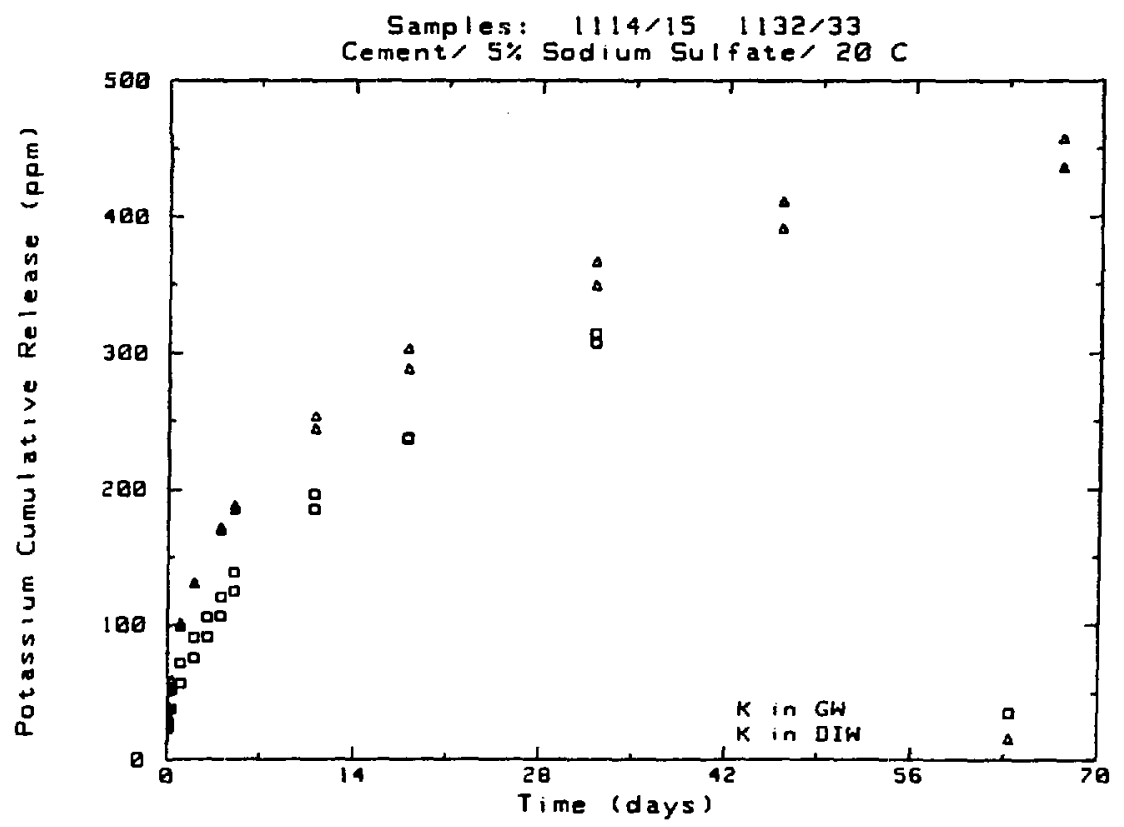

Figure 4.26

Potassium cumulative amount leached (ppm) vs. time from portland I cement containing 5 wtz sodium sulfate leached in DIW and oxic ground water at $20^{\circ} \mathrm{C}$. 


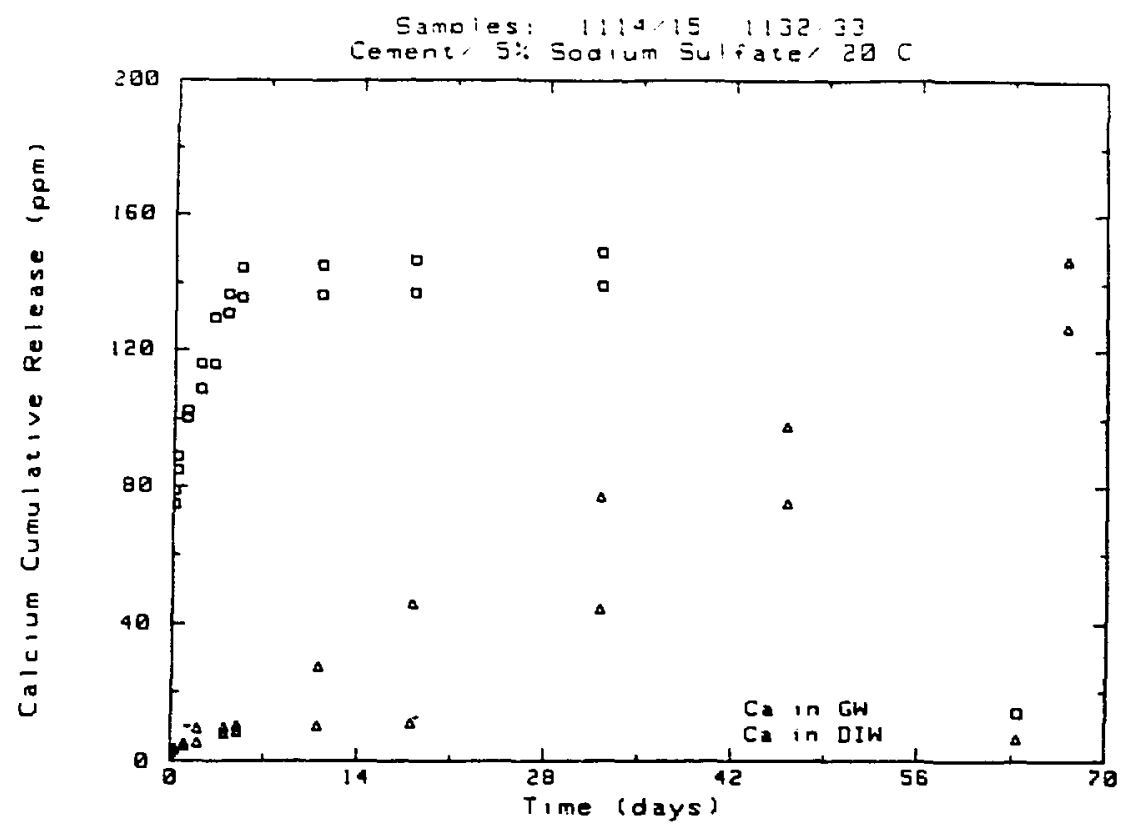

Figure 4.27

Calcium cumulative amount leached (ppm) vs. time from portland I cement containing 5 wt sodiur sulfate leached in DIW and oxic ground water at $20^{\circ} \mathrm{C}$.

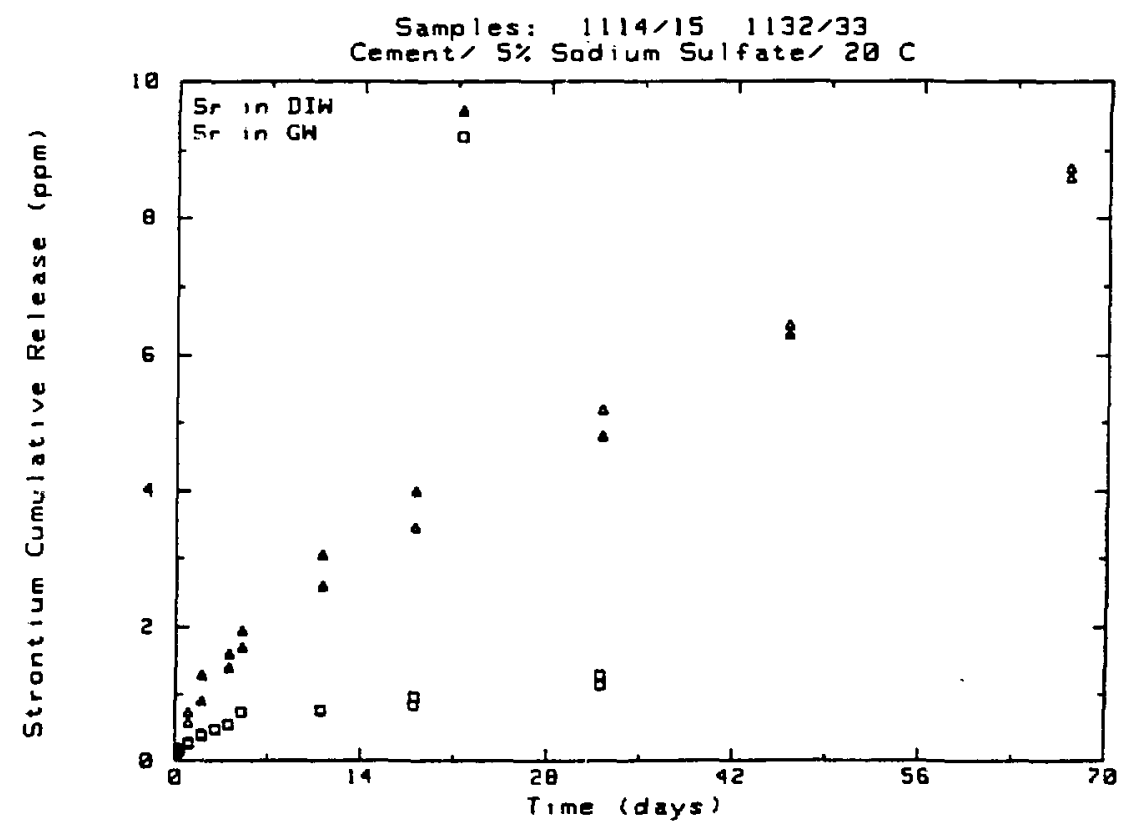

Figure 4.28

Strontium cunulative amount leached (ppm) vs. time from portland I cement containing 5 wt sodium sulfate leached in DIW and oxic ground water at $20^{\circ} \mathrm{C}$. 


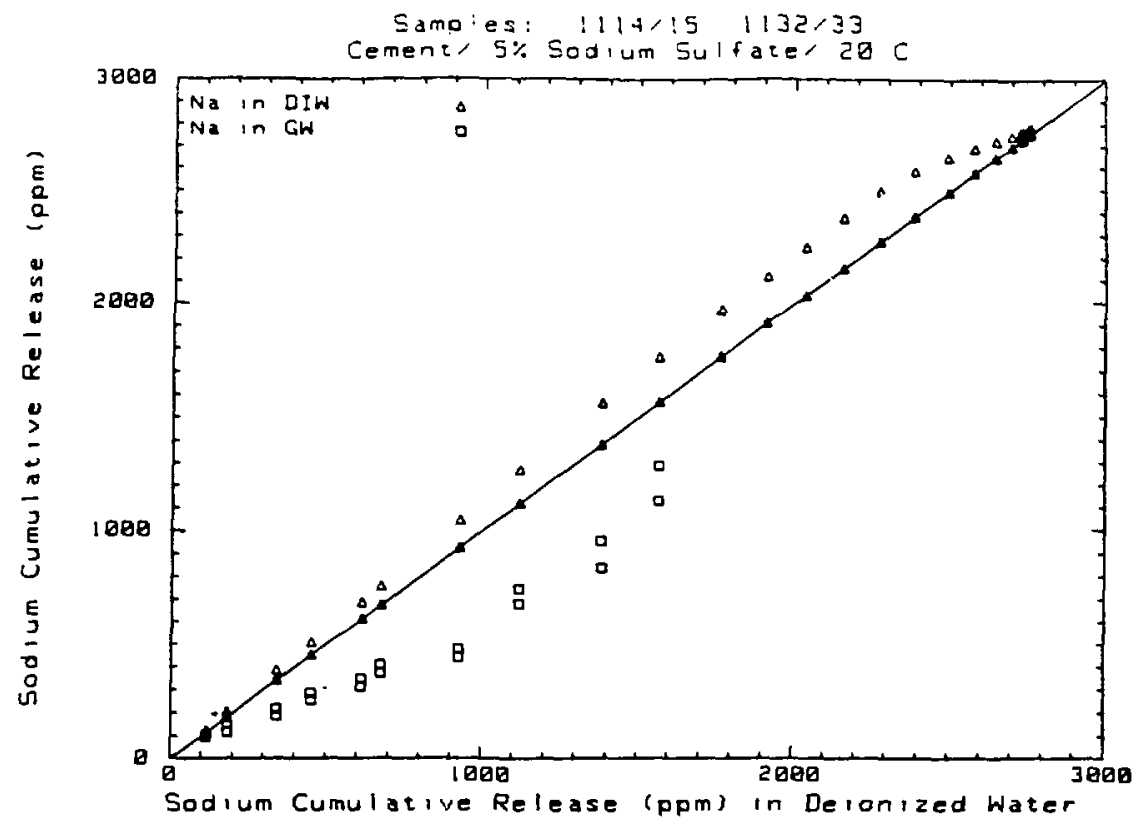

Figure 4.29

Linear correlation plots for Sodium leached from portland I cement containing 5 wt sodium sulfate in DIW and oxic ground water at $20^{\circ} \mathrm{C}$. Correlations are relative to the DIW data.

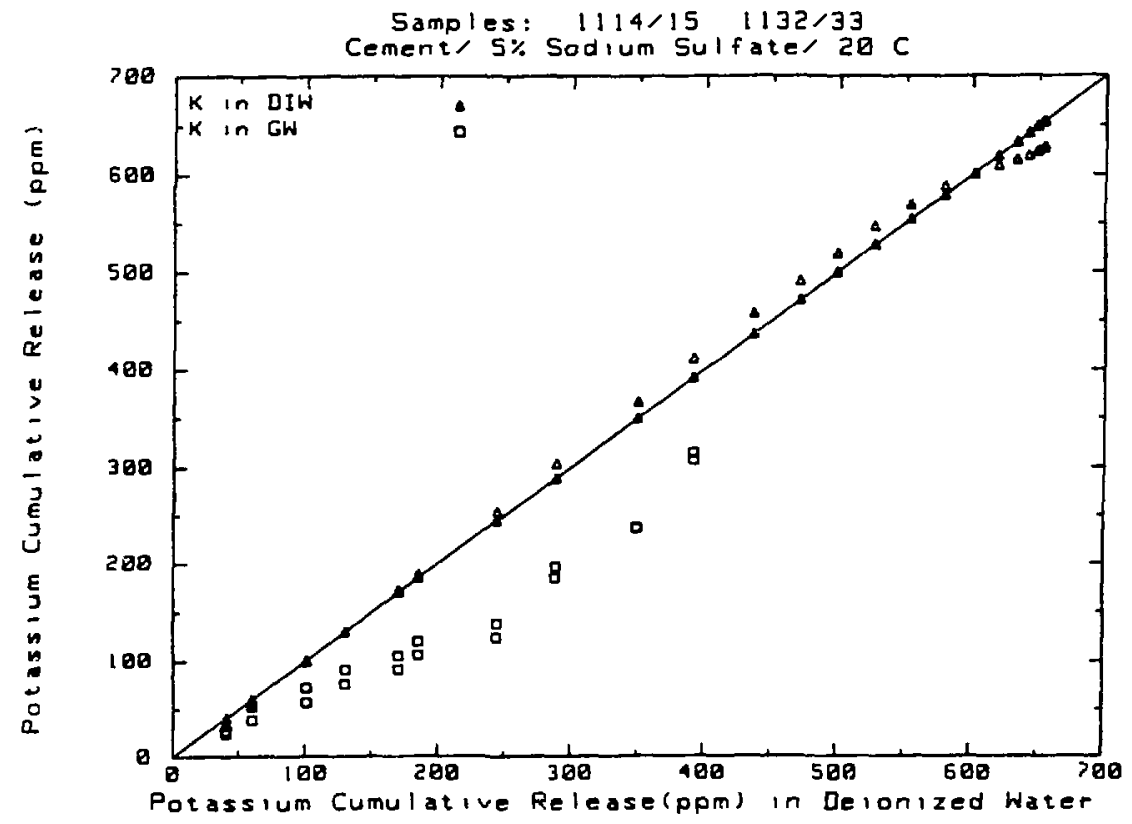

Figure 4.30

Linear correlation plots for Potassium leached from portland I cement containing $5 \mathrm{wtz}$ sodium sulfate in DIW and oxic ground water at $20^{\circ} \mathrm{C}$. Correlations are relative to the DIW data. 


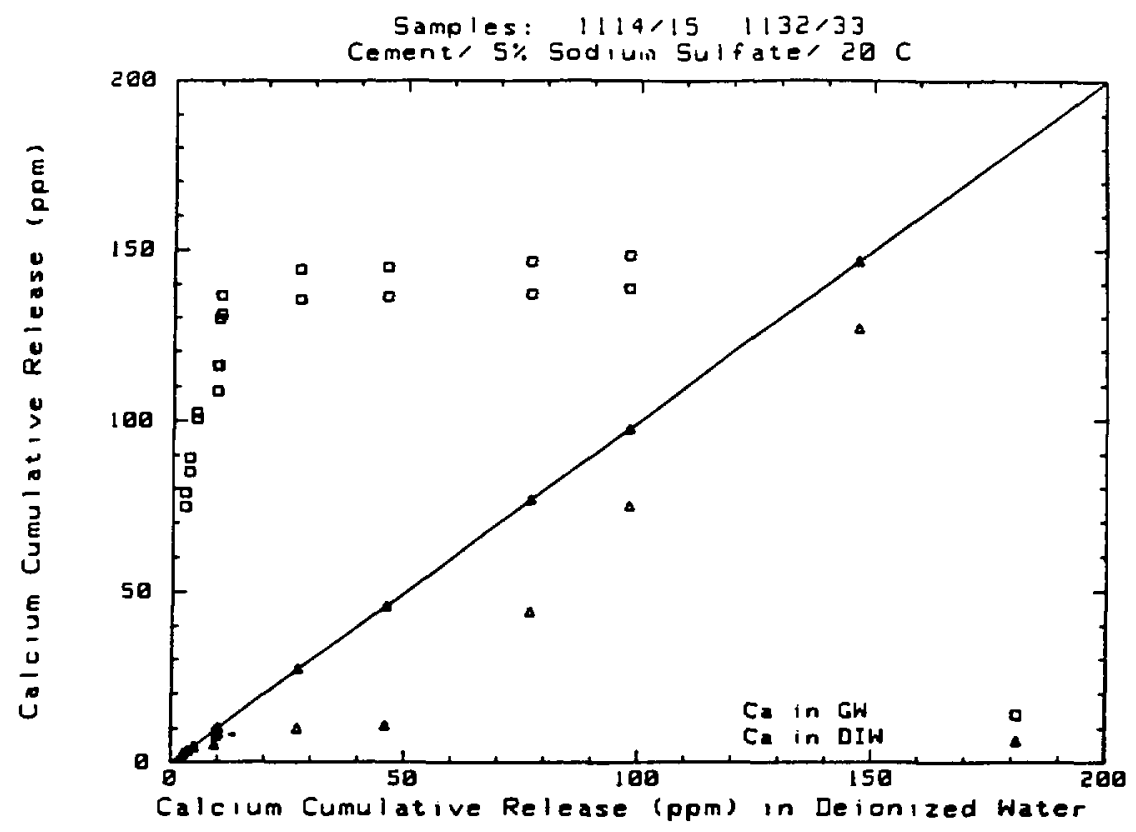

Figure 4.31

Linear correlation plots for calcium leached from portland I cenent containing 5 wto sodiun sulfate in DIW and oxic ground water at $20^{\circ} \mathrm{C}$. Correlations are relative to the DIW data.

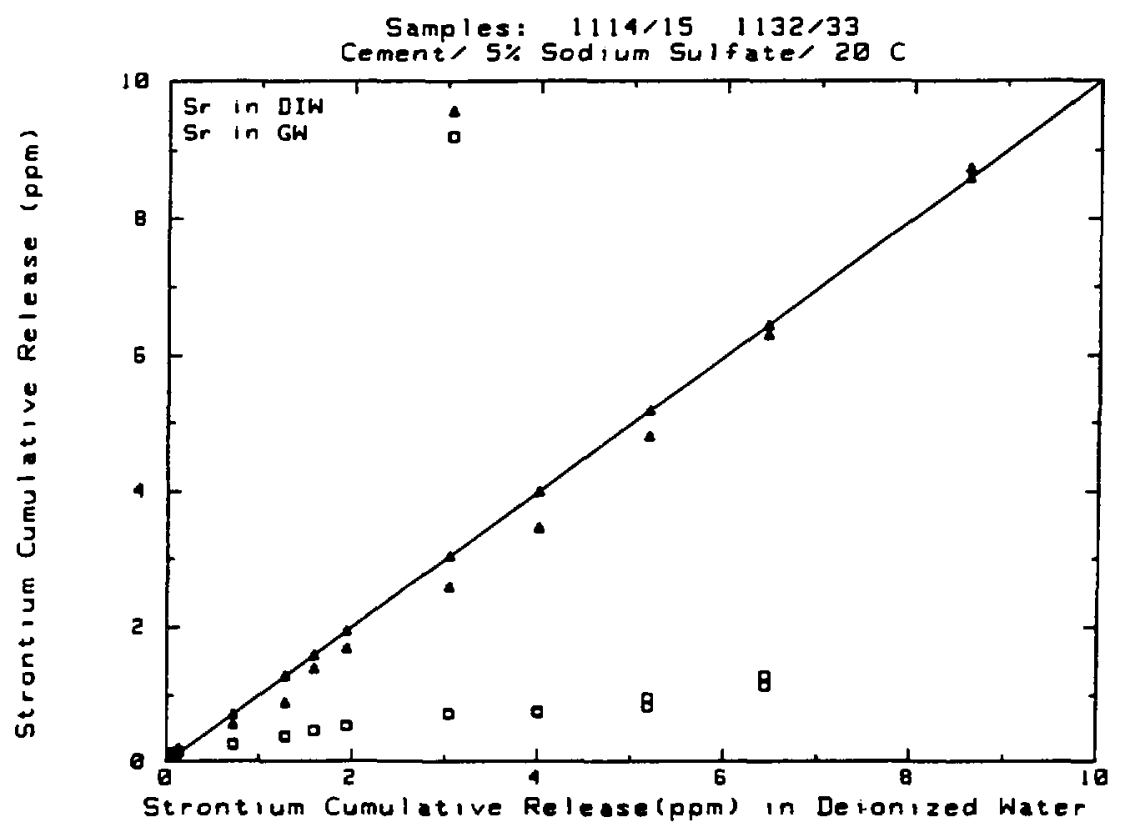

Figure 4.32

Linear correlation plots for strontium leached from portland I cement containing 5 wt sodiun sulfate in DIW and oxic ground water at $20^{\circ} \mathrm{C}$. Correlations are relative to the DIW data. 


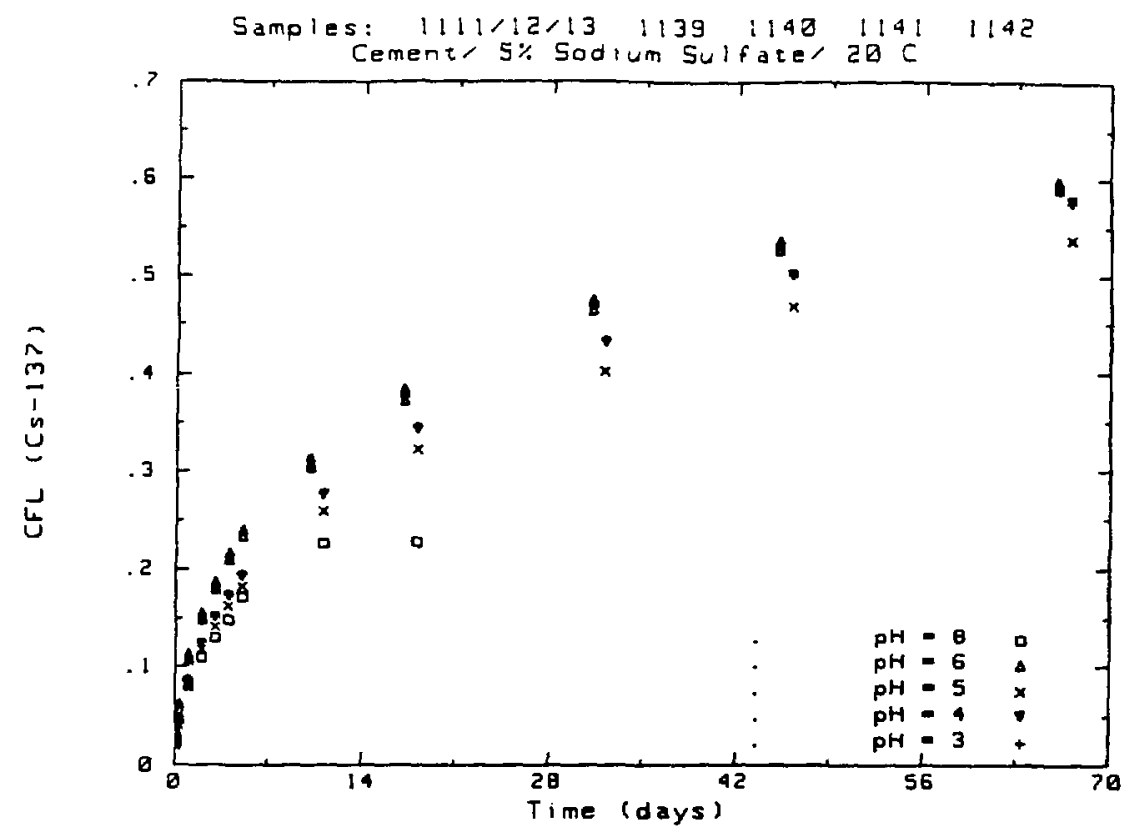

Figure 4.33

Cs-137 cumulative fraction leached vs. time from portland I cement containing 5 wt sodium sulfate leached at $20^{\circ} \mathrm{C}$ in leachants with initial $\mathrm{pH}$ values of $3,4,5,6$ and 8 .

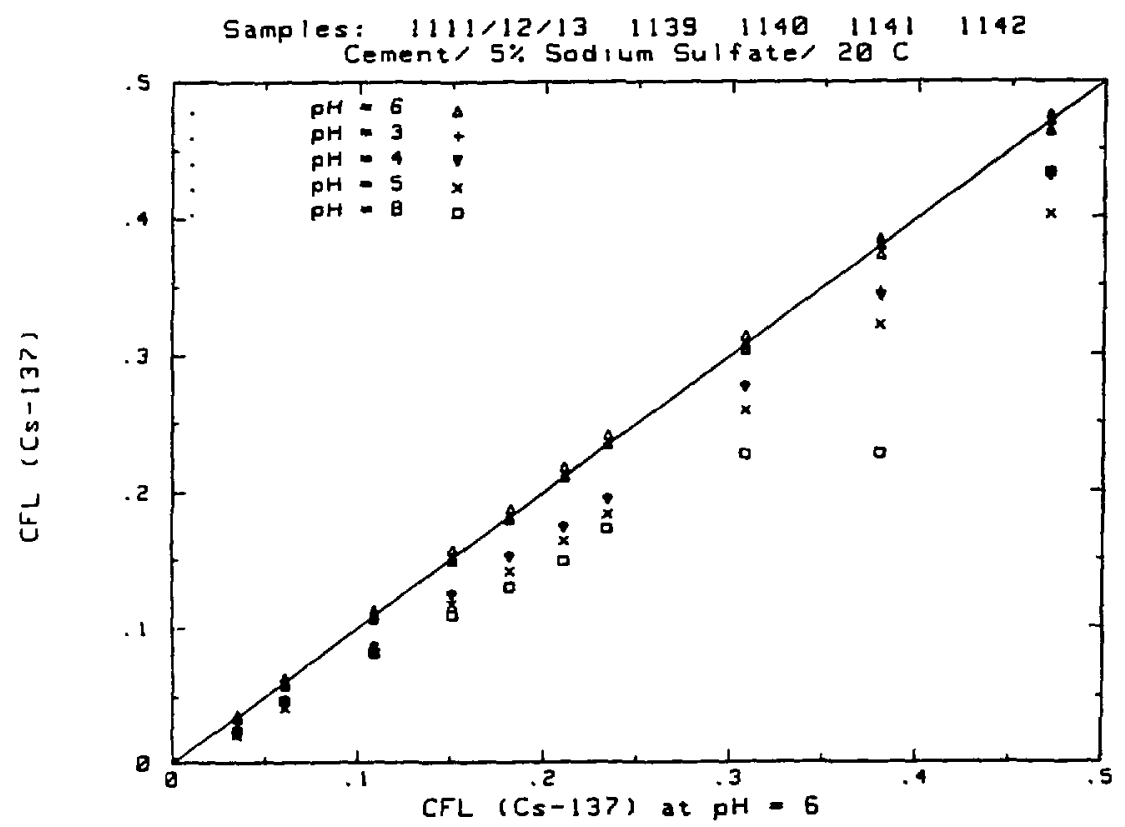

Figure 4.34

Linear correlation plots for Cs-137 leached from portland I cement containing 5 wt sodium sulfate in leachants with initial $\mathrm{pH}$ values of $3,4,5,6$ and 8 . Correlations are relative to the pH 6 (DIW) data. Samples were leached at $20^{\circ} \mathrm{C}$. 


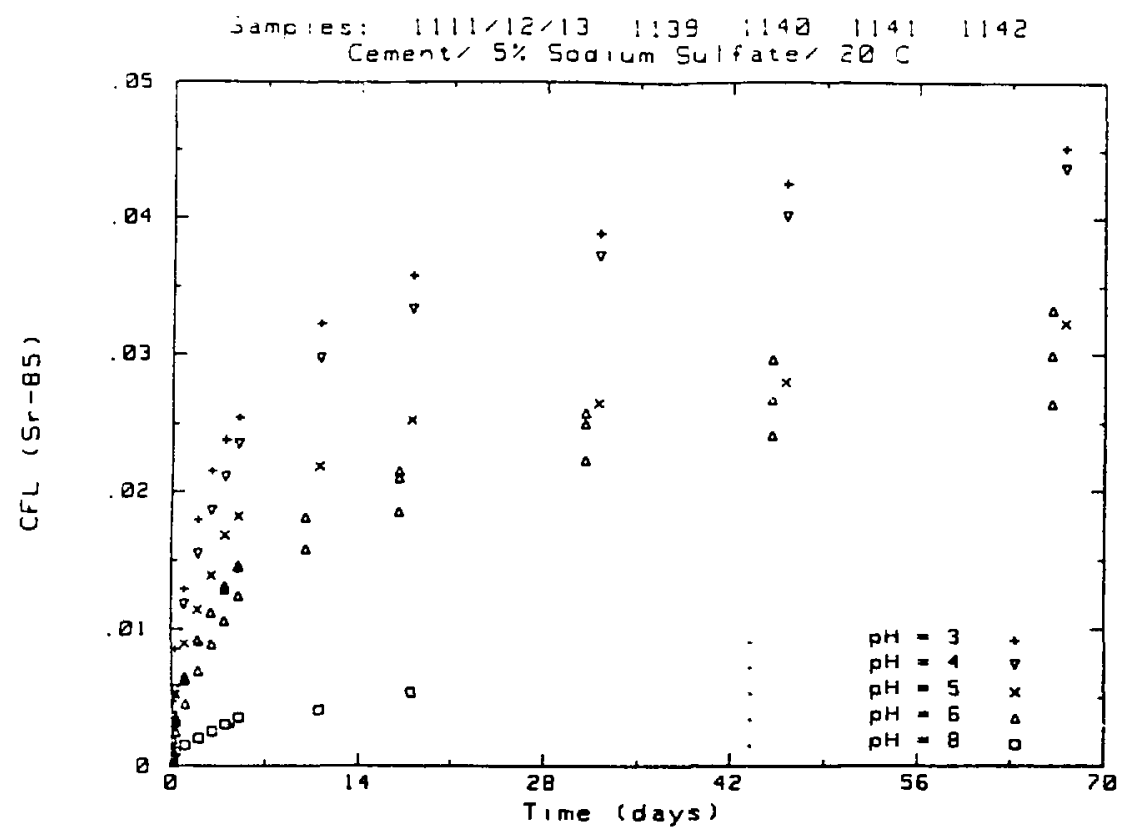

Figure 4.35

Sr-85 cumulative fraction leached vs. time from portland I cement containing 5 wt sodium sulfate leached at $20^{\circ} \mathrm{C}$ in leachants with initial $\mathrm{pH}$ values of $3,4,5,6$ and 8 .

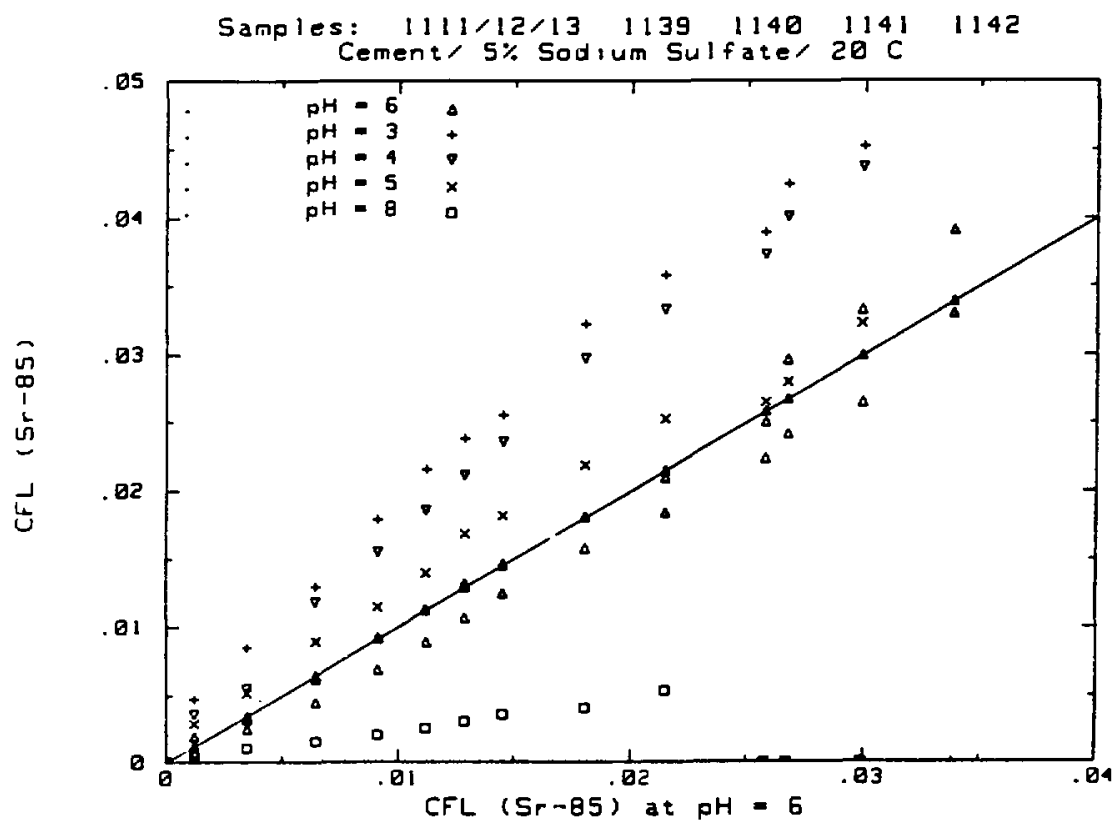

Figure 4.36 Linear correlation plots for Sr-85 leached from portland $I$ cement containing 5 wt sodium sulfate in leachants with initial pH values of $3,4,5,6$ and 8 . Correlations are relative to the pH 6 (DIW) data. Samples were leached at $20^{\circ} \mathrm{C}$. 


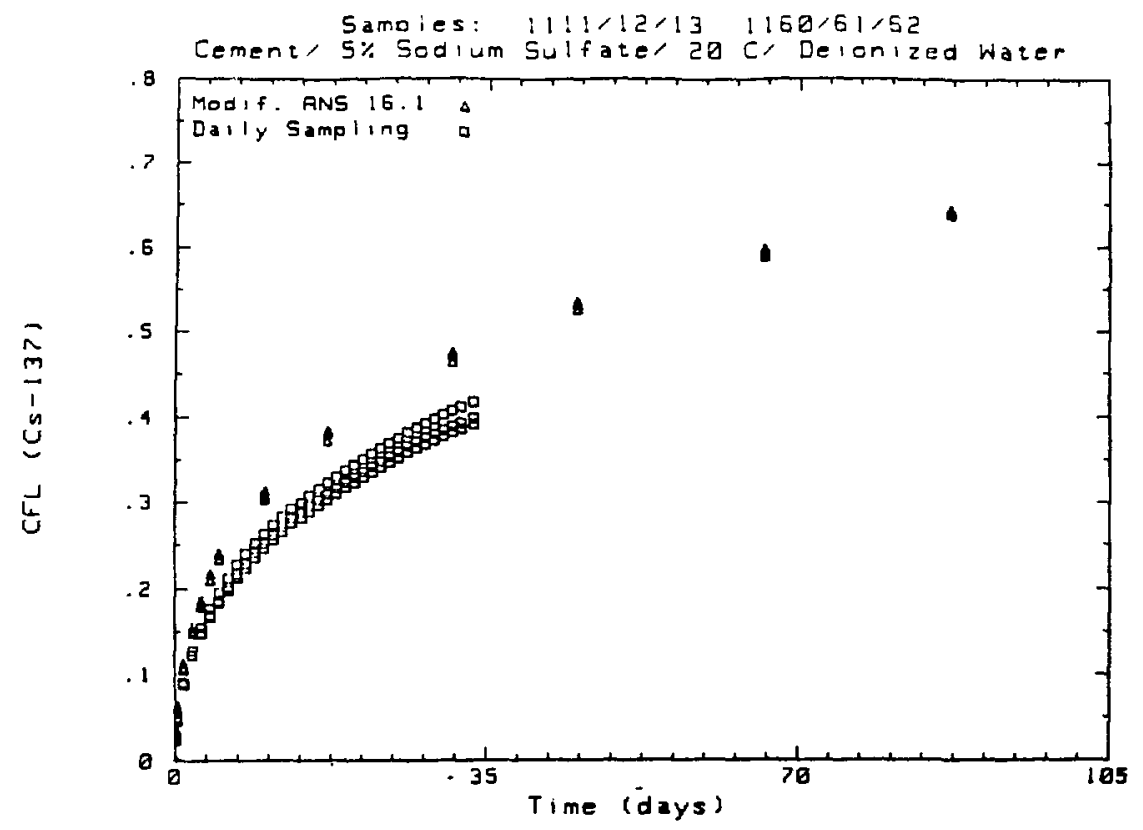

Figure 4.37 Cs.137 cumulative fraction leached vs. time from daily leachant replacement and from modified ANS 16.1 leachant replacement schedule for portland I cement waste forms containing 5 wto sodium sulfate leached at $20^{\circ} \mathrm{C}$.

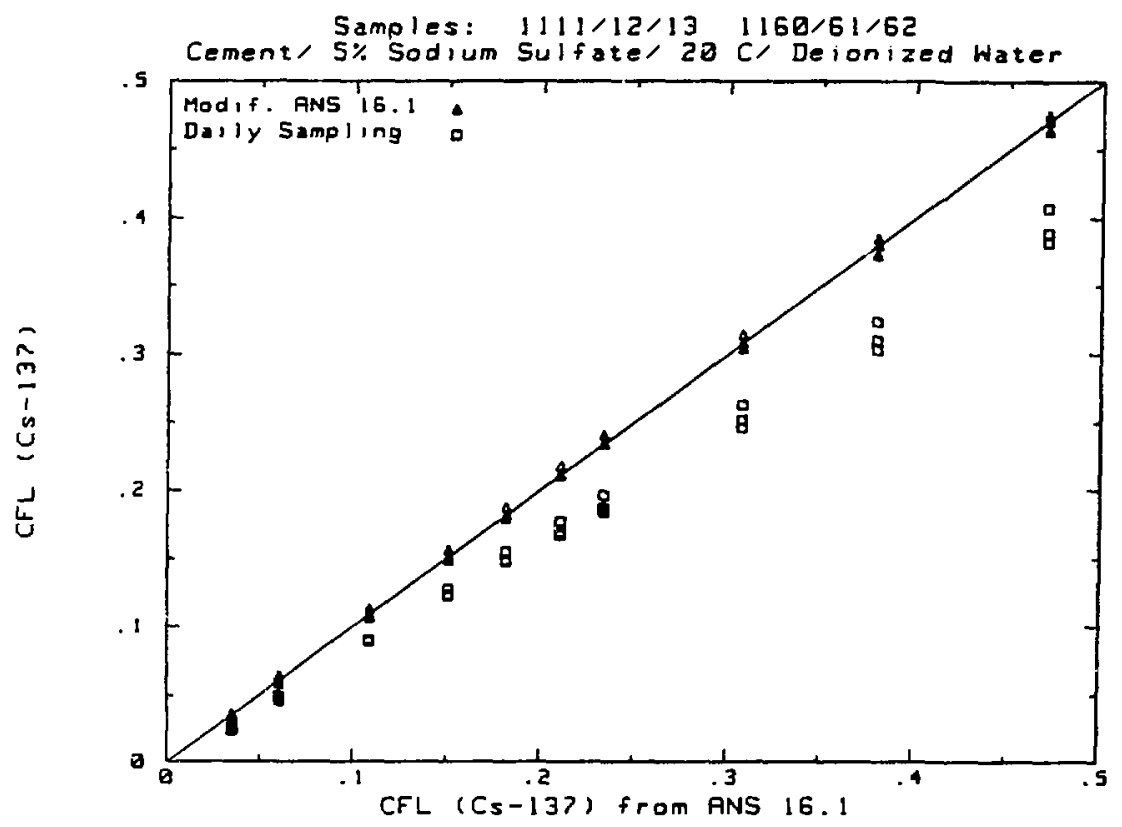

Figure 4.38

Linear correlation plots for Cs-137 leached at $20^{\circ} \mathrm{C}$ using daily leachant replacement and the modified ANS 16.1 leachant replacement schedule for portland I cement waste forms containing 5 wto sodium sulfate. 


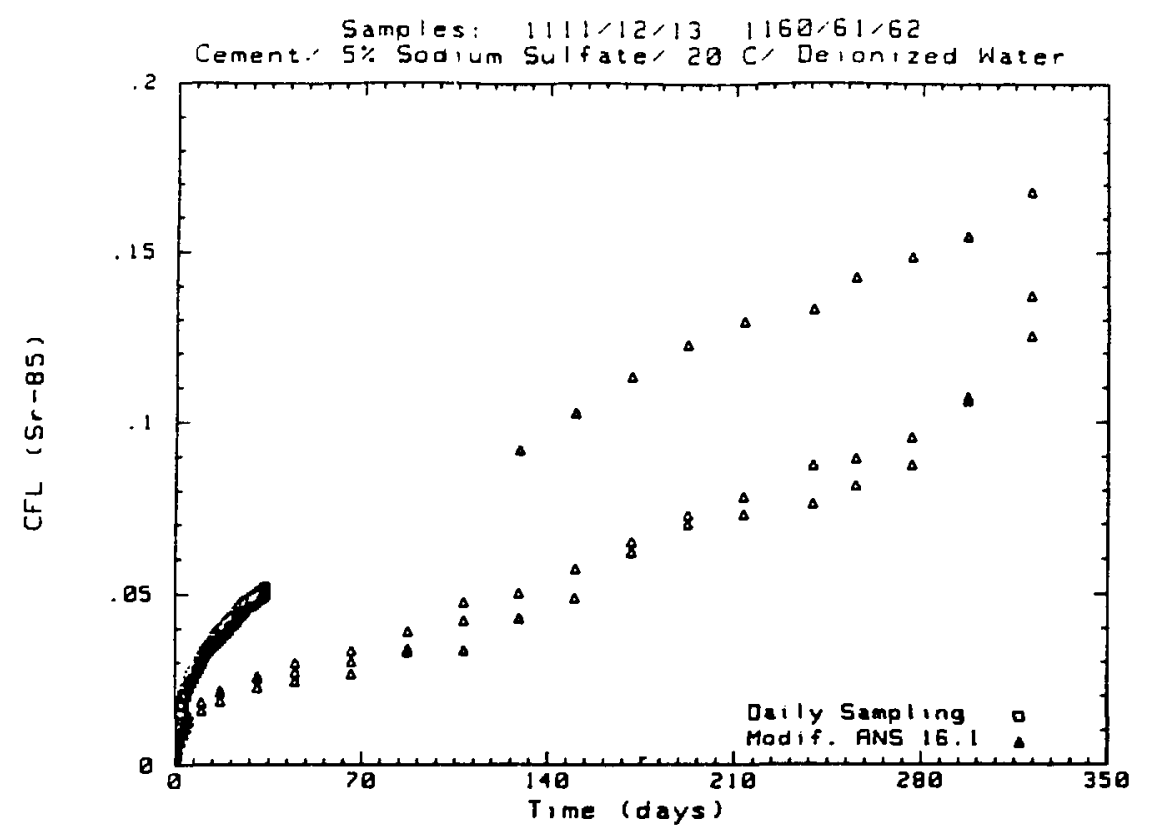

Figure 4.39

Sr-85 cumulative fraction leached vs. time from daily leachant replacenent and from modified ANS 16.1 leachant replacement schedule for portland I cement waste forms containing 5 wt sodium sulfate leached at $20^{\circ} \mathrm{C}$.

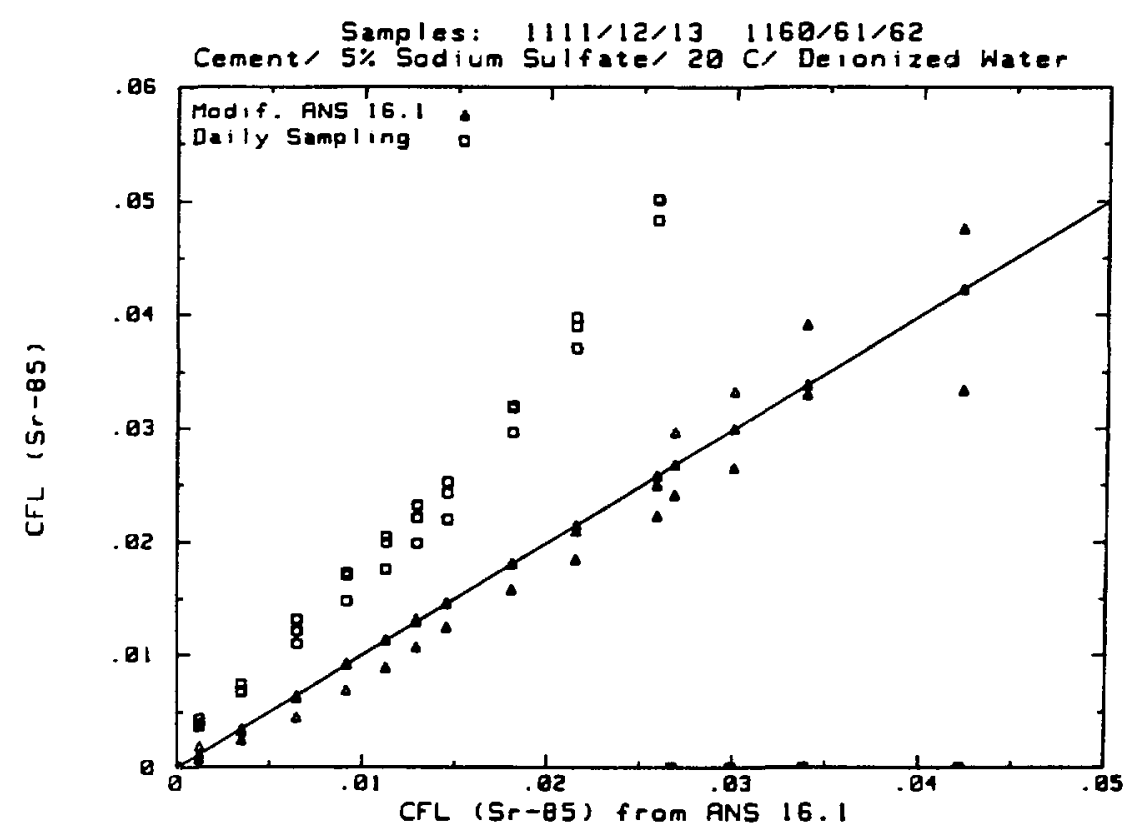

Figure 4.40

Linear correlation plots for Sr-85 leached at $20^{\circ} \mathrm{C}$ using daily leachant replacement and the modified ANS 16.1 leachant replacement schedule for portland I cement waste forns containing 5 wt sodium sulfate. Correlations are relative to the ANS 16.1 data. 

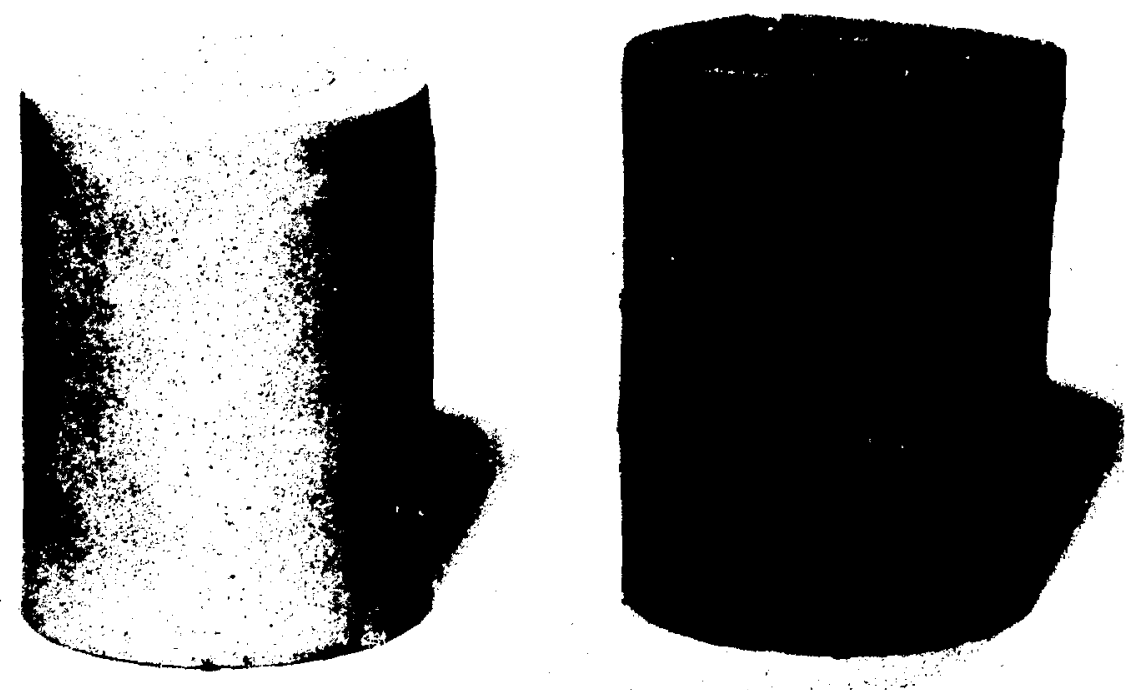

Figure 4.41

Portland I cement waste forms containing 5 wt 8 sodium sulfate. The one at left is as fabricated. The one at right was leached for 403 days in deionized water at $20^{\circ} \mathrm{C}$. Samples were $4.8 \mathrm{cn}$ diameter by $6.4 \mathrm{~cm}$ high right cylinders.

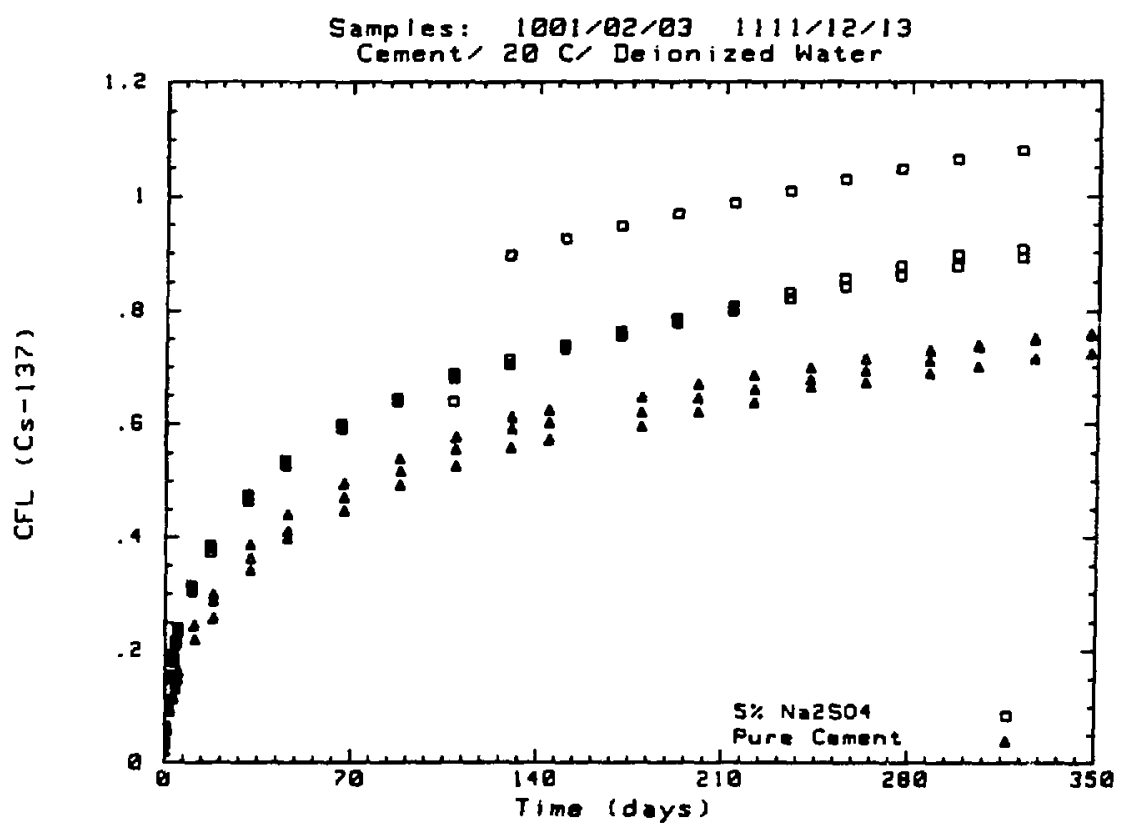

Figure 4.42

Cs-137 cumulative fraction leached vs. time from portland I cement waste forms containing 5 wto sodium sulfate and from pure portland I cement at $20^{\circ} \mathrm{C}$. 


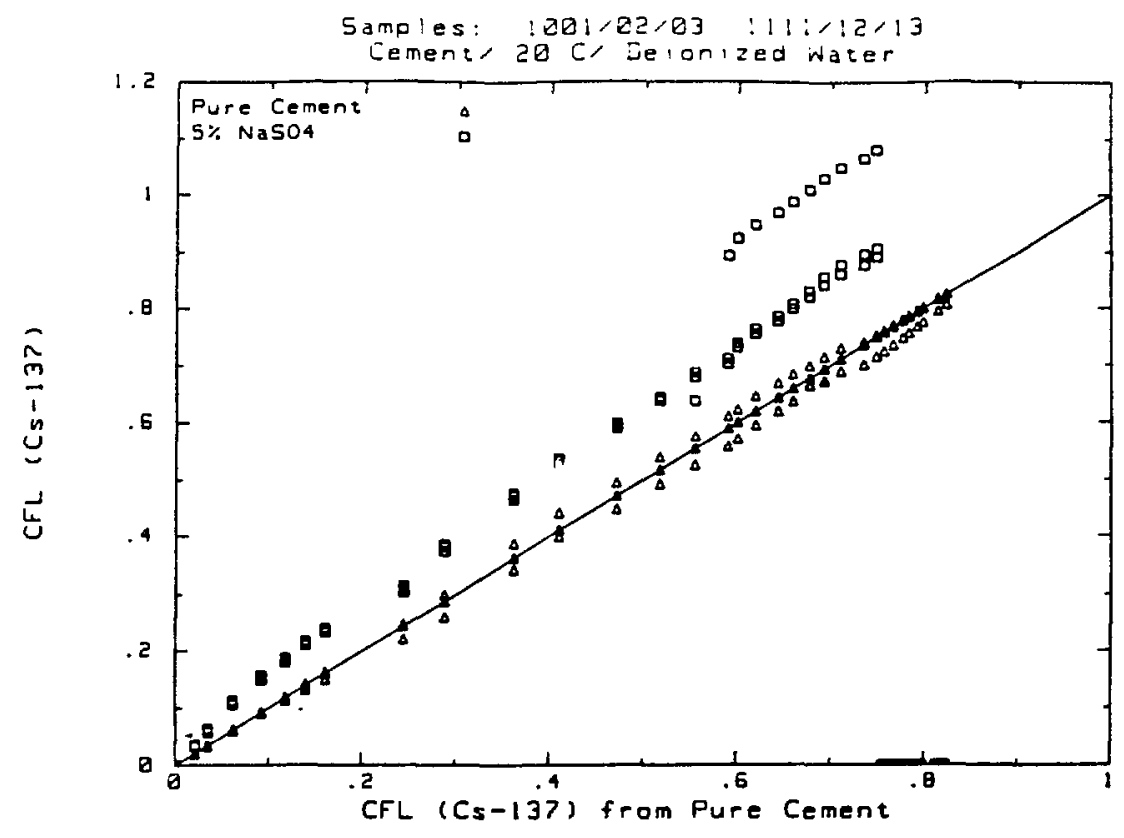

Figure 4.43

Linear correlation plots for Cs-137 leached at $20^{\circ} \mathrm{C}$ for portland I cement waste forms containing 5 wts sodium sulfate and pure portland I cement. Correlations are relative to pure cement.

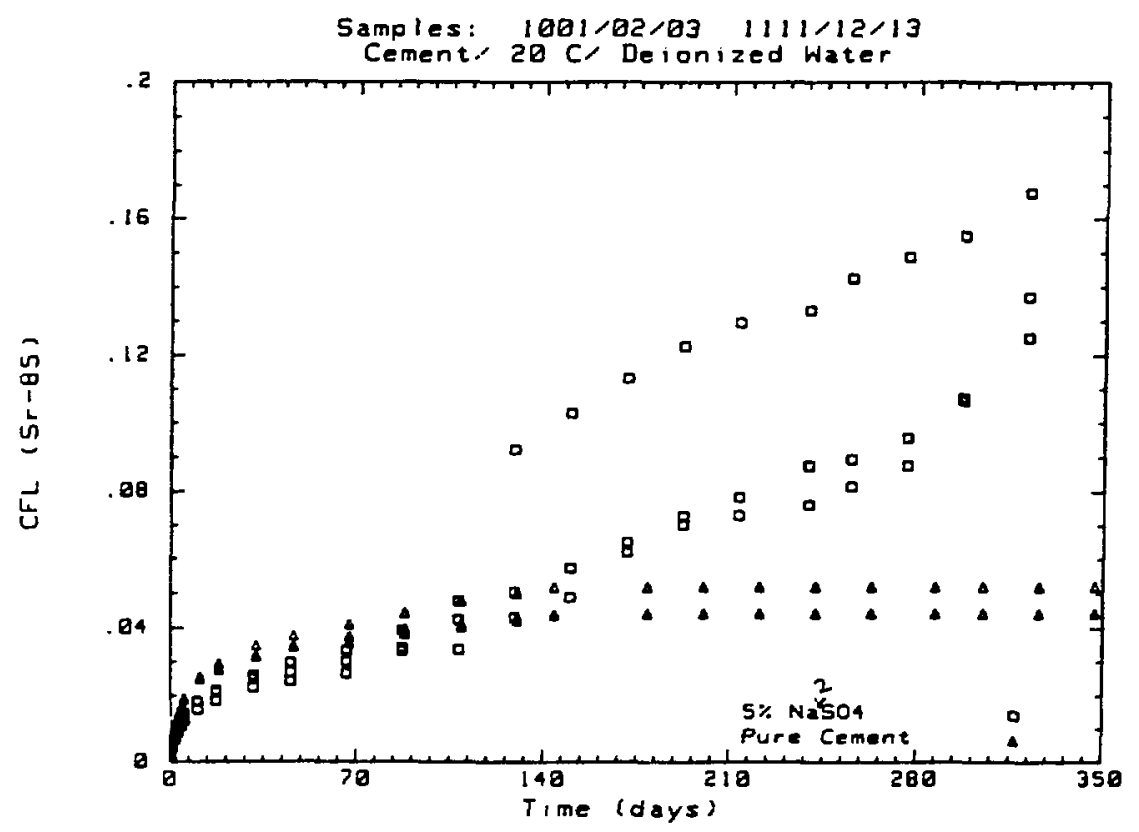

Figure 4.44

Sr-85 cumulative fraction leached vs. time from portland I cement waste forms containing 5 wt sodium sulfate and from pure portland I cement at $20^{\circ} \mathrm{C}$. 


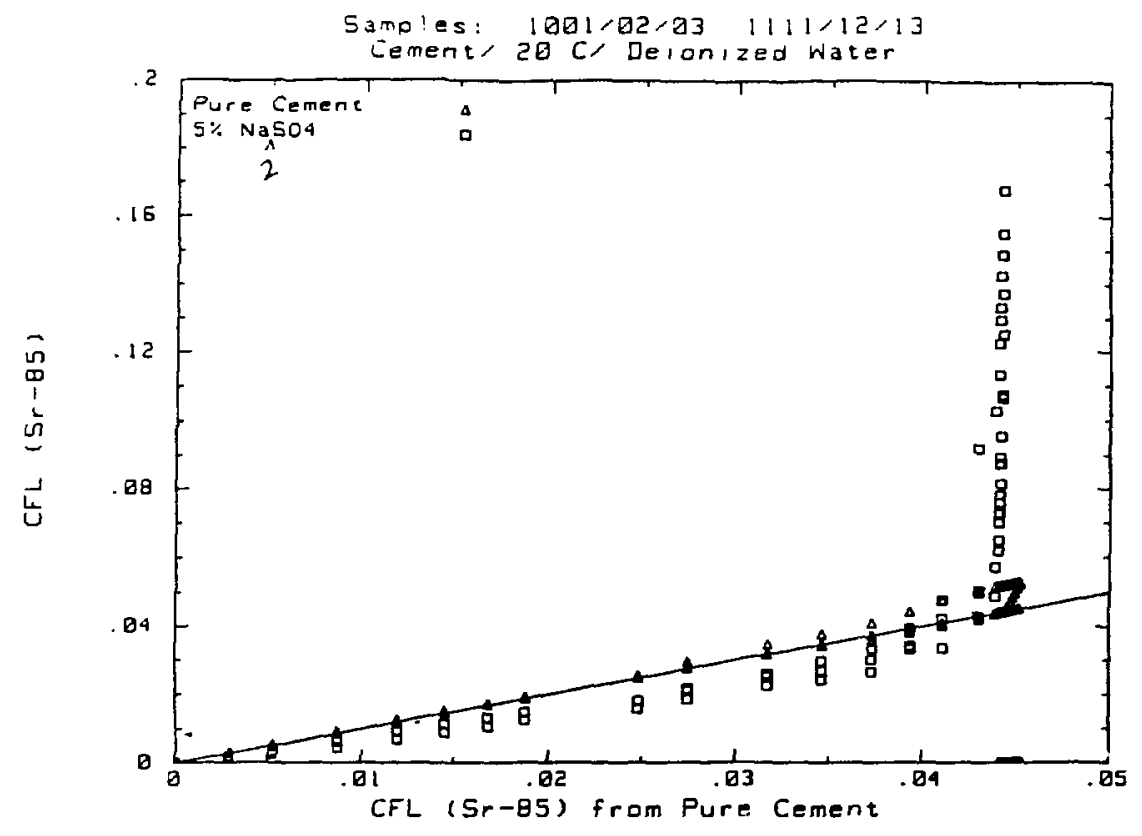

Figure 4.45 Linear correlation plots for Sr-85 leached at $20^{\circ} \mathrm{C}$ for portland I cement waste forms containing 5 wt sodium sulfate and pure portland I cement. Correlations are relative to pure cement.

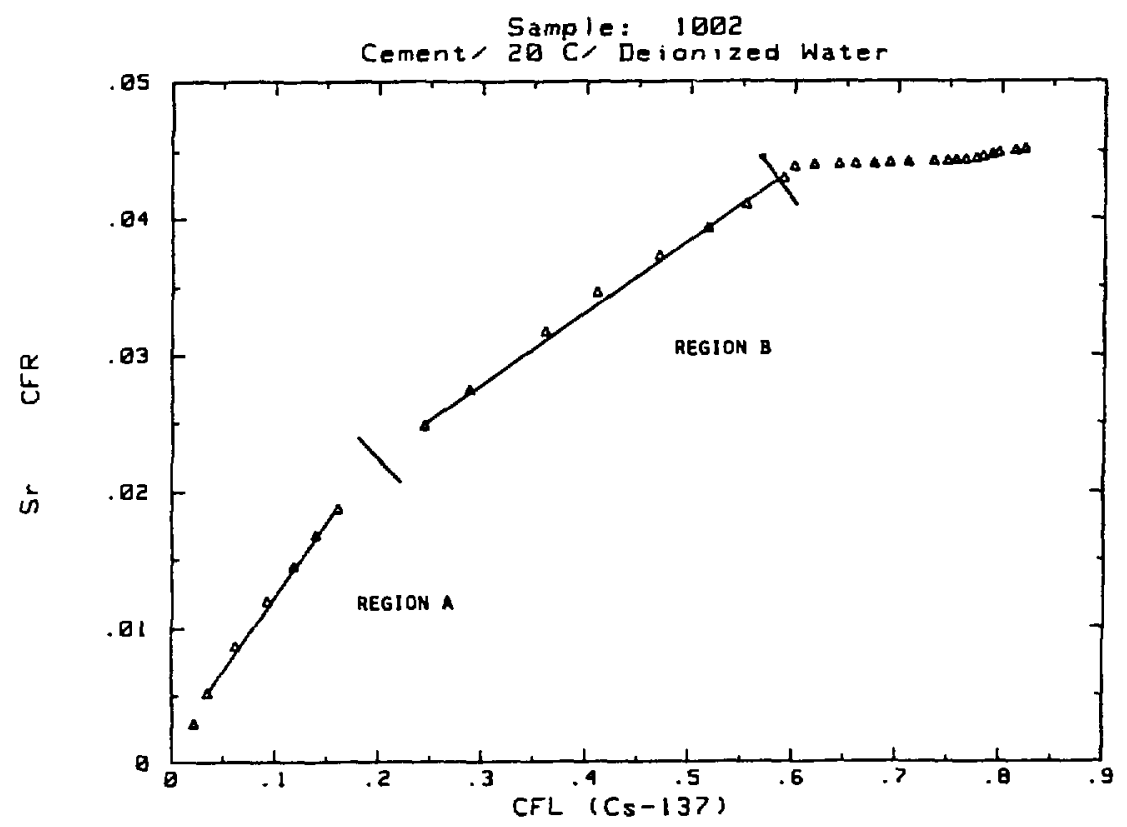

Figure 4.46 Linear correlation plot for Sr-85 versus Cs-137 leaching at $20^{\circ} \mathrm{C}$ for pure portland I cement. 


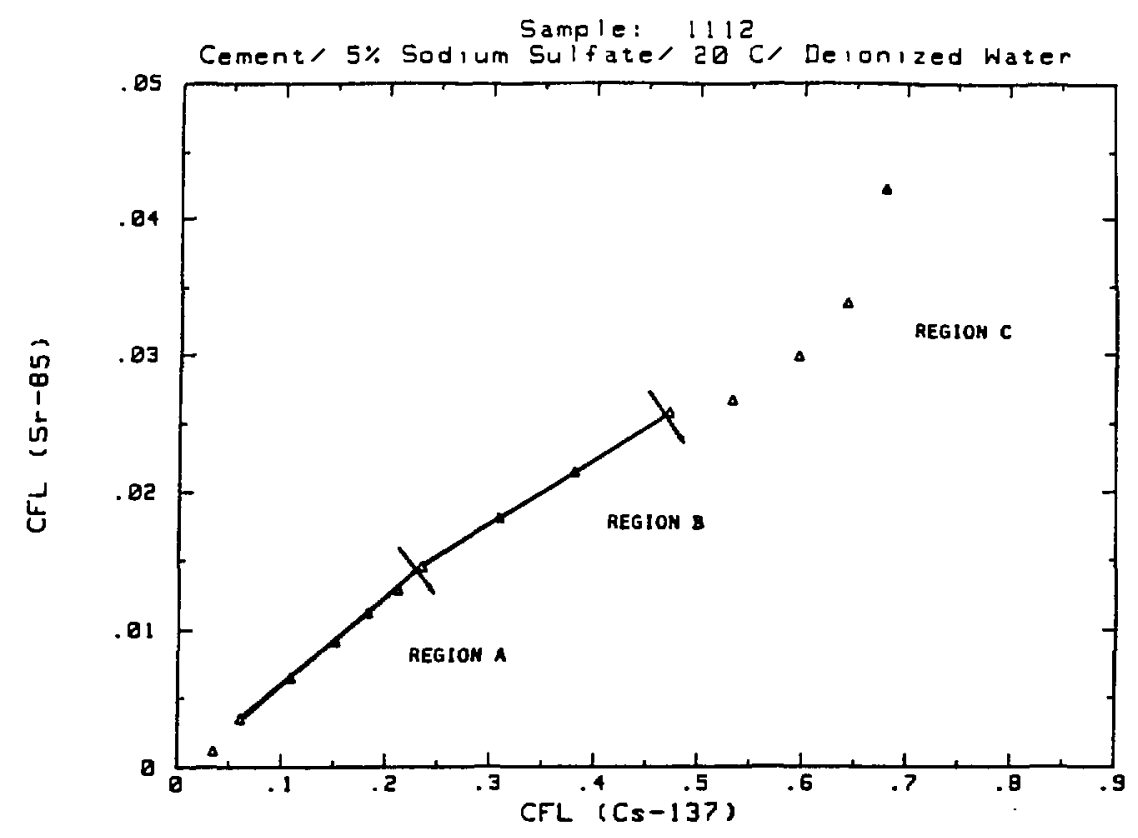

Figure 4.47

Linear correlation plot for Sr-85 versus Cs -137 leaching at $20^{\circ} \mathrm{C}$ for portland I cement containing 5 wto sodium sulfate.

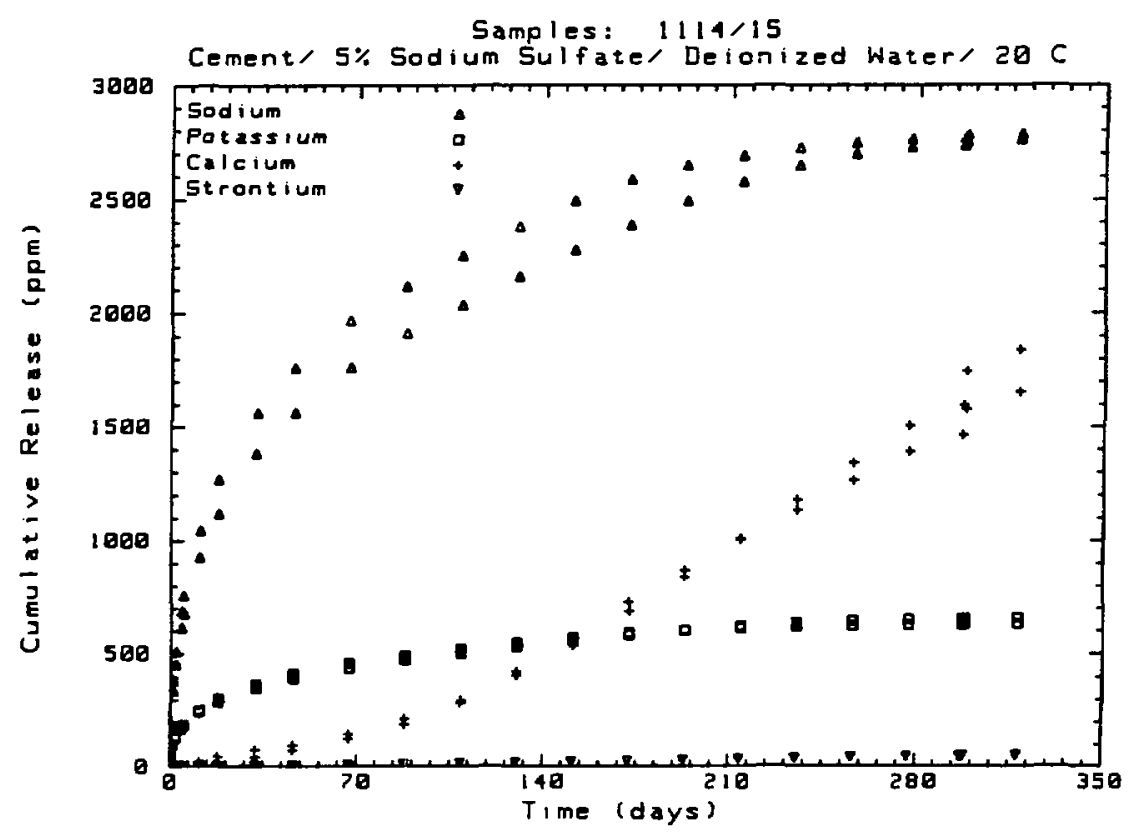

Figure 4.48

Leaching curves of cunulative release (ppm) vs. time of sodium, potassium, calcium and strontium from portland I cement containing 5 wt sodium sulfate. Samples were leached at $20^{\circ} \mathrm{C}$ in deionized water. 


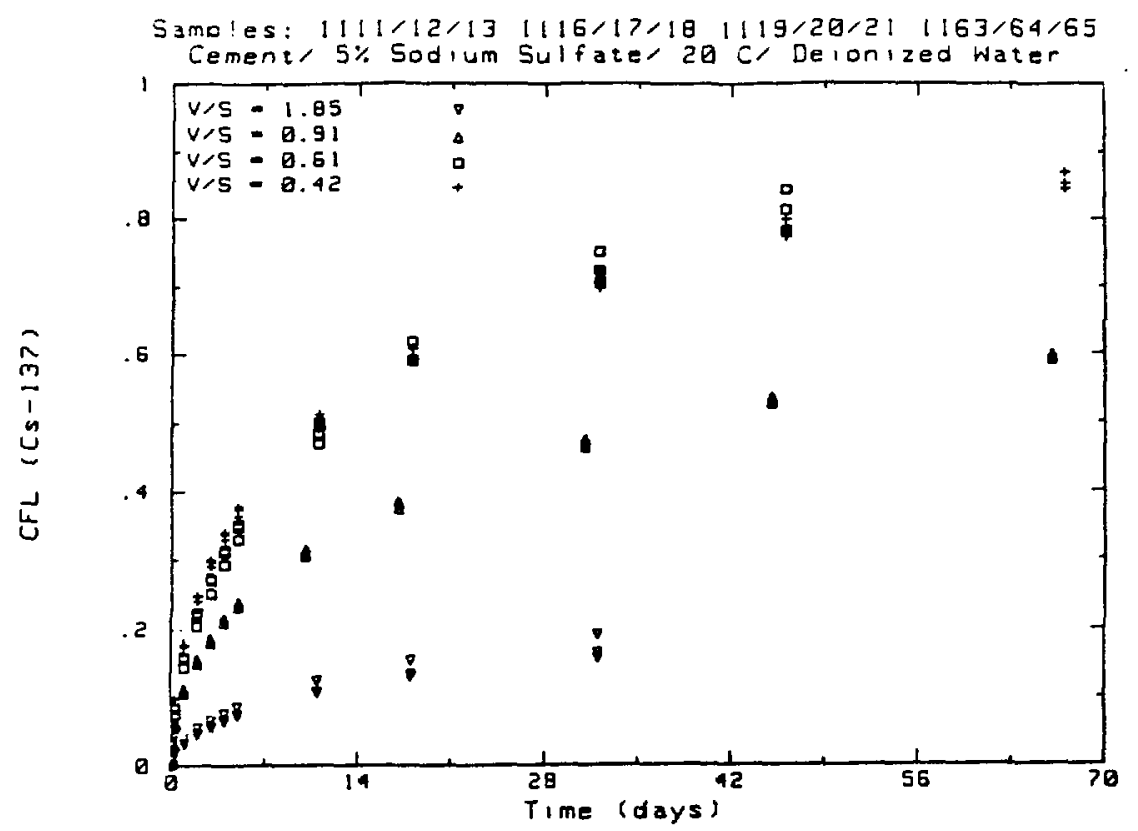

Figure 4.49

Cs-137 cumulative fraction leached vs. time from portland I cement containing 5 wto sodium sulfate at waste form volume to surface area (V/S) ratios of $0.42,0.61,0.85$ and 1.85 . Samples were leached in deionized water at $20^{\circ} \mathrm{C}$.

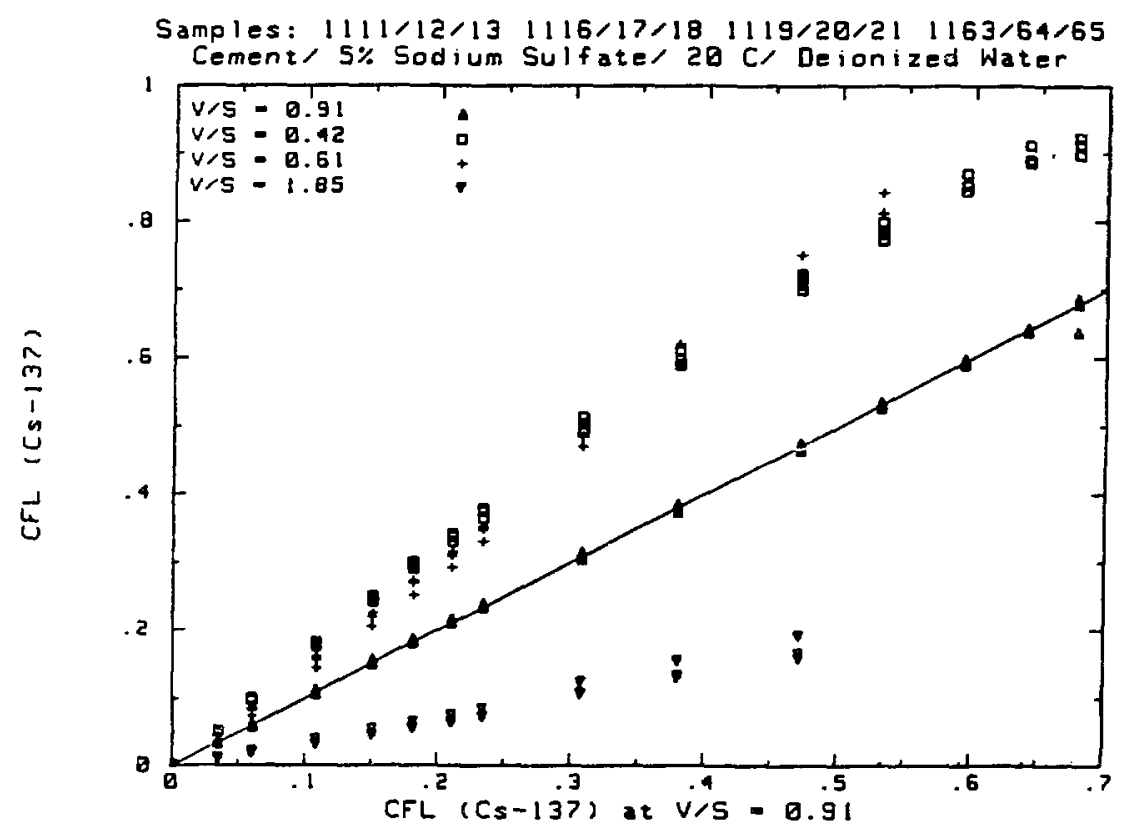

Figure 4.50

Linear correlation plots for Cs-137 leached from portland I cement containing 5 wt sodium sulfate at waste form volume to surface area ratios of 0.42 , $0.61,0.85$ and 1.85 . Correlations are relative to $\mathrm{V} / \mathrm{S}-0.85$. Samples were leached in delonized water at $20^{\circ} \mathrm{C}$. 


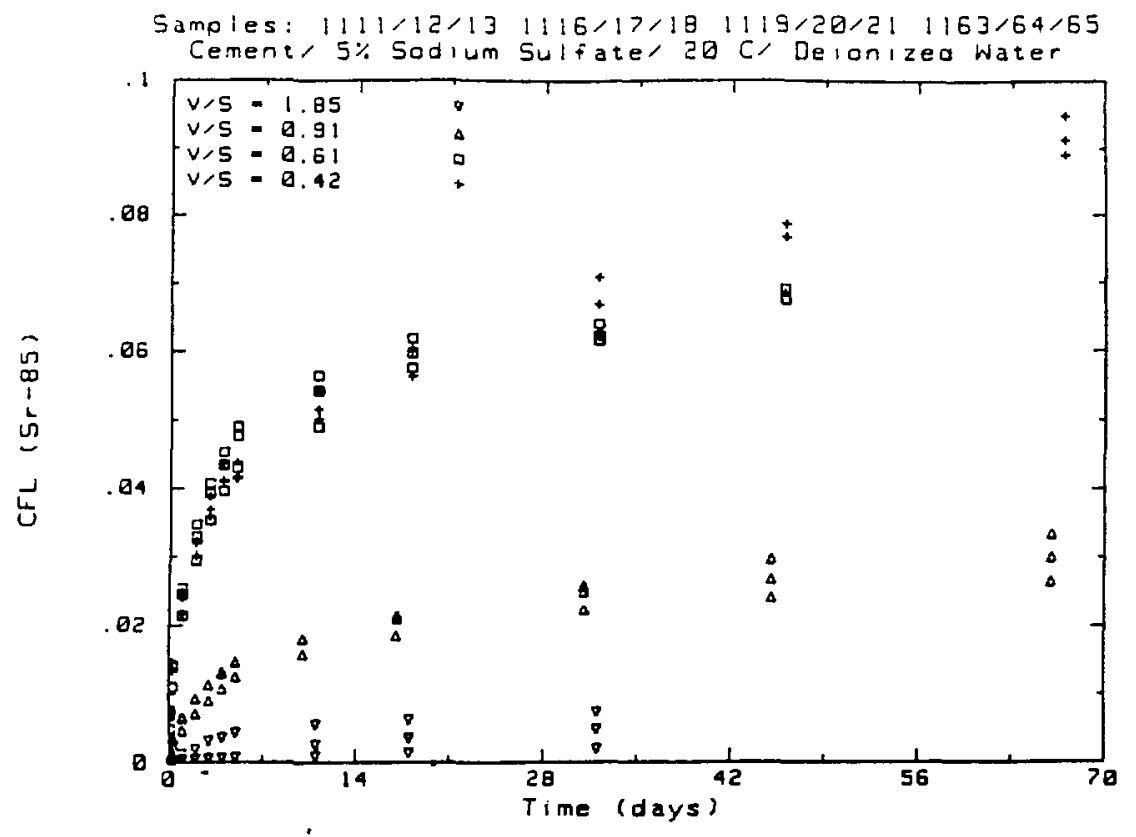

Figure 4.51 Sr-85 cumulative fraction leached vs. time from portland I cement containing 5 wto sodium sulfate at waste form volune to surface area $(\mathrm{V} / \mathrm{S})$ ratios of $0.42,0.61,0.85$ and 1.85 . Samples were leached in deionized water at $20^{\circ} \mathrm{C}$.

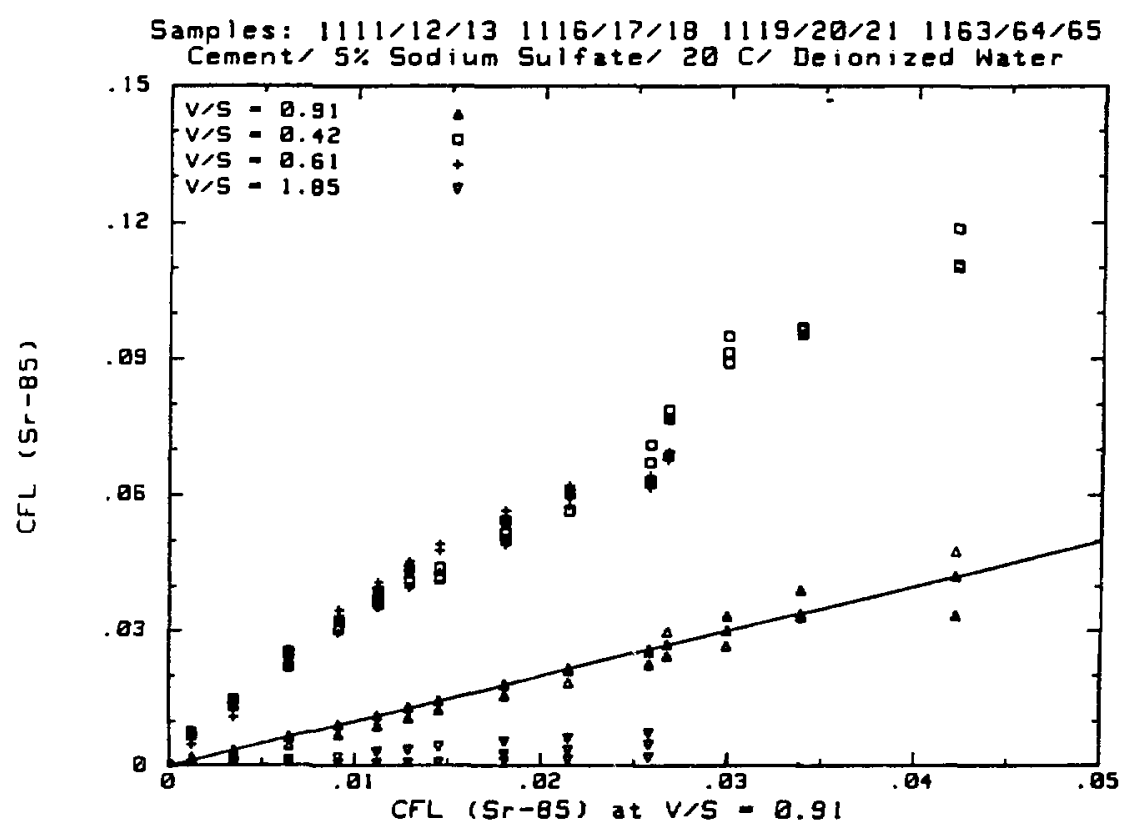

Figure 4.52

Linear correlation plots for $\mathrm{Sr}-85$ leached from portland I cement containing 5 wt sodiun sulfate at waste form volume to surface area $(V / S)$ ratios of $0.42,0.61,0.85$ and 1.85 . Correlations are relative to $\mathrm{V} / \mathrm{S}-0.85$. Samples were leached in deionized water at $20^{\circ} \mathrm{C}$. 


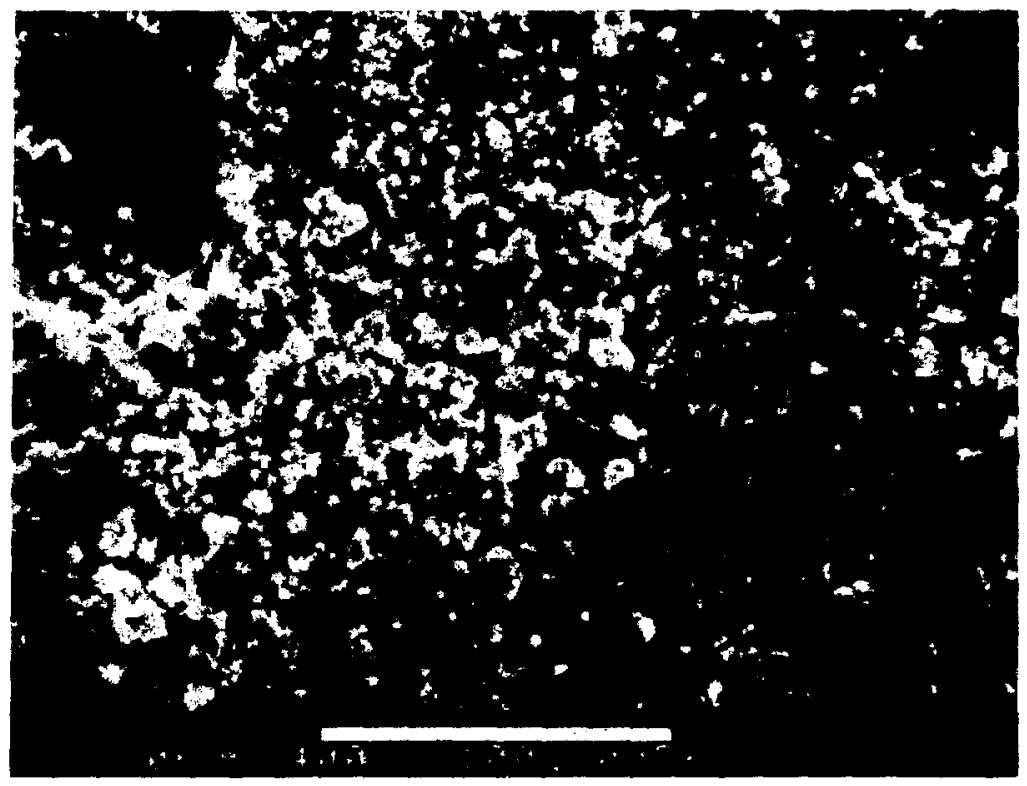

Figure 4.53

Outer surface of an unleached cement sample containing 58 sodium sulfate at a magnification of 400 times. This surface is indistinguishable from that of unleached pure cement.

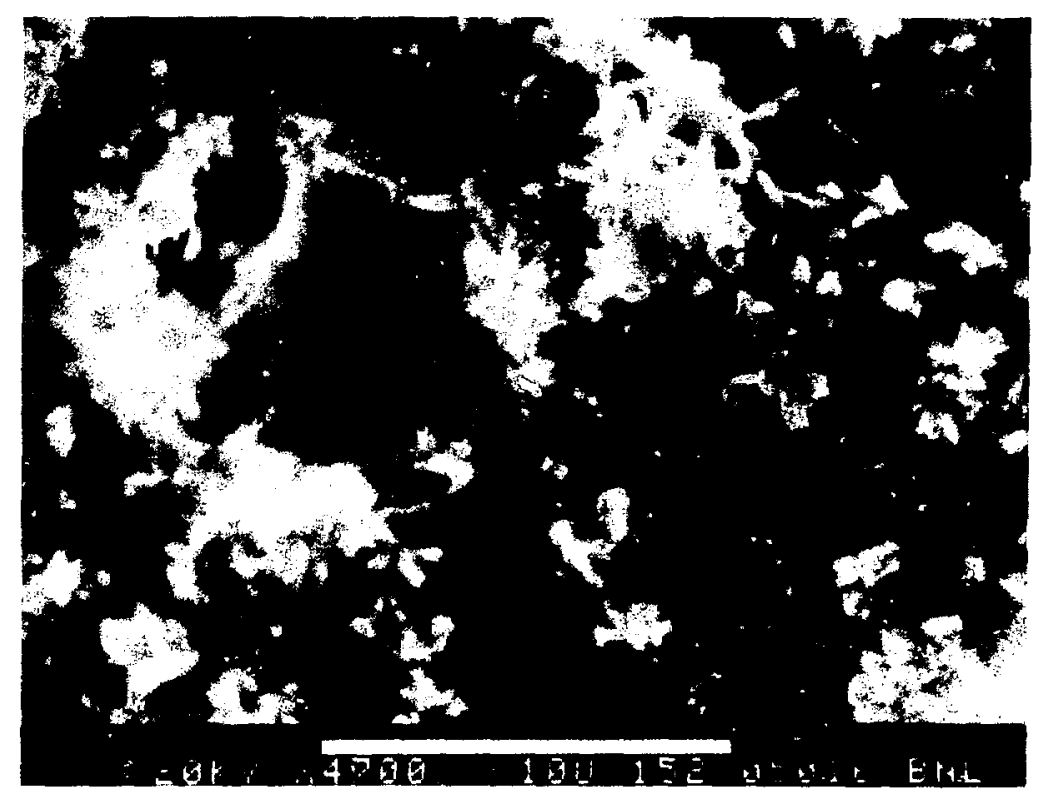

Figure 4.54

Outer surface of an unleached cement sample containing 58 sodium sulfate at a magnification of 4700 times. 


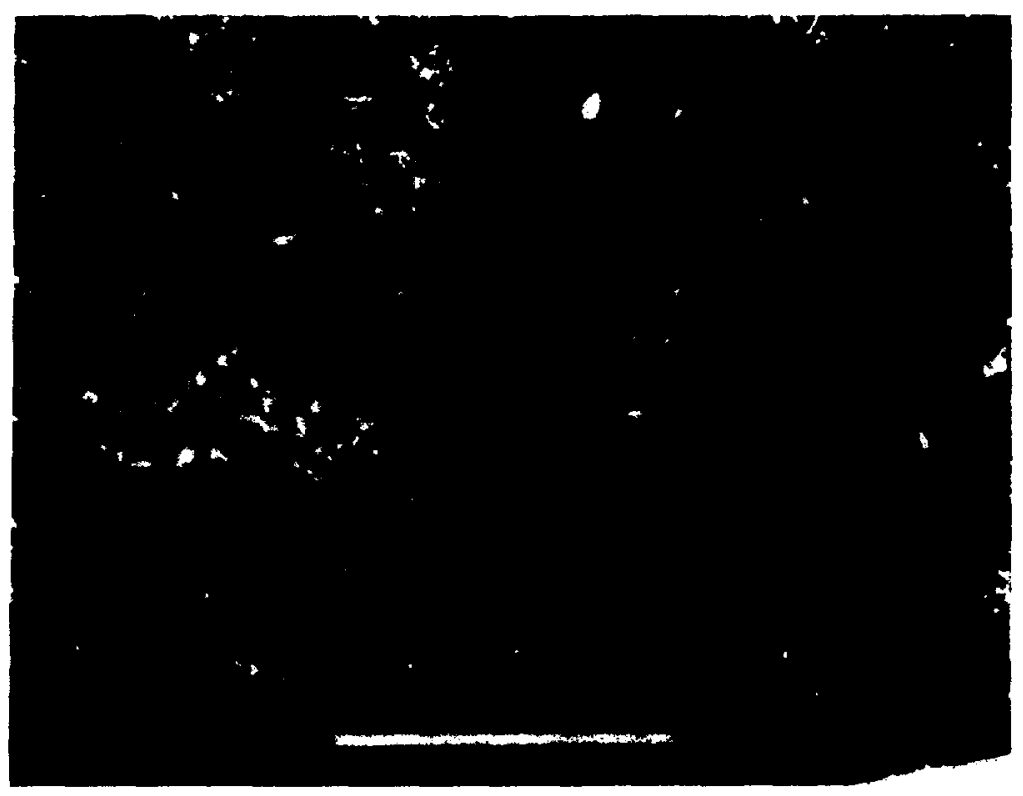

Figure 4.55

Outer surface of a cement sample containing 5 t sodium sulfate after static leaching for 55 days at $50^{\circ} \mathrm{C}$. Magnification is 400 times. Profuse crystal growth covers the surface.

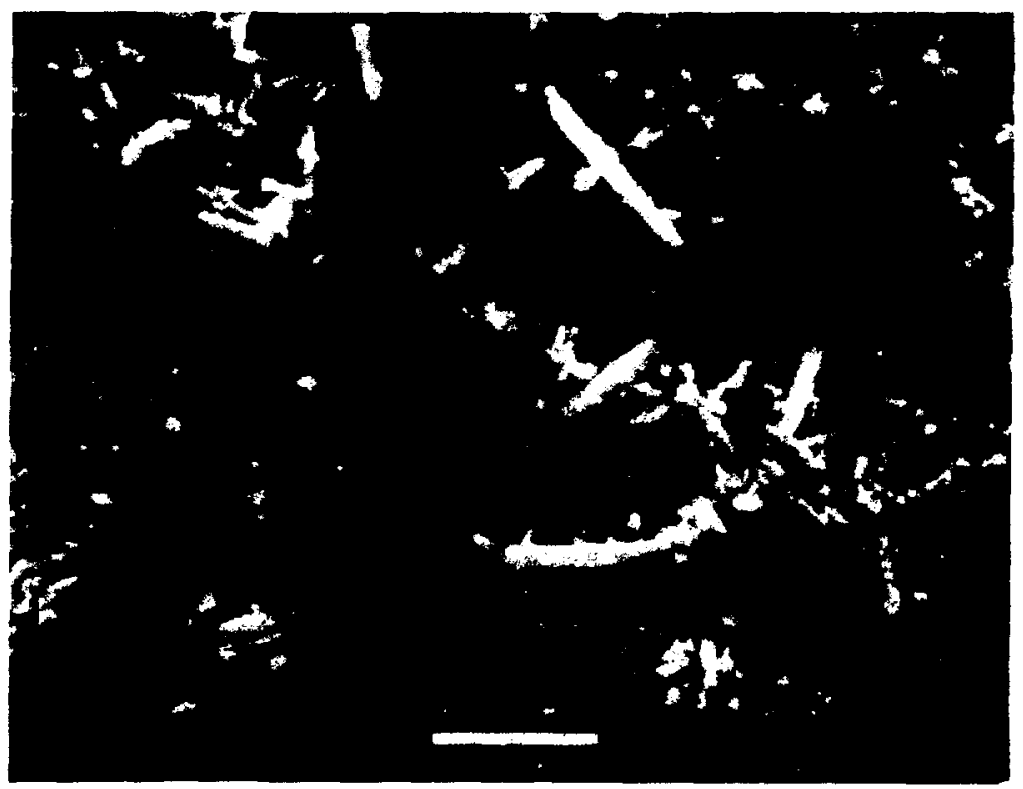

Figure 4.56

Outer surface of a cement sample containing 5* sodium sulfate after static leaching for 55 days at $50^{\circ} \mathrm{C}$. Magnification is 1900 times. 


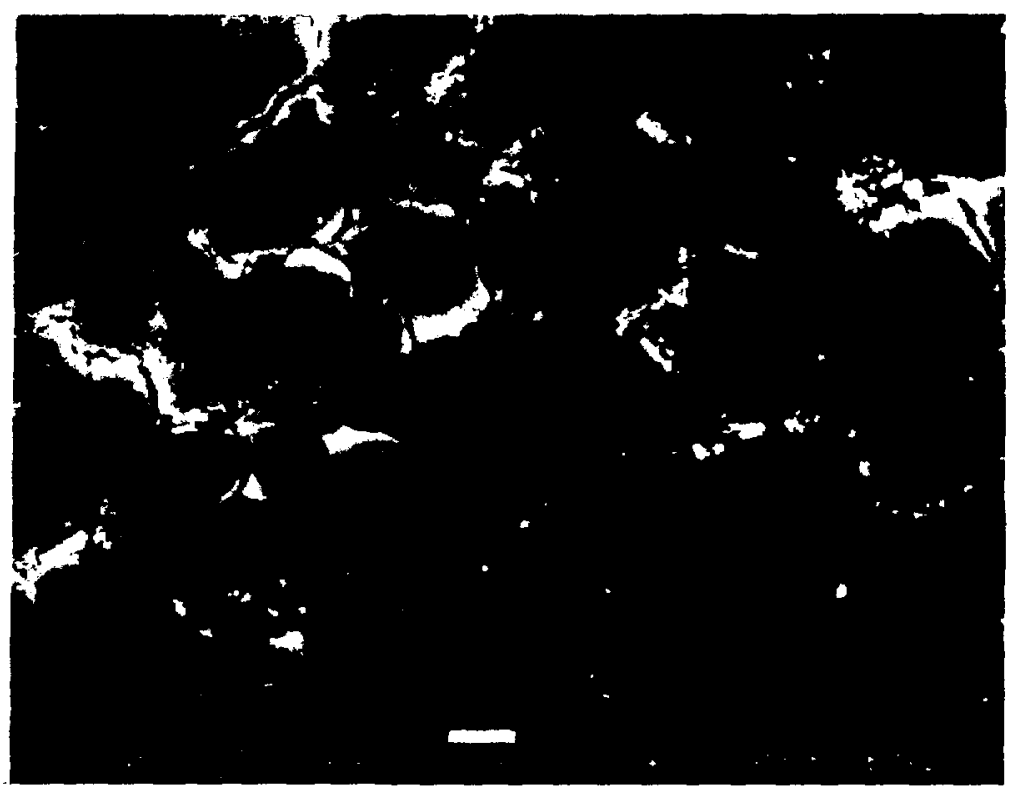

Figure 4.57

Interior of a cenent sample containing 5 sodiun sulfate after static leaching for 55 days at $50^{\circ} \mathrm{C}$. This is a cut sanple from 2 manside the outer edge. Note the many cracks.

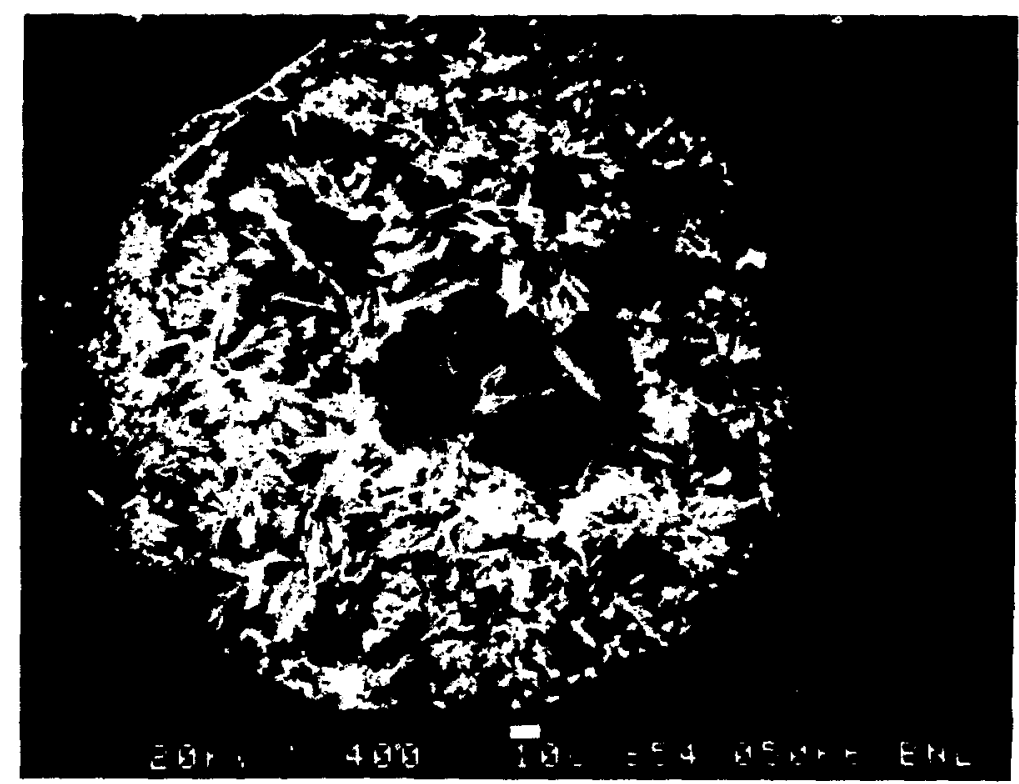

Figure 4.58

A bubble, after leaching, was full of crystals. This was typical of voids in the sample. 


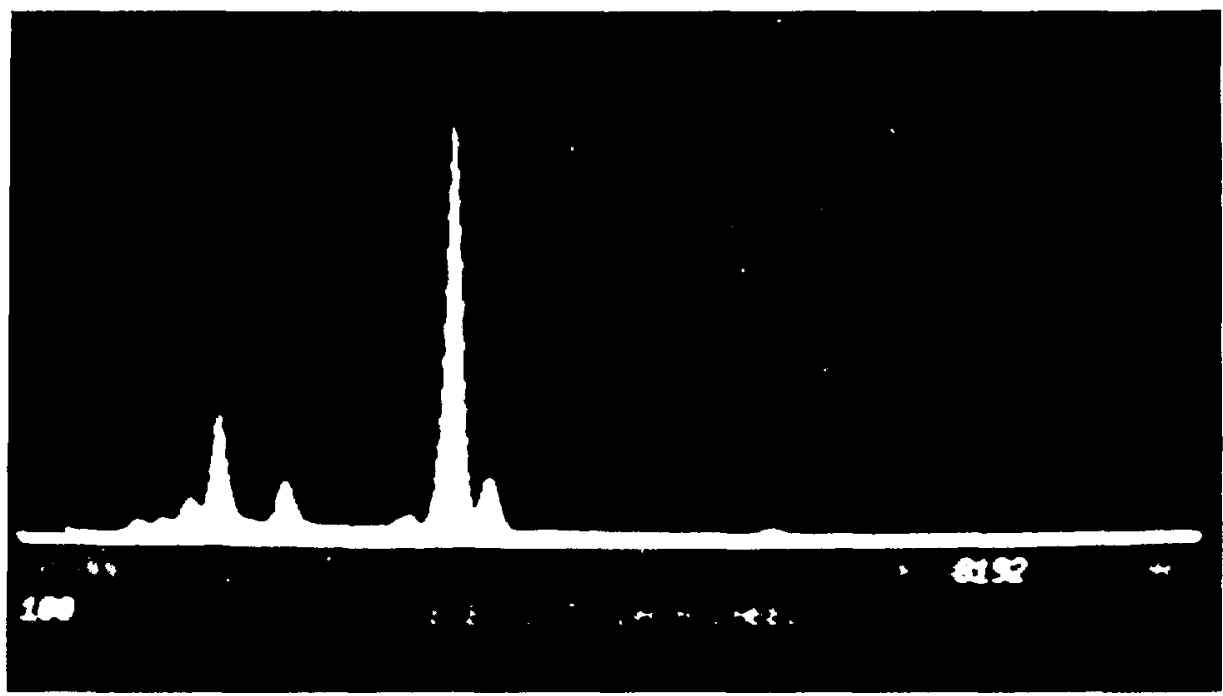

Figure 4.59

EDS spectrum of the outer surface of unleached cement sample containing sodiun sulfate. Note that small sodium and potassium peaks are present and that sulfur is enriched compared to pure cenent.

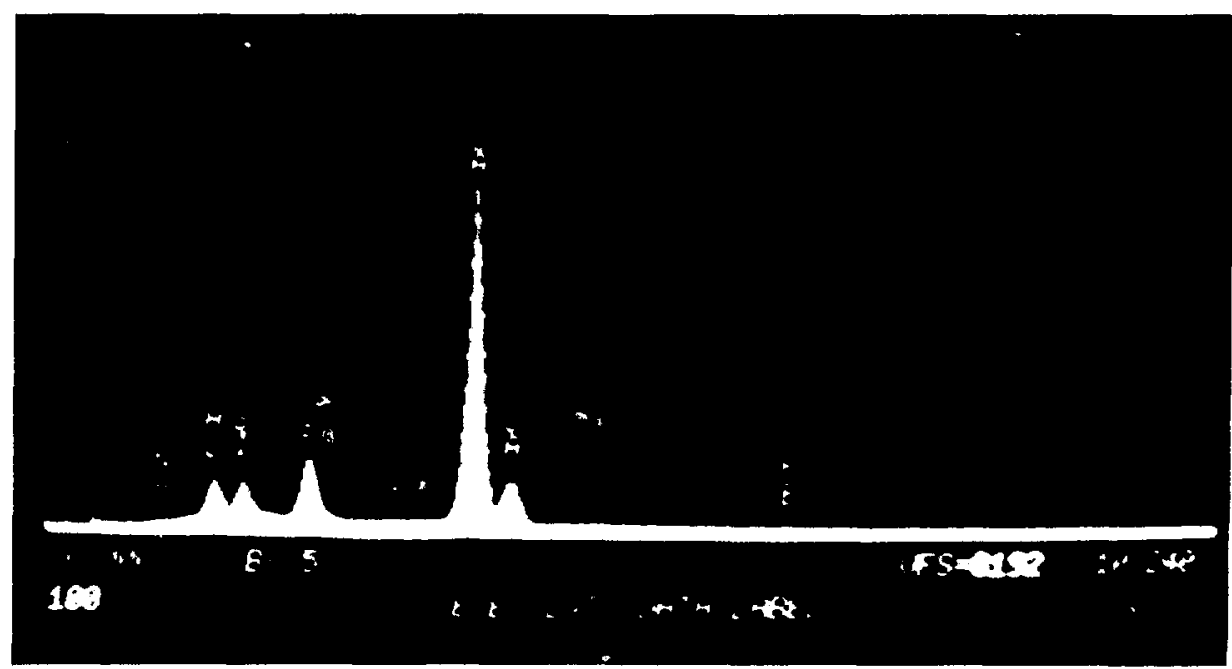

Figure 4.60

EDS spectrum of one of the crystals fron Figure 4.58. This spectrum is significantly different from that of the unleached cement containing sodium sulfate shown in Figure 4.59. Sulfur and aluminum are enriched while silicon is depleted relative to the unleached composition. 


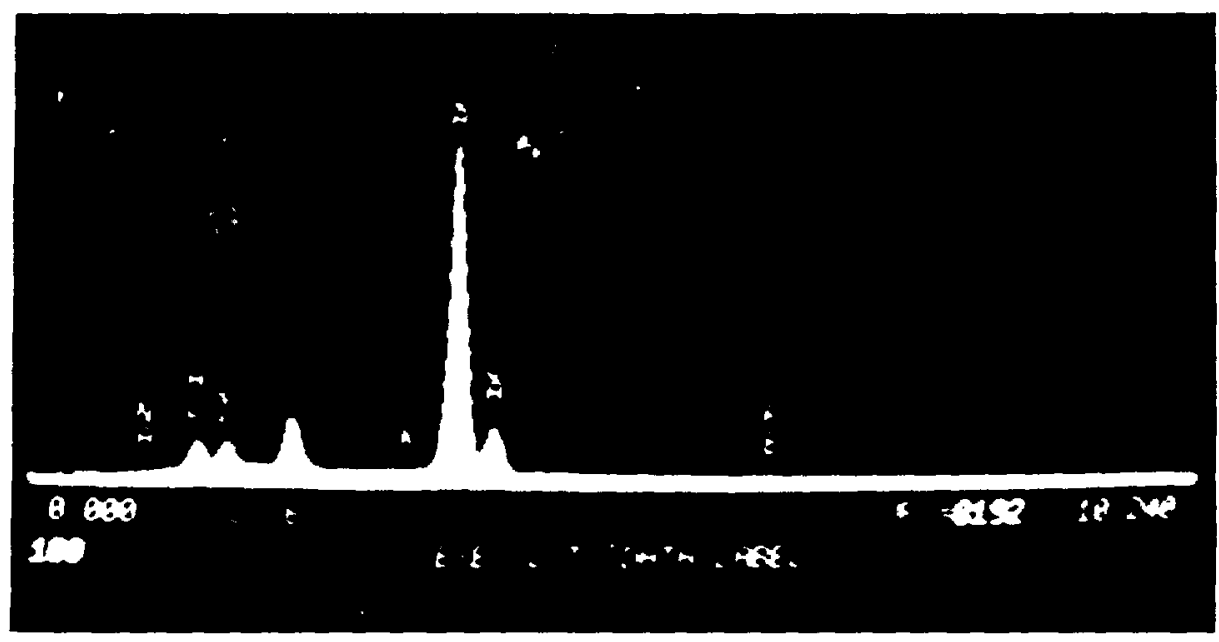

Figure 4.61

EDS spectrum of the leached surface of cement containing so sodiun sulfate using a large analytical area. This spectrum is identical to that in Figure 4.60 from a single crystal in a pore.

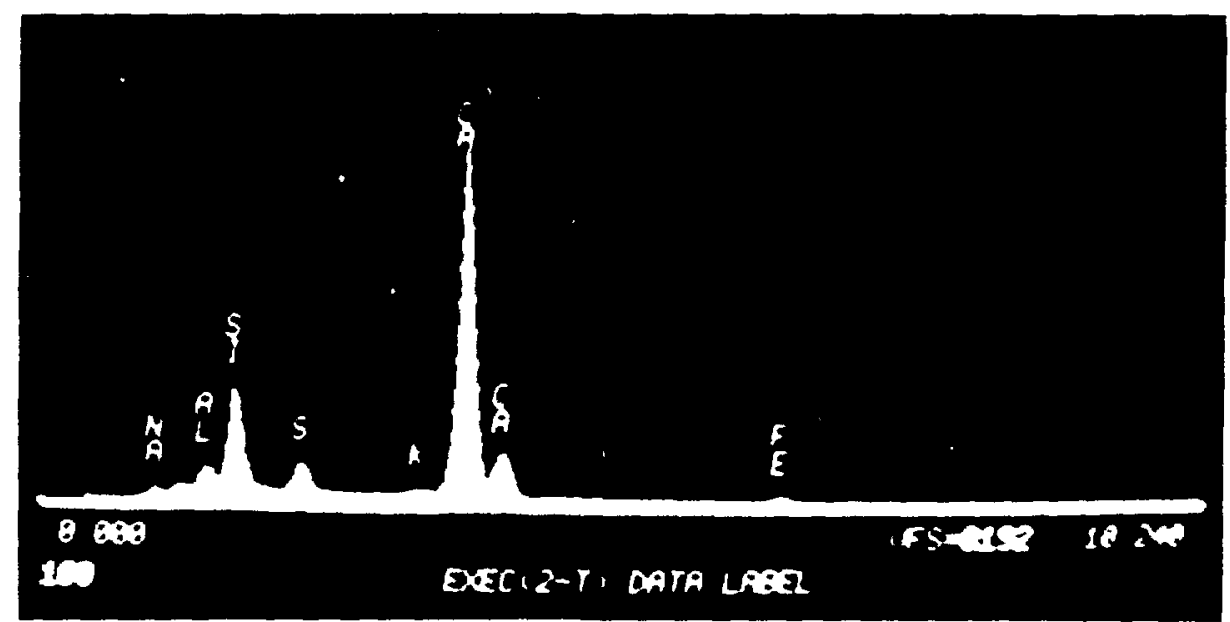

Figure 4.62

EDS spectrum of the center of the leached specimen. This more closely resembles the spectrum of the unleached material, Figure 4.59, than it does the leached surface, Figure 4.60 . 


\section{PORTLAND I CEMENT CONTAINING INCINERATOR ASH AS SIMULATED WASTE}

Portland cement, alone or blended with additives to enhance radionuclide retention, is the most commonly used solidification agent for low-level radwaste. Portland cement solidifies as the result of hydration reactions with water to form a porous, hydrophilic matrix of high surface area. The physical and chemical properties of portland cement have been well documented $[45-50]$.

In general, portland cement shows a rapid release of cesium in leaching experiments while strontium and cobalt leach substantially less readily $[1-3,10,11,29,51-58]$. As a result, sorbents for cesium are commonly blended with cement to reduce its leachability [51-61]. These blended cement + sorbent mixtures often are formulated for specific waste streams.

This section presents data and results obtained from leaching studies investigating the factors deemed potentially important for LLW forms, as discussed in Section 2 of this report, for waste forms consisting of portland I cement containing $15 \mathrm{wt}$ incinerator ash as simulated waste.

\subsection{Leaching Mechanisms}

The overview presented in Section 4.1 summarizes the leaching mechanisms for cement, determined from the literature survey [1] and from the experimental work in this task.

\subsection{Factors that Affect Leaching}

Leaching results from experiments designed to investigate each of the factors 1 isted in Table 2.1 for the cement waste forms containing incinerator ash are discussed in the following sections. The basis for evaluating the effect of each of the factors is a comparison with the results of tests on standard samples, i.e., $4.8 \mathrm{~cm}$ diameter by $6.4 \mathrm{~cm}$ high right cylinders, at $20^{\circ} \mathrm{C}$ in deionized water. Replicate tests, generally triplicates, provided a measure of the variability of the data.

5.2.1 Temperature. The effect of temperatures between 20 and $50^{\circ} \mathrm{C}$ on the leachability of portland I cement waste forms containing 15 wto incinerator ash was investigated. Activation energies for cesium and strontium were calculated from the elevated temperature data, based on the assumption that diffusion is the leaching mechanism and the rate constant is proportional to the release rate. An activation energy of 4 to $6 \mathrm{kcal} / \mathrm{mole}$ would be expected for pure diffusion of simple ions in water solution. Temperature had no effect on cobalt leaching in these studies, in that cobalt was not observed in any of the leachates.

Figures $5.1,5.2$ and 5.3 summarize the effect of temperature on the leaching of Cs-137. Figure 5.1 presents the cumulative fraction leached (CFL) versus time for the triplicate samples at 20 and $50^{\circ} \mathrm{C}$, and the duplicate samples at $40^{\circ} \mathrm{C}$. Figure 5.2 plots linear correlations of these data versus

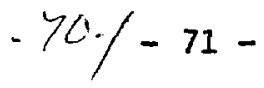


the $20^{\circ} \mathrm{C}$ data. Figure 5.3 is an Arrhenius plot of the incremental leach rates of these data.

Figure 5.1 shows that increasing temperature only slightly increases Cs-137 leachability. Also, the reproducibility, as indicated by the scatter of data at the same temperature, is decidedly better for the $20^{\circ} \mathrm{C}$ data than for the data at $40^{\circ}$ and $50^{\circ} \mathrm{C}$.

The correlation plots in Figure 5.2 indicate that the two $40^{\circ} \mathrm{C}$ data curves remain linear with respect to the $20^{\circ} \mathrm{C}$ data up to $0.3 \mathrm{CFL}$, while the $50^{\circ} \mathrm{C}$ data deviate from linearity beyond approximately $0.25 \mathrm{CFL}$. Since the $40^{\circ} \mathrm{C}$ data correlate with the $20^{\circ} \mathrm{C}$ data up to releases of approximately $0.3 \mathrm{CFL}$, depletion seems to be the cause of the deviation from linearity for the $50^{\circ} \mathrm{C}$ data. It has not been determined whether the deviation from linearity for the $40^{\circ}$ and $50^{\circ} \mathrm{C}$ data results from a change in the leaching mechanism.

In the Arrhenius plots of Figure 5.3, least-squares lines were drawn through the 20,40 and $50^{\circ} \mathrm{C}$ data for each leachant replacement interval. Since the leach rate generally decreases with time, the least-squares lines for each of the replacements proceed down the figure. Table 5.1 lists the apparent activation energies calculated from the slopes of these lines. The points for replacements 8 through 12 are not included. Scanning down the 1 ist in Table 5.1 suggests that the apparent activation energy, $E_{a}$, is near 4 to $6 \mathrm{kcal} / \mathrm{mole}$ through leachant replacement interval 7; a dashed line appears between the data for intervals 7 and 8 . Starting with interval 8 , the $E_{a}$ values decrease and become erratic, indicating that factors other than the activated diffusion process are affecting the leach rates. Depletion of both the $40^{\circ}$ and $50^{\circ} \mathrm{C}$ samples seems a most likely cause. Therefore, the $E_{a}$ value for the process $\left(E_{a}=4.9 \pm 1.5 \mathrm{kcal} / \mathrm{mole}\right)$ is taken to be the average of the individual $\mathrm{E}_{\mathrm{a}}$ values for replacement intervals 1 through 7 (Table 5.1). The activation energies for higher energy processes cannot be calculated because the exact form of the rate equation is not known. The average $E_{a}$ of $4.7 \pm 1.5 \mathrm{kcal} / \mathrm{mole}$ is consistent with that for diffusion of simple ions in water solution (4-6 $\mathrm{kcal} / \mathrm{mole}$ ).

Leaching at elevated temperature also was performed on portland type I cement samples containing radiotracers but № simulated bulk waste. See Sections 4.2.1.1 and 4.2.1.2 for these data and accompanying discussions.

Figures $5.4,5.5$ and 5.6 summarize the effect of temperature on the leaching of Sr-85 from portland I cement waste forms containing 15 wts incinerator ash. Figure 5.4 presents the cumulative fraction leached (CFL) versus time for the triplicate samples at 20 and $50^{\circ} \mathrm{C}$ and the duplicate samples at $40^{\circ} \mathrm{C}$. Figure 5.5 plots linear correlations of these data versus the $20^{\circ} \mathrm{C}$ data. Figure 5.6 is an Arrhenius plot of the incremental leach rates. 
Table 5.1

Apparent Activation Energies at each Leachant Replacement Interval for Sr-85 and Cs-137 From Portland I Cement Containing 15 Wto Incinerator Ash

$$
E_{a} \quad(\operatorname{Sr}-85)
$$

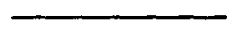

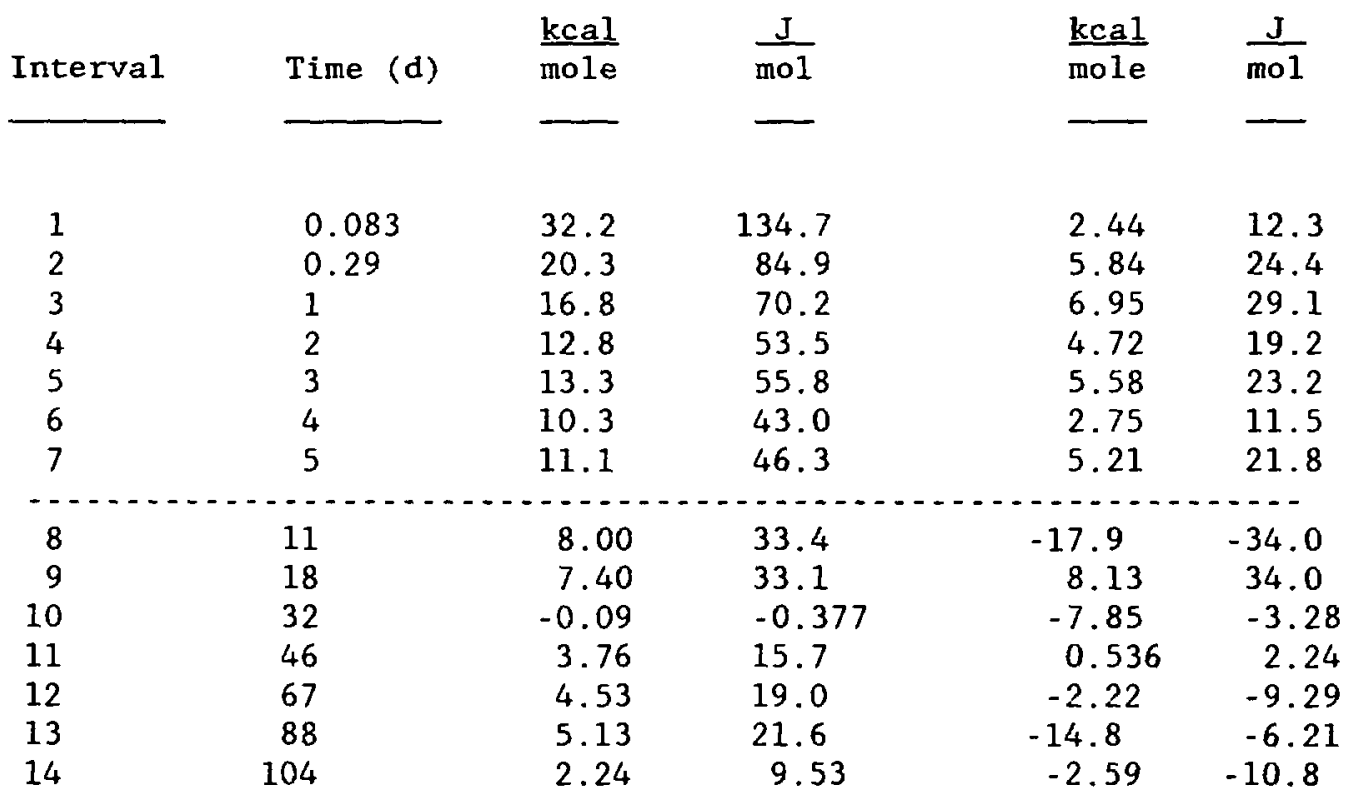


Figure 5.4 shows that increasing temperature increases the leachability of $\mathrm{Sr}-85$. The reproducibility, is somewhat better for the 20 and $40^{\circ} \mathrm{C}$ data than for that at $50^{\circ} \mathrm{C}$. Although temperature clearly accelerates leaching of $\mathrm{Sr}-85$, the lack of reproducibility limits its value as an accelerating factor.

Although the initial portions of the 40 and $50^{\circ} \mathrm{C}$ data curves are linear with respect to the $20^{\circ} \mathrm{C}$ data, the correlation plots in Figure 5.5 show that they deviate from linearity as the replacement intervals become longer than a week (i.e., approximately at replacement interval 9). Depletion cannot be the cause of the deviation from linearity, as the CFL is less than 208. It is probable that the deviation from linearity for these data results from carbonation of the surface of the waste form, which could reduce the solubility of strontium and thus reduce its leachability. This is a particularly likely mechanism since strontium is contained naturally in cement in amounts well above the trace levels of radiostrontium present in radwaste.

In the Arrhenius plots of Figure 5.6, least-squares lines were drawn through the 20,40 and $50^{\circ} \mathrm{C}$ data at each replacement interval. Since the leach rate decreases with time, the least-squares line for each of the replacements proceed down the figure. Table 5.1 lists the apparent activation energies calculated from the slopes of these lines. These energies are not consistent with those expected for pure diffusion, but inply the existence of other mechanisms for the release of strontium. Since the mechanisms are unknown for strontium release, the proper form of the rate equation and the temperature dependence of the rate constant cannot be determined.

Cobalt -60 , along with $\mathrm{Cs}-137$ and $\mathrm{Sr}-90$, is a radionuclide of concern in LLW. Co-57 was included as an analog of Co-60 in sample formulations for the test specimens containing radioactivity. No Co-57 activity above background was seen in any of the leachates for the cement samples containing sodium sulfate as simulated waste.

The leaching of sodium, potassium, calcium and strontium was measured from portland I cement waste forms containing 15 wto incinerator ash but no radiotracers. These "Blanks" were otherwise nominally identical to the samples containing radiotracers. Previous results $[2,3,29]$ showed that the first three elements listed above comprise the bulk of leachable cations from cement while the strontium that is in cement naturally may affect the leaching of radiostrontium. In the cement waste forms containing incinerator ash, the leached sodium comes from both the cement and from the ash.

Figures $5.7,5.8,5.9$ and 5.10 show the cumulative amounts leached (ppm) versus time plots for, respectively, sodium, potassium, calcium and strontium from duplicate portland I cement blanks containing 15 wto incinerator ash in deionized water at $50^{\circ} \mathrm{C}$. The data for the experiments at $20^{\circ} \mathrm{C}$ are included for comparison. The sodium and potassium data are similar in that they all show "typical" leaching curves--i.e.. monotonically increasing at a decreasing rate. However, calcium behaves differently. Specifically, calcium leaches at a linear release rate. Strontium leaches at a monotonically decreasing rate, but the shapes of the curves are clearly different from those of sodium and potassium. Possibly, strontium release can be separated into two rate 
components, a monotonically decreasing component and a constant rate component.

Figure 5.11 is the correlation plot of sodium and potassium leaching from the blanks compared to the Cs-137 leaching from nominally identical portland I cement waste forms containing 15 wt incinerator ash.

Figure 5.12 is the correlation plot for strontium leaching from the blanks compared to the Sr-85 leaching from the nominally identical waste forms containing 15 wto incinerator ash doped with radiotracers.

5.2.2 Ratio of Waste Form Surface Area to Leachant Volume. The ANS 16.1 leach test procedure specifies that the ratio of the leachant volume (cubic $\mathrm{cm}$ ) to the geometric surface area (square $\mathrm{cm}$ ) of the specimen be $10+$ $0.2(\mathrm{~cm})$. To investigate the effect of increasing this ratio on leaching behavior, ratio: of 20,30 and 50 were compared with results from the usual ratio of 10 for cement incorporating sodium sulfate. These experiments were not performed for cement with incinerator ash.

5.2.3 Composition of the Leachant. Deionized water (DIW) was the standard leachant used in the ANS 16.1 Leach Test. Leachants used to examine the effect of its composition on the leaching of portland I cement waste forms containing 15 wt incinerator ash were DIW and a simulated oxic groundwater from Oak Ridge National Lab (ORNL) [63]. The mineral content of the ORNL groundwater is listed in Table 3.3. The oxic groundwater contained soilextracted humic and fulvic acids to make the compositions more realistic. Humic and fulvic acids have strong affinities for metal ions and can act as complexing and chelating agents.

Figure 5.13 shows the leaching curves for Cs-137 from portland I cement containing $15 \mathrm{wtz}$ incinerator ash leached at $20^{\circ} \mathrm{C}$ in DIW, and oxic groundwaters. Figure 5.14 shows the correlation plot for these data, which is in accord with other groundwater leaching results [64,65] and is expected [3] because of the high ionic strength of the groundwater leachant. In sum, increasing the ionic strength of the leachant decreases Cs-137 leachability. Further, the presence of humic and fulvic acids and the oxic state of the leachant make little, if any, difference in Cs-137 leachability from these waste forms.

Figure 5.15 shows the corresponding leaching curves for Sr-85. Figure 5.16 shows the linear correlation plot for these data. The Sr-85 leachability is greatest in the oxic groundwater. This disagrees with other groundwater leaching results $[64,65]$ and was not expected [3] because of $x$ high ionic strength of the groundwater leachant. In sum, increasing the ionic strength of the leachant should decrease Sr-85 leachability, but the presence of humic and fulvic acids and the oxic state of the leachant enhanced the $5 r-85$ leachability.

No measurable Co-57 activity above background was leached from the waste forms containing incinerator ash in any of these experiments. 
As described in Section 5.2.1, the leaching of sodium, potassium, calcium and strontium was measured from nonradioactive "Blank" portland I cement waste forms containing incinerator ash.

Figures 5.17, 5.18,5.19 and 5.20 show the cumulative amounts leached (mg) versus time for, respectively, sodium, potassium, calcium and strontium from duplicate cement samples containing 15 wto incinerator ash leached in oxic groundwater. Sodium and potassium continuously increase at a decreasing rate. Calcium and strontium leaching continuously increased up to the fifth day, after which the cumulative release was nearly constant. At this point, leaching may be limited by the formation of insoluble carbonates.

Figures 5.21, 5.22, 5.23 and 5.24 plot the linear correlations of the data shown in Figures 5.17-5.20, respectively.

$5.2 .4 \mathrm{pH}$ of the Leachant. The $\mathrm{pH}$ of deionized water (DIW), the standard leachant in the ANS 16.1 leach test, is nominally 7 at $20^{\circ} \mathrm{C}$ but is actually about 6 due to dissolution of carbon dioxide from the air which makes the DIW slightly acidic. For cement waste forms, the initial pH of the leachant is not maintained since dissolution of soluble material from the cement matrix, primarily calcium hydroxide, shifts the pH higher. To investigate the effect of leachant $\mathrm{pH}$, initial $\mathrm{pH}$ values of 4 and 8 were compared with the nominal leaching results obtained in DIW at $\mathrm{pH} 6$. The results for Cs-137 and Sr-85 are shown in Figures 5.25 to 5.28.

Figure 5.25 indicates that the leachability of Cs-137 decreases as initial leachant $\mathrm{pH}$ values were made more acidic and more basic than the nominal pH of 6 for DIW. The apparent decrease in Cs-137 leachability with both decreased and increased leachant $\mathrm{pH}$ may be due to the increased ionic strength of the leachant solutions at $\mathrm{pH}$ values other than 6 , as is clear in the linear correlation plot of Figure 5.26. Changing the leachant pH was not promising as an accelerating factor for $\mathrm{Cs}-137$, so the experiments were not pursued.

Figure 5.27 shows the results of changing initial leachant pH on $\mathrm{Sr}-85$ leaching for the portland I cement waste forms containing 15 wto incinerator ash. There is an apparent decrease in leachability, which is clearer in the linear correlations plotted in Figure 5.28. These correlations show that acidic leachants are not useful for accelerating $\mathrm{Sr}-85$. The alkaline solution $(\mathrm{pH}=8)$ severely decreases leaching of $\mathrm{Sr}-85$, probably due to formation of carbonates.

No measurable Co-57 activity above background was leached from the waste forms containing incinerator ash in any of these experiments.

As described in Section 5.2.1, the leaching of sodium, potassium, calcium and strontium was measured from nonradioactive "Blank" portland I cement waste forms containing 15 wt incinerator ash. However, since changing the initial. leachant $\mathrm{pH}$ was not an accelerating factor for $\mathrm{Cs}-137$ and had only marginal poteitial for $\mathrm{Sr}-85$, no experiments varying the initial leachant $\mathrm{pH}$ were performed on this waste form. 
5.2.5 Leachant Flow Rate or Replacement Frequency. If the buildup of material in the solution affects leachability, then the flow rate or replacement frequency of the leachant is a factor in accelerated test development. The ANS 16.1 leach test provides for daily leachant replacement through day five following replacements at 2 hours and 7 hours the first day. After day five the leachant replacement intervals are much longer. To investigate the effect of continuous leachant flow versus periodic replacement the portland I cement waste forms containing $15 \mathrm{wt}$ incinerator ash were leached using a flow experiment based on the MCC4S flow test, described in the Material and Methods section 2.3 .3 .

Figure 5.2 shows the release rates of $\mathrm{Cs}-137$ leached from portland I cement containing 15 wto incinerator ash versus time are shown in Figure 5.29. The release rates from cement containing incinerator ash from the modified ANS 16.1 testing procedure are shown for comparison. The release rates from both experiments were very similar, but there is greater scattering in the flow experiment data. No useful degree of acceleration in the leach rates were observed.

The release rates of Sr-85 leached from portland I cement containing 15 wto incinerator ash versus time are shown in Figure 5.30. The release rate results from the modified ANS 16.1 procedure are also shown for comparison. The $\mathrm{Sr}-85$ release rates are generally an order of magnitude lower than those for Cs-137. The Sr-85 results for the flow test and modified ANS 16.1 are very similar, with a greater degree of scattering in the flow test data. No useful degree of accelerated leaching was observed for Sr-85 by the flow test.

No measurable Co-57 activity above background was leached from the portland I cement waste forms containing 15 wto incinerator ash. No experiments with continuously flowing leachant were performed to measure the release of nonradioactive elements.

\subsubsection{Composition of the Waste Form. Incinerator ash forms voids on} solidification of portland I cement waste forms [28] when the waste form cures by dehydration of the ash and water slurry during the solidification. Interaction of the ash and the cement does not appear to affect the leaching properties of the cement matrix at room temperature. No adverse affects on the physical integrity of the waste forms were observed after 320 days of leaching in deionized water. Figure 5.31 shows a waste form sample of portland I cement containing $15 \mathrm{wt}$ incinerator ash before and after 320 days of leaching in deionized water at $20^{\circ} \mathrm{C}$ : no changes were apparent, except for a darkening in color.

Radionuclide releases from cement containing 15 wto incinerator ash are shown in Figure 5.32, for triplicate specimens. Variability between the samples was small ( $<58$ at the 45 days). The leaching data for cement containing incinerator ash was compared to the results for neat cement. Up to 100 days the cement waste containing incinerator ash specimens leached faster. After 100 days Cs-137 leaching decreased for the samples containing incinerator ash waste. At 320 days the average ash sample CFL was 0.61 while that of pure cement was about 0.72 . The scatter of the leaching data from samples with ash was small, with a 958 confidence interval of 3.48 . 
To determine if the leaching mechanism of cement was altered by inclusion of ash waste, the CFL for Cs-137 from samples with waste was plot:ed against the CFL of samples without waste (Figure 5.33). The result is a continuously decreasing curve which is clearly nonlinear, implying that the leaching mechanism of cesium from cement samples containing ash differs from that of the neat cement samples. This difference may be attributed to two properties of the ash: (i) sorption of the radionuclide or (ii) pozzolanic reactions with the cement. The high release rates, compared to Cs-137 releases from neat cement, during the first few weeks of leaching followed by a rapid decrease in the release rate tend to favor the latter interpretation. The porosity of cement and ash specimens appears to be large before leaching as shown in Figure 5.31. How porosity is modified during leaching is under investigation.

The Sr-85 leaching results are shown in Figure 5.34 for triplicate specimens of cement containing 15 wt incinerator ash. Radioactive decay limits the detection of this isotope to about 150 days from specimens without waste, whereas specimens with incinerator ash contained a larger source term and the $\mathrm{Sr}-85$ remained detectable to over 300 days of leaching. Compared with the baseline samples of neat cement these data showed lower leacting with inclusion of the incinerator ash waste. Ideal behavior for waste form leaching controlled solely by diffusion of radionuclides from the matrix would show no difference in the leaching curves. Figure 5.35 is the linear correlation plot of the leaching results for $\mathrm{Sr}-85$ from cement containing incinerator ash compared to the results for neat cement. The curvature of the data for cement containing incinerator ash indicates a departure from ideal behavior. Figure 5.36 shows a linear correlation plot of Sr-85 versus Cs-137 from portland I cement containing 15 wto incinerator ash and neat cement. Why the $\mathrm{S} r-85$ release rate increased while the $\mathrm{Cs}-137$ rate decreased is unclear.

No measurable Co-57 activity was leached from the cement waste forms containing incinerator ash in these experiments.

Figure 5.37 shows the leaching curves of cumulative release (ppm) vs. time for sodium, potassium, strontium and calcium from cement containing 15 wto incinerator ash. The sodium and potassium data are similar, showing "typical" leaching curves, i.e., monotonically increasing at a decreasing rate. However, the calcium behaves differently, the releases increasing linearly with time to 320 days.

\subsubsection{Ratio of Volume to Surtace Area in the Waste Form (V/S). As} reviawed in section 2.7, small-scale test specimens, under certain conditions, can be used to accelerate the leaching that would be expected from full-scale waste forms. There are data that support the use of small-scale test samples to accelerate leaching from cement waste forms containing various types of bulk waste, including incinerator ash $[19,20,22]$. The ANS 16.1 leach test specifies that the sample must have minimum dimensions of one $\mathrm{cm}$. Experiments were performed using small-scale samples of various sizes to evaluate decreasing size (i.e., decreasing $V / S$ ) as an accelerating factor and to determine how 
small the samples can be and still produce reliable data. These results for Cs-137 and Sr-85 leaching from portland I cement waste forms containing 15 wto incinerator ash are shown in Figures 5.38 to 5.39 .

The Cs $-13 \%$ leaching results shown in Figure 5.38 indicate that leachability increases as $\mathrm{V} / \mathrm{S}$ decreases. The increase in $\mathrm{Cs}-137$ leachability with decreasing $\mathrm{V} / \mathrm{S}$ appears to saturate, or become ineffective, as $\mathrm{V} / \mathrm{S}$ falls below approximately 0.6 , since there is no significant difference between the samples at $V / S$ values of 0.61 and 0.42 . Samples with a $V / S$ ratio of 0.61 were disks that are expected to deplete more rapidly than right cylinders.

However, the difference in aspect ratio of the disk may make this data misleading. The scattering in the data for the cylindrical samples with a $\mathrm{V} / \mathrm{S}$ of 0.91 was appreciably better. A linear correlation plot is shown in Figure 5.39 .

Figure 5.40 shows the results of changing the ratio of volume to surface area $(\mathrm{V} / \mathrm{S})$ on $\mathrm{Sr}-85$ leaching for waste forms containing 15 wto incinerator ash. There is an increase in leachability of $\mathrm{Sr}-85$, which is more apparent in the linear correlations plotted in Figure 5.39. These correlations show that decreasing $V / S$ may be useful for accelerating $\mathrm{Sr}-85$ leaching, since the plots at $V / S$ values of 0.91 remain linear over the course of the experiments while those at $V / S$ values of 0.61 and 0.42 remain linear until the samples are affected by carbonation. A linear correlation plot for Sr-85 is shown in Figure 5.41 .

No measurable Co-57 activity above background was leached from these cement waste forms in any of these experiments.

5.2.8 Surface Condition and Porosity. No quantitative information is available regarding porosity in cement specimens containing incinerator ash. However, one unleached specimen was sectioned and micrographs were made by SEM (Figures 5.42 and 5.43 , magnification of 49 -fold). Large voids are characteristic of this material. The ash itself is often a large sponge-1ike particle which is more porous than the cement. Voids seem to form around the edges of the ash, perhaps due to generation of gas or differential sorption of water during mixing. No EDS analysis was performed because of the heterogeneity of this material. 


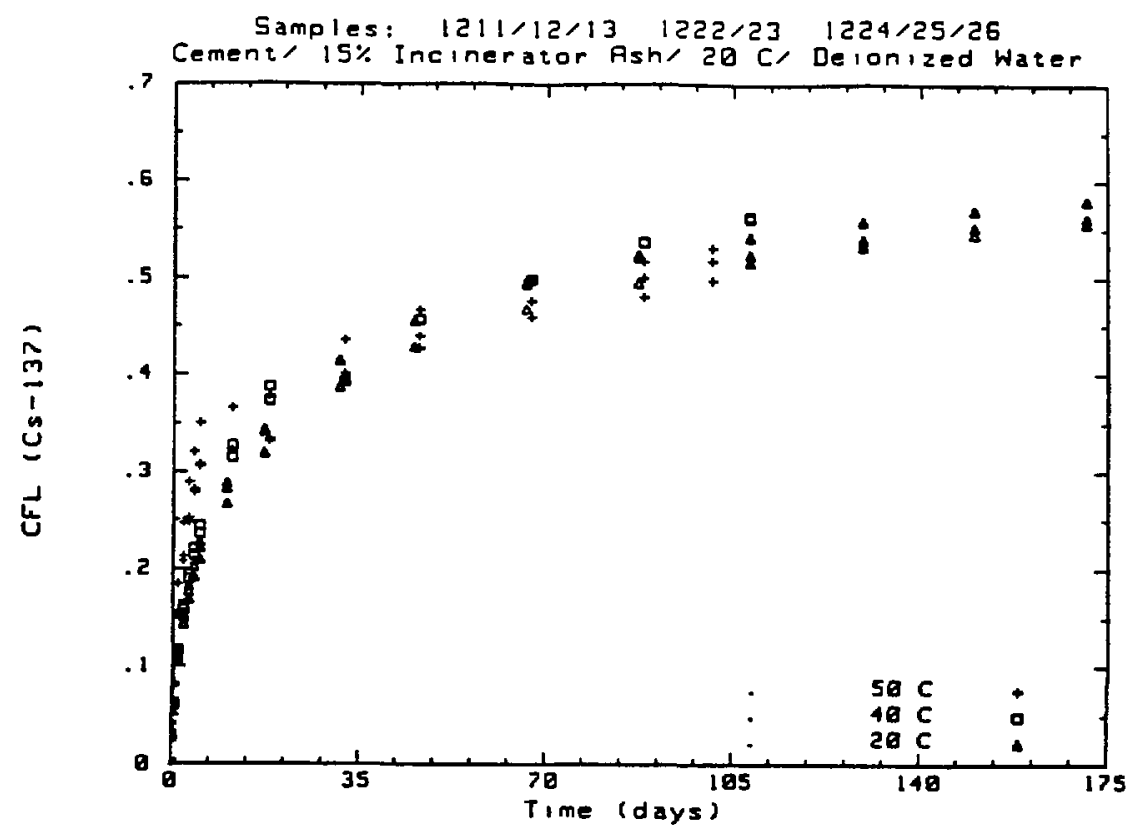

Figure 5.1

Cs-137 cumulative fraction leached vs. tine fron portland I cement containing 15 wt incinerator ash at 20,40 and $50^{\circ} \mathrm{C}$ in delonized water.

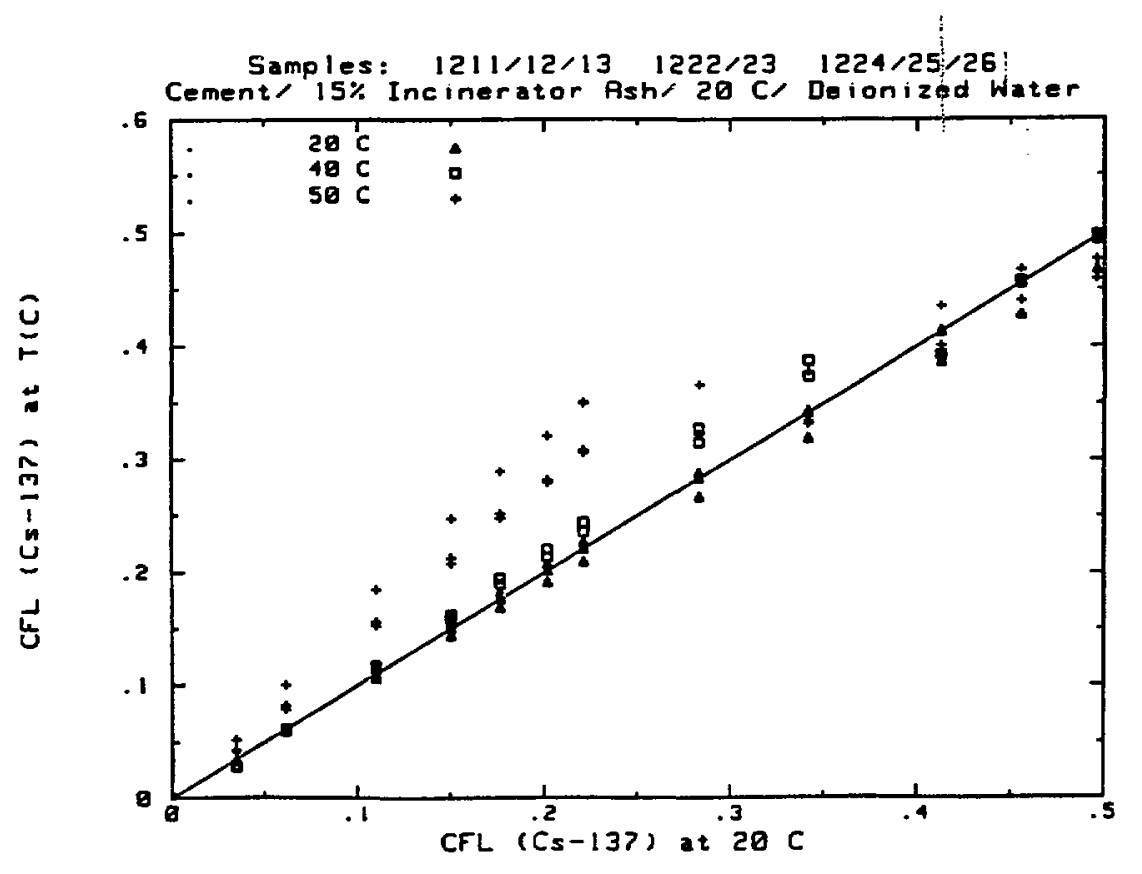

Figure 5.2

Linear correlation plots for Cs-137 leaching at 20, 40 and $50^{\circ} \mathrm{C}$ in deionized water from portland $\mathrm{I}$ cement containing 15 wt incinerator ash. Correlations are relative to the $20^{\circ} \mathrm{C}$ data. 


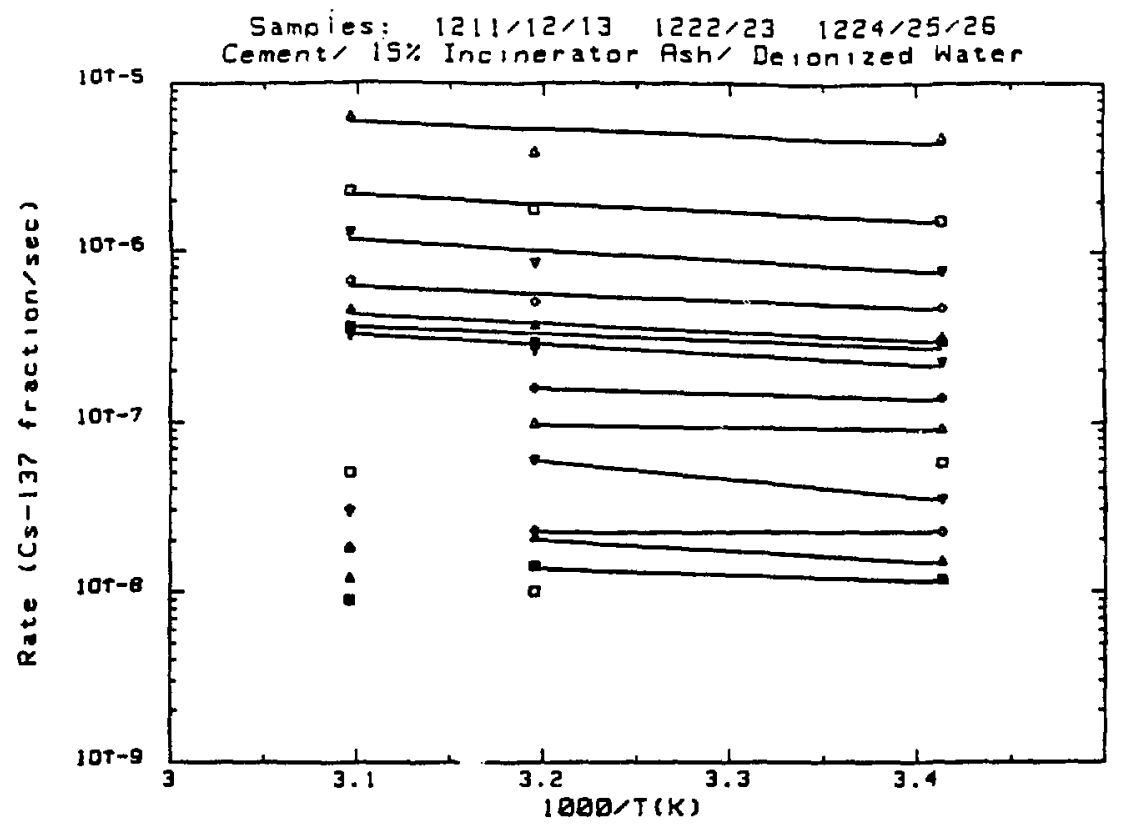

Figure 5.3 Arrhenius plot of Cs-137 incremental leach rates from portland I cement containing 15 wto incinerator ash leached at 20,40 and $50^{\circ} \mathrm{C}$ in deionized water.

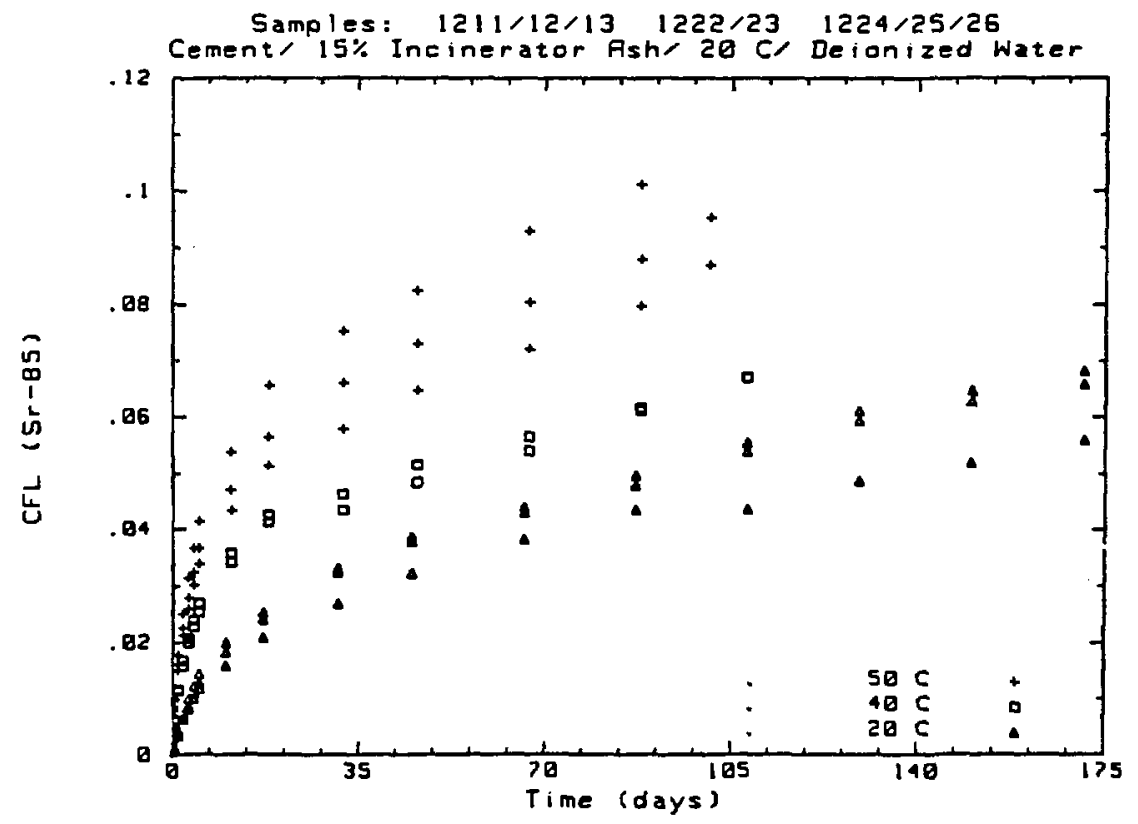

Figure 5.4 Sr-85 cumulative fraction leached vs. time from portland I cement containing 15 wto incinerator ash at 20,40 and $50^{\circ} \mathrm{C}$ in deionized water. 


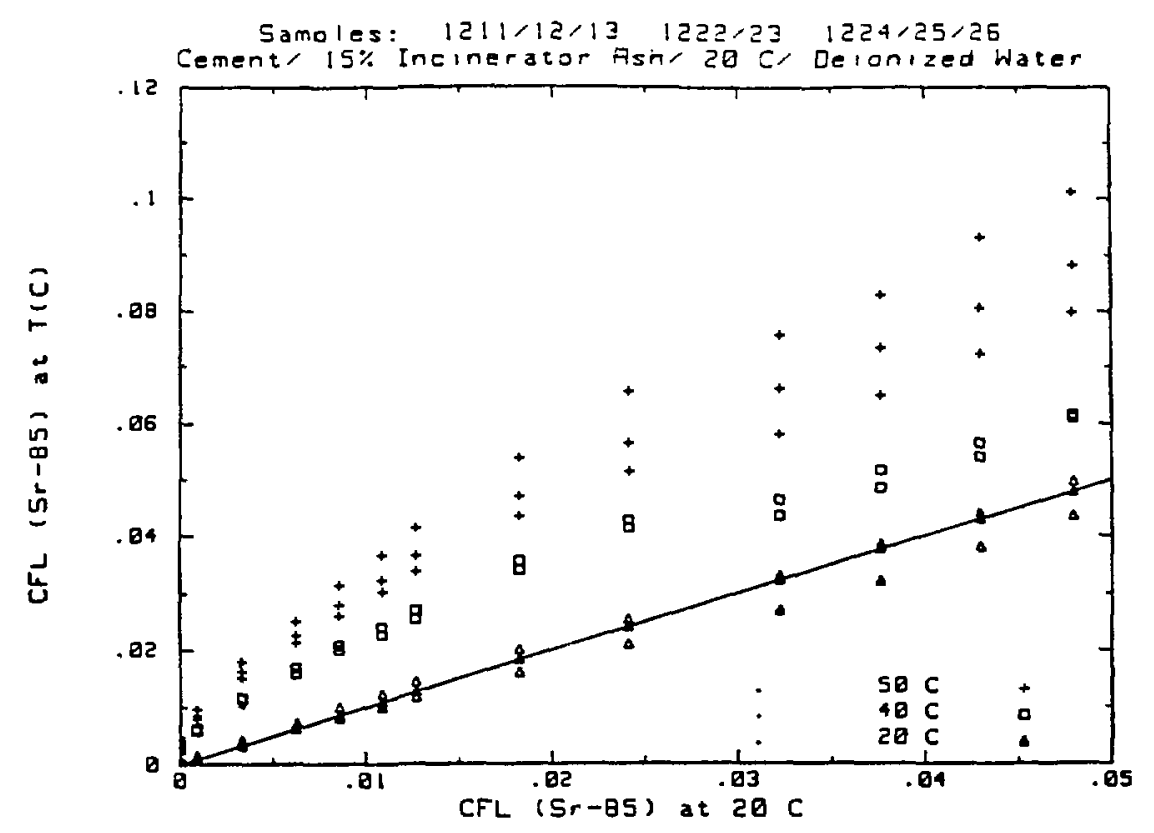

Figure 5.5

Linear correlation plots for $S r-85$ leaching at 20,40 and $50^{\circ} \mathrm{C}$ in deionized water from portland $\mathrm{I}$ cement containing 15 wt incinerator ash. Correlations are relative to the $20^{\circ} \mathrm{C}$ data.

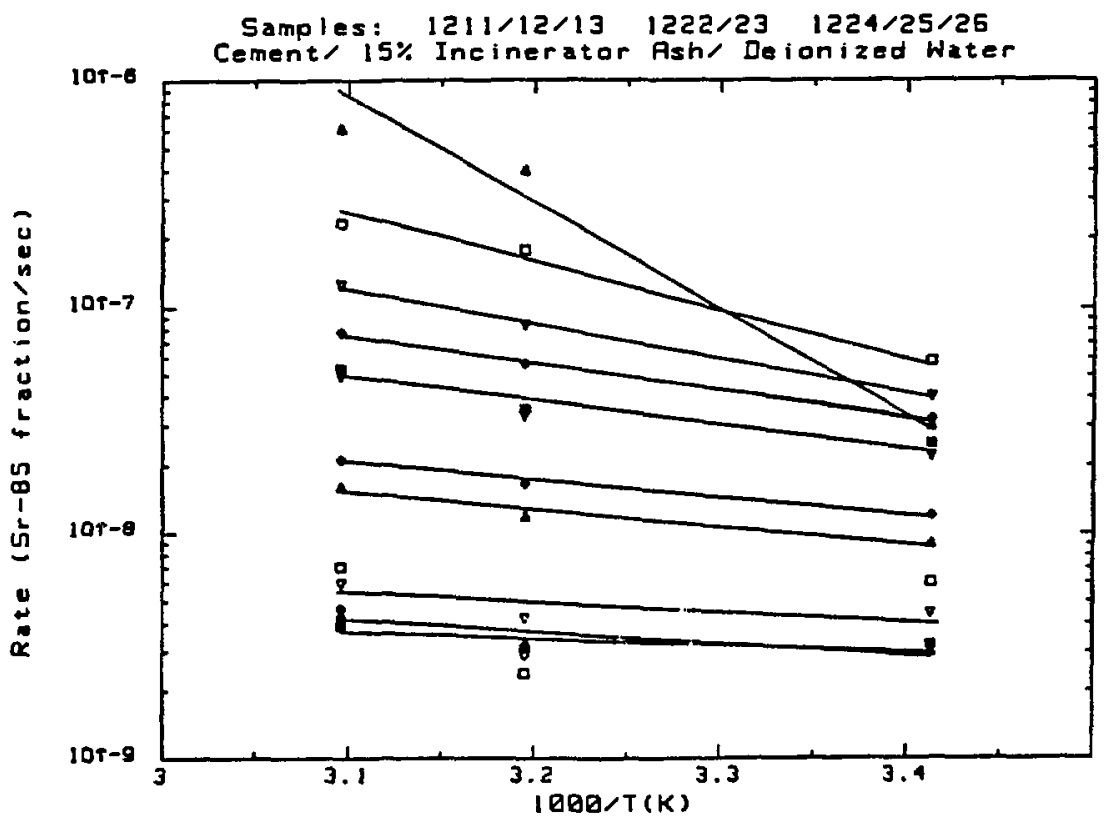

Figure 5.6

Arrhenius plot of Sr-85 incremental leach rates from portland I cement containing 15 wt incinerator ash leached at 20,40 and $50^{\circ} \mathrm{C}$ in deionized water. 


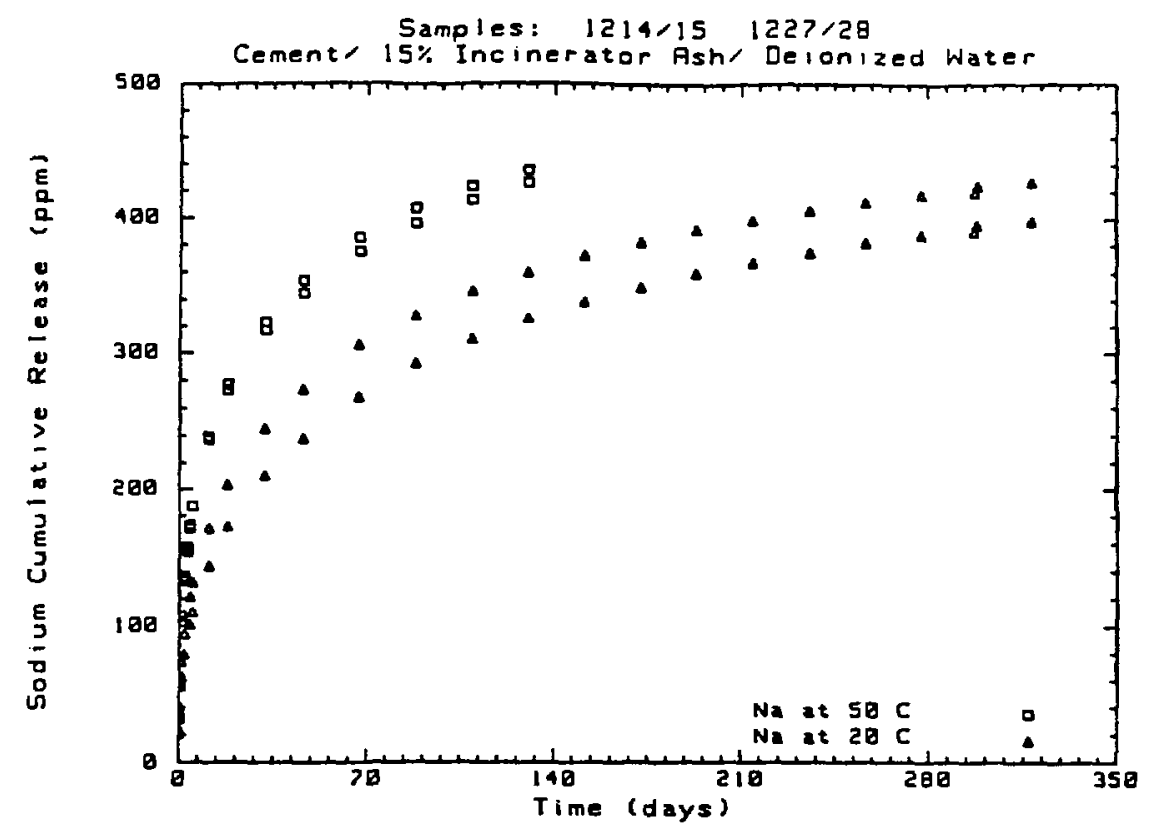

Figure 5.7

Sodium cumulative amount leached (ppm) vs. time from portland I cement containing 15 wt incinerator ash at 20 and $50^{\circ} \mathrm{C}$ in deionized water.

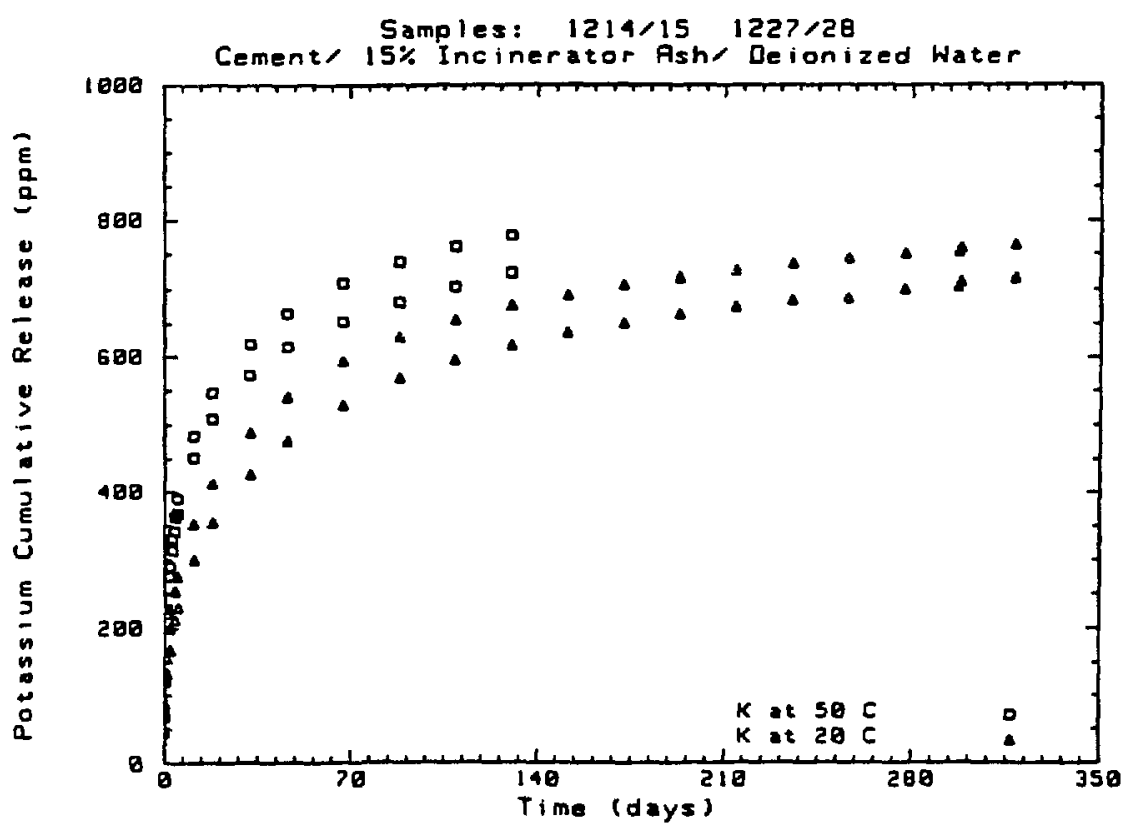

Figure 5.8

Potassium cumulative amount leached (ppm) vs. time from portland I cement containing $15 \mathrm{wt}$ incinerator ash at 20 and $50^{\circ} \mathrm{C}$ in deionized water. 


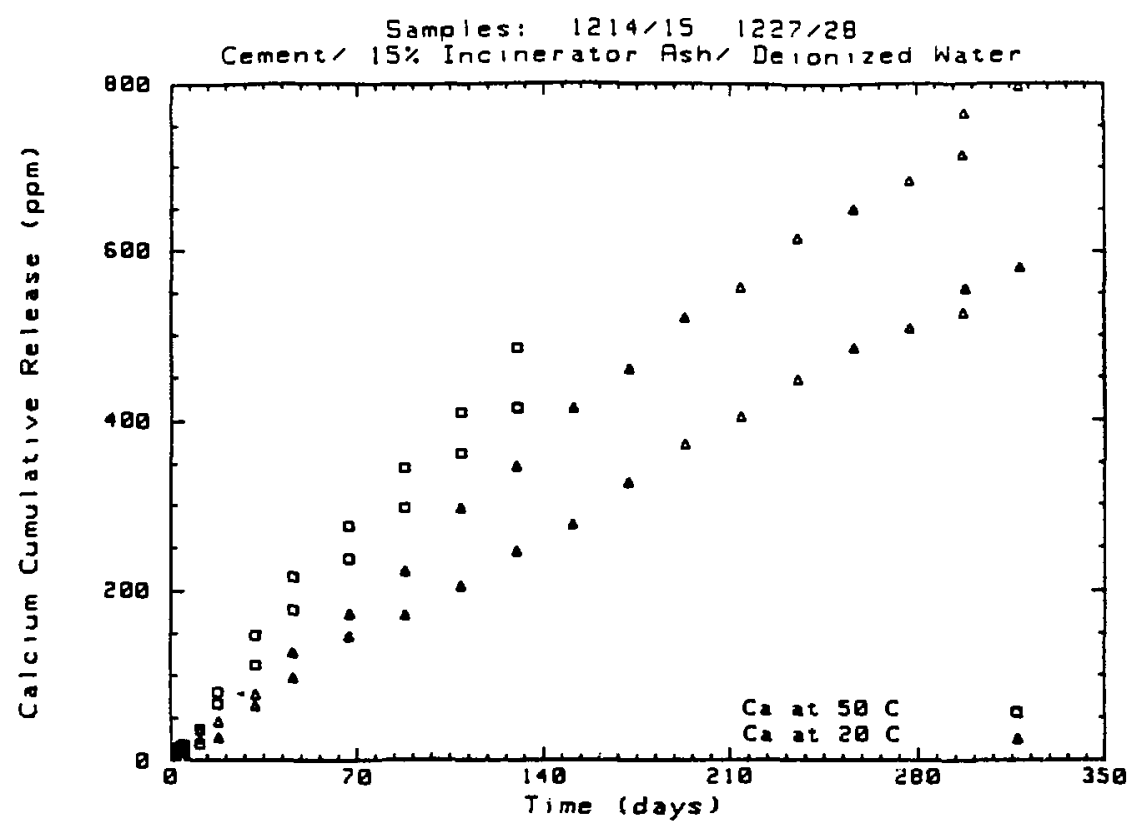

Figure 5.9

Calcium cumulative amount leached (ppm) vs. time from portland I cement containing 15 wto incinerator ash at 20 and $50^{\circ} \mathrm{C}$ in deionized water.

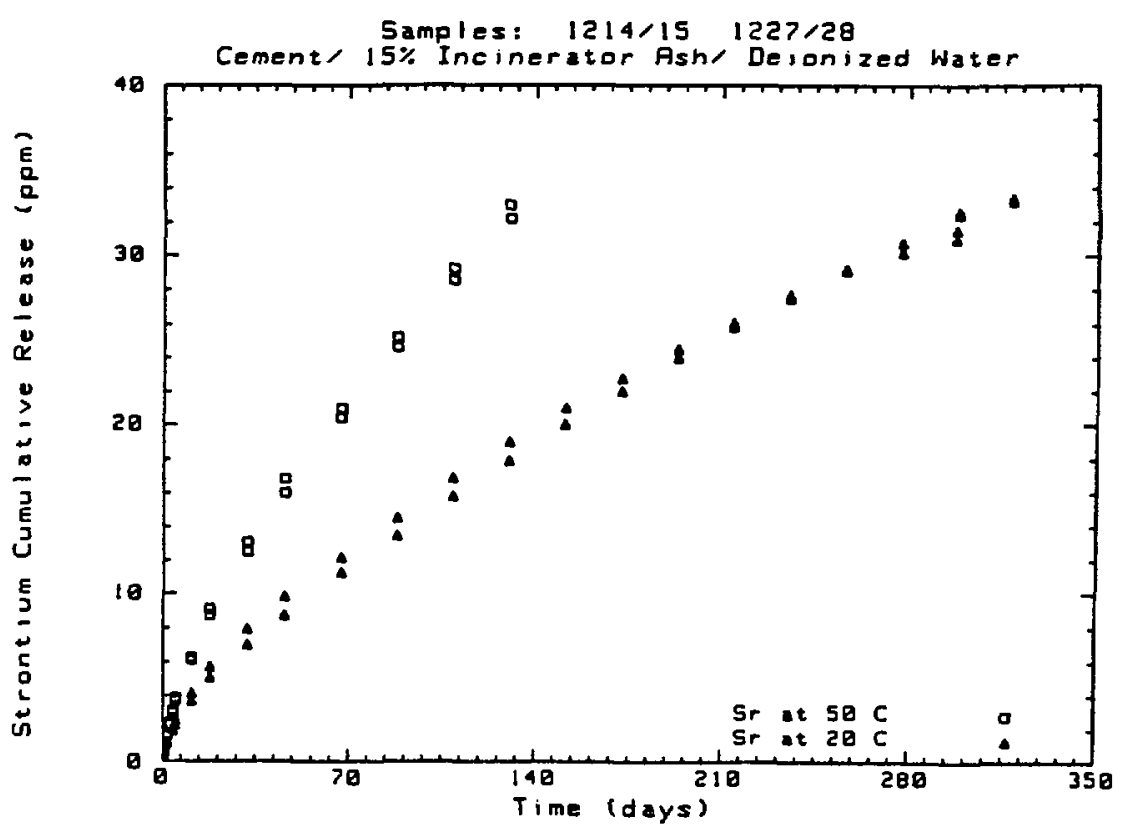

Figure 5.10

Strontium cumulative amount leached (ppm) vs. time from portland I cement containing 15 wtz incinerator ash at 20 and $50^{\circ} \mathrm{C}$ in deionized water. 


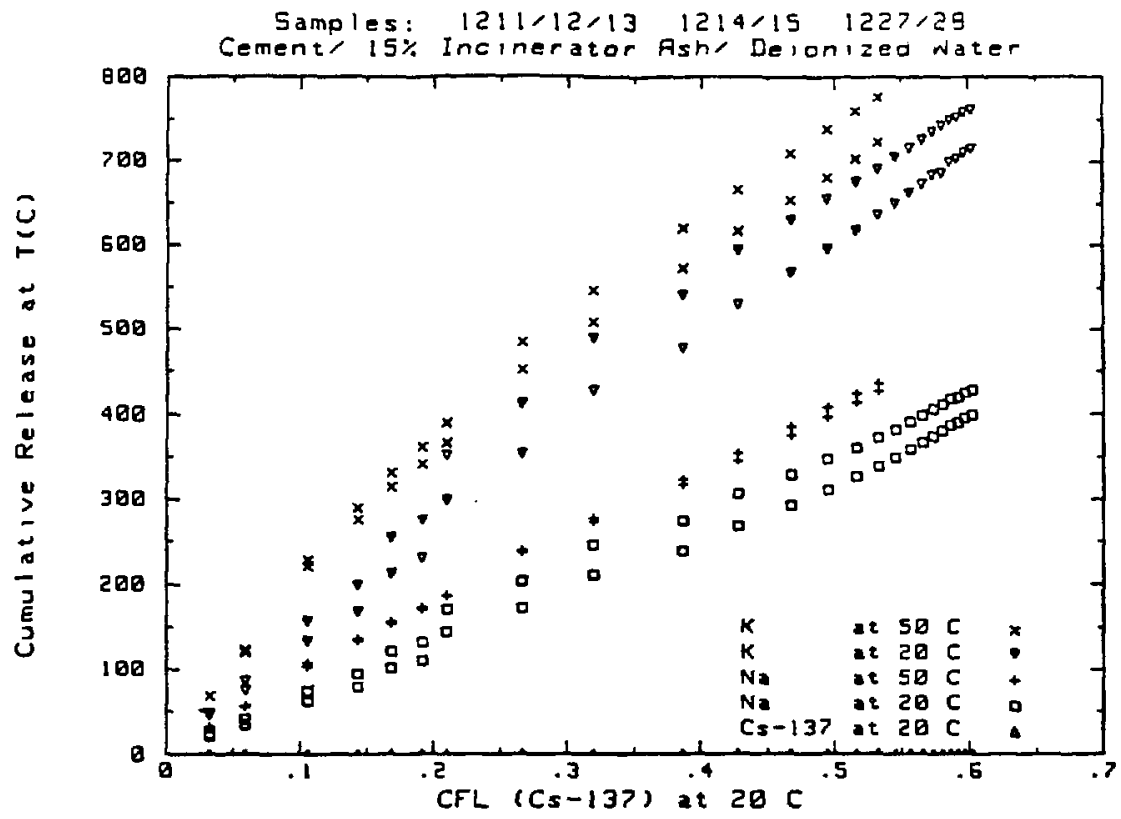

Figure 5.11

Linear correlation plots for Sodium, Potassium and $\mathrm{Cs}-137$ leaching at 20 and $50^{\circ} \mathrm{C}$ in deionized water from portland $I$ cement containing 15 wto incinerator ash. Correlations are relative to the Cs-137 data.

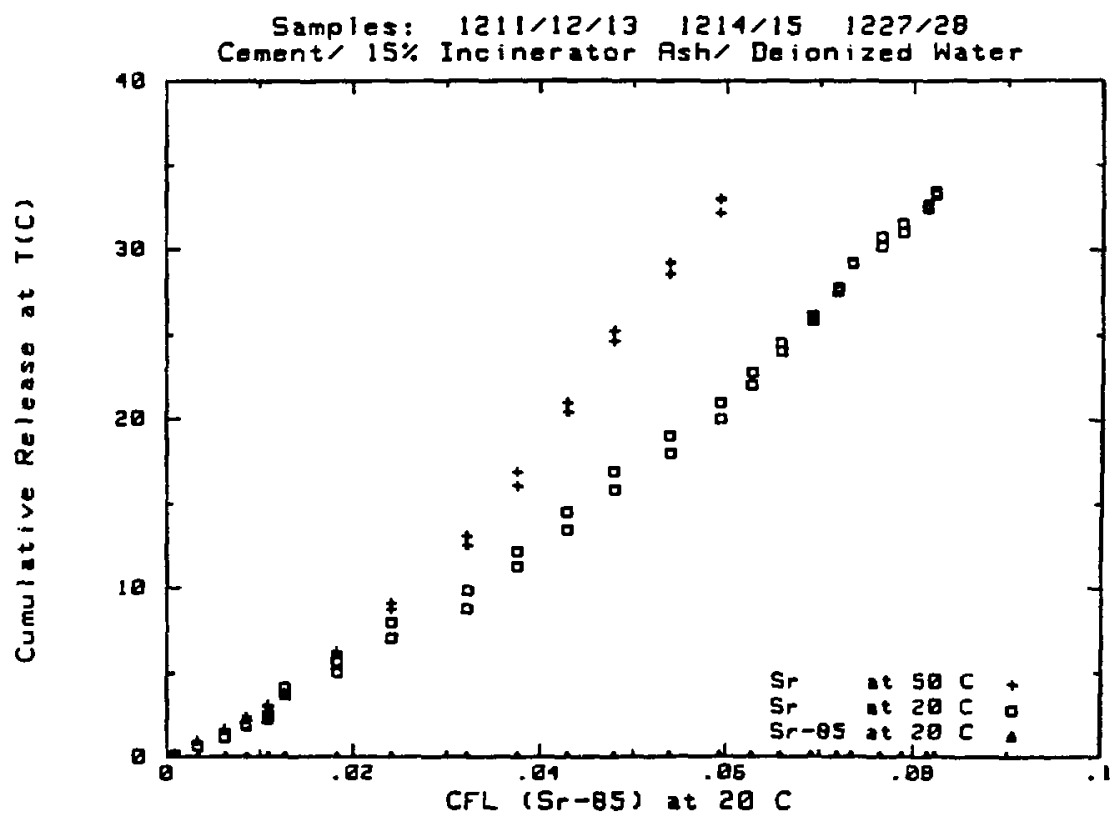

Figure 5.12

Linear correlation plots for Strontium and Sr-85 leaching at 20 and $50^{\circ} \mathrm{C}$ in deionized water from portland I cemert containing 15 wto incinerator ash. Correlations are relative to the $\mathrm{Sr}-85$ data. 


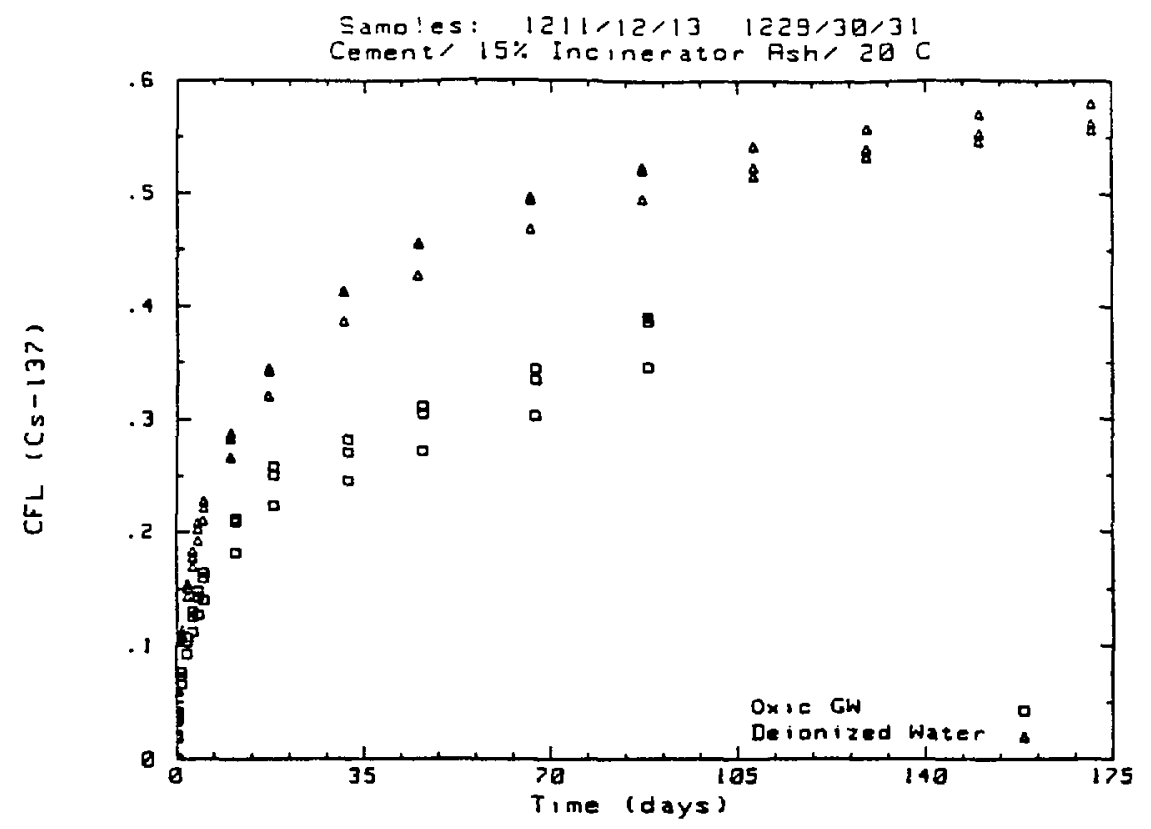

Figure 5.13

Cs-137 cumulative fraction leached vs, time from portland I cement containing 15 wt incinerator ash leached in DIW and oxic ground water at $20^{\circ} \mathrm{C}$.

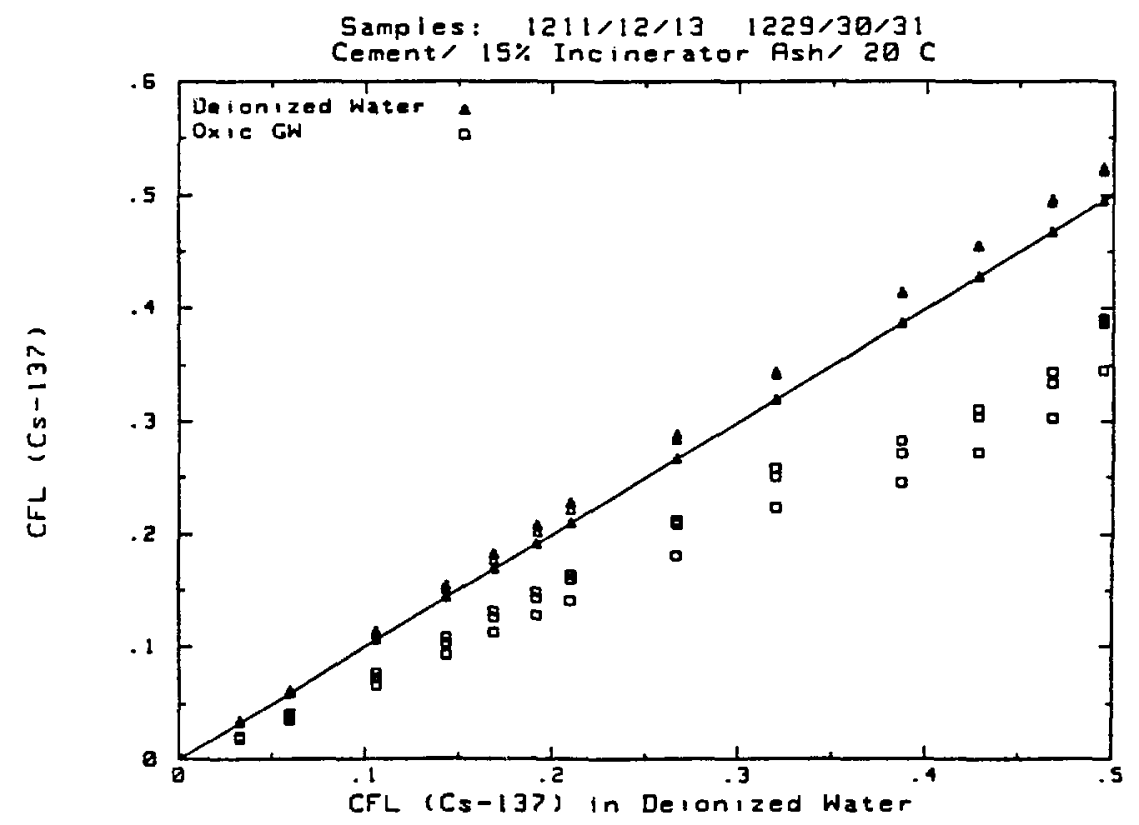

Figure 5.14

Linear correlation plots for Cs-137 leached at $20^{\circ} \mathrm{C}$ from portland I cement containing 15 wt incinerator ash leached in DIW and oxic ground water. Correlations are relative to the DIW data. 


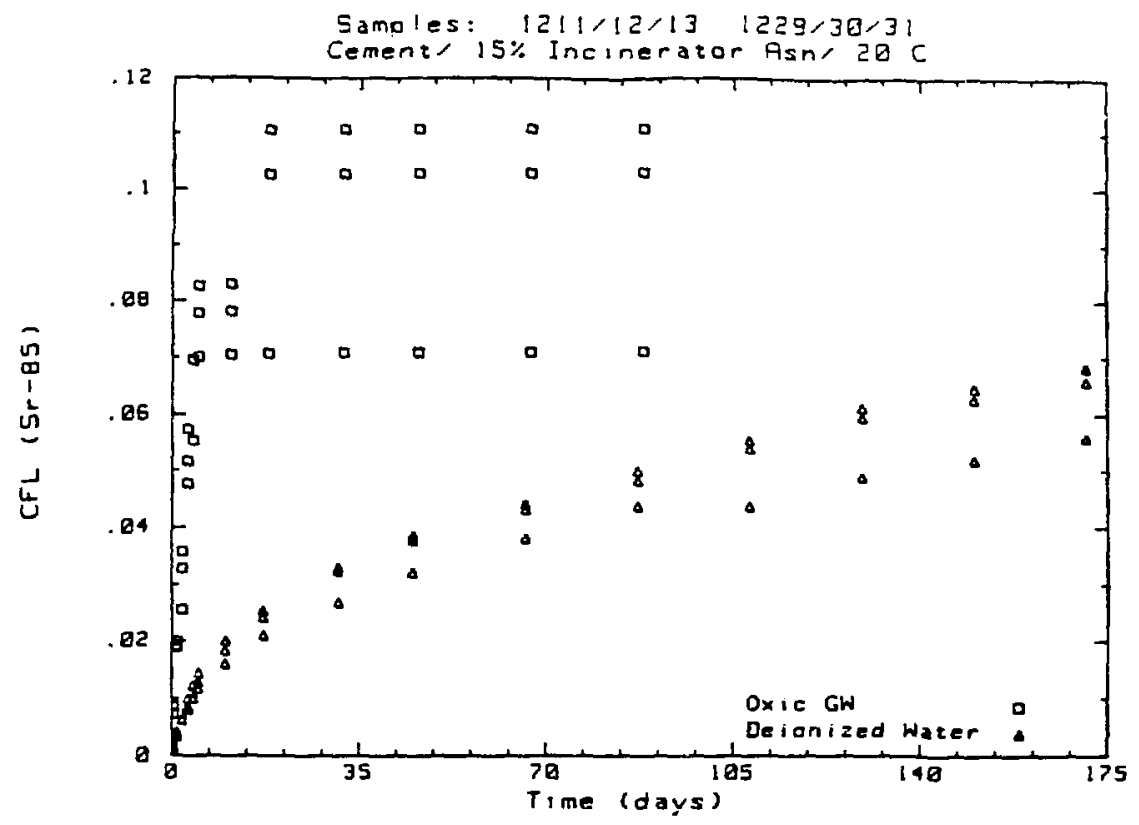

Figure 5.15 Sr-85 cumulative fraction leached vs. time from portland I cement containing 15 wto incinerator ash leached in DIW and oxic ground water at $20^{\circ} \mathrm{C}$.

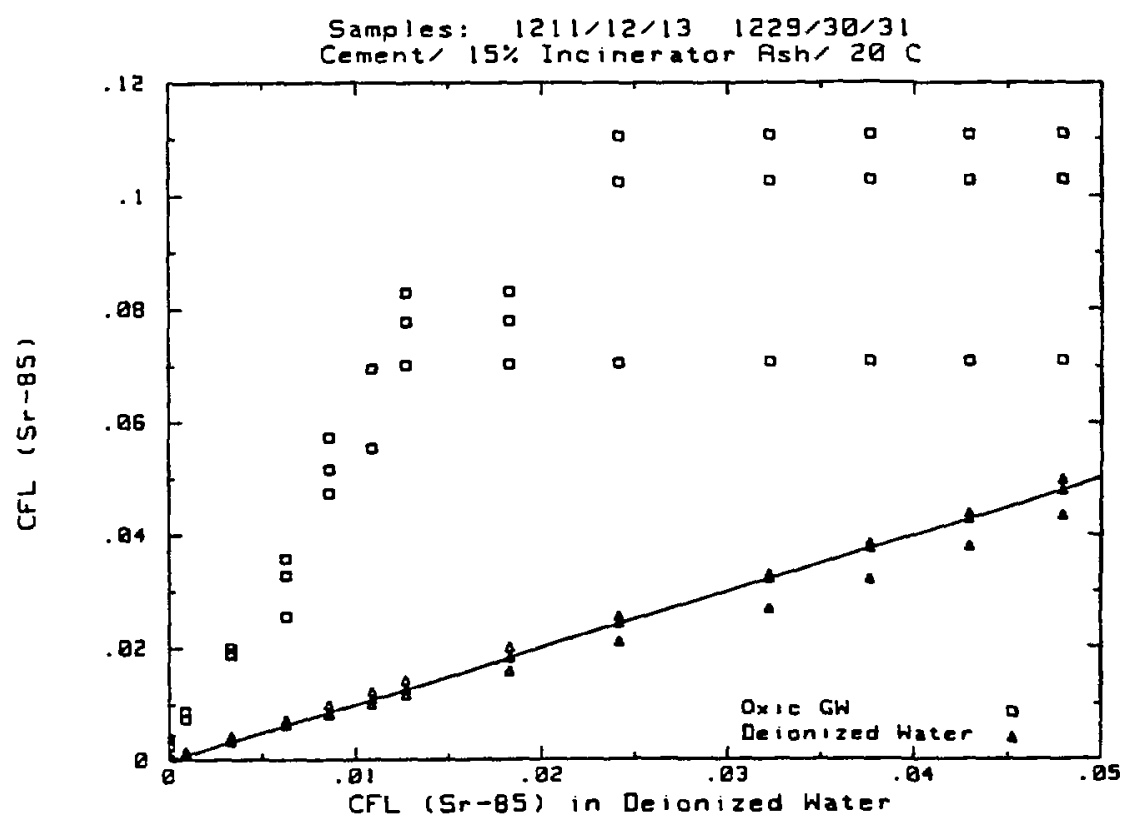

Figure 5.16

Linear correlation plots for Sr -85 leached at $20^{\circ} \mathrm{C}$ from portland I cement containing 15 wto incinerator ash in DIW and oxic ground water. Correlations are relative to the DIW data. 


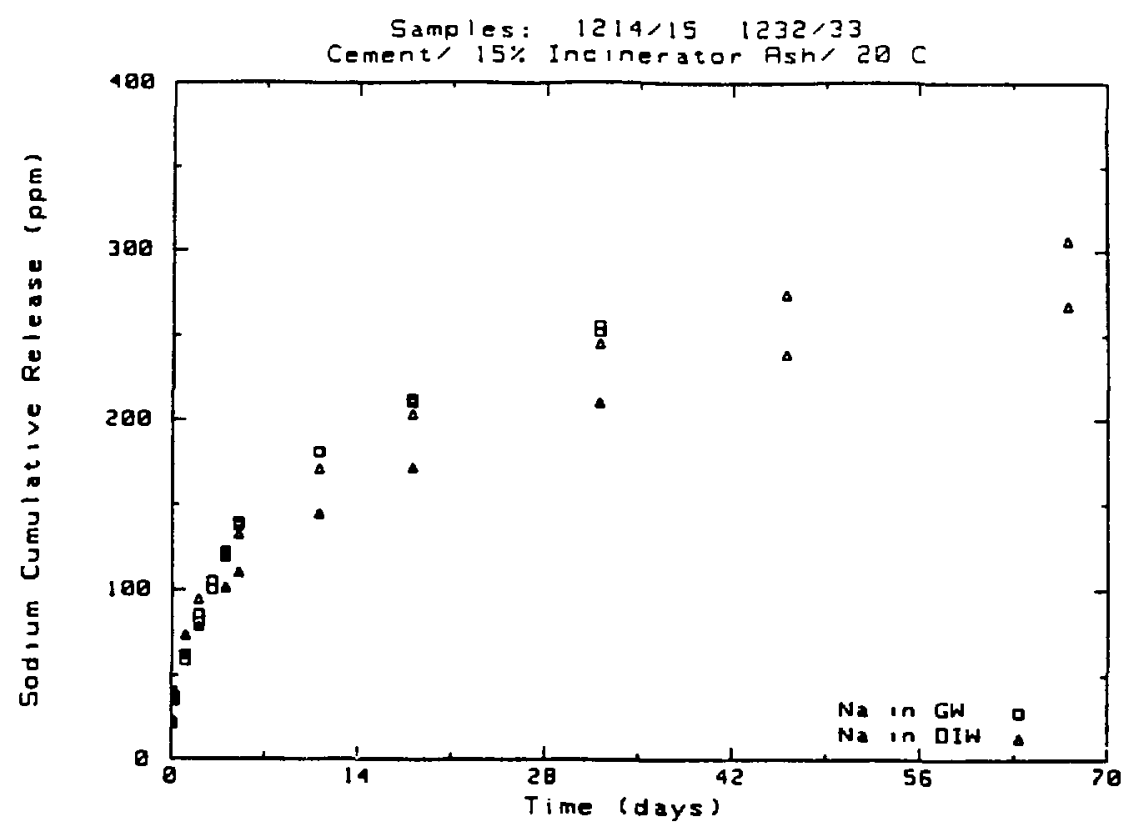

Figure 5.17

Sodium cumulative amount leached (ppm) vs. time from portland I cement containing 15 wt incinerator ash leached in DIW and oxic ground water at $20^{\circ} \mathrm{C}$.

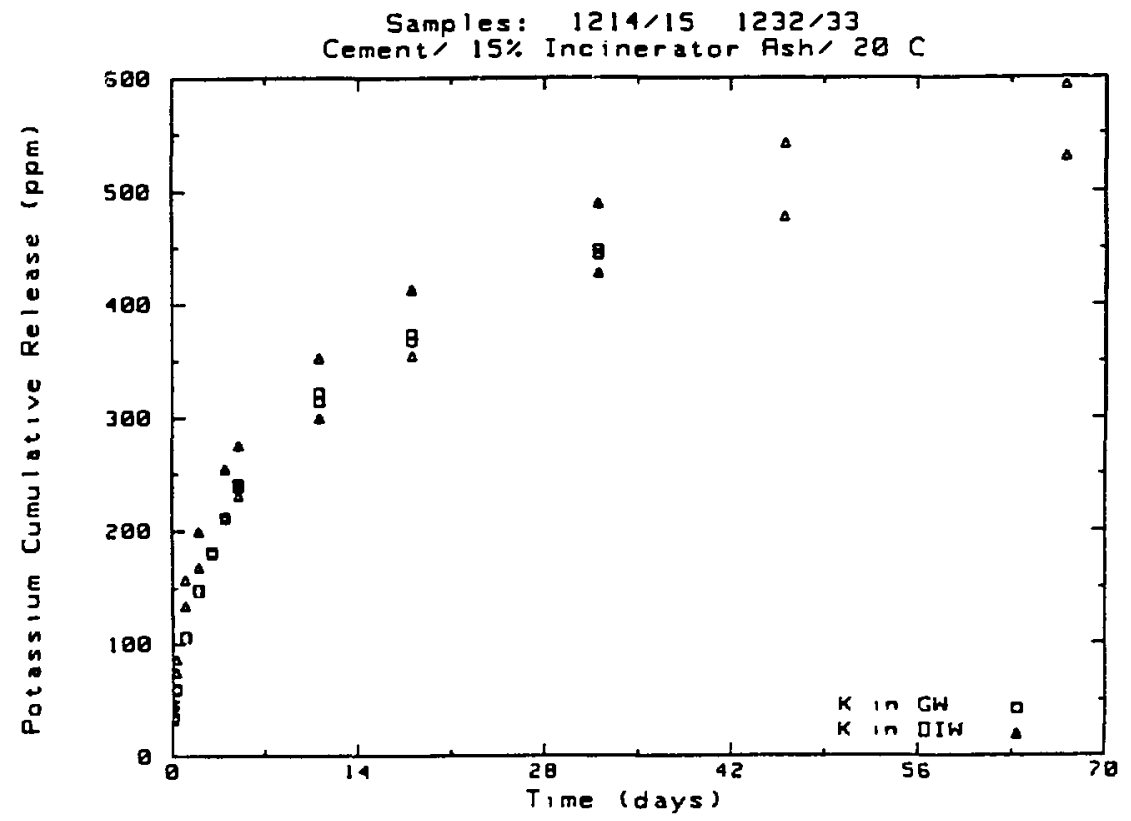

Figure 5.18

Potassium cumulative amount leached (ppm) vs. time from portland I cement containing 15 wto incinerator ash leached in DIW and oxic ground water at $20^{\circ} \mathrm{C}$. 


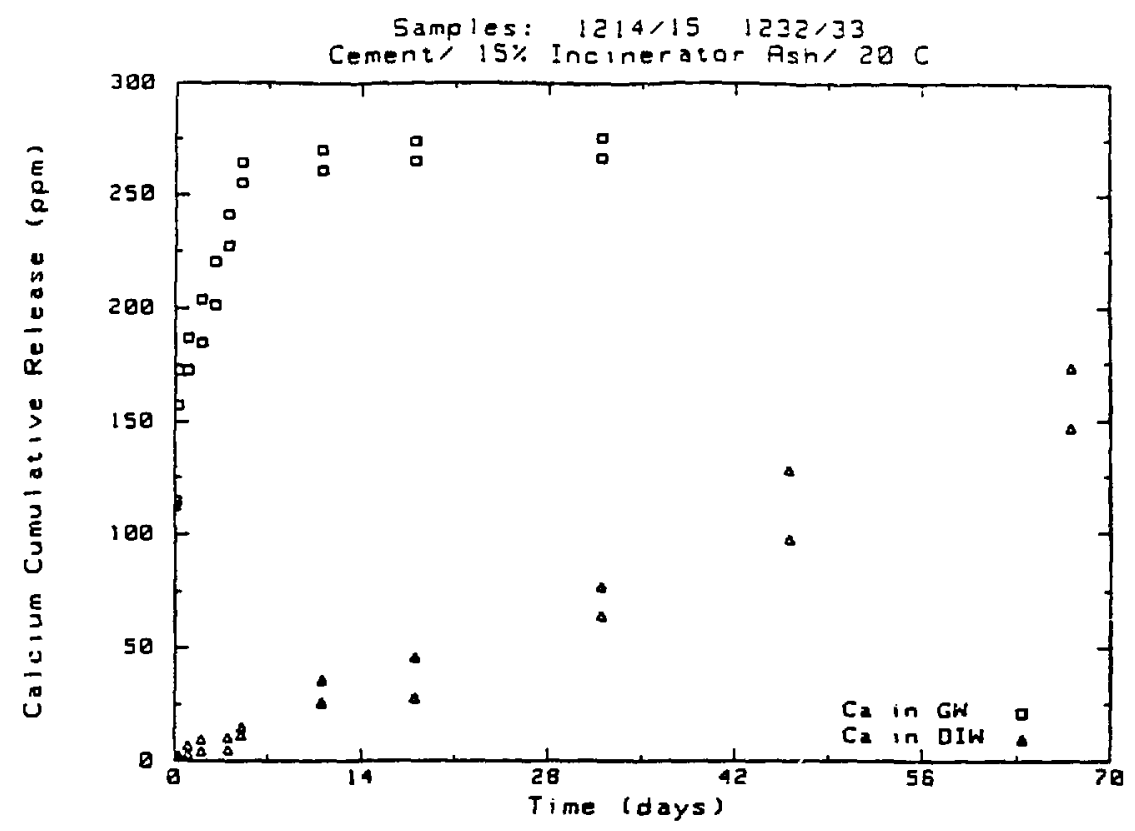

Figure 5.19

Calcium cumulative amount leached (ppm) vs. time from portland I cement containing 15 wts incinerator ash leached in DIW and oxic ground water at $20^{\circ} \mathrm{C}$.

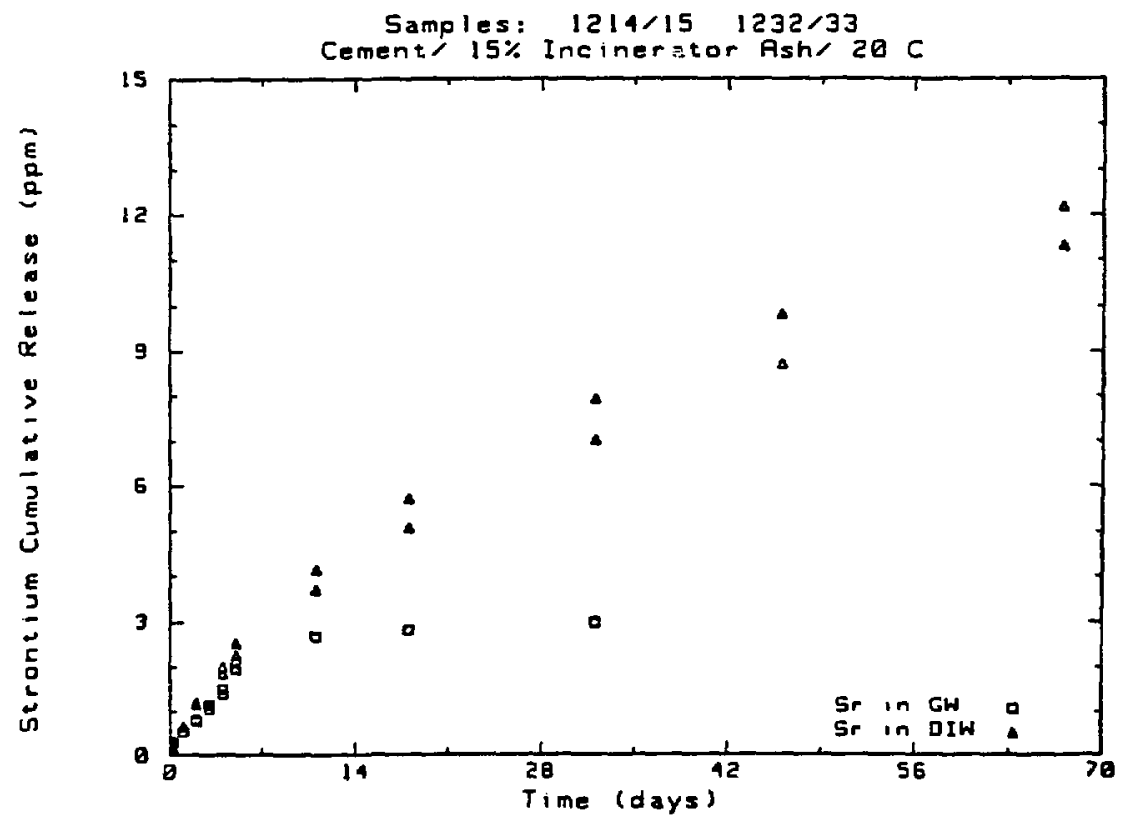

Figure 5.20

Strontium cumulative amount leached (ppm) vs. time from portland I cement containing 15 wto incinerator ash leached in DIW and oxic ground water at $20^{\circ} \mathrm{C}$. 


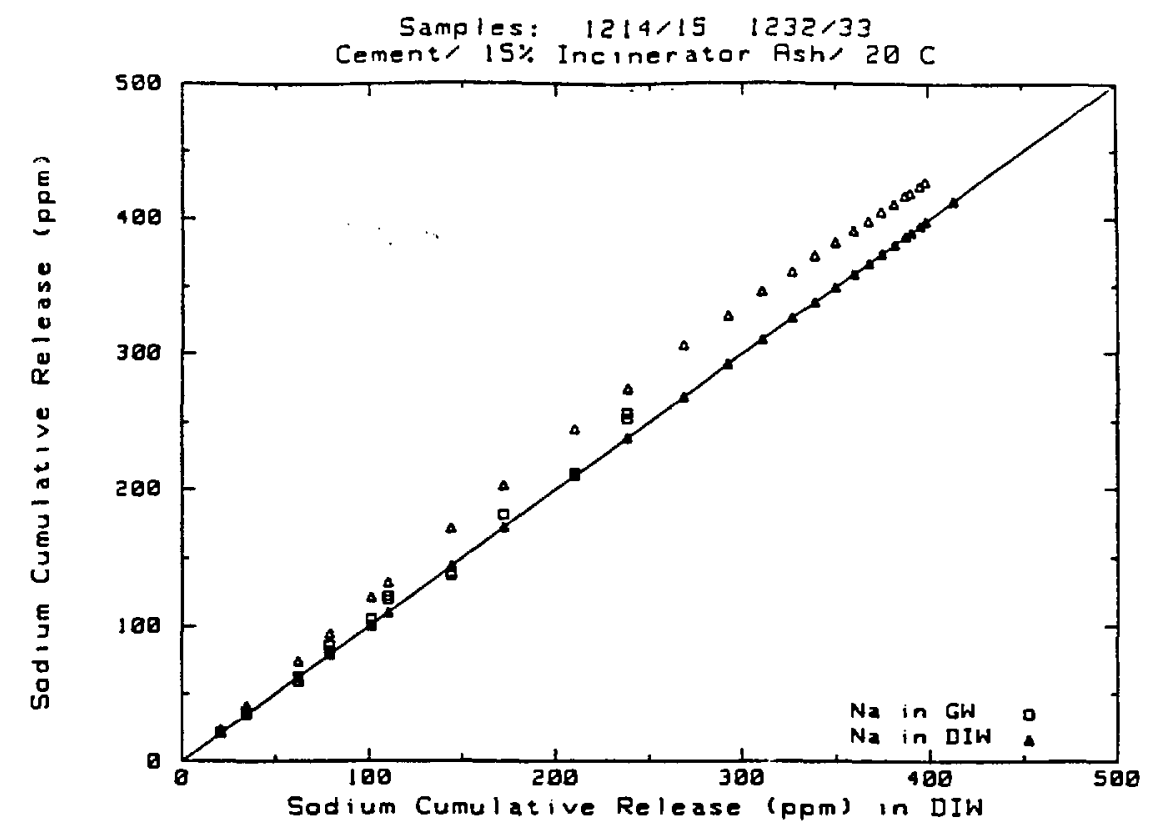

Figure 5.21

Linear correlation plots for Sodium leached at $20^{\circ} \mathrm{C}$ from portland I cement containing 15 wt incinerator ash in DIW and oxic ground water. Correlations are relative to the DIW data.

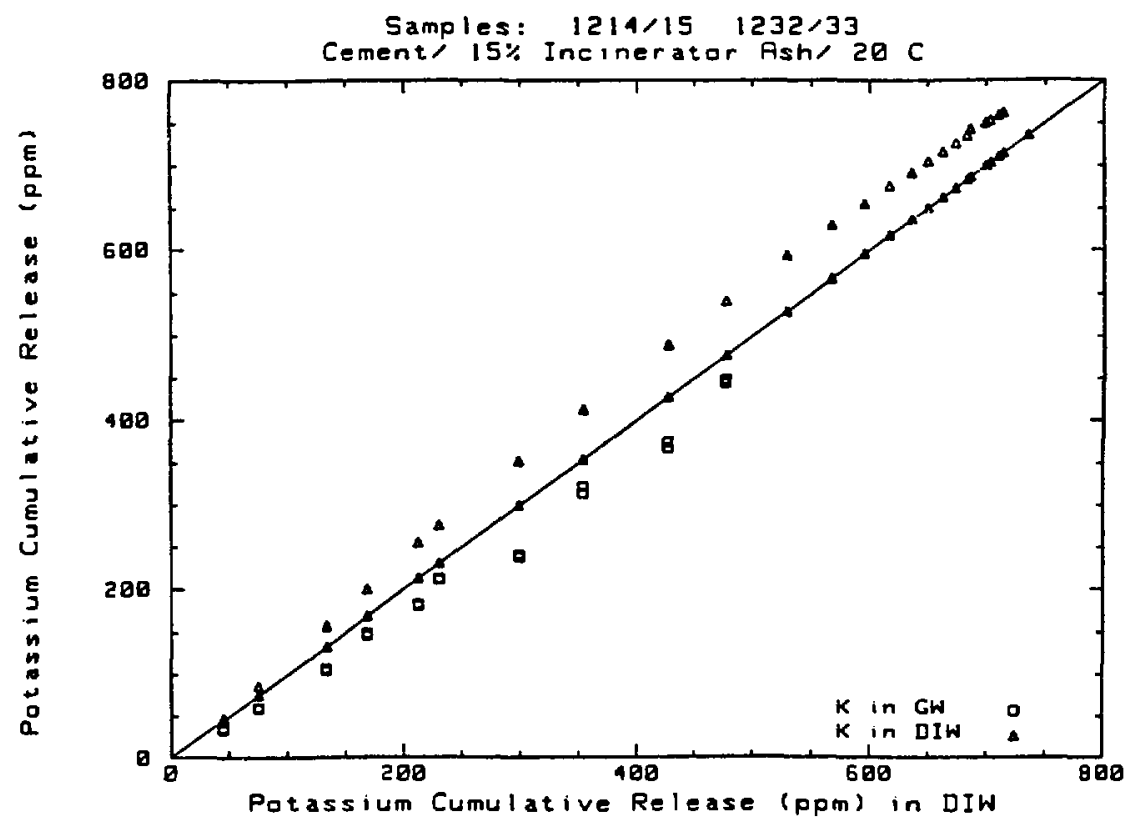

Figure 5.22 Linear correlation plots for Potassium leached at $20^{\circ} \mathrm{C}$ from portland I cement containing 15 wts incinerator ash in DIW and oxic ground water. Correlations are relative to the DIW data. 


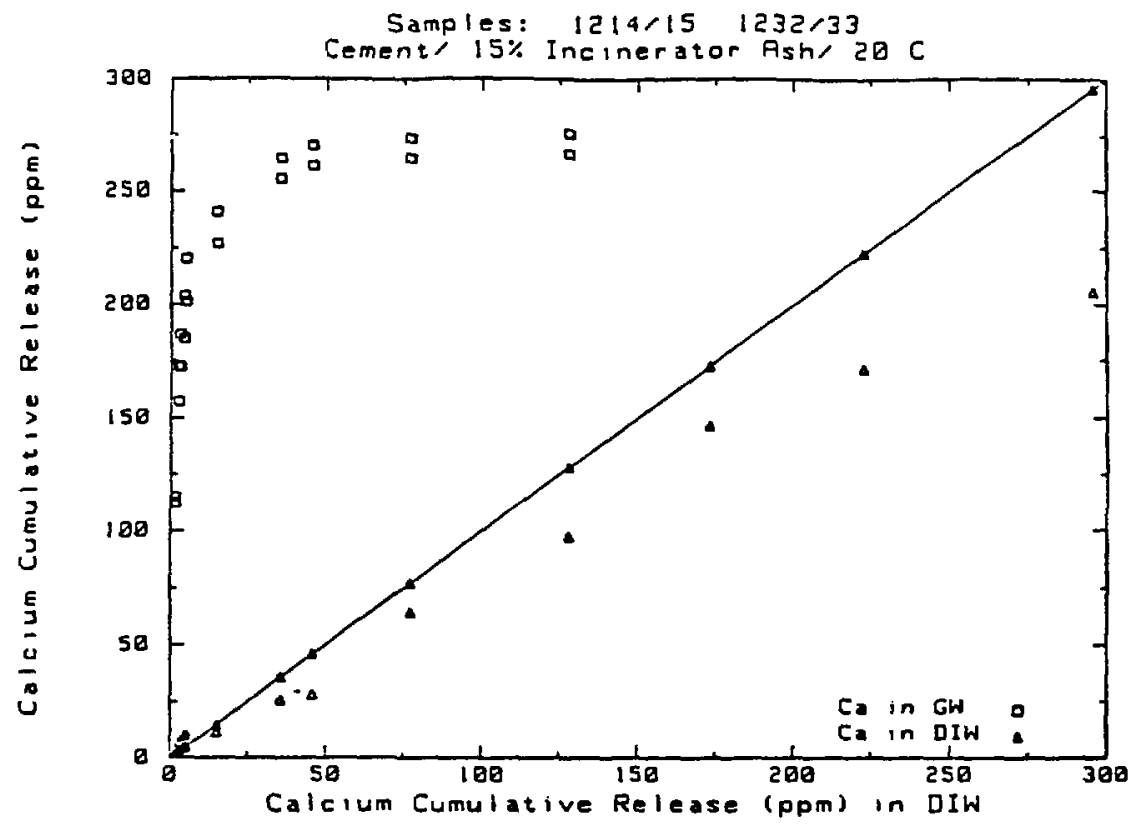

Figure 5.23 Linear correlation plots for calcium leached at $20^{\circ} \mathrm{C}$ from portland I cement containing 15 wt: incinerator ash in DIW and oxic ground water.

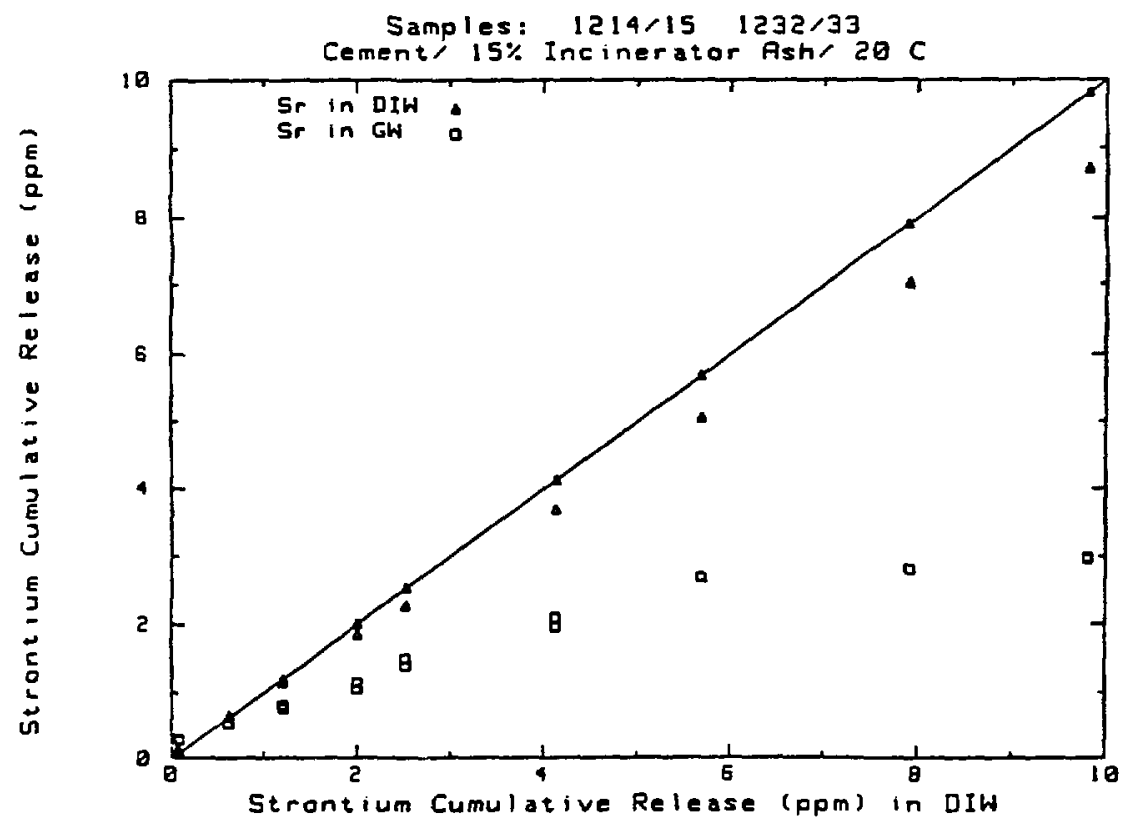

Figure 5.24 Linear correlation plots for strontium leached at $20^{\circ} \mathrm{C}$ from portland I cement containing 15 wto incinerator ash in DIW and oxic ground water. Correlations are relative to the DIW data. 


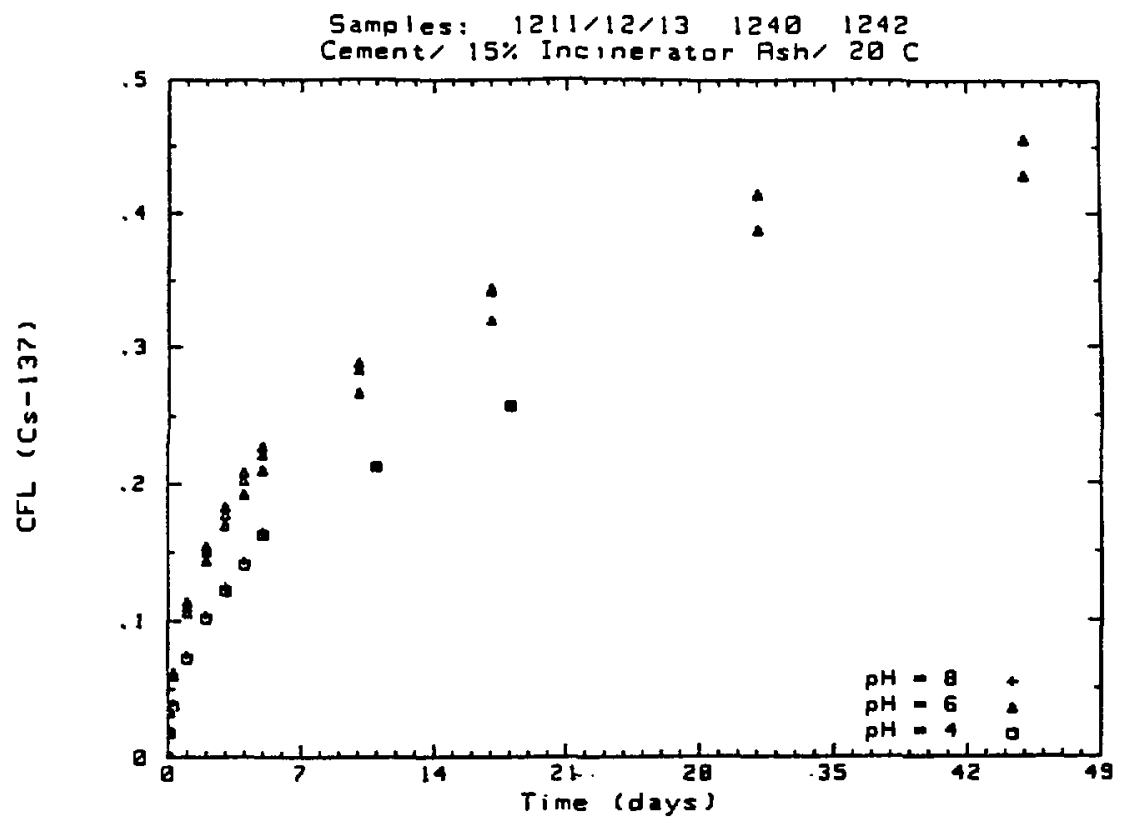

Figure 5.25

Cs -137 cumulative fraction leached vs. time fron portland I cement containing 15 wt incinerator ash leached at $20^{\circ} \mathrm{C}$ in leachants with initial $\mathrm{pH}$ values of 4,6 and 8 .

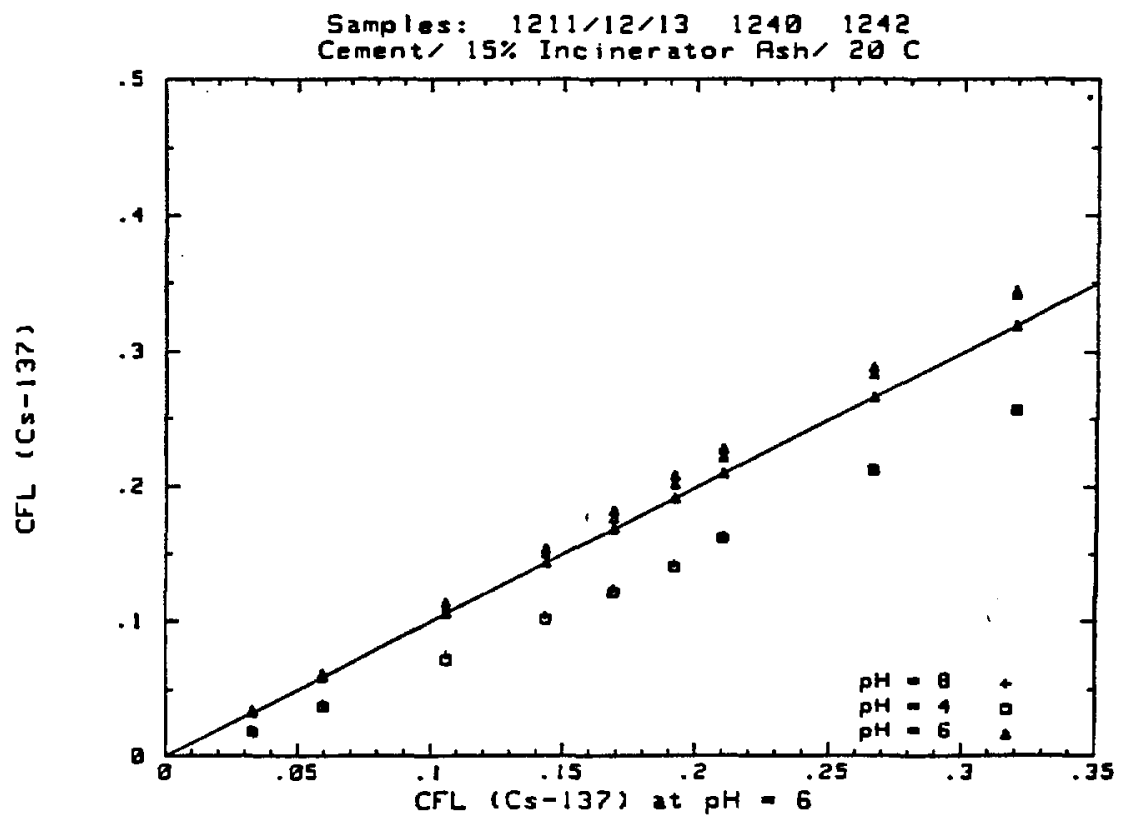

Figure 5.26 Linear correlation plots for Cs-137 leached at $20^{\circ} \mathrm{C}$ from portland I cement containing $15 \mathrm{wt}$ incinerator ash in leachants with initial $\mathrm{pH}$ values of 4,6 and 8 . Correlations are relative to the $\mathrm{pH} 6$ (DIW) data. 


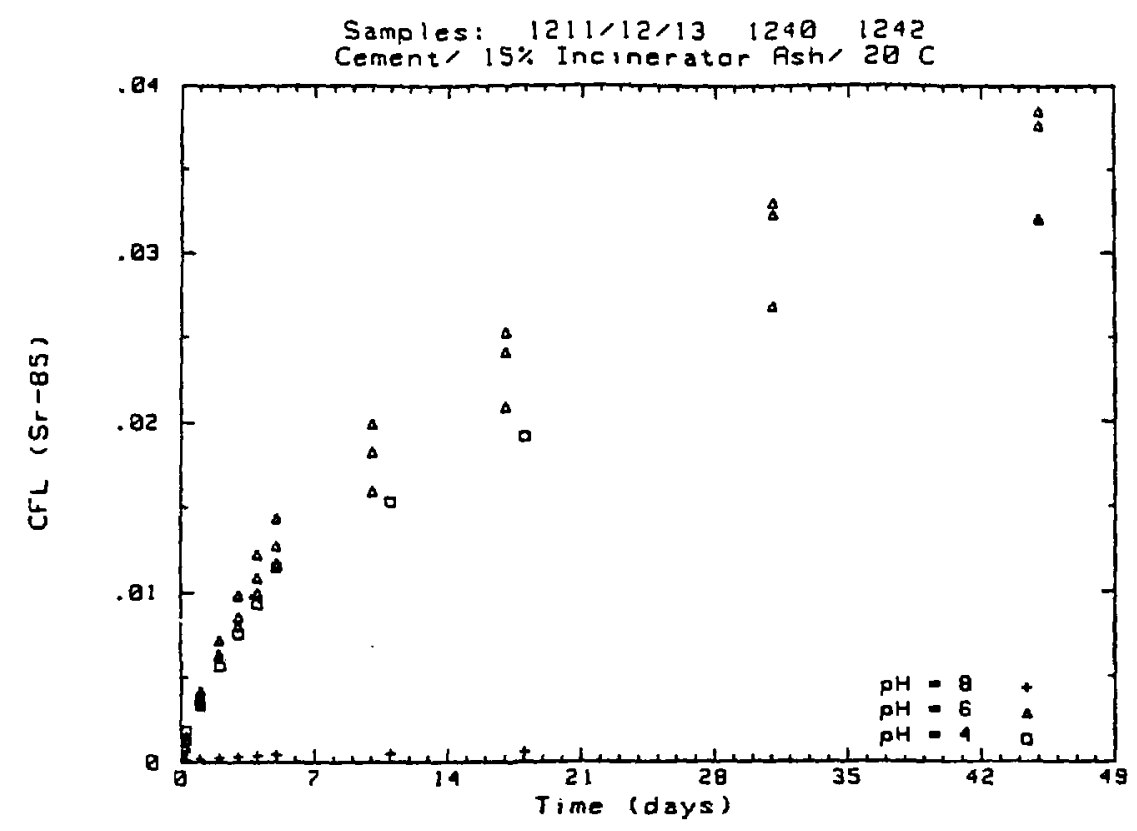

Figure 5.27

Sr-85 cumulative fraction leached vs. time from portland I cement containing 15 wto incinerator ash leached at $20^{\circ} \mathrm{C}$ in leachants with initial $\mathrm{pH}$ values of 4,6 and 8 .

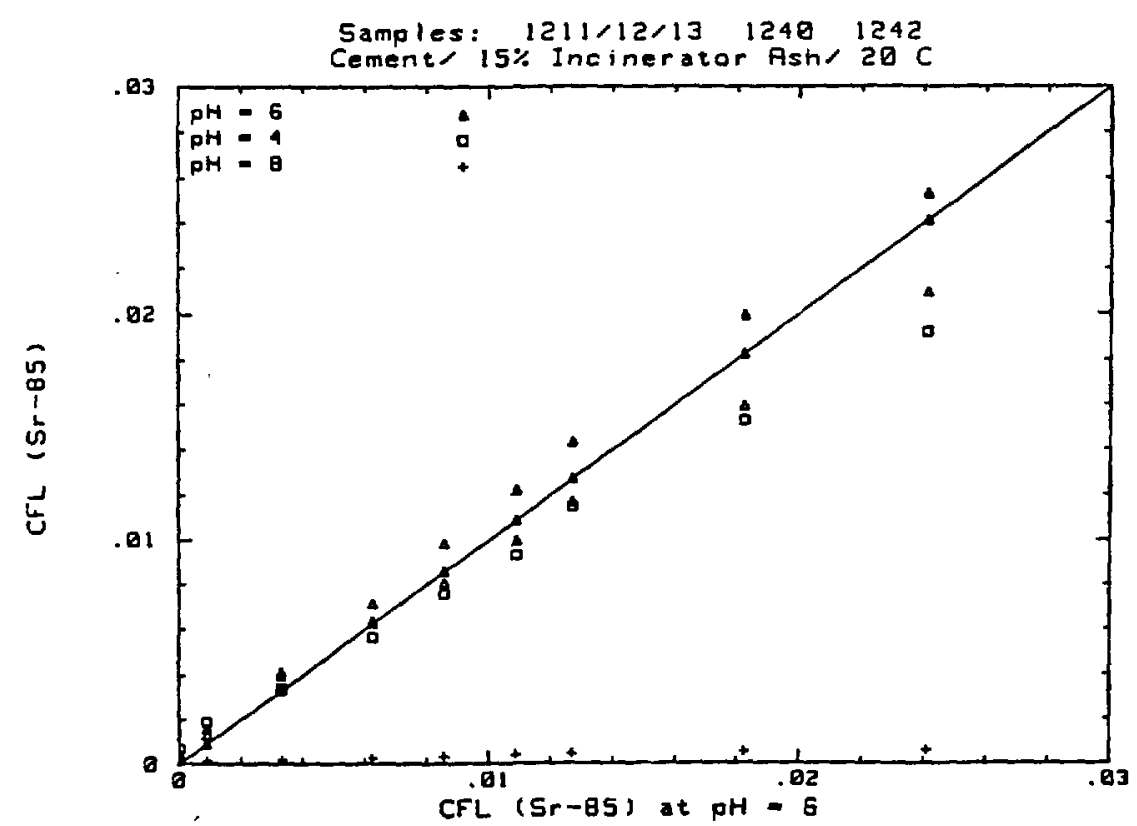

Figure 5.28

Linear correlation plots for Sr-85 leached at $20^{\circ} \mathrm{C}$ from portland I cement containing 15 wt incinerator ash in leachants with initial $\mathrm{pH}$ values of 4,6 and 8 . Correlations are relative to the pH 6 (DIW) data. 


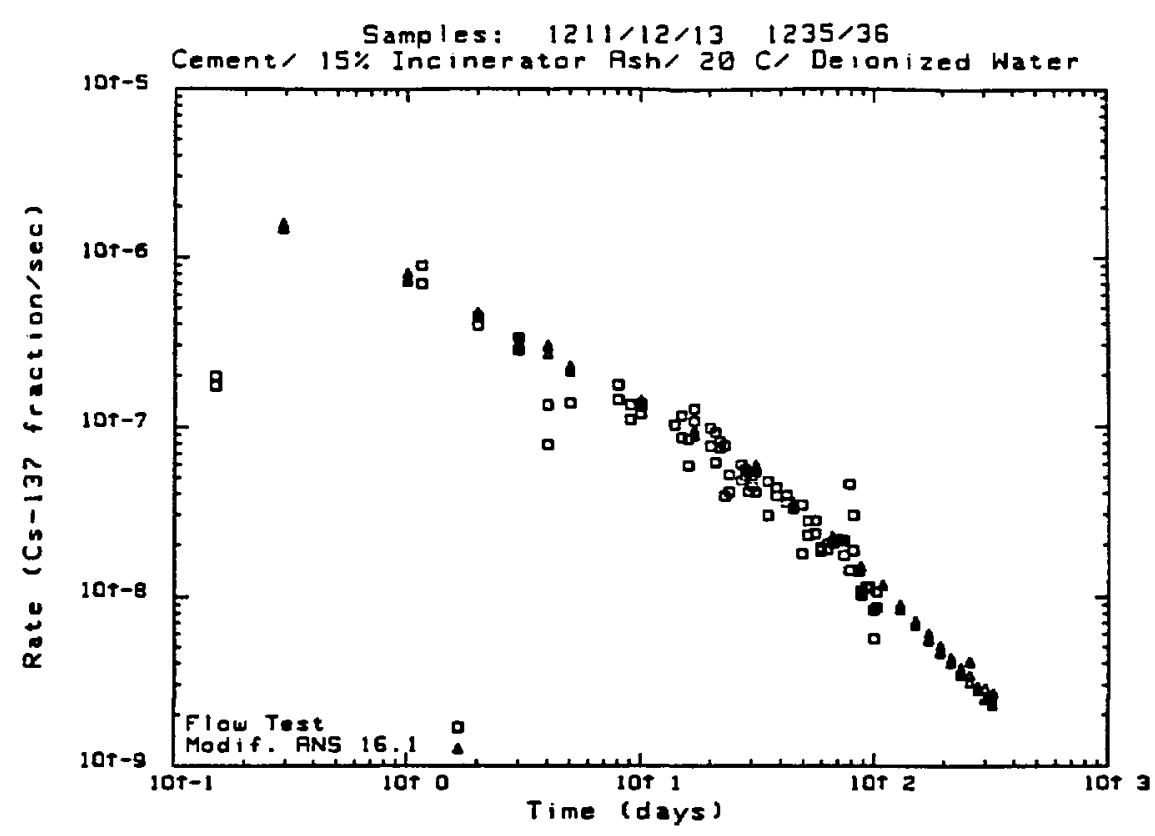

Figure 5.29

Cs-137 incremental leach rate vs. time from portland I cement containing 15 wt incinerator ash comparing results of MCC-4S flow test to modified ANS 16.1

leachant replacement schedule. Samples were leached at $20^{\circ} \mathrm{C}$.

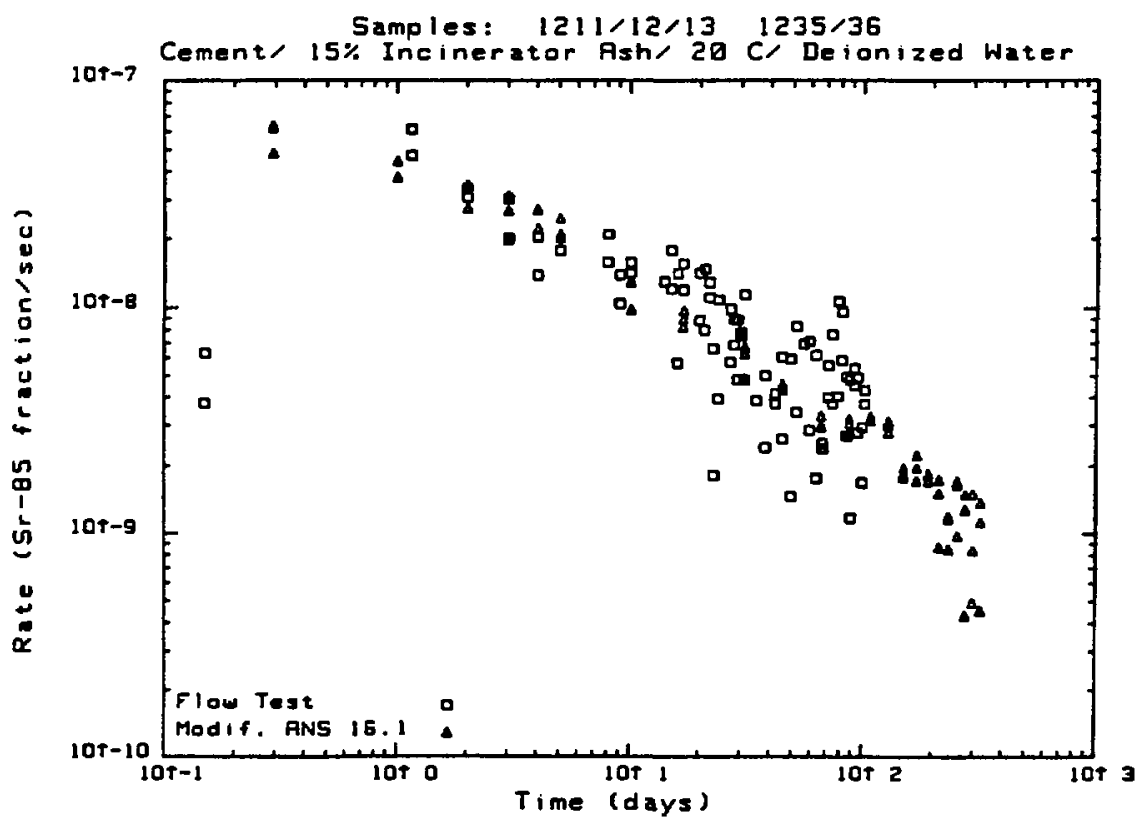

Figure 5.30

Sr-85 incremental leach rate vs. time from portland I cement containing 15 wt incinerator ash comparing result.s of MCC-4S flow test to modified ANS 16.1

leachant replacement schedule. Samples were leached at $20^{\circ} \mathrm{C}$. 

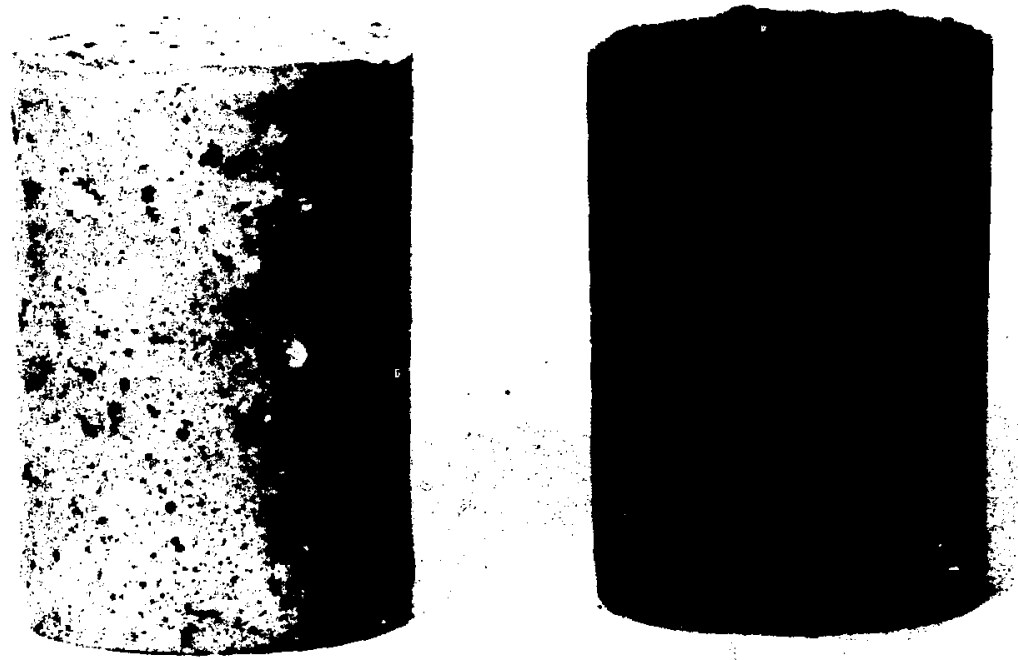

Figure 5.31

Portland I cement containing 15 wt incinerator ash. The form at left is as fabricated. The one at right was leached for 403 days in deionized water at $20^{\circ} \mathrm{C}$. Samples were $4.8 \mathrm{~cm}$ diameter by $6.4 \mathrm{~cm}$ high right cylinders.

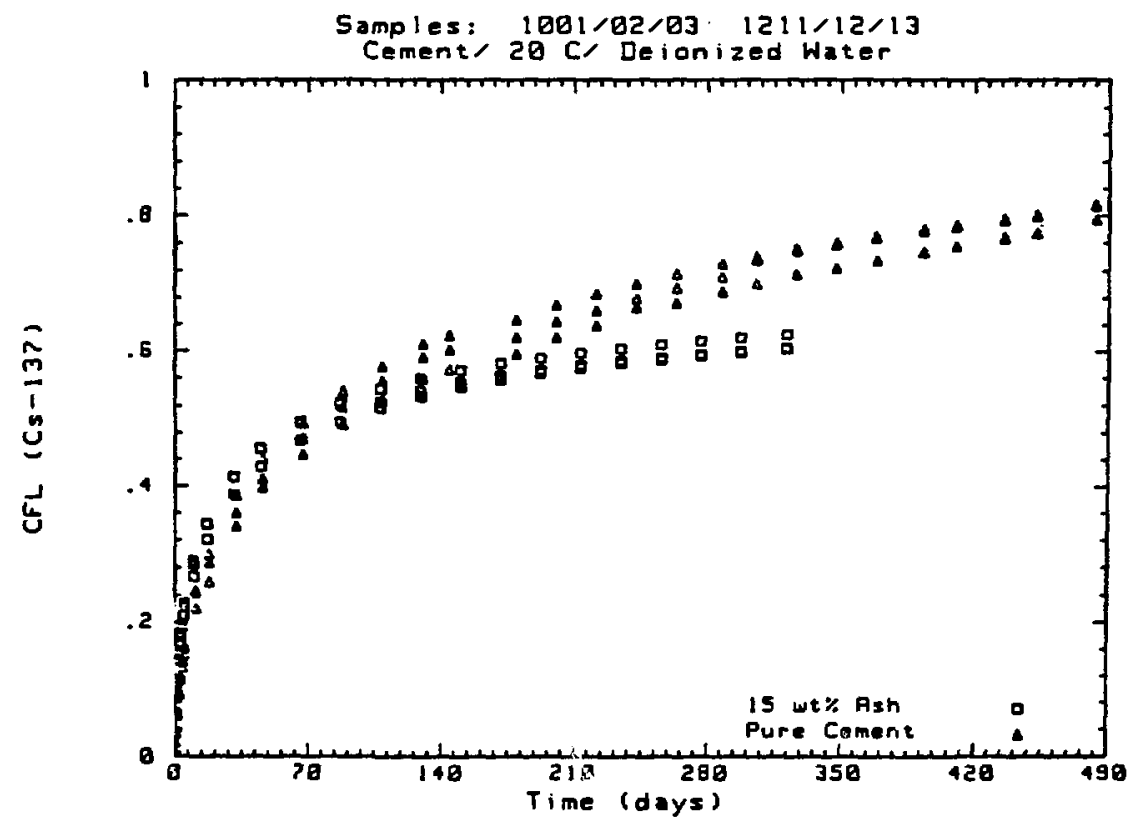

Figure 5.32

Cs -137 cumulative fraction leached vs. time from portland I cement containing 15 wt incinerator ash and from pure portland I cement at $20^{\circ} \mathrm{C}$. 


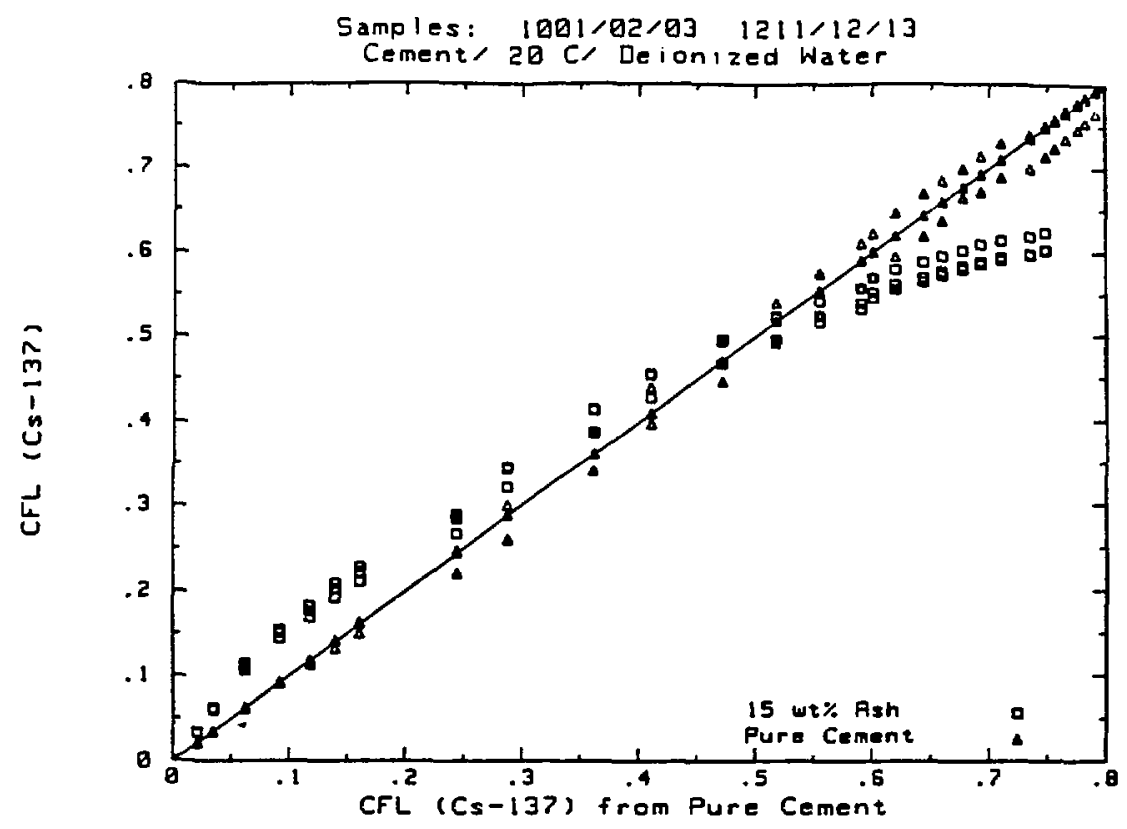

Figure 5.33 Linear correlation plots for Cs-137 leached at $20^{\circ} \mathrm{C}$ for portland I cement containing 15 wts incinerator ash and pure portland I cement. Correlations are relative to pure cement.

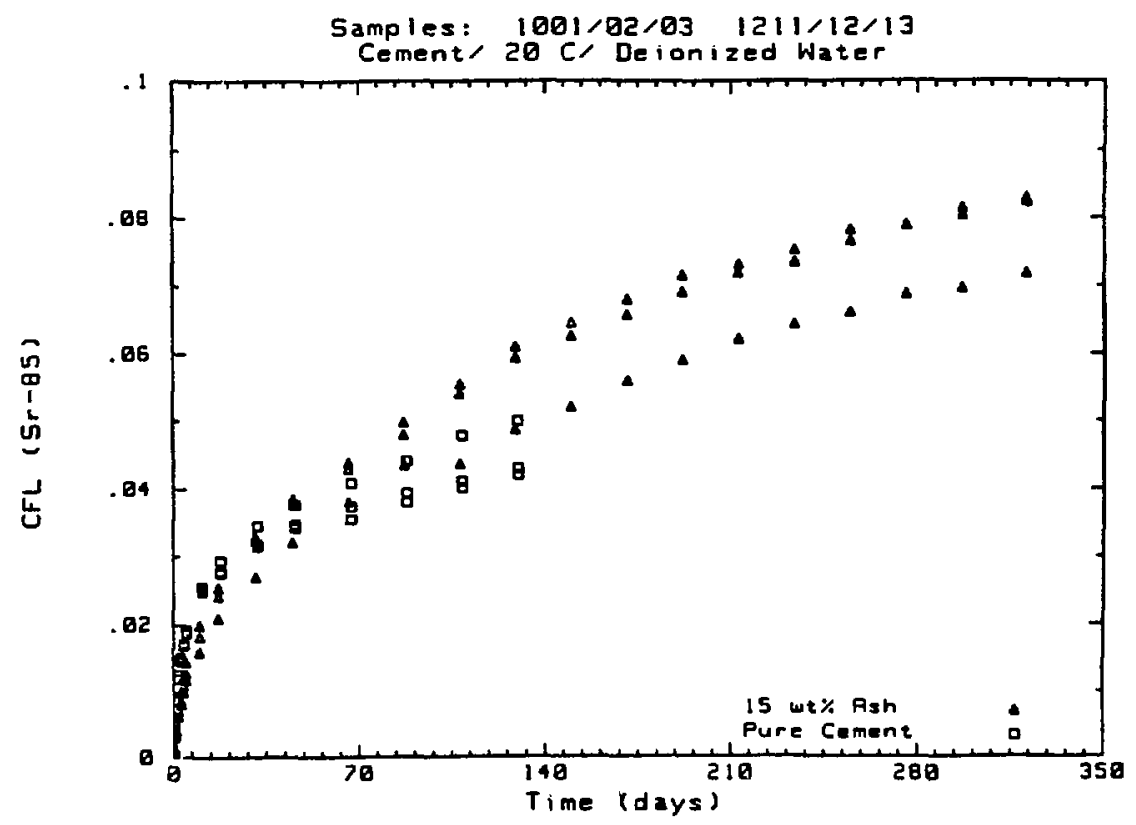

Figure 5.34 Sr-85 cumulative fraction leached vs. time from portland I cement containing 15 wt incinerator ash and from pure portland I cement leached in DIW at $20^{\circ} \mathrm{C}$. 


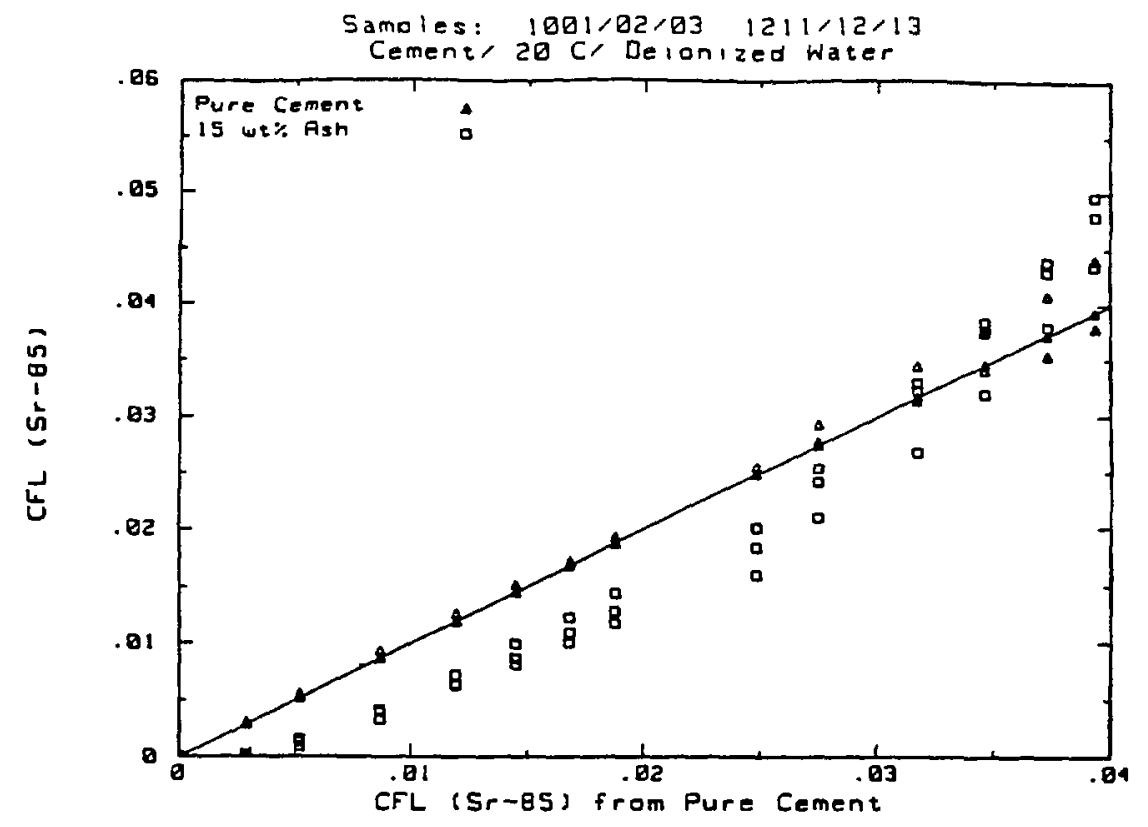

Figure 5.35 Linear correlation plots for Sr-85 leached from portland I cement containing 15 wt incinerator ash and from pure portland I cement. Correlations are relative to pure cement. Samples were leached in delonized water at $20^{\circ} \mathrm{C}$.

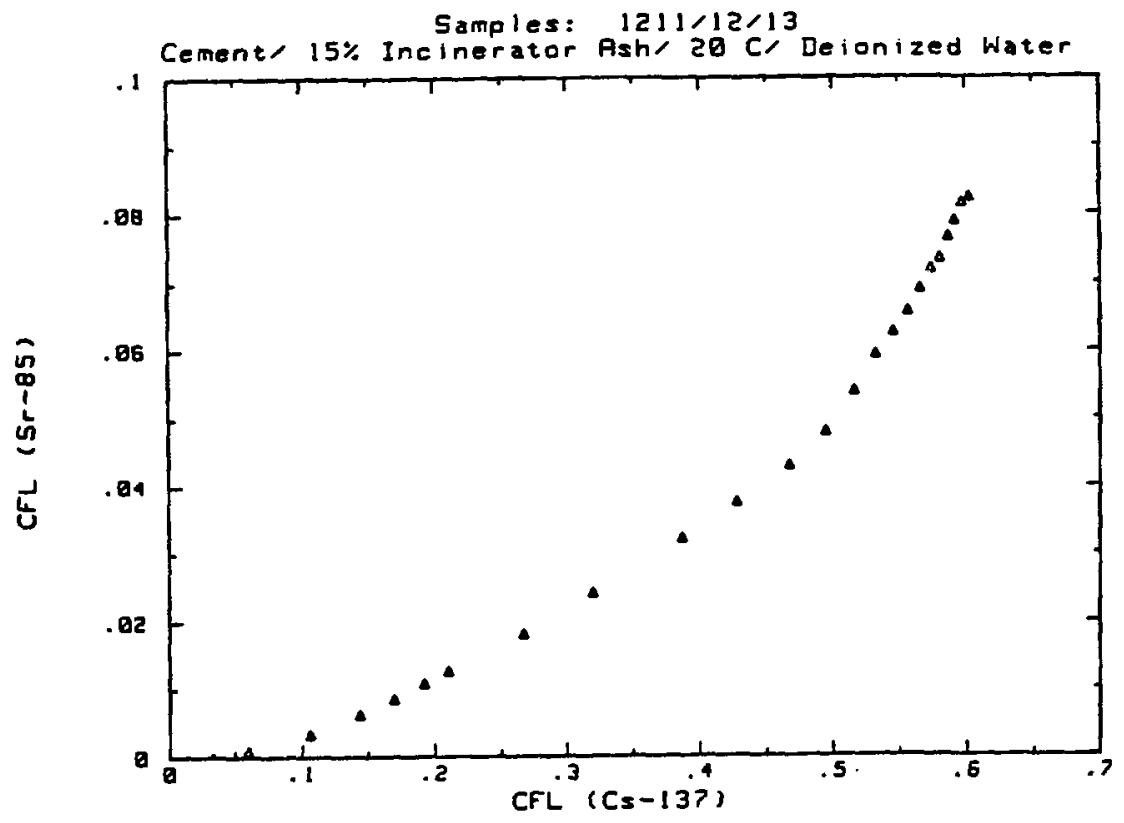

Figure 5.36 Linear correlation plot for Sr-85 versus Cs-137 leached from portland $I$ cement containing 15 wts incinerator ash in deionized water at $20^{\circ} \mathrm{C}$. 


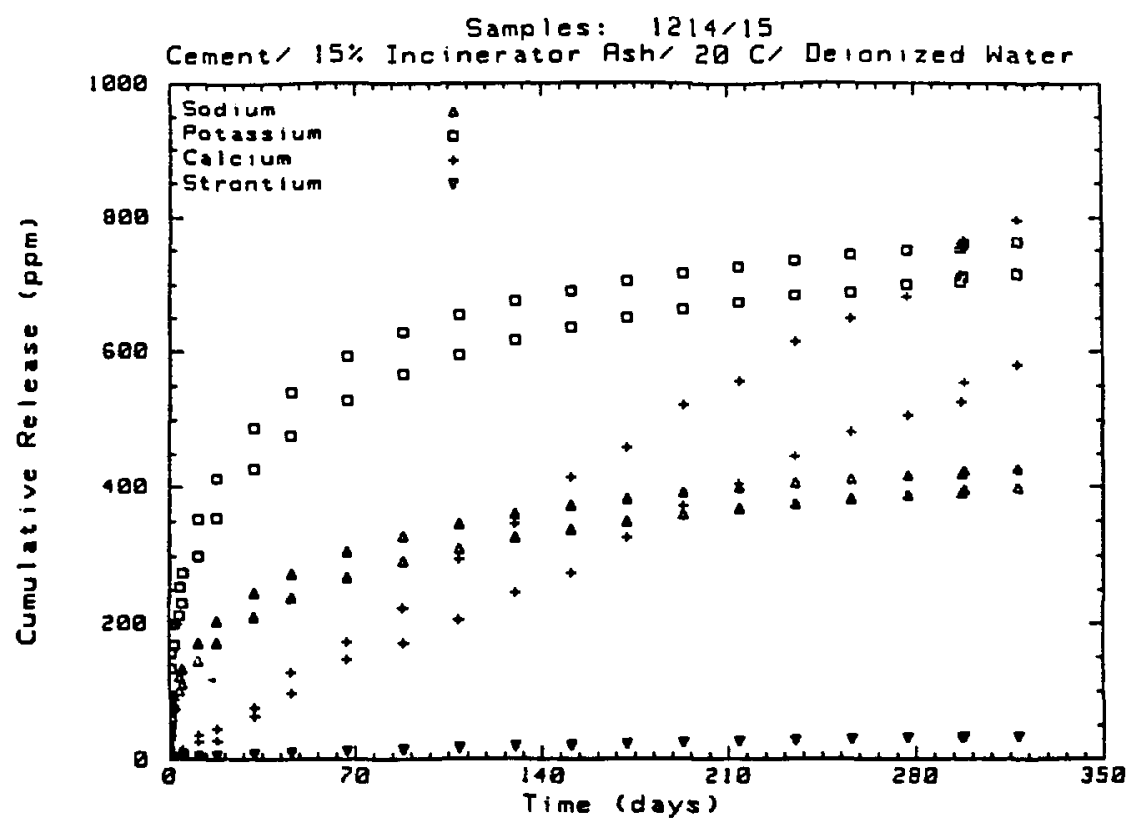

Figure 5.37

Leaching curves of cumulative release (ppm) vs. time for sodium, potassium, calcium and strontium from portland I cement containing 15 wt incinerator ash. Samples were leached at $20^{\circ} \mathrm{C}$ in deionized water.

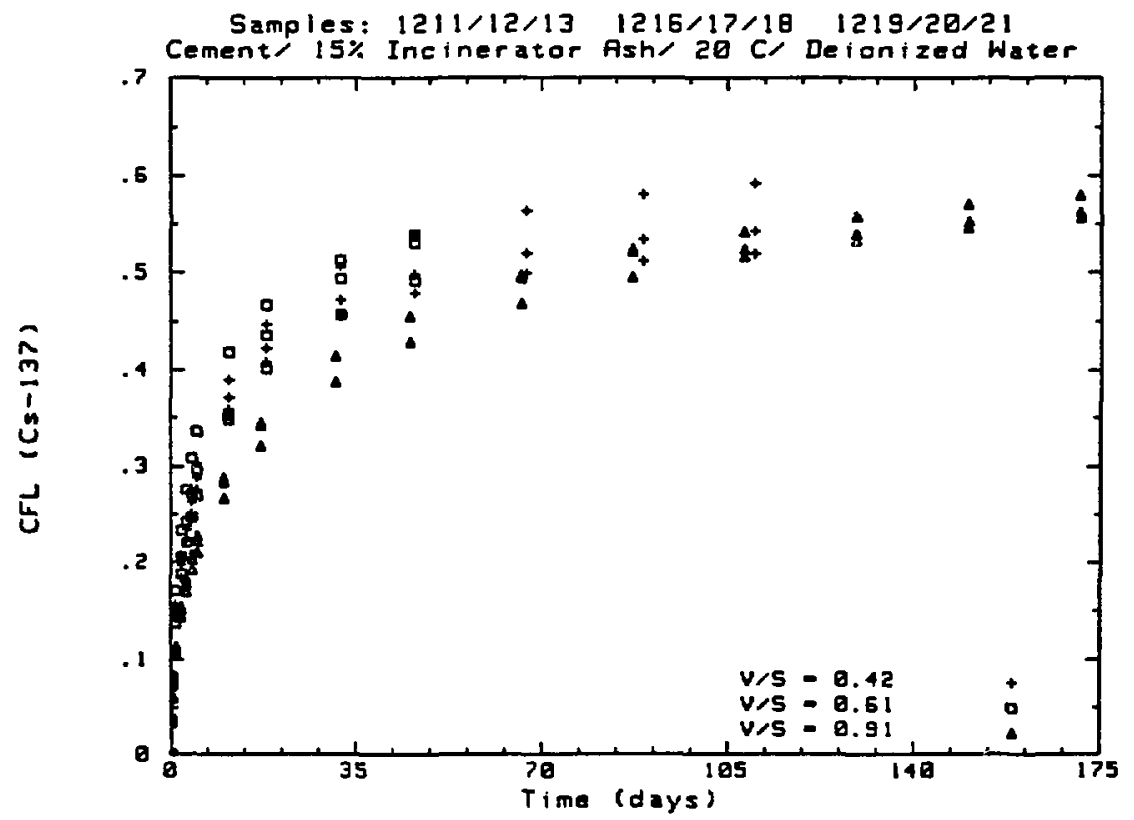

Figure 5.38 Cs-137 cumulative fraction leached vs. time from portland I cement containing $15 \mathrm{wtz}$ incinerator ash at waste form volume to surface area (V/S) ratios of $0.42,0.61$ and 0.91 . Samples were leached in deionized water at $20^{\circ} \mathrm{C}$. 


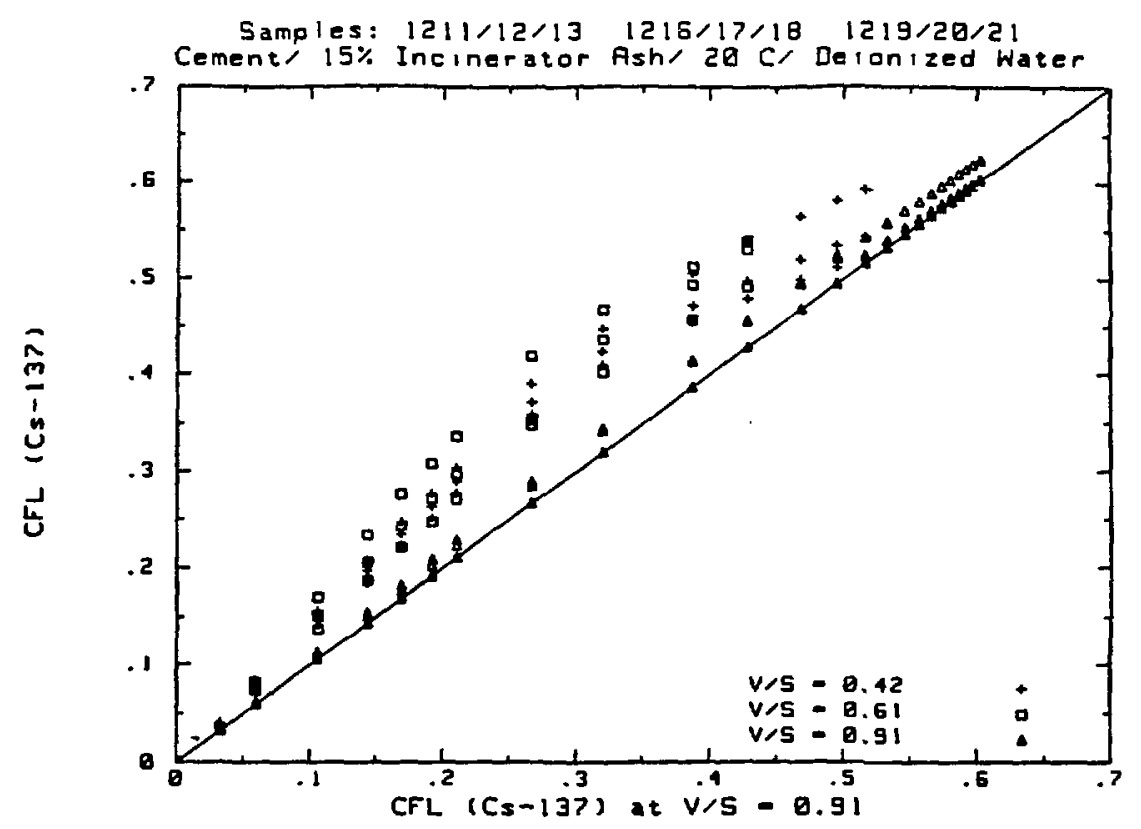

Figure 5.39 Linear correlation plots for Cs -137 leached from portland I cement containing 15 wt incinerator ash at waste form volume to surface area $(\mathrm{V} / \mathrm{S})$ ratios of $0.42,0.61$ and 0.91 . Correlations are relative to $\mathrm{V} / \mathrm{S}=0.91$. Samples were leached in delonized water at $20^{\circ} \mathrm{C}$.

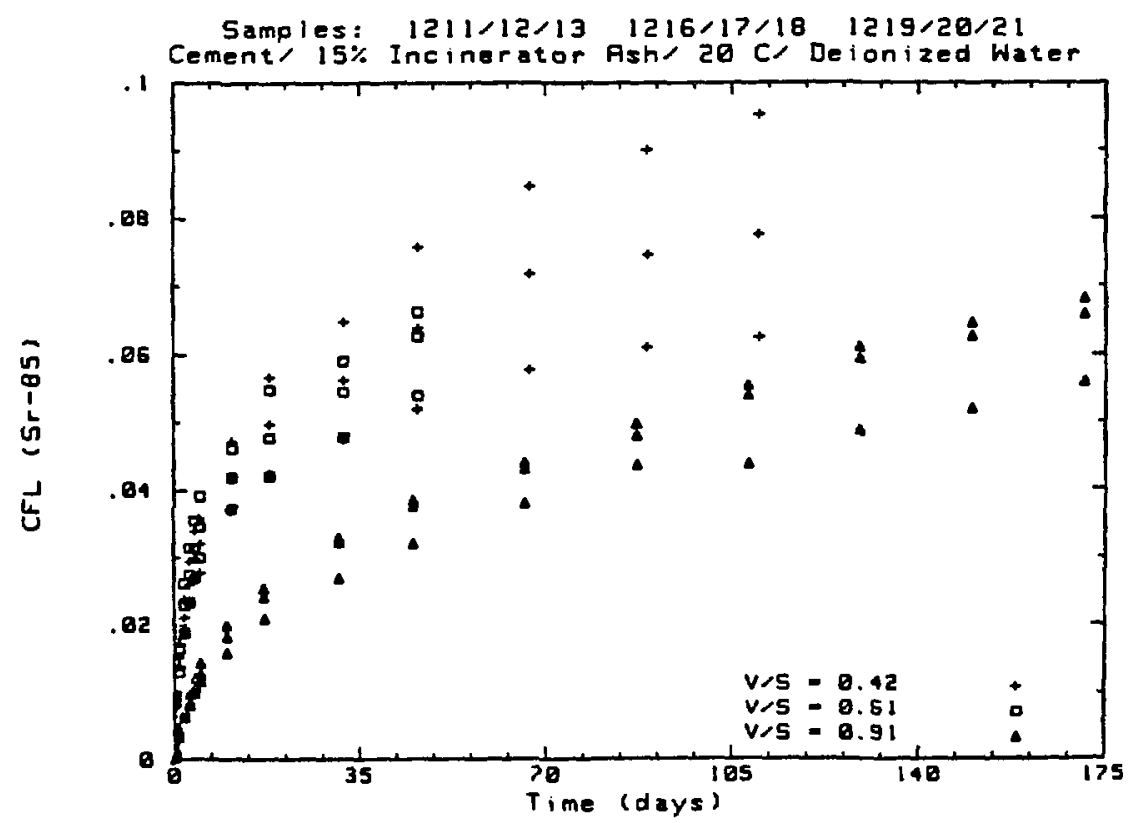

Figure 5.40

Sr-85 cumulative fraction leached vs. time from portland I cement containing 15 wto incinerator ash at waste form volume to surface area $(V / S)$ ratios of $0.42,0.61$ and 0.91 . Samples were leached in deionized water at $20^{\circ} \mathrm{C}$. 


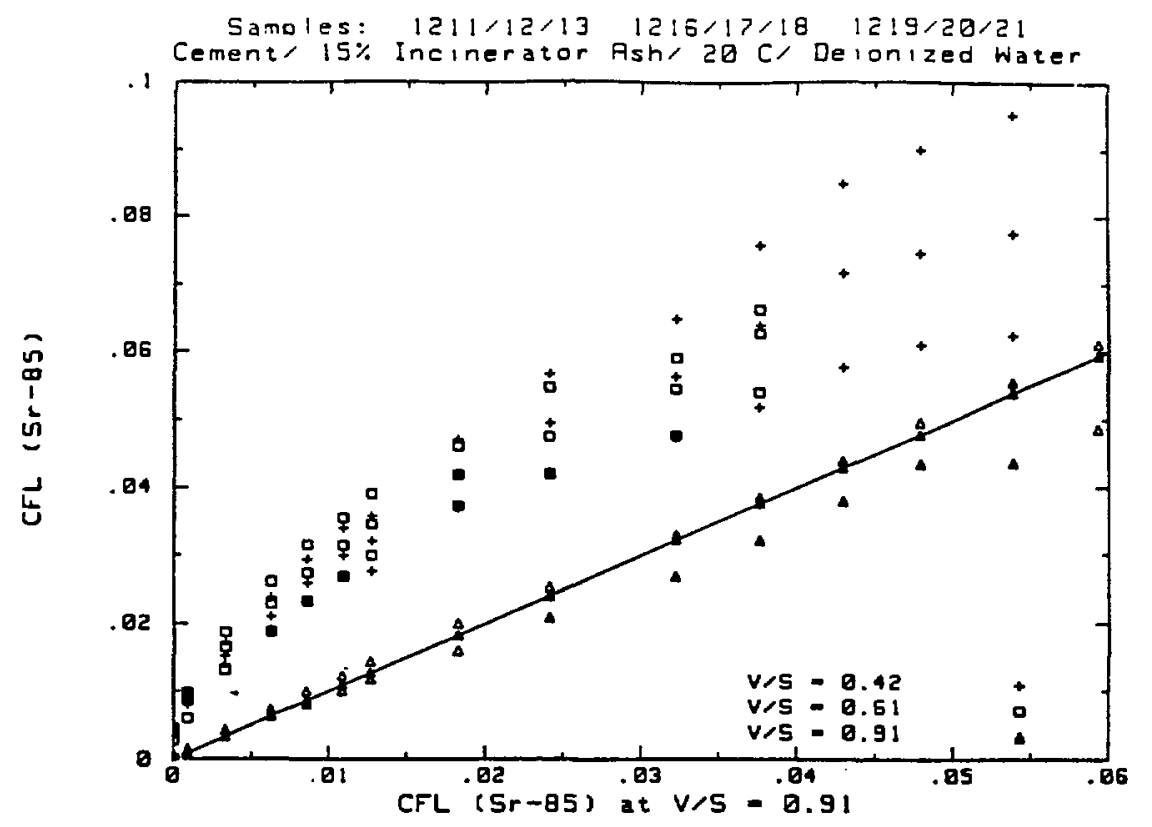

Figure 5.41

Linear correlation plots for $\mathrm{Sr}-85$ leached from portland I cement containing 15 wt incinerator ash at waste form volume to surface area (V/S) ratios of $0.42,0.61$ and 0.91 . Correlations are relative to $V / S$ $=0.91$. Samples were leached in deionized water at $20^{\circ} \mathrm{C}$.

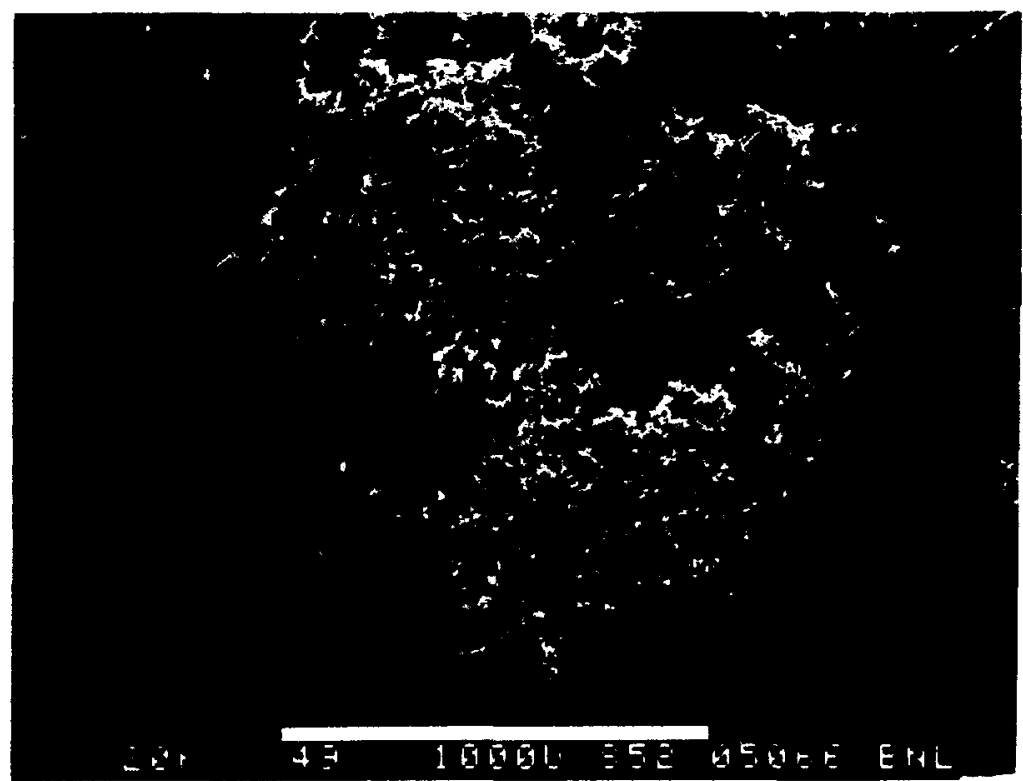

Figure 5.42

The ash itself is often more porous than the cement matrix in which it is solitifiod. 


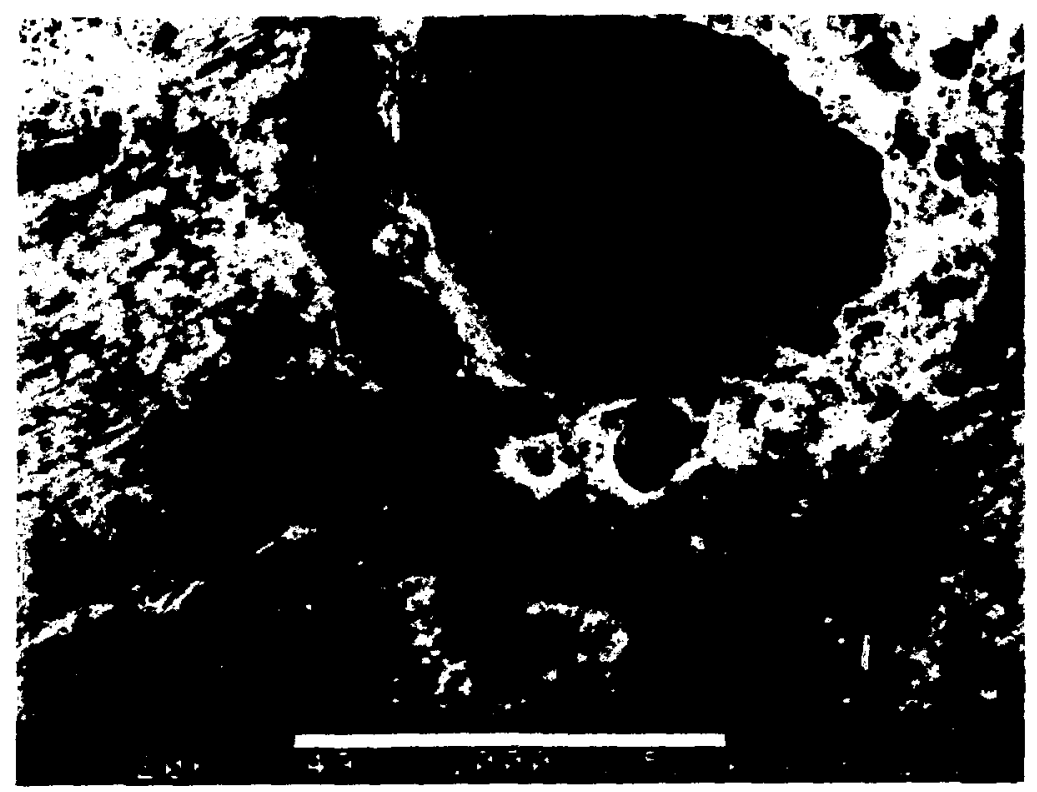

Figure 5.43

Large voids form possibly due to gas generation or differential water sorption between the cement and the ash. 


\section{VINYL ESTER-STYRENE (VES) EMULSION WITH AQUEOUS SODIUM SULFATE AS SIMULATED WASTE}

The vinyl ester-styrene (VES) copolymer system can be used to solidify aqueous waste streams, such as sulfate salt evaporator bottoms. This is done using high-shear mixing to form an emulsion of the comonomer and aqueous waste solutions and then polymerizing the comonomer phase to solidify the emulsion. Polymerization is normally accomplished using a catalyst and promoter system that is added to the comonomer along with the waste solution. Since polymerization involves a chemical reaction initiated by the catalyst-promoter system, interactions with the waste can be detrimental to solidification of the emulsion.

Although the vinyl ester-styrene process for solidifying emulsified liquid wastes was considered promising and was developed commercially [67-69], it has not come into widespread use. Therefore, experimental work on the VES emulsion process was de-emphasized and efforts were directed toward the use of VES to solidify dry salts, presented later in section 7 of this report. This section presents the results obtained using the VES emulsion process for solidifying aqueous sodium sulfate solution as simulated waste.

\subsection{Leaching Mechanisms}

No completely defensible physicochemical model of the leaching behavior of VES-aqueous waste emulsion waste forms was developed from this work. In part this stemmed from the redirection of effort, as mentioned above, and in part from the fact that only waste loading appeared to have any consistent effect on the leaching behavior of the VES emulsion waste forms with aqueous sodium sulfate. Three pertinent observations from section 6.2 that address the question of the leaching mechanism for VES emulsion waste forms are listed below.

(i) There is little difference in leachabilities of Cs-137, Sr-85 and Co-57 from VES emulsion waste forms. This finding suggests that there is little, if any, sorption of radionuclides by the solid polymer.

(ii) The physical structure of the solidified polymer consists of a matrix in which larger pores appear to be connected by much smaller pores. However, the overall connectedness of the pore structure was not determined. The structure would also depend on the ratio of waste-to-binder, the duration of mixing and, possib$1 y$, the time that the polymerization reaction takes to solidify the form.

(iii) Plots of radionuclide leaching releases often have a step-like appearance; this may indicate that small cells of the aqueous waste become accessible to leaching suddenly, such that a microburst of material is released.

$$
-102 y-103-
$$


These three observations suggest that the behavior of the polymer matrix is essentially inert toward the radionuclides investigated in this work, and that leaching is controlled by the physical structure of the emulsified form. The physical structure, in turn, is clearly a product of the thoroughness of the high-shear mixing. Item (iii) indicates that leaching may proceed as small bursts of release of waste material, perhaps driven by osmotic rupture of these regions. The leach rate then would slow as the tortuous rupturedregion layer increases in thickness and the diffusive path to the surface of the waste form lengthens. Under this scenario, the permeability of the polymer film itself would play only a minor role in the leachability of these waste forms.

\subsection{Factors that Affect Leaching}

This section presents our results on the effects that the factors listed in Table 2.1 have on the leaching behavior of vinyl ester-styrene (VES) emulsion waste forms containing aqueous sodium sulfate as simulated waste. Compositions of the test specimen are listed in Tables 3.1 and 3.2 for the VES emulsion with aqueous sodium sulfate solution and with DIW containing only radiotracers, respectively. The effects of each factors are based on comparison to the results from standard samples, i.e., $4.8 \mathrm{~cm}$ diameter by $6.4 \mathrm{~cm}$ tall right cylinders, leached at $20^{\circ} \mathrm{C}$ in DIW. Replicate tests, generally triplicates, provided a measure of the variability of the data.

6.2.1 Temperature. Investigations of the effect of temperature on the leachabilities of Cs-137, Sr-85 and Co-57 from VES emulsion with aqueous sodium sulfate solution showed that leachabilities of the three radionuclides differed substantially at 40 and $50^{\circ} \mathrm{C}$ compared to that at $20^{\circ} \mathrm{C}$. Specifically, the relative leaching releases of the three radionuclides at 40 and $50^{\circ} \mathrm{C}$ paralleled that at $20^{\circ} \mathrm{C}$ for about 50 days and then increased rapidly. This occurred somewhat sooner at $50^{\circ} \mathrm{C}$ than that at $40^{\circ} \mathrm{C}$. This behavior appears to result from relatively large and possibly constant leach rates developing following the initial (50 day) period of monotonically decreasing leach rates. Since the leach rates of the replicate $20^{\circ} \mathrm{C}$ data monotonically decreased to over 300 days it appears that the leaching mechanism may change at increased leaching temperature. Alternatively, the samples at $20^{\circ} \mathrm{C}$ may not have been leached long enough to unambiguously establish a constant leach rate, as may have happened for the samples at the higher temperatures. However, the longterm leaching releases at elevated temperature do not correlate with those at $20^{\circ} \mathrm{C}$, so elevated temperature cannot be considered a valid accelerating factor until this anomaly between the $20^{\circ} \mathrm{C}$ data and the 40 and $50^{\circ} \mathrm{C}$ data is resolved.

Figure 6.1 shows Cs -137 CFL versus time from the VES emulsion with aqueous sodium sulfate at 20,40 and $50^{\circ} \mathrm{C}$. The $20^{\circ} \mathrm{C}$ data evidence a monotoni cally decreasing leach rate to over 300 days. The 40 and $50^{\circ} \mathrm{C}$ data show similar behavior through approximately 50 days, at which point the leachability appears to become constant. The constant rate established at $50^{\circ} \mathrm{C}$ data is substantially greater than that at $40^{\circ} \mathrm{C}$ data. 
The linear correlations plotted in Figure 6.2 show that the differences in leaching behavior between the $20^{\circ} \mathrm{C}$ data and those at $40^{\circ}$ and $50^{\circ} \mathrm{C}$ are significant. There are two regions of behavior:

(i) The initial region in which Cs-137 leachabilities in the $40^{\circ}$ and $50^{\circ} \mathrm{C}$ experiments are lower, but appear to correlate well with those from the $20^{\circ} \mathrm{C}$ experiments, and

(ii) The long-term region in which the relative leachability at the higher temperatures increases rapidly compared to that at $20^{\circ} \mathrm{C}$.

However, overall, the higher temperature experiments do not correlate with those at $20^{\circ} \mathrm{C}$ and increased temperature does not provide a valid accelerating factor for waste forms consisting of VES emulsion with aqueous sodium sulfate.

Leaching processes for VES emulsion appear to be the same for the three radionuclides used in these experiments. Consequently, the comments made on the Cs-137 leaching also apply to $\mathrm{Sr}-85$ and Co-57. Figures 6.3 and 6.4 show $C F L$ versus time and the linear correlations for $S r-85$ leached at 20,40 and $50^{\circ} \mathrm{C}$. Figures 6.5 and 6.6 show the same types of plots, respectively, for Co- 57 .

Since temperature showed no clear promise as a potential accelerating factor, the leaching of non-radionuclides was not measured from the VES emulsion with aqueous sodium sulfate.

\subsubsection{Ratio of Leachant Volume to Waste Form Surface Area. These} experiments were not done for the VES emulsion waste forms with aqueous sodium sulfate as simulated waste: emphasis was placed on work with other materials.

6.2.3 Composition of the Leachant. The effect of the composition of the leachant on the leaching of Cs-137, Sr-85 and Co-57 from the VES emulsion with aqueous sodium sulfate was investigated, using the oxic ORNL-simulated ground water (described in Section 3). The leachabilities of all three radioisotopes were uniformly reduced approximately by a factor of two in the ground water compared to those in DIW. The fact that all three were reduced by the same factor indicates that solubility limits for $\mathrm{Sr}-85$ and $\mathrm{Co}-57$ did not significantly affect the leaching releases; otherwise the Sr-85 and/or Co-57 releases would be notably lower than the Cs-137 releases in the ground water. Figures $6.7,6.8$ and 6.9 are plots of CFL versus time for $\mathrm{Cs}-137, \mathrm{Sr}-85$ and Co-57 respectively.

No measurements were made of leaching of non-radionuclides from the VES emulsion since our emphasis shifted to VES-solidified dry salts.

6.2.4 $\mathrm{pH}$ of the Leachant. Leachants with initial $\mathrm{pH}$ values of 4 and 8 were conpared with $\mathrm{DIW}, \mathrm{pH}=6$. As mentioned previously, the nominal $\mathrm{pH}$ of DIW is 7 at $20^{\circ} \mathrm{C}$, but dissolution of carbon dioxide from air reduces the $\mathrm{pH}$ to approximately 6 . Leaching at $\mathrm{pH}$ values of 4 and 8 uniformly reduced the releases of $\mathrm{Cs}-137, \mathrm{Sr}-85$ and $\mathrm{Co}-57$ by over half. Thus, adjusting the initial $\mathrm{pH}$ of the leachant away from neutral appears to substantially decelerate 
leaching from VES emulsion with aqueous sodium sulfate. Figures 6.10, 6.11 and 6.12 are plots of CFL versus time for Cs-137, Sr-85 and Co-57, respectively, leaching in $\mathrm{DIW}(\mathrm{pH}=6)$ and in leachants with initial $\mathrm{pH}$ values of 4 and 8 .

No experiments were performed to measure leaching of non-radionuclides from the VES emulsion since our emphasis shifted to VES-solidified dry salts.

6.2.5 Effect of the Flow Rate or Replacement Frequency of the Leachant on VES Emulsion with Sodium Sulfate Solution. Leaching experiments using the MCC-4S flow test were performed for comparison to the results of the modified ANS 16.1 leach test used as the standard in this program. The nominal flow rates in these two tests are about the same for the first week $(1.01$ iter/day in the flow test compared to 1.3 liters/day in the modified ANS 16.1 test). As the ANS 16.1 test continued, sampling intervals increased to 21 days, giving an effective flow rate of 0.06 liters/day, while the flow test continued at 1.0 liters/day. In general, the flow test results paralleled those from the ANS 16.1 tests, but the former were less reproducible in that there was substantially greater scatter in the data. Therefore, the flow test was not a useful accelerating factor.

Figure 6.13 plots incremental leach rate versus time for Cs-137 leaching fru a the VES emulsion with the MCC-4S flow test and the modified ANS 16.1 test. During the first week, leach rates in the flow test were lower than those in the ANS 16.1 test, perhaps because of the lower rate of water exchange. After that time, the rates were essentially the same for the two tests. At about 70 days, a burst of activity was released from a specimen in the flow test, which increased the leach rate for approximately 14 days. Following this, the rate resumed its downward trend, with releases from the two tests being similar.

Figure 6.14 plots incremental leach rate versus time for Cs-137. Sr-85 leaching parallels that of Cs-137 very closely, with the same burst of activity being observed in the flow test at 70 days. Another burst was also observed for Sr-85 from the ANS 16.1 test after 300 days, but this is probably an artifact of an extremely low count rate due to radioactive decay of that radionuclide. This burst was not observed for Cs-137.

Figure 6.15 plots the incremental leach rate versus time for co- 60 . Co-60 releases followed closely those of $\mathrm{Cs}-137$ and $\mathrm{Sr}-85$. The burst of activity at 70 days was observed in the flow test. Otherwise, results of the two tests were quite similar.

6.2.6 Composition of the Waste Form. The composition of the waste form was investigated by comparing the leaching of the VES emulsion with sulfate salt solution and with DIW. Both waste types consisted of approximately equal volumes of waste (i.e., sulfate salt solution or DIW) and VES comonomer solution. The density of the salt solution was greater than that for DIW so that the waste form compositions listed in Tables 3.1 and 3.2 for the VES emulsion with sodium sulfate solution and with DIW, respectively, are different on the weight formulation basis used in the tables. The leachabilities of all three radionuclides (Cs-137, Sr-85 and Co-57) were much greater 
from the VES emulsion waste forms containing the sodium sulfate solution than from those with DIW as simulated waste.

There was no visible change in the VES emulsion with sodium sulfate solution after leaching 340 days at $20^{\circ} \mathrm{C}$ compared to the as-fabricated form (Figure 6.16), neither was there any noticeable change in the VEs emulsion with DIW leached for over 500 days at $20^{\circ} \mathrm{C}$ compared to the as-fabricated form (not shown). However, Figure 6.17 shows a surface layer delamination that occurred in the VES emulsion with sodium sulfate solution leached at $50^{\circ} \mathrm{C}$ for 100 days. Before sectioning, the leached form appeared to have blistered, but there was no visible cracking or other damage evident beyond the blistering. Further, blistering occurred only in the sample leached at $50^{\circ} \mathrm{C}$ and not in those leached at $40^{\circ} \mathrm{C}$ and $20^{\circ} \mathrm{C}$, although it might be expected to occur in the $40^{\circ} \mathrm{C}$ sample, and possibly the $20^{\circ} \mathrm{C}$ sample, at longer times.

Since only one waste loading of the sulfate salt solution was tested, no evaluation of varying the ratio of the waste to binder of the VES emulsion waste form type is available.

Figures $6.18,6.19$ and 6.20 show the leaching of $\mathrm{Cs}-137, \mathrm{Sr}-85$ and Co-57, respectively, from VES emulsion waste forms containing sodium sulface solution as simulated waste, compared to emulsions containing only DIW and radioactive tracers as simulated waste. The emulsion with the salt solution had large initial leach rates that decreased substantially after approximately 50 days.

Releases of Cs-137 showed a monotonically decreasing rate through 320 days leaching at $20^{\circ} \mathrm{C}$. Releases of $\mathrm{Sr}-85$ and $\mathrm{Co}-57$ appear to increase at about 250 days; this is probably an artifact of the very low count rates observed for those radionuclides near the end of the experiment, resulting from their short half-lives.

\subsubsection{Ratio of Volume to Surface Area of the Waste Form (V/S). As} reviewed in section 2.7 , small-scale test samples, under certain conditions, can be used to accelerate the leaching that would be expected from full-scale waste forms. However, for the VES emulsion waste forms containing sodium sulfate solution, size reduction was unsuccessful. The releases from the smaller samples did not correlate well with those from the standard $4.8 \mathrm{~cm}$ diameter by $6.4 \mathrm{~cm}$ tall samples $(\mathrm{V} / \mathrm{S}=0.91)$. In sum, the reproducibility of the data within each set of $(V / S)$ replicates was marginal and the scatter in the data between sets of replicate samples suggests that the formation of the emulsion may control leachability to a groater extent than does any external factor.

Figures $6.21,6.22$ and 6.23 show $\mathrm{Cs}-137, \mathrm{Sr}-85$ and $\mathrm{Co}-57$, respectively, leaching from VES emulsion waste forms containing sodium sulfate solution at waste form $V / S$ ratios from $0.91,0.62$ and 0.42 . Although the $V / S=0.62$ samples leached faster than the standard $(V / S=0.91)$, the smallest samples $(\mathrm{V} / \mathrm{S}=0.42)$ leached slower initially and established a linear rate of release, rather than monotonically decreasing. The findings were inconsistent with the idea that smaller samples should leach relatively faster than larger ones. This tends to go against common sense, if nothing else, suggesting that 
the details of sample fabrication may be the most important parameter affecting the leachability of the VES emulsion waste forms.

\subsubsection{Porosity and Surface Condition of the Waste Form. The VES} emulsion waste forms are fabricated using high-shear mixing of the comonomer and aqueous waste solutions. Since these solutions are not soluble in each other, the waste is a two-phase system. The waste forms fabricated for our experiments were approximately $50 \%$ by volume VES polymer (after solidification) and 508 by volume sodium sulfate solution.

Electron microscope images were obtained with blank samples, before and after leaching. Figure 6.24 shows the outer surface of a VES waste form magnified 400 times. Pores at the surface of the sample typically range from $12 \mu \mathrm{m}$ to about $30 \mu \mathrm{m}$. Inside the surficial pores, there are other openings that are much smaller, less than $1 \mu \mathrm{m}$ in diameter. Figure 6.25 shows the interior of the same sample: the structure is much like that of the surface. Figure 6.26 is an 1800-fold magnification of the VES surface and shows many small pores inside the larger pores and in the polymer, forming the network around the larger pores. Another view, taken of a cut section at the interior of the waste form, is shown in Figure 6.27. There is a large amount of cutting debris present because the polymer is somewhat elastic and tears rather than cuts cleanly. The interior contains pores of the same size range and configuration as the surface. Often polymers that form emulsions with water form a skin around the cast form that is less porous than the bulk of the material. In the VES emulsion, there does not appear to be any skin formation.

No physical changes were observed in polymer samples that had leached for 471 days. These organic materials released less than $2 \mathrm{~g} / \mathrm{ml}$ total organic carbon in leaching intervals that typically show high releases for soluble components. Therefore, it is not surprising that there was no change in physical form. 


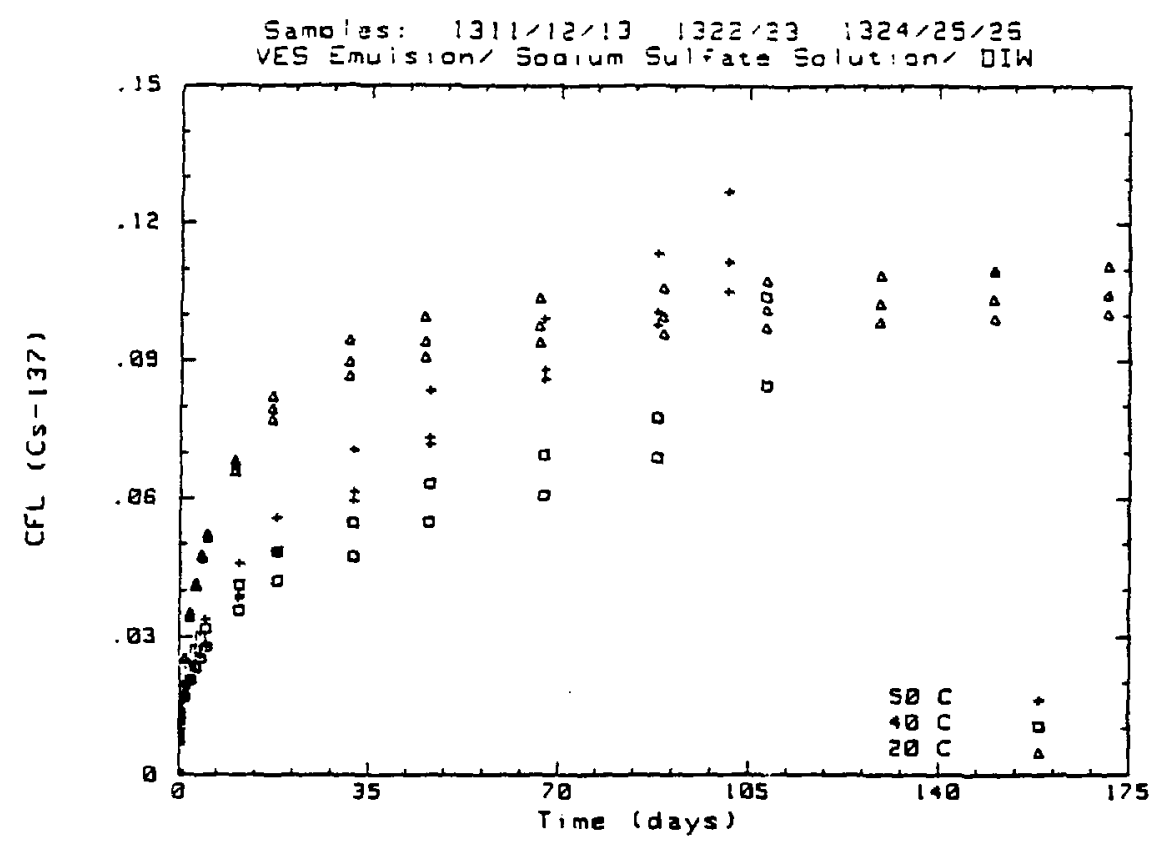

Figure 6.1 Cs-137 cumulative fraction leached vs, time from VES emulsion with aqueous sodium sulfate at 20,40 and $50^{\circ} \mathrm{C}$. Samples were leached in deionized water.

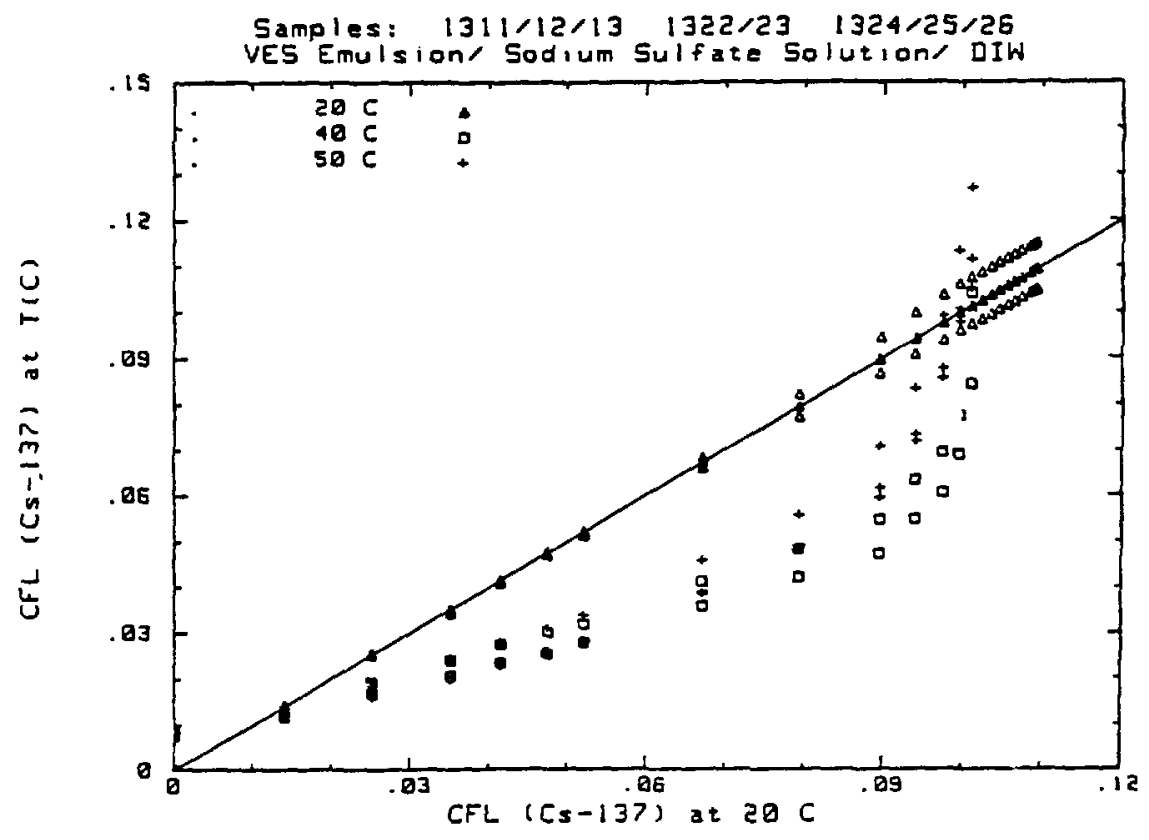

Figure 6.2

Linear correlation plots for Cs -137 leaching from VES emulsion with aqueous sodium sulfate at 20,40 and $50^{\circ} \mathrm{C}$. Correlations are relative to the $20^{\circ} \mathrm{C}$ data. Samples were leached in deionized water. 


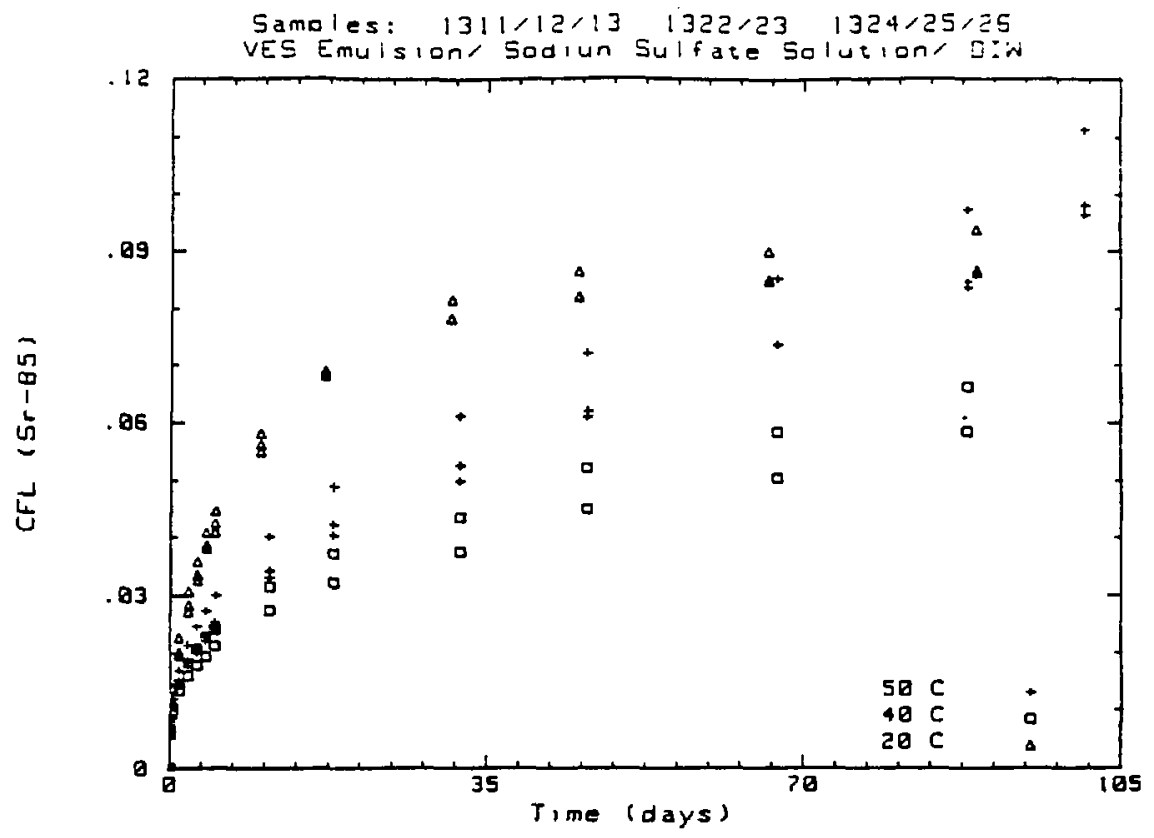

Figure 6.3

Sr-85 cumulative fraction leached vs. time from VES emulsion with aqueous sodium sulfate at 20,40 and $50^{\circ} \mathrm{C}$. Samples were leached in deionized water.

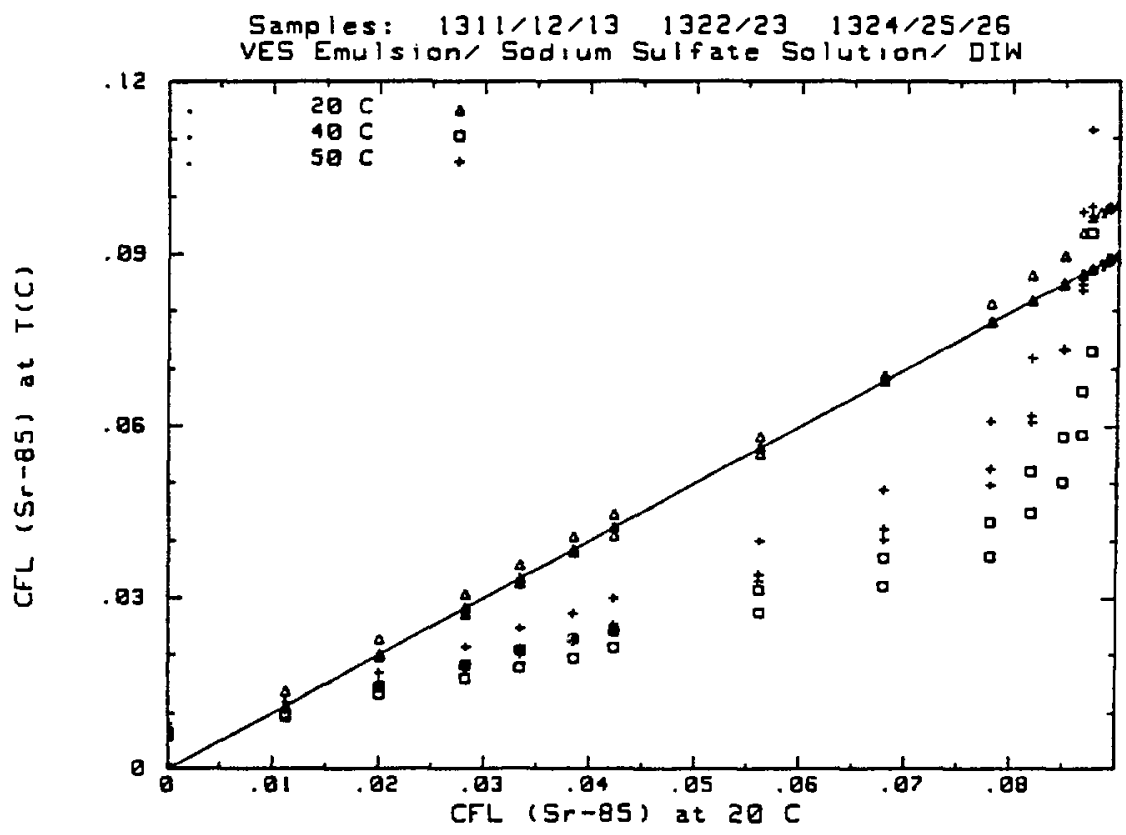

Figure 6.4

Linear correlation plots for Sr-85 leaching from VES emulsion with aqueous sodium sulfate at 20,40 and $50^{\circ} \mathrm{C}$. Correlations are relative to the $20^{\circ} \mathrm{C}$ data. Samples were leached in defonized water. 


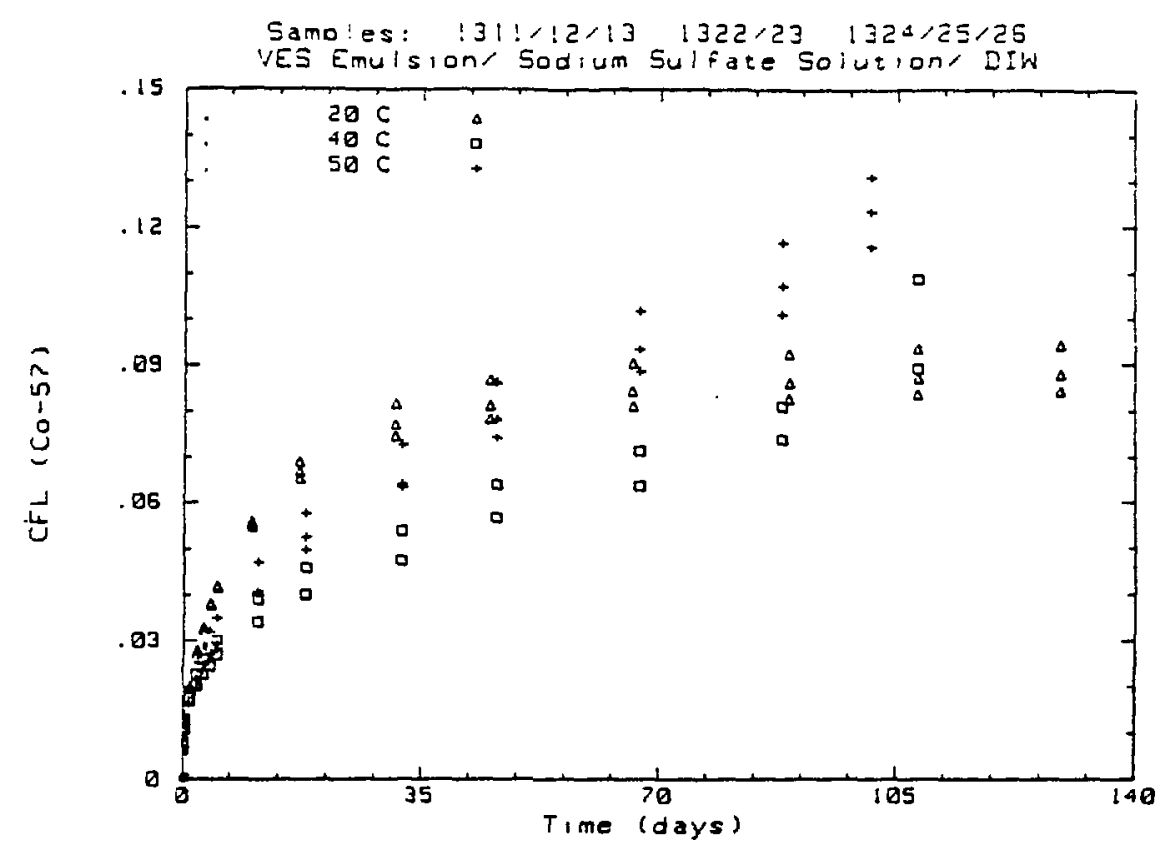

Figure 6.5 Co-57 cumulative fraction leached vs. time from VES emulsion with aqueous sodium sulfate at 20,40 and $50^{\circ} \mathrm{C}$. Samples were leached in deionized water.

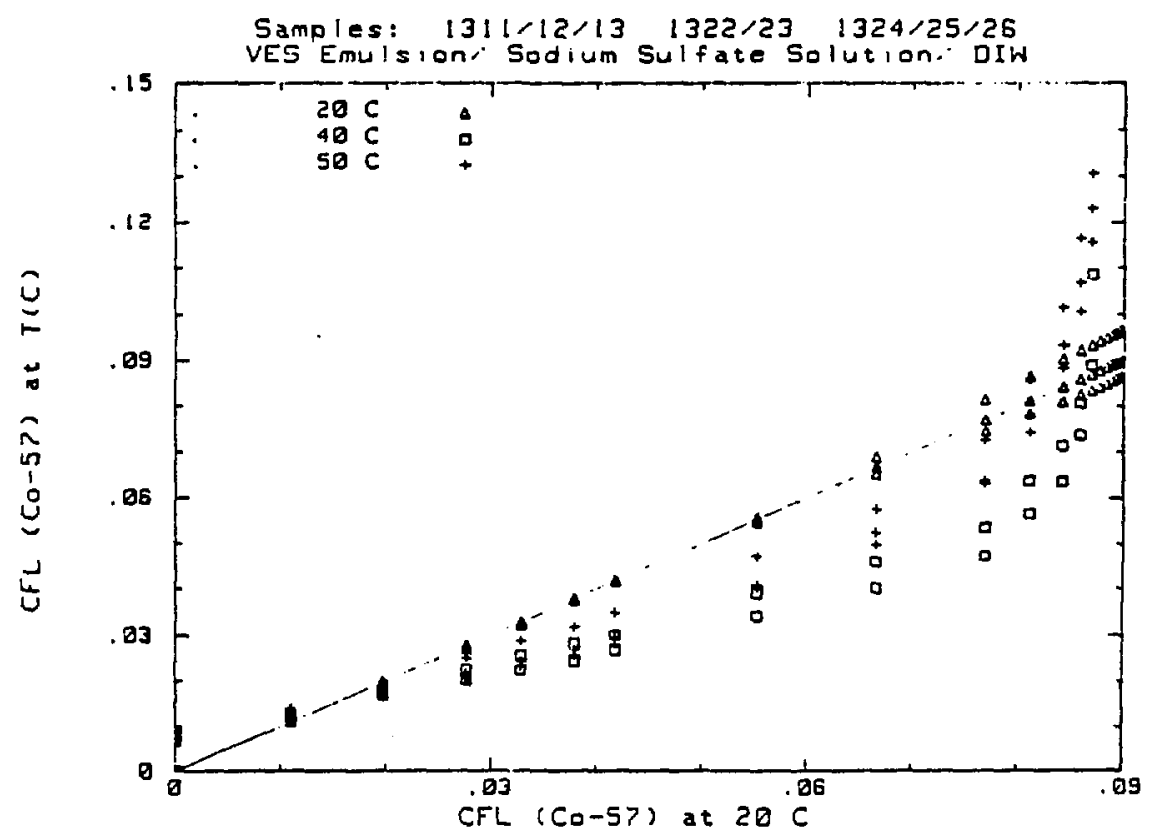

Figure 6.6

Linear correlation plots for Co-57 leaching from VES emulsion with aqueous sodium sulfate at 20,40 and $50^{\circ} \mathrm{C}$. Correlations are relative to the $20^{\circ} \mathrm{C}$ data. Samples were leached in deionized water. 


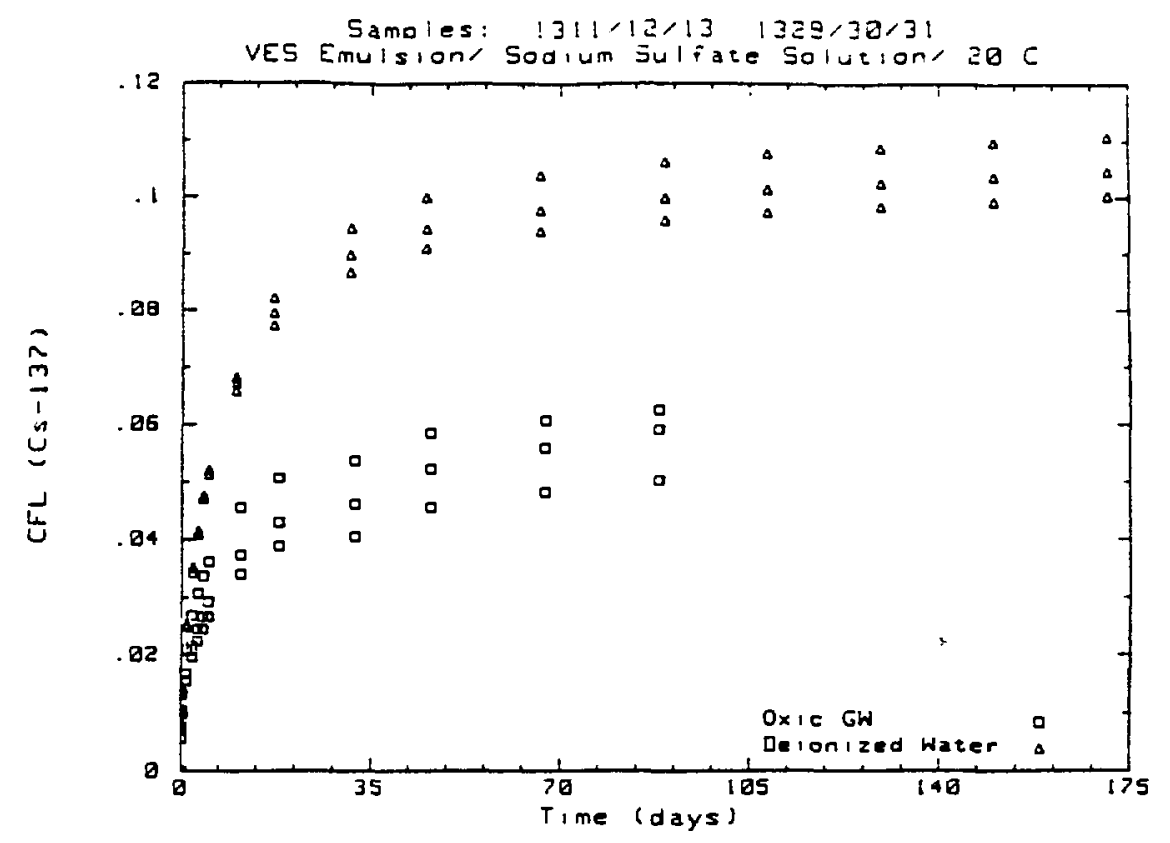

Figure 6.7

Cs-137 cumulative fraction leached vs. time from VES emulsion with aqueous sodium sulfate leached in DIW and oxic ground water at $20^{\circ} \mathrm{C}$.

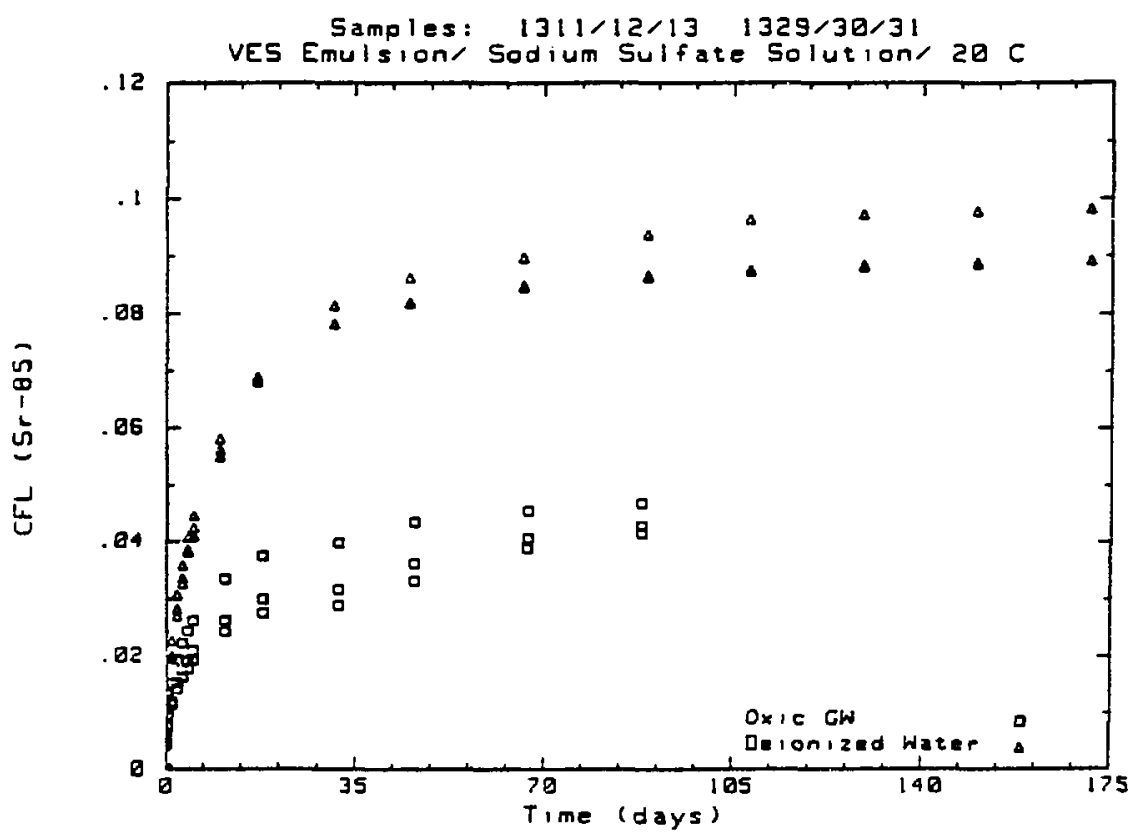

Figure 6.8

Sr-85 cumulative fraction leached vs. time from VES emulsion with aqueous sodium sulfate leached in DIW and oxic ground water at $20^{\circ} \mathrm{C}$. 


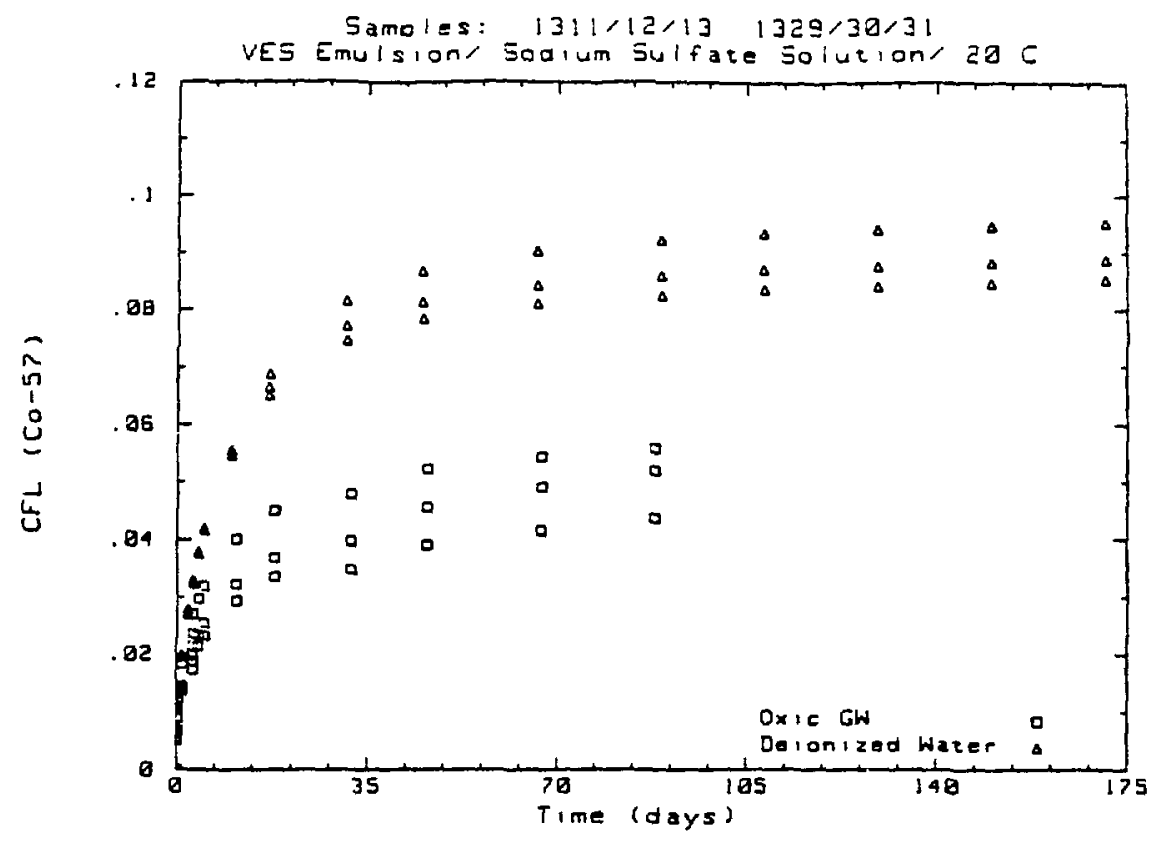

Figure 6.9

Co-57 cumulative fraction leached vs, time from VES emulsion with aqueous sodium sulfate leached in DIW and oxic ground water at $20^{\circ} \mathrm{C}$.

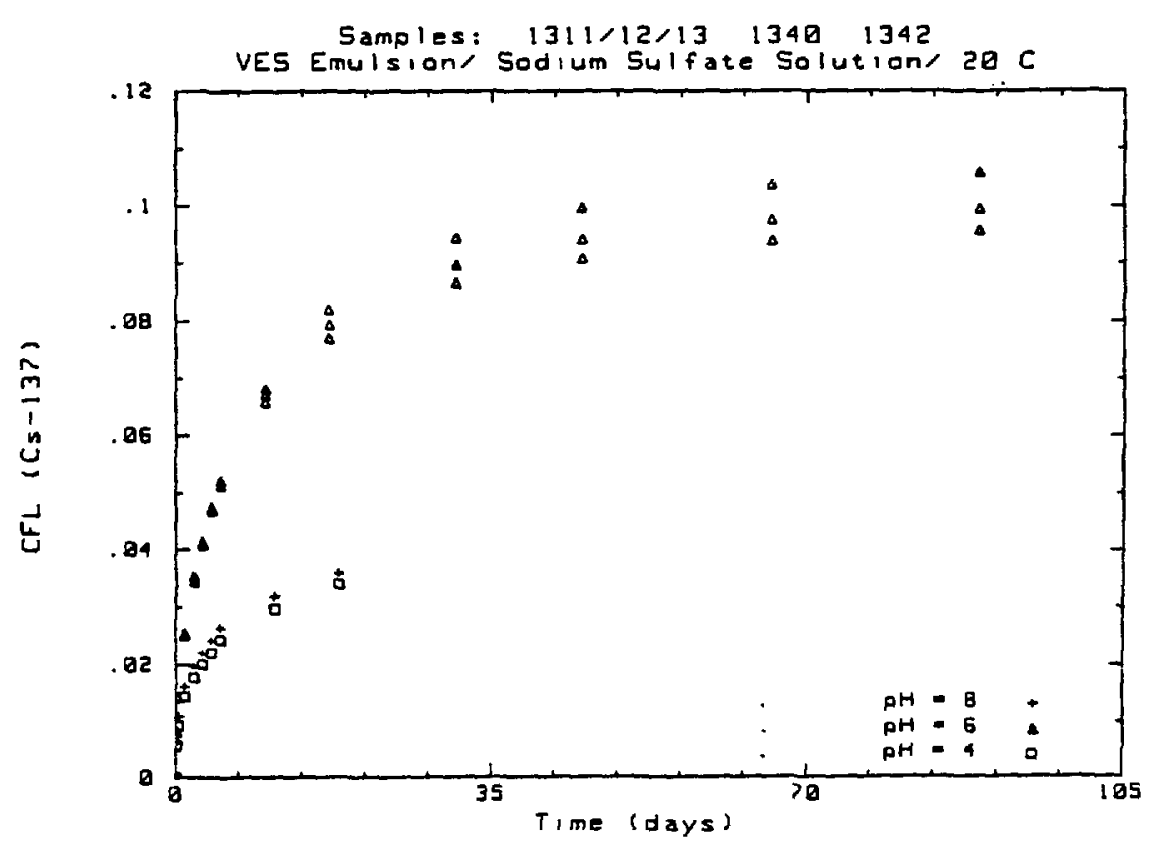

Figure 6.10

Cs-137 cumulative fraction leached vs, time from VES emulsion with aqueous sodium sulfate leached at $20^{\circ} \mathrm{C}$ in leachants with infitial pH values of 4,6 and 8 . 


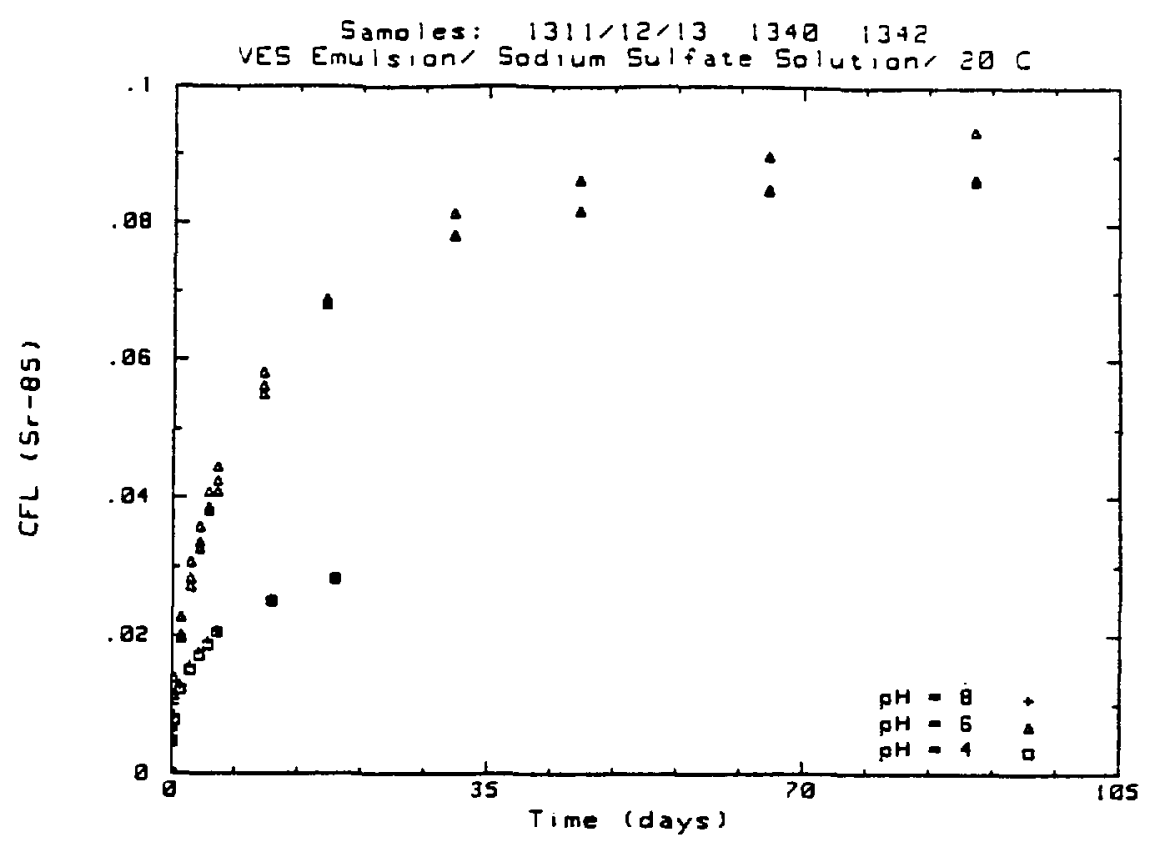

Figure 6.11 Sr-85 cumulative fraction leached vs, time from VES emulsion with aqueous sodium sulfate leached at $20^{\circ} \mathrm{C}$ in leachants with initial pH values of 4,6 and 8 .

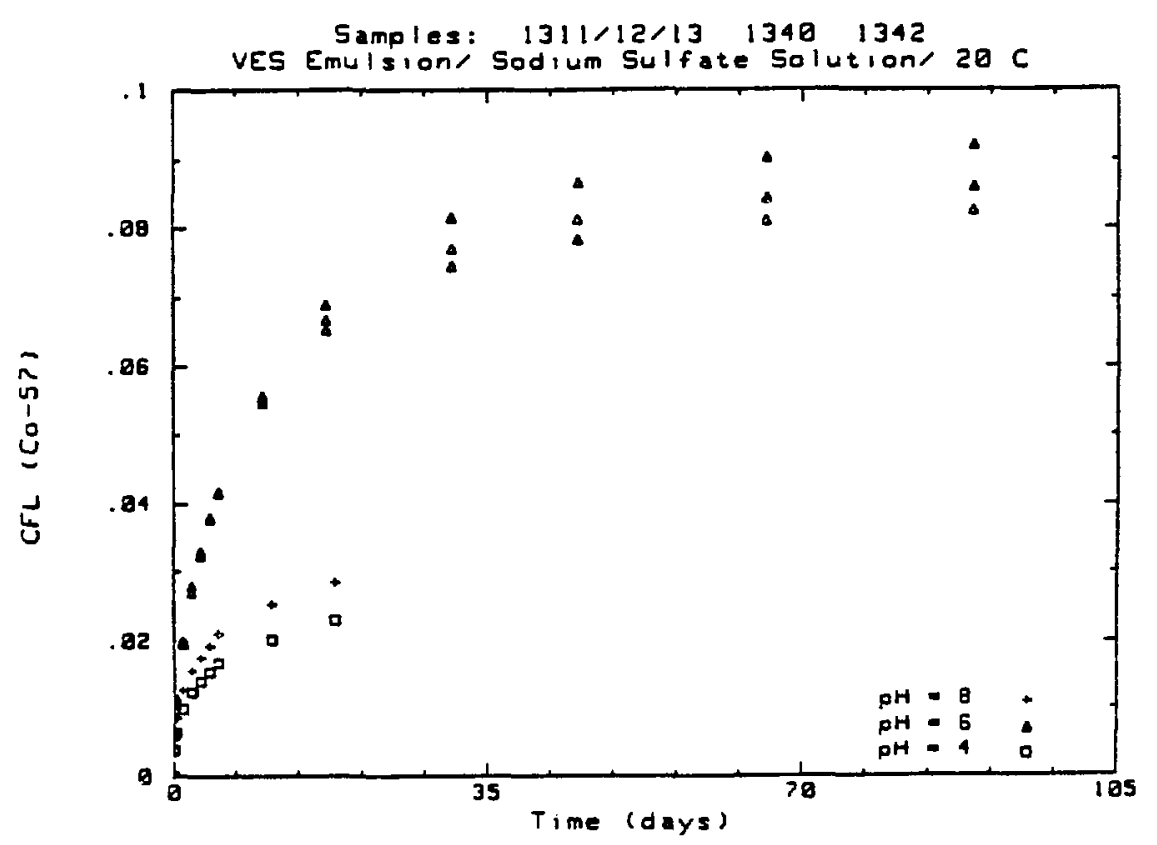

Figure 6.12

Co-57 cunulative fraction leached vs. time from VES emulsion with aqueous sodium sulfate leached at $20^{\circ} \mathrm{C}$ in leachants with initial pH values of 4,6 and 8 . 


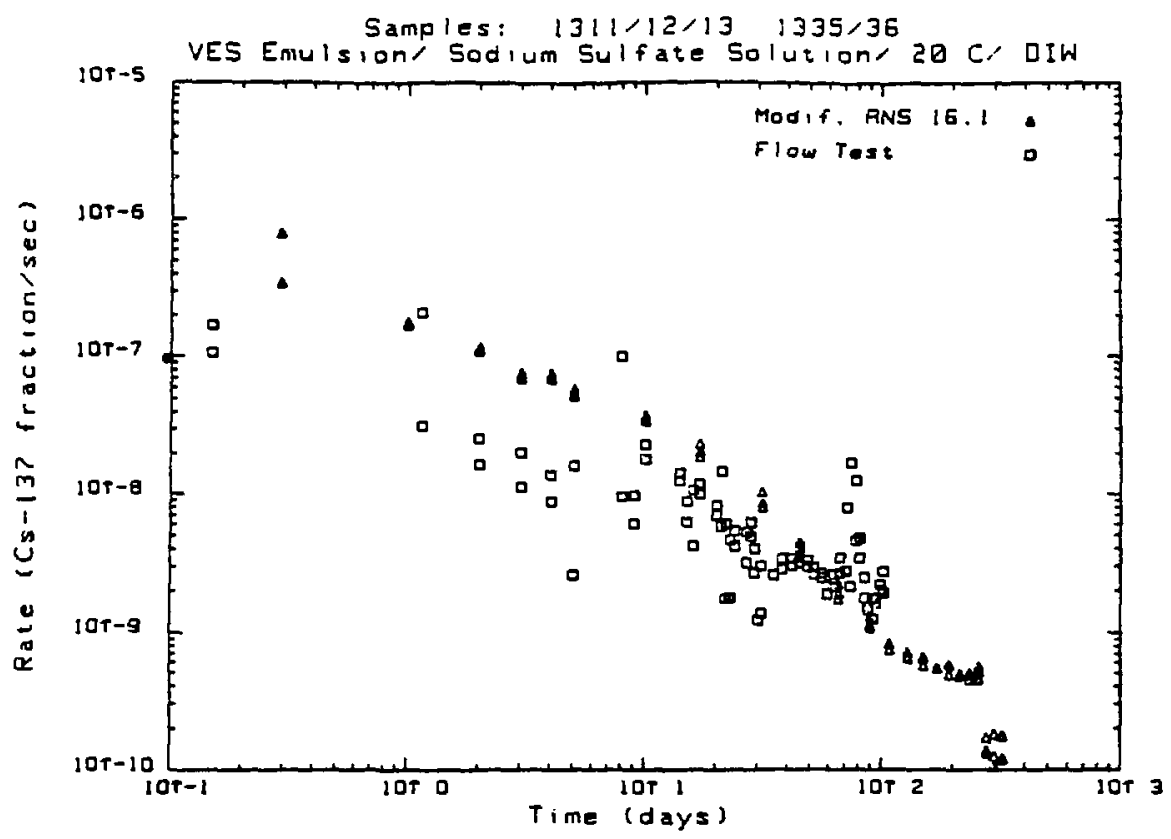

Figure 6.13

Cs-137 incremental leach rate vs. time from VES emulsion with sodium sulfate comparing results from MCC -4S flow test to modified ANS 16.1 leachant replacement schedule. Samples were leached at $20^{\circ} \mathrm{C}$ in deionized water.

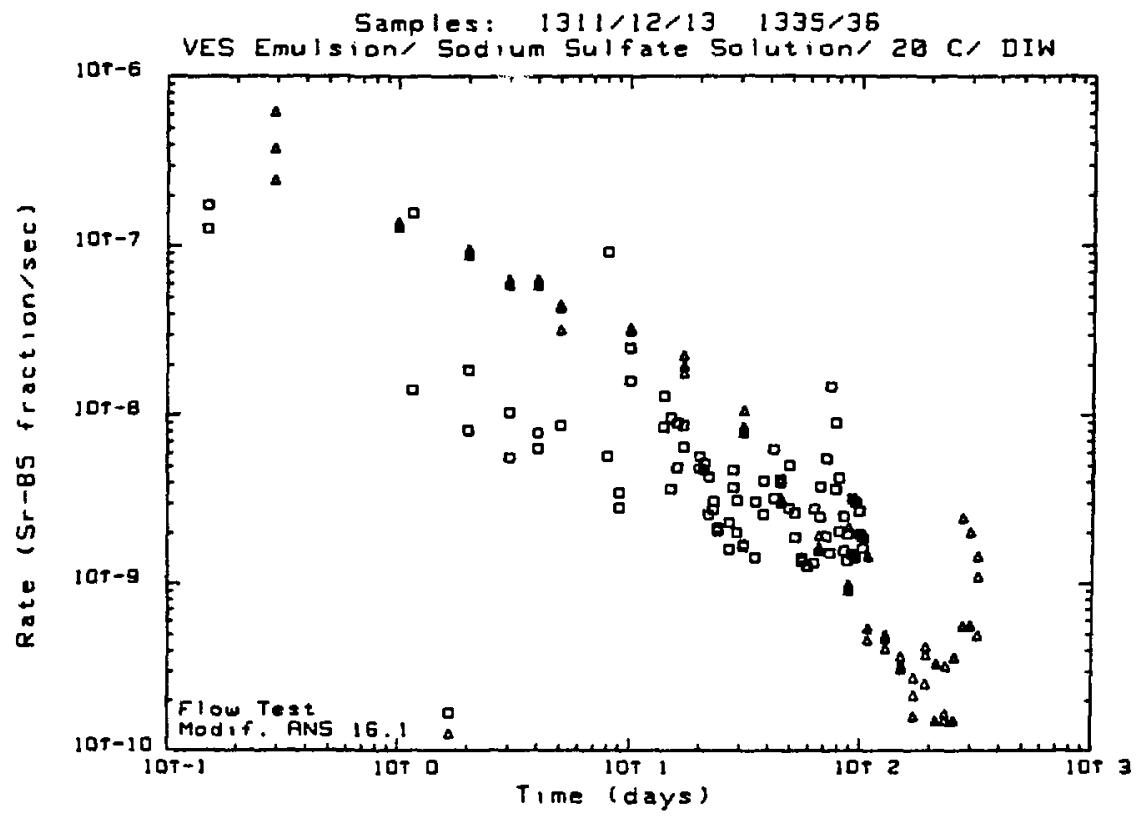

Figure 6.14

Sr-85 incremental leach rate vs. time from VES emulsion with sodium sulfate comparing results from MCC-4S flow test to modified ANS 16.1 leachant replacement schedule. Samples were leached at $20^{\circ} \mathrm{C}$ in deionized water. 


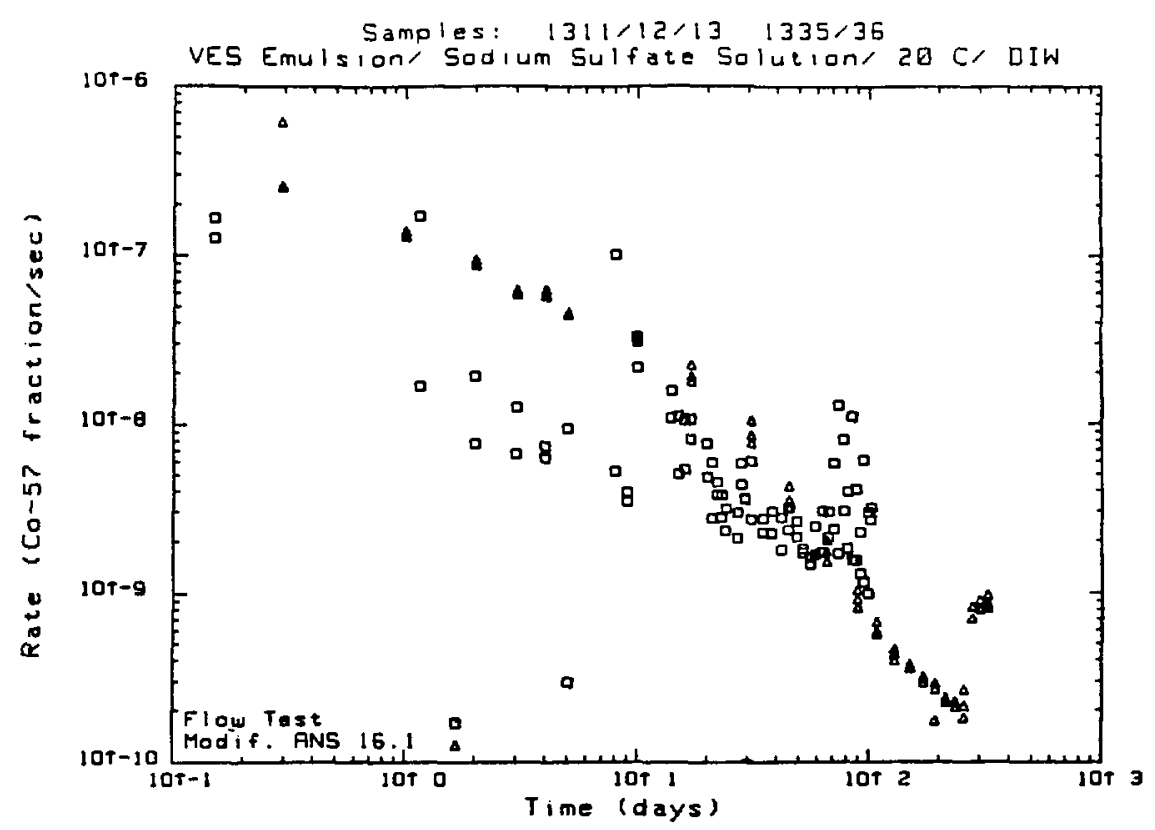

Figure 6.15

Co-57 incremental leach rate vs. time from vES emulsion with sodium sulfate comparing results from MCC-4S flow test to modifled ANS 16.1 leachant replacement schedule. Samples were leached at $20^{\circ} \mathrm{C}$ in deionized water.

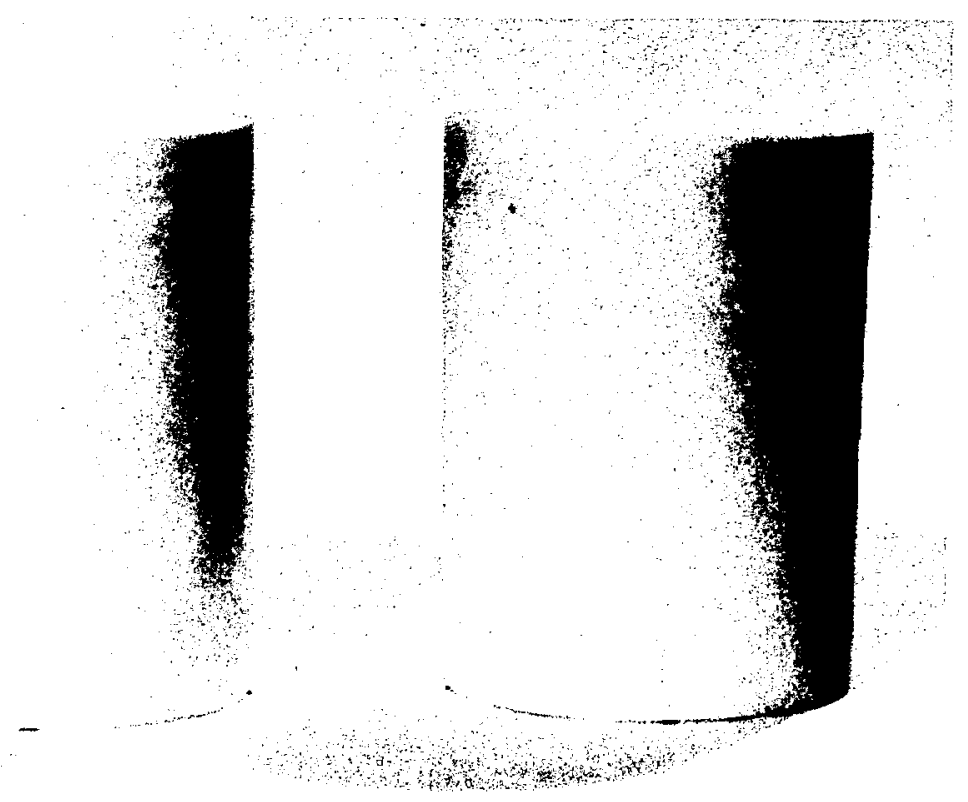

Figure 6.16

VES emulsion with aqueous sodium sulfate. The form at left is as fabricated. The one at right was leached for 403 days in deionized water at $20^{\circ} \mathrm{C}$. Samples were $4.8 \mathrm{~cm}$ diameter by $6.4 \mathrm{~cm}$ high right cylinders. 


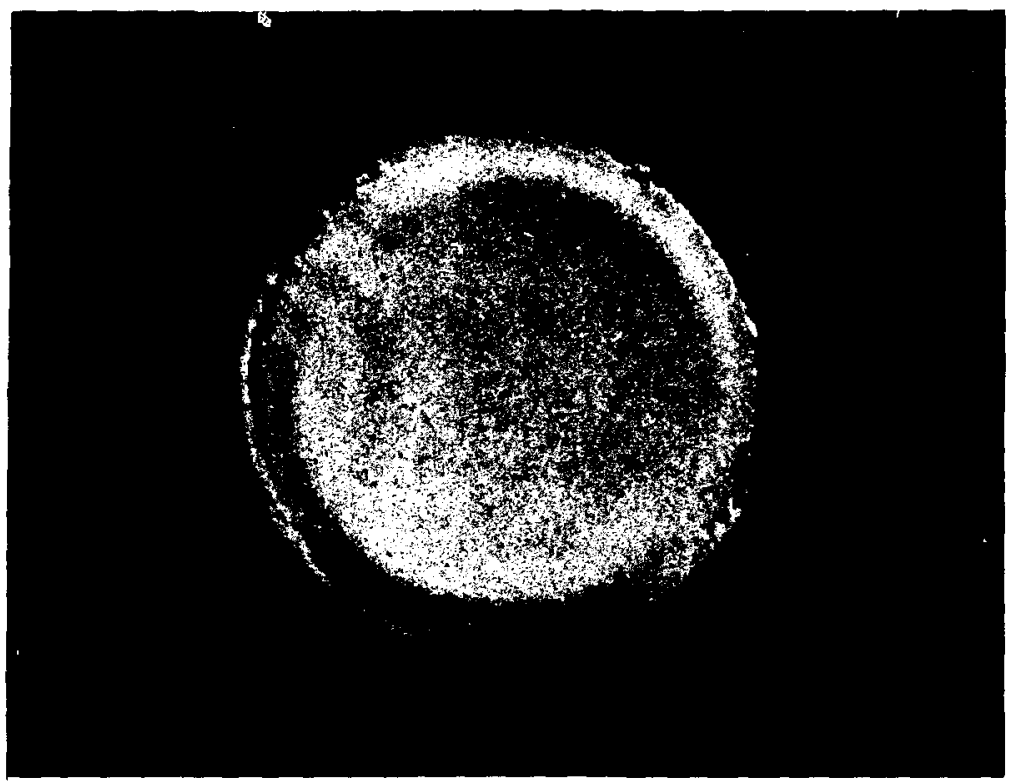

Figure 6.17

Sectioned specimen of VES emulsion with sodium sulfate solution that was leached for 100 days at $50^{\circ} \mathrm{C}$ showing delamination of surface.

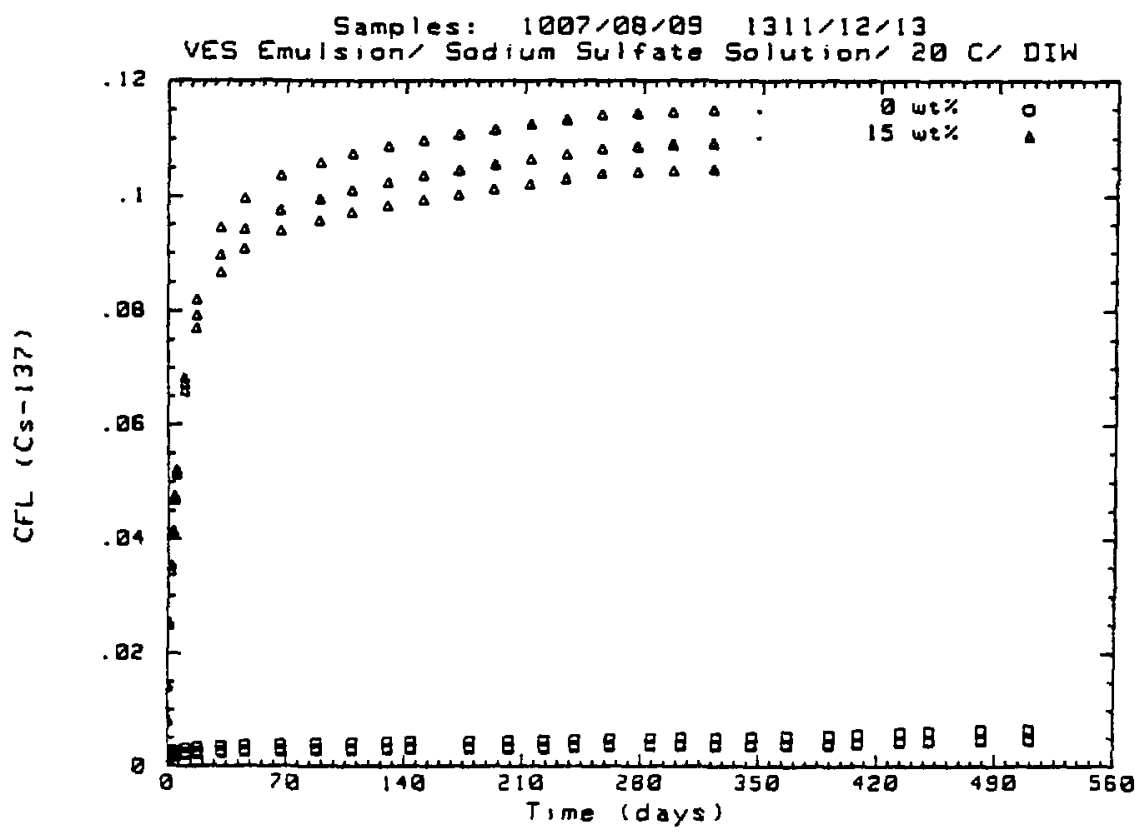

Figure 6.18

Cs-137 cumulative fraction leached vs. time from VES emulstion with aqueous sodium sulfate and from VES emulsion with DIW. Samples were leached at $20^{\circ} \mathrm{C}$ in deionized water. 


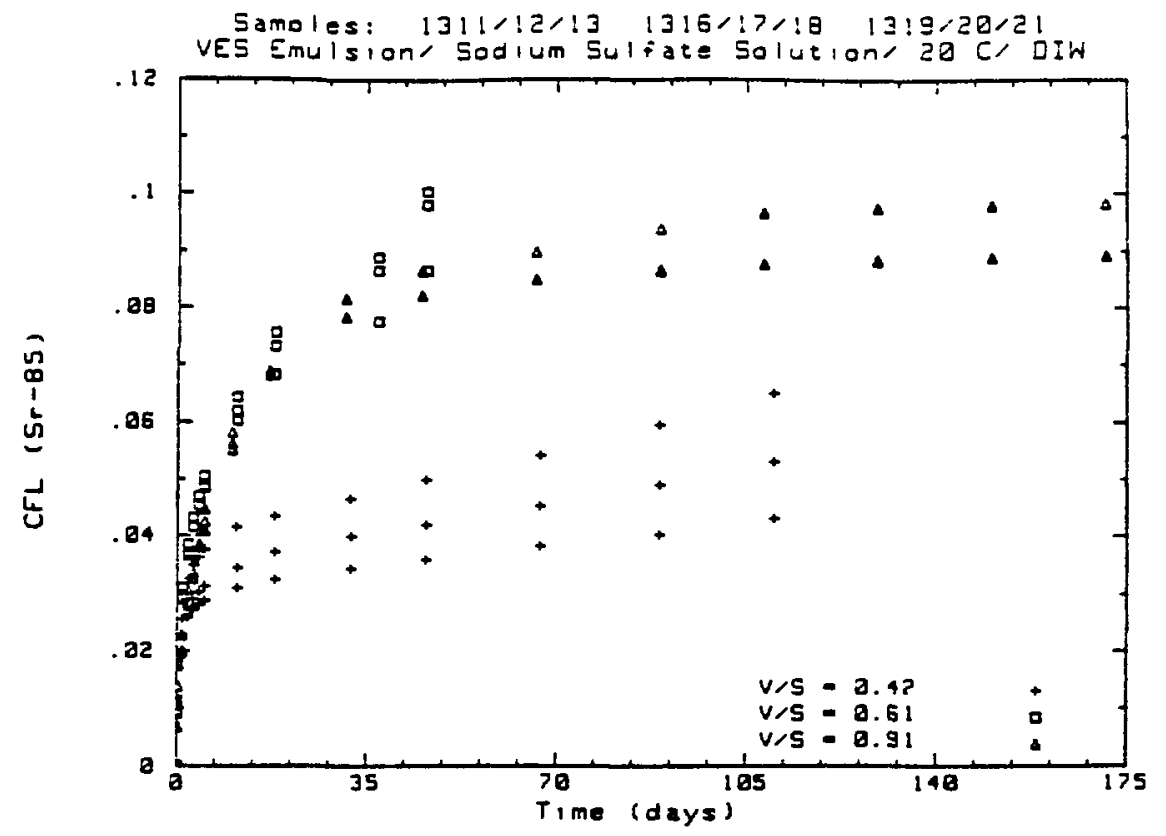

Figure 6.19 Sr-85 cumulative fraction leached vs. time from VES emulsion with aqueous sodium sulfate and from VES emulsion with DIW. Samples were leached at $20^{\circ} \mathrm{C}$ in deionized water.

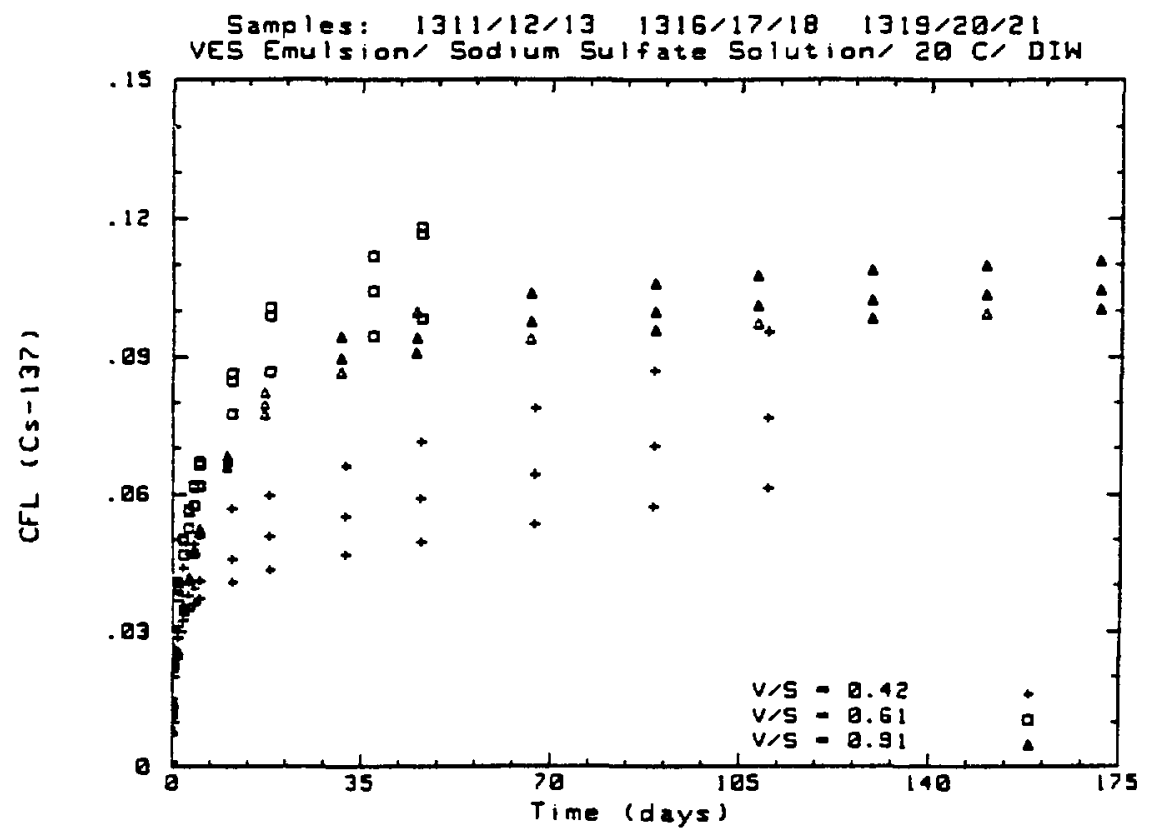

Figure 6.20

Co-57 cumulative fraction leached vs. time from VES emulsion with aqueous sodium sulfate and from VES emulsion with DIW. Samples were leached at $20^{\circ} \mathrm{C}$ in deionized water. 


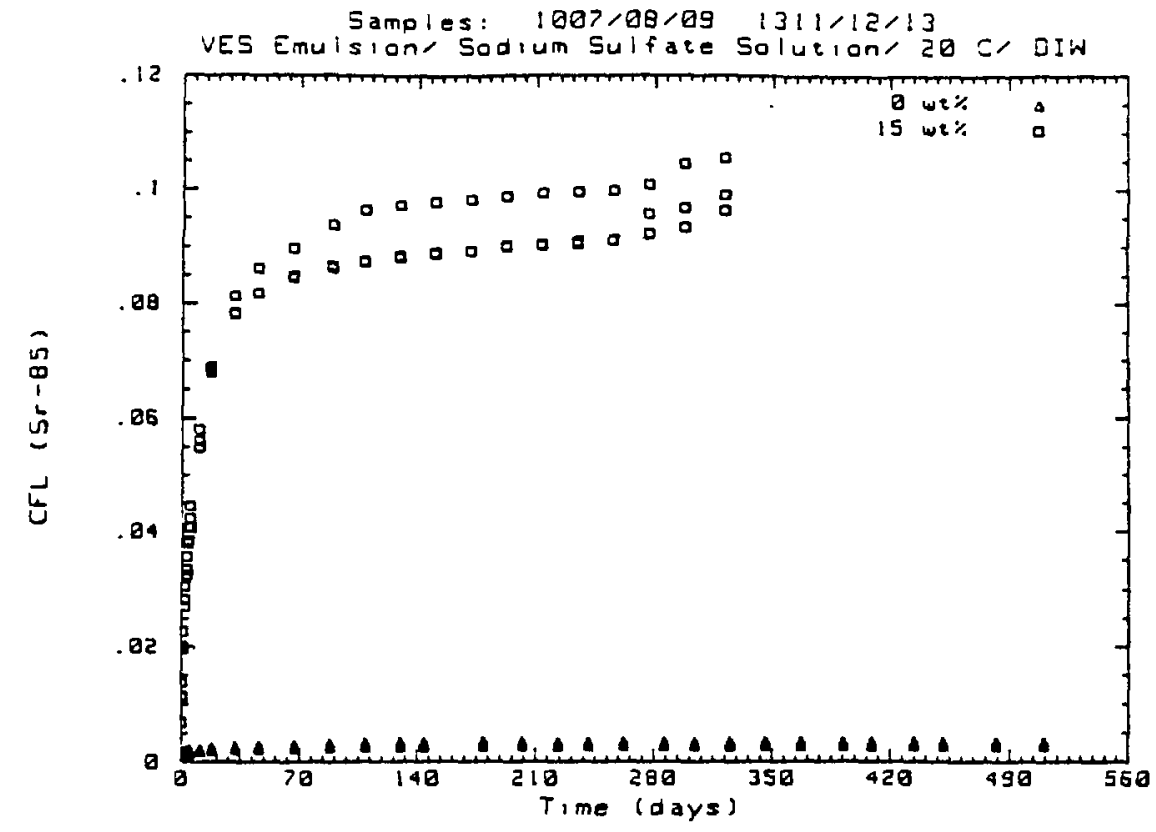

Figure 6.21 Cs-137 cumulative fraction leached vs. time from VES emulsion with aqueous sodium sulfate at waste form volume to surface area $(V / S)$ ratios of $0.42,0.62$ and 0.91 . Samples were leached in deionized water at $20^{\circ} \mathrm{C}$.

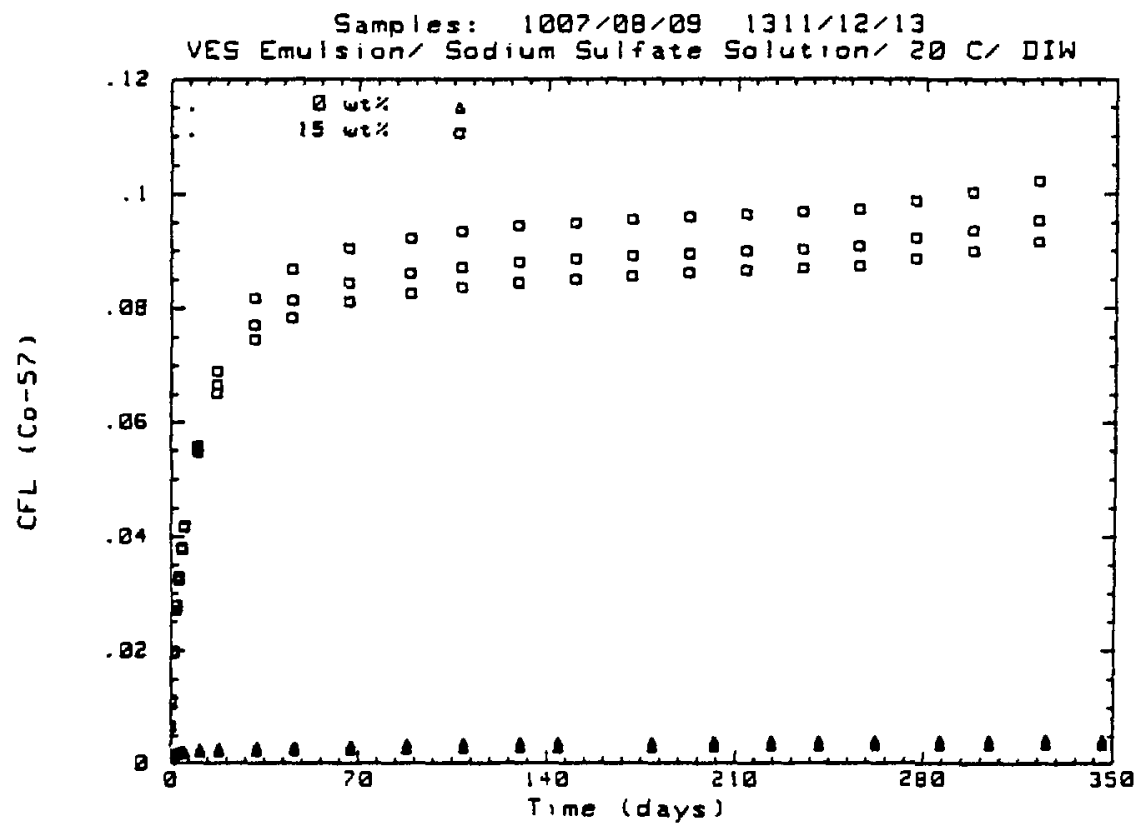

Figure 6.22 Sr-85 cumulative fraction leached vs. time from VES emulsion with aqueous sodium sulfate at waste form volume to surface area $(\mathrm{V} / \mathrm{S})$ ratios of $0.42,0.62$ and 0.91 . Samples were leach in deionized water at $20^{\circ} \mathrm{C}$. 


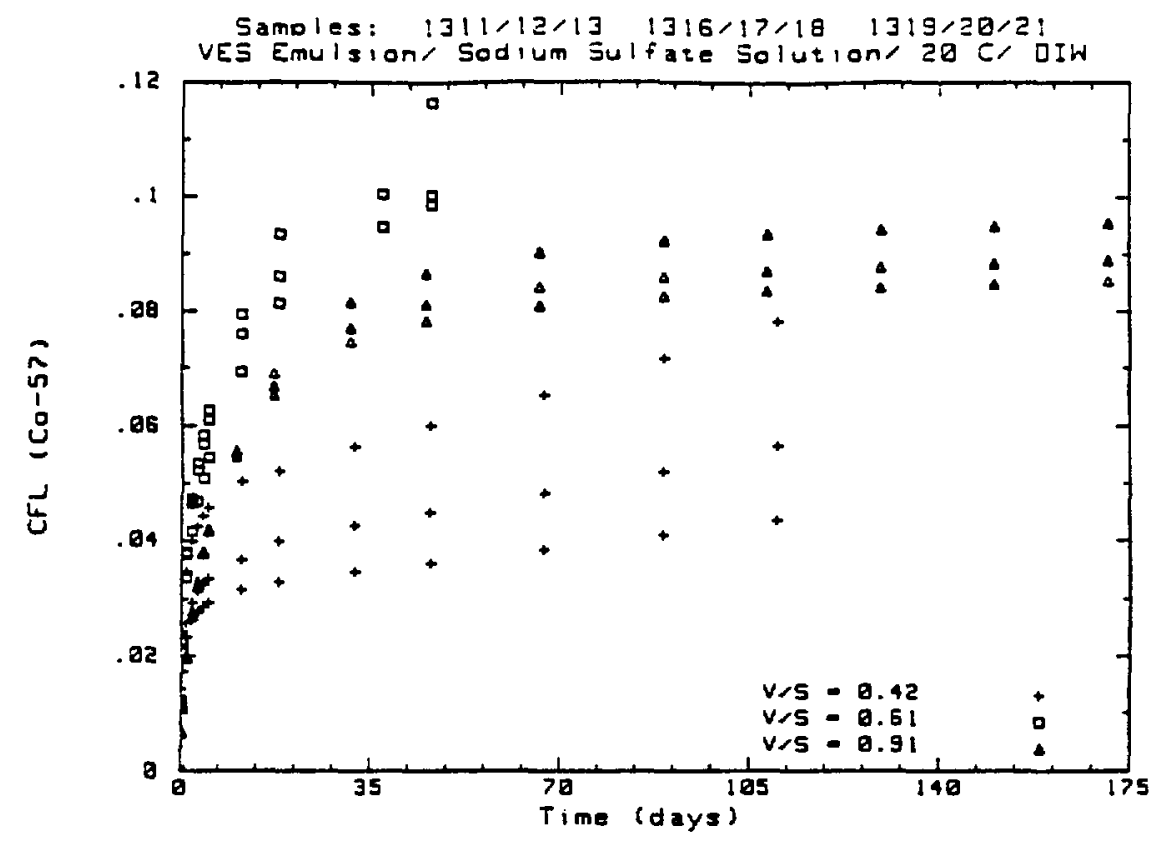

Figure 6.23

Co-57 cumulative fraction leached vs. time from VES emulsion with aqueous sodium sulfate at waste form volume to surface area $(\mathrm{V} / \mathrm{S})$ ratios of $0.42,0.62$ and 0.91 . Samples were leached in deionized water at $20^{\circ} \mathrm{C}$.

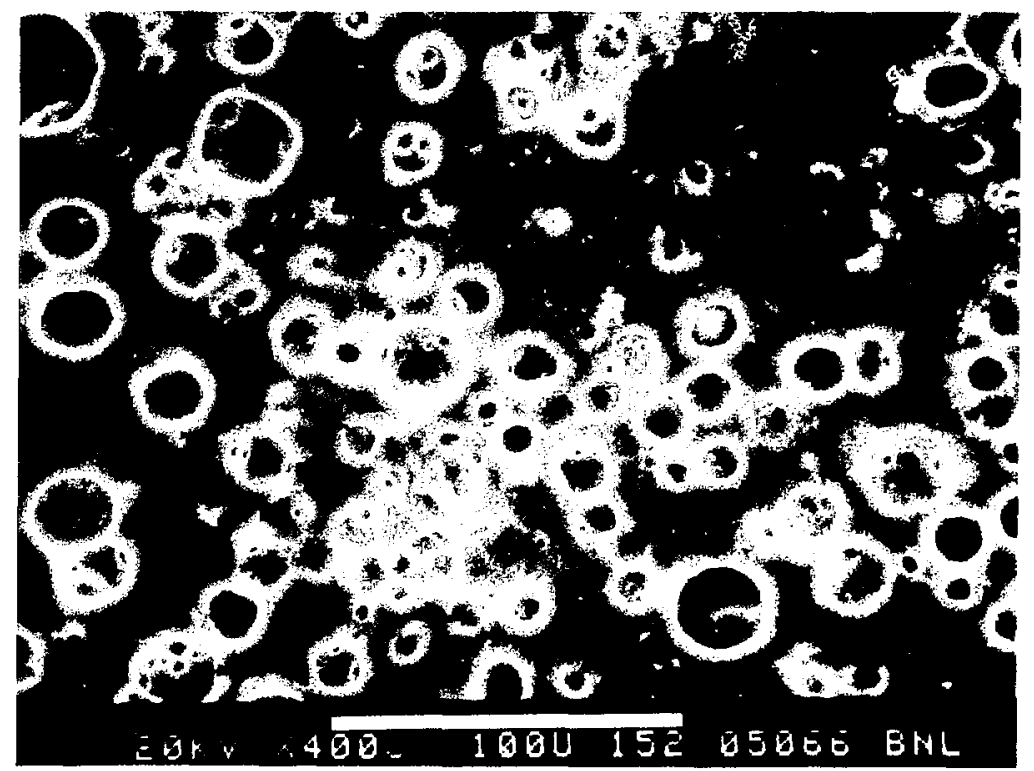

Figure 6.24

Surface of a VES emulsion sample at a magnification of 400 times. Most pores are approximately 5-10 microns in diameter. 


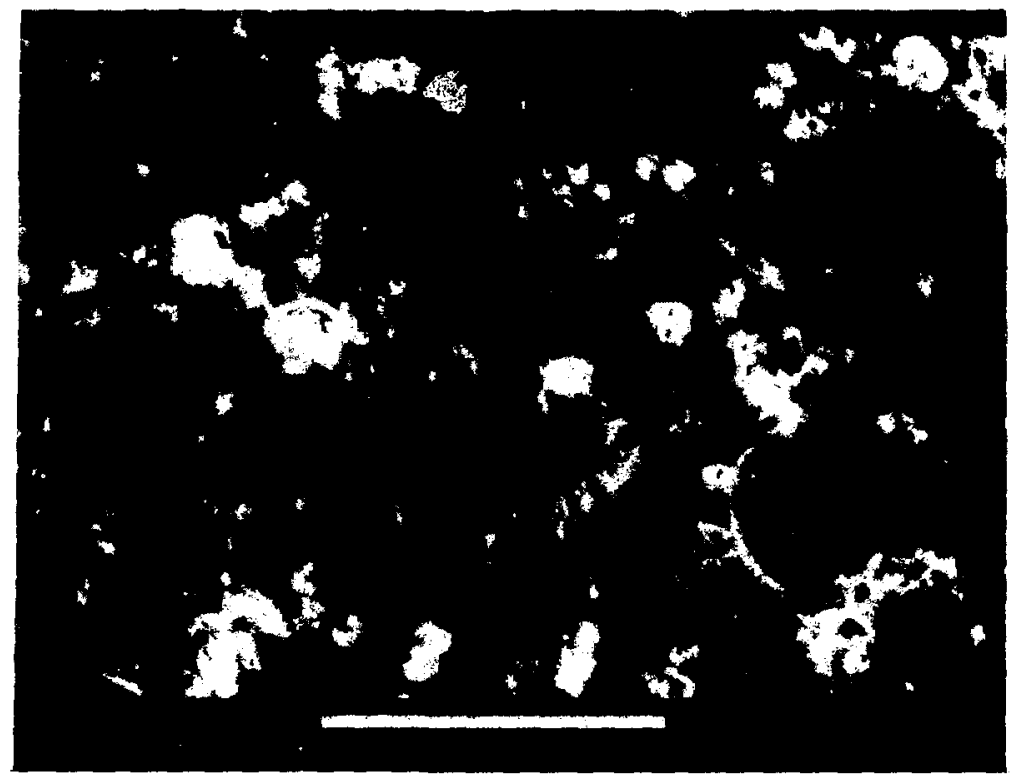

Figure 6.25

Interior section of a VES emulsion sample at a magnification of 400 times. The interior structure appears similar to that of the surface shown in Figure 6.24.

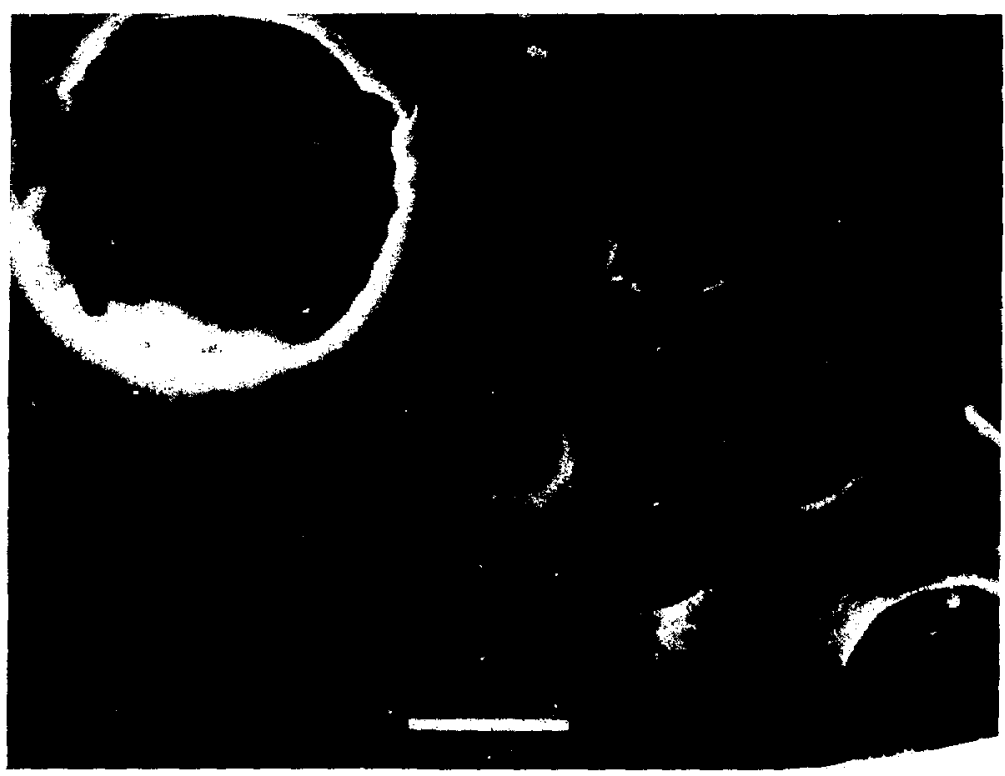

Figure 6.26

Surface of a VES emulsion sample at a magnification of 1900 times. Much smaller pores are visible with diameters less than one micron. 


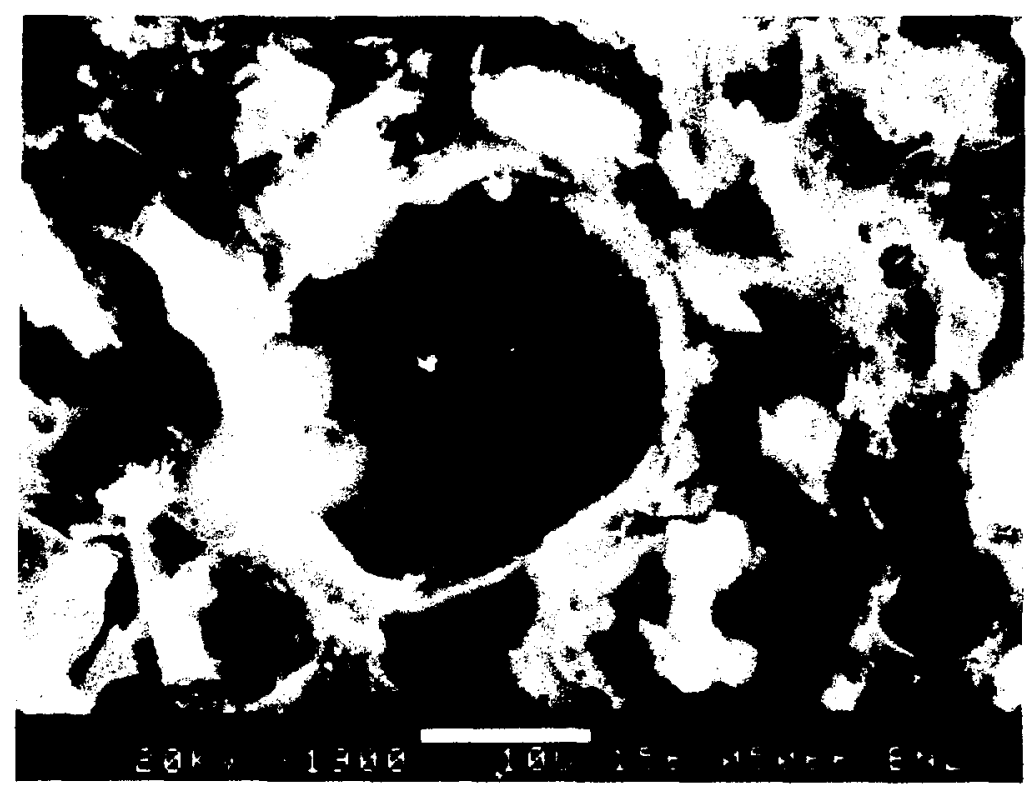

Figure 6.27

Interior section of a VES emulsion sample at a magnification of 1900 times. There is considerable saw debris, but the pores are in the same size range as those at the surface, shown in Figure 6.26. 


\section{VINYL ESTER-STYRENE (VES) CONTAINING SULFATE SALT AS SIMULATED WASTE}

The use of polymeric solidification agents for the disposal of low-level radioactive waste is of interest to the nuclear industry. A major benefit from these materials is the high waste loading that can be achieved when they are coupled to an advanced volume reduction system, such as an evaporator/ drier.

Application of thermosetting polymers for the solidification of dry waste is based on the physical encapsulation of the waste stream. Polymerization of the liquid monomer takes place when a catalyst and promoter are added, yielding a continuous matrix of cured polymer with small waste particles dispersed throughout. The polymer matrix is structurally rigid and of very limited permeability to water: this implies that the pore structure of the polymer matrix remains intact even though the waste may dissolve out of or otherwise be removed from the waste form. The impermeability of the polymer matrix to water means that mass transport of waste substances occurs through, and is constrained by, the pore structure of the matrix. The only other interaction between the polymer matrix and the waste that may affect leaching is sorption or ion exchange capacity. In our experiments these mechanisms were below detectable levels for the radionuclides of interest. There is little, if any, chemical reaction between the waste and the matrix. This discussion is predicated on the assumption that the waste has not interfered with the polymerization process itself.

This section presents data from studies investigating potential leach rate acceleration factors for waste forms consisting of vinyl ester-styrene copolymer and anhydrous sodium sulfate salt as simulated waste.

\subsection{Mechanisms of Leaching}

Vinyl ester-styrene specimens containing only radioactive tracers leached so slowly that no statistically significant activity was detected in the leachate [3]. Addition of $40 \mathrm{wt}$ dry salt increased leaching by a factor of 200 to 300 times, apparently by producing a network of interconnected pores that allowed water to enter and dissolved salt to leave the specimen.

Waste loading is a major determinant of leaching behavior in VES waste forms incorporating soluble salts. Such behavior is not explainable by assuming that the waste form approximates to a homogeneous medium. Instead, the two-phase nature of the waste form must be explicitly recognized as being a major factor that determines leaching behavior in this and similar systems.

The data presented in this section suggests a two-part leaching process for this material. In several experiments, leaching behavior during the first week was characterized by low scatter in the data and a positive response to acceleration factors. After this initial period, leaching became much more variable. This change may be the result of the structure of the specimens. Electron microscope images, presented in section 7.2.8, show that a coating of polymer (without salt particles) surrounds the main body of the waste/polymer composite. As a result, leaching may proceed in two steps: 
1. diffusion of water through the outer coating,

2. dissolution and transport of waste through the tortuous porosity which develop as leaching proceeds.

\subsection{Factors that Affect Leaching}

Leaching results from experiments designed to investigate each of the factors listed in Table 2.1 for vinyl ester-styrene waste forms containing sodium sulfate are discussed in the following sections. Each acceleration factor is evaluated by comparing results for that factor with those from a set of baseline leaching experiments on standard specimens (i.e., $4.8 \mathrm{~cm}$ diameter by $6.4 \mathrm{~cm}$ high right cylinders, at $20^{\circ} \mathrm{C}$ in 1.3 liter of deionized water). Replicate tests, generally triplicates, provided a measure of the variability of the data.

7.2.1 Temperature. The ability of increased temperature to accelerate leaching of VES waste forms containing sodium sulfate was investigated at 40 and $50^{\circ} \mathrm{C}$. Releases of $\mathrm{Cs}-137$ at these temperatures and at $20^{\circ} \mathrm{C}$ are shown in Figure 7.1. Releases below $0.2 \mathrm{CFL}$ and prior to 7 days leaching had little scatter and a general trend of increased leaching with temperature (Figure 7.2). With longer leaching times, the scatter among samples increased to the point where this trend was not observable. Releases stop at about $0.8 \mathrm{CFL}$. Assuming this is not a source term problem, the implication is that $20 \mathrm{o}$ of the waste is held in unconnected pores or has been permeated with VES. In either case, the waste is unavailable for leaching. This phenomenon was also observed for $\mathrm{Sr}-85$ and $\mathrm{Co}-57$ at the same CFL values, as shown in Figures 7.3 and 7.4 , respectively.

Linear correlations for Cs-137 CFL at different temperatures are shown in Figure 7.5. During the first week of the test, leaching at elevated temperatures resulted in non-linear releases compared to releases at $20^{\circ} \mathrm{C}$. Figures 7.6 and 7.7 give correlation plots for $\mathrm{Sr}-85$ and $\mathrm{Co-57}$, which appear more linear in this early stage of leaching than does the data for Cs-137.

The increase in leachability and scatter with the longer leaching intervals could be the effect of a change in properties of the polymer itself. More likely, it is caused by increasing porosity as salt dissolves. However, this is unknown as are the basic responses of the material to the effects of dissolution of salt and elevated temperature. Continued efforts with solid phase analysis will be needed to understand these processes.

7.2.2 Ratio of Waste Form Surface Area to Leachant Volume. To maximize release rates, the concentration gradient of any dissolved species, between the pore water of the waste form and the leachant, should be as large as possible. This effect can most easily be observed by increasing the volume of leachant. Typically for the sample size used for these tests the leachant volume was $1300 \mathrm{ml}$ (a surface area to leachant volume ratio of 10:1) but tests were also run at $2600 \mathrm{ml}(20: 1), 3900 \mathrm{ml}(30: 1)$ and $6500 \mathrm{ml}(50: 1)$. 
Results for the four ratios tested are shown in Figure 7.8 for Cs -137 and in Figures 7.9 and 7.10 for $\mathrm{Sr}-85$ and Co-57, respectively. In all cases release rates of specimens leached at ratios of 20,30 and 50 are not statistically different than the release rates in the reference ratio of 10 . This is reasonable, since the solubility of the hydrated sodium sulfate salt $\left(\mathrm{Na}_{2} \mathrm{SO}_{4} \cdot 10 \mathrm{H}_{2} \mathrm{O}\right)$ is $143 \mathrm{~g}$ in $1300 \mathrm{ml}$ of cold water. Each waste form contained approximately $44 \mathrm{~g}$ of anhydrous sodium sulfate (which weighed about $100 \mathrm{~g}$ when fully hydrated). Therefore each volume of leachant could have dissolved the total load of salt that was present in any waste form. Therefore, increasing the volume of the leachant is not a useful acceleration factor for VES containing dry sodium sulfate salt.

7.2.3 Composition of the Leachant. While deionized water was the standard leachant used, others were investigated for their potential as accelerating factors. These were:

1) a simulated ground water from Oak Ridge National Laboratory [63], under oxidizing and reducing conditions

2) a solution of $100 \mathrm{ppm}$ disodium EDTA

Figure 7.11 shows CFL for $\mathrm{Cs}-137$ for anoxic and oxic groundwater and, as a basis for comparison, deionized water. Anoxic ground water leached Cs-137 at a slower rate than did oxic ground water, probably because of the higher ionic strength of the anoxic solution. However, the two groundwaters are not statistically different than deionic $d$ water. Similar results were obtained for Sr-85 and Co-57, as shown in Figures 7.12 and 7.13 respectively. Co-57 is the only multivalent radionuclide that was investigated and here some effect of reducing conditions may be expected. In power-reactor waste the Co-60 is primarily associated with particulates and is not readily soluble under oxidizing conditions. In the simulated waste used in this study, the Co-57 already was in solution. Therefore, exposure to reducing conditions (which converts cobalt to a more soluble low valence state) would not alter leachability of cobalt in solution, but could strongly enhance the leaching of cobalt that was in the solid phase. Therefore, some enhanced releases of Co-60 could be expected from real waste under reducing conditions.

There was no discernable effect on the leaching of VES specimens in 100 ppm disodium EDTA, as shown in Figures $7.14,7.15$ and 7.16 for $\mathrm{Cs}-137, \mathrm{Sr}-85$ and Co-57, respectively. Again, some increase in Co-60 leaching from real reactor waste may be expected due to increased solubility of complexed cobalt.

7.2.4 pH of the Leachant. The effects of leachant $\mathrm{pH}$ were investigated at solution $\mathrm{pH}$ values of $8,6,5,4$ and 3 . The $\mathrm{pH}$ of the deionized water used in this study is nominally 7 at $20^{\circ} \mathrm{C}$, but dissolution of carbon dioxide from the air moves this value to around 6 . In fact, $\mathrm{pH}$ measurements of deionized water are difficult due to the very low ionic strength of the water.

Releases of Cs-137 from VES samples containing 40 wt sodium sulfate are shown in Figure 7.17. During the first ten days the test $\mathrm{pH}$ had a positive effect on leaching. Later, increased scatter in the data masked any acceleration (Figure 7.18). Releases of Sr-85 and Co-57 are shown in Figures 7.19 and 
7.20. Acceleration is less evident, although leaching at pH 8 shows a slight positive effect early in the experiments.

The linear correlation plot for Cs-137, Figure 7.21, indicates that acceleration occurred at $\mathrm{pH}=8$ but it was not linear. This may indicate that the matrix material was changing, or that there was an effect of the length of sampling interval.

7.2.5 Flow Rate or Replacement Frequency of the Leachant. The effects of increased exposure to water, to maximize the concentration gradient across the waste form, can be accomplished by increasing the volume of the leachant as discussed in section 7.2.2. It can also be done by increasing the frequency with which the leachant is replaced or by using a continuous flow-thro'dgh leach test, such as the MCC-4s procedure.

Figures $7.22,7.23$ and 7.24 show Cs-137, Sr-85 and Co-57 data from triplicate experiments with daily sampling intervals as well as for the ANS 16.1 tests. Daily samplings give results similar to those of the ANS 16.1 tests. While $\mathrm{Sr}-85$ and $\mathrm{Co}-57$ releases from the daily intervals appear lower than Cs -137 , the difference is not statistically significant.

Similarly, results from continuous flow-through tests show little difference from the ANS 16.1 test. Figures $7.25,7.26$ and 7.27 present the flow-through and ANS 16.1 results as rates (fraction release/second) because data from the flow-through test is not readily calculated as cumulative fraction leached. Again, the two tests are not discernibly different. The data for the ANS 16.1 test falls to low rates, but this fall occurs at times longer than the flow-through data was taken.

7.2.6 Composition of the Waste Form. Composition of the waste form, in the $:$ : e of waste loading, could be a useful acceleration factor if a syst.isutic increase in leaching is a function of waste content. This concept was explored for VES containing sodium sulfate at loadings of 20, 30 and 40 wt\%. Leachabilities at these loadings are shown in Figures $7.28,7.29$ and 7.30 for Cs-137, Sr-85 and Co-57. After 30 days of leaching, Cs-137 releases were related to the amount of loading, with the 20 wt: loading having the lowest CFL and the $40 \mathrm{wt}$ loading the highest. Earlier in the experiment, this was not so. Strontium-85 data shows no difference in leaching between the 20 and 30 wto specimens. Only single specimens were used for the 20 and 30 wto loadings, and the variability between samples makes it difficult to draw conclusions. It is unclear if this factor is a useful means of acceleration. From theoretical considerations, discussed earlier in this report, loading should accelerate leaching. More experimental work is needed in this area.

\subsubsection{Waste Form Volume to Surface Area Ratio. By altering the size} and shape of leaching specimens and by meeting required conditions of the leaching mechanism (e.g., control by diffusion) it is possible, on theoretical grounds, to accelerate leaching as discussed in section 2.7. Consequently tests were run with varying ratios of volume to surface area $(\mathrm{V} / \mathrm{S})$.

Several specimens were made of two sizes other than the standard $6.4 \mathrm{x}$ 4.8 cylinder $(V / S=0.91)$. The dimensions, volumes and surface areas of each 
sample are given in Appendis $A$. The specimens with $V / S=0.62$ were cylindrical disks measuring $1.6 \mathrm{~cm}$ in height and $13.8 \mathrm{~cm}$ in diameter. These were leached in $3650 \mathrm{ml}$ of water to maintain the surface area to leachant volume of 10. Specimens with $\mathrm{V} / \mathrm{S}=0.41$ were cylinders measuring $2.6 \mathrm{~cm}$ height by 2.4 $\mathrm{cm}$ in diameter, which were leached in $300 \mathrm{~m} 1$ of water.

Results are shown in Figures $7.31,7.32$ and 7.33 for Cs-137, Sr-85 and Co-57 respectively. Similar trends were observed for all isotopes. The small cylinders $(\mathrm{V} / \mathrm{S}=0.41)$ had greater releases than did the disks $(\mathrm{V} / \mathrm{S}=0.62)$. For the first week of leaching, the small specimens also leached significantly faster than the standard sized specimen. This was up to a CFL of about 0.40 . At this point depletion and scatter in the data from standard sized specimens make analysis difficult. Releases from the disk-shaped specimens were not significantly different than those from the standard leach rates for Cs-137. Leach rates for specimens of $\mathrm{V} / \mathrm{S}=0.42$ wers substantially greater than the others for the first 6 days. Results from the disk-shaped specimens may not be useful because the difference in aspect ratio of the disk versus the cylinders could give misleading results.

7.2.8 Porosity and Surface of the Waste Form. Little work was done to characterize solid phase controls on leachability of this material. The physical appearance of leached specimens as shown in Figure 7.34 was much like that of unleached replicates. To date there have been no studies conducted to determine how the VES matrix responds to leaching of soluble components from the waste form.

Figure 7.35 is an SEM micrograph, at 60 fold magnification, of the interior of an unleached VES specimen containing 408 sodium sulfate salt. Individual salt grains were surrounded by the polymer matrix. At this waste loading there is little contact between grains. There were several air bubbles with diameters of about $50-75 \mathrm{~m}$. When the surface of this specimen was observed by SEM (Figure 7.36), no salt was visible and the $x$-ray spectrum showed very little sodium or sulfur. Apparently a coating of polymer that contained no salt formed around the specimen. Some small pores leading through the coating are visible on this surface.

SEM examination of a leached specimen showed no phvsical difference from an unleached sample. The boundary between the polymer and salt grains was intact and the salt showed no signs of dissolution. This is shown in Figure 7.37 where the polymer matrix is visible, at the center of the photograph, between two salt grains. Energy-dispersive spectroscopy suggested that no sodium or sulfur was present in the matrix next to salt grains, even after leaching. The surface of the leached specimen was similar in appearance to the unleached surface, although more pores may have been present. A more detailed study of this material is necessary to relate the structure of the solid phase to its leaching behavior. 


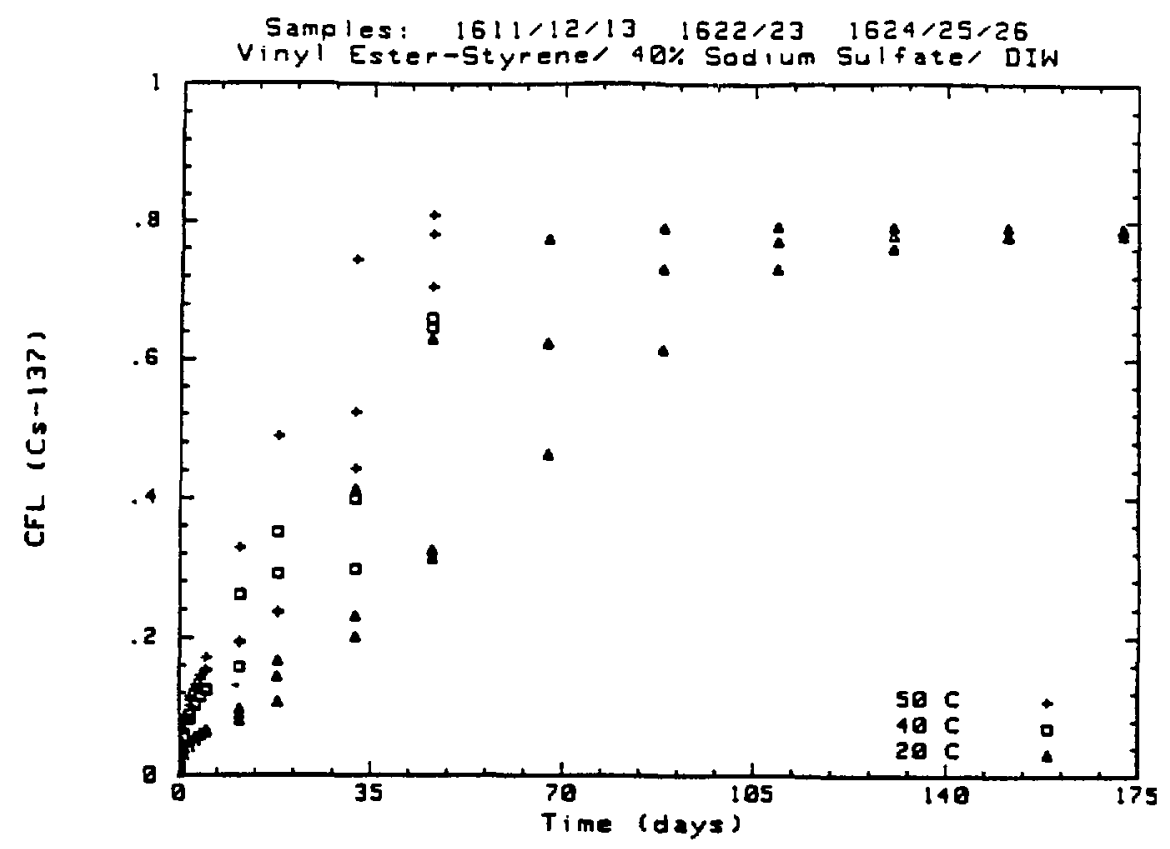

Figure 7.1

Cs-137 cumulative fraction leached vs. time fron VES containing 40 wt sodium sulfate at 20,40 and $50^{\circ} \mathrm{C}$. Samples were leached in deionized water.

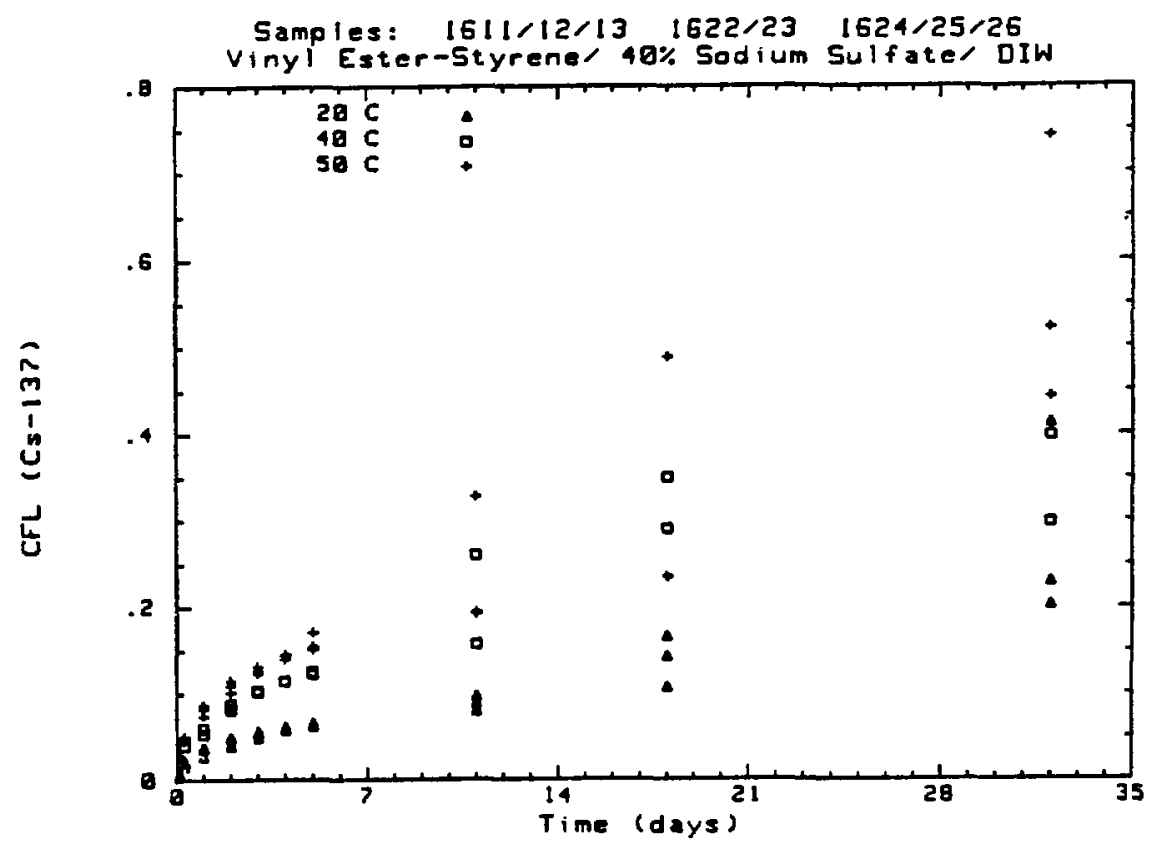

Figure 7.2

Cs -137 cumulative fraction leached vs. time fron VES containing 40 wt sodium sulfate at 20,40 and $50^{\circ} \mathrm{C}$ leached in deionized water. Data shown is for inftial 35 days of the experiment. 


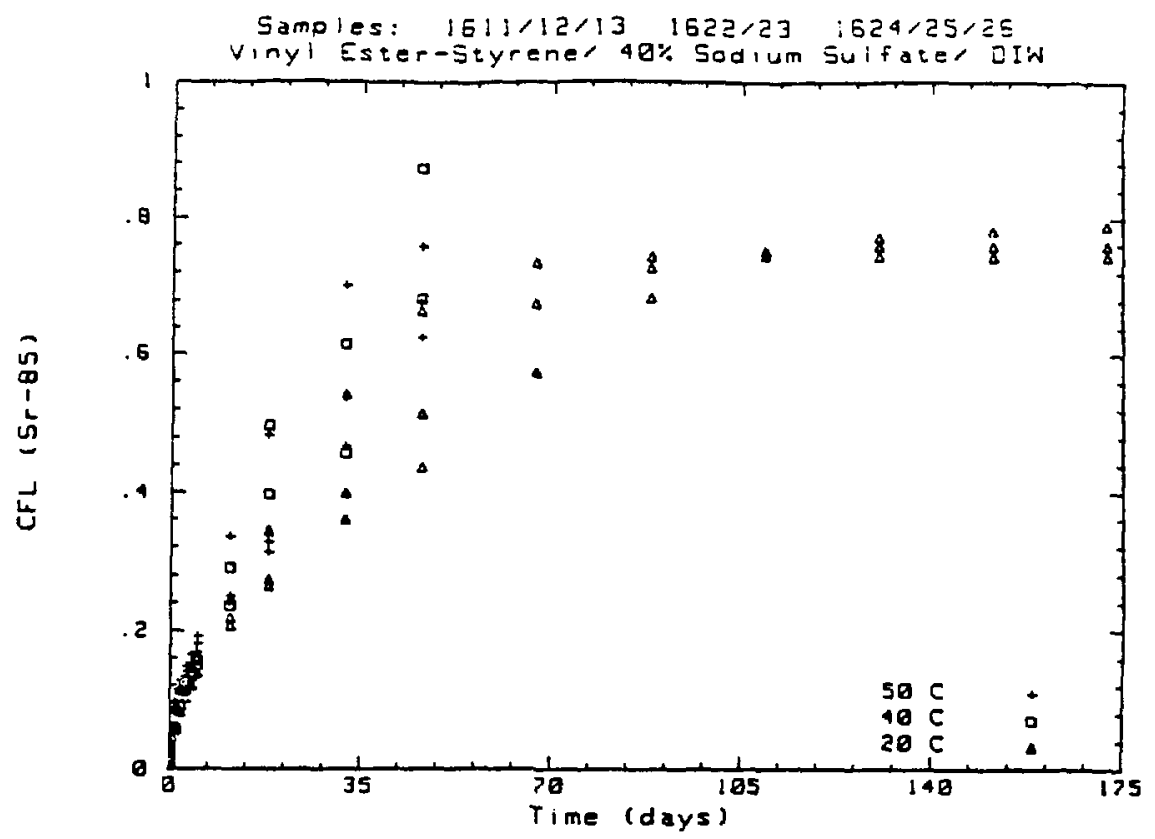

Figure 7.3 Sr-85 cumulative fraction leached vs. time from VES containing 40 wt sodium sulfate at 20,40 and $50^{\circ} \mathrm{C}$ in deionized water.

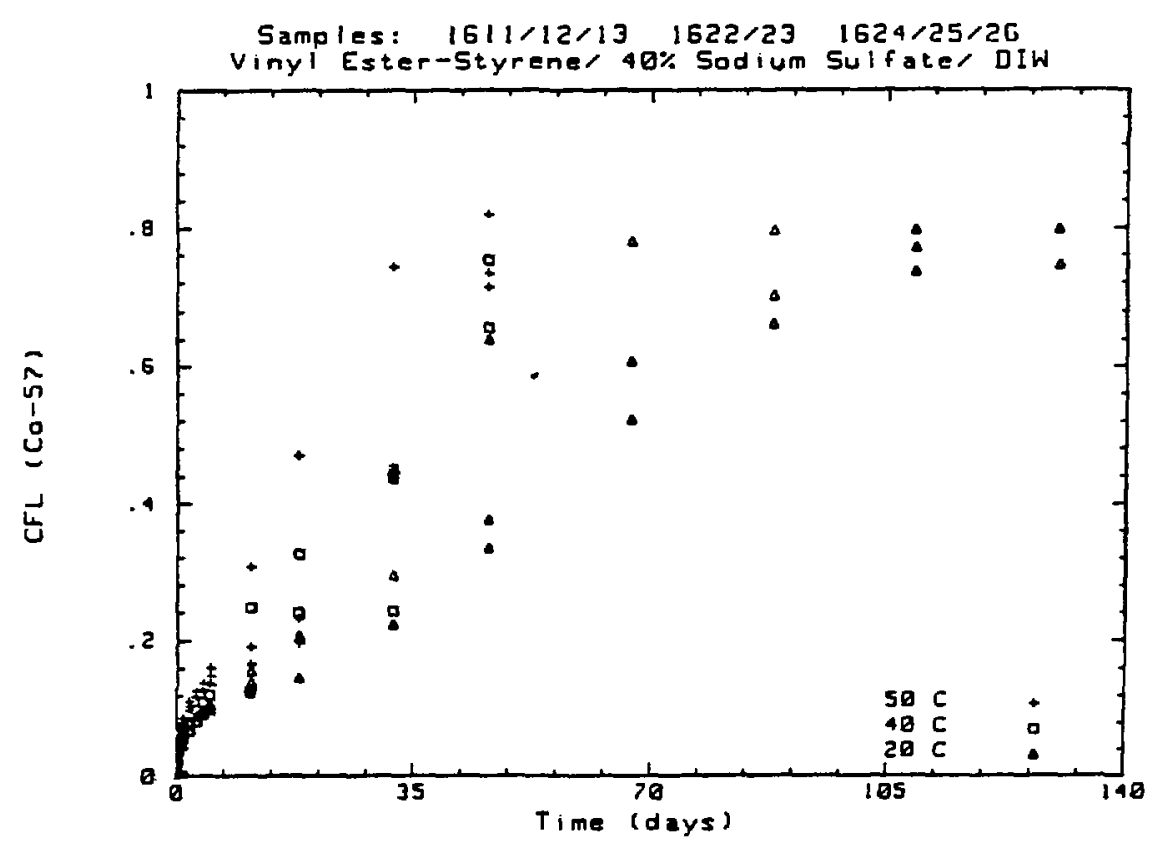

Figure 7.4

Co-57 cumulative fraction leached vs. time from VES containing 40 wto sodium sulfate at 20,40 and $50^{\circ} \mathrm{C}$ leached in deionized water. 


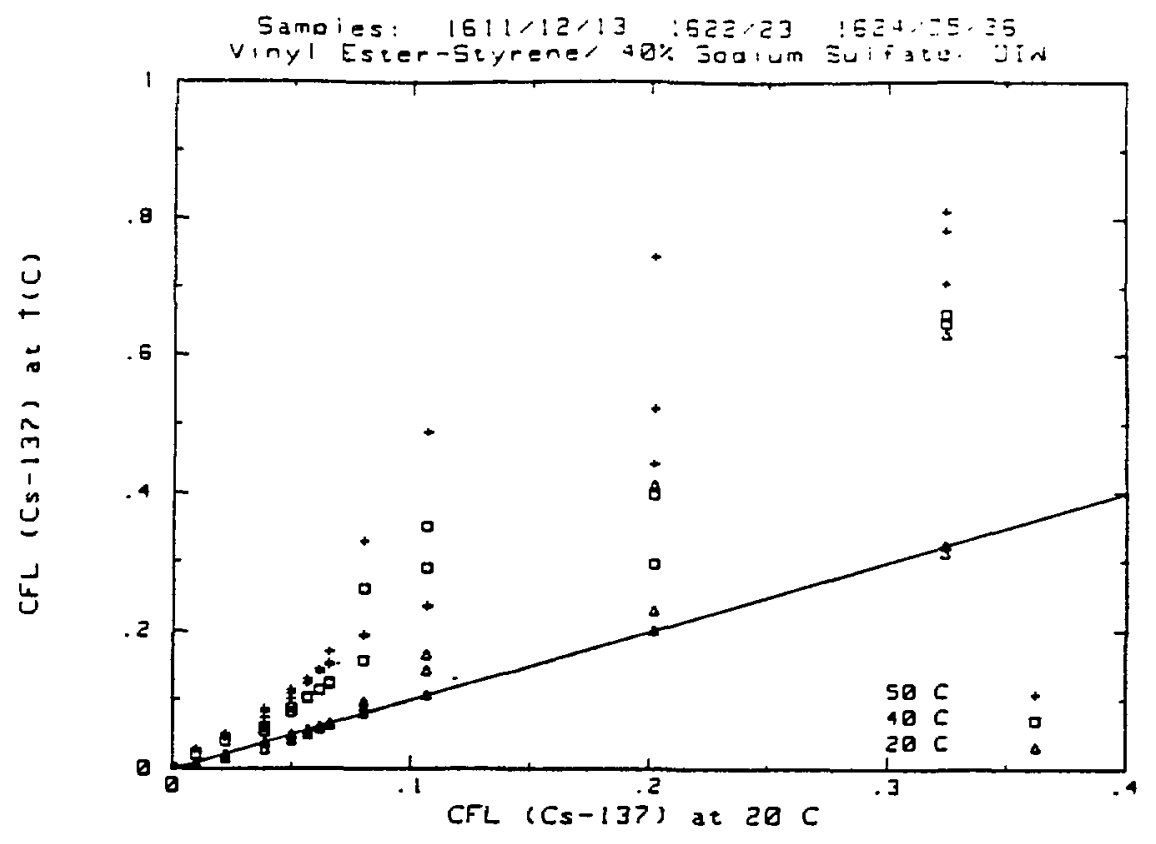

Figure 7.5

Linear correlation plots for Cs-137 leaching from VES containing 40 wto sodium sulfate at 20,40 and $50^{\circ} \mathrm{C}$. Correlations are relative to the $20^{\circ} \mathrm{C}$ data.

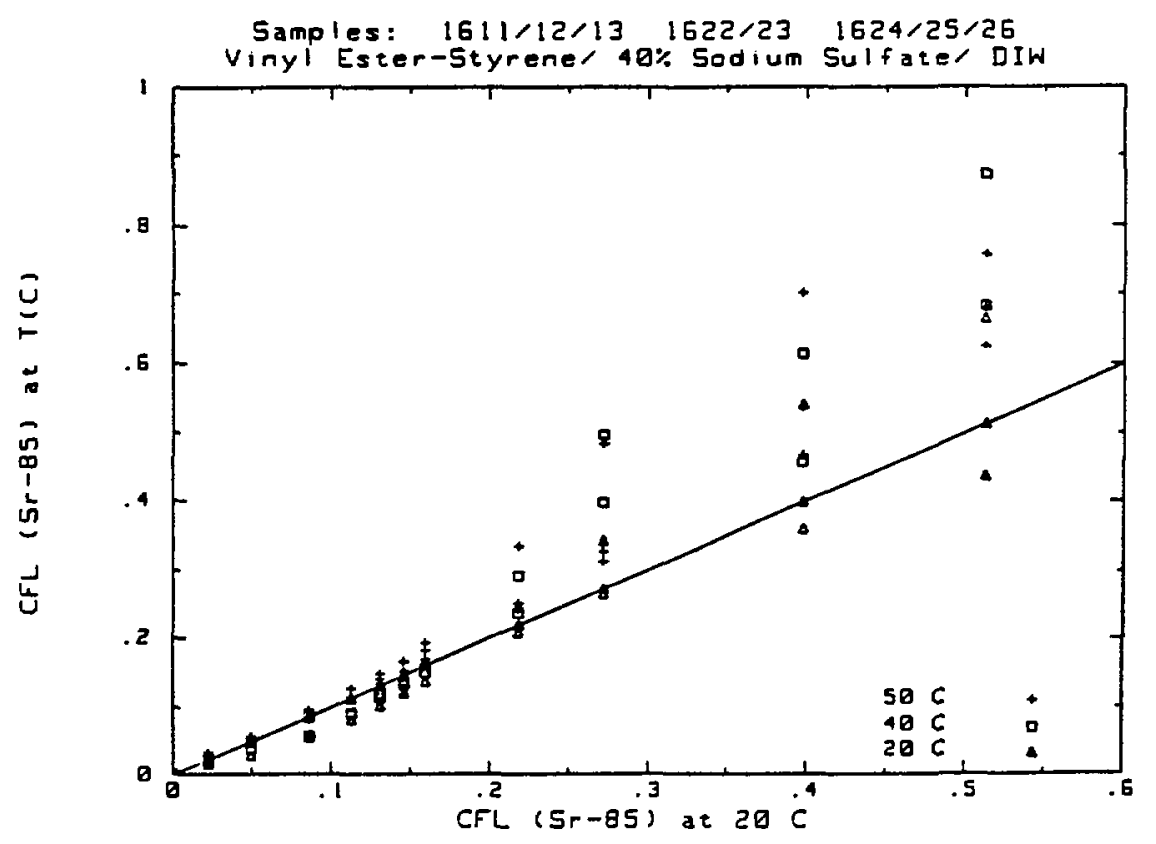

Figure 7.6

Linear correlation plots for $5 r-85$ leaching from VES containing 40 wt sodium sulfate at 20,40 and $50^{\circ} \mathrm{C}$. Correlations are relative to the $20^{\circ} \mathrm{C}$ data. Samples were leached in deionized water. 


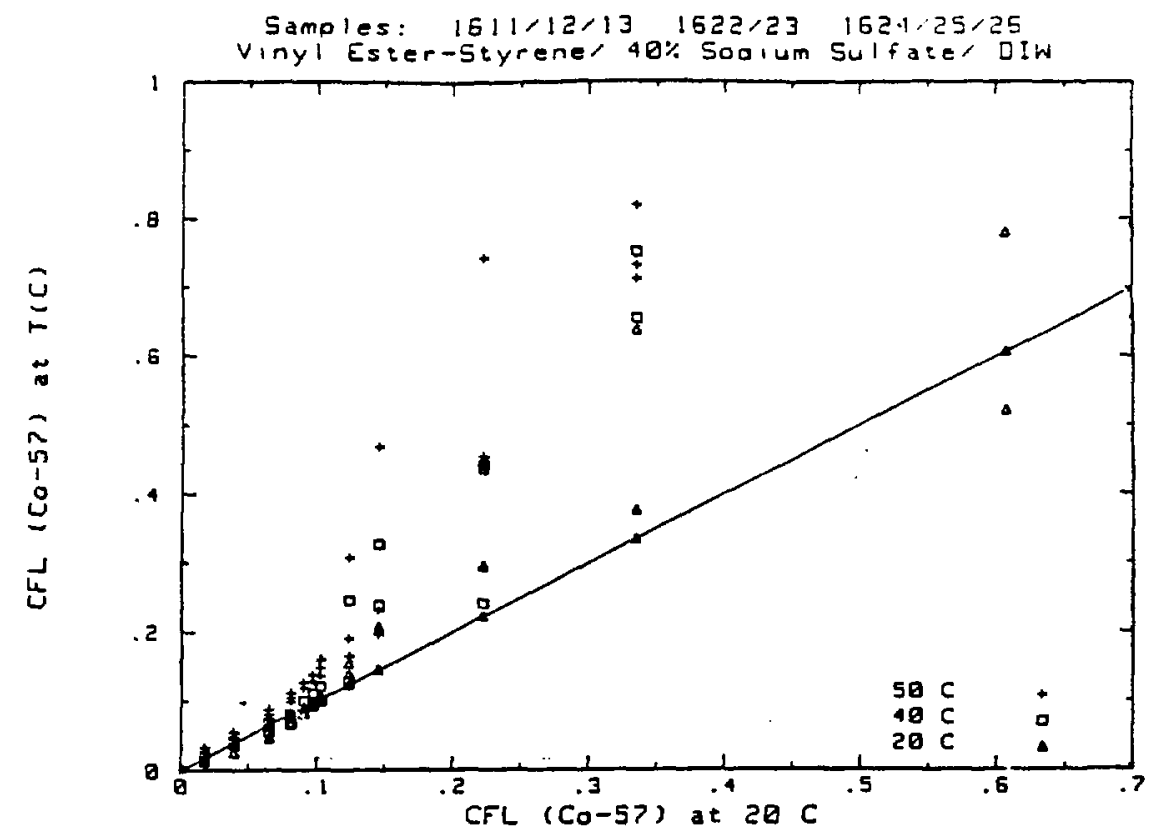

Figure 7.7 Linear correlation plots for Co.57 leaching from VES containing 40 wto sodium sulfate at 20,40 and $50^{\circ} \mathrm{C}$. Correlations are relative to the $20^{\circ} \mathrm{C}$ data. Samples were leached in delonized water.

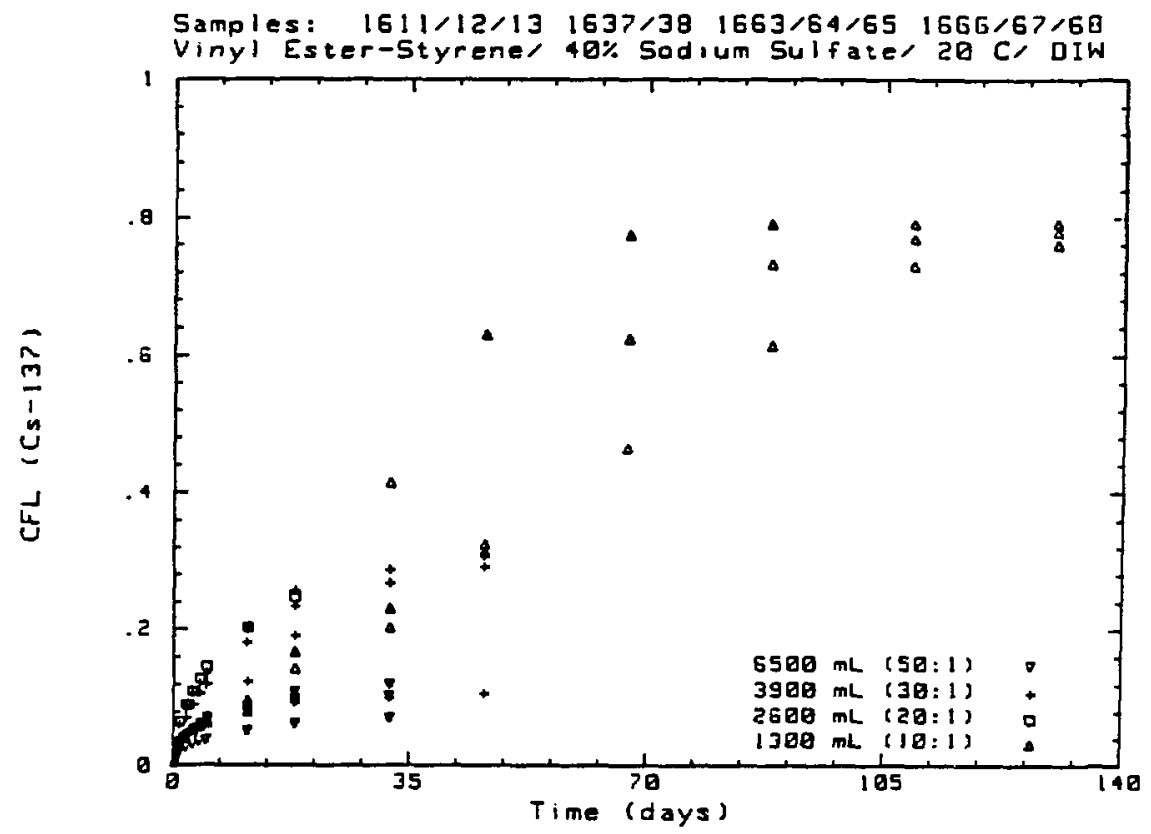

Figure 7.8

Cs-137 cumulative fraction leached vs. time from vES containing 40 wto sodium sulfate at leachant volume to waste form surface area ratios of $10,20,30$ and $50: 1$. Samples were leached in delonized water at $20^{\circ} \mathrm{C}$. 


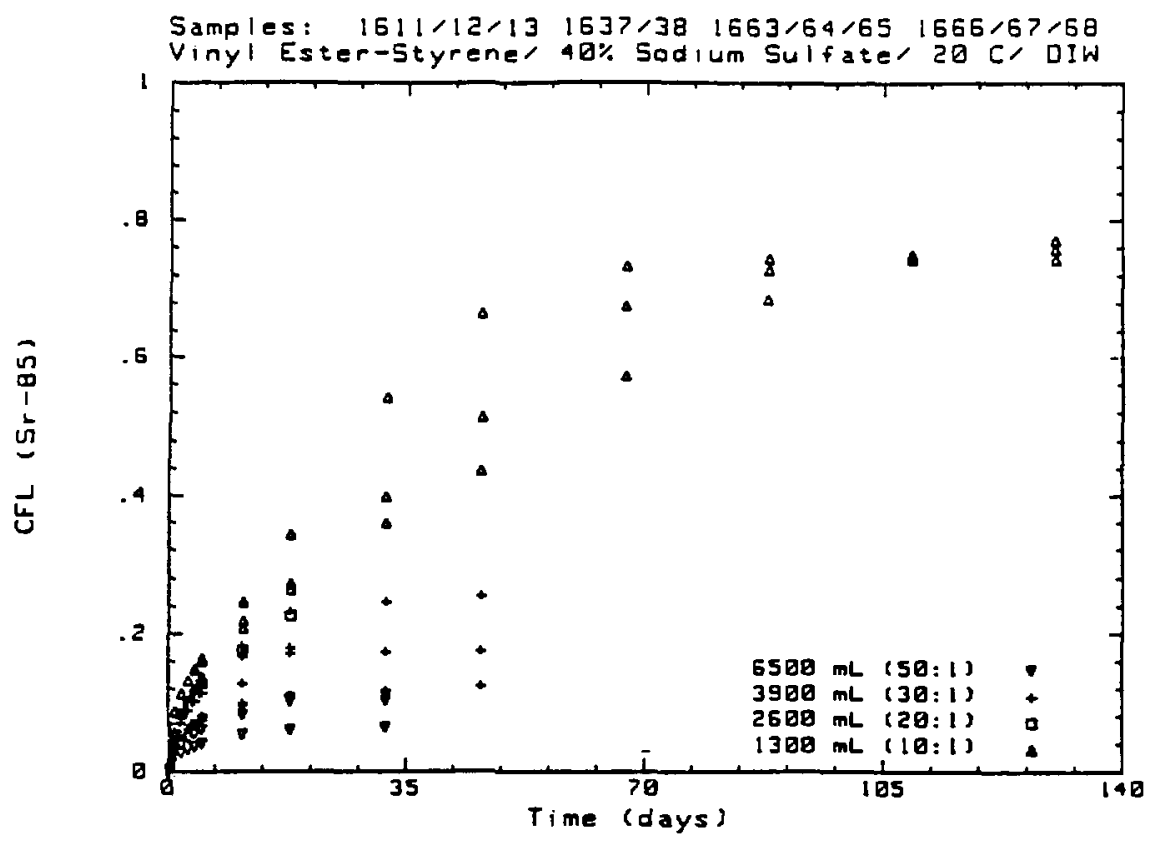

Figure 7.9

Sr-85 cumulative fraction leached vs. time from VES containing 40 wt sodium sulfate at leachant volume to waste form surface area ratios of $10,20,30$ and 50:1. Samples were leached in deionized water at $20^{\circ} \mathrm{C}$.

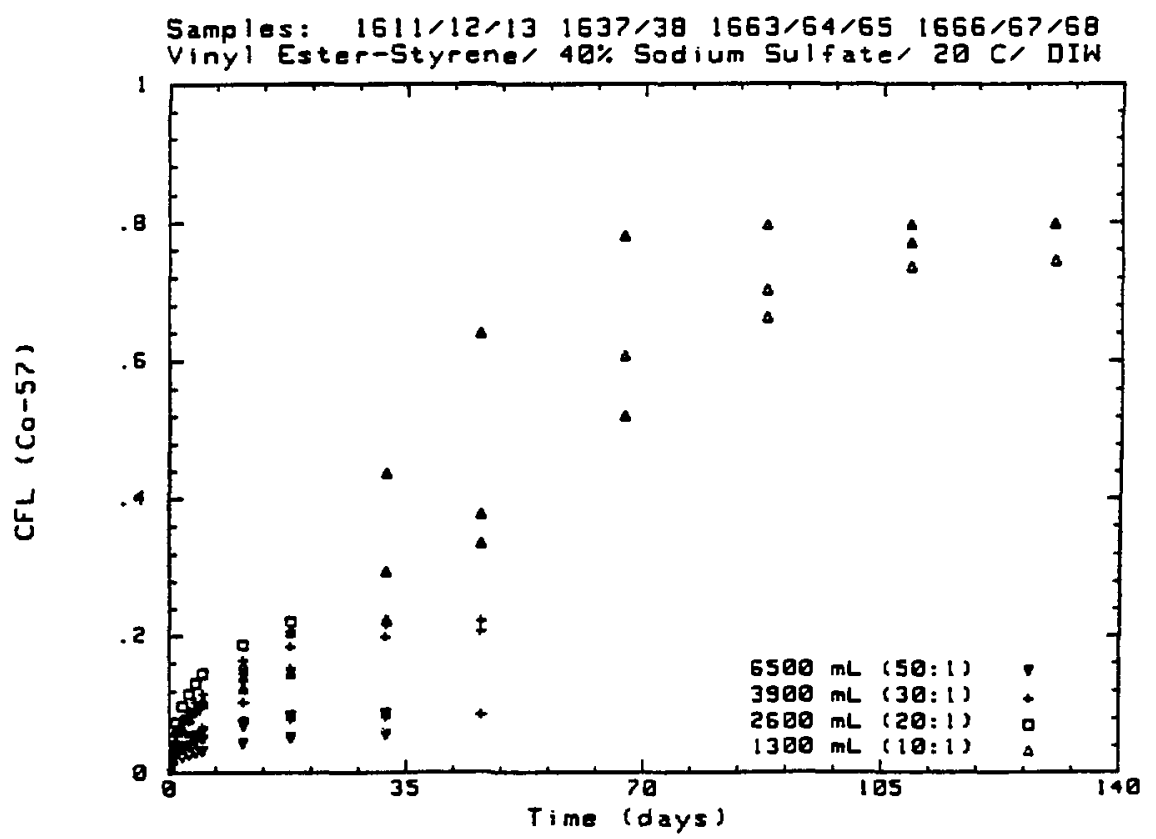

Figure 7.10 Co-57 cumulative fraction leached vs. time from VES containing 40 wt sodium sulfate at leachant volume to waste form surface area ratios of $10,20,30$ and 50:1. Samples were leached in deionized water at $20^{\circ} \mathrm{C}$. 


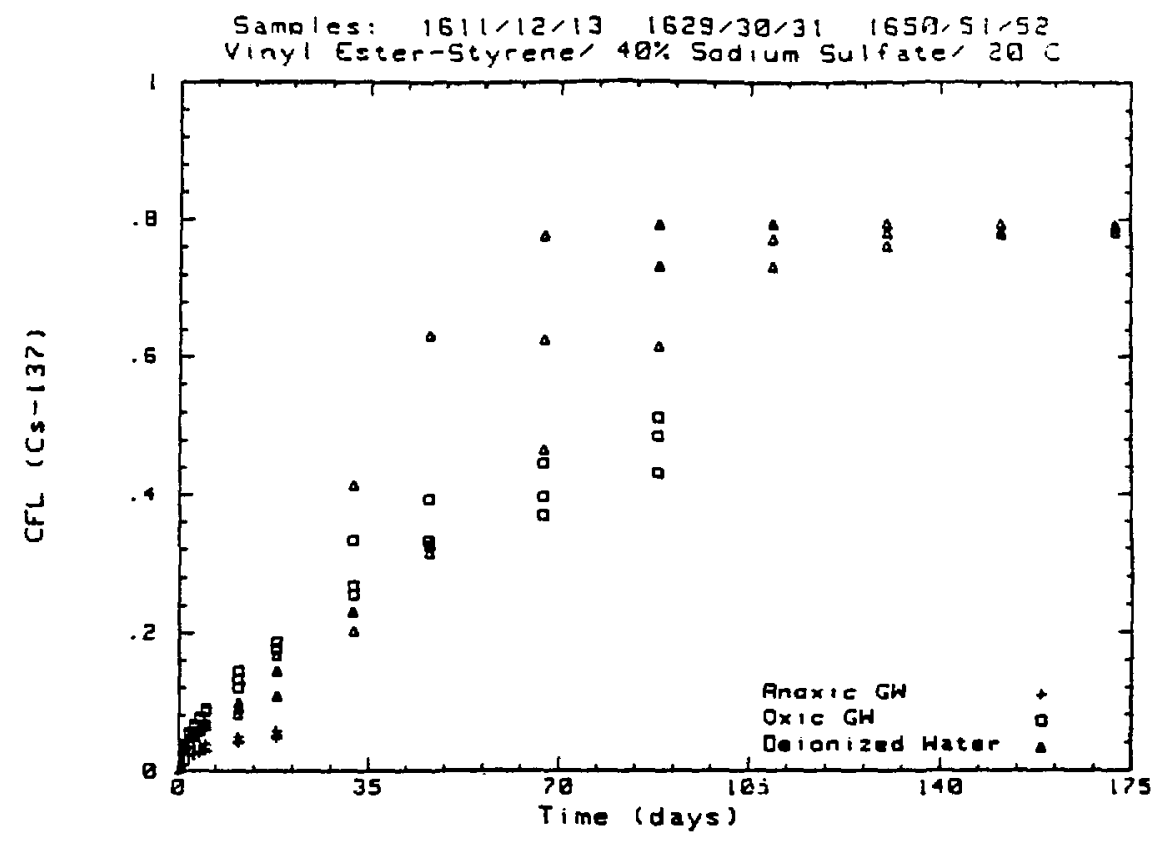

Figure 7.11 Cs-137 cumulative fraction leached vs. time from VES containing 40 wt sodium sulfate leached in DIW, oxic and anoxic ground waters at $20^{\circ} \mathrm{C}$.

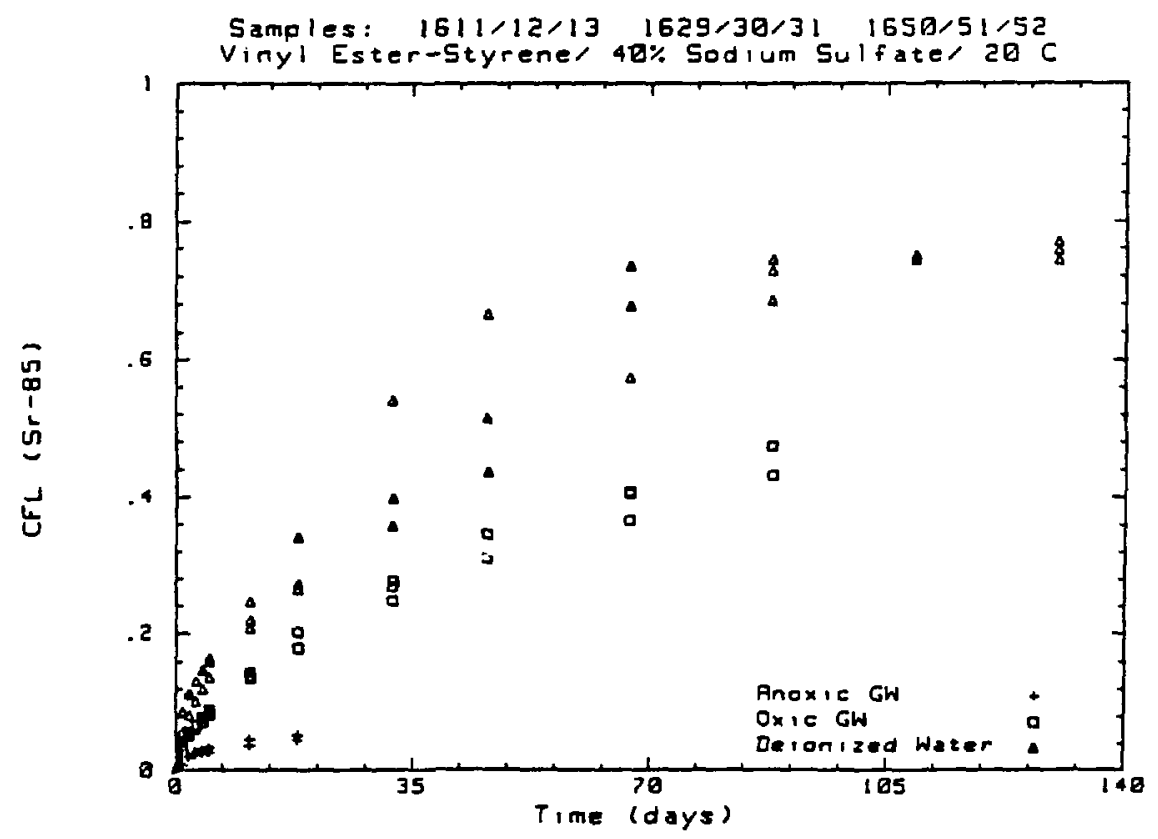

Figure 7.12 Sr-85 cumulative fraction leached vs. time from VES containing 40 wto sodium sulfate leached in DIW, oxic and anoxic ground waters at $20^{\circ} \mathrm{C}$. 


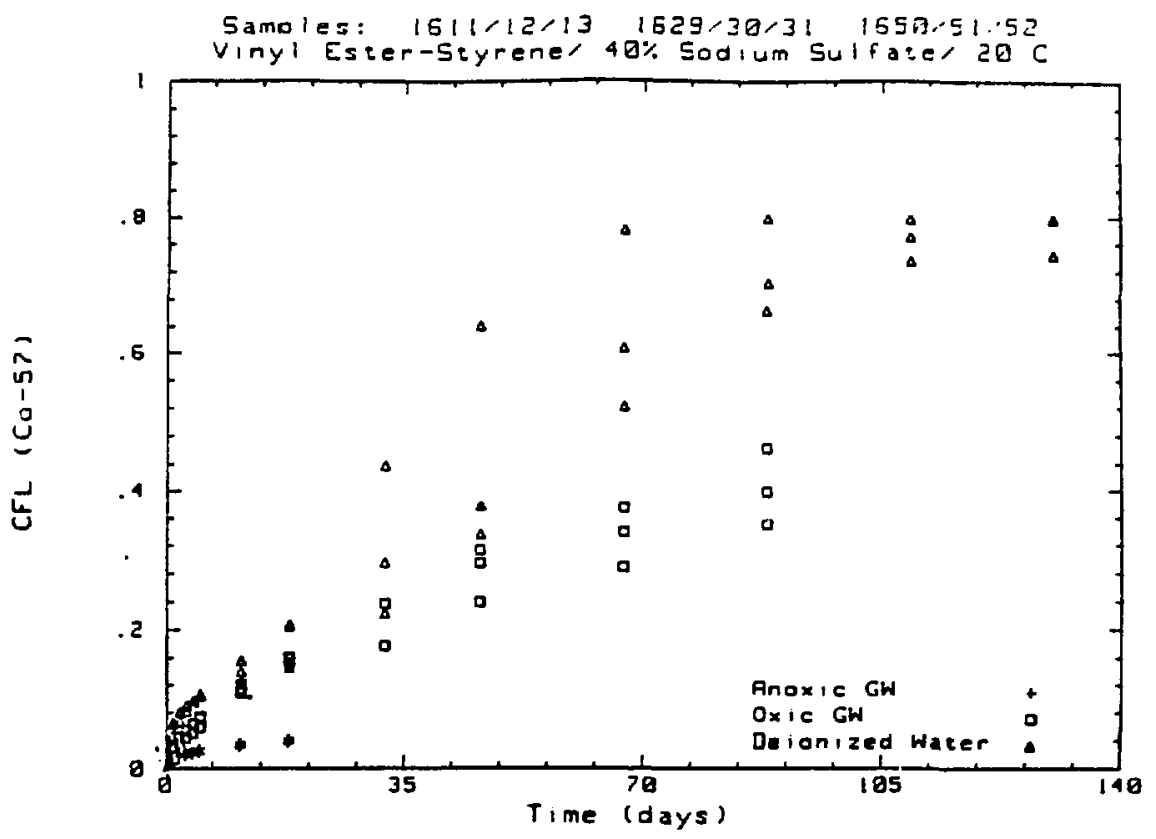

Figure 7.13 Co-57 cumulative fraction leached vs. time from VES containing 40 wt sodium sulfate leached in DIW, oxic and anoxic ground waters at $20^{\circ} \mathrm{C}$.

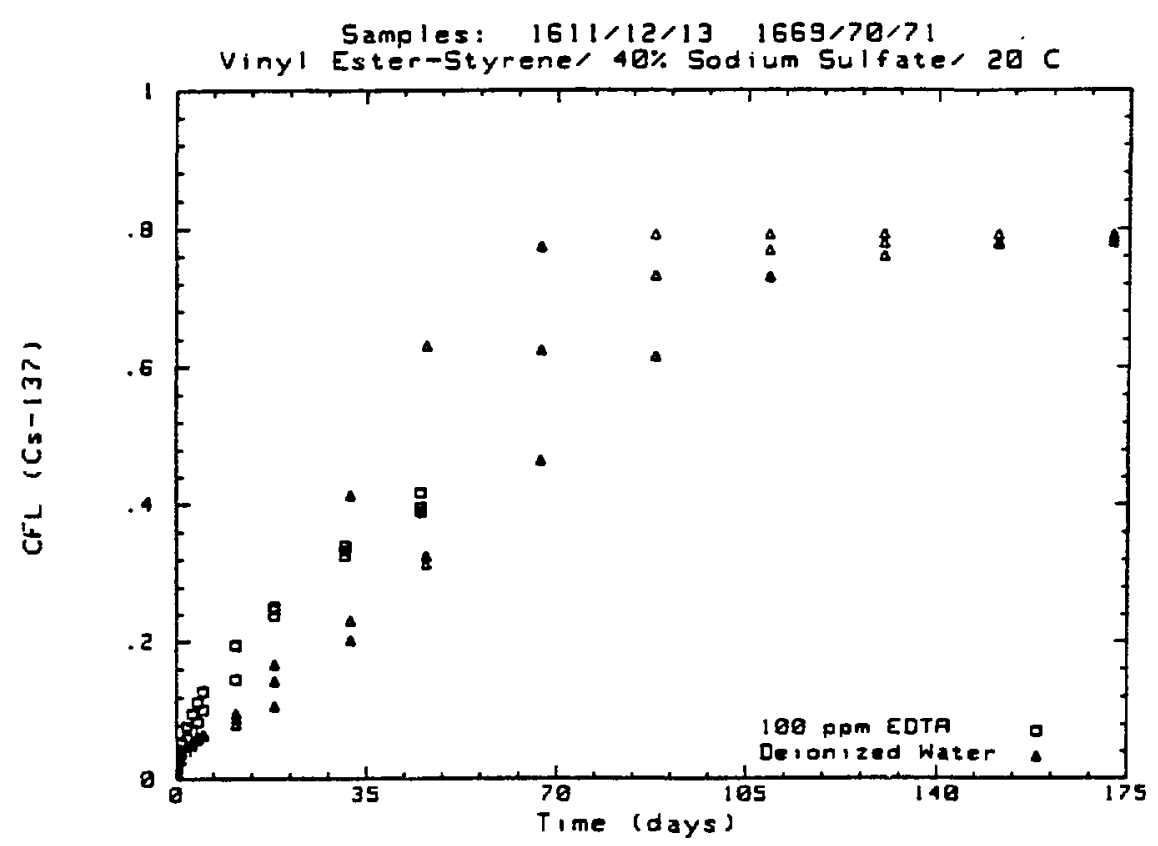

Figure 7.14

Cs-137 cumulative fraction leached vs. time from VES containing 40 wt sodium sulfate leached in DIW and in DIW containing $100 \mathrm{ppm}$ disodium EDTA at $20^{\circ} \mathrm{C}$. 


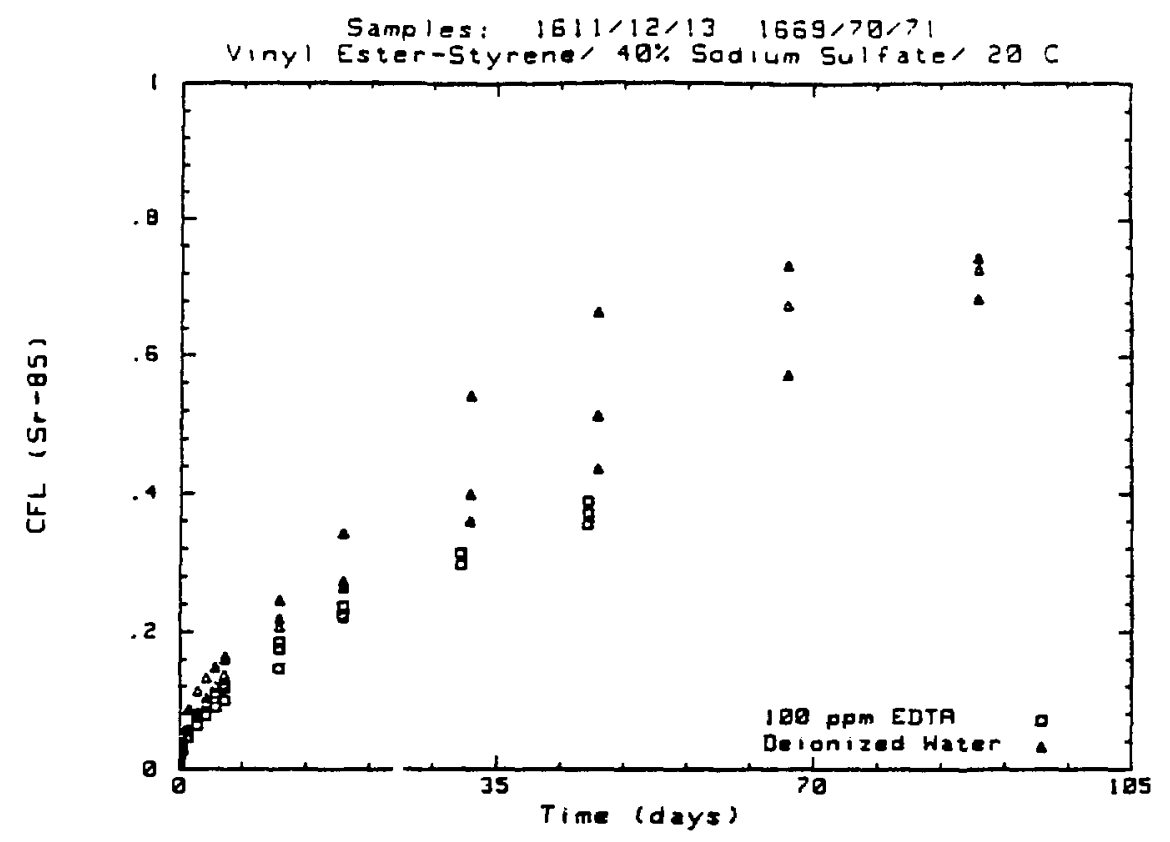

Figure 7.15 Sr-85 cumulative fraction leached vs. time from VES containing 40 wt sodiun sulfate leached in DIW and in DIW containing $100 \mathrm{ppn}$ disodium EDTA at $20^{\circ} \mathrm{C}$.

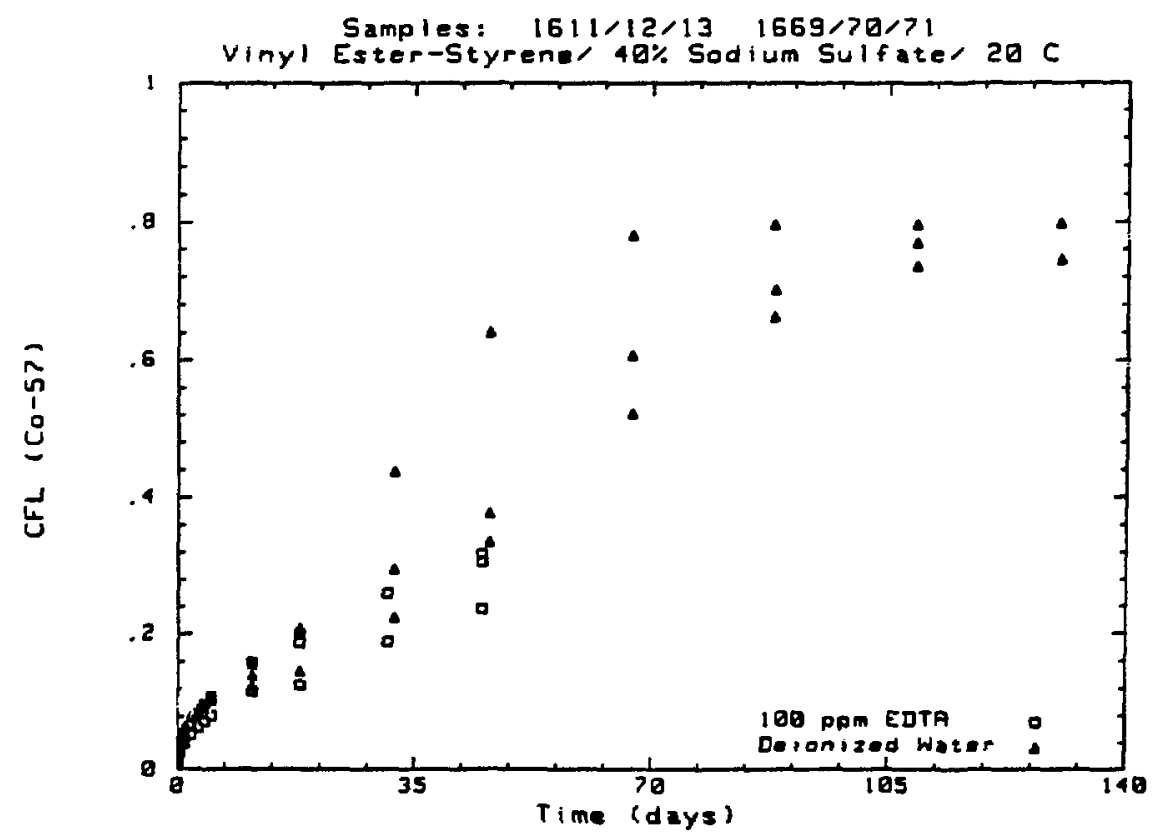

Figure 7.16

Co-57 cumulative fraction leached vs. time from vES containing 40 wt sodium sulfate leached in DIW and in DIW containing $100 \mathrm{ppm}$ disodium EDTA at $20^{\circ} \mathrm{C}$. 


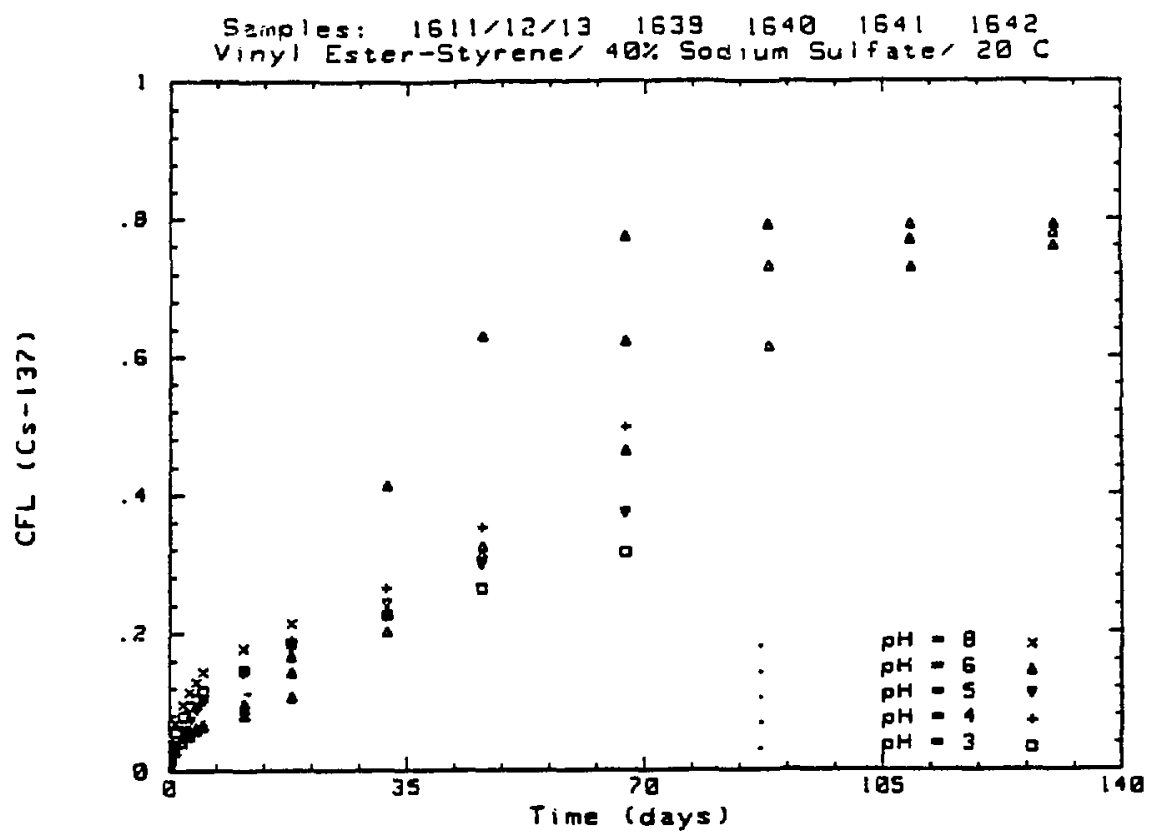

Figure 7.17

Cs-137 cumulative fraction leached vs. time from VES containing 40 wt sodium sulfate leached at $20^{\circ} \mathrm{C}$ in leachants with initial pH values of $3,4,5,6$ and 8 .

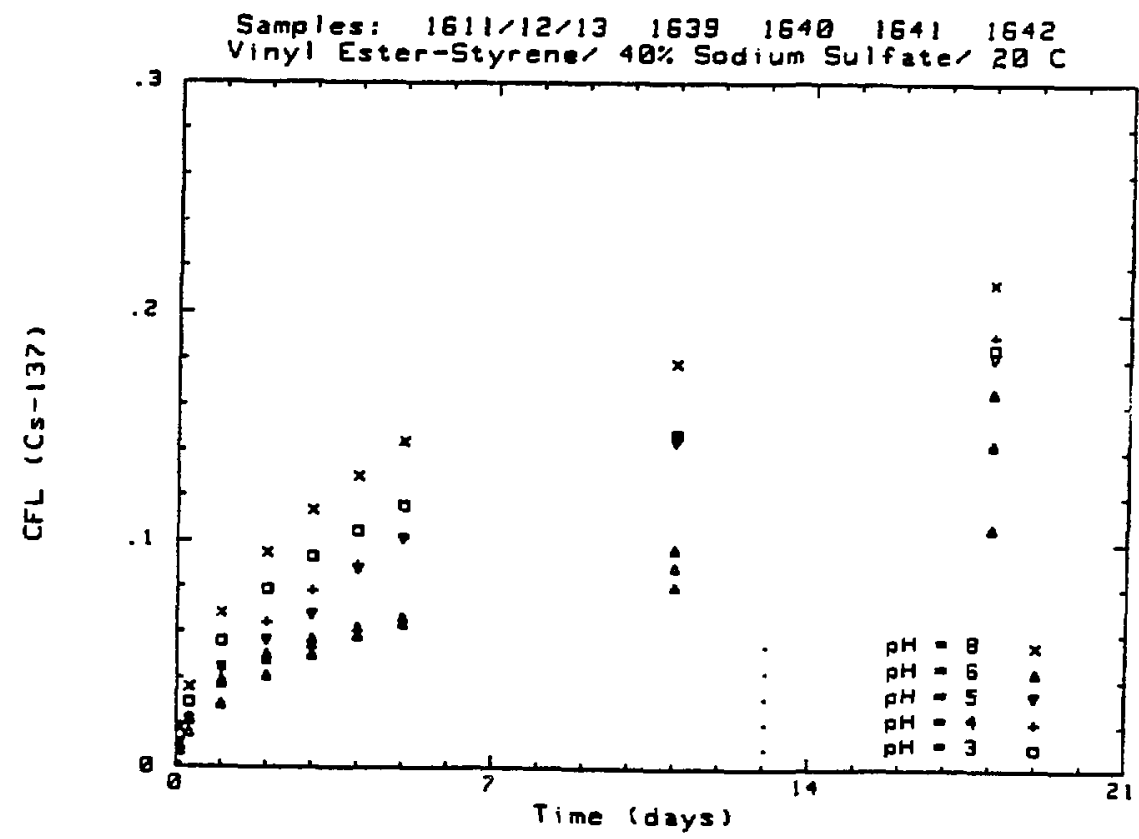

Figure 7.18

Cs-137 cumulative fraction leached vs. time from VES containing $40 \mathrm{wt}$ sodium sulfate leached at $20^{\circ} \mathrm{C}$ in leachants with inftial pH values of $3,4,5,6$ and 8 . First twenty days. 


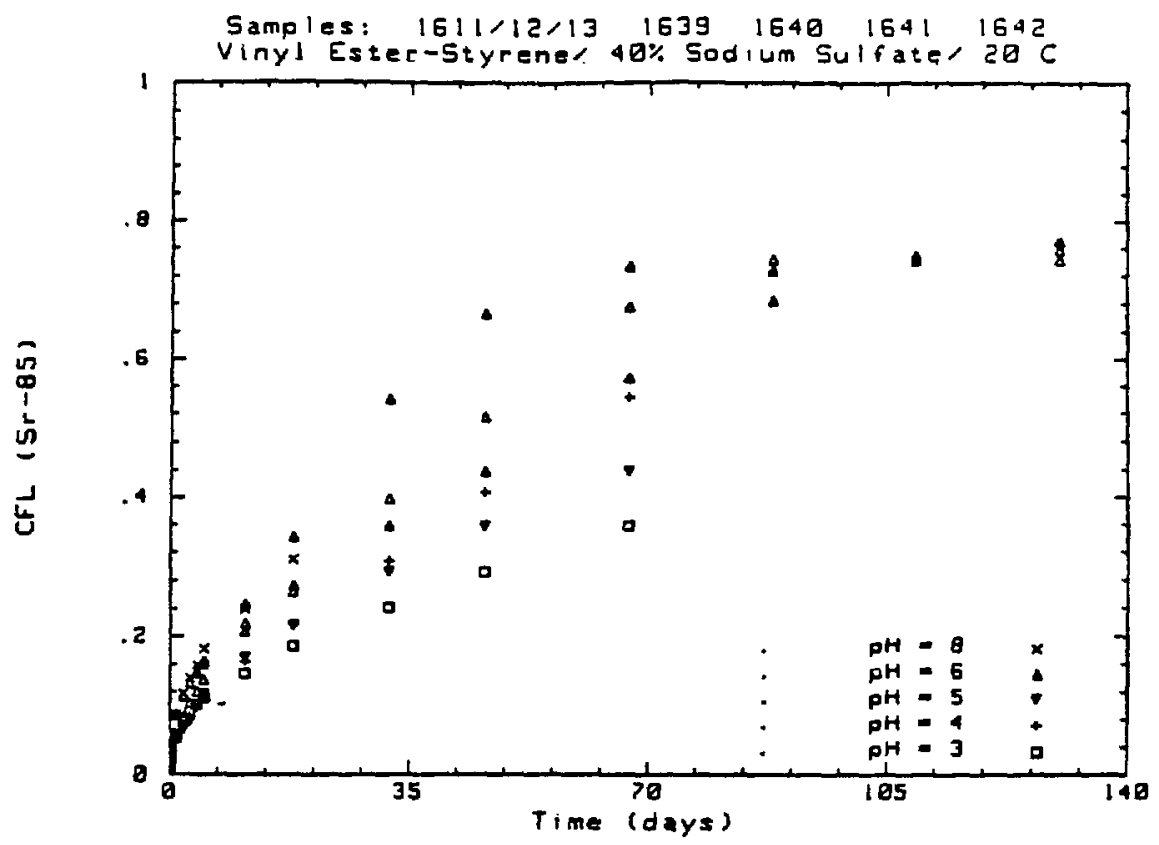

Figure 7.19 Sr-85 cunulative fraction leached vs, time from VES contalning $40 \mathrm{wt}$ sodiun sulfate leached at $20^{\circ} \mathrm{C}$ in leachants with initial pH values of $3,4,5,6$ and 8 .

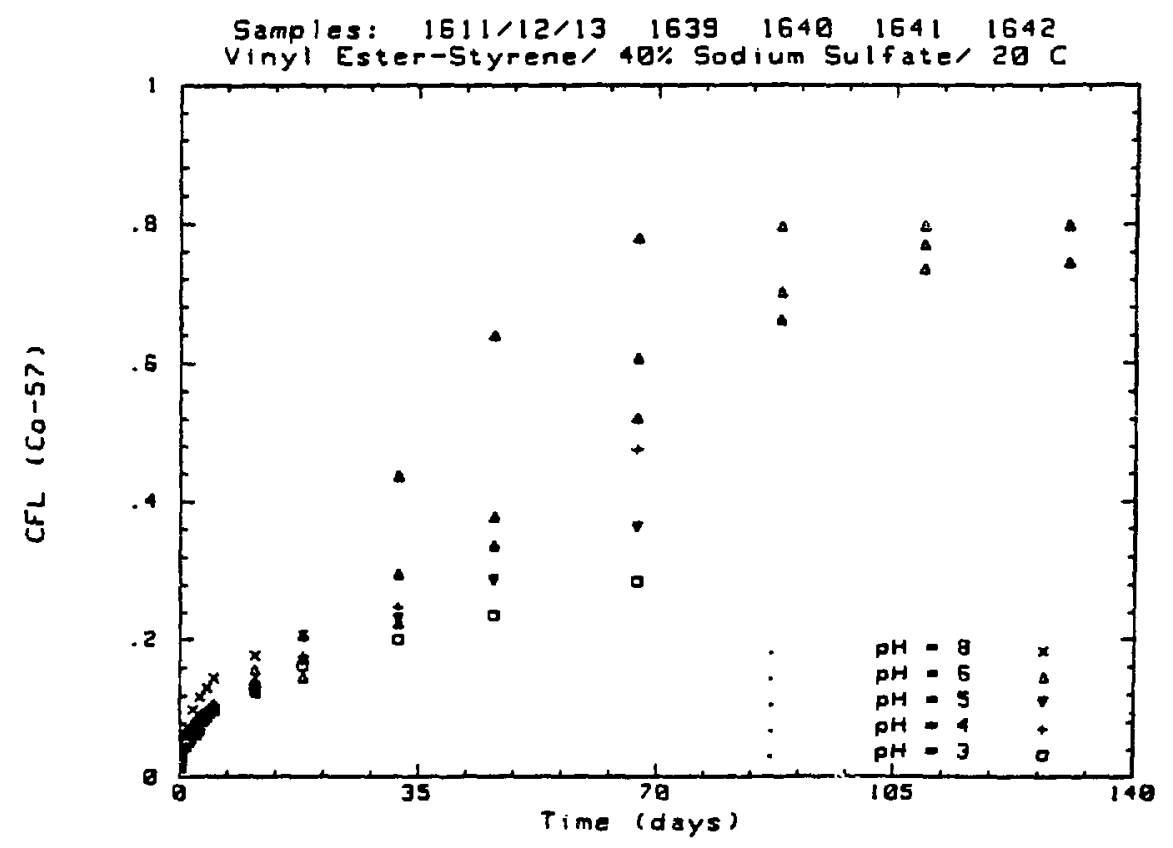

Figure 7.20

Co-57 cumulative fraction leached vs. time from VES contalning 40 wt sodium sulfate leached at $20^{\circ} \mathrm{C}$ in leachants with initial pH values of 3,4,5, 6 and 8 . 


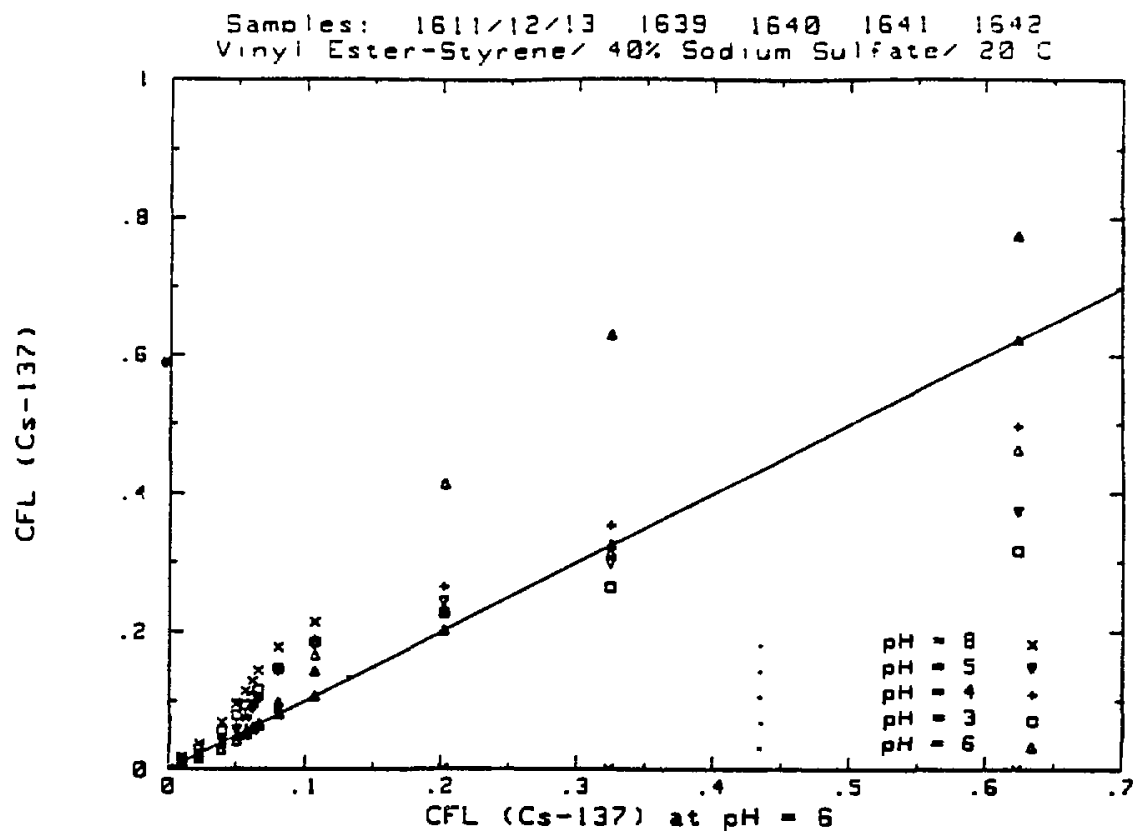

Figure 7.21

Linear correlation plots for Cs-137 leached from VES containing 40 wtz sodium sulfate in leachants with initial $\mathrm{pH}$ values of $3,4,5,6$ and 8 at $20^{\circ} \mathrm{C}$. Correlations are relative to the $\mathrm{pH} 6$ (DIW) data.

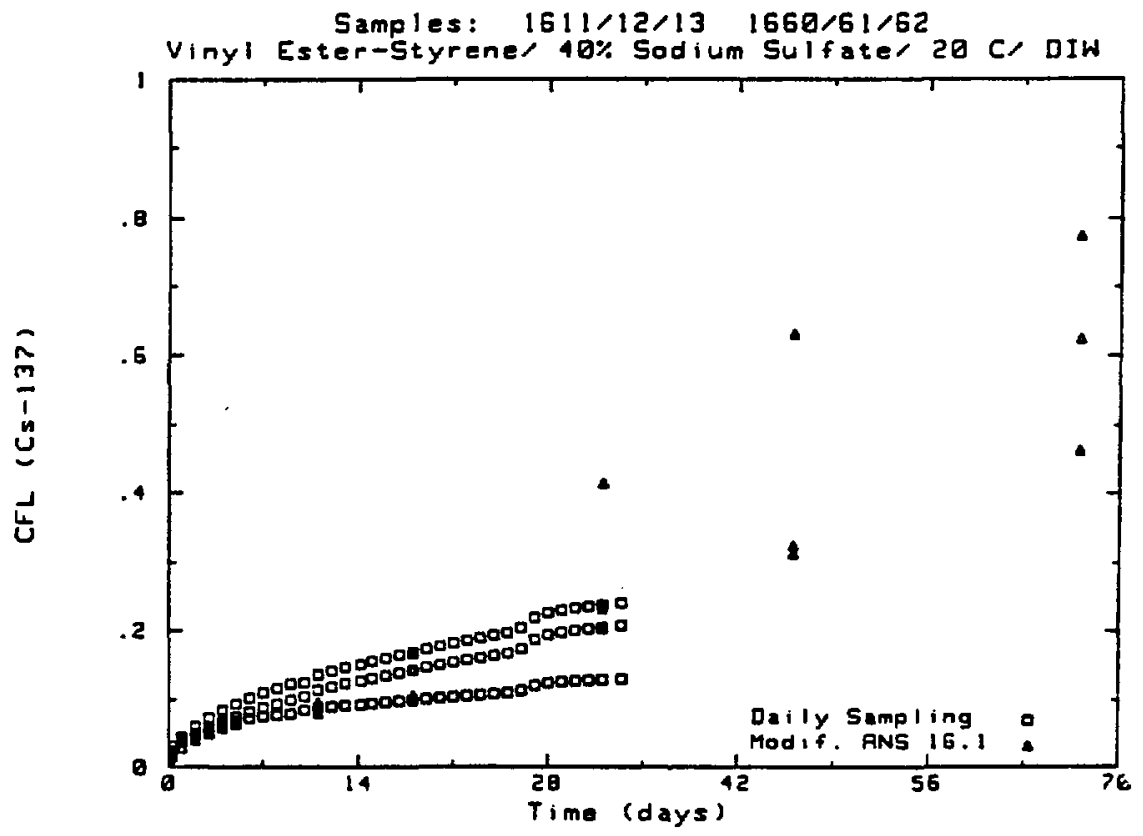

Figure 7.22 Cs-137 cumulative fraction leached vs. time from daily leachant replacement and from modified ANS 16.1 leachant replacement schedule for VES waste forms containing $40 \mathrm{wtg}$ sodium sulfate leached at $20^{\circ} \mathrm{C}$. 


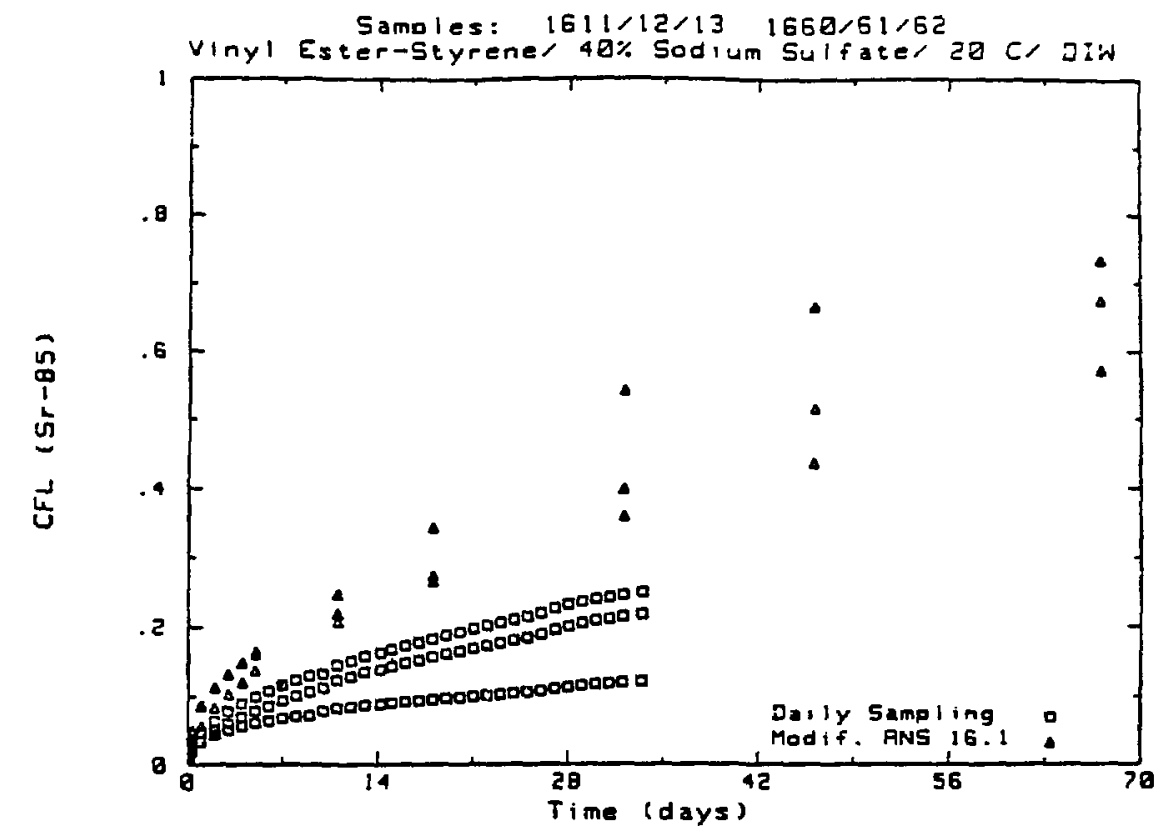

Figure $7.23 \quad$ Sr-85 cumulative fraction leached vs. time from daily leachant replacement and from modified ANS 16.1 leachant replacement schedule for VES waste forms containing 40 wt sodium sulfate leached at $20^{\circ} \mathrm{C}$.

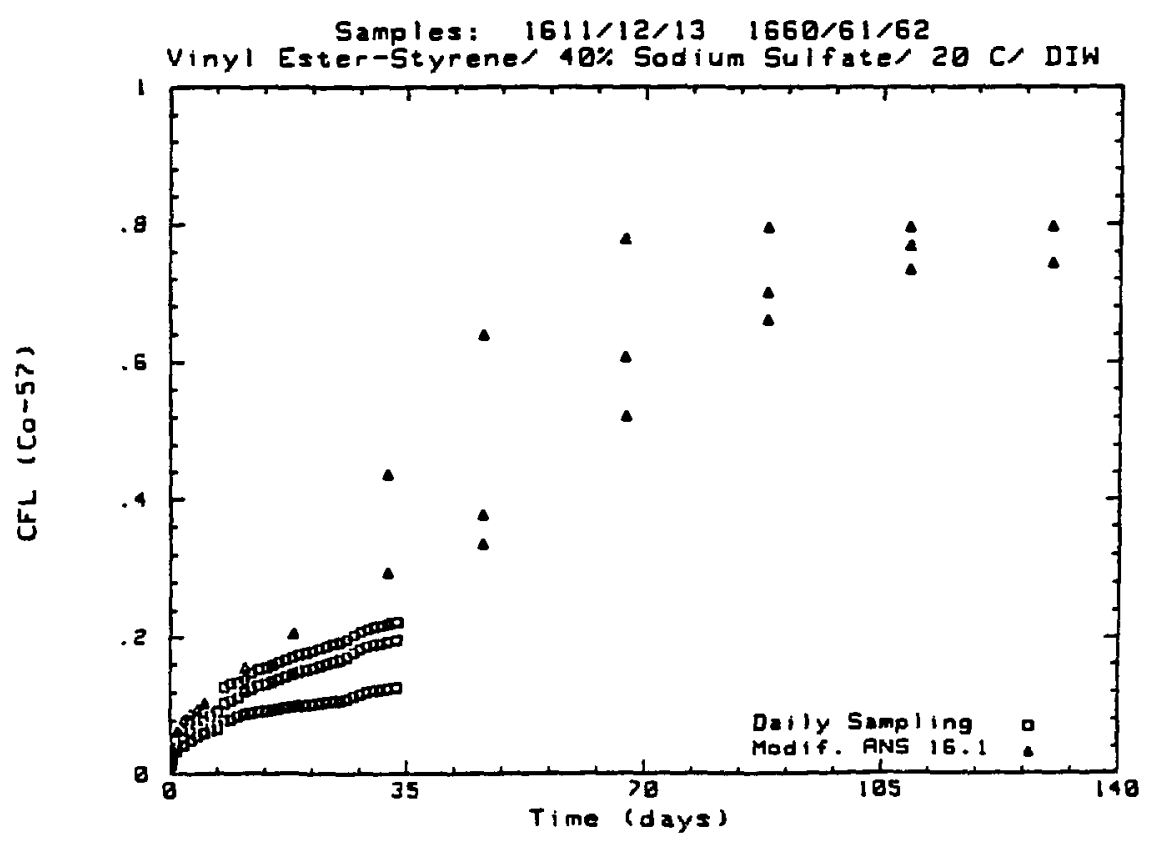

Figure 7.24 Co-57 cumulative fraction leached vs. time from daily leachant replacement and from modified ANS 16.1 leachant replacement schedule for VES waste forms containing 40 wt sodium sulfate leached at $20^{\circ} \mathrm{C}$. 


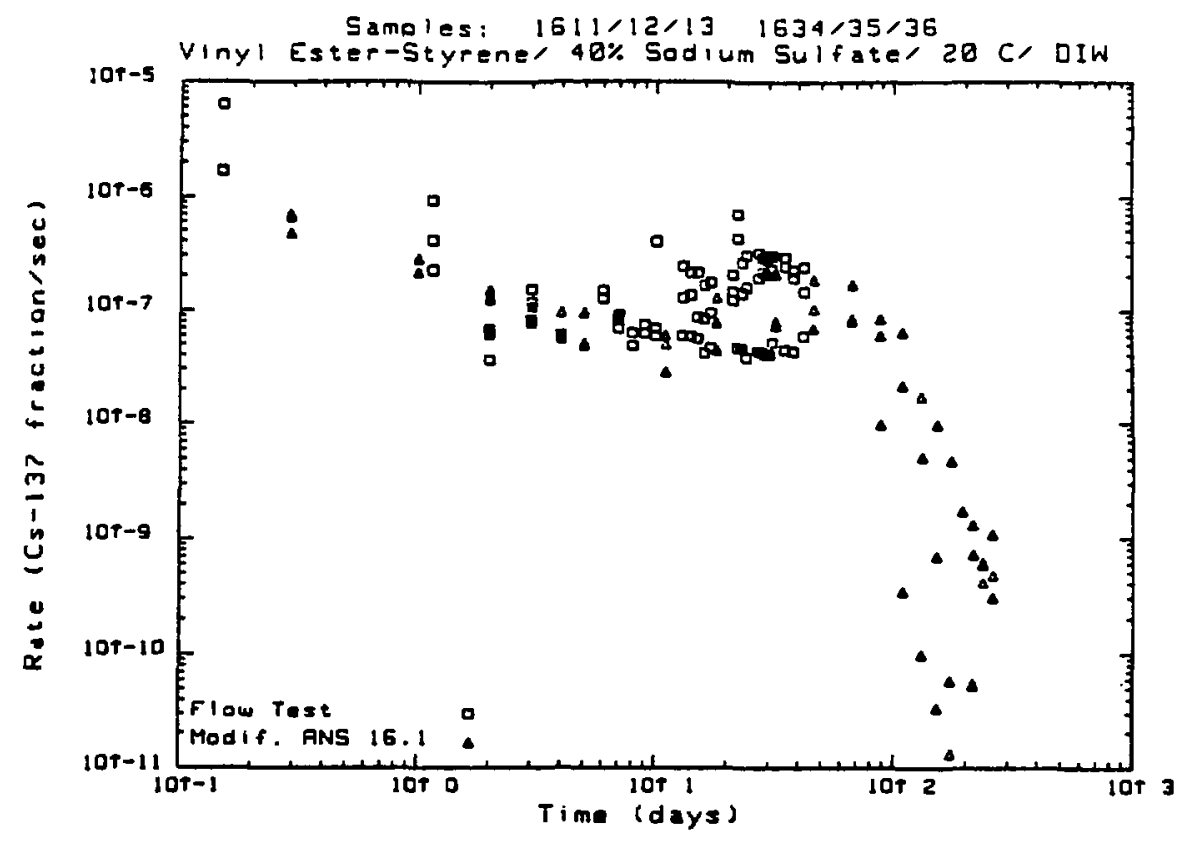

Figure 7.25

Cs-137 incremental leach rate vs. time from VES containing 40 wt sodiun sulfate comparing results of MCC-4S Flow test to modified ANS 16.1 leachant replacement schedule at $20^{\circ} \mathrm{C}$.

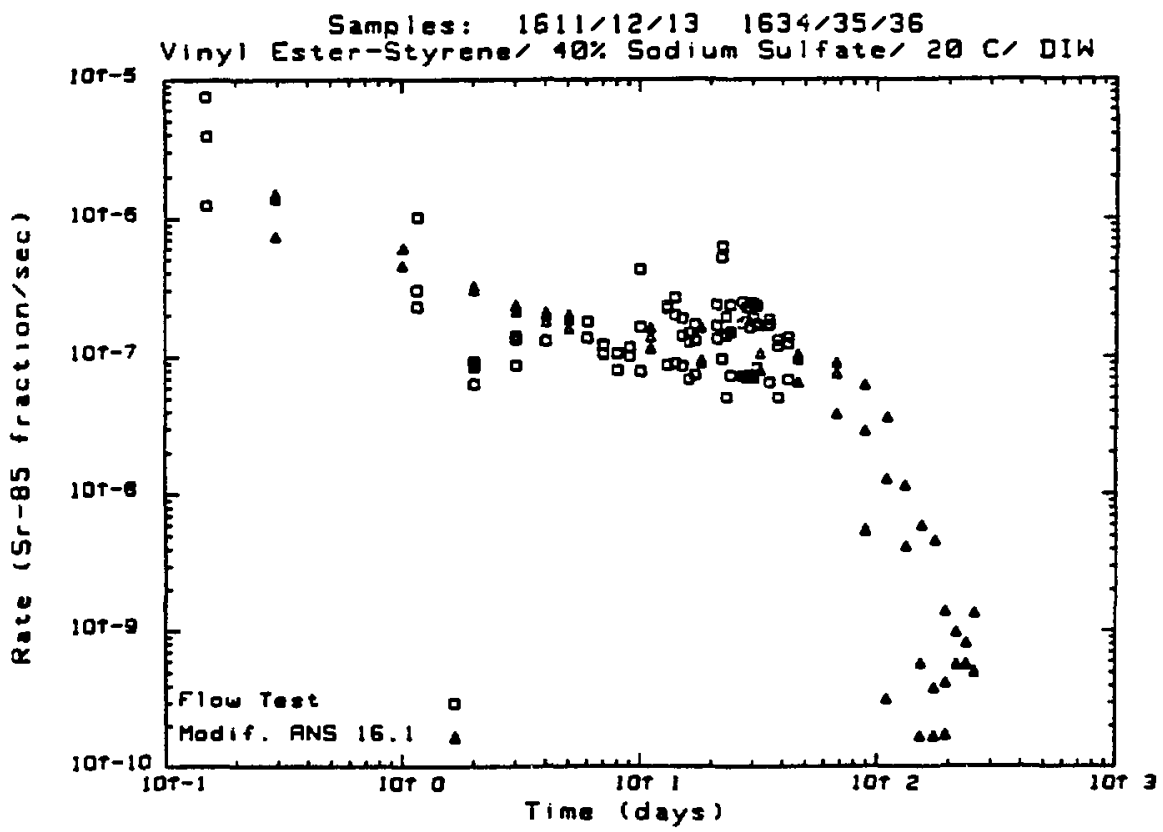

Figure 7.26

Sr-85 incremental leach rate vs. time. from VES containing 40 wt sodium sulfate comparing results of MCC-4S Flow test to modified ANS 16.1 leachant replacement schedule at $20^{\circ} \mathrm{C}$. 


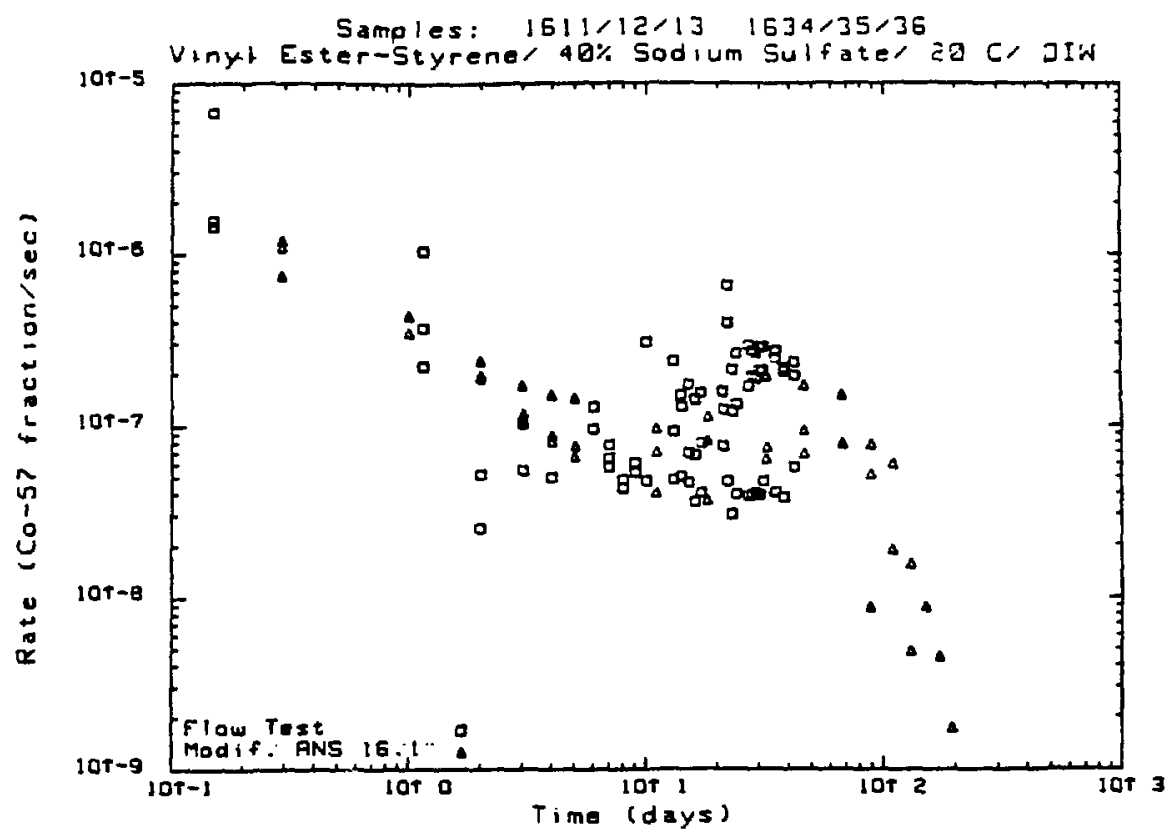

Figure 7.27

Co-57 incremental leach rate vs. time from VES containing 40 wto sodium sulfate comparing results of MCC-4S Flow test to modified ANS 16.1 leachant replacement schedule at $20^{\circ} \mathrm{C}$.

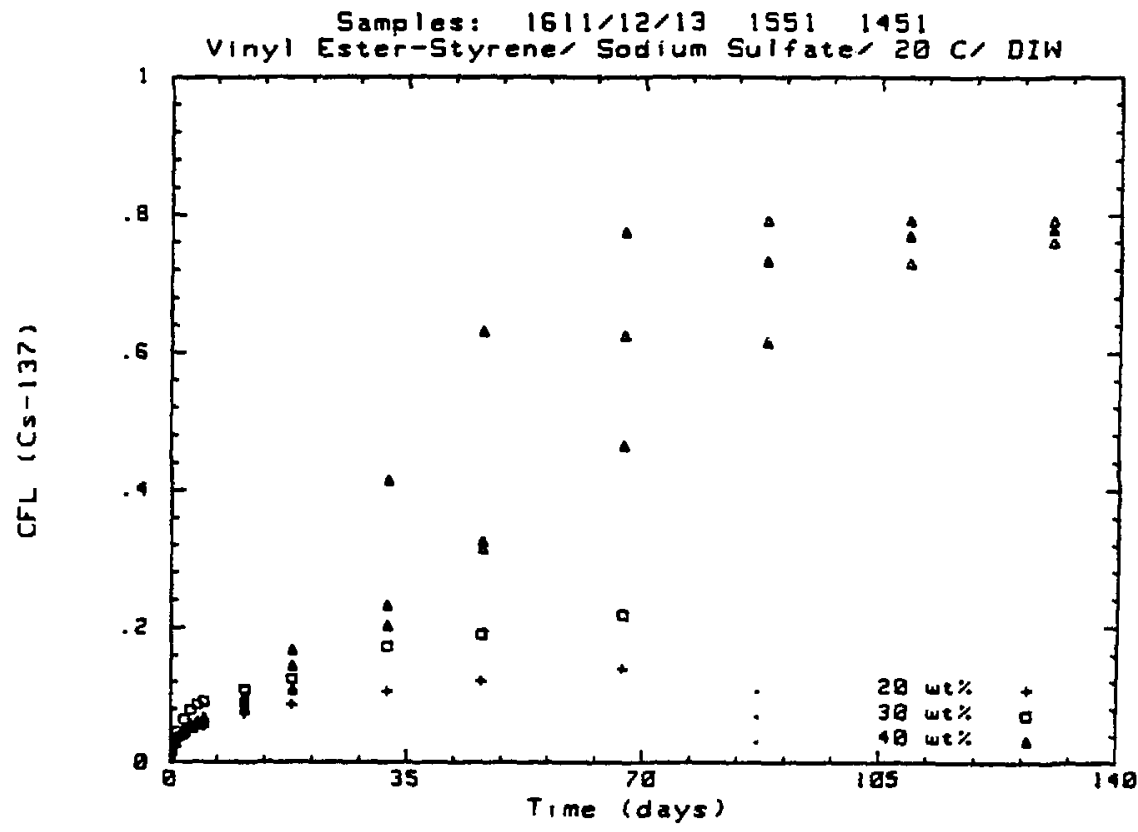

Figure 7.28 Cs-137 cumulative fraction leached vs, time from vES containing 20,30 and 40 wt sodium sulfate. Samples were leached in defonized water at $20^{\circ} \mathrm{C}$. 


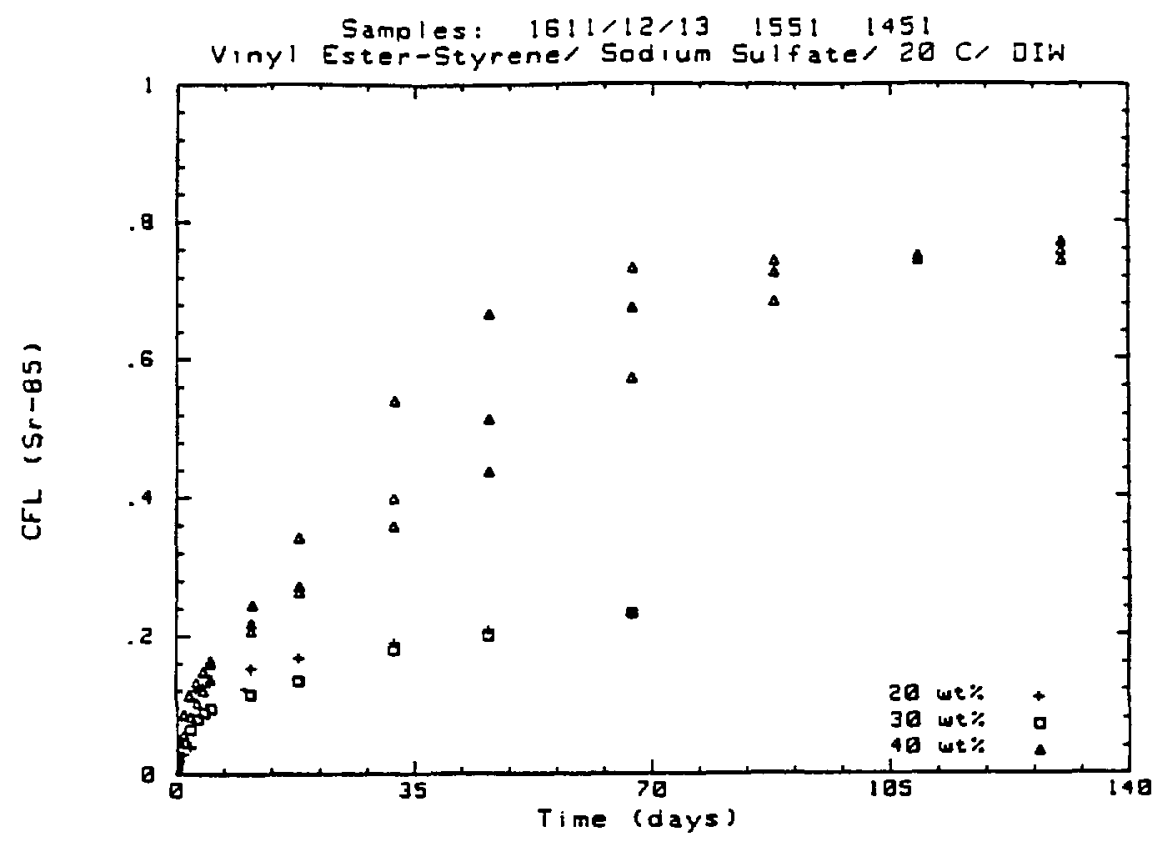

Figure 7.29

Sr-85 cumulative fraction leached vs. time from VES containing 20,30 and 40 wt sodium sulfate. Samples were leached in deionized water at $20^{\circ} \mathrm{C}$.

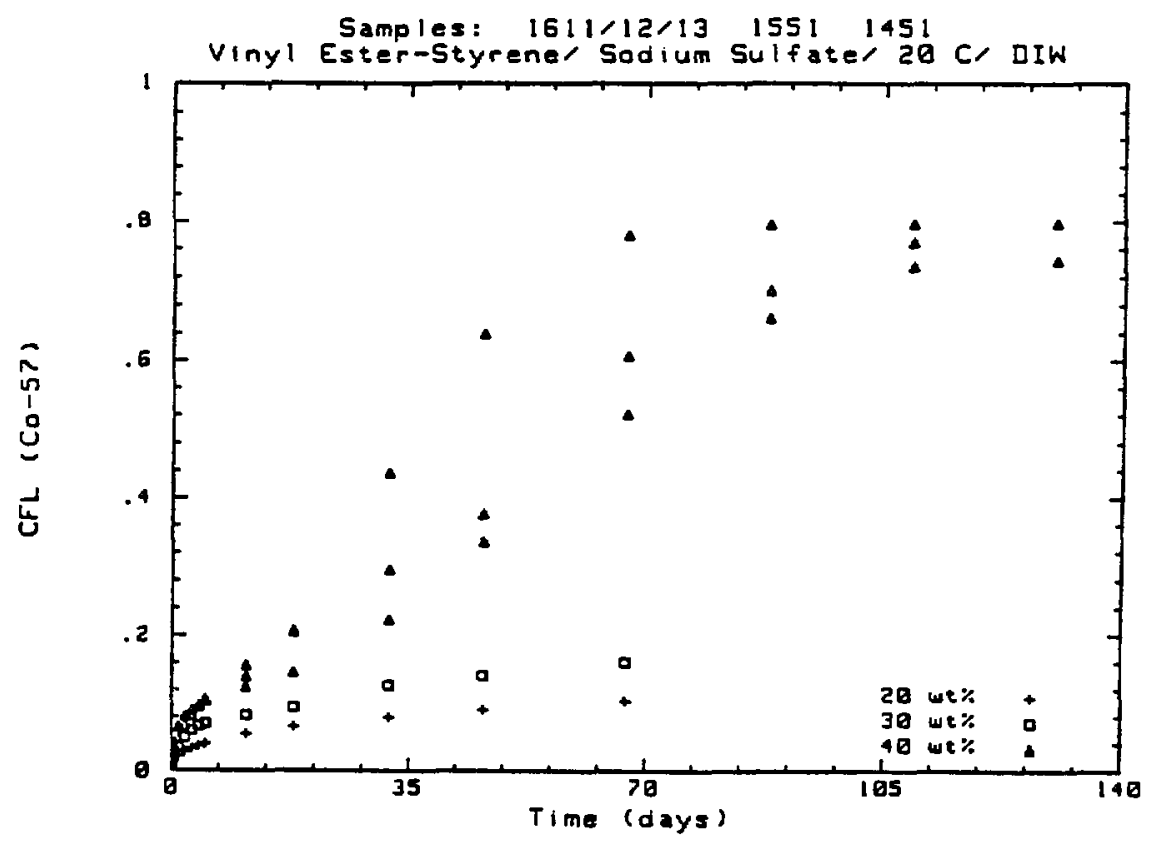

Figure 7.30

Co-57 cumulative fraction leached vs. time from VES containing 20,30 and 40 wt sodium sulfate. Samples were leached in deionized water at $20^{\circ} \mathrm{C}$. 


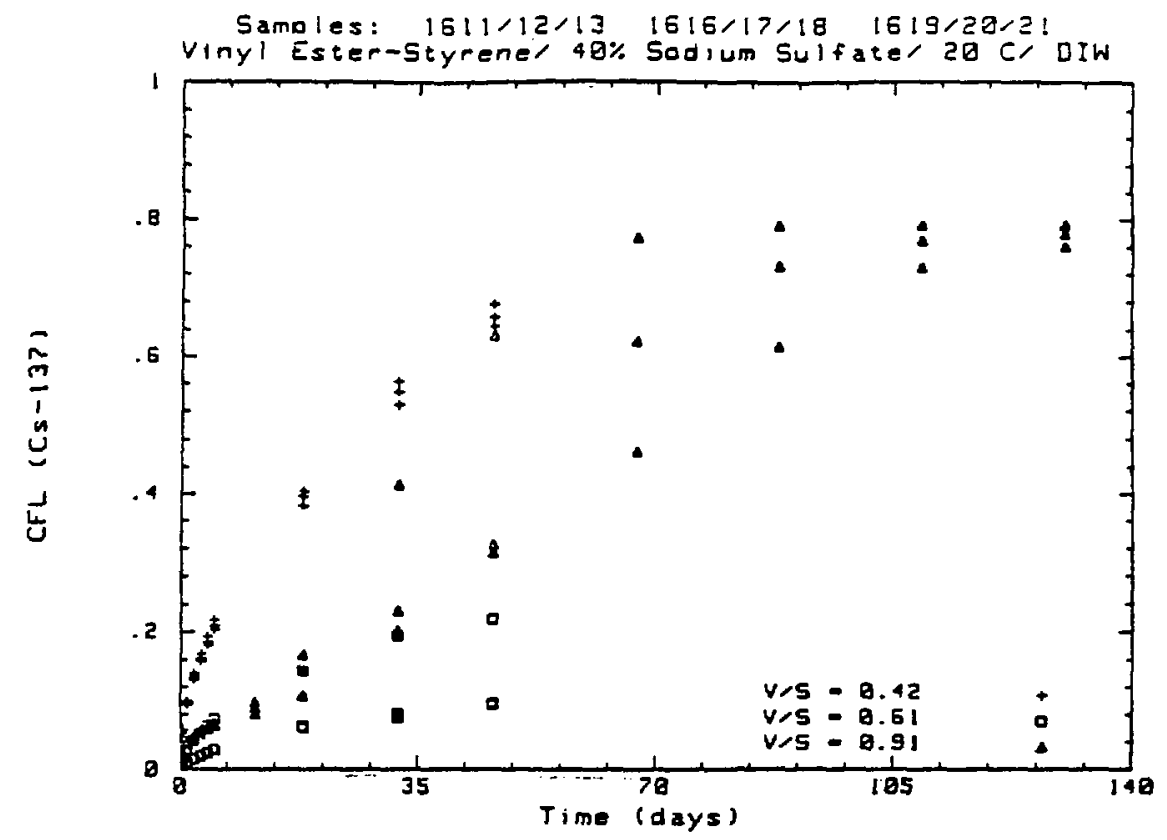

Figure 7.31 Cs-137 cumulative fraction leached vs. time from VES containing $40 \mathrm{wt}$ sodium sulfate at waste form volume to surface area $(\mathrm{V} / \mathrm{S})$ ratios of $0.42,0.62$ and 0.91 . Samples were leached in deionized water at $20^{\circ} \mathrm{C}$.

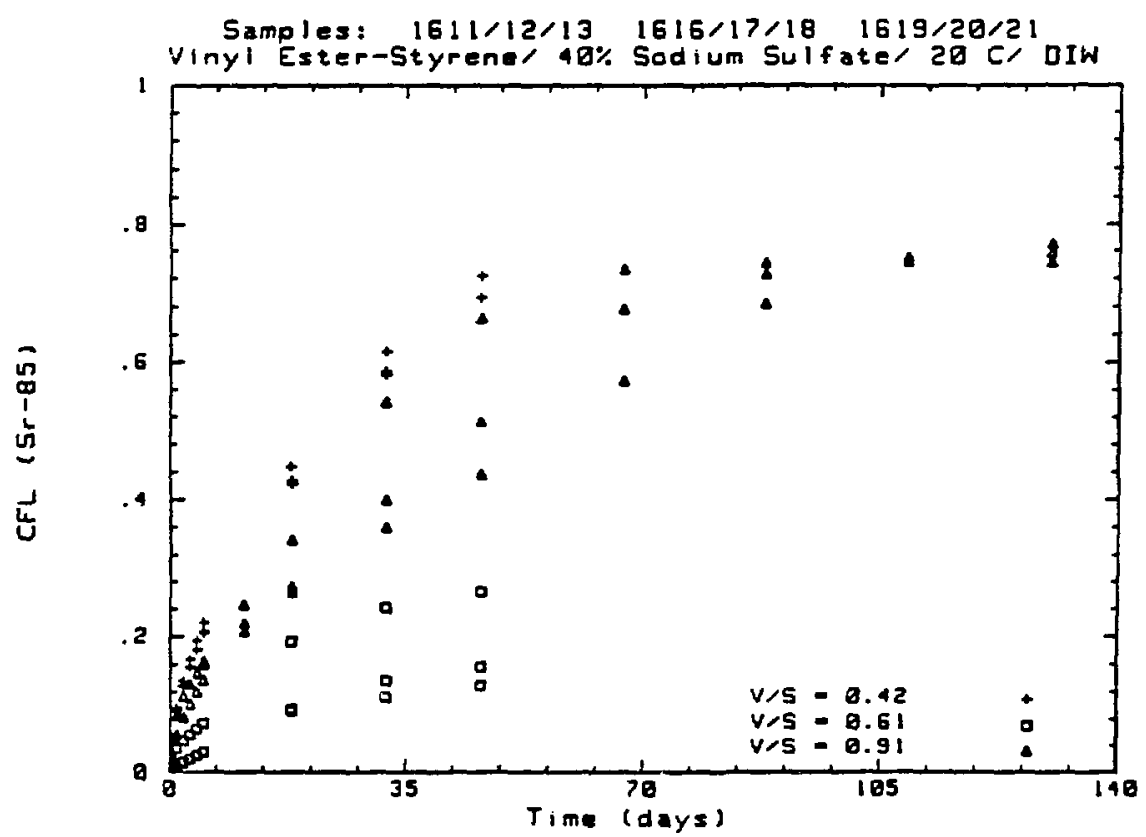

Figure 7.32

Sr-85 cimulative fraction leached vs. time from VES containing $40 \mathrm{wt}$ sodiun sulfate at waste form volume to surface area $(\mathrm{V} / \mathrm{S})$ ratios of $0.42,0.62$ and 0.91 . Samples were leached in deionized water at $20^{\circ} \mathrm{C}$. 


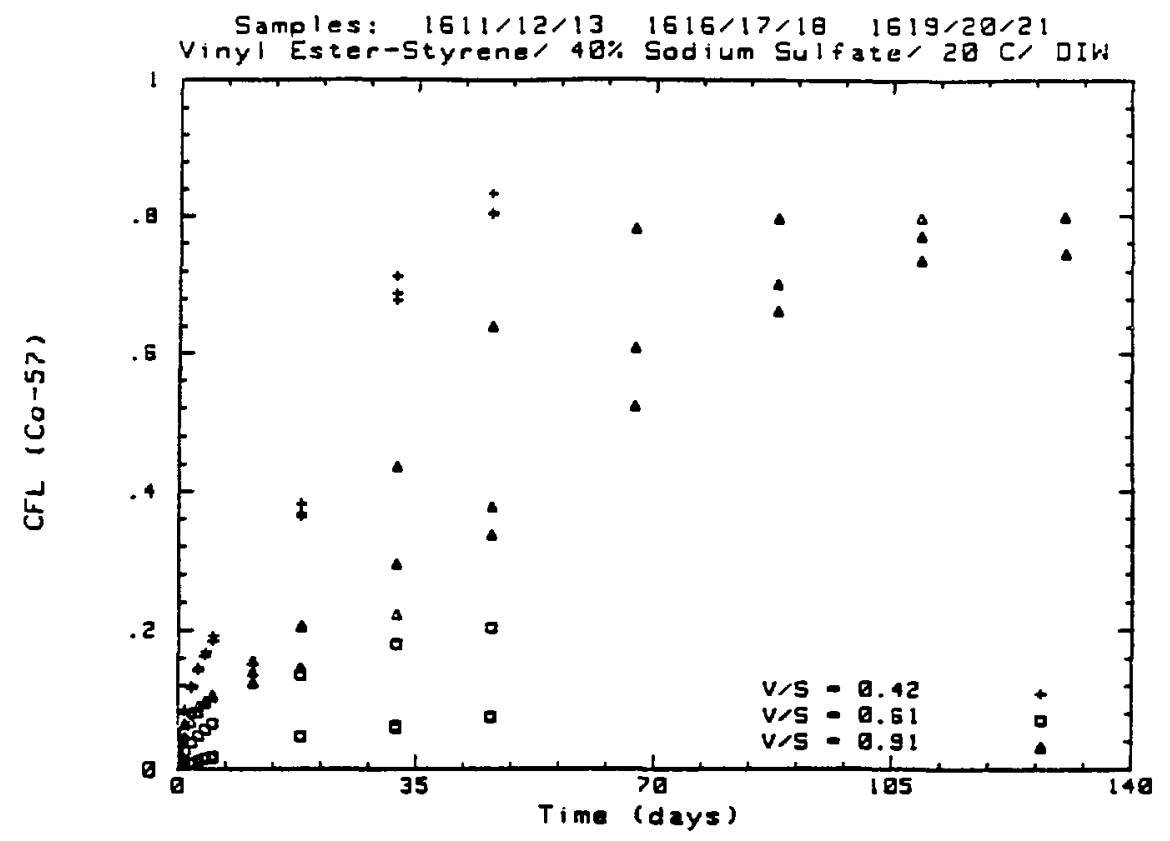

Figure 7.33

Co-57 cumulative fraction leached vs. time from VES containing 40 wto sodium sulfate at waste form volume to surface area (V/S) ratios of $0.42,0.62$ and 0.91 . Samples were leached in deionized water at $20^{\circ} \mathrm{C}$.
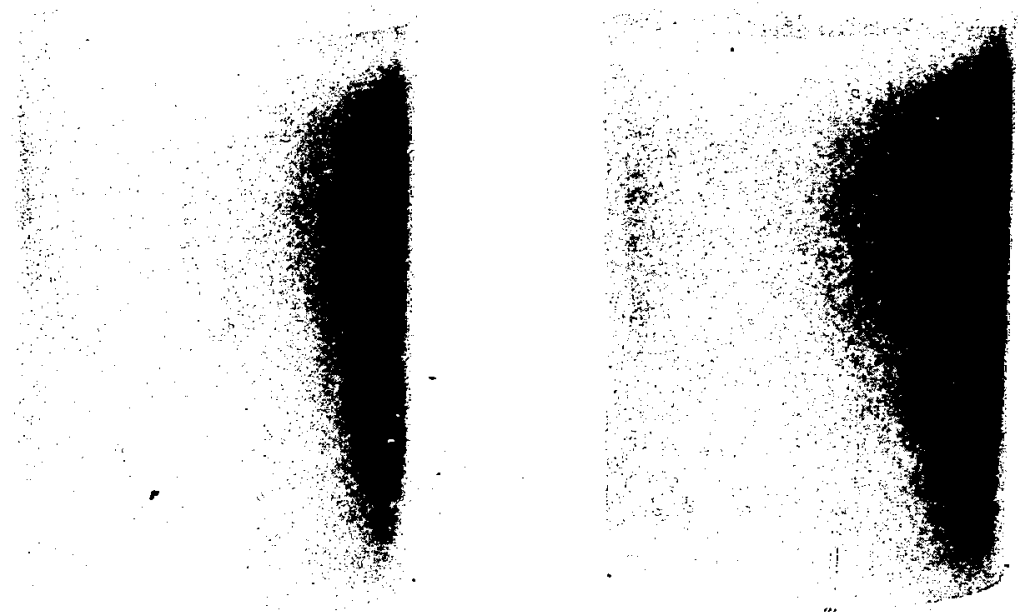

Figure 7.34

Vinyl ester-styrene forms containing 40 wt sodium sulfate. The one at left is as fabricated. The one at right was leached for 403 days in deionized water at $20^{\circ} \mathrm{C}$. Samples were $4.8 \mathrm{~cm}$ diameter by $6.4 \mathrm{~cm}$ high right cylinders. 


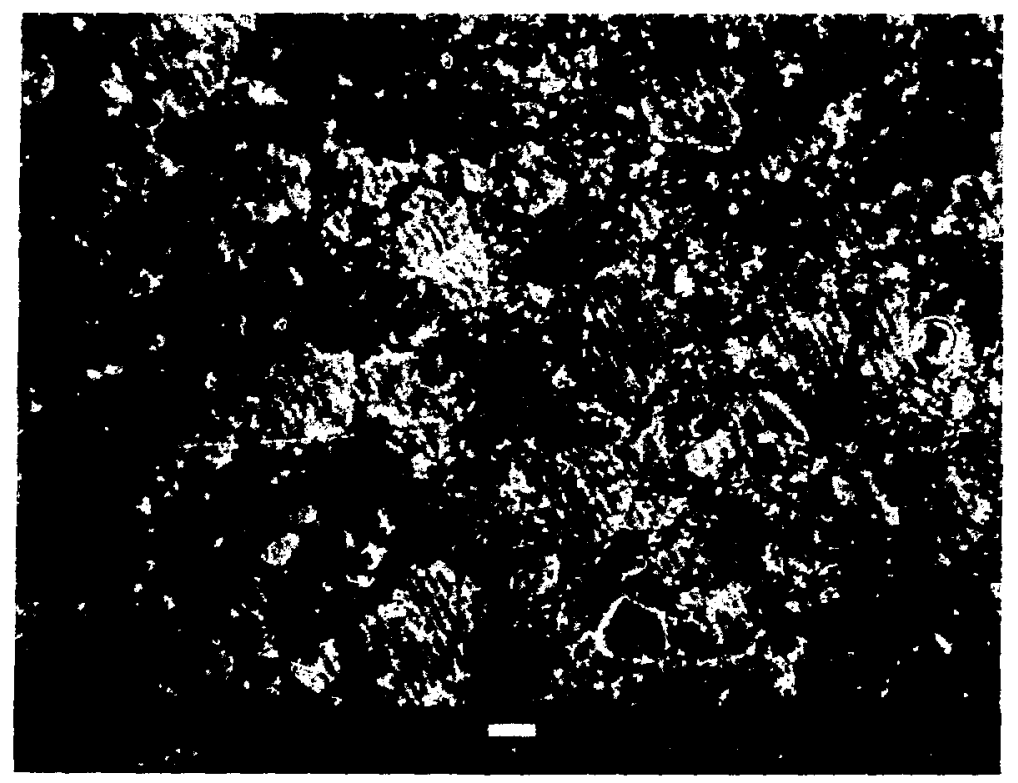

Figure 7.35

Interior of a sectioned, unleached VES specimen containing 40 wt sodium sulfate. There appears to be little contact between grains of salt.

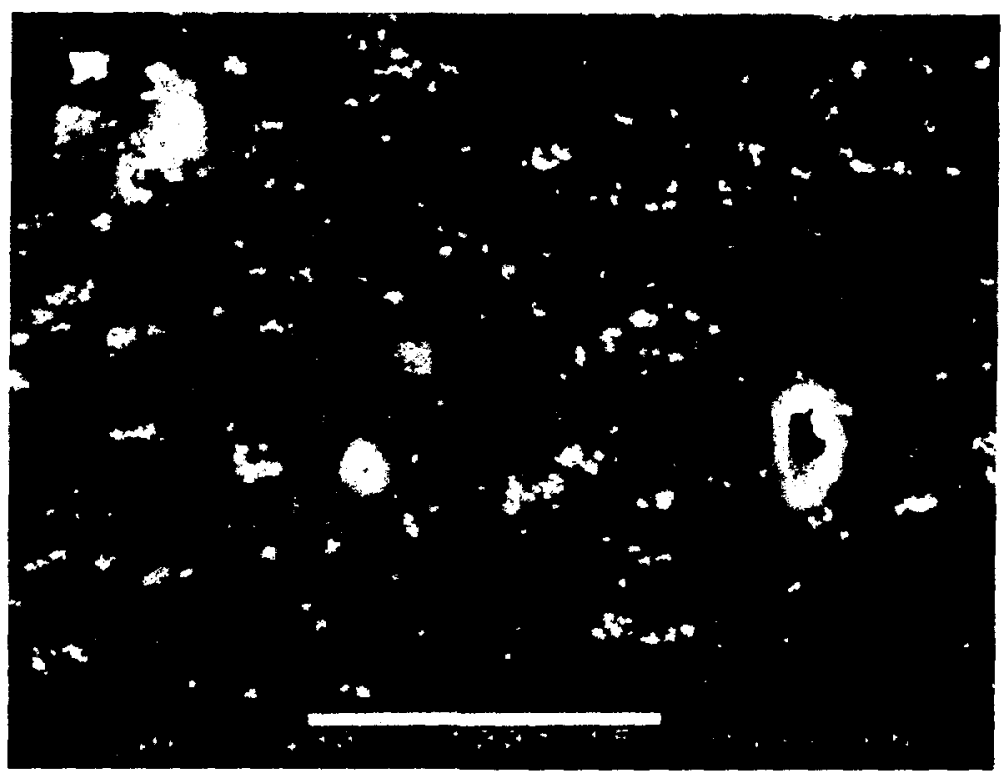

Figure 7.36

Unleached surface of a VES specimen containing 40 wto sodium sulfate. No salt grains are visible but several open pores are evident. A leached surface is similar in appearance. Magnification is 400 times. 


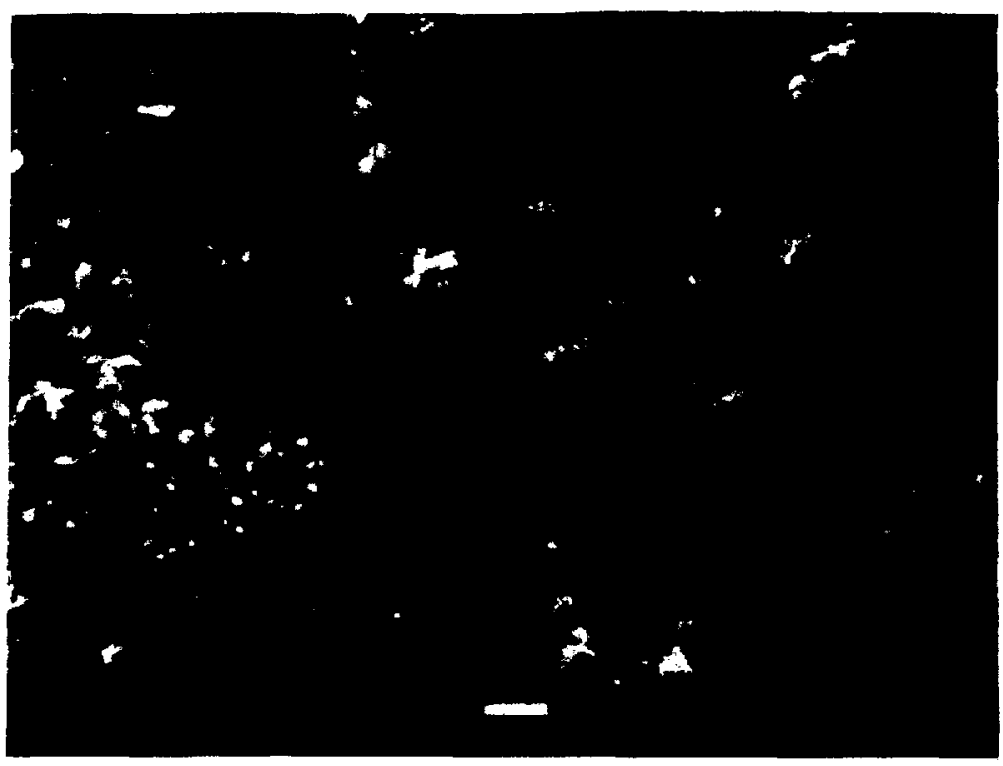

Figure 7.37

Two grains of salt separated by VES polymer. This specimen had been leached but no obvious effect from the leaching was noted. No sodium or sulfur was detected by EDS in the polymer between the grains. 


\section{BITUMEN CONTAINING SODIUM TETRABORATE AS SIMULATED WASTE}

Bitumen is any of several various mixtures of hydrocarbons and other substances, occurring naturally or obtained by distillation from coal or petroleum. Bitumen is found in asphalt and tar and used for surfacing roads and for water proofing. Asphalt, also called mineral pitch, is a brownishblack semisolid mixture of bitumens containing much mineral matter. The term bitumen refers to asphalt free of mineral matter. Tar, however, is a dark, oily, viscous mixture, consisting mainly of hydrocarbons, produced by the destructive distillation of organic substances such as wood, coal, or peat. Coal tar, for example, is a black liquid $[70,71]$.

Various types of bitumen have been used as solidification agents for LLW. Bitumens and asphalts are generally characterized by their softening point temperatures [72] and the process by which they were prepared [73]. An oxidized bitumen, Pioneer 321, which has been used for rad-waste processing, was used to prepare the waste forms for this experimental work.

This section presents results obtained from leaching studies investigating the factors deemed potentially important for LLW forms, as discussed in Section 2 of this report, consisting of bitumen incorporating sodium tetraborate.

\subsection{Leaching Mechanisms}

The following overview summarizes the leaching mechanisms for bitumen as determined from the literature survey [1] and the experimental work in this task.

The function of bitumen in the solidification of LLW is generally considered to be that of an adhesive coating. As such, the waste content of bituminized waste does not significantly change the mechanical properties of the solidified form until the waste loading exceeds approximately 60 weighto $[74,75]$. Conversely, the strength of a cement form depends on waste loading and reportedly decreases substantially at salt loadings greater than $130 \mathrm{~g}$ per $\mathrm{Kg}$ of cement product (i.e., 13 wto of waste form) [76]. The leaching data have been analyzed based on two postulated mechanisms [74,77]. In one, diffusion was presumed to be the mass transport process [77], whereas in the other [74], the solubility of the activity was presumed to control the leaching. Functionally, the diffusion-mechanism would result in a release rate proportional to $t-1 / 2$, while the solubility-controlled mechanism would give a constant rate of release of activity from the waste form. These different analyses may not be incompatible since the bitumens used for solidification, the waste and the process used to incorporate the wastes all differed.

Although bitumen is generally considered to be hydrophobic, it has a small, but definite, permeability to water. It is a viscoelastic material which has little mechanical strength at ordinary temperatures and creeps readily under the loads that are typical of shallow land burial. Because it forms an adhesive coating and is only slowly permeable to water, bitumen waste forms typically have low short-term leachabilities. However, bitumen wastes 
forms incorporating soluble wastes often swell at longer times during leaching and then the leach rate increases substantially. The onset of swelling is also a function of waste loading, as further discussed in section 8.2.6.

The results of the leach tests shown in this report for bitumen waste forms together with those referenced in the literature survey [1] showed that the leaching of bitumen waste forms incorporating soluble wastes generally had two distinct regions of behavior. There was an initial region of low rates normally associated with short-term leach tests on bitumen waste forms. The water uptake within the waste form is not sufficient to initiate swelling. However, as water uptake becomes sufficient to start the swelling and, as swelling progresses, the leach rate increases substantially. Severe swelling has been reported with waste forms incorporating salts and ion exchange resins [78]. With sodium sulfate, at loadings greater than approximately 17 wt 8 , the waste form cracks open and falls apart during immersion and leaching in deionized water. Bitumen waste incorporating insoluble wastes and wastes that do not swell should exhibit low leach rates, even at long immersion times. To summarize, the leaching mechanisms for bitumen must account for:

(i) Diffusion of radionuclides at low waste loadings and relatively short leaching times.

(ii) Water permeation and swelling, with its effect on leaching.

(iii) The rapid increase in leaching at longer leaching times and especially at waste loadings greater than approximately 20 wto.

\subsection{Factors that Affect Leaching}

Leaching results from experiments designed to investigate each of the factors listed in Table 2.1 for the bitumen (Pioneer 321 Asphalt) waste forms containing anhydrous sodium tetraborate are discussed in the following sections. The basis for evaluating the effect of each of the factors is a comparison with the results of tests on standard samples, i.e., $4.8 \mathrm{~cm}$ diameter by $6.4 \mathrm{~cm}$ high right cylinders, at $20^{\circ} \mathrm{C}$ in deionized water. Replicate tests, generally triplicates, provided a measure of the variability of the data.

8.2.1 Temperature. The effect of temperatures between 20 and $50^{\circ} \mathrm{C}$ on the leachability of bitumen waste forms containing 40 wt sodium tetraborate was investigated. Oxidized bitumen (Pioneer 321 ) softens between 70 and $140^{\circ} \mathrm{C}$ and has "good adhesive and self-healing properties" [73].

Figures 8.1 through 8.6 summarize the effect of temperature on the leaching of radionuclides from this form. Figures 8.1,8.3 and 8.5 present the cumulative fraction leached (CFL) versus time for Cs-137, Sr-85 and Co-57, respectively, at 20,40 and $50^{\circ} \mathrm{C}$. Figures $8.2,8.4$ and 8.6 show linear correlations of these data versus the $20^{\circ} \mathrm{C}$ data.

Elevated temperatures do not accelerate leaching from bitumen for any of the radionuclides investigated. The statistical scattering in the data is large but it seems that at $50^{\circ} \mathrm{C}$, leaching is actually reduced relative to that 
at $20^{\circ} \mathrm{C}$. This could be caused by a "self-healing" process in which bitumen would flow into pores that form as the salt begins to swell.

Since the leaching of radionuclides at elevated temperature is only marginally useful, the leaching of non-radionuclide elements from bitumen containing 40 wto sodium tetraborate was not presented.

\subsubsection{The Surface Area of the Waste Form to Leachant Volume. The ANS} 16.1 leach test specifies that the ratio of the leachant volume (cubic $\mathrm{cm}$ ) to the geometric surface area (square $\mathrm{cm}$ ) of the test specimen should be $10 \pm 0.2$ (cm). To investigate the effect of increasing this ratio on leaching be havior, ratios of 30 , and 50 were used. The results for Cs-137, Sr- 85 and Co-57 from bitumen containing 40 wto sodium tetraborate are shown in Figures $8.7,8.8$, and 8.9 .

No apparent increase in the leaching of Cs-137, $\mathrm{Sr}-85$ or Co-57 was observed (Figures $8.7,8.8$, and 8.9 ) due to an increase in the leachant volume to sample surface area ratio. The apparent decrease in the observed leaching (CFL) is probably an artifact: specifically, although all of the samples in these experiments were nominally identical, only the two sets at the larger volumes were replicates, whereas the samples at $1300 \mathrm{ml}$ (i.e., ratio of 10:1) were fabricated at a different time. Therefore, increasing the leachant volume to surface ratio was not promising as an accelerating factor for Cs137, Sr-85 or Co-57. Further experiments to measure the release of nonradionuclide elements were not pursued.

\subsubsection{Leachant Composition. Deionized water (DIW) was the standard} leschant used in the ANS 16.1 leach test. Leachants used to examine the effect of leachant composition on the leaching of bitumen waste forms containing 40 wt sodium tetraborate included DIW, simulated groundwater of an Oak Ridge National Lab (ORNL) well water [33] and DIW containing 100 ppm EDTA. The mineral content of the ORNL groundwater is listed in Table 3.3. In addition, we used two variations of the ORNL simulated groundwater:

(i) in a well-oxygenated state (i.e., oxic groundwater), and

(ii) in a solution depleted of oxygen (i.e., anoxic groundwater).

Both oxic and anoxic groundwaters contained soil-extracted humic acids to make the compositions more realistic. Humic acids have strong affinities for metal ions and can act as complexing and chelating agents [79]. The experiments with $100 \mathrm{ppm}$ EDTA in the leachant were used to examine the effect of a very strong chelating agent, the disodium ethylenediaminetetraacetate (EDTA) hexahydrate salt.

Figure 8.10 shows the leaching curves for Cs-137 from bitunen containing 40 wto sodium tetraborate leached at $20^{\circ} \mathrm{C}$ in $\mathrm{DIW}$, oxic and anoxic groundwaters. Figure 8.11 shows leaching curves for Cs-137 leached from bitumen in DIW, and in a solution of DIW with $100 \mathrm{ppm}$ EDTA. The greatest leachability was observed in DIW. Suppression of Cs-137 leaching might be expected because of the relatively higher ionic strength of the groundwater leachant [3] and is corroborated by other reports $[64,65]$. Since the EDTA would not affect the 
solubility of Cs-137, the increase in ionic strength of the leachant is the only obvious effect that it would have. Likewise, anoxic groundwater has a substantially greater ionic strength than does oxic groundwater, as shown in Table 3.3. In sum, the presence of chelating agents and the oxic or anoxic state of the leachant make little difference in the Cs-137 leachability from the bitumen waste forms, and increasing the ionic strength of the leachant decreases the Cs-137 leachability.

Figure 8.12 shows the comparable leaching curves for $\mathrm{Sr}-85$. Figure 8.13 shows the leaching curves for Sr-85 leached in DIW and a $100 \mathrm{ppm}$ solution of EDTA. In all cases $\mathrm{Sr}-85$ is more leachable in DIW. For either the oxic or anoxic groundwater the high carbonate content and the high ionic strength of the leachant would explain the reduced leachability of Sr-85. The presence of natural chelating agents, i.e., the humic acids or the synthetic chelating agent EDTA make little, if any, difference in the $\mathrm{Sr}-85$ leachability from these solutions. In fact, the relative increase in the ionic strength of the EDTA solution only decreases the Sr-85 leachability.

Figure 8.14 shows the leaching curves for Co-57 from bitumen containing 40 wto sodium tetraborate at $20^{\circ} \mathrm{C}$ in DIW, oxic and c.oxic groundwaters. Figure 8.15 shows the leaching curves for Co-57 in DIW and a $100 \mathrm{ppm}$ solution of EDTA. The Co-57 leachability was enhanced in both the oxic groundwater and the $100 \mathrm{ppm}$ solution of EDTA. However, the Co-57 leachability in the anoxic groundwater was lower than that of the DIW. The oxic groundwater, anoxic groundwater and the $100 \mathrm{ppm}$ solution all have ionic strengths that are greater than that of the DIW and would be expected to suppress leaching to some extent as was observed for both $\mathrm{Cs}-137$ and Sr-85 (discussed in Section 8.2.3). Cobalt(II) is the only stable oxidation state in aqueous solutions at room temperatures $\left(20^{\circ} \mathrm{C}\right)$ containing no complexing agents. In basic solution, cobaltous hydroxide is rather insoluble (Ksp=1E-16) [80,81]. However cobalt ions are strongly complexed in aqueous solutions, especially by EDTA. The presence of Co (III) in solution is not favored. But in the presence of complexing agents, such as humic acids or EDTA, and slightly basic conditions, the stability of Co(III) is greatly improved. The groundwater solutions are slightly basic and contain natural humic acids, which are known complexing agents [80]. Formation of a complex of Co(III) could possibly account for the increased leachability of Co-57 both in the oxic groundwater and the $100 \mathrm{ppm}$ solution of EDTA. The correlation diagrams in Figures 8.16 and 8.17 clearly show the increased leachability in oxic groundwater and the 100 ppm EDTA solution, respectively.

The leaching of sodium and boron from bitumen containing 40 wt 8 sodium tetraborate at $20^{\circ} \mathrm{C}$ in DIW and oxic groundwater is shown in Figure 8.18: Figure 8.19 shows the linear correlation plots for sodium, boron and Cs-137. Considerable leaching of sodium tetraborate was observed.

8.2.4 $\mathrm{pH}$ of the Leachant. The $\mathrm{pH}$ of deionized water (DIW), which is the standard leachant in the ANS 16.1 leach test, is nominally 7 at $20^{\circ} \mathrm{C}$ but is actually siightly acidic (about 6 ) due to dissolution of carbon dioxide from the air. Initial leachant $\mathrm{pH}$ values of 4,6 and 8 were used in the investigations. Increasing the acidity of the leaching solution would be expected to increase the leach rate of most constituents: conversely, 
decreased leachability of many constituents would be expected in basic solutions.

The results shown in Figure 8.20 for bitumen containing 40 wt sodium tetraborate leached at $20^{\circ} \mathrm{C}$ indicated that the leachability of $\mathrm{Cs}-137$ was not affected by the initial $\mathrm{pH}$ of the leachant over a range of 4 to 8 . Further experiments were not pursued since $\mathrm{pH}$ was not an accelerating factor for Cs-137. Similarly, the initial $\mathrm{pH}$ of the leachant solution also did not affect the leachability of $\mathrm{Sr}-85$ (Figure 8.21).

Leaching of Co-57, however, was different: Figure 8.22 shows the leaching data for Co-57 from bitumen containing 40 wt sodium tetraborate. Figure 8.23 shows a correlation plot of these data. The leaching of Co-57 is enhanced in the alkaline $(\mathrm{pH}-8)$ solution. This effect is consistent with the observations made for oxic groundwater and the $100 \mathrm{ppm}$ solution of EDTA reported in section 8.2 .3 for Co-57 leaching, namely that oxygen saturated, somewhat alkaline solutions that contain small amounts of complexing agents (natural or synthetic) may show enhanced leachability of Co-57 from these bitumen waste forms. Cobaltous hydroxide is rather insoluble in alkaline solutions and would not be expected to dissolve. Cobalt (II) is the only stable oxidation state of cobalt in aqueous solution at room temperature in the absence of complexing agents. However Co(III) existence is enhanced in slightly alkaline aqueous solutions containing complexing agents. Complexes of Co(III) are exceedingly numerous and have been extensively studied. Bitumen itself is a mixture of organic substances that could possibly act as chelating agents for $C o(I I I)$. But more importantly, the borate ion of the waste itself could possibly act as a chelating ligand [82].

\subsubsection{Flow and Replacement Frequency of the Leachant. The flow or} replacement frequency of the leachant may affect leachability because of the buildup of materials in the leachant. The ANS 16.1 leach test provides for daily replacements through day five following replacements at 2 hours and 7 hours and the first day. Following day five, the replacement intervals are much longer, up to three weeks in duration. The effect of changing the leaching period from daily to longer periods was investigated by conducting a leaching experiment in which the sampling intervals, after the first three short intervals, were one day. Daily leachant replacements continued until the end of the experiment ( 34 days). To investigate the effect of continucus replacement (flow) versus periodic replacement, bitumen waste forms containing 40 wt sodium tetraborate were leached in a flow experiment based on the MCC4S flow test. (Materials and Method section 2.3.3).

Figure 8.24 shows the CFL of Cs -137 from bitumen wastes for triplicate samples using the modified ANS 16.1 test and changing daily. Figure 8.25 shows the correlation diagram for the same data. There appears to be no useful acceleration due to maintaining the leaching interval at one day. Two experimental artifacts are worth noting. First, the final CFLs for Cs-137 from the modified ANS 16.1 test were considerably different from sample to sample, approximately 0.75 to 1.2. Second, one of the samples used in the daily test showed a large initial rise in the Cs-137 leaching. Both of these effects probably reflect the difficulty in preparing entirely uniform samples 
of the waste form which are essentially heterogeneous mixtures of dry solids in a viscid liquid.

The Cs-137 release rate versus in the flow test with duplicate bitumen waste forms are shown in Figure 8.26 where the time is shown because one cannot directly calculate the CFL from the MCC4S flow test data. For comparison, Figure 8.26 also shows the release rate of Cs-137 for the modified ANS 16.1 test. No observable increase in the release rate was found in the flowing leachate.

Figure 8.27 shows the leaching results for Sr-85 from the bitumen waste with 40 wt sodium tetraborate using the modified ANS 16.1 sampling schedule and sampling daily. Figure 8.28 shows the linear correlation diagram for this data. No apparent increase in the leaching was observed for changing the sampling periods to a daily basis. Figure 8.29 shows the leach rates for triplicate samples during the modified ANS 16.1 tests, and duplicate samples during the MCC4S flow test. No apparent difference in the rate of leaching was observed in this experiment.

The CFL of Co-57 from the bitumen waste observed during the modified ANS 16.1 test and the daily sampling test, using triplicate samples in both cases, are shown in Figure 8.30. Figure 8.31 shows the linear correlation for the same data. One sample in the daily sampling experiment exhibited enhanced leaching of Co-57. The other two waste forms did not. It is believed that this difference, for samples that are nominally identical, reflects the difficulty of preparing entirely uniform waste forms.

Figure 8.32 shows the release rates of Co-57 observed for triplicate samples during the modified ANS 16.1 test and duplicate samples used for the MCC4S flow test. No apparent difference in the leach rates were observed.

8.2.6 Composition of the Waste Form. The composition of the waste form is a major determinant in the leaching behavior of bitumen waste forms containing soluble salts. Bitumen has a small but definite permeability to water. The osmotic pressure gradient inside the waste form is between the soluble salt through the water-permeable bitumen membrane and the external leachate solution. This osmotic pressure causes the elastic bitumen binder to swell and the waste form to crack. The effect is strongly controlled by the amount of waste in the waste form. For sodium tetraborate, the swelling becomes noticeably rapid at waste loadings greater than 20 wto. Figure 8.33 shows the severe swelling and cracking of bitumen waste forms containing 40 wto sodium tetraborate before and after 403 days in DIW at $20^{\circ} \mathrm{C}$. To demonstrate these effects, experiments were conducted with neat bitumen and bitumen containing 20,30 and 40 wto sodium tetraborate in DIW at $20^{\circ} \mathrm{C}$.

Figure 8.34 shows the Cs-137 CFL data from triplicate samples in these experiments. All four sets of leaching curves are characterized by an initial period of relatively low leach rates. The neat bitumen continues to leach at a low rate for over 500 days. For the waste forms containing sodium tetraborate, the initial slow leaching period was followed by a rapid rise in the CFL of Cs-137. Although there is significant statistical scattering in the leaching curves, the behavior of the sets of leaching curves for each waste 
form waste loading can be distinguished clearly. The increase in the CFL corresponded to the waste form loading, that is, minimal leaching was observed for neat bitumen ( 0 wt 8 ) and maximal for bitumen containing 40 wt sodium tetraborate. The approximate time at which the leach rate increased was 100 days for $20 \mathrm{wtz}, 5$ days for $30 \mathrm{wtz}$ and 2 days for $40 \mathrm{wtz}$. This change corresponded to the start of swelling of the waste form and, presumably, to the permeation of water from the leachant.

The leaching behavior of Cs-137 for bitumen waste forms containing sodium tetraborate cannot be accounted for by diffusion alone since it appears to be dependent on the rate of permeation of water into the waste form.

The leaching data for Sr-85 from triplicate samples of bitumen waste forms containing $0,20,30$ and 40 wtz are shown in Figure 8.35. The data on $\mathrm{Sr}-85$ is quite similar to that of Cs-137. However, the statistical scattering the 20 and $30 \mathrm{wtz}$ waste loadings, after 5 days of leaching, falls into a broad band between the neat bitumen ( 0 wtz) samples and those containing 40 wtz sodium tetraborate. In sum, the CFL from bitumen is characterized by an initial slow rate of release, followed by a rapid rise in the CFL; at any time after the initial period this rate depends on the waste form loading, such that the greatest leaching was observed for the highest waste loading.

Figure 8.36 shows the leaching data for Co-57 from triplicate samples of these bitumen waste forms. Co-57 leaching is generally an order of magnitude lower than that of $\mathrm{Cs}-137$ and Sr-85. Still, the leaching behavior of Co-57 is quite similar to that of Sr-85. The major difference is that the relative rise in the leach rate is not as great but still clearly apparent for the samples containing sodiun tetraborate. The statistical scattering in the leaching data for the samples containing 20 and 30 wto sodium tetraborate is relatively large but falls into a broad band between that observed for neat bitumen ( 0 wts) and the samples containing 40 wto sodium tetraborate.

Leaching of sodium and boron from bitumen waste forms containing 40 wto sodium tetraborate are shown in Figure 8.18. Complete leaching of the sodium tetraborate waste was observed.

8.2.7 Ratio of Surface to Volume (V/S) in the Waste Form. Sample scale is a major accelerating factor for predicting the behavior of full-scale waste forms. For leaching behavior that can be accounted for by diffusion theory, the waste form volume to surface area ratio (V/S) can be theoretically correlated with the CFL of a radionuclide. To exanine the scaling behavior of small laboratory specimens, waste forms of bitumen containing 40 wto sodium tetraborate of three different sizes were leached with $\mathrm{DIW}$ at $20^{\circ} \mathrm{C}$.

Figure 8.37 shows the Cs-137 leaching data for triplicate samples of each size. There was no apparent acceleration for diminishing waste form volume to surface area $(\mathrm{V} / \mathrm{S})$ ratio. The rapid rise in the $\mathrm{Cs}-137$ leach rate apparently overwhelms any observable differences due to scale. The large scattering in the final CFL data reflects the difficulty of preparing uniform samples, which were nominally identical. 
The Sr-85 leaching data for triplicate samples of each sample size is shown in Figure 8.38. The increase in leaching of $\mathrm{Sr}-85$ appears to correlate with the ratio of volume to surface area $(\mathrm{V} / \mathrm{S})$ before depletion of the sample occurs. The broad statistical scattering of the final CFL data again reflects the problem of uniformity. Figure 8.39 shows the correlation diagram for the same data. The precision in the leaching data appears to be relatively good below $0.4 \mathrm{CFL}$, but deteriorates very significantly above this value. The scaling data for Sr-85 appears to be of limited usefulness.

Figure 8.40 shows that leaching data for co-57. The statistical scattering fo: the small sample was quite appreciable above about $0.1 \mathrm{CFL}$. The leaching behavior appears to increase with decreasing ratio of waste form volume to surface area $(\mathrm{V} / \mathrm{S})$. This is further illustrated in the correlation diagram Figure 8.41. At about $0.025 \mathrm{CFL}$, the leaching behavior of each sample size falls into three broad but separate bands. The statistical uncertainties in the Co-57 CFL data may limit the usefulness of these results.

8.2.8 Porosity and Surface Condition of the Waste Form. The porosity of bitumen waste forms is known to be very small, but the swelling of waste forms containing $40 \mathrm{wt}$ sodium tetraborate indicates that water permeability is a critical factor in the performance of the waste form. 


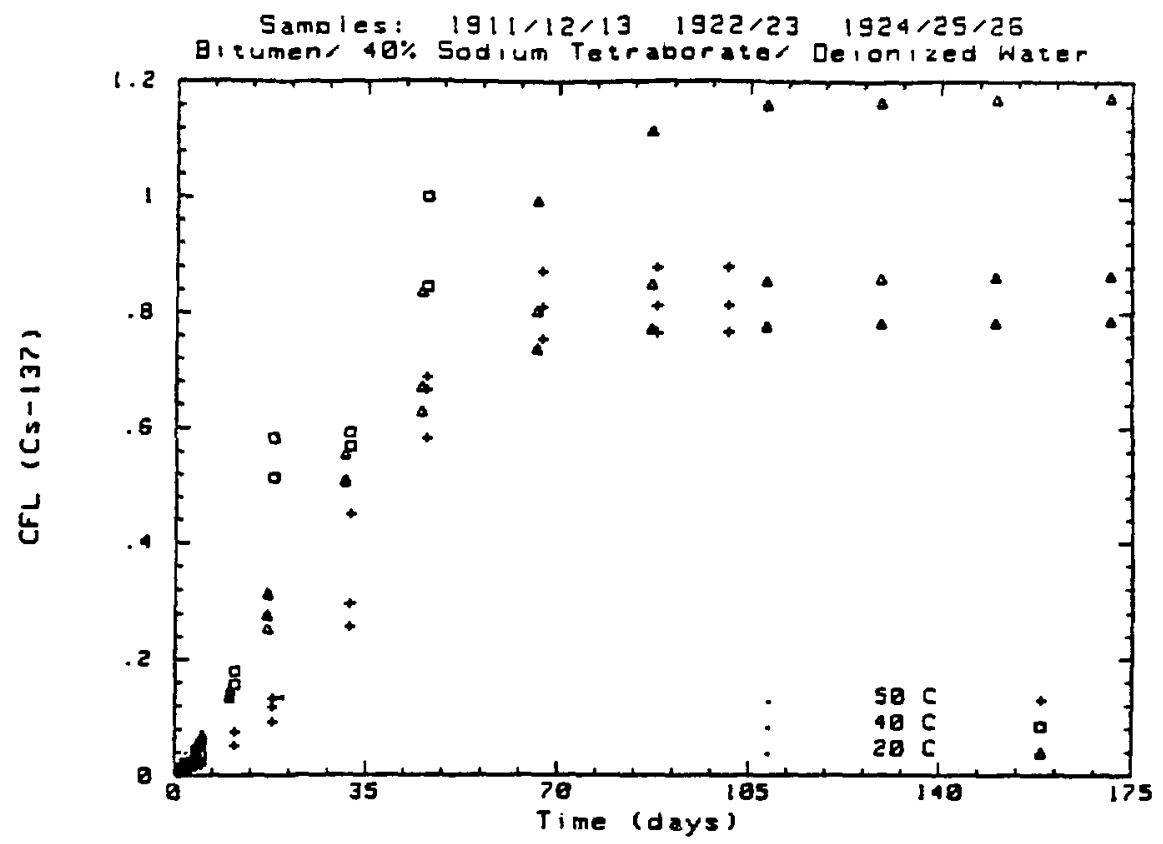

Figure 8.1 Cs-137 cumulative fraction leached vs. time fron bitumen containing 40 wt sodium tetraborate at 20 , 40 and $50^{\circ} \mathrm{C}$ leached in deionized water.

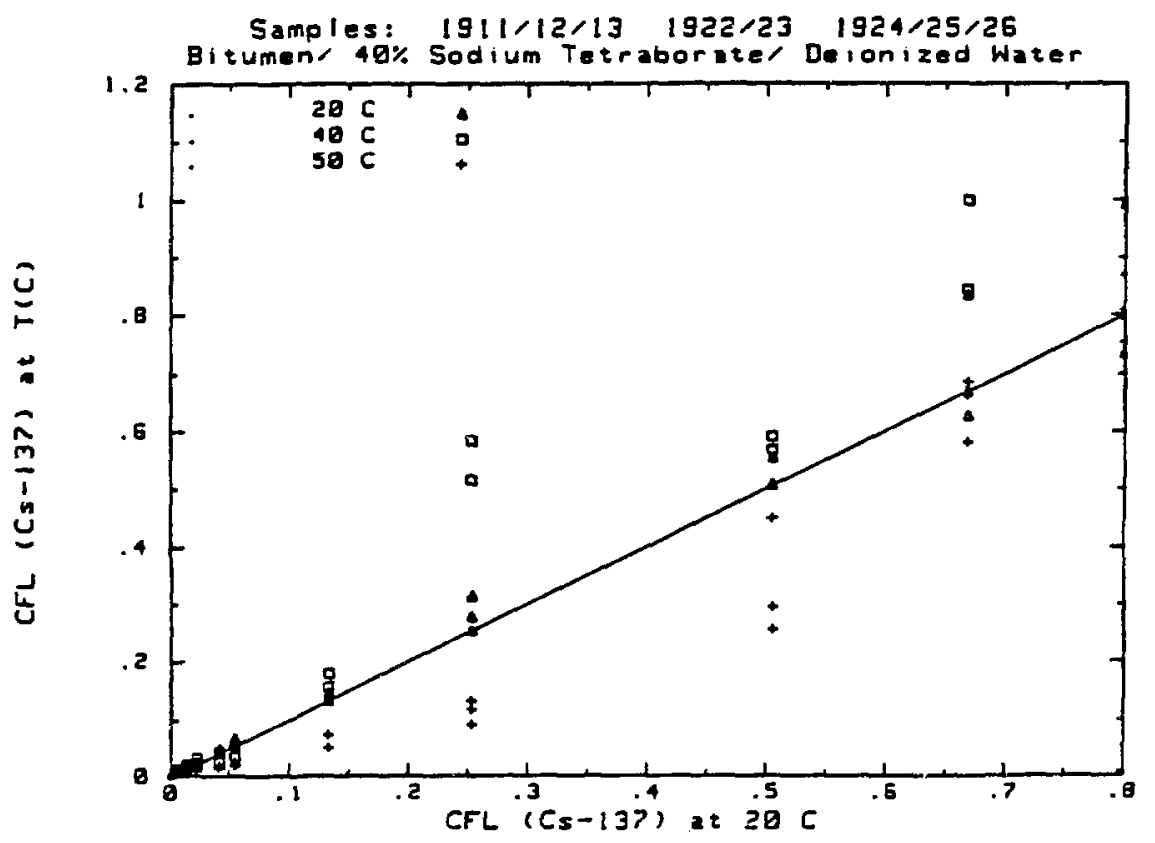

Figure 8.2

Linear correlation plots for Cs-137 leaching from bitumen containing 40 wt sodium tetraborate at 20 , 40 and $50^{\circ} \mathrm{C}$. Correlations are relative to the $20^{\circ} \mathrm{C}$ data. 


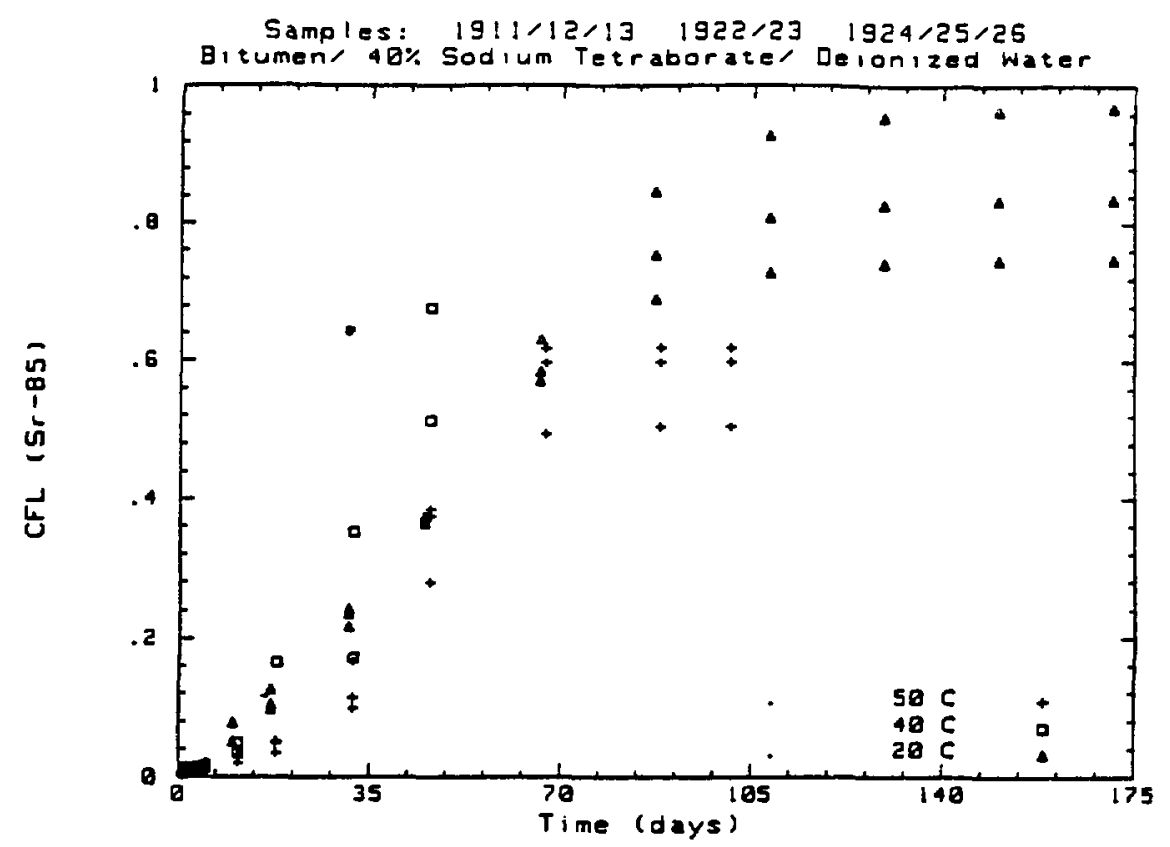

Figure 8.3

Sr-85 cumulative fraction leached vs. time from bitumen containing 40 wt sodium tetraborate at 20 , 40 and $50^{\circ} \mathrm{C}$ leached in DIW.

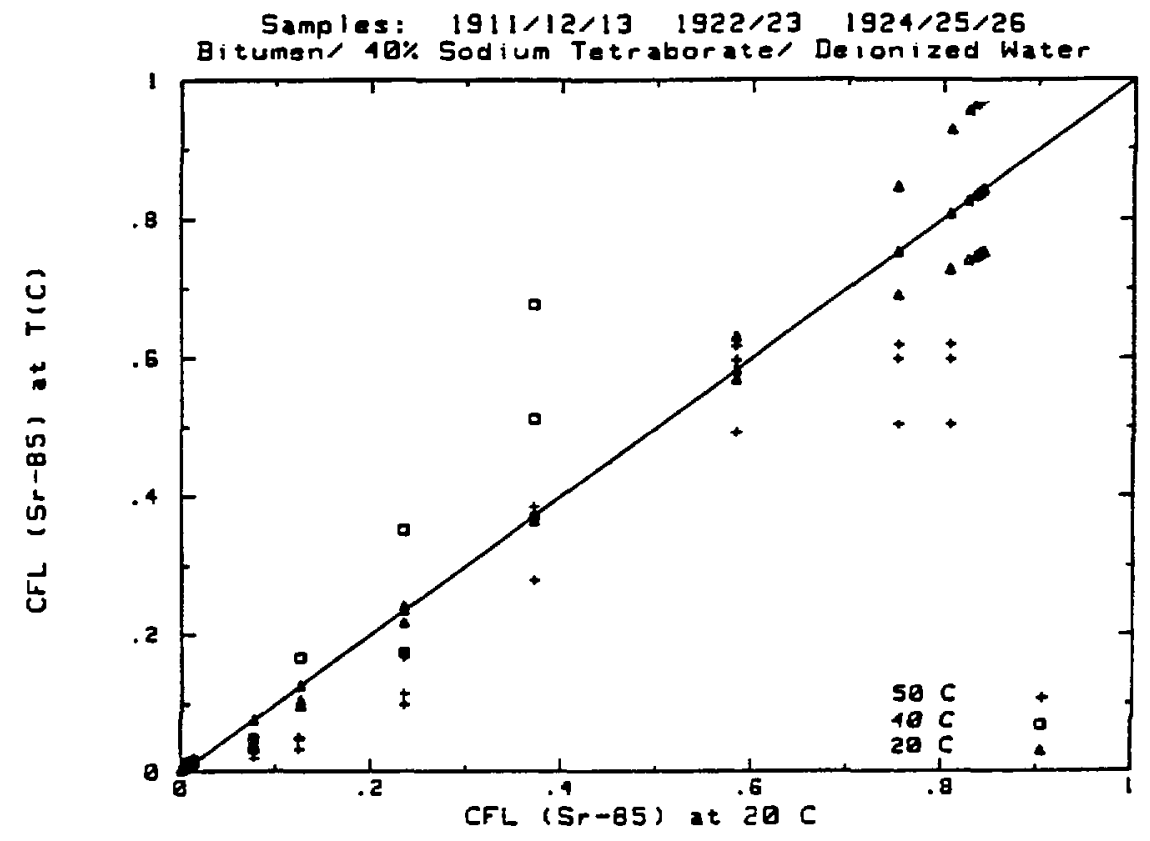

Figure 8.4

Linear correlation plots for Sr-85 leaching from bitumen containing 40 wt sodium tetraborate at 20 , 40 and $50^{\circ} \mathrm{C}$. Correlations are relative to the $20^{\circ} \mathrm{C}$ data. 


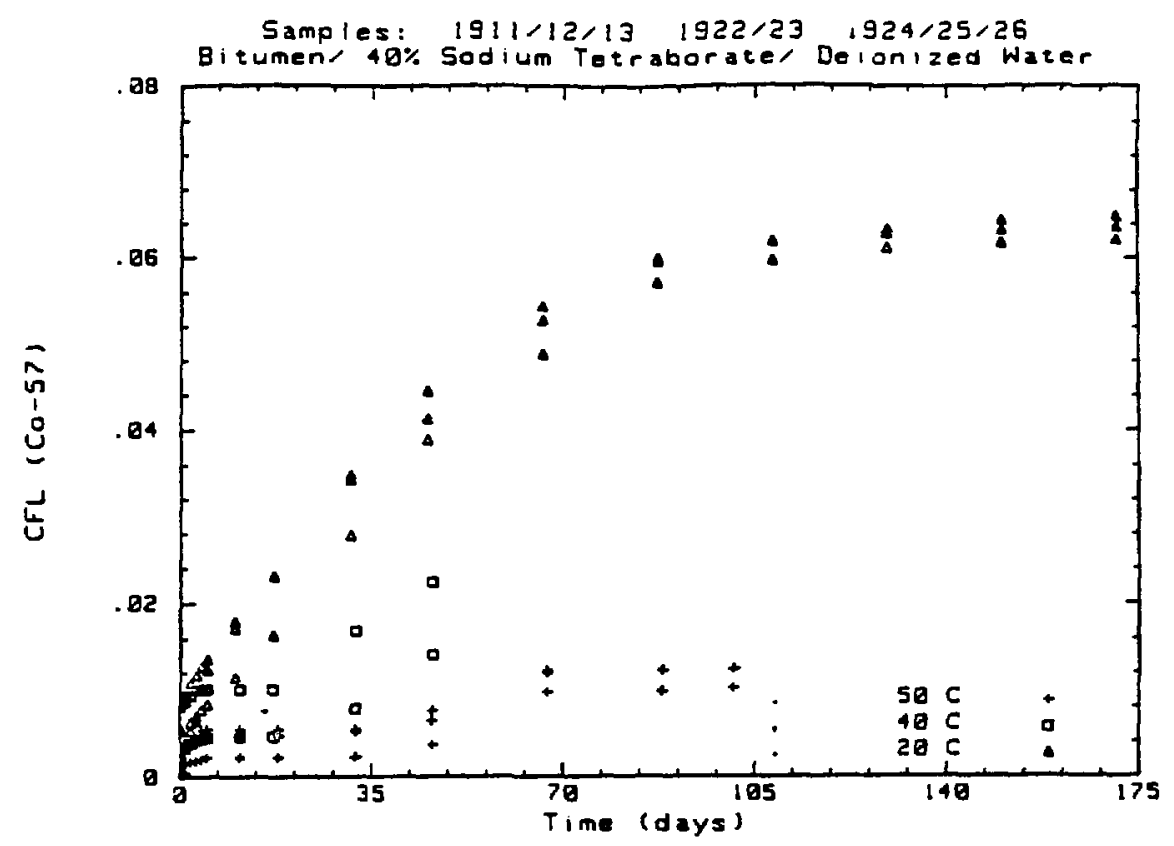

Figure 8.5 Co.57 cumulative fraction leached vs time from bitumen containing 40 wt sodium tetraborate at 20 , 40 and $50^{\circ} \mathrm{C}$ leached in $\mathrm{DIN}$.

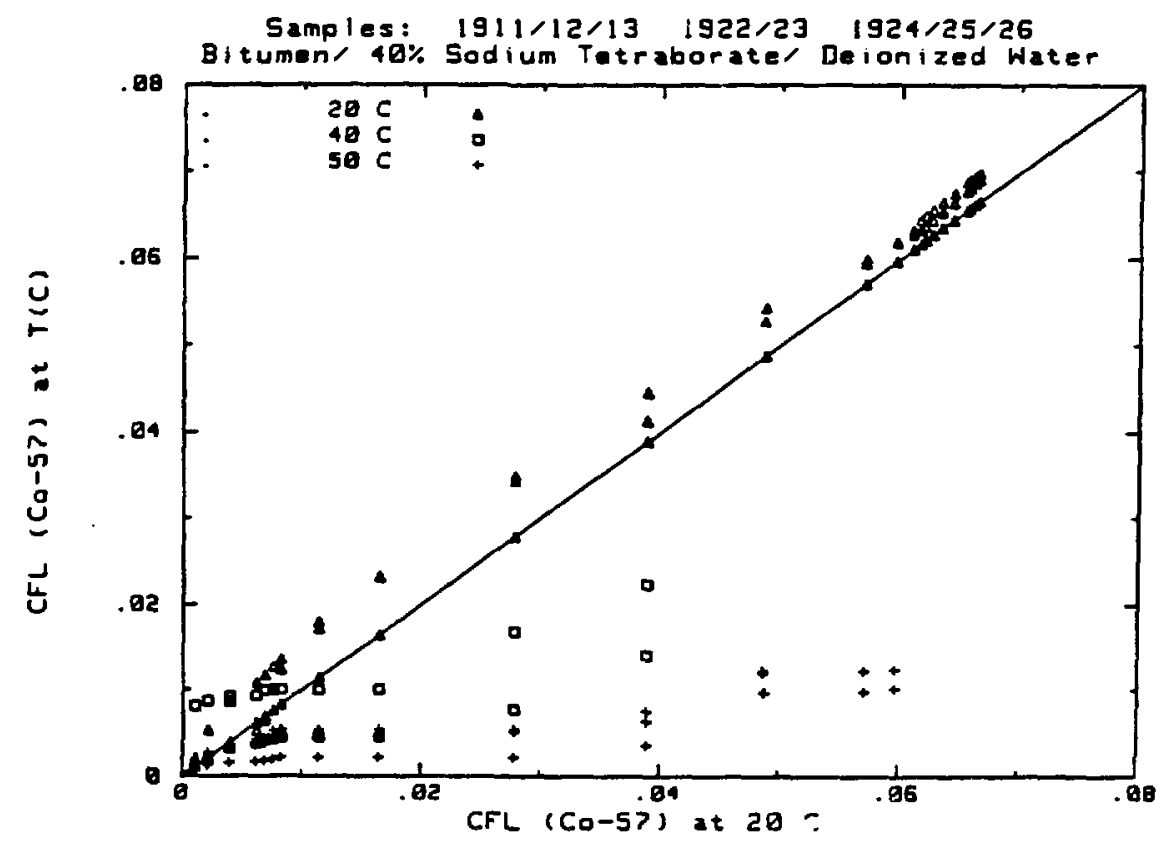

Figure 8.6

Linear worrelation plots for Co-57 leaching from bitumen containing 40 wt sodiun tetraborate at 20 , 40 and $50^{\circ} \mathrm{C}$. Correlations are relative to the $20^{\circ} \mathrm{C}$ data. 


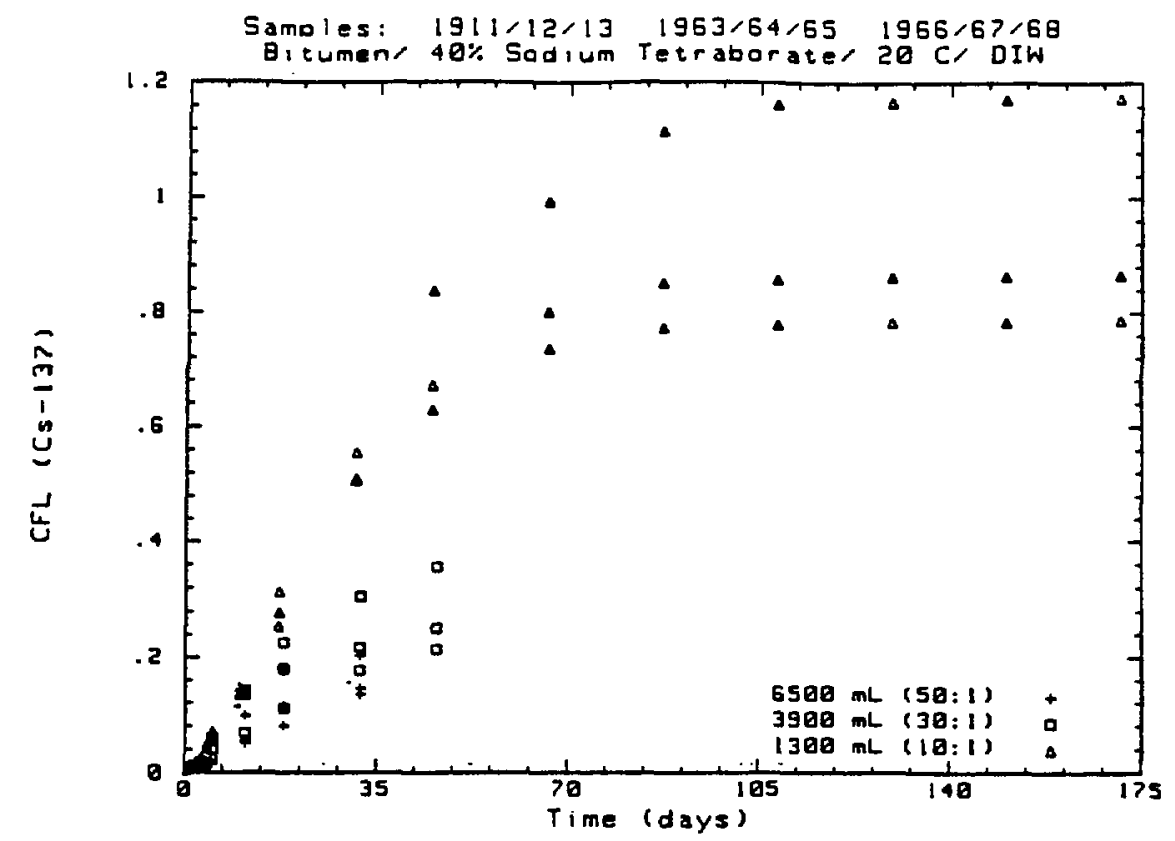

Figure 8.7 Cs.137 cumulative fraction leached vs. time from bitumen containing 40 wt sodium tetraborate at leachant volume to waste form surface area ratios of 10,30 and 50:1. Samples were leached in DIW at $20^{\circ} \mathrm{C}$.

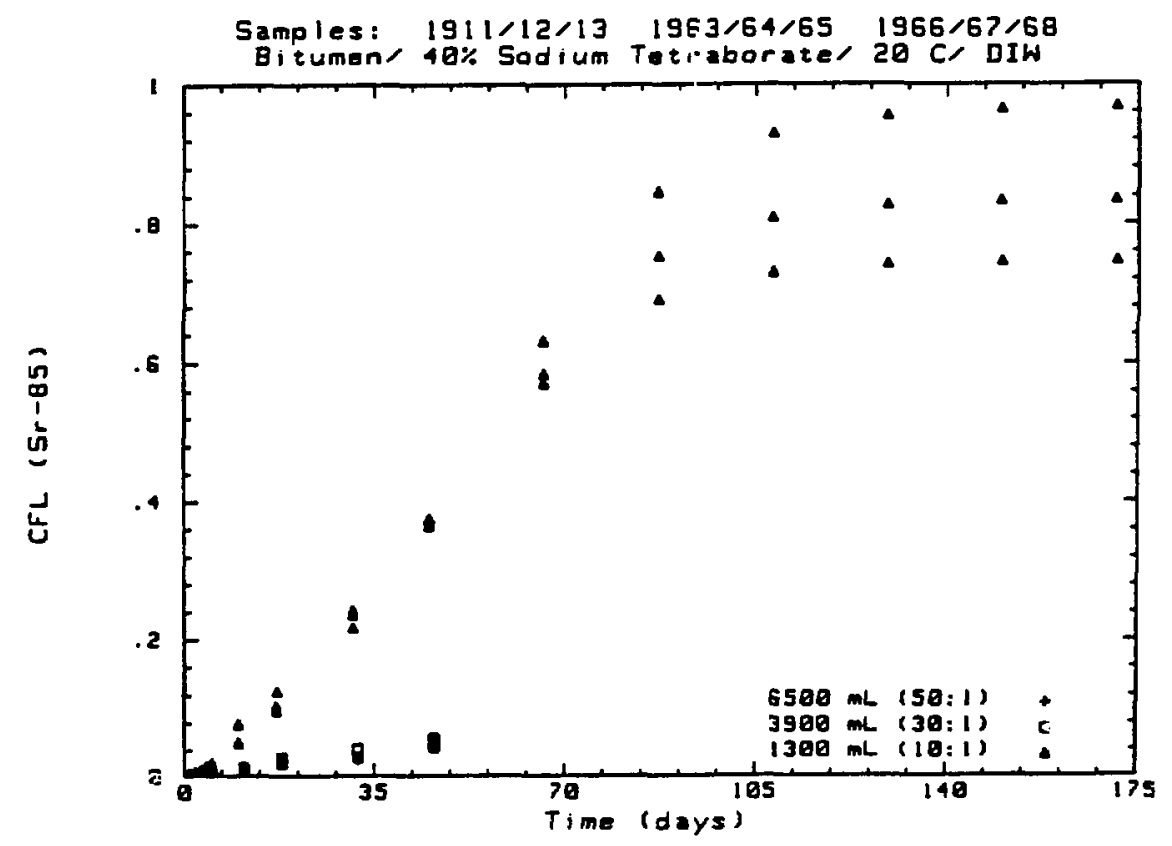

Figure 8.8

Sr-85 cumulative fraction leached vs. time from bitumen containing 40 wt sodium tetraborate at leachant volume to waste form surface area ratios of 10, 30 and 50:1. Samples were leached in DIW at $20^{\circ} \mathrm{C}$. 


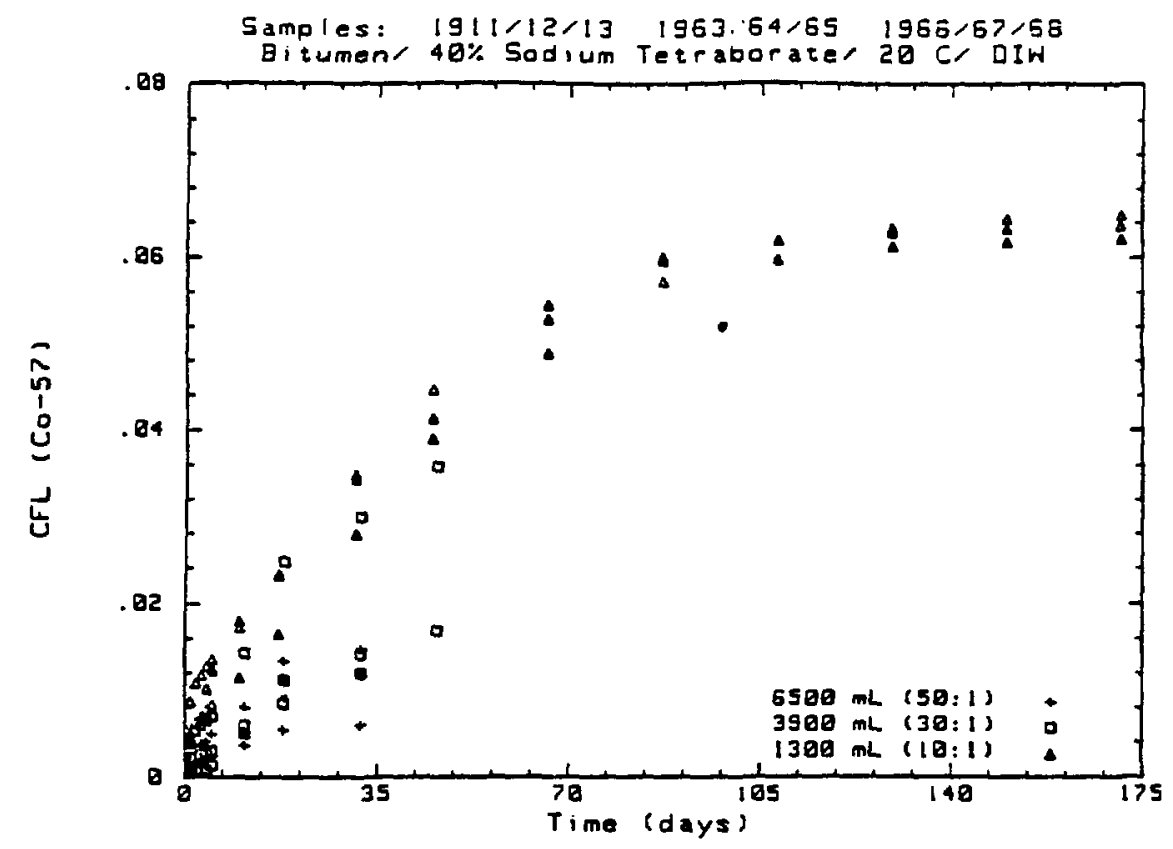

Figure 8.9 Co-57 cumulative fraction leached vs. time from bitumen containing 40 wt 8 sodium tetraborate at leachant volume to waste form surface area ratios of 10,30 and $50: 1$. Samples were leached in DIW at $20^{\circ} \mathrm{C}$.

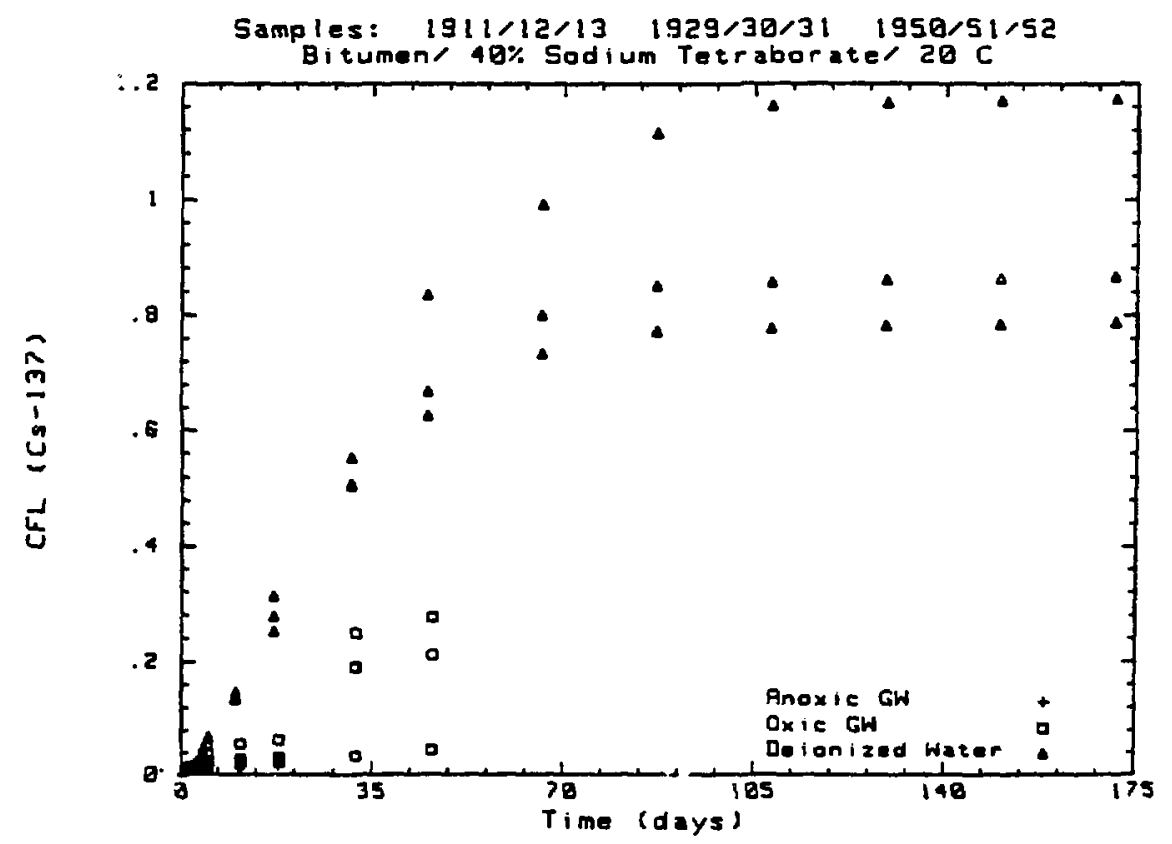

Figure 8.10 Cs-137 cumulative fraction leached vs. time from bitumen containing 40 wt sodium tetraborate leached in DIW, oxic and anoxic ground waters at $20^{\circ} \mathrm{C}$. 


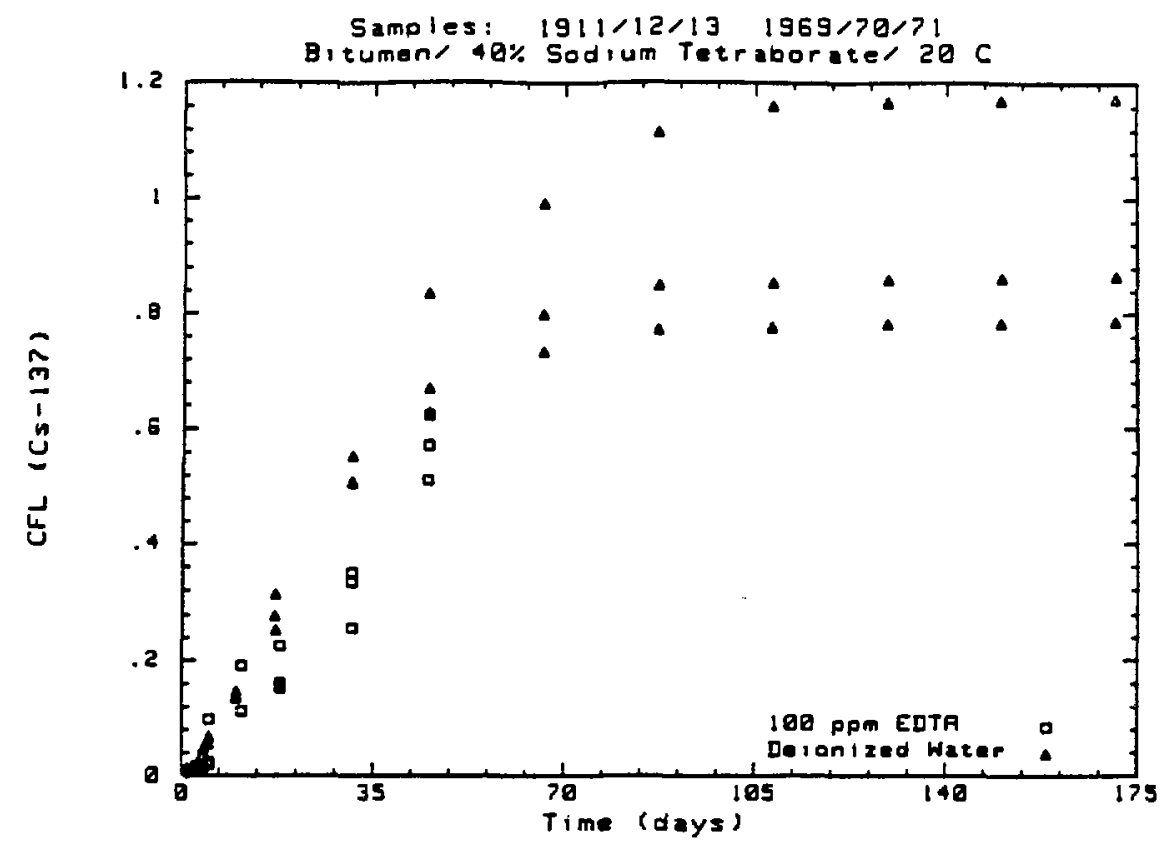

Figure 8.11 Cs-137 cumulative fraction leached vs. time from bitumen containing 40 wt sodium tetraborate leached in DIW and in DIW containing $100 \mathrm{ppm}$ disodium EDTA at $20^{\circ} \mathrm{C}$.

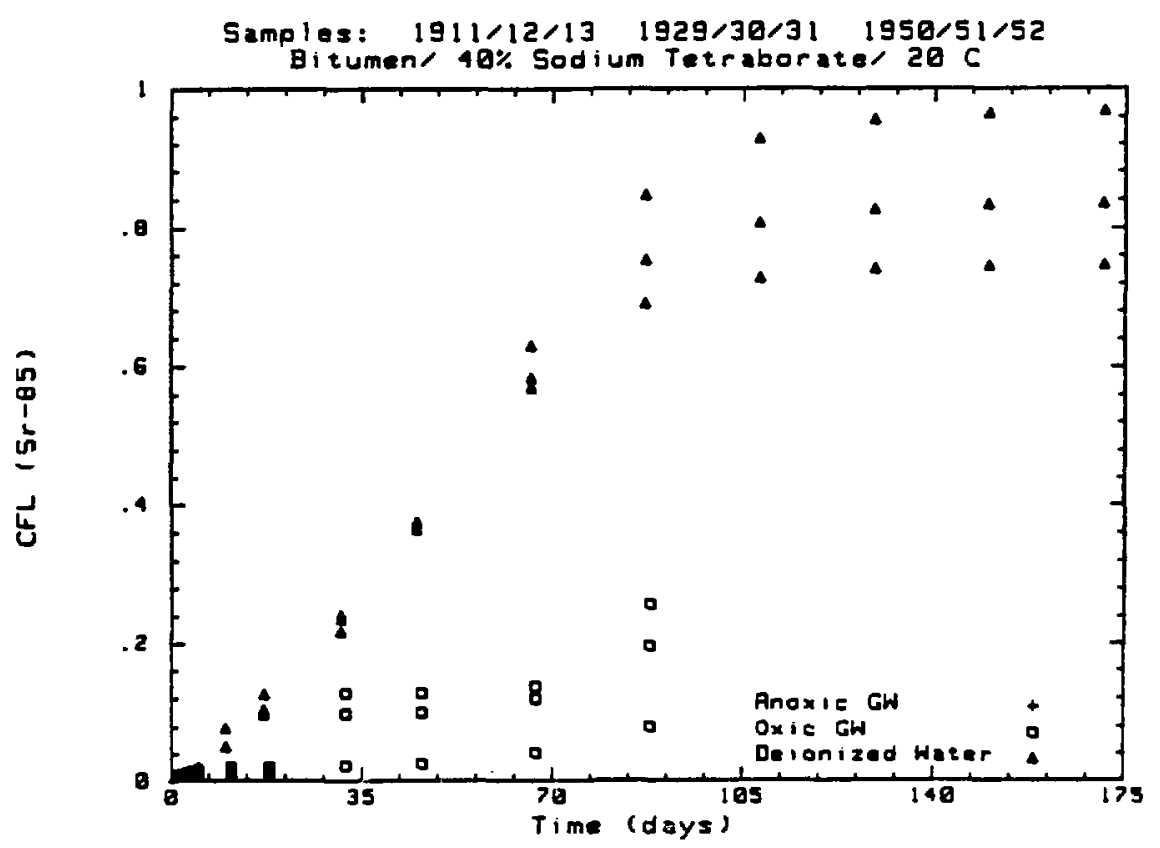

Figure 8.12 Sr-85 cumulative fraction leached vs. time from bitumen containing 40 wt sodium tetraborate leached in DIW, oxic and anoxic ground waters at $20^{\circ} \mathrm{C}$. 


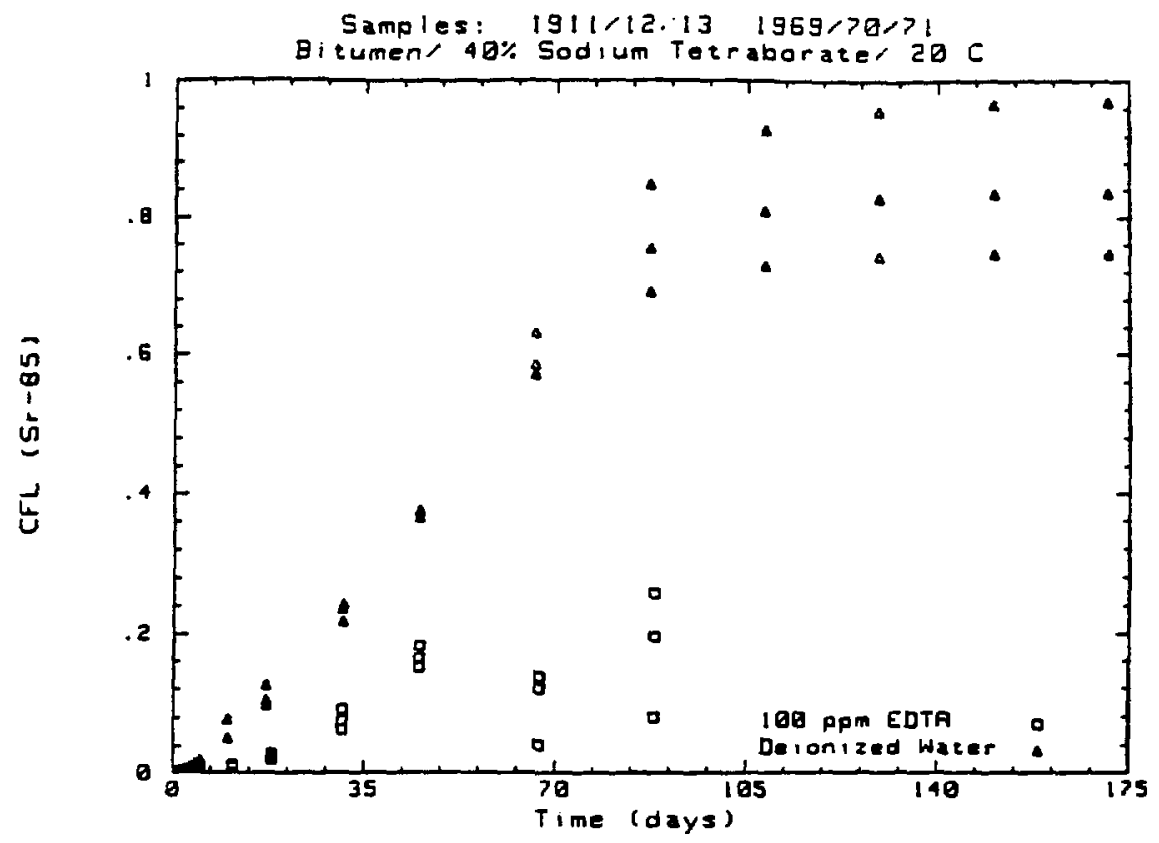

Figure 8.13 Sr-85 cumulative fraction leached vs. time from bitumen containing 40 wt sodium tetraborate leached in DIW and in DIW containing $100 \mathrm{ppm}$ disodiun EDTA at $20^{\circ} \mathrm{C}$.

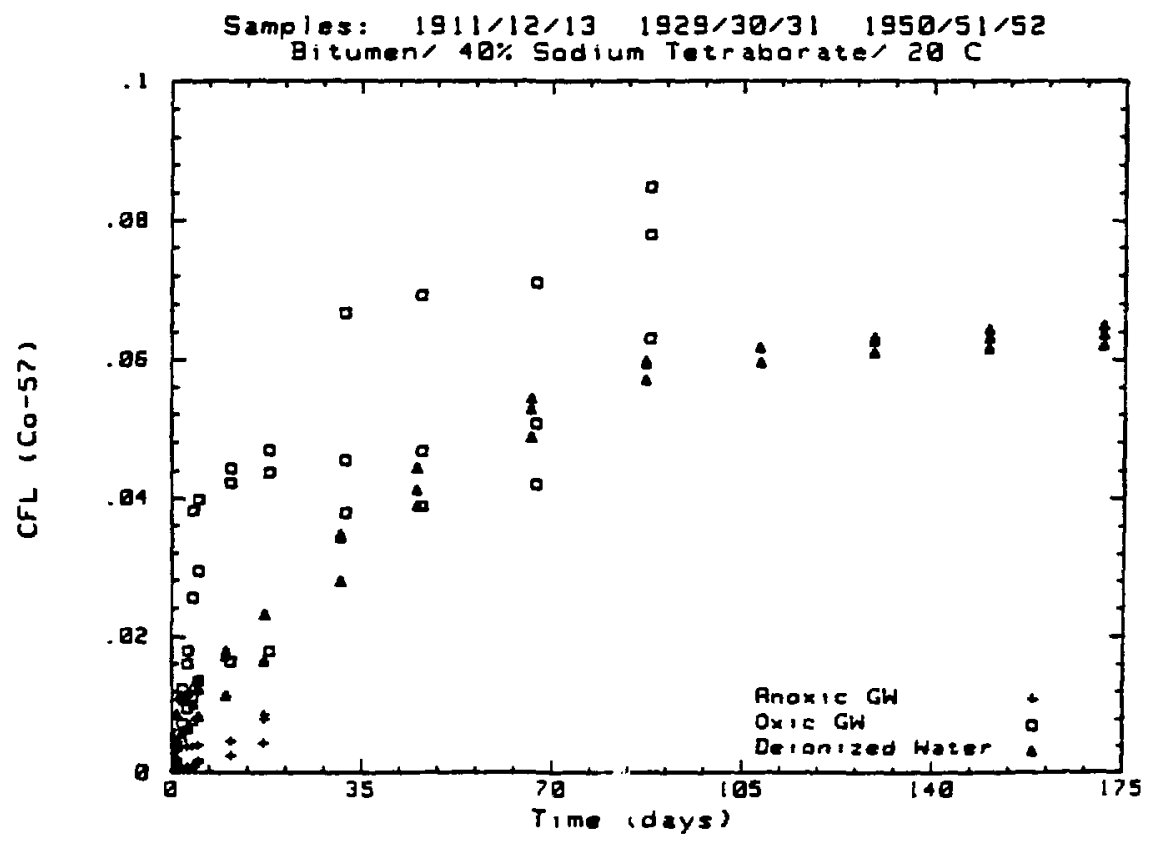

Figure 8.14 Co-57 cumulative fraction leached vs. time from bitumen containing 40 wt sodium tetraborate leached in DIW, oxic and anoxic ground waters at $20^{\circ} \mathrm{C}$. 


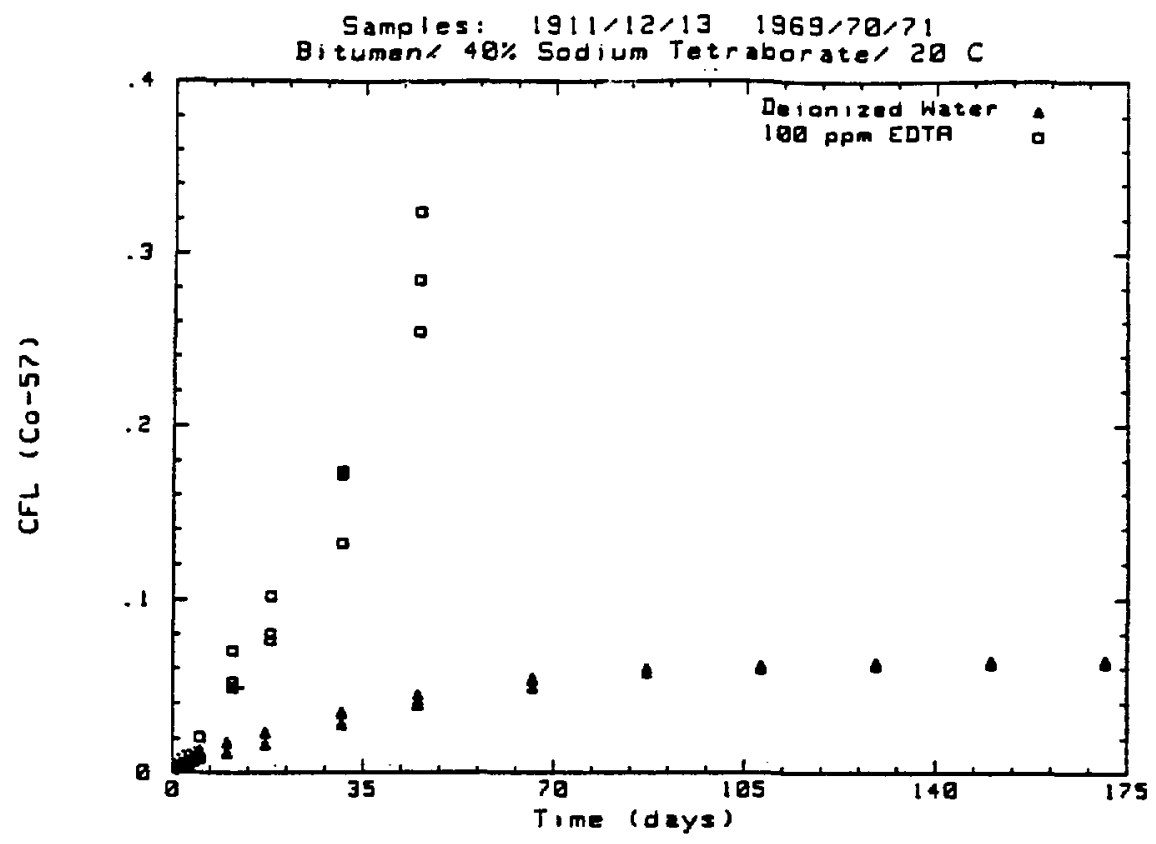

Figure 8.15 Co-57 cumulative fraction leached vs. time from bitumen containing 40 wt sodium tetraborate leached in DIW and in DIW containing $100 \mathrm{ppm}$ disodium EDTA at $20^{\circ} \mathrm{C}$.

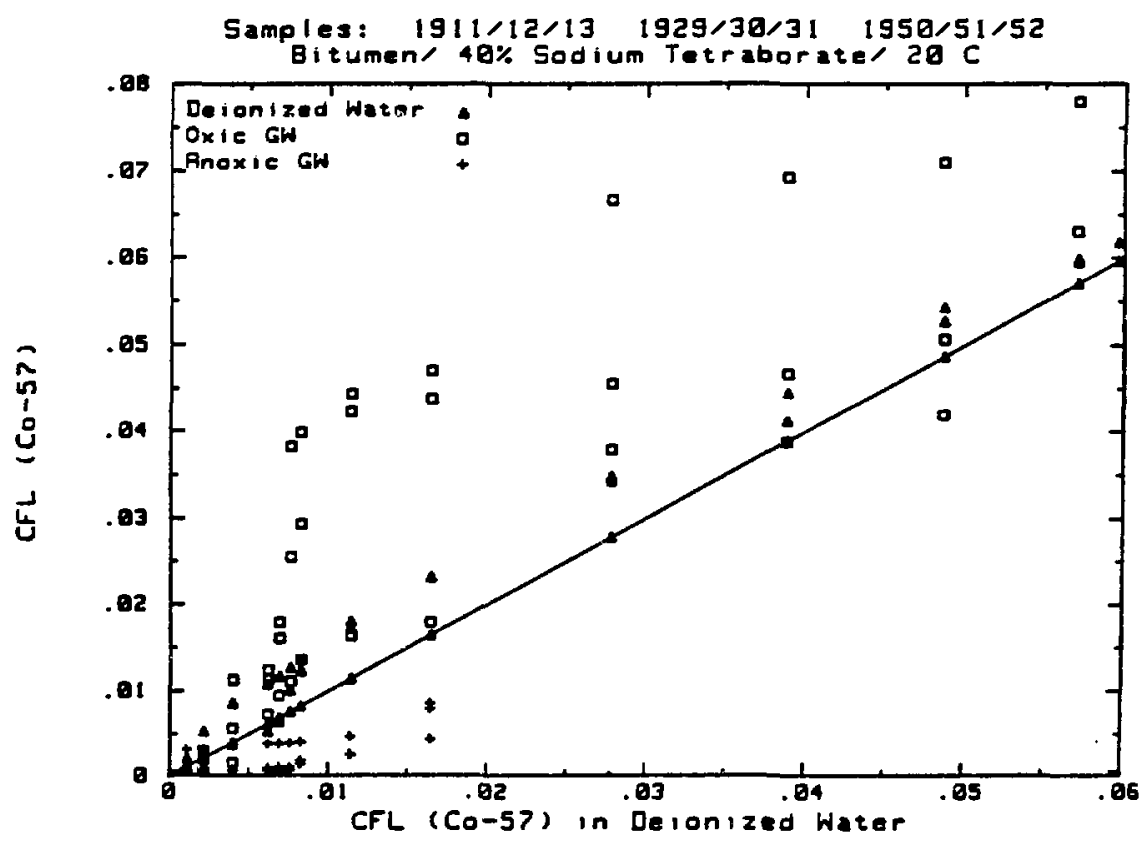

Figure 8.16

Linear correlation plots for Co-57 leached fron bitumen containing 40 wt sodiun tetraborate in DIW, oxic and anoxic ground waters. Correlations are relative to the DIW data. 


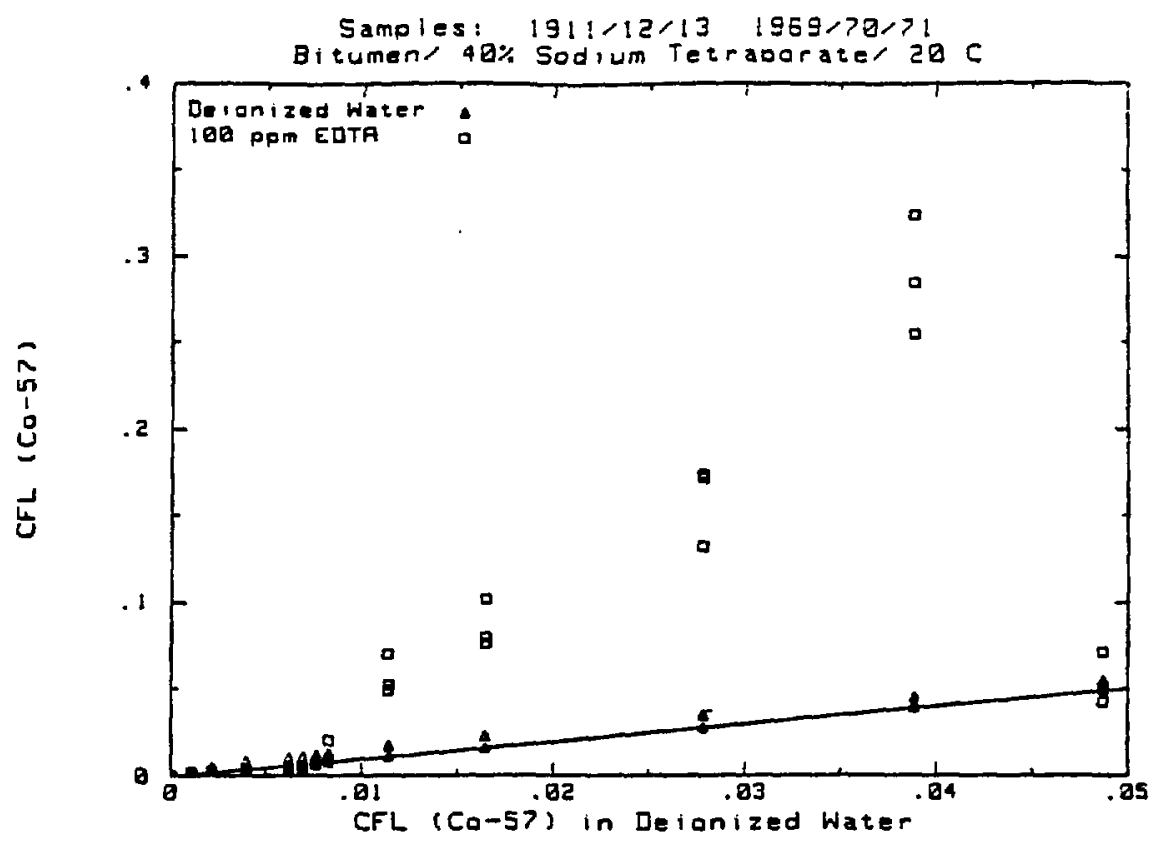

Figure 8.17 Linear correlation plots for Co.57 leached from bitumen containing 40 wts sodium tetraborate in DIW and DIW containing 100 ppm disodium EDTA.

Correlations are relative to the DIW data.

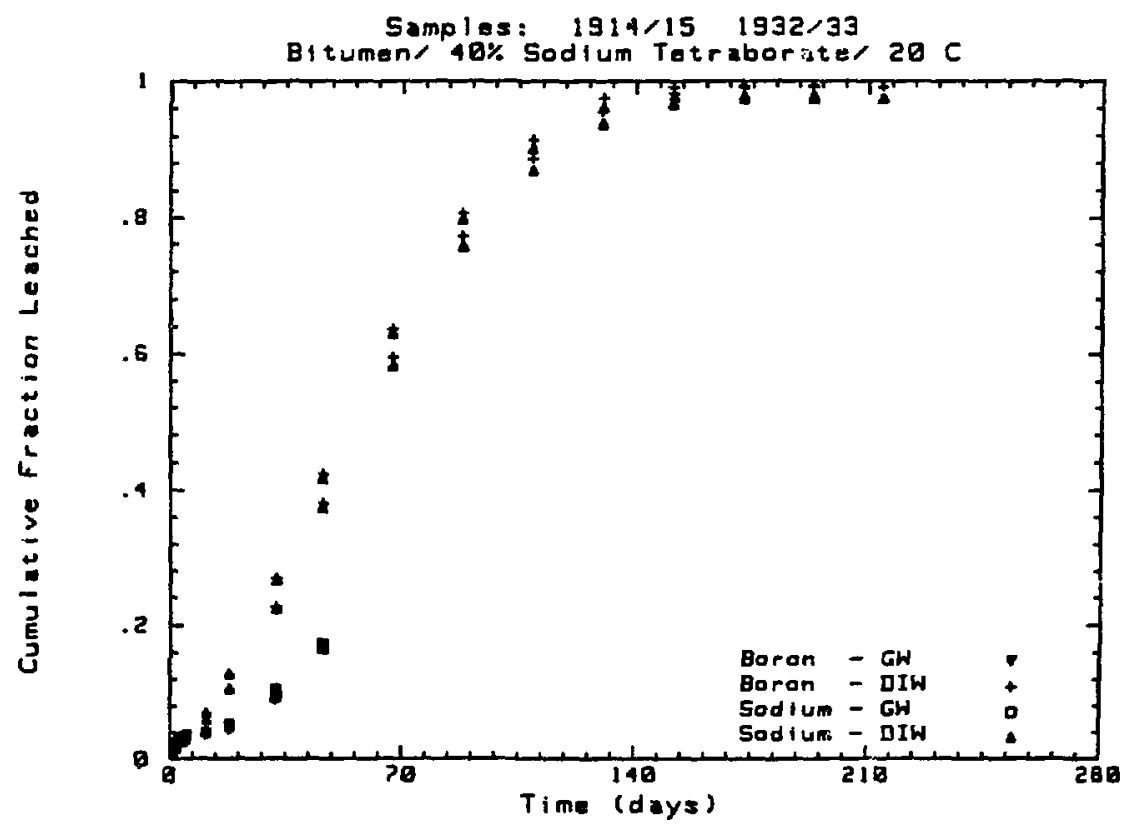

Figure 8.18 Cumulative fraction leached of sodium and boron versus time from bitumen containing 40 wto sodium tetraborate leached in DIW and oxic ground water at $20^{\circ} \mathrm{C}$. 


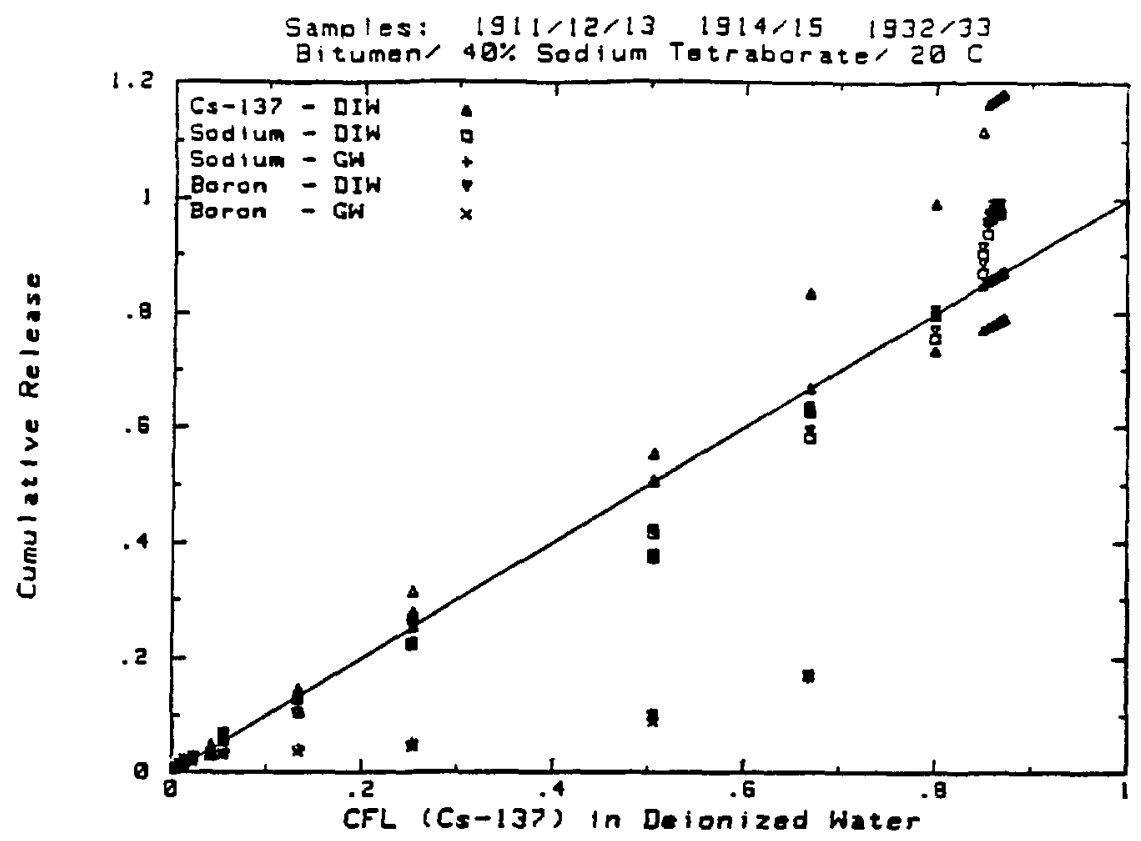

Figure 8.19

Linear correlation plots for sodium, boron and Cs-137 leached from bitumen containing 40 wt sodium tetraborate in DIW and oxic ground water at $20^{\circ} \mathrm{C}$. Correlations are relative to the data for Cs -137 leached in DIW.

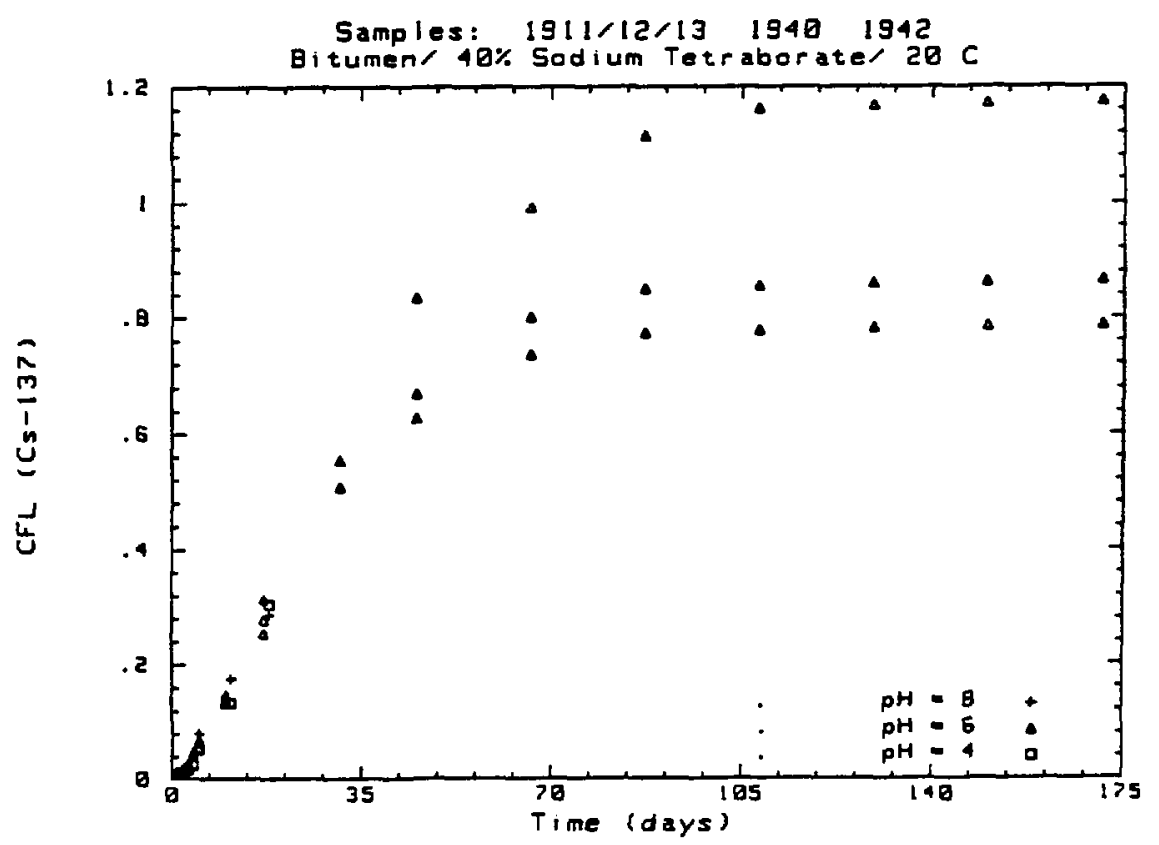

Figure 8.20

Cs-137 cumulative fraction leached vs. time from bitumen containing 40 wt sodium tetraborate leached in leachants with initial $\mathrm{pH}$ values of 4,6 and 8 at $20^{\circ} \mathrm{C}$. 


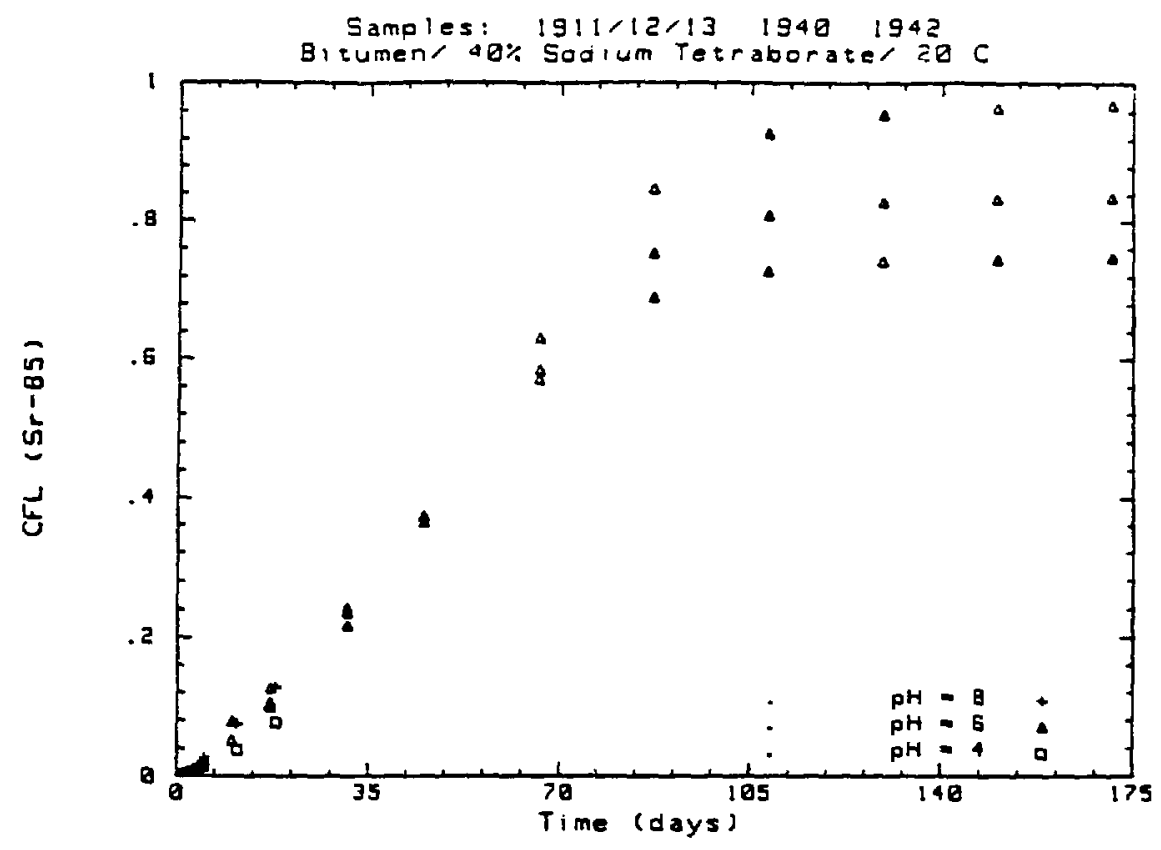

Figure 8.21 Sr-85 cumulative fraction leached.vs. time from bitumen containing 40 wt sodium tetraborate leached in leachants with initial pH values of 4,6 and 8 at $20^{\circ} \mathrm{C}$.

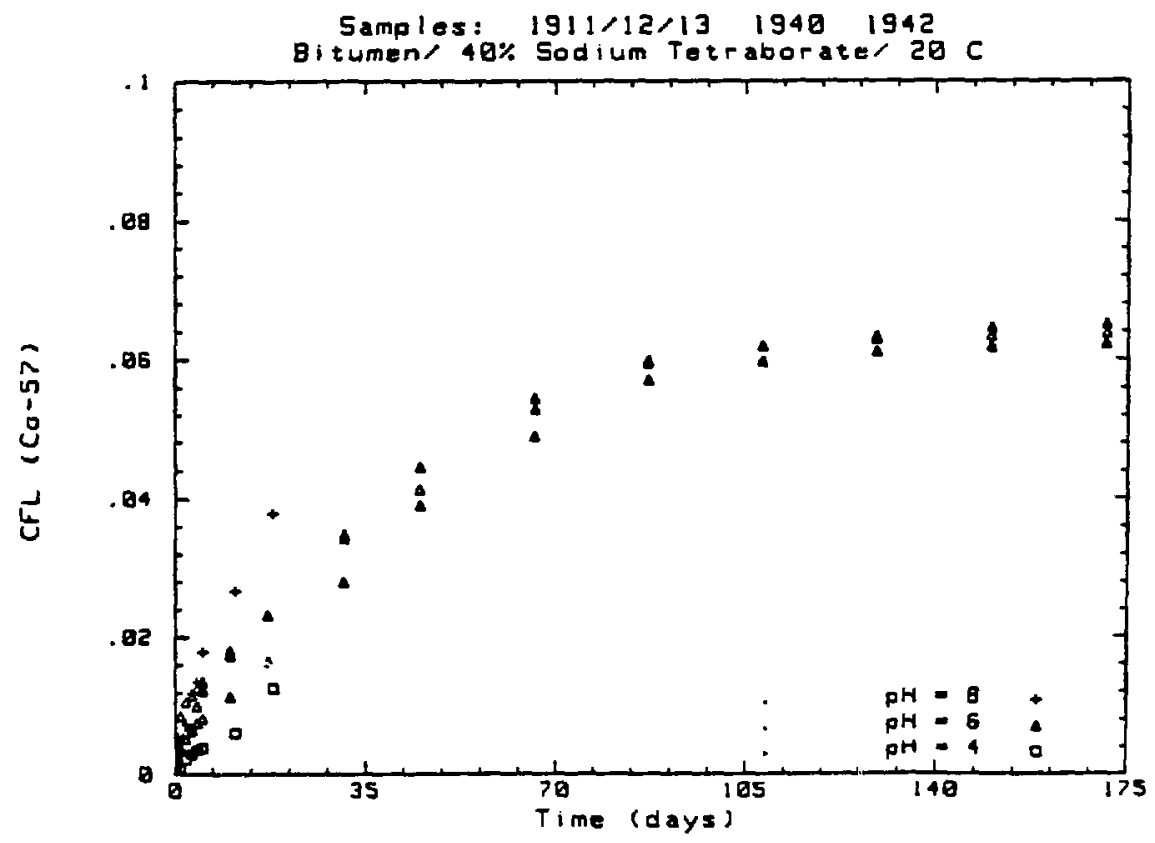

Figure 8.22

Co-57 cumulative fraction leached vs. time from bitumen containing 40 wt sodium tetraborate in leachants with initial $\mathrm{pH}$ values of 4,6 and 8 at $20^{\circ} \mathrm{C}$. 


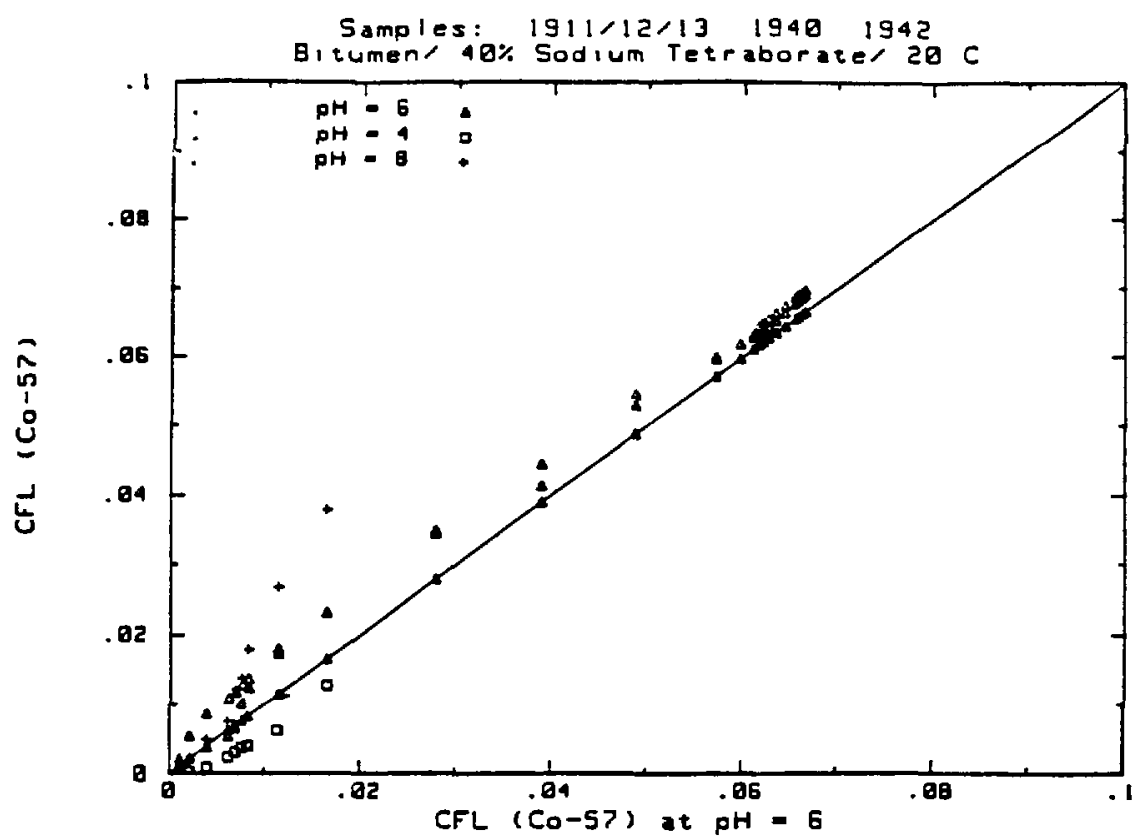

Figure 8.23 Linear correlation plots for Co-57 leached from bitumen containing 40 sodium tetraborate in leachants with initial pH values of 4,6 and 8 . Correlations are relative to the pH 6 (DIW) data.

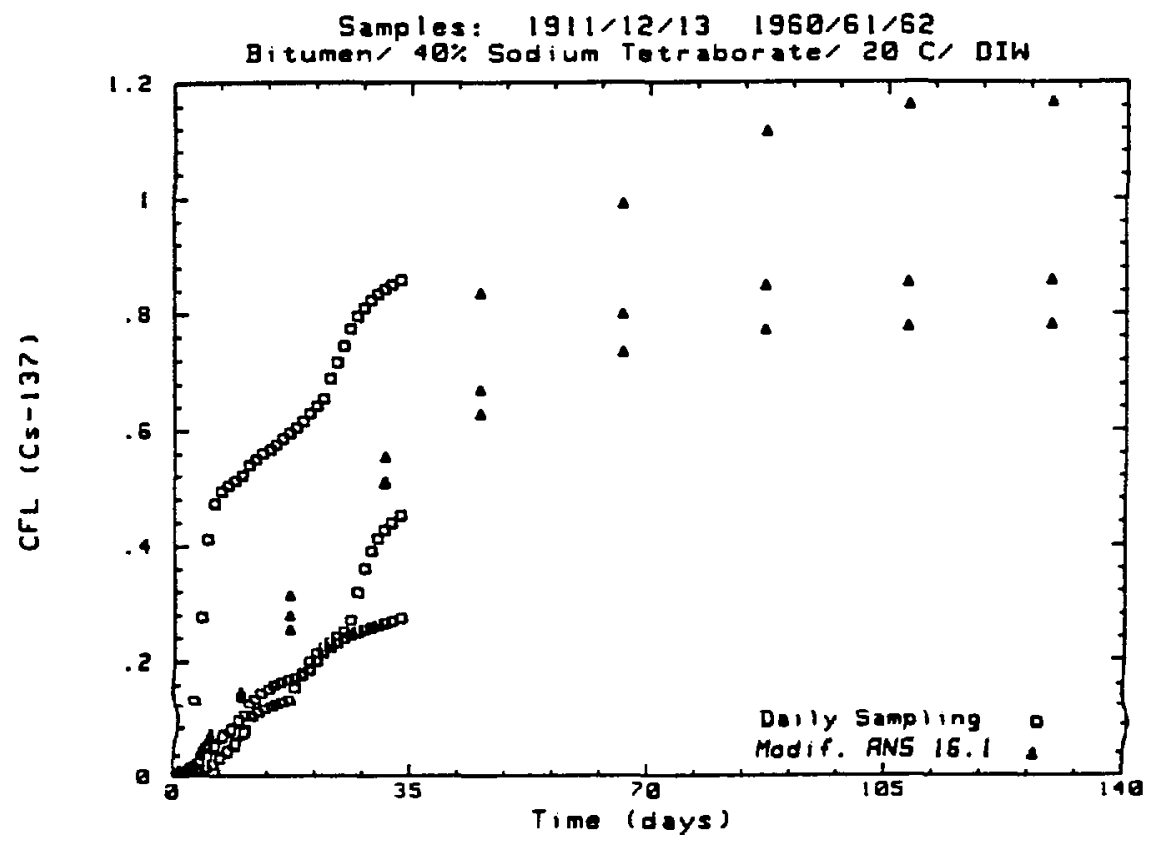

Figure 8.24

Cs -137 cumulative fraction leached vs. time from daily leachant replacement and from modified ANS 16.1 leachant replacement schedule for bitumen waste forms containing 40 wtz sodium tetraborate leached at $20^{\circ} \mathrm{C}$. 


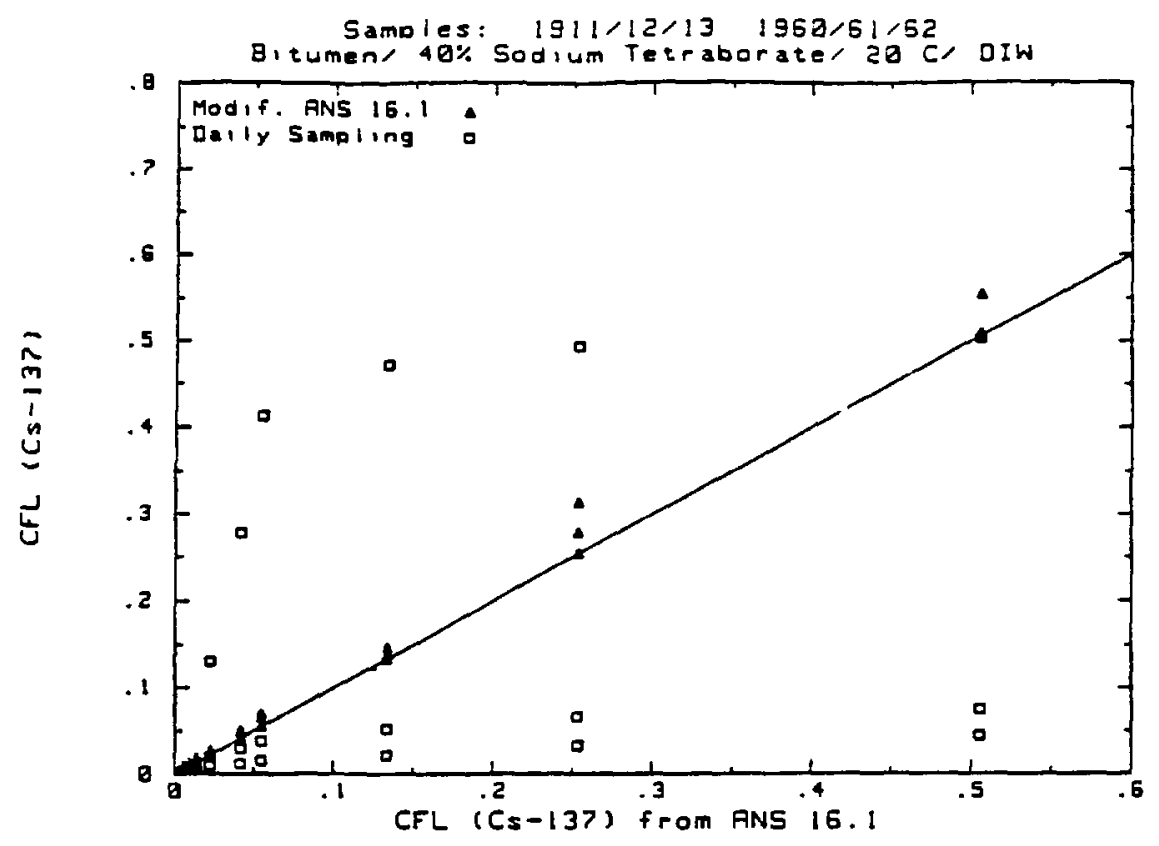

Figure 8.25

Linear correlation plots for Cs-137 leached from bitumen waste forms containing 40 wto sodium tetraborate using daily leachant replacement and the modified ANS 16.1 leachant replacement schedule.

Correlations are relative to the ANS 16.1 data.

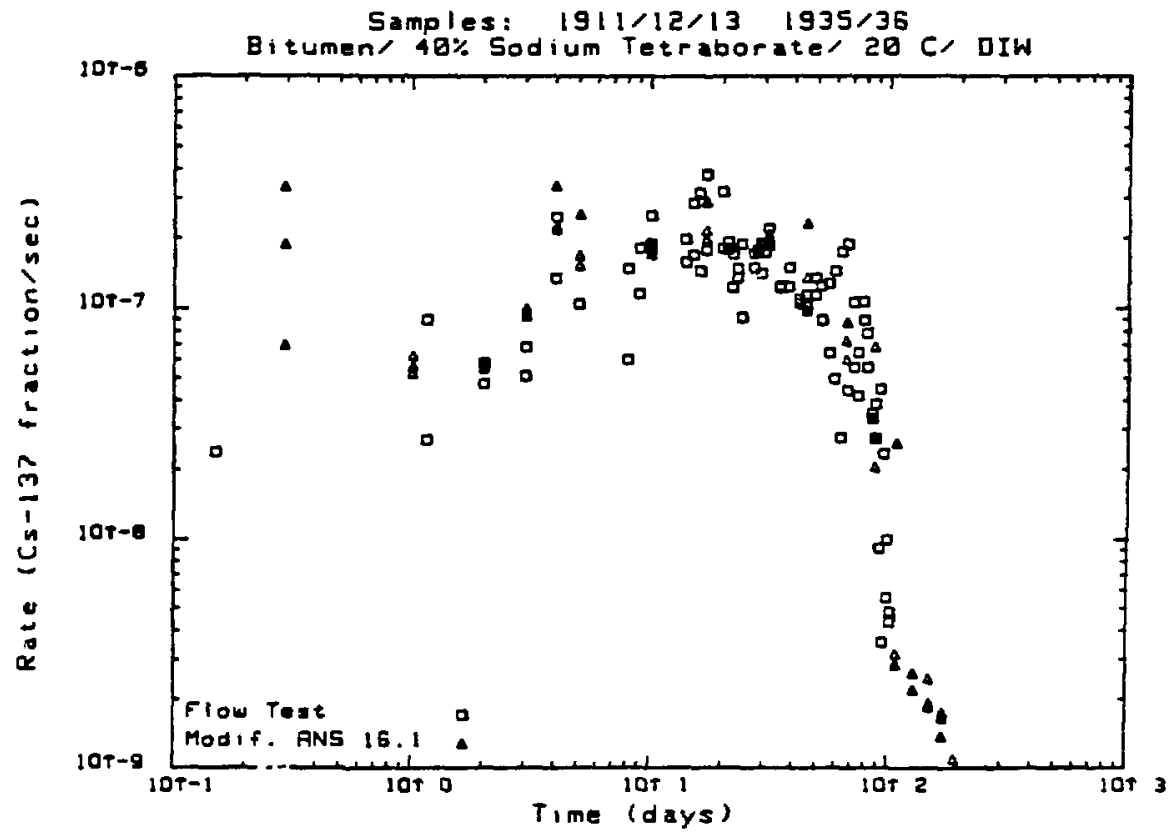

Figure 8.26

Cs-137 incremental leach rate vs. time from bitumen waste forms containing 40 wt sodium tetraborate comparing results of MCC-4S Flow test to modified ANS 16.1 leachant replacement schedule at $20^{\circ} \mathrm{C}$. 


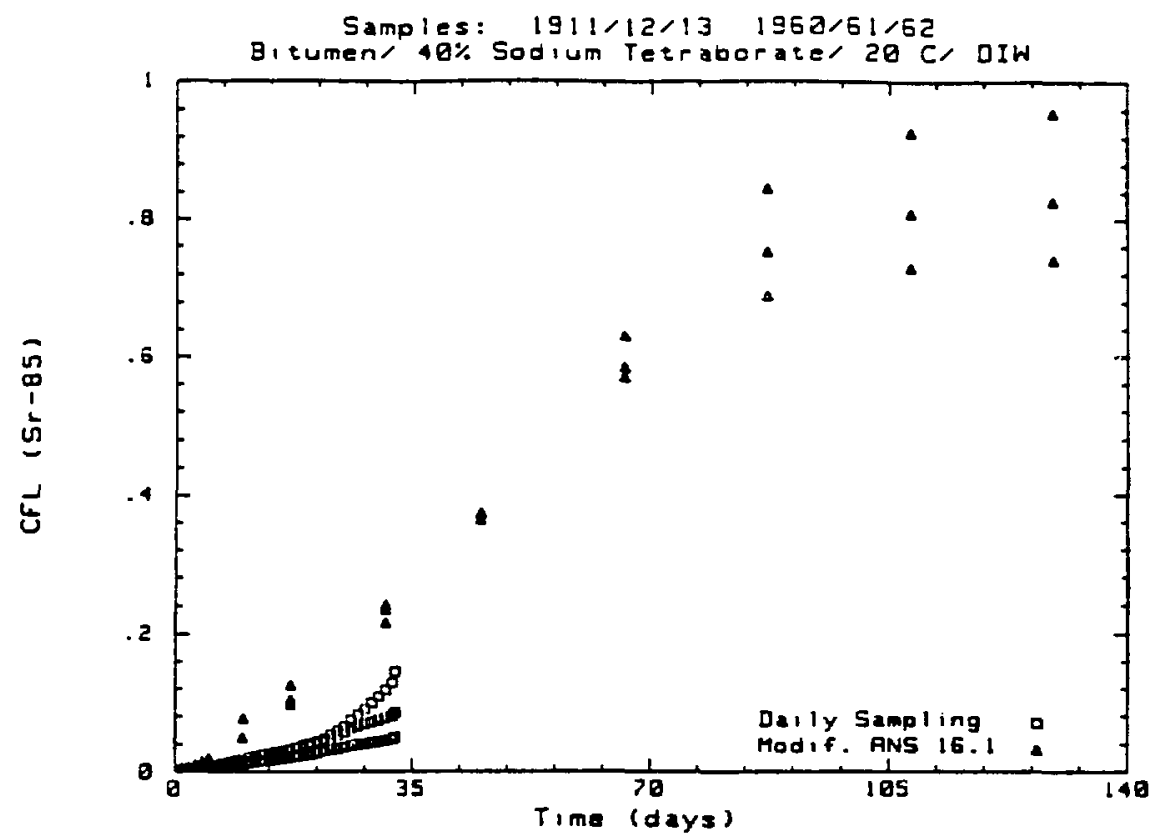

Figure 8.27

Sr-85 cumulative fraction leached vs. time from daily leachant replacement and fron modified ANS 16.1 leachant replacement schedule for bitumen waste forms containing 40 wt sodium tetraborate leached at $20^{\circ} \mathrm{C}$.

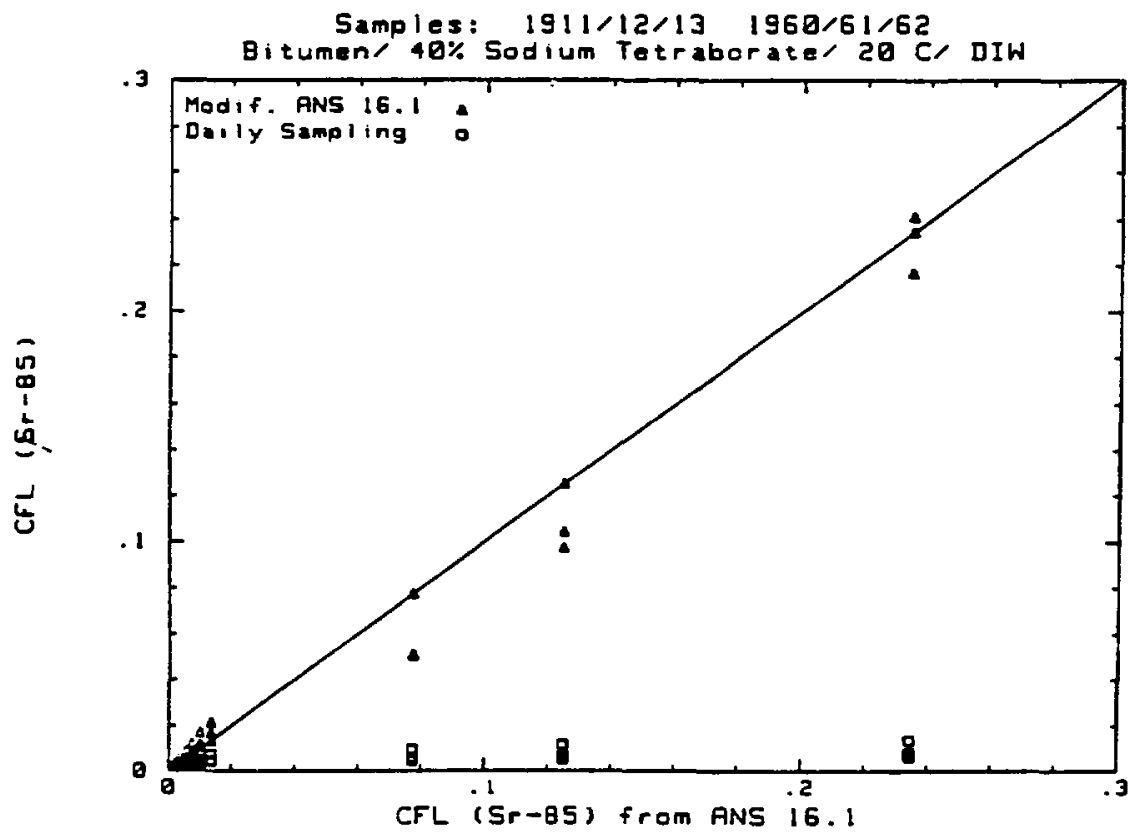

Figure 8.28

Linear correlation plots for $\mathrm{Sr}-85$ leached from bitumen waste forms containing 40 wt sodium tetraborate using daily leachant replacement and the modified ANS 16.1 leachant replacement schedule. Correlations are relative to the ANS 16.1 data. 


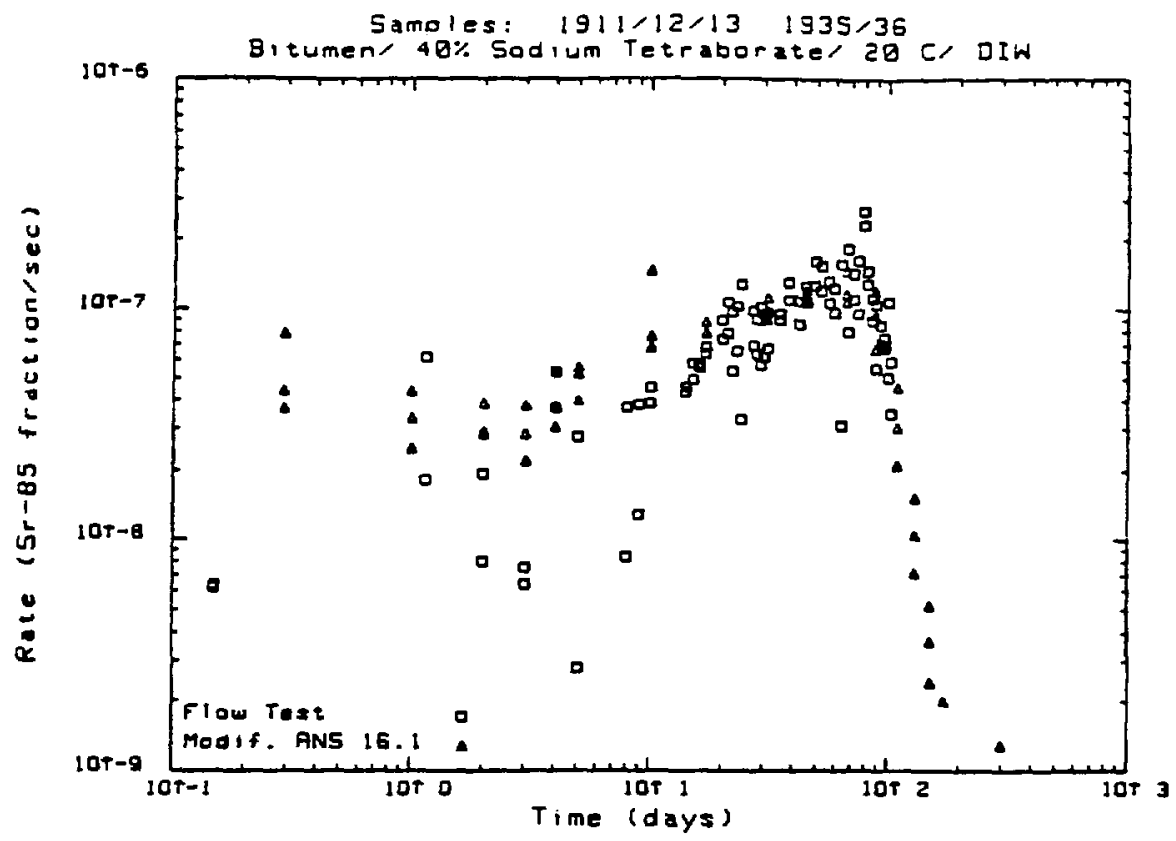

Figure 8.29 Sr-85 incremental leach rate vs, time from bitumen waste forms containing 40 wto sodium tetraborate comparing results of MCC-4S Flow test to modified ANS 16.1 leachant replacement schedule at $20^{\circ} \mathrm{C}$.

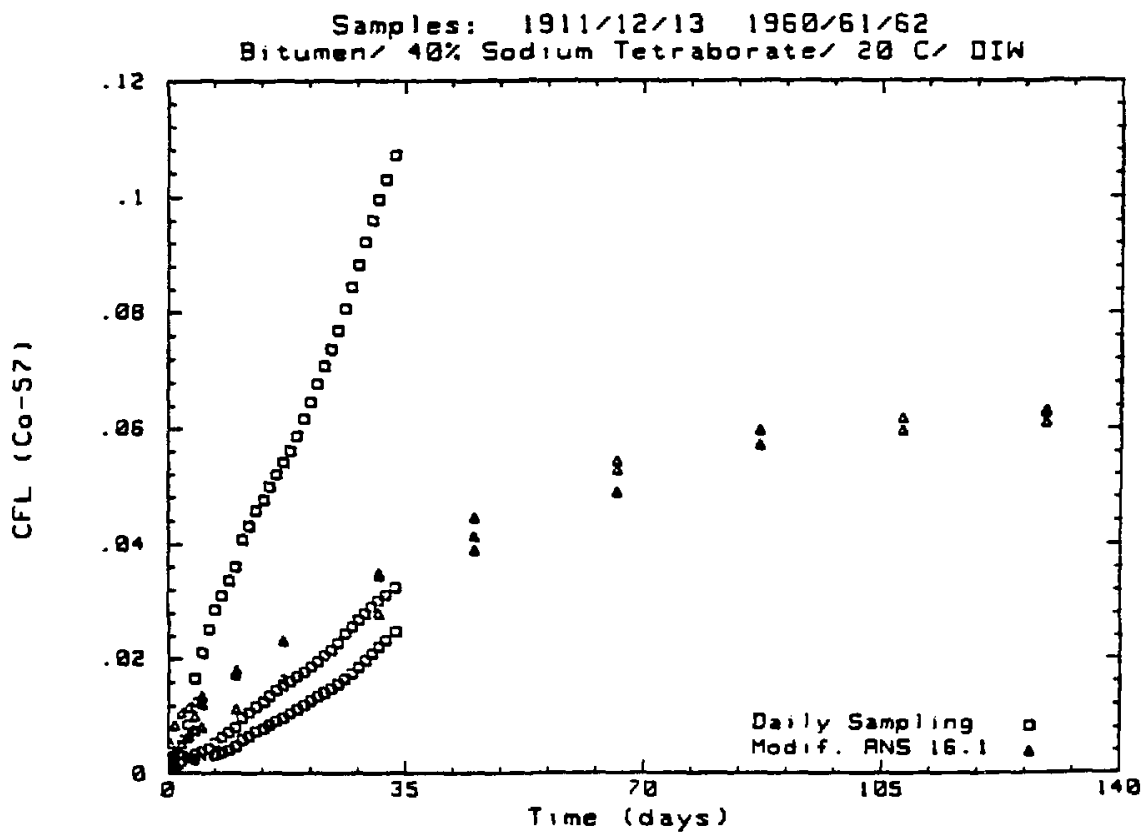

Figure 8.30 Co-57 cumulative fraction leached vs. time from daily leachant replacement and from modified ANS 16.1 leachant replacement schedule for bitumen waste forms containing 40 wt sodium tetraborate leached at $20^{\circ} \mathrm{C}$. 


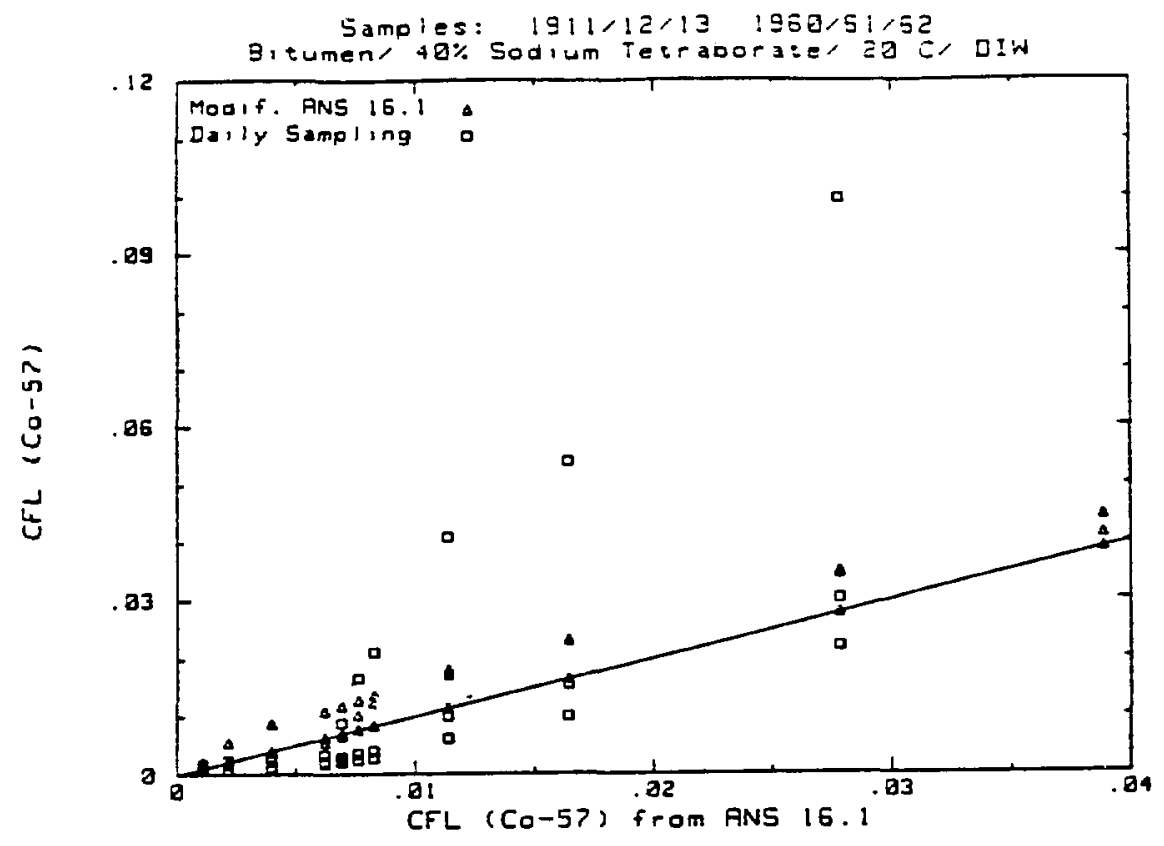

Figure 8.31 Linear correlation plots for Co-57 leached from bitumen waste forms containing 40 wt sodiun tetraborate using daily leachant replacement and the modified ANS 16.1 leachant replacement schedule. Correlations are relative to the ANS 16.1 data.

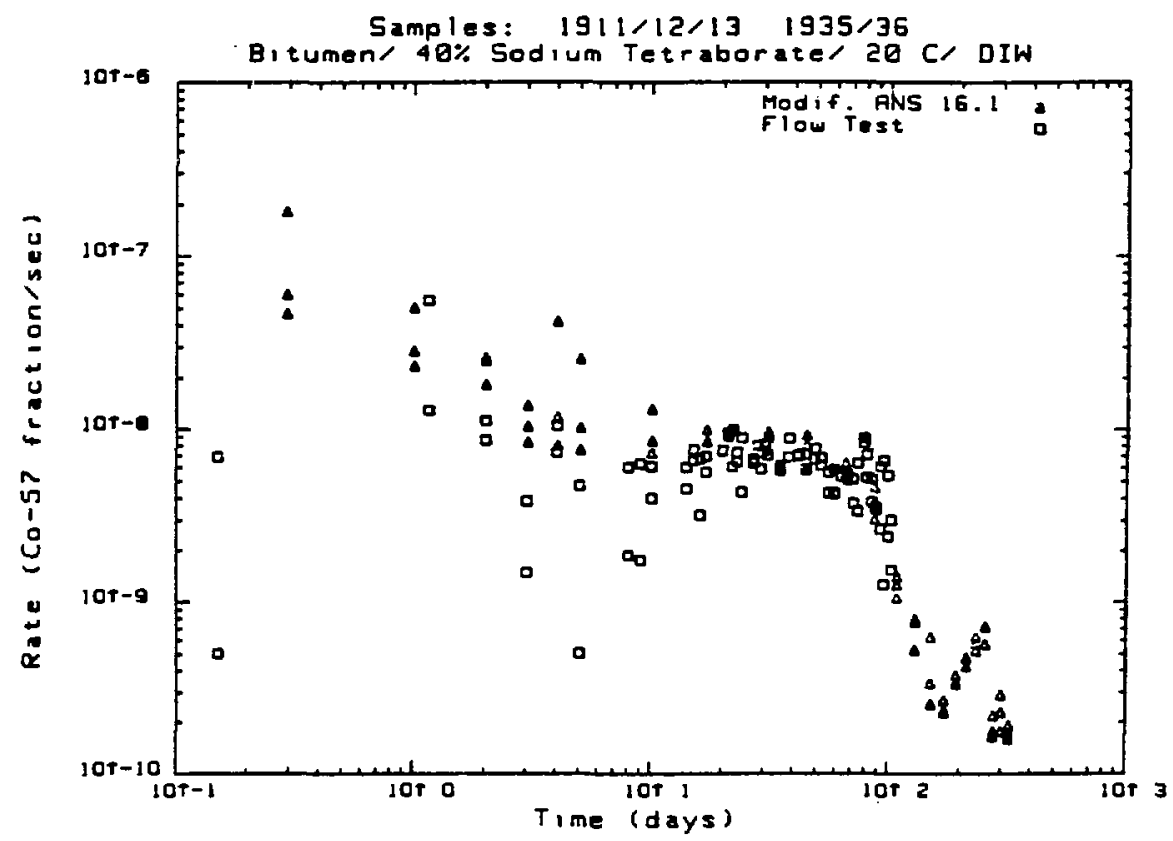

Figure 8.32 Co-57 incremental leach rate vs. time from bitumen containing 40 wto sodium tetraborate comparing results of MCC-4S Flow test to modified ANS 16.1 leachant replacement schedule at $20^{\circ} \mathrm{C}$. 


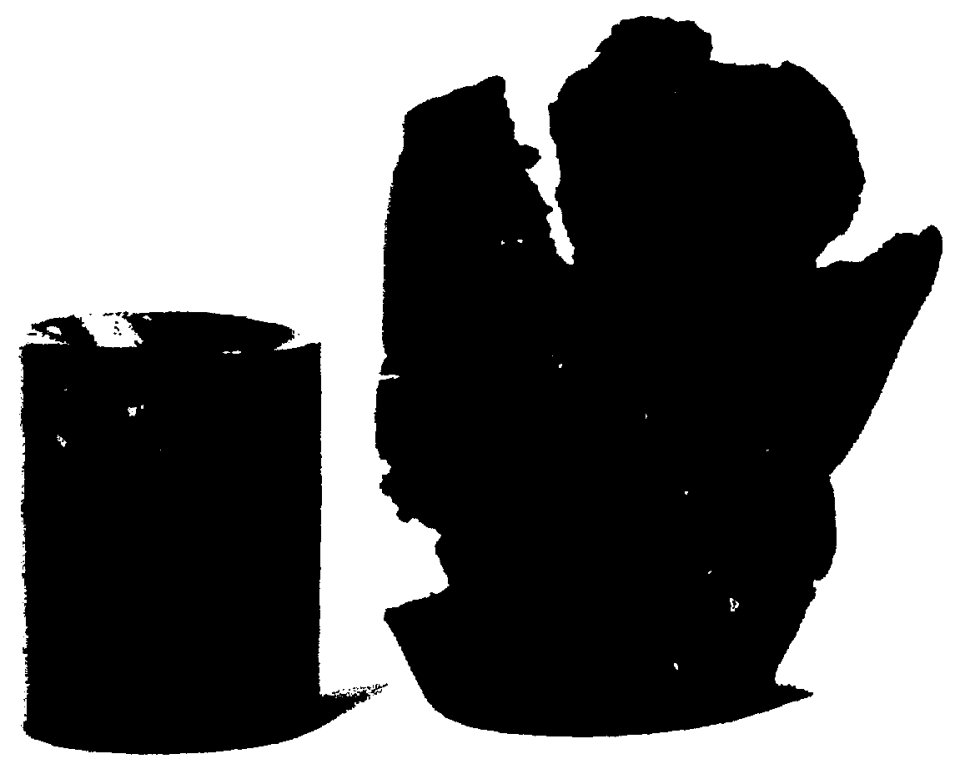

Figure 8.33

Bitumen forms containing 40 wt sodium tetraborate. The one at left is as fabricated. The one at right was leached for 320 days in deionized water at $20^{\circ} \mathrm{C}$. Samples were $4.8 \mathrm{~cm}$ diameter by $6.4 \mathrm{~cm}$ high right cylinders.

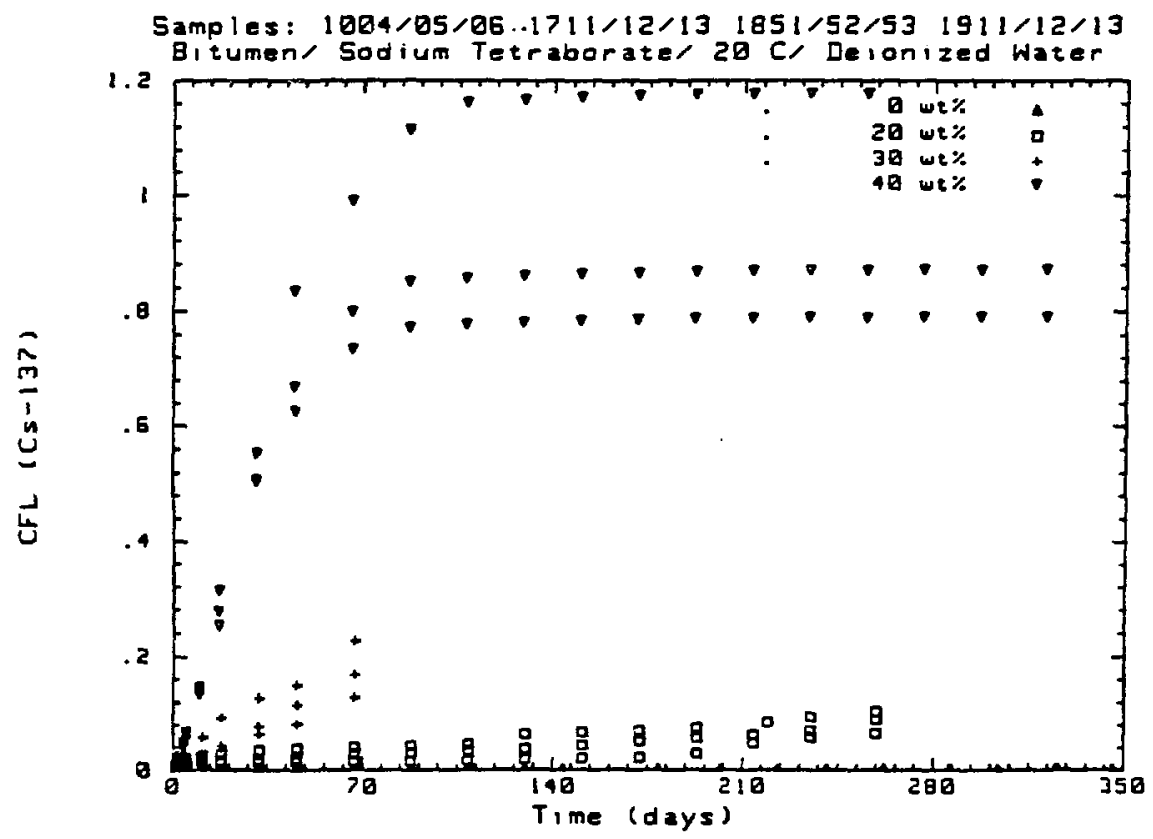

Figure 8,34 Cs-137 cumulative fraction leached vs. time from bitumen containing $0,20,30$ and 40 wt sodium tetraborate. Samples were leached in DIW at $20^{\circ} \mathrm{C}$. 


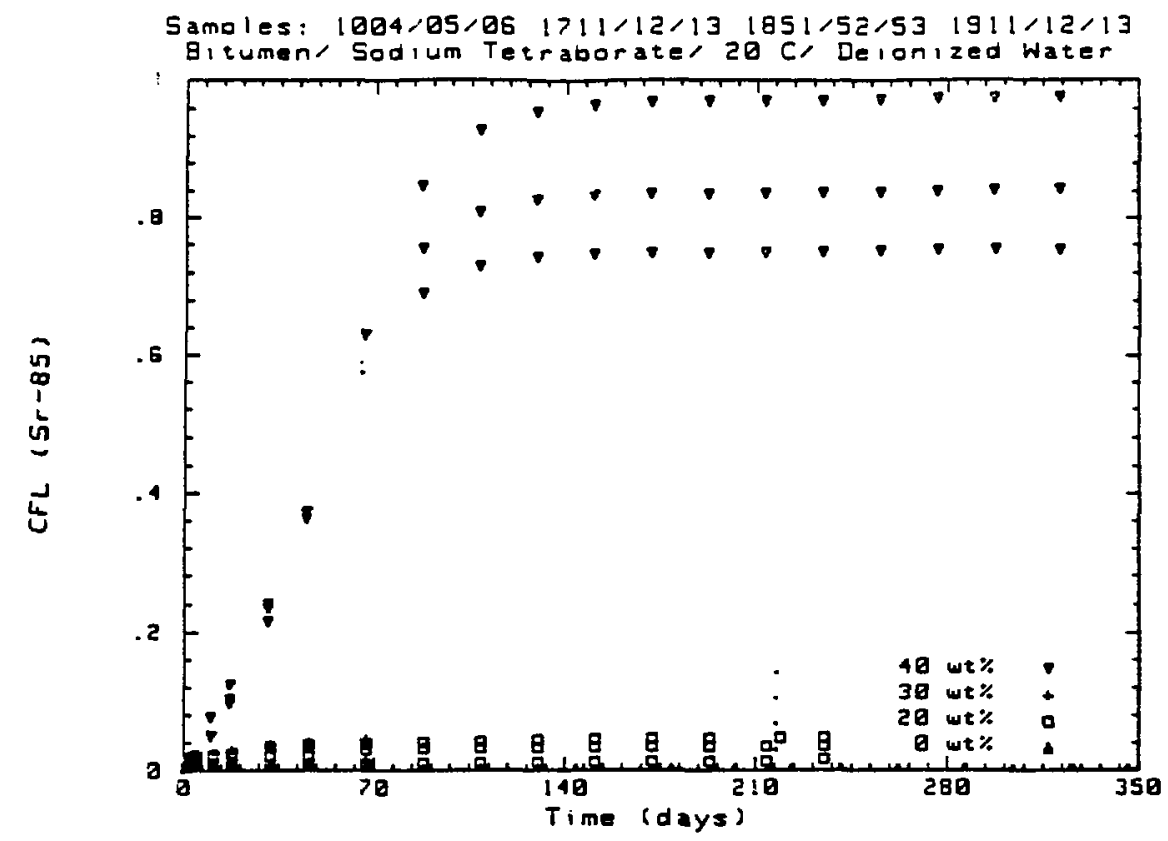

Figure 8.35 Sr-85 cumulative Eraction leached vs. time fron bitumen containing $0,20,30$ and 40 wto sodium tetraborate. Samples were leached in DIW at $20^{\circ} \mathrm{C}$.

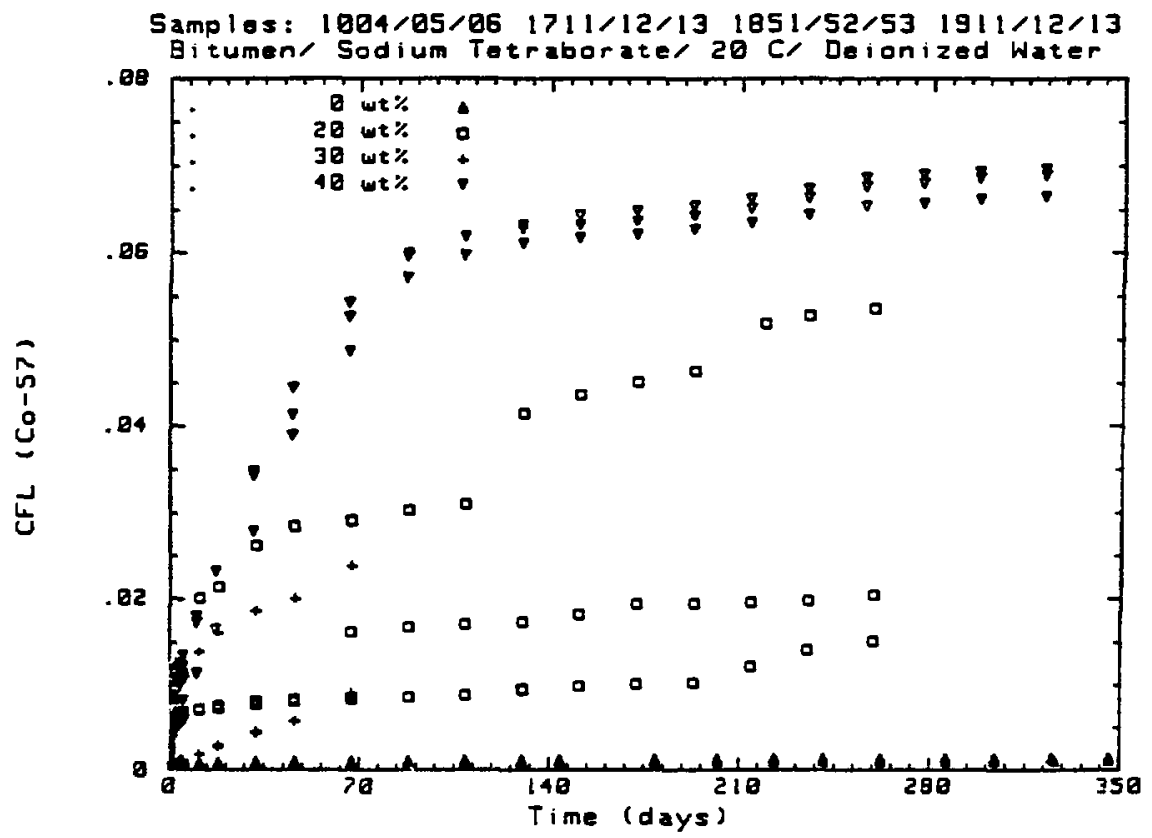

Figure 8.36 Co-57 cumulative fraction leached vs. time from bitumen containing $0,20,30$ and 40 wt sodium tetraborate. Samples were leached in DIW at $20^{\circ} \mathrm{C}$. 


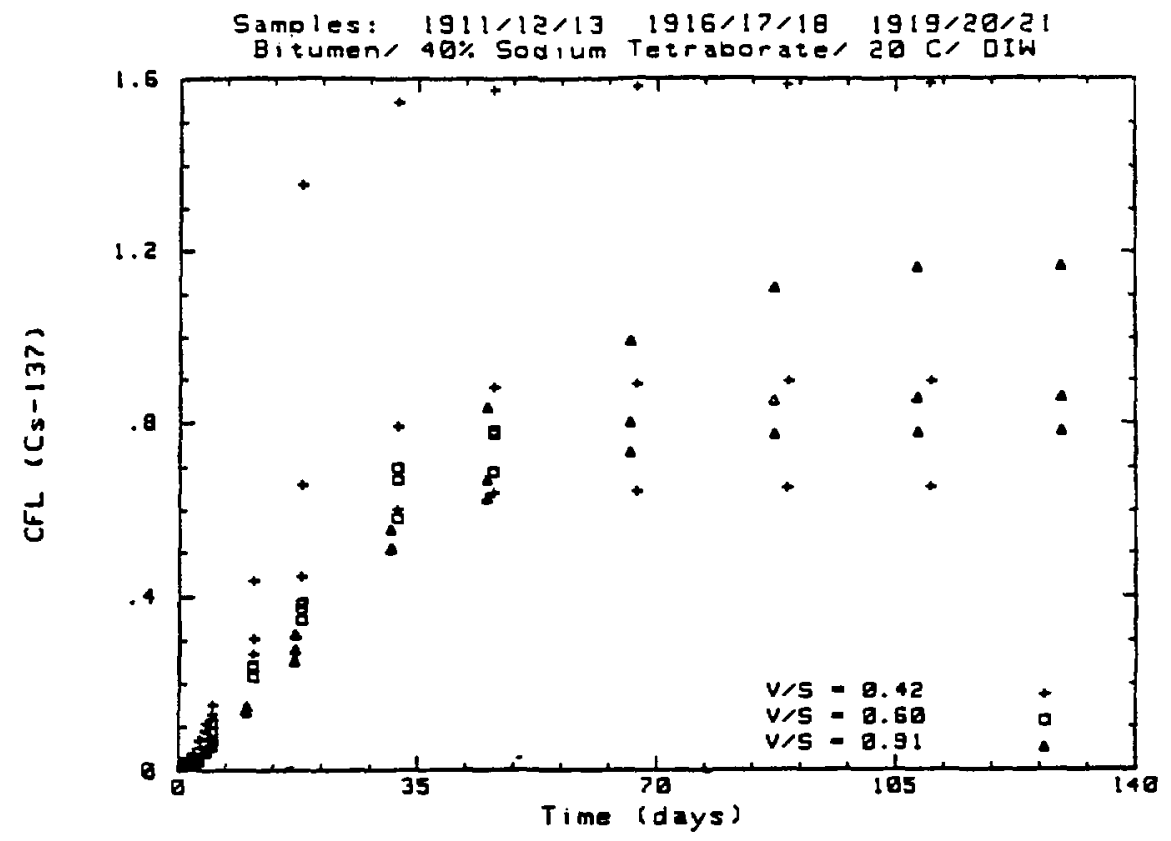

Figure 8.37 Cs-137 cumulative fraction leached vs. time from bitumen containing 40 wt sodium tetraborate at waste form volume to surface area ( $V / S$ ) ratios of 0.42 , 0.62 and 0.91 . Samples were leached in deionized water at $20^{\circ} \mathrm{C}$.

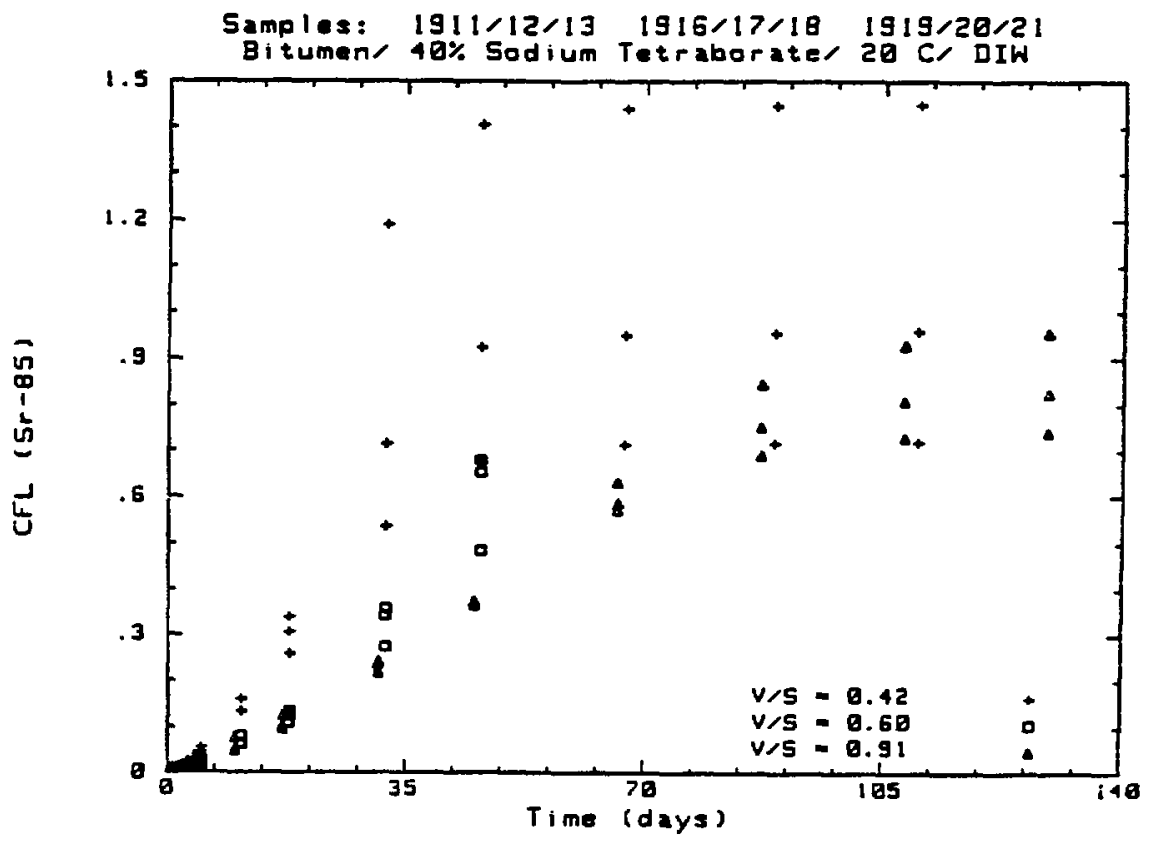

Figure 8.38

Sr-85 cumulative fraction leached vs. time from bitumen containing 40 wt sodium tetraborate at waste form volume to surface area ( $V / S$ ) ratios of 0.42 , 0.62 and 0.91 . Samples were leached in deionized water at $20^{\circ} \mathrm{C}$. 


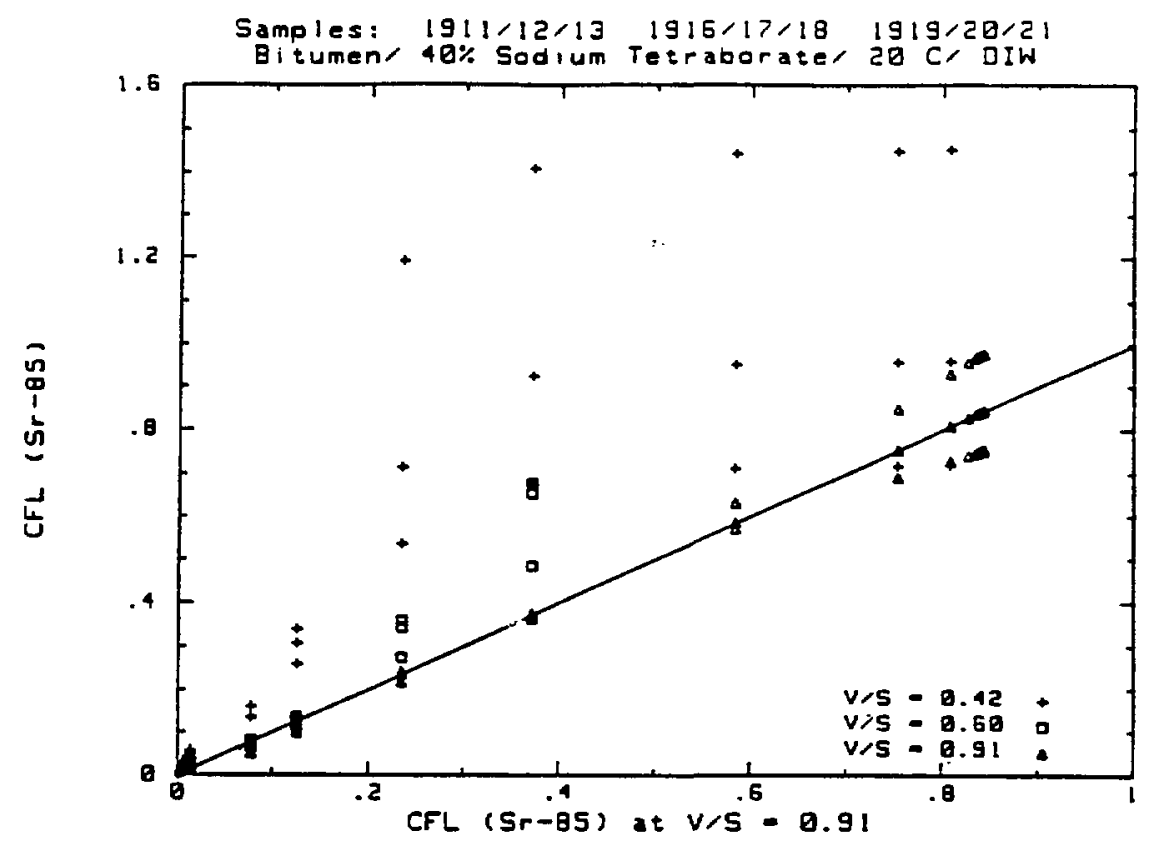

Figure 8.39

Linear correlation plots for Sr-8j leached fron bitumen waste forns containing 40 wt sodium tetraborate at waste forn volume to surface area ratios $(V / S)$ of $0.42,0.62$ and 0.91 . Correlations are relative to the $\mathrm{V} / \mathrm{S}-0.91$ data.

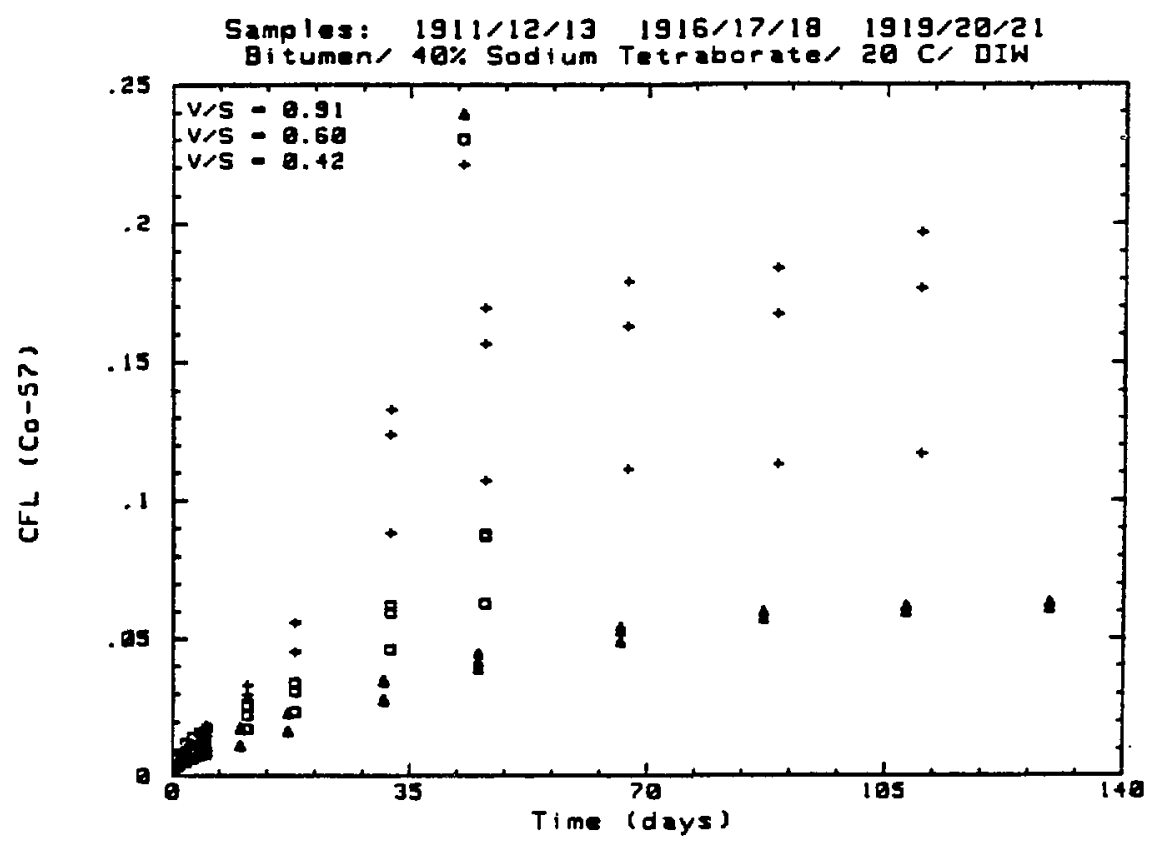

Figure 8.40

Co-57 cumulative fraction leached vs. time from bitumen contalning 40 wt sodiun tetraborate at waste form volune to surface area $(\mathrm{V} / \mathrm{S})$ ratios of 0.42 , 0.62 and 0.91 . Samples were leached in deionized water at $20^{\circ} \mathrm{C}$. 


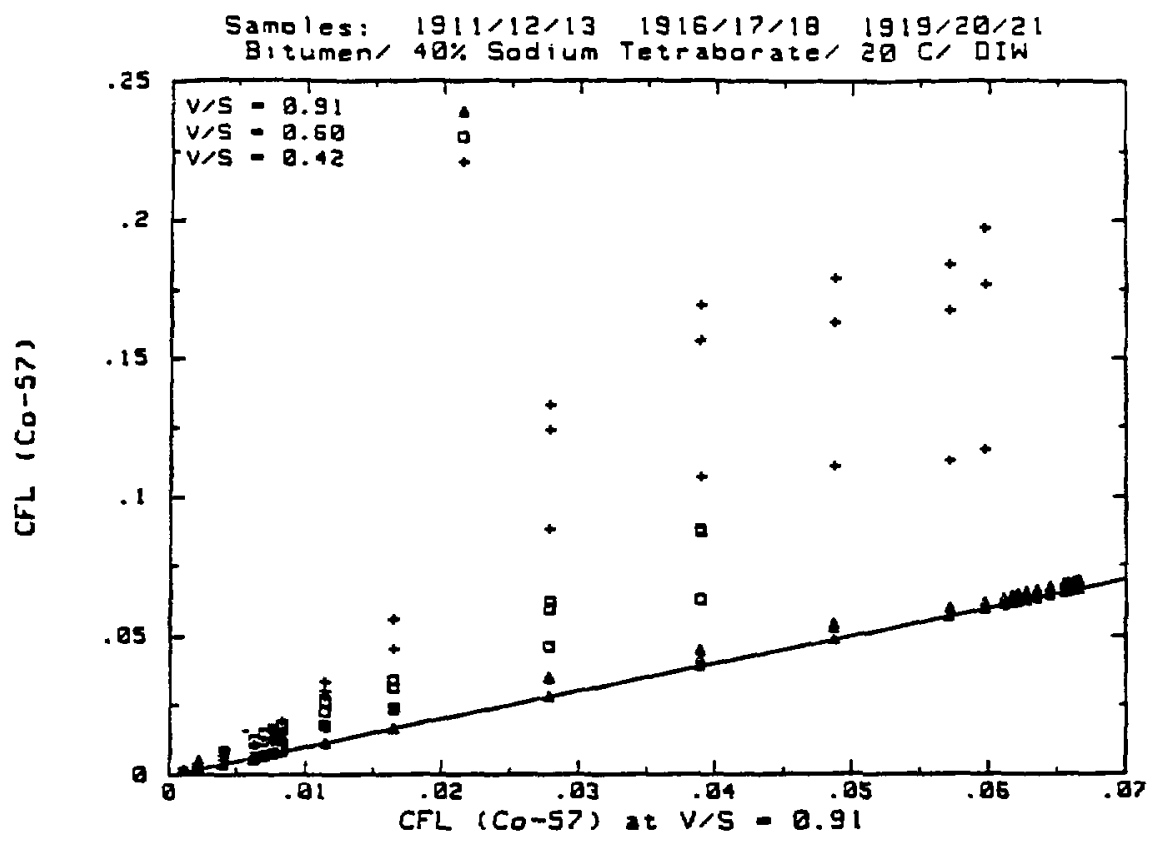

Figure 8.41

Linear correlation plots for Co-57 leached from bitumen waste forms containing 40 wt sodium tetraborate at waste form volume to surface area ratios $(\mathrm{V} / \mathrm{S})$ of $0.42,0.62$ and 0.91 . Correlations are relative to the $\mathrm{V} / \mathrm{S}-0.91$ data. 


\section{SODA-LIME GLASS INCORPORATING INCINERATOR ASH AS SIMULATED WASTE}

The glass waste form samples that we investigated were produced by Mound Laboratory [4]. Mound Laboratory investigated the glass solidification of LLW using a process in which combustible LLW was fed into an electrically heated glass furnace for incineration. Solid residue from the incineration either dissolves in the glass or is suspended in the glass as ash particulates. The volume fraction of ash is typically small and the porosity due to the ash inclusions is unconnected.

The samples provided were not ideal because of the their low radionuclide activity levels (c.f., Table 3.1). This, plus the inherently low leachability of glass, resulted in unmeasurably low releases in the leach tests. Three leach tests were performed:

(i) ANS 16.1 Leach Test in deionized water at $50^{\circ} \mathrm{C}$ for 67 days. Sample was a right cylinder, $1 \mathrm{~cm}$ diameter by $1 \mathrm{~cm}$ high.

(ii) 28 -day static leach test at $90^{\circ} \mathrm{C}$ in deionized water. Sample was a right cylinder $1 \mathrm{~cm}$ diameter by $1 \mathrm{~cm}$ high.

(iii) MCC3 Agitated Powder Leach Test.

No activity above background was detected in any of the leachates, precluding any evaluation of factors that affect leachability. 


\section{SUMMARY AND CONCLUSIONS}

This experimental investigation of the factors that affect leaching was specifically directed toward finding those that accelerate the leach rate without changing the leaching mechanisms of solidified low-level waste forms. Each of these sought-for factors is summarized in this section, while the complete results for these potential accelerating factors is contained in sections 4 through 8 of this report along with the information obtained on those factors that showed no acceleration and/or changed the leaching mechanism.

Tables $10.1,10.2$ and 10.3 summarize the results of the leaching studies for each acceleration factors of Cs-137, Sr-85 and Co-57, respectively. Positive acceleration which did not alter leaching mechanisms is shown as a "yes." Clearly negative results, either slowed leaching, statistically insignificant changes in leaching or changes in mechanisms are indicated by a "no." Results that are promising but unclear are marked by an "mixed." For exanple, releases from VES containing sodium sulfate salt appear to be accelerated by temperature during the first week of leaching. Later, however, the data becomes scattered, making any final conclusion uncertain. This factor may still be useful as one of several combined factors. In general, a better understanding of release mechanisms is also necessary for materials in the "mixed" category.

Results of these leaching studies on single acceleration factors will be used in the next stage of this program to determine what combinations of individual factors will be tested. In general, the most effective acceleration factors were:

- temperatura

- composition of the waste form

- size

Often some of the materials investigated responded in very different ways to various acceleration factors and these reactions are not well understood. Indeed, the leaching mechanisms for some are not conclusively defined. Some have been observed to change with time, even when no acceleration factors were applied. follows.

A brief review of the acceleration factors that proved to be positive

Temperature - Perhaps the single most clear-cut acceleration factor for cement waste forms is temperature. Temperature substantially accelerated Cs-137 leaching from plain cement, from cement with sodium sulfate salt and from cement with incinerator ash. Leach rates may be increased by more than twenty-fold, giving the equivalent of one year of data in 18 days. This is particularly important since cement materials are the most commonly used 
solidification agents and the most likely materials to be used for engineered barriers.

Strontium release from cement materials is not accelerated very well by temperature. This finding is not unreasonable because, as cement ages, carbonation of its surface inhibits strontium leaching. This topic requires more study, particularly regarding the rate changes of carbonate formation and its relationship to strontium uptake.

Cobalt is not generally released from cement (unless complexed in real waste) and it is not released from experiments using temperature as an acceleration factor. So this is a case where "no" for acceleration is required.

Accelerated leach tests of other materials using temperature had less conclusive results. At $40^{\circ} \mathrm{C}$ bitumen specimens may show some increased leaching; however, at $50^{\circ} \mathrm{C}$ leaching decreased, apparently because heated bitumen can flow and heal itself. Moreover, the statistical scatter is greater at elevated temperatures than at $20^{\circ} \mathrm{C}$.

Releases from VES with sodium sulfate salt increased with temperature during the first week of leaching. After that the scatter in the data obscured any trends. This effect may be related to the leaching mechanism, as discussed in Section 7. Nevertheless, temperature may be a useful açceleration factor for VES.

Composition of the Waste Form - Increasing waste loading tends to increase releases. Whether the increase in leachability is a reproducible function of loading is not clear, but there is some evidence that it may be for borate salts in bitumen. If this is so, testing waste forms with greater salt loadings may give accelerated results for specimens with lower loadings. It also will give information about the integrity of the waste form since increased leaching and degradation of the waste are associated phenomena.

Size - A theoretical discussion of the effect of waste form size on leaching is given in Section 2.7. Reduction in size for portland cement materials accelerates leaching of $\mathrm{Cs}-137$ and $\mathrm{Sr}-85$, as long as size changes keep the same aspect ratio. A particular problem with this concept is maintaining homogeneous and representative specimens at small sizes. Nevertheless, for the cement-based waste forms tested in this program, it is a useful acceleration factor.

The releases from VES specimens of different sizes containing dry sulfate salt were mixed. For the first 6 days leach rates were higher from the small specimens than from those of standard size. After reaching a CFL of 0.40 , increased scatter and depletion masked any trends. If the early portion of leaching is representative of long-term releases from this material, then size could be used as an acceleration factor.

Other Factors - Other factors had positive results that influenced only certain radionuclides from specific solidification agents. The best example $s$ leaching of $\mathrm{Co}-57$ from bitumen, which were accelerated by in oxic groundwater, 
$100 \mathrm{ppm}$ EDTA solution and in buffered solutions at $\mathrm{pH} 8$. Cobalt is the only multivalent isotope used in this study, and was expected to behave differently under various conditions.

\subsection{Prelude to Future Works}

Combining some acceleration factors may not only be expected to result in faster leaching, but also in some marginal cases, more consistent results. In exploring the effects of combined factors it will be important to more fully understand the physical and chemical controls on leaching. For most materials tested it has become clear that responses to leaching (either with or without acceleration factors) change with time; carbonate layers grow on cement, bitumen heals developing pores at $50^{\circ} \mathrm{C}$, VES may have a two-step leaching mechariism related to a skin of clean polymer at its surface. These observations coming from this program have impacts not only on work to develop an accelerated leach test, but also on understanding the long-term durability of these materials. 
Table 10.1

Summary of Acceleration Factor Effects for Cs-137

\begin{tabular}{|c|c|c|c|c|c|}
\hline Acceleration Factors & $\begin{array}{l}\text { Portland Cement } \\
+\mathrm{Na}_{2} \mathrm{SO}_{4}\end{array}$ & $\begin{array}{l}\text { Portland Cement } \\
+ \text { Incinerator Ash }\end{array}$ & $\begin{array}{l}\text { VES Emulsion } \\
+\mathrm{Na}_{2} \mathrm{SO}_{4} \mathrm{Sol}\end{array}$ & $\begin{array}{l}\text { VES } \\
+\mathrm{Na}_{2} \mathrm{SO}_{4} \mathrm{Salt}\end{array}$ & $\begin{array}{l}\text { Bitumen } \\
+\mathrm{Na}_{2} \mathrm{~B}_{4} \mathrm{O}_{7}\end{array}$ \\
\hline $\begin{array}{l}\text { Tenperature }{ }^{\circ} \mathrm{C} \\
40 \\
50\end{array}$ & $\begin{array}{l}\text { yes } \\
\text { yes }\end{array}$ & $\begin{array}{l}\text { yes } \\
\text { yes }\end{array}$ & $\begin{array}{l}\text { no } \\
\text { no }\end{array}$ & $\begin{array}{l}\text { mixed } \\
\text { mixed }\end{array}$ & $\begin{array}{l}\text { mixed } \\
\text { no }\end{array}$ \\
\hline $\begin{array}{l}\text { Leachant Volume to Surfac } \\
\text { Area of the Waste Form }\end{array}$ & ce & ND & ND & no & no \\
\hline $\begin{array}{l}\text { Leachant Composition } \\
\text { Oxic GW } \\
\text { Anoxic GW } \\
100 \text { PPn EDTA }\end{array}$ & $\begin{array}{l}\text { no } \\
\text { no } \\
\text { no }\end{array}$ & $\begin{array}{l}\text { no } \\
\text { ND } \\
\text { ND }\end{array}$ & $\begin{array}{l}\text { no } \\
\text { ND } \\
\text { ND }\end{array}$ & $\begin{array}{l}\text { no } \\
\text { nr: } \\
\text { nixed }\end{array}$ & $\begin{array}{l}\text { no } \\
\text { no } \\
\text { no }\end{array}$ \\
\hline Leachant $\mathrm{pH}$ & no & no & no & no & no \\
\hline $\begin{array}{l}\text { Leachant Replacement } \\
\text { Flow Test } \\
\text { Daily }\end{array}$ & $\begin{array}{l}\text { no } \\
\text { no }\end{array}$ & $\begin{array}{l}\text { no } \\
\text { ND }\end{array}$ & $\begin{array}{l}\text { mixed } \\
\text { ND }\end{array}$ & $\begin{array}{l}\text { no } \\
\text { no }\end{array}$ & $\begin{array}{l}\text { no } \\
\text { no }\end{array}$ \\
\hline Waste Form Composition & mixed & mixed & yes & mixed & yes \\
\hline Size $(V / S)$ & yes & yes & mixed & yes & yes \\
\hline
\end{tabular}

Yes - definite acceleration with consistent mechanism.

No - no acceleration or change in mechanism.

Mixed - unclear results, but some positive potential.

ND - not done. 
Table 10.2

Summary of Acceleration Factor Effects for $\mathrm{Sr}-85$

\begin{tabular}{|c|c|c|c|c|c|}
\hline Acceleration Factors & $\begin{array}{l}\text { Portland Cement } \\
+\mathrm{Na}_{2} \mathrm{SO}_{4}\end{array}$ & $\begin{array}{l}\text { Portland Cement } \\
+ \text { Incinerator Ash }\end{array}$ & $\begin{array}{l}\text { VES Emulsion } \\
+\mathrm{Na}_{2} \mathrm{SO}_{4} \mathrm{Sol}\end{array}$ & $\begin{array}{l}\text { VES } \\
+\mathrm{Na}_{2} \mathrm{SO}_{4} \mathrm{Salt}\end{array}$ & $\begin{array}{l}\text { Bit tumen } \\
+\mathrm{Na}_{2} \mathrm{~B}_{4} \mathrm{O}_{7}\end{array}$ \\
\hline $\begin{array}{l}\text { Temperature }{ }^{\circ} \mathrm{C} \\
\quad 40 \\
50\end{array}$ & $\begin{array}{l}\text { yes } \\
\text { yes }\end{array}$ & $\begin{array}{l}\text { yes } \\
\text { yes }\end{array}$ & $\begin{array}{l}\text { no } \\
\text { no }\end{array}$ & $\begin{array}{l}\text { mixed } \\
\text { mixed }\end{array}$ & $\begin{array}{l}\text { mixed } \\
\text { no }\end{array}$ \\
\hline $\begin{array}{l}\text { Leachant Volume to Waste } \\
\text { Form Surface Area }\end{array}$ & no & ND & ND & no & no \\
\hline $\begin{array}{l}\text { Leachant Composition } \\
\text { Oxic GW } \\
\text { Anoxic GW } \\
100 \text { ppm EDTA }\end{array}$ & $\begin{array}{l}\text { no } \\
\text { no } \\
\text { yes }\end{array}$ & $\begin{array}{l}\text { yes } \\
\text { ND } \\
\text { ND }\end{array}$ & $\begin{array}{l}\text { no } \\
\text { ND } \\
\text { ND }\end{array}$ & $\begin{array}{l}\text { no } \\
\text { no } \\
\text { no }\end{array}$ & $\begin{array}{l}\text { no } \\
\text { no } \\
\text { no }\end{array}$ \\
\hline Leachant $\mathrm{pH}$ & yes & no & no & no & no \\
\hline $\begin{array}{l}\text { Leachant Replacement } \\
\text { Flow Test } \\
\text { Daily }\end{array}$ & $\begin{array}{l}\text { no } \\
\text { yes }\end{array}$ & $\begin{array}{l}\text { no } \\
\text { ND }\end{array}$ & $\begin{array}{l}\text { no } \\
\text { ND }\end{array}$ & $\begin{array}{l}\text { no } \\
\text { no }\end{array}$ & $\begin{array}{l}\text { no } \\
\text { no }\end{array}$ \\
\hline Waste Form Composition & no & no & yes & yes & yes \\
\hline Size $(V / S)$ & yes & yes & yes & yes & yes \\
\hline
\end{tabular}

Yes - definite acceleration with consistent mechanism.

No - no acceleration or change in mechanism.

Mixed - unclear results, but some positive potential.

ND - not done. 
Table 10.3

Summary of Acceleration Factor Effects for Co-57

\begin{tabular}{|c|c|c|c|c|c|}
\hline Acceleration Factors & $\begin{array}{l}\text { Portland Cement } \\
+\mathrm{Na}_{2} \mathrm{SO}_{4}\end{array}$ & $\begin{array}{l}\text { Portland Cement } \\
+ \text { Incinerator Ash }\end{array}$ & $\begin{array}{l}\text { VES Emulsion } \\
+\mathrm{Na}_{2} \mathrm{SO}_{4} \mathrm{Sol}\end{array}$ & $\begin{array}{l}\text { VES } \\
+\mathrm{Na}_{2} \mathrm{SO}_{4} \mathrm{Salt}\end{array}$ & $\begin{array}{l}\text { Bi tumen } \\
+\mathrm{Na}_{2} \mathrm{~B}_{4} \mathrm{O}_{7}\end{array}$ \\
\hline \multicolumn{6}{|l|}{ Temperature ${ }^{\circ} \mathrm{C}$} \\
\hline 40 & NRO & NRO & no & mixed & no \\
\hline 50 & NRO & NRO & no & mixed & no \\
\hline $\begin{array}{l}\text { Leachant Volume to Waste } \\
\text { Form Surface Area }\end{array}$ & NRO & ND & ND & no & no \\
\hline \multicolumn{6}{|l|}{ Leachant Composition } \\
\hline Oxic GW & NRO & NRO & no & no & yes \\
\hline Anoxic GW & NRO & ND & ND & no & no \\
\hline $100 \mathrm{ppm}$ EDTA & NRO & ND & ND & no & yes \\
\hline Leachant $\mathrm{pH}$ & NRO & NRO & no & no & yes \\
\hline \multicolumn{6}{|l|}{ Leachant Replacement } \\
\hline Flow Test & NRO & NRO & no & no & no \\
\hline Daily & NRO & ND & ND & no & no \\
\hline Waste Form Composition & NRO & NRO & yes & mixed & yes \\
\hline Size $(V / S)$ & NRO & NRO & yes & yes & yes \\
\hline
\end{tabular}




\section{REFERENCES}

1. Dougherty, D.R. and P. Colombo, "Leaching Mechanisms of Solidified Low Level Wastes: The Literature Survey," Brookhaven National Laboratory, BNL-51899, June, 1985.

2. Dougherty, D.R., M. Fuhrmann and P. Colombo, "Accelerated Leach Test(s) Program Annual Report," Brookhaven National Laboratory, BNL-51955, September 1985 .

3. Dougherty, D.R., R.F. Pietrzak, M. Fuhrmann and P. Colombo, "Accelerated Leach Test(s) Program Annual Report," Brookhaven National Laboratory, BNL-52042, September 1986.

4. Armstrong, K.M. and L.M. Klingler, "Evaluation of a Processing Technique for Immobilization of Low-Level Radioactive Waste, " Mound Laboratory, MLM-3149, July 1984 .

5. Godbee, H.W. and D.S. Joy, Assessment of the Loss of Radioactive Isotopes From Waste Solids to the Environment, Part I, Background and Theory, ORNL-TM-4333, Oak Ridge National Laboratory, February 1974.

6. Nestor, C.W., Jr., Diffusion From Solid Cylinders, Oak Ridge National Laboratory, ORNL/CSD/TM-84, January 1980 .

7. Dayal, R., H. Arora and N. Morcos, "Estimation of Cesium-137 Release From Waste/Cement Composites Using Data From Small-Scale Specimens," Brookhaven National Laboratory, NUREG/CR-3382, BNL-NUREG-51690, July 1983.

8. Zhou, H. and P. Colcmbo, "Solidification of Low-Level Radioactive Wastes in Masonry Cement," Brookhaven National Laboratory, BNL-52074, March 1987.

9. Stone, J.A., "An Overview of Factors Affecting the Leachability of Nuclear Waste Forms," Nuclear and Chemical Waste Management, Pergamon Press, Ltd., 1981, Volume 2, pp. 113-118.

10. Dayal, R., D.G. Schweitzer and R.E. Davis, "Wet and Dry Cycle Leaching: Aspects of Releases in the Unsaturated Zone," Proceedings of the U.S. Nuclear Regulatory Commission, NRC Nuclear Waste Geochemistry '83, NUREG/CP-0052, 1983, PP. 440-453.

11. Daya1, R., H. Arora, J.C. Clinton and L. Milian, "Leaching Studies of Low-Level Radioactive Waste Forms," Brookhaven National Laboratory, BNL-NUREG-37071, presented at the Seventh Annual Participants' Information Meeting, DOE Low-Level Waste Management Program, Las Vegas, Nevada, September, 1985. 
REFERENCES (con't)

12. Sambe11, R.A.J., R. De Batist, P. Van Iseghem, W. Timmermans and K. Brodersen, "Characterization of Low- and Medium-level Radioactive Waste Forms, Commission of the European Communities," PB84-212976, EUR 8663 EN, 1983, pp. 60-61.

13. Hespe, E.D., "Leach Testing of Immobilized Radioactive Waste Solids, A Proposal for a Standard Method", Atomic Energy Review, 9, 1971, pp. 195-207.

14. Seefeldt, W.B., "Review of Simulated-Flow and True-Flow Leach Tests," Fuel Cycle Programs Quarterly Progress Report April-June 1982, Argonne National Laboratory, ANL 82-58, December 1982, pp. 98-125.

15. Materials Characterization Center, MCC-1 Static Leach Test, Pacific Northwest Laboratory, August 1980.

16. Pacific Northwest Laboratory, Final Report of the Defense High-Level Waste Leaching Mechanisms Program, J.W. Mendel, compiler, PNL-5157, UC-70, August 1984.

17. Machiels, A.J. and C. Pescatore, "The Functional Dependence of Leaching on the Surface Area-to-Solution Volume Ratio." Scientific Basis for Nuclear Waste Management, ed., D.G. Brookins, North-Holland, New York, 1983, Volume VI, pp. 209-216.

18. Ethridge, E.C., D.E. Clark and L.L. Hench, "Effects of Glass Surface Area to Solution Volume Ratio on Glass Corrosion," Phys. Chem. Glasses, $20: 35-40,1978$.

19. Oversby, V.M., "Leach Testing of Waste Forms: Interrelationship of ISO and MCC Type Tests." Materials Characterization Center Workshop on Leaching Mechanisms of Nuclear Waste Forms, ed., J.E. Mende1. May 19-21, 1982, Gaithersburg, Maryland. PNL-4382, 1982.

20. Pederson, L.R., C.Q. Buckwalter, G.L. McVay and B.L. Riddle, "Glass Surface Area to Solution Volume Ratio and Its Implications to Accelerated Leach Testing." Scientific Basis for Nuclear Waste Management, VI, ed., D.G. Brookins, North-Holland, New York, 1983, pp. 47-54.

21. Matsuzuru, H. and A. Ito, "Effect of Dimension of Specimen on Amounts of ${ }^{137} \mathrm{Cs},{ }^{90} \mathrm{Sr}$ and ${ }^{60} \mathrm{Co}$ Leached from Matrix of Hardened Cement," I. Nucl. Sci. Tech., 1978, 15:296-301.

22. Matsuzuru, H. and A. Ito, Annals of Nucl. Energy, 4, 1977.

23. Crank, J., The Mathematics of Diffusion, 2nd Edition, Clarendon Press, Oxford, 1975. 


\section{REFERENCES (con' $t$ )}

24. Speranzini, R.A. and L.P. Buckley, "Treatment of Spent Ion-Exchange Resins for Disposal," AECL - 7411, September 1981.

25. Van Brake1, J. and P.M. Heertjes, "Analysis of Diffusion in Macroporous Media in Terms of a Porosity, a Tortuosity and a Constrictivity Factor," Int. J. Heat and Mass Transfer, 1974, Vo1. 17, pp. 1093-1103.

26. Colombo, P. and R.M. Neilson, Jr., "Properties of Radioactive Wastes and Waste Containers," NUREG/CR-1168, BNL-NUREG-51114, 1979.

27. Neilson, R.M. and P. Colombo, "Waste Form Development Program Annual Progress Report," BNL-51614, 1982.

28. R.L. Buschbom, et al., "Characterization of Cement and Bitumen Waste Forms Containing Simulated Low-Leve1 Waste Incinerator Ash," NUREG/CR-3798, PNL-5153, 1984.

29. Westic, J.H., compiler, "Characterization of Cement and Bitumen Waste Forms Containing Simulated Low-Level Waste Incinerator Ash," Pacific Northwest Laboratory, NUREG/CR-3798, PNL-5153, August 1984.

30. U.S. Energy Research and Development Administrations (USERDA), "Alternatives for Managing Wastes from Reactors and Post-Fission Operation in the LWR Fuel Cycle," Vol. 2, Alternatives for Waste Treatment, ERDA-76-43, 1976.

31. McKercher, B.B., C.C. Miller and M.D. Naughton, "Operation Experience of the Palisade Station Volume Reduction System - The First Two Months," Post (editor) Waste Management 84, Volume 2, Tucson, AZ Symposium, 1984.

32. American Nuclear Society, "Measurement of the Leachability of Solidified Low-Level Radioactive Wastes," ANS Standards Committee, ANS 16.1, June 20,984 .

33. Davis, E.C. and P.M. Craig, "Summary of Rainfa11, Runoff, Water Table, and Water Quality Data From ORNL's Solid Waste Storage Area Six Engineered Test Facility: 1980-1984 Data Base," ORNL/NFW-84/41, August 1984.

34. Materials Characterization Center, Agitated Powder Leach Test Method, MCC 3 s, 1981.

35. Materials Characterization Center, Low-Flow-Rate Leach Test Method, MCCS4, 1981.

36. American Society for Testing and Materials, "Standard Practices for the Measurements of Radioactivity," ASTM Standard D-3648 in 1982 Annual Book of ASTM Standards, Part 31, Water. 
REFERENCES (con't)

37. American Society for Testing and Materials, "Standard Practices for Gamma-Ray Spectrometry, " ASTM Standard D-3649, in 1982 Annual Book of ASTM Standards, Part 31, Water.

38. American Society for Testing and Materials, "Standard Practice for Flame Atomic Absorption Analysis," Standard E663, in 1982 Annual Book of ASTM Standards, Part 42, Analytical Methods-Spectroscopy; Chromatography; Computerized Systems.

39. Perkin-Elmer, Analytical Methods for Atomic Absorption Spectroscopy, Perkin-Elmer Corporation, 1982.

40. Greenberg, A.E., J.J. Connors and D. Jenkins, editors, "Alkalinity, Method 403," in Standard Methods for the Examination of Water and Waste Water, 15th edition, American Public Health Association, Washington, DC, 1981.

41. American Society for Testing and Materials, "Standard Test Methods for $\mathrm{pH}$ of Water," Standard D-1293 in 1982 Annual Book of ASTM Standards, Part 3, Water.

42. American Society for Testing and Materials, "Standard Test Methods for Electrical Conductivity and Resistivity of Water," Standard D-1125 in 1982 Annual Book of ASTM Standards, Part 31, Water.

43. Goldstein, J.I. and H. Yakowinz, (editors), Practical Scanning Electron Microscopy, Electron and Ion Microprobe Analysis, Plenum Press, 1975.

44. Lea, F.J. The Chemistry of Cement and Concrete, Third Edition, F. Arnold (Publishers), Ltd., 1970.

45. Soroka, I., Portland Cement Paste and Concrete, Chemical Publishing Co., Inc., New York, 1980, p. 49.

46. Powers, T.C., "Physical Properties of Cement Paste," Proceedings of the Washington Symposium on the Chemistry of Cement, 1960, 2:577-613.

47. Feldman, R.F., "Density and Porosity Studies of Hydrated Portland Cement," Cement Technology, 3(1), 1972, pp. 5-14.

48. Brunauer, S. and L.E. Copeland, "The Chemistry of Concrete," Scientific American, April 1964, 210:81-92.

49. Double, D.D. and A. Hellawell, "The Solidification of Cement," Scientific American, 1977, pp. 82-90.

50. Kirk-0thmer, Encyclopedia of Chemical Technology, Third Edition, Volume 5, John wiley, 1979, pp. 163-193. 


\section{REFERENCES (con't)}

51. Crawford, R.W., F.P. Glasser, A.A. Rahman, M.J. Angus and C.E. McCulloch, "Diffusion Mechanisms and Factors Affecting Leaching of Cesium-134 from Cement-Based Waste Matrices," Radioactive Waste Management and the Nuclear Fuel Cycle, 6(2), Harwood Academic Publishers, 1985, pp. 177-196.

52. Crawford, R.W., F.P. Glasser, A.A. Rahman, M.J. Angus and C.E. McCu1loch, "Diffusion Mechanisms and Factors Affecting Leaching of Cesium-134 From Cement-Based Waste Matrices", Radioactive Waste Management and the Nuclear Fuel Cycle, 6(2), June 1985, pp. 187-192.

53. Matsuzuru, H. and A. Ito, "Effect of Dimension of Specimen on Amounts of Cesium-137, Strontium-90 and Cobalt-60 Leached From Matrix of Hardened Cement Grout", Journal of Nuclear Science and Technology, 15, 1978, pp. $296-301$.

54. Godbee, H.W., E.L. Compere, D.S. Joy, A.H. Kibbey, J.G. Moore, C.W. Nestor, O.U. Anders and R.M. Neilson, Jr., "Application of Mass Transport Theory to the Leaching of Radionuclides From Waste Solids", Nuclear and Chemical Waste Management, 1, 1980, pp. 29-35.

55. Glasser, F.P., A.A. Rahman, R.W. Crawford, C.E. McCulloch and M.J. Angus, "Immobilization and Leaching Mechanisms of Radwaste in CementBased Matrices, " First Half-Yearly Progress Report, DOE/RW 82.050, March 1982 , p. 61 .

56. Glasser, F.P., A.A. Rahman, R.W. Crawford, C.E. McCulloch and M.J. Angus, "Immobilization and Leaching Mechanisms of Radwaste in CementBased Matrices," Second Half-Yearly Progress Report, DOE/RW 82.108, March 1982, p. 106.

57. Komarnerni, S. and D.M. Roy, "Mechanisms of Immobilization of Nuclear Waste Elements by Cement Minerals, Cement and Mortar," Cement and Concrete Research, 11, 1981, pp. 789-794.

58. Atkinson, A., A.K. Nickerson and T.M. Valentine, "The Mechanisms of Leaching From Some Cement-Based Nuclear Waste Forms," United Kingdom Atomic Energy Authority, Harwell, AERE-R10809, June 1983.

59. McDanie1, E.W., M.T. Morgan, J.G. Moore, H.E. Devaney and L.R. Dole, "Strontium Leachability of Hydrofracture Grouts for Sludge-Slurries," ORNL/TM-8198, 1984.

60. Moore, J.G., H.W. Godbee and A.H. Kibbey, "Leach Behavior of Hydrofracture Grout Incorporating Radioactive Wastes, " Nuclear Technology, $1977,32: 39-52$. 
61. Moore, J.G., H.W. Godbee and A.H. Kibbey and D.S. Joy, Development of Cementitious Grouts for the Incorporation of Radioactive Wastes, Part I. Leach Studies, ORNL-4962, Oak Ridge National Laboratory, 1975.

62. Fuhrmann, M. and P. Colombo, "Leaching Induced Concentration Profiles in the Solid Phase of Cement," presented at the 4th International Hazardous Waste Symposium on Environmental Aspects of Stabilization/Solidification Hazardous and Radioactive Wastes, Atlanta, Georgia, May $3-6,1987$.

64. Dayal, R., R.F. Pietrzak, and J. Clinton, "Geochemical Studies of Commercial Low-Level Radioactive Waste Disposal Sites, a Topical Report," NUREG/CR-3993, Sept. 1984.

65. Dayal, R., R.F. Pietrzak, and J. Clinton, "Geochemical Studies of Commercial Low-Level Radioactive Waste Disposal Sites, a Topical Report," NUREG/CR-4644, BNL/NUREG-52004, June 1986.

66. Fuhrmann, M. and P. Colombo, "Radionuclide Releases From Cement in Seawater, Draft Report, EPA, July 1987.

67. Filter, H.E. and Robertson, K., The Dow System for Solidification of Low-Level Waste From Nuclear Power Plants, Dow Chemical Company, Midland, Michigan 1977.

68. Filter, H.E., Vinyl Ester Solidification of Low-level Radioactive Waste, Dow Chemical Company, Midland, Michigan, 1979.

69. Filter, H.G., The Dow System for Solidification of Low-Level Radioactive Waste from Nuclear Power Plants, Dow Chemical Company, Midland, Michigan, 1978.

70. Kirk-Othmer, Encyclopedia of Chemical Technology, Third Edition, Volume John Wiley and Sons, 1978, pp. 284-324.

71. Brady, G.S. and H.R. Clausen, Materials Handbook, Eleventh Edition, McGraw-Hill Book Company, New York, 1984, pp. 68-71.

72. ASTM P 312-78, "Standard Specification for Asphalt Used in Roofing," in Annual Book of ASTM Standards, Part 15, American Society for Testing Materials, 1986.

73. Fuhrmann, M., R.M. Neilson and P. Colombo, "A Survery of Agents and Techniques Applicable to the Solidification of Low-Level Radioactive Waste," BNL-51521, 1981. 


\section{REFERENCES (con' $t$ )}

74. Blanco, R.E., W. Davis, Jr., H.W. Godbee, L.J. King, J.T. Roberts and W.C. Yee, "Recent Developments in Treating Low- and Intermediate-Level Radioactive Wastes in the USA," Practices in the Treatment of Low-and Intermediate-Level Radioactive Wastes, IAEA and ENEA-(SM-71/26), $793-839,1966$.

75. International Atomic Energy Agency, Bituminization of Radioactive Wastes, IAEA Technical Reports Series No. 116, 1970, pp. 69-89.

76. Peltonen, E.K., J.U. Heinonen and J. Kuusi, "Incorporation of Radioactive Wastes From Nuclear Power Plants Into Concrete and Bitumen," Management of Radioactive Wastes from the Nuclear Fuel Cycle, II, IAEA-SM-207/5, 1976, Pp. 97-105.

77. Dejonghe, P., L. Baetsle, N. Van de Voorde, W. Maes, P. Staner, J. Pyck and J. Souffriau, "Asphalt Conditioning and Underground Storage of Concentrates of Medium Activity," Proc. Int. Conf. Peaceful Uses Atom. Energy, UN, New York, 1964, 14:343.

79. Boggs, S. Jr., and D.L. Livermore and M.G. Seitz, "Humic Substance in Natural Water and Their Complexation With Trace Metals and Radionuc1ides. A Review," ANL-84-78, July 1985.

80. Cotton, F.A. and G. Wilkenson, Advanced Inorganic Chemistry, 4th Edition, Interscience Publishers, John Wily and Sons, New York, 1980, pp. $776-778$.

81. Basolo, F. and R.G. Pearson, Mechanisms of Inorganic Reactions, A Study of Metal Complexes in Solution, 2nd Edition, John Wiley and Sons, 1968.

82. Burkingham, D.A. and A.M. Sargeson, "Oxidation-Reduction Potentials as Functions of Donor Atom and Ligand," Chelating Agents and Metal Chelates, Dwyer, F.P. and D.P. Mellor, Academic Press, New York, 1964, pp. $237-280$. 
Appendix A contains ten tables that list the sample parameters (weight, height, diameter, volume and surface area), leachant type and volume and the leaching temperature $\left( \pm 2^{\circ} \mathrm{C}\right)$ for each of the samples containing radiotracers (Cs-137, Sr-85 and Co-60 or Co-57) fabricated and tested in this task. Each sample has been assigned a TESTID and a SAMPLEID for identification in the text and in the figures. Each table contains the parameters for a single sample type (i.e., composition), as follows:

- Table Al: Portland type I cement containing 5 wt sodium sulfate salt as simulated waste

- Table A2: Portland type I cement containing 15 wto incinerator ash as simulated waste

- Table A3: Vinyl ester-styrene emulsion with aqueous sodium sulfate solution as simulated waste

- Table A4: Vinyl ester-styrene containing 20 wto sodium sulfate salt as simulated waste

- Table A5: Vinyl ester-styrene containing "30 wto sodium sulfate simulated waste

- Table A6: Vinyl ester-styrene containing 40 wto sodium sulfate salt as simulated waste

- Table A7: Bitumen containing 20 wto sodium tetraborate salt as simulated waste

- Table A8: Bitumen containing 30 wto sodium tetraborate salt as simulated waste

- Table A9: Bitumen containing 40 wto sodium tetraborate salt as simulated waste

- Table Al0: Portland type I cement containing only radiotracers of $\mathrm{Cs}, \mathrm{Sr}$ and Co as simulated waste 
Test and Sample Paraneters for Portland I Cement With Sodium Sulfate (5 wt 8 ) Type Waste. Waste-to-Binder Ratio $(w / w)-0.54^{1}$. Samples Contain Co-57, Sr-85 and Cs-137.

\begin{tabular}{|c|c|c|c|c|c|c|c|c|c|}
\hline $\begin{array}{l}\text { Sample } \\
\text { ID }\end{array}$ & $\begin{array}{l}\text { Test } \\
\text { ID }\end{array}$ & $\begin{array}{l}\text { Weight } \\
\text { (g) }\end{array}$ & $\begin{array}{l}\text { Helght } \\
\text { (ca) }\end{array}$ & $\begin{array}{l}\text { Diameter } \\
(\mathrm{cm})\end{array}$ & $\begin{array}{l}\text { Sample } \\
\text { Volume } \\
\left(\mathrm{cm}^{3}\right)\end{array}$ & $\begin{array}{l}\text { Surface } \\
\text { Area }\left(\mathrm{cm}^{2}\right)\end{array}$ & $\begin{array}{l}\text { Leachant } \\
\text { Type }\end{array}$ & $\begin{array}{l}\text { Leachate } \\
\text { Volume }\left(\mathrm{cm}^{3}\right)\end{array}$ & $\begin{array}{c}\text { Temperature } \\
\left({ }^{\circ} \mathrm{C}\right)\end{array}$ \\
\hline 1111 & PS1A & 208.9 & 6.25 & 4.70 & 108 & 127 & $\mathrm{DIW}^{2}$ & 1300 & 20 \\
\hline 1112 & PS1B & 206.3 & 6.20 & 4.60 & 103 & 123 & DIW & 1300 & 20 \\
\hline 1113 & PS1C & 208.5 & 6.30 & 4.60 & 105 & 124 & DIW & 1300 & 20 \\
\hline 1116 & PS1F & 21.9 & 2.50 & 2.50 & 12.3 & 29.4 & DIW & 300 & 20 \\
\hline 1117 & PS1G & 23.4 & 2.60 & 2.50 & 12.8 & 30.2 & DIW & 300 & 20 \\
\hline 1118 & PS1H & 21.8 & 2.40 & 2.50 & 11.8 & 28.7 & DIW & 300 & 20 \\
\hline 1119 & PS1I & 412.9 & 1.50 & 13.9 & 228 & 369 & DIW & 3650 & 20 \\
\hline 1120 & PS1.J & 420.8 & 1.50 & 13.9 & 228 & 369 & DIW & 3650 & 20 \\
\hline 1121 & PS1K & 413.9 & 1.50 & 13.9 & 228 & 369 & DIW & 3650 & 20 \\
\hline 1122 & PS2L & 216.3 & 6.70 & 4.70 & 116 & 134 & DIW & 1300 & 40 \\
\hline 1123 & PS2M & 202.3 & 6.20 & 4.70 & 108 & 126 & DIW & 1300 & 40 \\
\hline 1124 & PS3A & 204.4 & 6.20 & 4.70 & 111 & 129 & DIW & 1300 & 50 \\
\hline 1125 & PS3B & 196.6 & 6.20 & 4.70 & 108 & 126 & DIW & 1300 & 50 \\
\hline 1126 & PS3C & 210.0 & 6.50 & 4.70 & 113 & 131 & DIW & 1300 & 50 \\
\hline
\end{tabular}


Table Al (cont.)

Test and Sample Parameters for Portland I Cement With Sodium Sulfate (5 wt 8 ) Type Waste Waste-to-Binder Ratio $(w / w)=0.54^{1}$. Samples Contain Co-57, Sr-85 and Cs-137.

\begin{tabular}{|c|c|c|c|c|c|c|c|c|c|}
\hline $\begin{array}{l}\text { Sample } \\
\text { ID }\end{array}$ & $\begin{array}{l}\text { Test } \\
\text { ID }\end{array}$ & $\begin{array}{c}\text { Weight } \\
(\mathrm{g})\end{array}$ & $\begin{array}{l}\text { Height } \\
\text { (cD) }\end{array}$ & $\begin{array}{l}\text { Diameter } \\
(\mathrm{cm})\end{array}$ & $\begin{array}{l}\text { Sample } \\
\text { Volume } \\
\left(\mathrm{cm}^{3}\right)\end{array}$ & $\begin{array}{l}\text { Surface } \\
\text { Area }\left(\mathrm{cm}^{2}\right)\end{array}$ & $\begin{array}{l}\text { Leachant } \\
\text { Type }\end{array}$ & $\begin{array}{l}\text { Leachate } \\
\text { Volume }\left(\mathrm{cm}^{3}\right)\end{array}$ & $\begin{array}{c}\text { Temperature } \\
\left({ }^{\circ} \mathrm{C}\right)\end{array}$ \\
\hline 1129 & PS4A & 211.8 & 6.50 & 4.60 & 108 & 127 & $\mathrm{GW}^{3}$ & 1300 & 20 \\
\hline 1130 & PS4B & 205.6 & 6.40 & 4.60 & 106 & 126 & GW & 1300 & 20 \\
\hline 1131 & PS4C & 209.2 & 6.50 & 4.60 & 108 & 127 & GW & 1300 & 20 \\
\hline 1135 & PS7B & 205.6 & 6.30 & 4.70 & 109 & 128 & $\mathrm{DIW}^{4}$ & 1000 & 20 \\
\hline 1136 & PS7C & 198.9 & 6.10 & 4.60 & 101 & 121 & DIW & 1000 & 20 \\
\hline 1137 & PS6A & 211.4 & 6.50 & 4.60 & 108 & 127 & DIW & 2600 & 20 \\
\hline 1138 & PS6B & 190.0 & 5.80 & 4.70 & 100 & 120 & DIW & 3900 & 20 \\
\hline 1139 & PS10A & 204.6 & 6.40 & 4.60 & 101 & 126 & $\mathrm{pH}^{5}$ & 1300 & 20 \\
\hline 1140 & PS10B & 209.3 & 6.40 & 4.60 & 106 & 126 & $\mathrm{pH}^{5}$ & 1300 & 20 \\
\hline 1141 & PS10C & 208.4 & 6.40 & 4.60 & 106 & 126 & $\mathrm{pH}^{5}$ & 1300 & 20 \\
\hline 1142 & PS10D & 215.0 & 6.60 & 4.60 & 110 & 129 & $\mathrm{pH}^{6}$ & 1300 & 20 \\
\hline
\end{tabular}


Table A: (cont.)

Test and Sample Parameters for Portland I Cement With Sodium Sulfate (5 wt $)$ Type Waste. Waste-to-Binder Ratio $(w / w)=0.54^{1}$. Samples Contain Co-57, Sr-85 and Cs-137.

\begin{tabular}{|c|c|c|c|c|c|c|c|c|c|}
\hline $\begin{array}{l}\text { Sample } \\
\text { ID }\end{array}$ & $\begin{array}{l}\text { Test } \\
\text { ID }\end{array}$ & $\begin{array}{l}\text { Weight } \\
(\mathrm{g})\end{array}$ & $\begin{array}{l}\text { Height } \\
\text { (cm) }\end{array}$ & $\begin{array}{l}\text { Diameter } \\
\text { (c⿴囗十) }\end{array}$ & $\begin{array}{l}\text { Sample } \\
\text { Volume } \\
\left(\mathrm{cm}^{3}\right)\end{array}$ & $\begin{array}{l}\text { Surface } \\
\text { Area }\left(\mathrm{cm}^{2}\right)\end{array}$ & $\begin{array}{l}\text { Leachant } \\
\text { Type }\end{array}$ & $\begin{array}{l}\text { Leachate } \\
\text { Volume }\left(\mathrm{cm}^{3}\right)\end{array}$ & $\begin{array}{c}\text { Temperature } \\
\left({ }^{\circ} \mathrm{C}\right)\end{array}$ \\
\hline 1150 & 7-PS2A & 203.5 & 6.20 & 4.70 & 108 & 126 & ANOXIC & 1300 & 20 \\
\hline 1151 & 7-PS2B & 217.7 & 6.60 & 4.80 & 119 & 136 & ANOXIC & 1300 & 20 \\
\hline 1152 & $7-P S 2 C$ & 209.1 & 6.40 & 4.70 & 111 & 129 & ANOXIC & 1300 & 20 \\
\hline 1160 & 7-PSSA & 210.3 & 6.40 & 4.60 & 106 & 126 & DIW & 1300 & 20 \\
\hline 1161 & $7-P S 5 B$ & 211.7 & 6.30 & 4.60 & 105 & 124 & DIW & 1300 & 20 \\
\hline 1162 & 7-PS5C & 202.9 & 6.20 & 4.60 & 103 & 123 & DIW & 1300 & 20 \\
\hline 1163 & 7-PS7A & 2234 & 14.2 & 10.0 & 112 & 603 & DIW & 6000 & 20 \\
\hline 1164 & 7-PS7B & 2220 & 14.0 & 10.1 & 112 & 604 & DIW & 6000 & 20 \\
\hline 1165 & 7-PS7C & 2238 & 14.0 & 10.0 & 110 & 597 & DIW & 6000 & 20 \\
\hline 1168 & 7-PS8A & 206.4 & 6.20 & 4.70 & 108 & 126 & DIW & 3900 & 20 \\
\hline 1169 & 7-PS8B & 215.9 & 6.50 & 4.70 & 113 & 131 & DIW & 3900 & 20 \\
\hline 1170 & 7-PSBC & 223.9 & 6.90 & 4.70 & 120 & 137 & DIW & 3900 & 20 \\
\hline 1171 & 7-PS9A & 211.3 & 6.40 & 4.60 & 106 & 126 & DIW & 6500 & 20 \\
\hline 1172 & 7-PS9B & 202.9 & 6.20 & 4.60 & 103 & 123 & DIW & 6500 & 20 \\
\hline 1173 & 7-PS9C & 223.5 & 6.70 & 4.60 & 111 & 130 & DIW & 6500 & 20 \\
\hline
\end{tabular}


Table Al (cont.)

Test and Sample Parameters for Portland I Cement With Sodium Sulfate (5 wt8) Type Waste. Waste-to-Binder Ratio $(w / w)-0.54^{1}$. Samples Contain Co-57, Sr-85 and Cs-137.

\begin{tabular}{|c|c|c|c|c|c|c|c|c|c|}
\hline $\begin{array}{l}\text { Sanple } \\
\text { ID }\end{array}$ & $\begin{array}{l}\text { Test } \\
\text { ID }\end{array}$ & $\begin{array}{l}\text { Weight } \\
(\mathrm{g})\end{array}$ & $\begin{array}{l}\text { Hel ght } \\
\text { (cII) }\end{array}$ & $\begin{array}{l}\text { Diameter } \\
\text { (cm) }\end{array}$ & $\begin{array}{l}\text { Sample } \\
\text { Volume } \\
\left(\mathrm{cm}^{3}\right)\end{array}$ & $\begin{array}{l}\text { Surface } \\
\text { Area }\left(\mathrm{cm}^{2}\right)\end{array}$ & $\begin{array}{l}\text { Leachant } \\
\text { Type }\end{array}$ & $\begin{array}{l}\text { Leachate } \\
\text { Volume }\left(\mathrm{cm}^{3}\right)\end{array}$ & $\begin{array}{c}\text { Temperature } \\
\left({ }^{\circ} \mathrm{C}\right)\end{array}$ \\
\hline 1174 & 7-PS11A & 213.7 & 6.40 & 4.60 & 106 & 126 & $\operatorname{EDTA}^{8}$ & 1300 & 20 \\
\hline 1175 & 7-PS11B & 215.6 & 6.50 & 4.60 & 108 & 127 & EDTA & 1300 & 20 \\
\hline 1176 & 7-PS11C & 212.1 & 6.50 & 4.60 & 108 & 127 & EDTA & 1300 & 20 \\
\hline 1177 & 7-PS12A & 24.4 & 2.70 & 2.40 & 12.2 & 29.4 & DIW & 300 & 50 \\
\hline 1178 & $7-P S 12 B$ & 25.4 & 2.70 & 2.40 & 12.2 & 29.4 & DIW & 300 & 50 \\
\hline 1179 & $7-P S 12 C$ & 27.1 & 3.00 & 2.40 & 13.8 & 31.7 & DIW & 300 & 50 \\
\hline
\end{tabular}

1. A 14.3 wt solution of $\mathrm{Na}_{2} \mathrm{SO}_{4}$ in water was used as the waste simulant.

2. DIW - deionized water.

3. GW - simulated groundwater.

4. Flow Test MCC4S, 1L/day.

5. $\mathrm{HNO}_{3}$ solution.

6. $\mathrm{NaHCO}_{3}$ solution $(0.5 \mathrm{~g} / \mathrm{L})$.

7. Anoxic - simulated anoxic groundwater.

8. EDTA - $100 \mathrm{ppm}$ solution of disodium ethylenediamine tetraacetate dihydrate. 
Sample and Test Parameters for Portland Type I Cement With Incinerator Ash (60 wtz cement, 15 wtz ash, 30 wtz water). Waste-to-Binder Ratio $(w / w)=0.58^{1}$. Samples Contain Co-57, Sr-85 and Cs-137.

\begin{tabular}{|c|c|c|c|c|c|c|c|c|c|}
\hline $\begin{array}{l}\text { Sample } \\
\text { ID }\end{array}$ & $\begin{array}{l}\text { Test } \\
\text { ID }\end{array}$ & $\begin{array}{l}\text { We ight } \\
\text { (g) }\end{array}$ & $\begin{array}{l}\text { Helght } \\
\text { (cm) }\end{array}$ & $\begin{array}{l}\text { Diameter } \\
(\mathrm{cm})\end{array}$ & $\begin{array}{l}\text { Sample } \\
\text { Volume } \\
\left(\mathrm{cm}^{3}\right)\end{array}$ & $\begin{array}{l}\text { Surface } \\
\text { Area }\left(\mathrm{cm}^{2}\right)\end{array}$ & $\begin{array}{l}\text { Leachant } \\
\text { Type }\end{array}$ & $\begin{array}{l}\text { Leachate } \\
\text { Volume }\left(\mathrm{cm}^{3}\right)\end{array}$ & $\begin{array}{c}\text { Temperature } \\
\left({ }^{\circ} \mathrm{C}\right)\end{array}$ \\
\hline 1211 & PAlA & 216.6 & 6.80 & 4.70 & 118 & 135 & $\mathrm{DIW}^{2}$ & 1300 & 20 \\
\hline 1212 & PAIB & 207.2 & 6.45 & 4.70 & 112 & 130 & DIW & 1300 & 20 \\
\hline 1213 & PAIC & 214.8 & 6.50 & 4.60 & 108 & 127 & DIW & 1300 & 20 \\
\hline 1216 & PA1F & 22.9 & 2.60 & 2.50 & 12.8 & 30.2 & DIW & 300 & 20 \\
\hline 1217 & PA1G & 23.3 & 2.60 & 2.50 & 12.8 & 30.2 & DIW & 300 & 20 \\
\hline 1218 & PAlH & 24.0 & 2.70 & 2.50 & 13.2 & 31.0 & DIW & 300 & 20 \\
\hline 1219 & PAlI & 423.3 & 1.50 & 13.9 & 227 & 369 & DIW & 3650 & 20 \\
\hline 1220 & PAIJ & 397.3 & 1.50 & 13.9 & 227 & 369 & DIW & 3650 & 20 \\
\hline 1221 & PAlK & 426.0 & 1.50 & 13.9 & 227 & 369 & DIW & 3650 & 20 \\
\hline 1222 & PA2L & 210.9 & 6.50 & 4.70 & 113 & 131 & DIW & 1300 & 40 \\
\hline 1223 & PA2M & 203.6 & 6.40 & 4.70 & 111 & 129 & DIW & 1300 & 40 \\
\hline 1224 & PA3A & 213.4 & 6.50 & 4.70 & 113 & 131 & DIW & 1300 & 50 \\
\hline 1225 & РA3B & 221.9 & 6.30 & 4.70 & 109 & 128 & DIW & 1300 & 50 \\
\hline 1226 & PA3C & 207.4 & 6.40 & 4.70 & 111 & 129 & DIW & 1300 & 50 \\
\hline
\end{tabular}


Table A2 (cont.)

Sample and Test Parameters for Portland Type I Cement With Incinerator Ash (60 wt8 cement, 15 wtz ash, 30 wt8 water). Waste-to-Binder Ratio $(w / w)-0.581$. Samples Contain Co-57, Sr-85 and Cs-137.

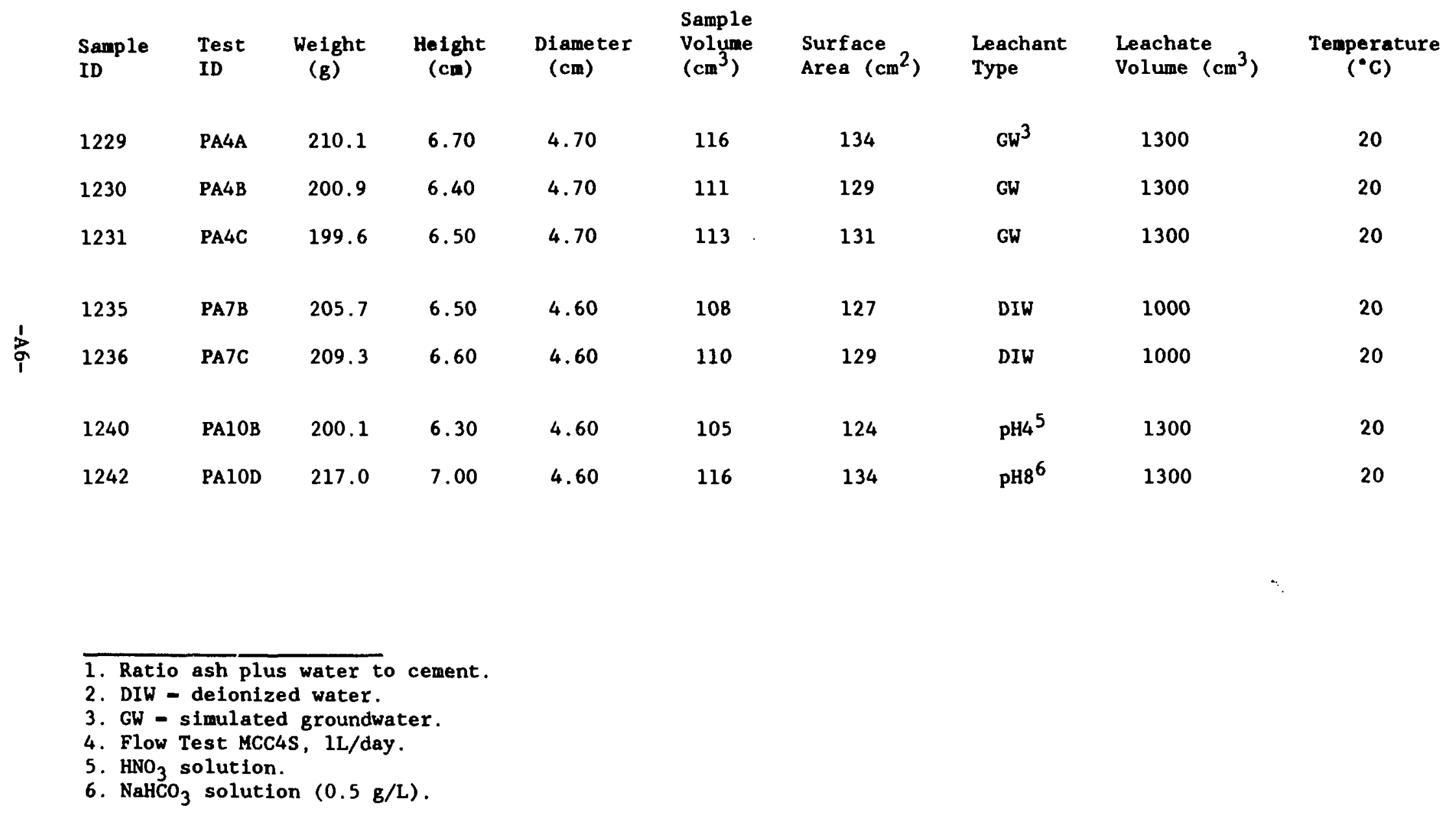


Sample and Test Parameters for Vinyl Ester-Styrene (DOW) Emulsion With Sodium Sulfate (15 wtz) Type Waste. Waste-to-Binder Ratio $(w / w)=1.5^{1}$. Samples Contain Co-57, Sr-85 and Cs-137.

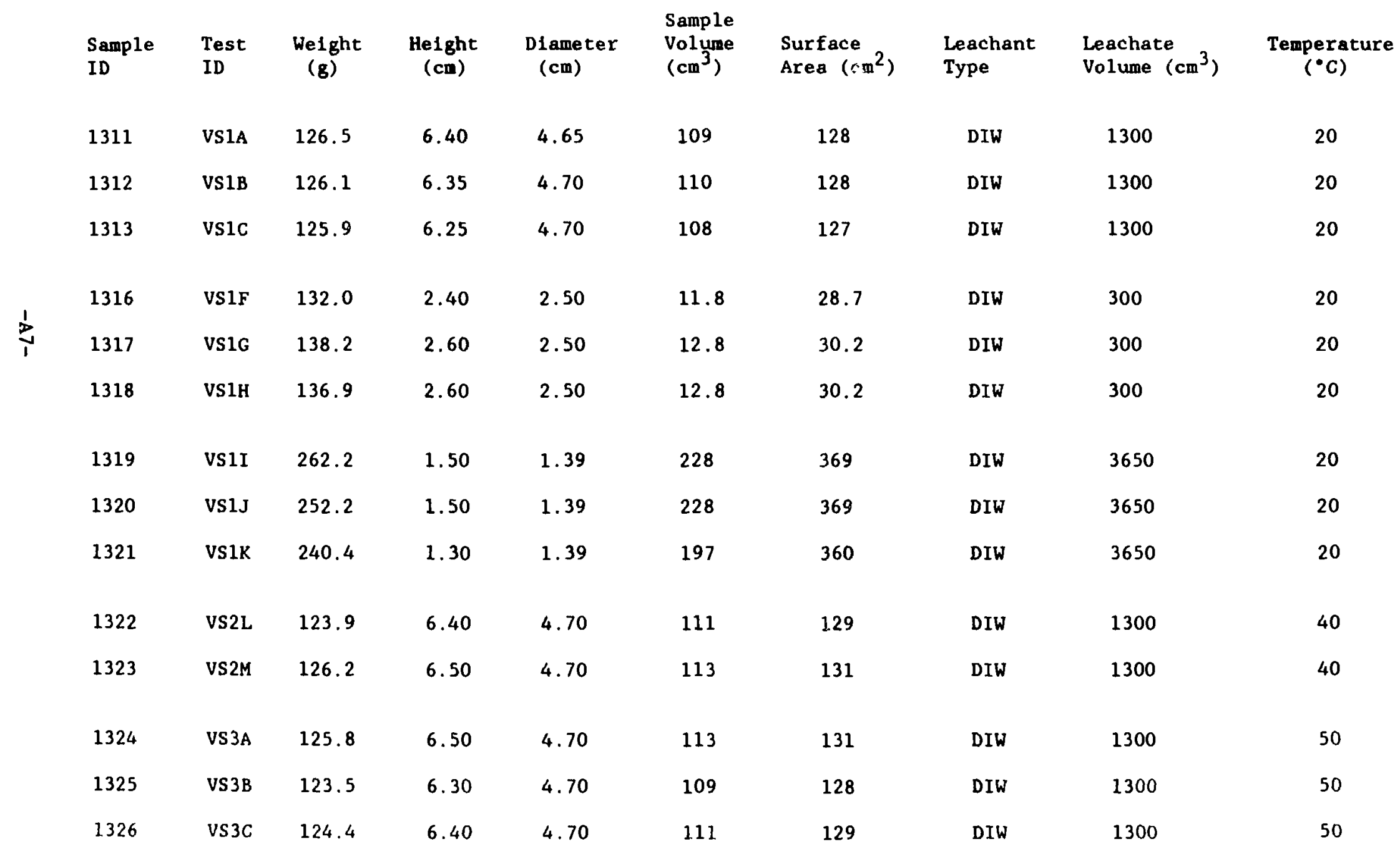


Sample and Test Parameters for Vinyl Ester-Styrene (DOW) Emulsion With Sodium Sulfate (I5 wt 8 ) Type Waste. Waste-to-Binder Ratio $(w / w)=1.5^{1}$. Samples Contain Co-57, Sr-85 and Cs-137.

\begin{tabular}{|c|c|c|c|c|c|c|c|c|c|}
\hline $\begin{array}{l}\text { Sample } \\
\text { ID }\end{array}$ & $\begin{array}{l}\text { Test } \\
\text { ID }\end{array}$ & $\begin{array}{l}\text { Weight } \\
(g)\end{array}$ & $\begin{array}{l}\text { Height } \\
\text { (cn) }\end{array}$ & $\begin{array}{l}\text { Diameter } \\
(\mathrm{cm})\end{array}$ & $\begin{array}{l}\text { Sample } \\
\text { Volume } \\
\left(\mathrm{cm}^{3}\right)\end{array}$ & $\begin{array}{l}\text { Surface } \\
\text { Area }\left(\mathrm{cm}^{2}\right)\end{array}$ & $\begin{array}{l}\text { Leachant } \\
\text { Type }\end{array}$ & $\begin{array}{l}\text { Leachate } \\
\text { Volume }\left(\mathrm{cm}^{3}\right)\end{array}$ & $\begin{array}{c}\text { Temperature } \\
\left({ }^{\circ} \mathrm{C}\right)\end{array}$ \\
\hline 1329 & VS4A & 125.7 & 6.40 & 4.70 & 111 & 129 & $\mathrm{Gw}^{3}$ & 1300 & 20 \\
\hline 1330 & VS4B & 127.0 & 6.40 & 4.70 & 111 & 129 & GW & 1300 & 20 \\
\hline 1331 & VS4C & 130.0 & 6.60 & 4.70 & 114 & 132 & GW & 1300 & 20 \\
\hline 1335 & VS7B & 124.5 & 6.20 & 4.70 & 108 & 126 & DIW $^{4}$ & 1000 & 20 \\
\hline 1336 & vs7C & 124.4 & 6.20 & 4.70 & 108 & 126 & DIW & 1000 & 20 \\
\hline 1340 & VS10B & 124.6 & 6.30 & 4.60 & 105 & 124 & $\mathrm{pH}_{4}^{5}$ & 1300 & 20 \\
\hline 1342 & VS10D & 125.3 & 6.30 & 4.60 & 105 & 124 & $\mathrm{pH}^{6}$ & 1300 & 20 \\
\hline
\end{tabular}

1. Prepared using a 25 wt solution of sodium sulfate.

2. DIW - deionized water.

3. GW - simulated groundwater.

4. Flow Test MCC4S, 1L/day.

5. $\mathrm{HNO}_{3}$ solution.

6. $\mathrm{NaHCO}_{3}$ solution $(0.5 \mathrm{~g} / \mathrm{L})$. 
Sample and Test Parameters for Vinyl Ester-Styrene (DOW) With Sodium Sulfate (20 wtz) Type Waste ${ }^{1}$. Waste-to-Binder Ratio $(w / w)=0.25$. Samples Contain Co-57, Sr-85, Cs-137.

$\begin{array}{llcccccccc}\begin{array}{l}\text { Sample } \\ \text { ID }\end{array} & \begin{array}{l}\text { Test } \\ \text { ID }\end{array} & \begin{array}{c}\text { Weight } \\ (\mathrm{g})\end{array} & \begin{array}{c}\text { Height } \\ (\mathrm{cm})\end{array} & \begin{array}{c}\text { Diameter } \\ (\mathrm{cm})\end{array} & \begin{array}{l}\text { Sample } \\ \text { Volume } \\ \left(\mathrm{cm}^{3}\right)\end{array} & \begin{array}{l}\text { Surface } \\ \text { Area }\left(\mathrm{cm}^{2}\right)\end{array} & \begin{array}{l}\text { Leachant } \\ \text { Type }\end{array} & \begin{array}{l}\text { Leachate } \\ \text { Volume }\left(\mathrm{cm}^{3}\right)\end{array} & \begin{array}{c}\text { Teaperature } \\ \left({ }^{\circ} \mathrm{C}\right)\end{array} \\ 1451 & \text { V2S1A } & 124.7 & 6.20 & 4.50 & 98.6 & 120 & \text { DIW } & 1300 & 20 \\ 1452 & \text { V2S3A } & 124.7 & 6.30 & 4.60 & 105 & 124 & \text { DIW } & 1300 & 50 \\ 1454 & \text { V2S7A } & 16.8 & 3.00 & 2.40 & 13.6 & 31.7 & \text { DIW } & 300 & 20 \\ 1455 & \text { V2S12A } & 20.3 & 3.60 & 2.40 & 16.3 & 36.2 & \text { DIW } & 300 & 50\end{array}$

1. Anhydrous salt.

2. DIW - deionized water. 
Table A5

Sample and Test Parameters for Vinyl Ester-Styrene (DOW) and Sodium Sulfate ( 30 wt 8 ) Type Waste. 1 Waste-to-Binder Ratio $(w / w)=0.43$. Samples Contain Co-57, Sr-85, Cs-137.

\begin{tabular}{|c|c|c|c|c|c|c|c|c|c|}
\hline $\begin{array}{l}\text { Sample } \\
\text { ID }\end{array}$ & $\begin{array}{l}\text { Test } \\
\text { ID }\end{array}$ & $\begin{array}{l}\text { Weight } \\
\text { (g) }\end{array}$ & $\begin{array}{l}\text { Helght } \\
\text { (cn) }\end{array}$ & $\begin{array}{l}\text { DLameter } \\
(\mathrm{cm})\end{array}$ & $\begin{array}{l}\text { Sample } \\
\text { Volume } \\
\left(\mathrm{cm}^{3}\right)\end{array}$ & $\begin{array}{l}\text { Surface } \\
\text { Area }\left(\mathrm{cm}^{2}\right)\end{array}$ & $\begin{array}{l}\text { Leachant } \\
\text { Type }\end{array}$ & $\begin{array}{l}\text { Leachate } \\
\text { Volume }\left(\mathrm{cm}^{3}\right)\end{array}$ & $\begin{array}{c}\text { Temperature } \\
\left({ }^{\circ} \mathrm{C}\right)\end{array}$ \\
\hline 1551 & V3SIA & 127 & 6.25 & 4.50 & 99.4 & 120 & $\mathrm{DIW}^{2}$ & 1300 & 20 \\
\hline 1552 & V3S3B & 124 & 6.20 & 4.60 & 103 & 123 & DIW & 1300 & 50 \\
\hline 1554 & V3S7A & 18.2 & 3.10 & 2.40 & 14.2 & 32.4 & DIW & 300 & 20 \\
\hline 1555 & V3S12A & 17.5 & 3.10 & 2.40 & 14.2 & 32.4 & DIW & 300 & 50 \\
\hline
\end{tabular}

1. Anhydrous salt.

2. DIW - jelonized water. 
Sample and Test Parameters for Vinyl Ester-Styrene (DOW) W1th Sodiun Sulfate (40 wt $)$ Type Waste. Waste-to-Binder Ratio $(w / w)=0.67$. Samples Contain Co-57, Sr-85 and Cs-137.

\begin{tabular}{|c|c|c|c|c|c|c|c|c|c|}
\hline $\begin{array}{l}\text { Sample } \\
\text { ID }\end{array}$ & $\begin{array}{l}\text { Test } \\
\text { ID }\end{array}$ & $\begin{array}{l}\text { Weight } \\
\text { (g) }\end{array}$ & $\begin{array}{l}\text { Height } \\
(\mathrm{cm})\end{array}$ & $\begin{array}{l}\text { Diameter } \\
(\mathrm{cm})\end{array}$ & $\begin{array}{l}\text { Sample } \\
\text { Volume } \\
\left(\mathrm{cm}^{3}\right)\end{array}$ & $\begin{array}{l}\text { Surface } \\
\text { Area }\left(\mathrm{cm}^{2}\right)\end{array}$ & $\begin{array}{l}\text { Leachant } \\
\text { Type }\end{array}$ & $\begin{array}{l}\text { Leachate } \\
\text { Volume }\left(\mathrm{cm}^{3}\right)\end{array}$ & $\begin{array}{c}\text { Temperature } \\
\text { ("C) }\end{array}$ \\
\hline 1611 & VDS1A & 145.5 & 6.40 & 4.50 & 102 & 122 & $\mathrm{DIW}^{2}$ & 1300 & 20 \\
\hline 1612 & vDS1B & 144.4 & 6.30 & 4.60 & 105 & 124 & DIW & 1300 & 20 \\
\hline 1613 & VDS1C & 146.6 & 6.50 & 4.60 & 108 & 127 & DIW & 1300 & 20 \\
\hline 1616 & VDS1F & 16.5 & 2.70 & 2.30 & 11.2 & 27.8 & DIW & 300 & 20 \\
\hline 1617 & VDS1G & 15.8 & 2.60 & 2.40 & 11.7 & 28.6 & DIW & 300 & 20 \\
\hline 1618 & VDS1H & 15.7 & 2.60 & 2.40 & 11.7 & 28.6 & DIW & 300 & 20 \\
\hline 1619 & VDS1I & 289.8 & 1.60 & 13.8 & 239 & 369 & DIW & 3650 & 20 \\
\hline 1620 & VDS1J & 292.3 & 1.70 & 13.8 & 254 & 373 & DIW & 3650 & 20 \\
\hline 1621 & VDS1K & 263.1 & 1.40 & 13.8 & 200 & 346 & DIW & 3650 & 20 \\
\hline 1622 & VDS2L & 145.2 & 6.20 & 4.50 & 98.6 & 120 & DIW & 1300 & 40 \\
\hline 1623 & VDS2M & 142.0 & 6.40 & 4.50 & 102 & 122 & DIW & 1300 & 40 \\
\hline 1624 & $\operatorname{VDS} 3 A$ & 145.2 & 6.40 & 4.50 & 102 & 122 & DIW & 1300 & 50 \\
\hline 1625 & VDS3B & 142.4 & 6.60 & 4.50 & 105 & 125 & DIW & 1300 & 50 \\
\hline 1626 & VDS3C & 148.5 & 6.50 & 4.50 & 103 & 124 & DIW & 1300 & 50 \\
\hline
\end{tabular}


Table A6 (cont.)

Sample and Test Parameters for Vinyl Ester-Styrene (DOW) With Sodium Sulfate (40 wt ) Type Waste. Waste-to-Binder Ratio $(w / w)-0.67$. Samples Contailil Co-57, Sr-85 and Cs-137. 1

\begin{tabular}{|c|c|c|c|c|c|c|c|c|c|}
\hline $\begin{array}{l}\text { Sample } \\
\text { ID }\end{array}$ & $\begin{array}{l}\text { Test } \\
\text { ID }\end{array}$ & $\begin{array}{l}\text { Weight } \\
(\mathrm{g})\end{array}$ & $\begin{array}{l}\text { Height } \\
\text { (cm) }\end{array}$ & $\begin{array}{l}\text { Diameter } \\
(\mathrm{cm})\end{array}$ & $\begin{array}{l}\text { Sample } \\
\text { Volume } \\
\left(\mathrm{cm}^{3}\right)\end{array}$ & $\begin{array}{l}\text { Surface } \\
\text { Area }\left(\mathrm{cm}^{2}\right)\end{array}$ & $\begin{array}{l}\text { Leachant } \\
\text { Type }\end{array}$ & $\begin{array}{l}\text { Leachate } \\
\text { Volume }\left(\mathrm{cm}^{3}\right)\end{array}$ & $\begin{array}{c}\text { Temperature } \\
\left({ }^{\circ} \mathrm{C}\right)\end{array}$ \\
\hline 1629 & VDS4A & 143.0 & 6.20 & 4.60 & 103 & 123 & $G w^{3}$ & 1300 & 20 \\
\hline 1630 & VDS4B & 146.1 & 6.40 & 4.60 & 106 & 126 & GW & 1300 & 20 \\
\hline 1631 & VDS4C & 146.4 & 6.40 & 4.60 & 106 & 126 & GW & 1300 & 20 \\
\hline 1634 & VDS7A & 141.9 & 6.30 & 4.50 & 100 & 121 & $\mathrm{DIW}^{4}$ & 1000 & 20 \\
\hline 1635 & VDS7B & 145.9 & 6.40 & 4.50 & 102 & 122 & DIW & 1000 & 20 \\
\hline 1636 & VDS7C & 148.1 & 6.50 & 4.50 & 103 & 124 & DIW & 1000 & 20 \\
\hline 1637 & VDS6A & 148.0 & 6.50 & 4.60 & 108 & 127 & DIW & 2600 & 20 \\
\hline 1638 & VDS6B & 145.4 & 6.30 & 4.70 & 109 & 128 & DIW & 3900 & 20 \\
\hline 1639 & VDS10A & 145.5 & 6.30 & 4.60 & 105 & 124 & $\mathrm{pH}^{5}$ & 1300 & 20 \\
\hline 1640 & VDS10B & 146.2 & 6.30 & 4.50 & 100 & 121 & $\mathrm{pH}^{5}$ & 1300 & 20 \\
\hline 1641 & VDS10C & 147.7 & 6.30 & 4.50 & 100 & 121 & $\mathrm{pH}^{5}$ & 1300 & 20 \\
\hline 1642 & VDS10D & 143.0 & 6.30 & 4.60 & 105 & 124 & pH10 6 & 1300 & 20 \\
\hline
\end{tabular}


Sample and Test Parameters for Vinyl Ester-Styrene (DOW) With Sodium Sulfate (40 wtz) Type Waste. Waste-to-Binder Ratio $(w / w)=0.67$. Samples Contain Co-57, Sr-85 and Cs-137.1

\begin{tabular}{|c|c|c|c|c|c|c|c|c|c|}
\hline $\begin{array}{l}\text { Sample } \\
\text { ID }\end{array}$ & $\begin{array}{l}\text { Test } \\
\text { ID }\end{array}$ & $\begin{array}{l}\text { Weight } \\
\text { (g) }\end{array}$ & $\begin{array}{l}\text { Height } \\
(\mathrm{cm})\end{array}$ & $\begin{array}{l}\text { Diameter } \\
(\mathrm{cm})\end{array}$ & $\begin{array}{l}\text { Sample } \\
\text { Volume } \\
\left(\mathrm{cm}^{3}\right)\end{array}$ & $\begin{array}{l}\text { Surface } \\
\text { Area }\left(\mathrm{cm}^{2}\right)\end{array}$ & $\begin{array}{l}\text { Leachant } \\
\text { Type }\end{array}$ & $\begin{array}{l}\text { Leachate } \\
\text { Volume }\left(\mathrm{cm}^{3}\right)\end{array}$ & $\begin{array}{c}\text { Temperature } \\
\left({ }^{\circ} \mathrm{C}\right)\end{array}$ \\
\hline 1650 & V4S2A & 138.2 & 6.20 & 4.60 & 103 & 123 & ANOXIC $^{7}$ & 1300 & 20 \\
\hline 1651 & V4S2B & 143.9 & 6.30 & 4.70 & 109 & 128 & ANOXIC & 1300 & 20 \\
\hline 1652 & V4S2C & 145.0 & 6.30 & 4.70 & 109 & 128 & ANOXIC & 1300 & 20 \\
\hline 1660 & V4S5A & 144.9 & 6.30 & 4.50 & 100 & 121 & DIW & 1300 & 20 \\
\hline 1661 & V4S5B & 141.6 & 6.20 & 4.50 & 98.6 & 120 & DIW & 1300 & 20 \\
\hline 1662 & V4S5C & 146.6 & 6.30 & 4.50 & 100 & 121 & DIW & 1300 & 20 \\
\hline 1663 & V4S8A & 144.3 & 6.20 & 4.70 & 108 & 126 & DIW & 3900 & 20 \\
\hline 1664 & V4S8B & 141.8 & 6.40 & 4.60 & 106 & 126 & DIW & 3900 & 20 \\
\hline 1665 & V4S8C & 139.7 & 6.10 & 4.60 & 101 & 121 & DIW & 3900 & 20 \\
\hline 1666 & V4S9A & 147.6 & 6.30 & 4.60 & 105 & 124 & DIW & 6500 & 20 \\
\hline 1667 & V4S9B & 144.8 & 6.20 & 4.50 & 98.6 & 120 & DIW & 6500 & 20 \\
\hline 1668 & V4S9C & 148.3 & 6.40 & 4.60 & 106 & 126 & DIW & 6500 & 20 \\
\hline
\end{tabular}


Sample and Test Parameters for Vinyl Ester-Styrene (DOW) With Sodium Sulfate (40 wt8) Type Waste. Waste-to-Binder Ratio $(w / w)-0.67$. Samples Contain Co-57, Sr-85 and Cs-137. 1

\begin{tabular}{|c|c|c|c|c|c|c|c|c|c|}
\hline $\begin{array}{l}\text { Sample } \\
\text { ID }\end{array}$ & $\begin{array}{l}\text { Test } \\
\text { ID }\end{array}$ & $\begin{array}{l}\text { Weight } \\
\text { (g) }\end{array}$ & $\begin{array}{l}\text { Helght } \\
(\mathrm{cm})\end{array}$ & $\begin{array}{l}\text { Diameter } \\
(\mathrm{cm})\end{array}$ & $\begin{array}{l}\text { Sample } \\
\text { Volume } \\
\left(\mathrm{cm}^{3}\right)\end{array}$ & $\begin{array}{l}\text { Surface } \\
\text { Area }\left(\mathrm{cm}^{2}\right)\end{array}$ & $\begin{array}{l}\text { Leachant } \\
\text { Type }\end{array}$ & $\begin{array}{l}\text { Leachate } \\
\text { Volune }\left(\mathrm{cm}^{3}\right)\end{array}$ & $\begin{array}{l}\text { Temperature } \\
\left({ }^{\circ} \mathrm{C}\right)\end{array}$ \\
\hline 1669 & V4S11A & 139.8 & 6.00 & 4.60 & 99.7 & 120 & EDTA $^{8}$ & 1300 & 20 \\
\hline 1670 & V4S11B & 147.9 & 6.30 & 4.60 & 105 & 124 & EDTA & 1300 & 20 \\
\hline 1671 & V4silc & 144.2 & 6.10 & 4.60 & 101 & 121 & EDTA & 1300 & 20 \\
\hline 1672 & V4S12A & 16.7 & 2.70 & 2.40 & 12.2 & 29.4 & DIW & 300 & 20 \\
\hline 1673 & V4S12B & 16.0 & 2.60 & 2.40 & 11.8 & 28.6 & DIW & 300 & 20 \\
\hline 1674 & V4S12C & 15.4 & 2.40 & 2.40 & 10.9 & 27.1 & DIW & 300 & 20 \\
\hline
\end{tabular}

1. Anhydrous salt.

2. DIW - deionized water.

3. GW - groundwater.

4. Flow Test MCC4S, 1L/day.

5. $\mathrm{HNO}_{3}$ solution.

6. $\mathrm{NaHCO}_{3}$ solution $(0.5 \mathrm{~B} / \mathrm{L})$.

7. Anoxic - simulated anoxic groundwater.

8. EDTA - $100 \mathrm{ppm}$ solution of disodium ethylenediamine tetraacetate dihyrate. 
Sample and Test Parameters for Bitumen With Sodium Tetraborate (20 wtz) Type Waste ${ }^{1}$. Waste-to-Binder Ratio $(w / w)-0.25$. Samples Contain Co-57, Sr-85 and Cs-137.

\begin{tabular}{|c|c|c|c|c|c|c|c|c|c|}
\hline $\begin{array}{l}\text { Sample } \\
\text { ID }\end{array}$ & $\begin{array}{l}\text { Test } \\
\text { ID }\end{array}$ & $\begin{array}{l}\text { Weight } \\
\text { (g) }\end{array}$ & $\begin{array}{l}\text { Helght } \\
\text { (cm) }\end{array}$ & $\begin{array}{l}\text { Diameter } \\
(\mathrm{cm})\end{array}$ & $\begin{array}{l}\text { Sample } \\
\text { Volume } \\
\left(\mathrm{cm}^{3}\right)\end{array}$ & $\begin{array}{l}\text { Surface } \\
\text { Area }\left(\mathrm{cm}^{2}\right)\end{array}$ & $\begin{array}{l}\text { Leachant } \\
\text { Type }\end{array}$ & $\begin{array}{l}\text { Leachate } \\
\text { Volume }\left(\mathrm{cm}^{3}\right)\end{array}$ & $\begin{array}{c}\text { Teaperature } \\
\left({ }^{\circ} \mathrm{C}\right)\end{array}$ \\
\hline 1711 & B2B1A & 110.3 & 6.10 & 4.80 & 110 & 128 & $\mathrm{DIW}^{2}$ & 1300 & 20 \\
\hline 1712 & B2B1B & 110.1 & 6.10 & 4.60 & 101 & 121 & DIW & 1300 & 20 \\
\hline 1713 & B2B1C & 110.0 & 6.10 & 4.70 & 106 & 125 & DIW & 1300 & 20 \\
\hline 1716 & B2B1F & 12.0 & 2.60 & 2.40 & 11.8 & 28.6 & DIW & 300 & 20 \\
\hline 1717 & B2B1G & 12.8 & 2.60 & 2.40 & 11.8 & 28.6 & DIW & 300 & 20 \\
\hline 1718 & B2B1H & 14.1 & 2.90 & 2.40 & 13.1 & 30.9 & DIW & 300 & 20 \\
\hline 1719 & B2B1I & 127.9 & 2.00 & 10.8 & 183 & 251 & DIW & 2725 & 20 \\
\hline 1720 & B2B1J & 140.6 & 2.00 & 11.0 & 190 & 259 & DIW & 2725 & 20 \\
\hline 1721 & B2B1K & 175.3 & 2.50 & 11.5 & 260 & 298 & DIW & 2725 & 20 \\
\hline 1722 & B2B2L & 114.3 & 6.10 & 4.60 & 101 & 121 & DIW & 1300 & 40 \\
\hline 1723 & B2B2M & 112.9 & 6.10 & 4.60 & 101 & 121 & DIW & 1300 & 40 \\
\hline 1724 & B2B3A & 113.3 & 6.20 & 4.70 & 108 & 126 & DIW & 1300 & 50 \\
\hline 1725 & B2B3B & 115.1 & 6.10 & 4.50 & 90.7 & 118 & DIW & 1300 & 50 \\
\hline 1726 & B2B 3C & 110.3 & 6.00 & 4.50 & 95.3 & 117 & DIW & 1300 & 50 \\
\hline
\end{tabular}


Sample and Test Parameters for Bitumen With Sodium Tetraborate (20 wt 8 ) Type Waste ${ }^{1}$. Waste-to-Binder Ratio $(w / w)=0.25$. Samples Contain Co-57, Sr-85 and Cs-137.

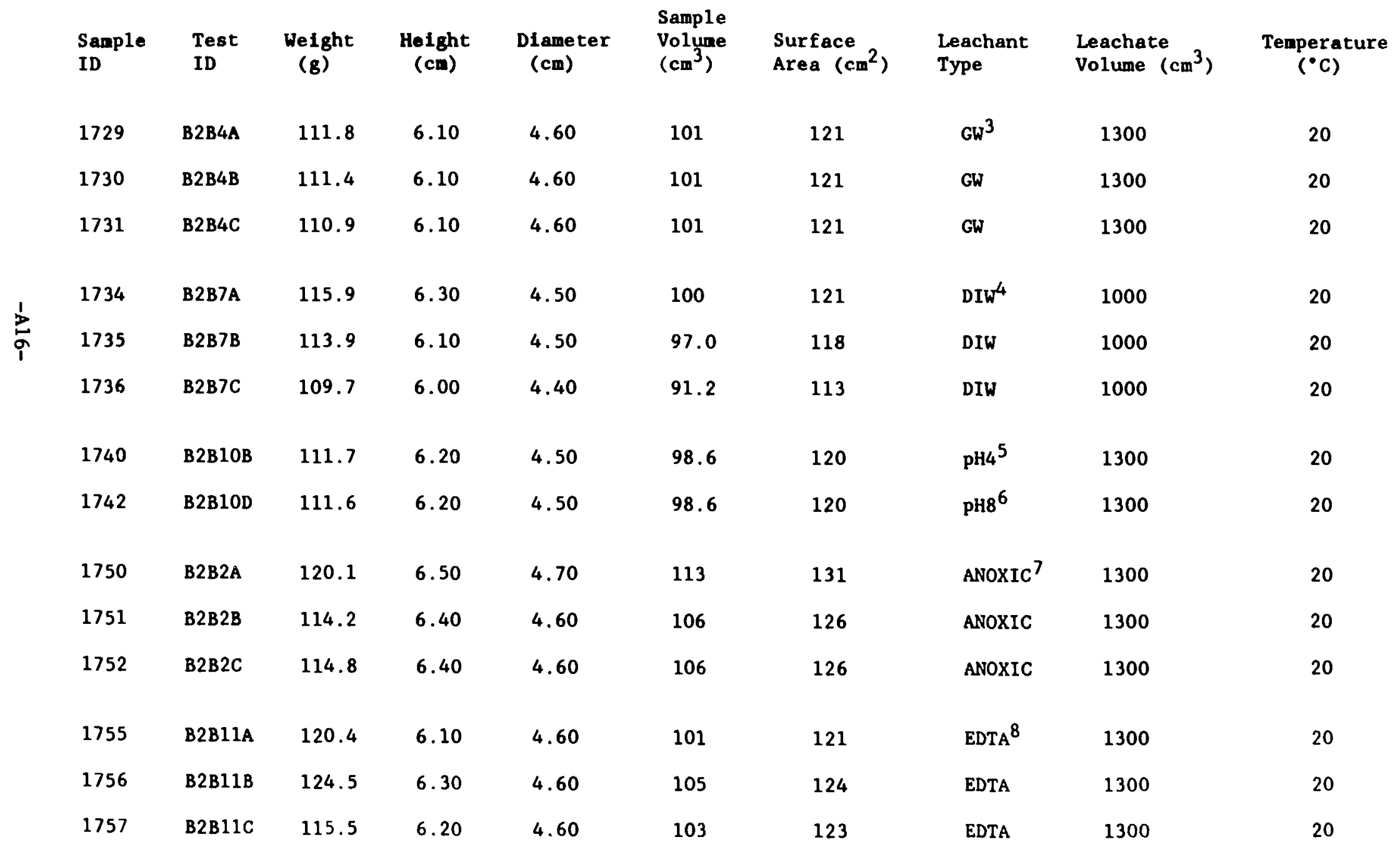


Sample and Test Parameters for Bitumen With Sodium Tetraborate (20 wt 8 ) Type Waste 1 .

Waste-to-Binder Ratio $(w / w)=0.25$. Samples Contain Co-57, Sr-85 and Cs-137.

\begin{tabular}{|c|c|c|c|c|c|c|c|c|c|}
\hline $\begin{array}{l}\text { Sample } \\
\text { ID }\end{array}$ & $\begin{array}{l}\text { Test } \\
\text { ID }\end{array}$ & $\begin{array}{l}\text { Weight } \\
(\mathrm{g})\end{array}$ & $\begin{array}{l}\text { Height } \\
\text { (cm) }\end{array}$ & $\begin{array}{l}\text { Diameter } \\
(\mathrm{cm})\end{array}$ & $\begin{array}{l}\text { Sample } \\
\text { Volume } \\
\left(\mathrm{cm}^{3}\right)\end{array}$ & $\begin{array}{l}\text { Surface } \\
\text { Area }\left(\mathrm{cm}^{2}\right)\end{array}$ & $\begin{array}{l}\text { Leachant } \\
\text { Type }\end{array}$ & $\begin{array}{l}\text { Leachate } \\
\text { Volume }\left(\mathrm{cm}^{3}\right)\end{array}$ & $\begin{array}{c}\text { Temperature } \\
\left({ }^{\circ} \mathrm{C}\right)\end{array}$ \\
\hline 1758 & B2B12A & 16.6 & 3.10 & 2.40 & 14.2 & 32.4 & DIW & 300 & 50 \\
\hline 1759 & B2B12B & 12.8 & 2.40 & 2.40 & 10.9 & 27.1 & DIW & 300 & 50 \\
\hline 1760 & B2B12C & 14.7 & 2.80 & 2.40 & 12.7 & 30.2 & DIW & 300 & 50 \\
\hline
\end{tabular}

1. Anhydrous salt.

2. DIW - delonized water.

3. GW = simulated groundwater.

4. Flow Test MCC4S, 1L/day.

5. $\mathrm{HNO}_{3}$ solution.

6. $\mathrm{NaHCO}_{3}$ solution $(0.5 \mathrm{~g} / \mathrm{L})$.

7. Anoxic - simulated anoxic groundwater.

8. EDTA - 100 ppm solution of disodium ethylenediamine tetraacetate dihydrate. 
Sample and Test Parameters for Bitumen With Sodium Tetraborate (30 wt 8 ) Type Waste ${ }^{1}$. Waste-to-Binder Ratio $(w / w)-0.43$. Samples Contain Co-57, Sr-85 and Cs-137.

\begin{tabular}{|c|c|c|c|c|c|c|c|c|c|}
\hline $\begin{array}{l}\text { Sample } \\
\text { ID }\end{array}$ & $\begin{array}{l}\text { Test } \\
\text { ID }\end{array}$ & $\begin{array}{l}\text { Weight } \\
(\mathrm{g})\end{array}$ & $\begin{array}{l}\text { Helght } \\
\text { (ca) }\end{array}$ & $\begin{array}{l}\text { Diameter } \\
(\mathrm{cm})\end{array}$ & $\begin{array}{l}\text { Sample } \\
\text { Volume } \\
\left(\mathrm{cm}^{3}\right)\end{array}$ & $\begin{array}{l}\text { Surface } \\
\text { Area }\left(\mathrm{cm}^{2}\right)\end{array}$ & $\begin{array}{l}\text { Leachant } \\
\text { Type }\end{array}$ & $\begin{array}{l}\text { Leachate } \\
\text { Volume }\left(\mathrm{cm}^{3}\right)\end{array}$ & $\begin{array}{c}\text { Temperature } \\
\left({ }^{\circ} \mathrm{C}\right)\end{array}$ \\
\hline 1851 & B3B1A & 124.6 & 6.10 & 4.50 & 97.0 & 118 & $\mathrm{DIW}^{2}$ & 1300 & 20 \\
\hline 1852 & B3B1B & 129.4 & 6.30 & 4.50 & 100 & 121 & DIW & 1300 & 20 \\
\hline 1853 & B3B1C & 138.1 & 6.70 & 4.50 & 107 & 126 & DIW & 1300 & 20 \\
\hline 1854 & B3B3A & 132.4 & 6.60 & 4.60 & 110 & 129 & DIW & 1300 & 50 \\
\hline 1855 & B3B3B & 128.8 & 6.30 & 4.60 & 105 & 124 & DIW & 1300 & 50 \\
\hline 1856 & B3B3C & 131.7 & 6.50 & 4.60 & 108 & 127 & DIW & 1300 & 50 \\
\hline 1857 & B3B7A & 14.0 & 2.30 & 2.40 & 10.4 & 26.4 & DIW & 300 & 20 \\
\hline 1858 & B3B7B & 14.4 & 2.50 & 2.40 & 11.3 & 27.9 & DIW & 300 & 20 \\
\hline 1859 & B 3B7C & 13.3 & 2.40 & 2.40 & 10.9 & 27.1 & DIW & 300 & 20 \\
\hline 1860 & B3B12A & 13.3 & 2.40 & 2.40 & 10.9 & 27.1 & DIW & 300 & 50 \\
\hline 1861 & B3B12B & 14.9 & 2.60 & 2.40 & 11.8 & 28.6 & DIW & 300 & 50 \\
\hline 1862 & B3B12C & 14.1 & 2.50 & 2.40 & 11.3 & 27.9 & DIW & 300 & 50 \\
\hline
\end{tabular}


Sample and Test Parameters for Bitumen with Sodium Tetraborate (40 wtz) Type Waste ${ }^{1}$.

Waste-to-Binder Ratio $(w / w)-0.67$. Samples Contain Co-57, Sr-85 and Cs-137.

\begin{tabular}{|c|c|c|c|c|c|c|c|c|c|}
\hline $\begin{array}{l}\text { Sample } \\
\text { ID }\end{array}$ & $\begin{array}{l}\text { Test } \\
\text { ID }\end{array}$ & $\begin{array}{l}\text { We ight } \\
\text { (g) }\end{array}$ & $\begin{array}{l}\text { Height } \\
(\mathrm{cm})\end{array}$ & $\begin{array}{l}\text { Diameter } \\
(\mathrm{cm})\end{array}$ & $\begin{array}{l}\text { Sample } \\
\text { Volume } \\
\left(\mathrm{cm}^{3}\right)\end{array}$ & $\begin{array}{l}\text { Surface } \\
\text { Area }\left(\mathrm{cm}^{2}\right)\end{array}$ & $\begin{array}{l}\text { Leachant } \\
\text { Type }\end{array}$ & $\begin{array}{l}\text { Leachate } \\
\text { Volume }\left(\mathrm{cm}^{3}\right)\end{array}$ & $\begin{array}{c}\text { Temperature } \\
\left({ }^{\circ} \mathrm{C}\right)\end{array}$ \\
\hline 1911 & BB1A & 127.3 & 6.00 & 4.65 & 102 & 122 & $\mathrm{DIW}^{2}$ & 1300 & 20 \\
\hline 1912 & BB1B & 129.0 & 6.25 & 4.70 & 108 & 127 & DIW & 1300 & 20 \\
\hline 1913 & $\mathrm{BB} 1 \mathrm{C}$ & 130.8 & 6.25 & 4.60 & 104 & 124 & DIW & 1300 & 20 \\
\hline 1916 & BB1F & 13.5 & 2.60 & 2.50 & 12.8 & 30.2 & DIW & 300 & 20 \\
\hline 1917 & BB1G & 12.7 & 2.60 & 2.50 & 12.8 & 30.2 & DIW & 300 & 20 \\
\hline 1918 & BB1H & 14.2 & 2.70 & 2.50 & 13.2 & 31.0 & DIW & 300 & 20 \\
\hline 1919 & BB1I & 188.2 & 1.50 & 118 & 164 & 274 & DIW & 2725 & 20 \\
\hline 1920 & BB1J & 190.8 & 1.60 & 117 & 172 & 274 & DIW & 2725 & 20 \\
\hline 1921 & BB1K & 188.6 & 1.60 & 116 & 169 & 270 & DIW & 2725 & 20 \\
\hline 1922 & BB2I & 129.1 & 6.20 & 4.70 & 108 & 126 & DIW & 1300 & 40 \\
\hline 1923 & BB 2M & 126.5 & 6.30 & 4.70 & 109 & 128 & DIW & 1300 & 40 \\
\hline
\end{tabular}


Sample and Test Parameters for Bitumen With Sodium Tetraborate (40 wt8) Type Waste ${ }^{1}$. Waste-to-Binder Ratio $(w / w)=0.67$. Samples Contain Co-57, Sr-85 and Cs-137.

\begin{tabular}{|c|c|c|c|c|c|c|c|c|c|}
\hline $\begin{array}{l}\text { Sample } \\
\text { ID }\end{array}$ & $\begin{array}{l}\text { Test } \\
\text { ID }\end{array}$ & $\begin{array}{l}\text { Weight } \\
\text { (g) }\end{array}$ & $\begin{array}{l}\text { Height } \\
\text { (cn) }\end{array}$ & $\begin{array}{l}\text { Dlameter } \\
\text { (cn) }\end{array}$ & $\begin{array}{l}\text { Sample } \\
\text { Volume } \\
\left(\mathrm{cm}^{3}\right)\end{array}$ & $\begin{array}{l}\text { Surface } \\
\text { Area }\left(\mathrm{cm}^{2}\right)\end{array}$ & $\begin{array}{l}\text { Leachant } \\
\text { Type }\end{array}$ & $\begin{array}{l}\text { Leachate } \\
\text { Volume }\left(\mathrm{cm}^{3}\right)\end{array}$ & $\begin{array}{c}\text { Tenperature } \\
\left({ }^{\circ} \mathrm{C}\right)\end{array}$ \\
\hline 1924 & BB3A & 132.6 & 6.30 & 4.70 & 109 & 128 & DIW & 1300 & 50 \\
\hline 1925 & BB3B & 130.4 & 6.30 & 4.70 & 109 & 128 & DIW & 1300 & 50 \\
\hline 1926 & BB3C & 131.9 & 6.40 & 4.70 & 111 & 129 & DIW & 1300 & 50 \\
\hline 1929 & BB4A & 132.2 & 6.10 & 4.60 & 101 & 121 & $\mathrm{GW}^{3}$ & 1300 & 20 \\
\hline 1930 & BB4B & 132.6 & 6.20 & 4.60 & 103 & 123 & GW & 1300 & 20 \\
\hline 1931 & BB4C & 127.1 & 6.10 & 4.60 & 101 & 121 & GW & 1300 & 20 \\
\hline 1935 & BB7B & 131.6 & 6.20 & 4.70 & 108 & 126 & DIW ${ }^{4}$ & 1000 & 20 \\
\hline 1936 & BB7C & 128.7 & 6.00 & 4.60 & 99.7 & 120 & DIW & 1000 & 20 \\
\hline 1940 & BB10B & 124.8 & 6.00 & 4.50 & 95.4 & 117 & $\mathrm{pH}^{5}$ & 1300 & 20 \\
\hline 1942 & BB10D & 128.2 & 6.10 & 4.60 & 101 & 121 & $\mathrm{pH} 8^{6}$ & 1300 & 20 \\
\hline 1950 & B4B2A & 127.3 & 6.00 & 4.50 & 95.4 & 111 & ANOXIC 7 & 1300 & 20 \\
\hline 1951 & B4B2B & 134.1 & 6.30 & 4.60 & 105 & 124 & ANOXIC & 1300 & 20 \\
\hline 1952 & B4B2C & 141.4 & 6.60 & 4.60 & 110 & 129 & ANOXIC & 1300 & 20 \\
\hline
\end{tabular}


Table A9 (cont.)

Sample and Test Parameters for Bitumen With Sodium Tetraborate (40 wtz) Type Waste ${ }^{1}$. Waste-to-Binder Ratio $(w / w)=0.67$. Samples Contain Co-57, Sr-85 and Gs-137.

\begin{tabular}{|c|c|c|c|c|c|c|c|c|c|}
\hline $\begin{array}{l}\text { Sample } \\
\text { ID }\end{array}$ & $\begin{array}{l}\text { Test } \\
\text { ID }\end{array}$ & $\begin{array}{l}\text { Weight } \\
\text { (g) }\end{array}$ & $\begin{array}{l}\text { Height } \\
(\mathrm{cm})\end{array}$ & $\begin{array}{l}\text { Diameter } \\
\text { (cm) }\end{array}$ & $\begin{array}{l}\text { Sample } \\
\text { Volume } \\
\left(\mathrm{cm}^{3}\right)\end{array}$ & $\begin{array}{l}\text { Surface } \\
\text { Area }\left(\mathrm{cm}^{2}\right)\end{array}$ & $\begin{array}{l}\text { Leachant } \\
\text { Type }\end{array}$ & $\begin{array}{l}\text { Leachate } \\
\text { Volume }\left(\mathrm{cm}^{3}\right)\end{array}$ & $\begin{array}{c}\text { Temperature } \\
\left({ }^{\circ} \mathrm{C}\right)\end{array}$ \\
\hline 1960 & B4B5A & 137.6 & 6.10 & 4.50 & 97.0 & 118 & DIW & 1300 & 20 \\
\hline 1961 & B4B5B & 138.1 & 6.20 & 4.50 & 98.6 & 120 & DIW & 1300 & 20 \\
\hline 1962 & B4B5C & 137.4 & 6.10 & 4.50 & 97.0 & 118 & DIW & 1300 & 20 \\
\hline 1963 & B4B8A & 139.1 & 6.40 & 4.70 & 111 & 129 & DIW & 3900 & 20 \\
\hline 1964 & B4B8B & 139.8 & 6.20 & 4.70 & 108 & 126 & DIW & 3900 & 20 \\
\hline 1965 & B4B8C & 136.7 & 6.40 & 4.70 & 111 & 129 & DIW & 3900 & 20 \\
\hline 1966 & B4B9A & 130.5 & 5.90 & 4.60 & 102 & 118 & DIW & 6500 & 20 \\
\hline 1967 & B4B9B & 134.9 & 6.10 & 4.60 & 106 & 121 & DIW & 6500 & 20 \\
\hline 1968 & B4B9C & 138.8 & 6.20 & 4.60 & 108 & 123 & DIW & 6500 & 20 \\
\hline
\end{tabular}


Table A9 (cont.)

Sample and Test Parametars for Bitumen With Sodium Tetraborate (40 wt 8 ) Type Waste ${ }^{1}$. Waste-to-Binder Ratio $(w / w)=0.67$. Samples Contain Co-57, Sr-85 and Cs-137.

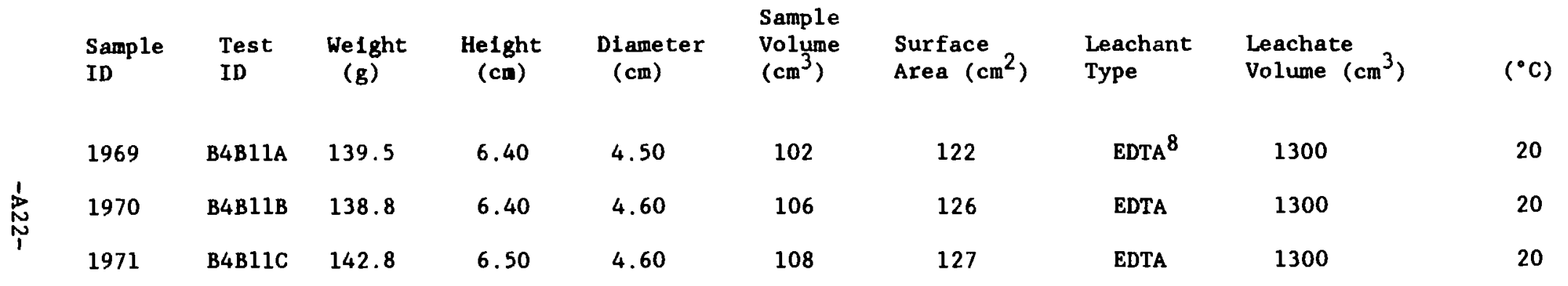

1. Anhydrous salt.

2. DIW = delonized water.

3. $g w$ - simulated groundwater.

4. Flow Test MCC4S, 1L/day.

5. $\mathrm{HNO}_{3}$ solution.

6. $\mathrm{NaHCO}_{3}$ solution $(0.5 \mathrm{~g} / \mathrm{L})$.

7. Anoxic - simulated anoxic groundwater.

8. $100 \mathrm{ppm}$ solution of disodium ethylenediamine tetraacetate dehydrate. 
Sample and Test Parameters for Solidification Agents for Baseline Leaching Tests 1

\begin{tabular}{|c|c|c|c|c|c|c|c|c|c|}
\hline $\begin{array}{l}\text { Sample } \\
\text { ID }\end{array}$ & $\begin{array}{l}\text { Test } \\
\text { ID }\end{array}$ & $\begin{array}{l}\text { Weight } \\
\text { (g) }\end{array}$ & $\begin{array}{l}\text { Height } \\
(\mathrm{cm})\end{array}$ & $\begin{array}{l}\text { Diameter } \\
(\mathrm{cm})\end{array}$ & $\begin{array}{l}\text { Sample } \\
\text { Volume } \\
\left(\mathrm{cm}^{3}\right)\end{array}$ & $\begin{array}{l}\text { Surface } \\
\text { Area }\left(\mathrm{cm}^{2}\right)\end{array}$ & $\begin{array}{l}\text { Leachant } \\
\text { Type }\end{array}$ & $\begin{array}{l}\text { Leachant } \\
\text { Volume }\left(\mathrm{cm}^{3}\right)\end{array}$ & $\begin{array}{c}\text { Temperature } \\
\left({ }^{\circ} \mathrm{C}\right)\end{array}$ \\
\hline 1001 & $P C-A^{2}$ & 199.5 & 6.30 & 4.80 & 114 & 131 & $\mathrm{DIW}^{3}$ & 1300 & 20 \\
\hline 1002 & $P C-B$ & 198.6 & 6.30 & 4.80 & 114 & 131 & DIW & 1300 & 20 \\
\hline 1003 & $\mathrm{PC}-\mathrm{C}$ & 198.6 & 6.30 & 4.80 & 114 & 131 & DIW & 1300 & 20 \\
\hline 1004 & $B I T-A^{4}$ & 111.0 & 6.40 & 4.70 & 111 & 129 & DIW & 1300 & 20 \\
\hline 1005 & BIT - B & 107.2 & 6.40 & 4.70 & 111 & 129 & DIW & 1300 & 20 \\
\hline 1006 & BIT-C & 108.7 & 6.40 & 4.70 & 111 & 129 & DIW & 1300 & 20 \\
\hline 1007 & VES - $A^{5}$ & 98.1 & 6.00 & 4.80 & 109 & 127 & DIW & 1300 & 20 \\
\hline 1008 & VES - B & 102.7 & 6.00 & 4.80 & 109 & 127 & DIW & 1300 & 20 \\
\hline 1009 & VES - C & 99.0 & 6.00 & 4.80 & 109 & 127 & DIW & 1300 & 20 \\
\hline
\end{tabular}

1. Replicates A, B and C contain Co-57, Sr-85 and Cs-137.

2. Portland Type I Cement.

3. DIW - deionized water.

4. Bitumen.

5. Vinyl Ester-Styrene Emulsion. 


\section{APPENDIX B}

Appendix B contains seven tables that list the sample parameters (weight, height, diameter, volume and surface area), leachant type and volume and the leaching temperature $\left( \pm 2^{\circ} \mathrm{C}\right.$ ) for each of the BLANK samples (i.e., those not containing radiotracers) fabricated and tested in this task. Each sample has been assigned a TESTID and a SAMPLEID for identification in the text and in the figures. Each table contains the parameters for a single sample type (i.e., composition), as follows:

- Table Bl: Portland type I cement containing 5 wto sodium sulfate salt as simulated waste

- Table B2: Portland type I cement containing 15 wto incinerator ash as simulated waste

- Table B3: Vinyl ester-styrene emulsion with aqueous sodium sulfate solution as simulated waste

- Table B4: Vinyl ester-styrene containing 40 wto sodium sulfate salt as simulated waste

- Table B5: Bitumen containing 20 wto sodium tetraborate salt as simulated waste

- Table B6: Bitumen containing 40 wto sodium tetraborate salt as simulated waste

- Table B7: Portland type I cement (neat), pure bitumen and viny1 ester-styrene emulsion with deionized water 
Sample and Test Parameters for Portland I Cement with Sodium Sulfate (5 wtz) Type Waste. Waste-to-Binder $(w / w)=0.54^{1}$. Blank Specimens.

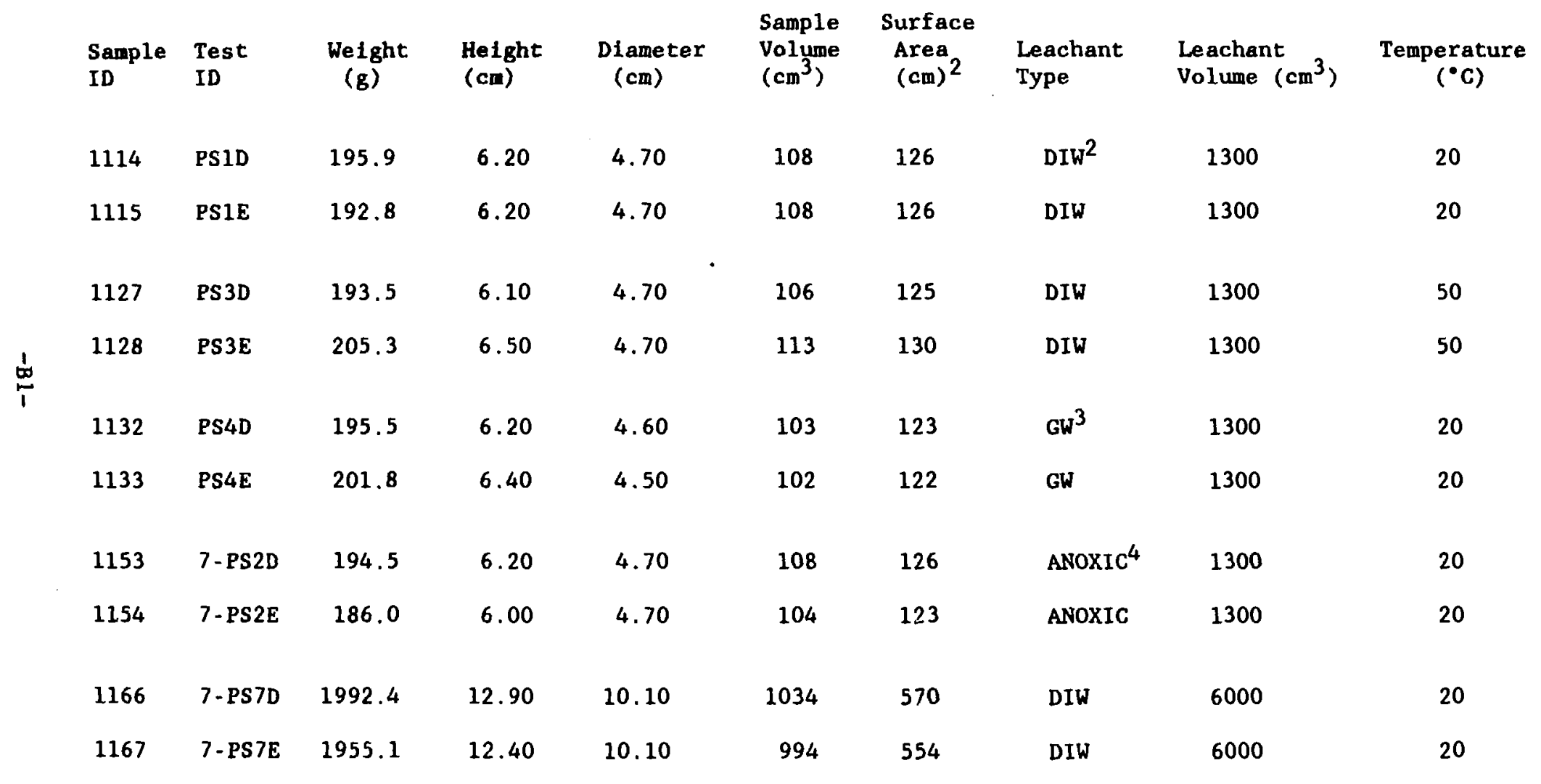

2. DIW - deionized water.

3. $G W$ - simulated groundwater.

4. Anoxic - simulated anoxic groundwater. 
Table $\mathrm{B} 2$

Sample and Test Parameters for Portland Type I Cement With Incinerator Ash (60 wto cement, 15 wt8 incinerator ash, 30 wto water $)$. Waste-to-Binder $(w / w)=0.58 .^{1}$ Blank specimens.

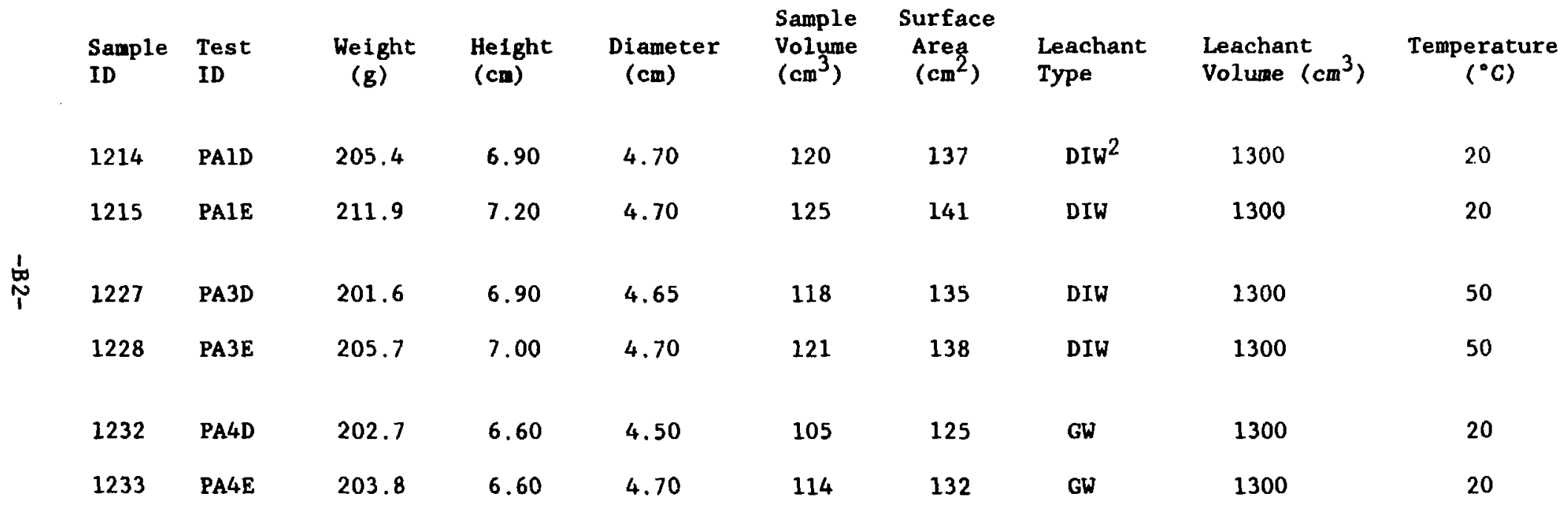

1. Ratio of ash plus water to cement.

2. DIW - deionized water.

3. GW - simulated groundwater. 
Sample and Test Parameters for Vinyl Ester-Styrene (DOW) Emulsion With Sodium Sulfate (15 wtz) Type Waste. Waste-to-Binder Ratio $(w / w)-1.5$. Blank Specimens. ${ }^{1}$

\begin{tabular}{|c|c|c|c|c|c|c|c|c|c|}
\hline $\begin{array}{l}\text { Sample } \\
\text { ID }\end{array}$ & $\begin{array}{l}\text { Test } \\
\text { ID }\end{array}$ & $\begin{array}{l}\text { Weight } \\
\text { (g) }\end{array}$ & $\begin{array}{l}\text { Height } \\
\text { (cm) }\end{array}$ & $\begin{array}{l}\text { Diameter } \\
(\mathrm{cm})\end{array}$ & $\begin{array}{l}\text { Sample } \\
\text { Volume } \\
\left(\mathrm{cm}^{3}\right)\end{array}$ & $\begin{array}{l}\text { Surface } \\
\text { Area }\left(\mathrm{cm}^{2}\right)\end{array}$ & $\begin{array}{l}\text { Leachant } \\
\text { Type }\end{array}$ & $\begin{array}{l}\text { Leachate } \\
\text { Volume }\left(\mathrm{cm}^{3}\right)\end{array}$ & $\begin{array}{c}\text { Temperature } \\
\left({ }^{\circ} \mathrm{C}\right)\end{array}$ \\
\hline 1314 & VS1D & 122.9 & 6.10 & 4.65 & 104 & 123 & $\mathrm{DIW}^{2}$ & 1300 & 20 \\
\hline 1315 & VS1E & 127.2 & 6.40 & 4.65 & 109 & 128 & DIW & 1300 & 20 \\
\hline 1327 & VS3D & 125.5 & 6.40 & 4.65 & 109 & 128 & DIW & 1300 & 50 \\
\hline 1328 & VS3E & 125.8 & 6.40 & 4.60 & 106 & 126 & DIW & 1300 & 50 \\
\hline 1332 & VS4D & 121.1 & 6.10 & 4.60 & 101 & 121 & $\mathrm{GW}^{3}$ & 1300 & 20 \\
\hline 1333 & VS4E & 120.1 & 6.10 & 4.60 & 101 & 121 & GW & 1300 & 20 \\
\hline
\end{tabular}

1. Prepared using a 25 wt solution of sodium sulfate.

2. DIW - deionized water.

3. GW - simulated groundwater. 
Table B4

Sample and Test Parameters for Vinyl Ester-Styrene (DOW) W1th Sodium Sulfate (40 wtz) Type Waste ${ }^{1}$. Waste-to-Binder Ratio $(w / w)-0.67$. Blank Specimens.

\begin{tabular}{|c|c|c|c|c|c|c|c|c|c|}
\hline $\begin{array}{l}\text { Samplo } \\
\text { ID }\end{array}$ & $\begin{array}{l}\text { Test } \\
\text { ID }\end{array}$ & $\begin{array}{l}\text { We1ght } \\
(g)\end{array}$ & $\begin{array}{l}\text { He1ght } \\
\text { (cn) }\end{array}$ & $\begin{array}{l}\text { Diameter } \\
(\mathrm{cm})\end{array}$ & $\begin{array}{l}\text { Sample } \\
\text { Volune } \\
\left(\mathrm{cm}^{3}\right)\end{array}$ & $\begin{array}{l}\text { Surface } \\
\text { Area }\left(\mathrm{cm}^{2}\right)\end{array}$ & $\begin{array}{l}\text { Leachant } \\
\text { Type }\end{array}$ & $\begin{array}{l}\text { Leachate } \\
\text { Volume }\left(\mathrm{cm}^{3}\right)\end{array}$ & $\begin{array}{c}\text { Temperature } \\
\left({ }^{\circ} \mathrm{C}\right)\end{array}$ \\
\hline 1615 & VDS1D & 148.2 & 6.40 & 4.60 & 106 & 126 & $\mathrm{DIW}^{2}$ & 1300 & 20 \\
\hline 1616 & VDS1E & 149.1 & 6.40 & 4.60 & 106 & 126 & DIW & 1300 & 20 \\
\hline 1627 & VDS3D & 149.4 & 6.40 & 4.60 & 106 & 126 & DIW & 1300 & 50 \\
\hline 1628 & VDS 3E & 154.5 & 6.60 & 4.60 & 110 & 129 & DIW & 1300 & 50 \\
\hline 1632 & VDS4D & 147.7 & 6.20 & 4.50 & 98.6 & 120 & $\mathrm{GW}^{3}$ & 1300 & 20 \\
\hline 1633 & VDS4E & 149.7 & 6.40 & 4.60 & 106 & 126 & GW & 1300 & 20 \\
\hline 1653 & $V 4 S 2 D$ & 148.5 & 6.40 & 4.60 & 106 & 126 & ANOXIC 4 & 1300 & 20 \\
\hline 1654 & V4S2E & 147.1 & 6.40 & 4.60 & 106 & 126 & ANOXIC & 1300 & 20 \\
\hline $\begin{array}{l}\text { 1. Anh } \\
\text { 2. DIW } \\
\text { 3. GW } \\
\text { 4. Ano }\end{array}$ & $=s$ & & & & & & & & \\
\hline
\end{tabular}


Sample and Test Parameters for Bitumen with Sodium Tetraborate (20 wt8) Type Waste.1 Waste-to-Binder Ratio $(w / w)-0.25$. Blank Specimens.

\begin{tabular}{|c|c|c|c|c|c|c|c|c|c|}
\hline $\begin{array}{l}\text { Sanple } \\
\text { ID }\end{array}$ & $\begin{array}{l}\text { Test } \\
\text { ID }\end{array}$ & $\begin{array}{l}\text { Weight } \\
(\mathrm{g})\end{array}$ & $\begin{array}{l}\text { Helght } \\
\text { (cn) }\end{array}$ & $\begin{array}{l}\text { Diameter } \\
\text { (cm) }\end{array}$ & $\begin{array}{l}\text { Sample } \\
\text { Volume } \\
\left(\mathrm{cm}^{3}\right)\end{array}$ & $\begin{array}{l}\text { Surface } \\
\text { Area }\left(\mathrm{cm}^{2}\right)\end{array}$ & $\begin{array}{l}\text { Leachant } \\
\text { Type }\end{array}$ & $\begin{array}{l}\text { Leachate } \\
\text { Volume }\left(\mathrm{cm}^{3}\right)\end{array}$ & $\begin{array}{c}\text { Tenperature } \\
\text { ("C) }\end{array}$ \\
\hline 1714 & B2B1D & 115.2 & 6.20 & 4.60 & 103 & 123 & $\mathrm{DIw}^{2}$ & 1300 & 20 \\
\hline 1715 & B2B1E & 114.6 & 6.10 & 4.60 & 101 & 121 & DIW & 1300 & 20 \\
\hline 1727 & B2B3D & 113.1 & 6.00 & 4.50 & 95.4 & 117 & DIW & 1300 & 50 \\
\hline 1728 & B2B3E & 111.7 & 6.00 & 4.50 & 95.4 & 117 & DIW & 1300 & 50 \\
\hline 1732 & $B 2 B 4 D$ & 114.1 & 6.00 & 4.70 & 104 & 123 & $\mathrm{GW}^{3}$ & 1300 & 20 \\
\hline 1733 & B2B4E & 120.5 & 6.20 & 4.60 & 103 & 123 & GW & 1300 & 20 \\
\hline 1753 & B2B2D & 109.6 & 5.80 & 4.60 & 93.4 & 117 & ANOXIC 4 & 1300 & 20 \\
\hline 1754 & B2B2E & 110.5 & 6.00 & 4.50 & 95.4 & 117 & ANOXIC & 1300 & 20 \\
\hline
\end{tabular}

1. Anhydrous salt.

2. DIW - deionized water.

3. GW - simulated groundwater.

4. Anoxic - simulated anoxic groundwater. 
Sample and Test Paraneters for Bitumen With Sodiun Tetraborate (40 wt8) Type Waste ${ }^{1}$. Waste-to-Binder Ratio $(w / w)-0.67$. Blank Specimens.

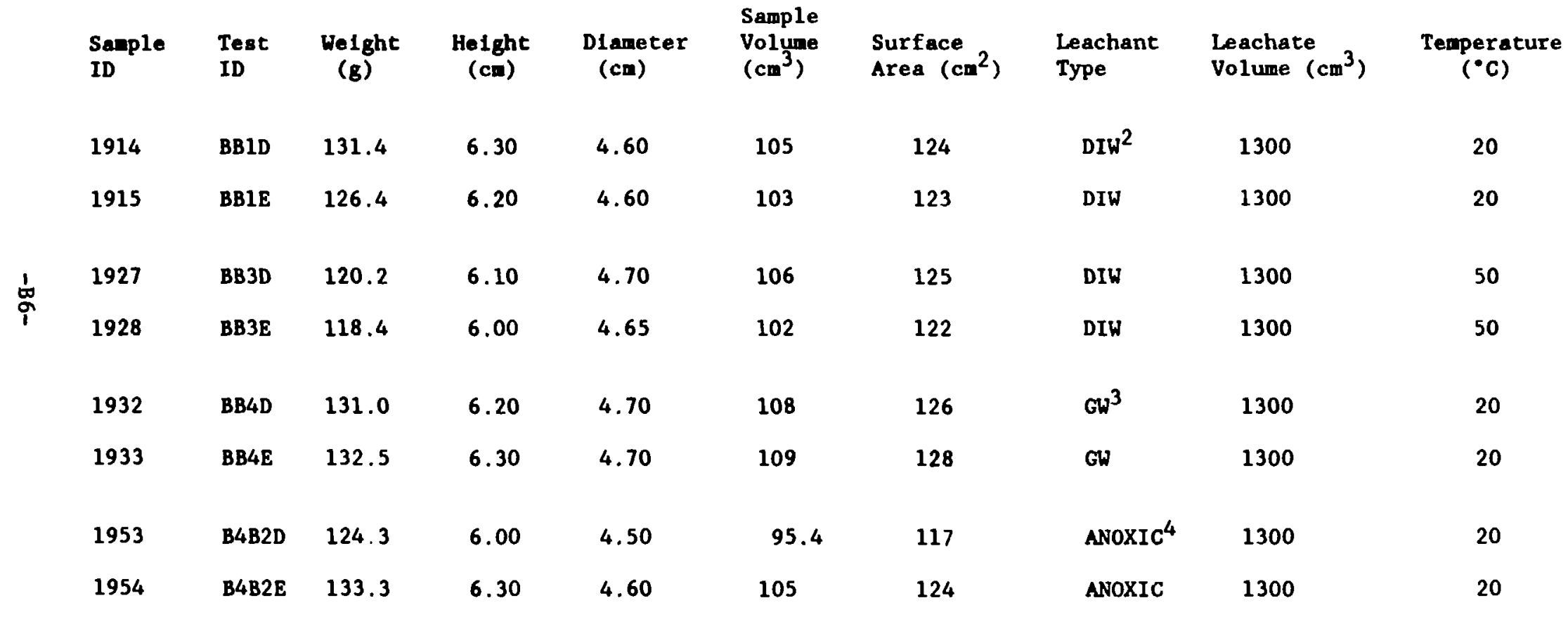

\footnotetext{
1. Anhydrous salt.

2. DIW - deionized water.

3. GW - simulated groundwater.

4. Anoxic - simulated anoxic groundwater.
} 
Table B7

Sample and Test Parameters for Solldification Agents for Baseline Leaching Tests ${ }^{1}$

\begin{tabular}{|c|c|c|c|c|c|c|c|c|c|}
\hline $\begin{array}{l}\text { Sample } \\
\text { ID }\end{array}$ & $\begin{array}{l}\text { Test } \\
\text { ID }\end{array}$ & $\begin{array}{l}\text { Weight } \\
\text { (g) }\end{array}$ & $\begin{array}{l}\text { Height } \\
(\mathrm{cm})\end{array}$ & $\begin{array}{l}\text { Diameter } \\
\text { (cm) }\end{array}$ & $\begin{array}{l}\text { Sample } \\
\text { Volume } \\
\left(\mathrm{cm}^{3}\right)\end{array}$ & $\begin{array}{l}\text { Surface } \\
\text { Area }\left(\mathrm{cm}^{2}\right)\end{array}$ & $\begin{array}{l}\text { Leachant } \\
\text { Type }\end{array}$ & $\begin{array}{l}\text { Leachant } \\
\text { Volume }\left(\mathrm{cm}^{3}\right)\end{array}$ & $\begin{array}{c}\text { Temperature } \\
\left({ }^{\circ} \mathrm{C}\right)\end{array}$ \\
\hline 1011 & PC-Blank & 198.8 & 6.30 & 4.80 & 114 & 131 & DIW & 1300 & 20 \\
\hline 1012 & BIT-Blank & 110.2 & 6.40 & 4.70 & 111 & 129 & DIW & 1300 & 20 \\
\hline 1013 & VES-Blank & 108.5 & 6.10 & 4.80 & 110 & 128 & DIW & 1300 & 20 \\
\hline
\end{tabular}

1. PC-Blank is Portland Type I Cement neat.

2. B1tumen

3. Viny1 Ester-Styrene Emulsion (DOW) 